\title{
Sozialpädagogik
}

\section{Umriss einer}

erziehungswissenschaftlichen Disziplin und Prinzipien ihrer praktischen Anwendung

\section{Werner Naumann}



Werner Naumann

\section{SOZIALPÄDAGOGIK}

Umriss einer erziehungswissenschaftlichen Disziplin und Prinzipien ihrer praktischen Anwendung

Logos Verlag Berlin

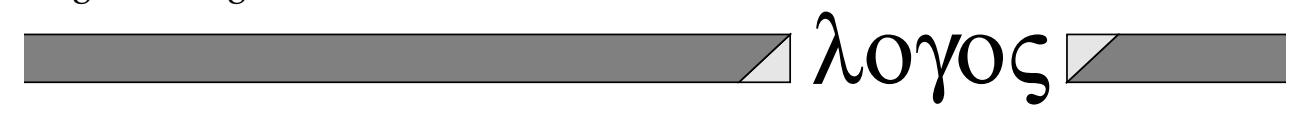


Bibliografische Information der Deutschen Nationalbibliothek

Die Deutsche Nationalbibliothek verzeichnet diese Publikation in der Deutschen Nationalbibliografie; detaillierte bibliografische Daten sind im Internet über http://dnb.d-nb.de abrufbar.

(C) Copyright Logos Verlag Berlin GmbH 2008

5., überarbeitete und ergänzte Auflage 2020

Alle Rechte vorbehalten.

ISBN 978-3-8325-2068-7

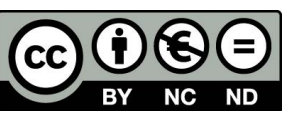

Logos Verlag Berlin GmbH

Georg-Knorr-Str. 4, Geb. 10

12681 Berlin

Tel.: $\quad+49(0) 30 / 42851090$

Fax: $\quad+49(0) 30 / 42851092$

http://www.logos-verlag.de 


\section{Vorwort}

Während der Abwicklung der Pädagogischen Hochschule Güstrow wurde ich vom Kultusminister Mecklenburg-Vorpommerns mit einem Dankschreiben vom 19. Dezember 1991 als Professor für Allgemeine Pädagogik an der Universität Rostock - AuBenstelle Güstrow - abberufen und zum 1. Januar 1992 in den Vorruhestand entlassen. Einen Abbruch aller wissenschaftlichen und pädagogischen Aktivitäten wollte ich allerdings nicht hinnehmen. Daher ging ich gern auf das Angebot eines Bildungsmanagers aus Solingen ein, unter seiner Geschäftsführung in Güstrow eine Sozialakademie aufzubauen und zu leiten.

Hinzu kam, dass sich eine wachsende Dringlichkeit sozialpädagogischen Handelns und damit auch der Ausbildung von Sozialpädagogen ${ }^{1}$ abzeichnete, und zwar nicht nur wegen der notwendigen politisch-pädagogischen Umorientierung pädagogischer Fachkräfte, sondern vor allem wegen anwachsenden Erziehungsprobleme in den neuen Bundesländern. Diese resultierten u. a. aus einer allgemeinen Verunsicherung vieler Eltern, Erzieher und Lehrer, aber auch der Heranwachsenden selbst. Letztere produzierten zunehmend Verhaltensweisen, die offensichtlich aus einem falschen Demokratie- und Freiheitsverständnis resultierten. Die pädagogischen Fachkräfte wiederum scheuten sich vielfach, auch berechtigte Forderungen gegenüber ihren Schützlingen durchzusetzen, häufig aus Sorge, einer kommunistischen Kommandopädagogik verdächtigt zu werden, was in Anbetracht der einsetzenden Entlassungswelle in den neuen Bundesländern Befürchtungen um den Verlust des Arbeitsplatzes auslöste. Den Namen Makarenko wagte kaum noch jemand auszusprechen und an seine Erziehungsgrundsätze sollte und wollte möglichst niemand mehr erinnert werden. Allein schon unter diesem Aspekt verdienen die Leistungen zur wissenschaftlichen Aufarbeitung von Makarenkos Erbe durch die Marburger Wissenschaftler Leonhard Froese, Götz Hillig, Siegfried Weitz u. a. hohe Anerkennung.

Ab 1. März 1992 nahm ich meine Tätigkeit an der Sozialakademie Mecklenburg-Vorpommern auf und bemühte mich um die Organisation von Lehrgängen im Bereich der Sozialpädagogik. Die Erlasse der Kultusministerin im Jahre 1992 zur Anpassungsqualifizierung von Erzieherinnen zu staatlich anerkannten Erzieherinnen und zur $\mathrm{Zu}$ satzqualifikation von pädagogisch vorgebildeten Kräften zu staatlich anerkannten Sozialarbeitern/Sozialpädagogen erleichterten die Organisation der Kurse, weil damit eine gesetzliche Grundlage gegeben war und eine finanzielle Förderung der Kursteilnehmer möglich wurde. Zudem konnte die Sozialakademie in Güstrow auf Lehrkräfte

1 Zwecks besserer Lesbarkeit wird im vorliegenden Buch auf die explizite Nennung beider Geschlechter verzichtet. In der Regel sind stets Sozialpädagoginnen und Sozialpädagogen, Klienten und Klientinnen usw. gemeint. 
für Pädagogik, Psychologie und Soziologie aus der ehemaligen PH und von ihren früheren Kooperationspartnern zurückgreifen. In den juristischen Disziplinen sowie bei einigen Spezialthemen der Sozialen Arbeit wurde die Sozialakademie durch Gastdozenten aus Hamburg, Bielefeld und der Fachhochschule für Öffentliche Verwaltung und Rechtspflege in Güstrow unterstützt, so dass im Verlaufe von 11 Jahren über 400 Kursteilnehmer in berufsbegleitenden ein- bis dreijährigen Kursen zu sozialpädagogischen Berufsabschlüssen bzw. Qualifikationsnachweisen geführt werden konnten.

Die in den Lehrgängen zu vermittelnden pädagogischen Kenntnisse mussten nicht nur dem Erkenntnisstand der Erziehungswissenschaften in den alten Bundesländern entsprechen, sondern auch den verschiedenen Arbeitsfeldern der Kursteilnehmer Rechnung tragen. Unter diesen Umständen besann ich mich auf theoretische Positionen meines Lehrers Prof. Dr. Herbert Schaller vom Institut für Erwachsenenbildung der Universität Leipzig, um auf dieser Grundlage ein möglichst gegenstands- und situationsadäquates Konzept zu erarbeiten. Mit Hilfe der Fachliteratur und der zahlreichen Belegund Abschlussarbeiten (schriftlichen Hausarbeiten) der Kursteilnehmer entwickelte ich auf der Grundlage der Schallerschen Systemvorstellungen von Pädagogik eine Konzeption für eine relativ allgemeine, arbeitsfeldübergreifende Sozialpädagogik, die durch viele Diskussionen mit den Kursteilnehmern bereichert worden ist.

Der Rückgriff auf Schaller bot sich an, weil ich von der Tragfähigkeit seiner Auffassungen über Erziehung und Pädagogik überzeugt bin. In der DDR wurden Schallers marxistische Auffassungen von manchen Vertretern in Führungsgremien der SED und in der Pädagogik mit einigem Misstrauen betrachtet, und zwar nicht nur wegen seiner eigenwilligen Terminologie. Schaller war wegen seiner Mitgliedschaft in der linken Abspaltung von der SPD, der Sozialistischen Arbeiterpartei Deutschlands, und wegen seiner kritischen Äußerungen zu stalinistischen Positionen in den Gesellschaftswissenschaften bestimmten Gremien der SED verdächtig. In kritischen Situationen kam ihm wohl zugute, dass er dreimal in Gestapogefängnissen gesessen, Hausdurchsuchungen erlitten und bis 1945 Berufsverbot hatte.

Wenn abweichendes Verhalten nicht nur in sog. sozialen Randgruppen zu einer weit verbreiteten Erscheinung wird, wie z. B. Jugendpfarrer Dietrich Lauter aus Ludwigshafen schon 1993 (S. 147/148) festgestellt hat, dann ist auch die Wissenschaft verstärkt gefordert, und zwar nicht nur in Form spezieller Forschungsarbeiten und Ausarbeitungen praktikabler Anleitungsmaterialien entsprechend der einzelnen Felder der Sozialen Arbeit, sondern auch durch die Entwicklung einer möglichst umfassenden Allgemeinen Sozialpädagogik zwecks Rationalisierung der Ausbildung von vielfältig einsetz̧baren Fachkräften. Daraus resultiert der Versuch zum Umriss einer Allgemeinen Sozialpädagogik aus dialektisch-materialistischer Sicht, der in diesem Buch vorgestellt wird. 
Für meinen Einstieg in die spezifischen Probleme sozialpädagogischer Prozesse waren die Lehrveranstaltungen und Veröffentlichungen von Prof. Dr. Hans Josef Tymister (Universität Hamburg), die mir unmittelbar nach der Grenzöffnung zugänglich wurden, von maßgeblichem Einfluss. In den offenen Familienberatungen des Kollegen Tymister mit Eltern und deren schwierigen Kindern vor jeweils mehr als 100 Studierenden konnte ich mich u. a. von der Brauchbarkeit individualpsychologischer Positionen für eine sozialpädagogische Theoriebildung überzeugen. Die Erkenntnisse aus Schriften Alfred Adlers und seines Schülers Ferdinand Birnbaum, Schuldirektor in einem sozialen Brennpunkt Wiens, ließen sich nämlich auf bemerkenswert schlüssige Weise mit meinen Vorstellungen von der Struktur und Dynamik pädagogischer Prozesse verknüpfen (vgl. Kapitel 6).

In Ergänzung zu den bisherigen Ausführungen aus dem Vorwort seit der 1. Auflage ist für die nunmehr vorliegende 5. Auflage zu bemerken, dass abgesehen von zahlreichen inhaltlichen Präzisierungen, stilistischen und formalen Korrekturen eine konzeptionelle Neuorientierung vorgenommen worden ist. Nach dem Studium der Abhandlungen der Leibniz-Sozietät der Wissenschaften (Band 27) unter dem Titel „Wissenschaft im Kontext. Inter- und Transdisziplinarität in Theorie und Praxis“ und der weiteren Auswertung zahlreicher Veröffentlichungen zur Entwicklung einer Sozialarbeitswissenschaft als transdisziplinäre Handlungswissenschaft habe ich meine ursprüngliche Skepsis (1. Auflage, S. 94) gegenüber diesen Bemühungen im Bereich der Wissenschaften von der Sozialen Arbeit korrigiert (s. S. 93). Es zeigt sich nämlich, dass die von mir dargestellte Sozialpädagogik ihrem Wesen nach transdisziplinären Charakter besitzt, was in der 5. Auflage mehrfach verdeutlicht wird. Damit ergeben sich auch neue Möglichkeiten zur Integration sozialpädagogischer Erkenntnisse in eine umfassende Sozialarbeitswissenschaft als Handlungsdisziplin. Auf eine eigenständige Sozialpädagogik im Sinne einer erziehungswissenschaftlichen Disziplin kann aber ebenso wenig verzichtet werden wie auf andere Bezugswissenschaften der Sozialen Arbeit.

Ich bedanke mich bei meinen Kursteilnehmern, die durch Diskussionen und mit ihren Hausarbeiten viel empirische Substanz für das vorliegende Buch geliefert haben, sowie bei den Kollegen Prof. Dr. Herbert Hörz, Prof. Dr. Hans Josef Tymister, Prof. Dr. Franz Prüß, Prof. Dr. Heinz Hogau, PD Dr. Götz Hillig, Prof. Dr. Manfred Widmann, Dr. Edgar Günther-Schellheimer, Dr. Frank Naumann und bei meiner Frau, Dr. Christa Naumann, für ihre theoretischen Anregungen und sachdienlichen Hinweise. Mein Dank gilt schließlich auch Frank Wiese und Katrin Kadelke für ihre technische Unterstützung bei der Herstellung des Typoskripts. 


\section{Inhaltsverzeichnis}

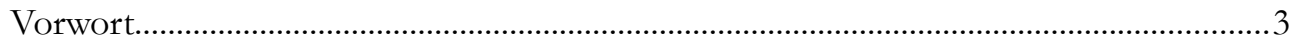

1. Philosophische und allgemeine pädagogische Positionen..........................9

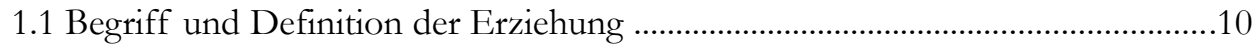

1.2 Zur Fundierung eines Systems pädagogischer Erkenntnisse..............................29

1.3 Struktur, Dynamik und Funktionen der Erziehung .............................................31

1.4 Notwendigkeit und Möglichkeit, Kraft und Grenzen der Erziehung...................43

1.5 Zur statistischen Gesetzeskonzeption in der Pädagogik......................................50

1.6 Prinzipien und Regeln - ihre Bedeutung für pädagogisches Handeln.................65

2. Historische Wurzeln, Gegenstand und Aufgaben der Sozialpädagogik .........73

2.1 Das Wort „Pädagogik“، und seine Bedeutungswandlungen..................................74

2.2 Soziale Nöte als Auslöser für Sozialarbeit und Sozialpädagogik..........................84

2.3 Zur Neubestimmung der Sozialpädagogik.............................................................95

2.4 Sozialarbeit und Sozialpädagogik in der Sozialen Arbeit....................................113

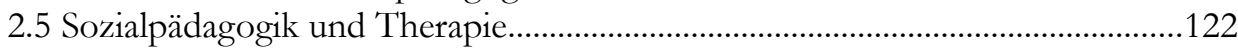

2.6 Aufgaben der Sozialpädagogik im Ensemble der Wissenschaften

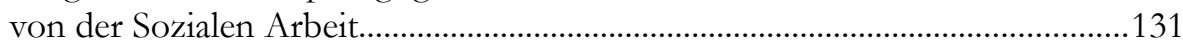

3. Besonderheiten der Zielgruppen in sozialpädagogischen Prozessen............141

3.1 Zöglingsbegriff und Devianz in neuerer Zeit ..................................................142

3.2 Theorien über die Entstehung devianten Verhaltens .........................................152

3.3 Zur Bedeutung der vorgestellten Theorien über deviantes Verhalten für Sozialpädagogen........................................................................................203

4. Ziele und Inhalte der psychosozialen Intensiverziehung ................................209

4.1 Begriff und Erscheinungsformen des pädagogischen Ziels...............................210

4.2 Legitimation und Bestimmung pädagogischer Ziele...........................................214

4.3 Werte und Normen als Grundlagen von Zielbestimmungen

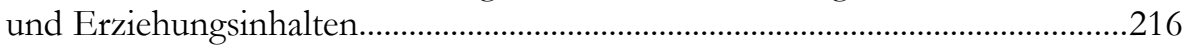

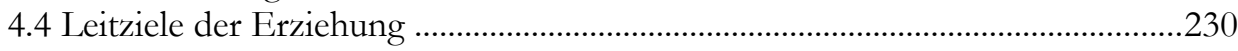

4.5 Zur Erarbeitung und Nutzung konkreter Erziehungsziele.................................243

4.6 Konzeptprinzipien als Grundlage konzeptioneller und prozessimmanenter Planung.............................................................................248

4.7 Fallbeispiel zur Anwendung der Konzeptprinzipien........................................259

5. Erzieherische Verhältnisse in der psychosozialen Intensiverziehung ...........263

5.1 Gesellschaft, Gemeinschaft und Individuum...................................................264

5.2 Merkmale erzieherischer Verhältnisse - Anforderungen an Erzieher..............266

5.3 Zum Autoritätsproblem in der Pädagogik...........................................................2. 275

5.4 Entwicklung und Wirksamkeit von Gemeinschaftsbeziehungen......................283 
5.5 Sozialpädagogische Strukturprinzipien - ihre Begründung und Bedeutung

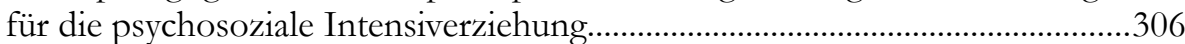

5.6 Fallbeispiel zur Anwendung der Strukturprinzipien............................................313

\section{Zur organisatorisch-methodischen Gestaltung sozialpädagogischer}

Prozesse

6.1 Theoretische Grundlagen einer funktionalen Betrachtung und Darstellung sozialpädagogischer Prozesse.

6.2 Sozialpädagogische Funktionsprinzipien - ihre Begründung und Bedeutung für die Prozessgestaltung.

6.3 Sozialpädagogische Funktionen und Prinzipien in ihrer Anwendung bei der Prozessgestaltung.

Schlussbemerkungen

Anlagen

I. Aufgaben der Sozialen Arbeit

II. Auszug aus dem Inhaltsverzeichnis: Peter Lüssi: Systemische Sozialabeit 386

III. Sozialpädagogische Prinzipien (gruppiert von W. Naumann) 388

Literaturverzeichnis 389 



\section{Kapitel}

\section{Philosophische und allgemeine pädagogische Positionen}




\subsection{Begriff und Definition der Erziehung}

Der Prozess der Menschwerdung ist seit dem homo habilis und dem homo ergaster vor rund 2 Millionen Jahren wesentlich mit Arbeitshandlungen verbunden, wie in Afrika und anderswo gefundene Steinwerkzeuge belegen. Das Zusammenleben und Überleben der Urmenschen war charakterisiert bzw. bedingt durch Kooperation und damit durch viele unbeabsichtigte und bewusste wechselseitige Beeinflussungen, deren Wirkungen die Kommunikationspartner erlebten. In Auswertung dieser Effekte lernten sie, mögliche Wirkungen ihrer Äußerungen auf das Verhalten ihres Kommunikationspartners vorauszusehen und auch bewusst so zu gestalten, dass die jeweils gewünschte Reaktion eintrat, wenn auch nicht in jedem Falle. In dem Maße, wie eine zunehmend bewusste Beeinflussung eines weniger erfahrenen bzw. noch ungeschickten Interaktions- und Kommunikationspartners durch einen kompetenten regulärer Bestandteil der Lebenspraxis wurde, entstand jene Komponente des sozialen, ökonomischen und schließlich geistig-kulturellen Reproduktions- und Entwicklungsprozesses, die wir Erziehung nennen.

Unsere urgeschichtlichen Ahnen konnten sich bei der „Aufzucht“ ihres Nachwuchses auf eine genetische Ausstattung und entsprechende Dispositionen (mögliche Fähigkeiten) stützen, die sich teilweise schon bei ihren ,äffischen Vorfahren“ entwickelt hatten, wie folgender Bericht über das Verhalten von Schimpansenmüttern vermuten lässt:

„Schon ehe ein Baby vier Monate alt ist, lässt die Mutter das Bauch-zu-Bauch-Sitzen nicht mehr zu. Manchmal versucht sie, das Kleine auf ihrem Rücken zu tragen, auch wenn es erst ein paar Tage alt ist. In diesem Alter kann sich das Baby aber dort noch nicht selbst festhalten, und so nimmt es die Mutter schnell wieder an ihren Bauch. Später kann und muss ein Baby dann wenigstens eine kurze Zeit sich auf dem Rücken der Mutter halten. Sobald es eine Gelegenheit sieht, um wieder an ihren Bauch zu rutschen, wird es das auch tun. Zunächst vereitelt die Mutter dies, indem sie die Arme dicht vor den Leib hält, so daß das Baby nicht durchschlüpfen kann, oder es bewegt sich so, daß das Kleine wieder auf den Rücken geschoben wird. Ist das Kind schon älter, wird das Kind von der Mutter gestraft, indem sie es schlägt oder schmerzhaft beißt, wenn es immer wieder versucht, auf den Platz am mütterlichen Bauch zu gelangen.

Mutter »Fifi« machte die Rückenstellung für ihr Baby »Freud« dadurch anziehend, daß sie es nicht etwa immer wieder hinaufschob, sondern ihm beibrachte, selbst hinaufzuklettern. Um dies zu erreichen, setzte sie »Freud« auf einen Stein, drehte sich dann um und neigte den Rücken, stupste das Kleine an und schaute zu ihm hin. Mit unendlicher Geduld wartete sie, bis es auf ihrem Rücken saß. Dann macht sie ein paar Schritte und kehrte wieder zum gleichen Stein zurück. Mehrere Male wiederholte sie die Lektion, und immer behender kletterte ihr das Kleine auf den Rücken. Noch am gleichen Tag nutzte »Fifi« jede Gelegenheit, um »Freud» selbständig auf ihren Rücken klettern zu lassen. Von da ab hatte die Schimpansenmutter nicht 
die geringste Mühe mehr, ihr Kind auf dem Rücken zu tragen“ (van de Rijt-Plovij/Plovij 1978, S. 183/184).

Der Bericht lässt erkennen, dass

- bereits Affenbabys lernfähig sind,

- Affenmütter mit unterschiedlichen Verfahren ihre Kinder zu den Handlungen und Leistungen veranlassen, die lebenswichtig sind, wobei auffällt, dass

- Schlagen und Beißen als „Strafmethoden“ offenbar üblich sind und

- in einzelnen Fällen eine Affenmutter anstelle der Bestrafung ihres Kindes bereits Anfänge einer milden und effektiveren „Erziehungsmethode“ anwendet, nämlich:

- Nutzung des Bewegungsdrangs des Kleinen für Übungen unter gleichen und ähnlichen Bedingungen,

- geduldiges Warten bis das Kleine hinreichend Mut gefasst hat und sich zum Sprung auf den Rücken überwindet,

- $\quad$ wobei es von der Mutter durch Blicke und Stupsen ermuntert wird;

- Durchführung der Übung unter veränderten Bedingungen bis die gewünschte „Handlungs- und Verhaltensweise“ gefestigt ist.

Weitere Belege für das Auftreten von Keimformen der Erziehung und Unterweisung liefern die Experimente und Beobachtungen des US-amerikanischen Tierpsychologen und Primatenforschers Roger Fouts (Fouts/Mills 2000). Er wies nach, dass und wie Schimpansenkinder beim Erwerb und Gebrauch der Gebärdensprache in der Abfolge der Gebärden auch die grammatische Struktur richtig nutzen lernten, seines Erachtens ohne einen „Spracherwerbsapparat“ mit „Universalgrammatik“ im Sinne Chomskys. So konnte der Schimpansenjunge Ally sehr genau unterscheiden zwischen „ZAHNBÜRSTE AUF DECKE und DECKE AUF ZAHNBÜRSTE“ (a. a. O., S. 204). Mit seinen Versuchen und Beobachtungen konnte Fouts nicht nur Irrtümer in den vorherrschenden Theorien über den Spracherwerb von Menschen aufzeigen, und zwar sowohl bei Chomsky als auch bei Skinner; er erkannte auch die Fähigkeit von Schimpansen, eine von Menschen entwickelte und übermittelte Gebärdensprache obne Unterstützung durch Menschen an einen jungen Schimpansen weiter zu vermitteln.

Als die Schimpansin Washoe 14 Jahre alt war und ihr eigenes Baby einige Tage nach der Geburt starb, brachte Fouts ihr einen wenige Monate alten Schimpansenjungen namens Loulis, dessen Mutter im Yerkes Center (einem der größten amerikanischen Forschungseinrichtungen für Primaten) durch die dort mit ihr veranstalteten Experimente an der Aufzucht des Jungen gehindert war. Das Versuchskonzept von Fouts sah vor, dass nur sieben Wörter bzw. Gebärden von den Pflegern in Loulis' Gegen- 
wart gebraucht werden dürfen, um eine Kontrollmöglichkeit zu haben bezüglich anderer Gebärden, die er voraussichtlich von seiner Adoptivmutter übernehmen würde. Ansonsten verständigten sie sich mit Washoe auf englisch, das sie in beschränktem Maße verstand. Über Loulis’ Lernprozess schrieb Fouts:

„Es war klar, daß Washoe ihn nicht eigens zu unterrichten brauchte, denn wie ein menschliches Kind lernte Loulis die Sprache aus einem tief verwurzelten Bedürfnis nach sozialer Kommunikation. Dennoch gab sie ihm hin und wider Unterricht. Einmal stellte sie einen Stuhl vor Loulis hin und zeigte ihm fünfmal hintereinander die Gebärden STUHL SITZEN. Ein andermal brachte einer der Volontäre ihr einen Napf Hafergrütze, und während Loulis zusah, führte Washoe ihm immer wieder die Gebärde ESSEN vor. Anschließend formte sie seine Hand zu der Gebärde ESSEN und führte sie mehrmals an seinen Mund - genauso, wie ich es in Nevada mit ihr gemacht hatte und wie es auch Eltern von gehörlosen Kindern häufig tun. Die praktische Anleitung schien sich zu bewähren, denn Loulis lernte promt die Gebärde für ESSEN. [...] Nach lediglich acht Wochen sprach der einjährige Loulis regelmäßig Menschen und Schimpansen mit Gebärden an“" (a. a. O., S. 296).

Das qualitätsbestimmende Merkmal für die Entwicklung der Erziehung war offenbar eine ,erwachende“ und wachsende erzieherische Bewusstheit der Erwachsenen. Zweifellos hat sich auch das Lernen in der Tätigkeit der zu Erziehenden unter den Bedingungen direkter Beziehungen zwischen Mutter und Kind entwickelt, denn auf Grund dieser engen Beziehungen war ja auch eine Kontrolle und Verbesserung der Lernerfolge möglich. Aus dieser evolutionären Sichtweise heraus ist verständlich, dass die dialektisch-materialistische Pädagogik die Auffassung der anthropologischen Pädagogik teilt, nach der „Erziehbarkeit und Erziehungsbedürftigkeit schon in der leiblichen Verfassung des Menschen verwurzelt sind“" (Bollnow 1983, S. 42), d. h. auch natürliche Grundlagen haben.

In fast jedem Lehrbuch oder Nachschlagewerk der Pädagogik wird darauf hingewiesen, dass es viele Auffassungen von Erziehung gibt (Heid bei Lenzen 1994, S. 51). Mit Bezugnahme auf Immanuel Kant (1724-1804) schreibt Winfried Böhm:

„Die pädagogische Wissenschaft kann nicht auf einem Aggregat von zufälligen und beschränkten Erfahrungen aufbauen, sondern muß auf Grundsätzen oder Prinzipien beruhen und als systematisch »zusammenhängendes Bestreben« aufgebaut werden; diesen systematischen Zusammenhang ermöglicht eine Idee bzw. ein idealischer, nicht empirischer Begriff der Erziehung: »eine Idee ist nichts anderes, als der Begriff von einer Vollkommenheit, die sich in der Erfahrung noch nicht vorfindet«" (Böhm bei Benner/Oelkers 2004, S. 772; Kant 1923, S. 444).

Es ist leicht einzusehen, dass es die Erziehung real nicht gibt (vgl. Kron 1991, S. 45); aber es ist möglich, einen wissenschaftlichen Erziehungsbegriff zu bilden, der eine Klasse von Prozessen widerspiegelt. Herbert Schaller (1899-1966) hat sich bemüht, in der 
Merkmalsvielfalt von Erziehungsprozessen einige invariante und wesentliche Merkmale $\mathrm{zu}$ finden, um mit ihrer Hilfe durch generalisierende und idealisierende Abstraktionen von fließenden Übergängen einen „,idealischen Begriff“ zu bilden. Diesen Erziehungsbegriff hat er entsprechend einer seit der Antike bekannten Regel $^{2}$ definiert, nämlich durch

- die Kennzeichnung des nächsthöheren Gattungsbegriffs für Erziehung und

- die Feststellung artspezifischer Merkmale.

Er formulierte als Kurzfassung: „Erziehung ist bewusste, direkte Menschenformung zwecks optimaler gesamtgesellschaftlicher Produktivität" (oder: „optimaler Gestaltung von Natur und Gesellschaft") (Vorlesungsmitschrift vom 26.11.1953, Privatarchiv). Die Wahl des Gattungsbegriffs „Menschenformung“ stieß vielfach auf Ablehnung, weil damit mechanistische Vorstellungen verbunden wurden, die Schaller aber nicht meinte. Als Verehrer Goethes (1749-1832) traf er seine Wortwahl unter dem Einfluss der Zeilen aus dem „Prometheus":

„Hier sitz ich, forme Menschen

Nach meinem Bilde,

Ein Geschlecht, das mir gleich sei,

$\mathrm{Zu}$ leiden, zu weinen,

$\mathrm{Zu}$ genießen und $\mathrm{zu}$ freuen sich,

Und dein nicht zu achten,

Wie ich."

In seinen Erläuterungen hat Schaller nicht nur allgemein seine aufklärerische und dialektisch-materialistische Position verdeutlicht, sondern direkt Bezug genommen auf die 3. These über Feuerbach von Karl Marx (1818-1883):

„Das Zusammenfallen des Ändern(s) der Umstände und der menschlichen Tätigkeit oder Selbstveränderung kann nur als revolutionäre Praxis gefaßt und rationell verstanden werden" (MEW, Bd. 3, S. 6).

Mit dem Begriff der Selbstveränderung in der revolutionären Praxis - oder ,umwälzenden Praxis"wie Friedrich Engels (1820-1895) später schrieb (MEW, Bd. 3, S. 534) - meinte Marx die Selbstveränderung des Menschen als Gattungswesen; aber darin ist faktisch und logisch die Selbstveränderung des Individuums in der Tätigkeit mit eingeschlossen (vgl. Rubinstein 1958, S. 835). Kant formulierte diese Erkenntnis schlicht so:

„Die Gemütskräfte werden am besten dadurch kultiviert, wenn man das alles selbst thut, was man leisten will“" (Kant 1890, S. 161).

Da der Begriff der Menschenformung immer wieder Missverständnisse erzeugte, haben Schallers Schüler vielfach den Begriff der Persönlichkeitsentwicklung als Gattungsbegriff verwendet, was neue Schwierigkeiten hervorrief, etwa mit der Frage: können dann

2 Definitio fit per genus proximum et differentiam specificam. 
auch bewusst gestaltete Prozesse, die offensichtlich auf eine Deformation der Persönlichkeit zielen - wie z. B. im Faschismus - als Erziehung bezeichnet werden? Hierauf ist zunächst zu antworten, dass die Erziehung insgesamt im sog. 3. Reich nicht nur verbrecherische Ziele und Zwecke, die natürlich uneingeschränkt zu verurteilen sind, verfolgt hat! Außerdem ist zu berücksichtigen, dass in der o. g. Definition ein dialektischer Entwicklungsbegriff unterstellt wird, d. h. einer, der Werden und Vergehen, Vervollkommnung und Verfall (also auch destruktive Momente) im jeweiligen Gesamtprozess einschließt. Gerade dadurch ist es möglich, Erziehungsprozesse unterschiedlicher Qualität begrifflich zu erfassen und sodann explizit zu bewerten.

Ein zweites Problem dieser Definition ist mit dem Begriff der Persönlichkeit verbunden. Nach Philip G. Zimbardo meint dieser ein

„wichtiges psychologisches Konzept, um die Einzigartigkeit des Individuums zu betonen. P. bezieht sich auf die einzigartigen psychologischen Merkmale des Individuums, die eine Vielzahl von charakteristischen konsistenten Verhaltensmustern in verschiedenen Situationen und zu verschiedenen Zeitpunkten beeinflussen“ (Zimbardo 1992, S. 620).

Die Definition von Zimbardo hat den Nachteil, dass sie keine Abgrenzung zum Begriff der Individualität des Menschen erkennen lässt. Deshalb wird in Übereinstimmung mit Ulrich Ihlefeld (1925-1999) vorgeschlagen, den Persönlichkeitsbegriff unter Nutzung seiner historischen Wortwurzel zu bestimmen (vgl. Erlebach/Ihlefeld/Zehner 1974, S. 86). Das lateinische Wort „persona“ bedeutet Maske des Schauspielers oder Rolle, so dass man sagen kann: Persönlichkeit meint jene durch natürliche und gesellschaftliche Faktoren bedingte individuelle soziale Qualität des Menschen, die sich durch seine Tätigkeiten (einschließlich der kommunikativen) und seine Rolle im gesellschaftlichen Leben entwickelt und äußert, wobei die soziale Qualität (insbesondere Sittlichkeit) wesentlich die Rolle bestimmt.

Unter Berücksichtigung dieser Gesichtspunkte hat der Autor in seiner „Einführung in die Pädagogik“" definiert:

„Erziehung ist bewußte, in unmittelbaren zwischenmenschlichen Beziehungen und durch Auseinandersetzung mit der Umwelt und sich selbst erfolgende Bewusstseinsentwicklung und körperliche Entwicklung der Persönlichkeit“ (1977, S. 25/26).

Damit wurde der in der DDR gebräuchliche Begriff der Bewusstseinsentwicklung von Persönlichkeiten verwendet und durch den Hinweis auf die bewusst geförderte körperliche Entwicklung ergänzt. In der Substanz blieb der Schallersche Erziehungsbegriff erhalten, allerdings war inzwischen die theoretische Begründung der Definition von Wolfram Knöchel (1926-2008) und mir vertieft worden. Wir konnten nämlich 1968 nachweisen, dass Schallers Erziehungsdefinition die Erfordernisse einer dialektischen Definition erfüllt. Das bedeutet: nach der Auffassung des ungarischen Philosophen György Tamás muss der Gattungsbegriff jenen Bereich widerspiegeln, aus dem heraus sich die 
zu definierende Erscheinung entwickelt hat, und als artsperifische Merkmale sind jene zu finden, durch deren Auftreten, Entwicklung und Wirksamkeit die zu definierende Erscheinung entstanden ist (vgl. Tamás 1964, S. 130). In der Anthropogenese erlangte die Menschenformung, d. h. also die Selbstveränderung des Menschen in der Tätigkeit durch zielbewusste und methodische Lenkung der darin eingeschlossenen Lernprozesse die Qualität von Erziehung im Sinne von bewusster und direkter Persönlichkeitsveränderung (siehe S. 19ff. und S. 28).

Der Hinweis auf die körperliche Entwicklung bedeutet, dass Erziehung nicht nur auf einen intellektuellen und sittlichen Lernprozess der zu Erziehenden zielt, sondern auch alle physischen Veränderungen bzw. Kräftigungen mit einschließt, die im Zusammenhang stehen mit körperlichem Training. Außerdem fördern körperliche Betätigungen das Wachstum neuer Hirnzellen (vgl. Hüther, G.: Ohne Gefühl geht gar nichts. [online] http://www.youtube.com/watch?v=Lr184Ms5hlE\&feature=related; Zugriff: 30.03.2012). Die Auseinandersetzungen der Menschen mit ihrer Umwelt und sich selbst vollziehen sich in ihrer gesamten Lebenstätigkeit, wobei die Arbeit - historisch und entwicklungspsychologisch betrachtet - von besonderer Bedeutung ist.

Als qualitätsbestimmendes artspezifisches Merkmal von Erziehung tritt Bewusstheit in Erscheinung, was sich zunächst äußert in erzieherischen Absichten, d. h. in Zielvorstellungen (Zielbewusstheit) des Erziehers (z. B. der Mutter) und in bedachten Handlungen, die der Zielrealisierung dienen. Die Entwicklung erzieherischer Bewusstheit äußert sich in der Entstehung differenzierterer Zielvorstellungen sowie in der Auswertung von Effekten und Erfahrungen hinsichtlich erfolgreicher Handlungen von Erziehern und Zöglingen. Bewusstheit kann auch individuell in zunehmendem Maße so zum Qualitätsmerkmal von Lernprozessen werden, dass diese in Selbsterziehungsprozesse umschlagen (vgl. Kant 1890, S. 115). Mit der Entstehung der Pädagogik als Wissenschaft von der Erziehung und ihrer Anwendung wird es dann möglich, von pädagogischer Bewusstheit zu sprechen.

Das spezifische Merkmal der „unmittelbaren zwischenmenschlichen Beziehungen“ (Direktheit) war in vorindustriellen Gesellschaften von vorn herein ein ,natürliches“ Wesensmerkmal jeder mitmenschlichen Beeinflussung. Das änderte sich mit der Entwicklung der Schrift, des Buchdrucks und moderner Medien bzw. Kommunikationstechniken. Schon die Entwicklung der Schrift und der dadurch mögliche Briefverkehr schafft die Voraussetzungen für technisch vermittelte Beeinflussungen - also solchen, die nicht mehr im persönlichen Kontakt erfolgen. Das hat gravierende Folgen für die entsprechenden Prozessverläufe und deren Qualität: Es besteht nämlich nicht mehr in jedem Falle die Möglichkeit der direkten und relativ kontinuierlichen Rückmeldungen über die Effekte der Beeinflussungsbemühungen und die abgelaufenen Aneignungsprozesse, die mit zum Erziehungsprozess gehören. So wie sich ein Produkt erst im Prozess des Verkaufs als Ware realisiert, so vollendet sich auch ein Erziehungsprozess erst in seinem mehr oder weniger Ziel gemäßen Resultat, das der Erzieher wenigstens in seinen Grundzügen erkennen 
muss, um beurteilen zu können, ob es sich um Erziehung oder um gescheiterte Bemühungen gehandelt hat. Es ist ein Irrtum zu meinen, eine pädagogisch absichtsvolle Handlung eines Erziehers sei schon Erziehung. Allerdings sind die prä- und postinteraktiven Aktivitäten des Erziehers - also seine Planungen und Auswertungen bzw. Reflexionen - ebenfalls Bestandteile der Erziehung, wenn sie auf die mehr oder weniger erfolgreichen Interaktionen bezogen sind und den Grad der pädagogischen Bewusstheit mit bestimmen.

Seit der Erfindung der Presseerzeugnisse, des Rundfunks und Fernsehens erfolgen zahlreiche technisch vermittelte (also indirekte) Beeinflussungsprozesse, bei denen in der Regel keine Rückmeldung über erzielte Effekte erfolgt, die sofort in der weiteren Prozessgestaltung berücksichtigt werden. Das artspezifische Wesensmerkmal direkte soziale Interaktion (das ja nicht nur wegen des Feedbacks bedeutsam ist!) entfällt im Bereich der Medienwirkungen weitgehend. Zwar gibt es bei bestimmten Fernseh- und Rundfunksendungen von den Zuschauern bzw. Hörern Rückmeldungen, aber diese sind nicht durchgängig charakteristisch oder unmittelbar gestaltungswirksam im jeweiligen medialen Prozess. Dass Art und Grad der Bewusstheit in Erziehungsprozessen historisch und individuell unterschiedlich ausgeprägt waren und sind, ist ebenso klar wie die jeweils unterschiedliche Intensität und Qualität der „Direktheit“, d. h. der unmittelbaren zwischenmenschlichen Beziehungen zwischen den Personen in den sozialen Interaktionen. Soziale Interaktionen vollziehen sich in Kommunikationsprozessen, in denen verbal und nonverbal (durch Mimik, Gesten, Körperhaltung) Informationen ausgetauscht werden, die Erkenntnisse und Gefühle vermitteln bzw. erzeugen. Bei der Bildung allgemeiner Begriffe zwecks wissenschaftlicher Erfassung komplizierter Objekte wird von den realen historisch und individuell bzw. situativ unterschiedlichen Ausprägungsgraden der einzelnen Merkmale abgesehen, d. h. abstrabiert. Wissenschaftliche Begriffe sind ihrem Wesen nach isolierende und idealisierende Abstraktionen, d. h., sie lösen empirisch beobachtbare Merkmale aus ihrem realen Zusammenhang heraus und fassen sie zum Zweck der Begriffsdefinition in reiner oder idealisierter Form. Eine solche Verknüpfung abstrahierter Merkmale liegt auch in der o. g. Erziehungsdefinition vor. Es handelt sich beim Erziehungsbegriff um einen Begriff, der eine Klasse von Prozessen erfasst, die durch Handlungen hervorgerufen werden (z. B. Unterrichten, angeleitetes Üben, Loben, Strafen usw.) und in diesem Sinne durchaus um einen „Handlungsbegriff“ und nicht nur um einen „Legitimationsbegriff“, wie Hermann Giesecke meint (1996, S. 8).

Mit dem Begriff der Bewusstheit wird nicht nur die Absicht erzieherischer Kräfte charakterisiert, sondern auch ein mehr oder weniger differenziertes Wissen um die Bedingungen und Möglichkeiten ihres Handelns. Wenn in der Definition schlechthin von Bewusstheit gesprochen wird, dann drückt sich darin der idealisierende Charakter der Abstraktion aus, denn es ist klar, dass es keine totale Bewusstheit und kein rein bewusstes Handeln gibt. Niemand ist in der Lage, alle Bedingungen und Möglichkeiten seines erzieherischen 
Handelns zu berücksichtigen. Es treten immer spontane Regungen in den Zöglingen und zufällige Umwelteinflüsse auf, die erzieherische Erfolge oder auch Misserfolge mit bestimmen, was u. a. Eduard Spranger (1882-1963) veranlasst hat, ein Buch zum „Gesetz der ungewollten Nebenwirkungen in der Erziehung“ zu schreiben (1962).

Dass es sich bei dem Merkmal der Bewusstheit auch um eine Abstraktion von fließenden Übergängen handelt, ist leicht einzusehen; man prüfe nur einmal, wie viel erzieherische $B e$ wusstheit (im Sinne von Ziel- und Methodenbewusstheit) bei verschiedenen Müttern im Umgang mit ihren Kindern tatsächlich im Spiele ist - von pädagogischer Bewusstheit im Sinne erziehungswissenschaftlich begründeter ganz zu schweigen! Vielfach entsteht erzieherische Bewusstheit aus der normalen Interaktion heraus in dem Moment, in dem eine Mutter meint, ihr Kind durch Verbot (= Methode) vor einer schädlichen Handlung bewahren oder durch Aufforderung zu einer nütəlichen Handlung bewegen zu müssen. Die meisten Interaktions- und Kommunikationsprozesse verlaufen obne erzieherische Absichten und zeichnen sich allenfalls durch die Beispielwirkung der Kommunikationspartner bezüglich bestimmter Lebensanschauungen, Lebensstile und Handlungsweisen aus. Abgesehen von den individuellen Unterschieden in der Bewusstheit von Prozessen der Persönlichkeitsveränderung bei Erziehern und zu Erziehenden, gibt es natürlich auch historisch bedingte Arten und Grade von Bewusstheit bei den erzieherischen Kräften, was jeder Vergleich aktueller Schulverhältnisse mit überlieferten historischen Darstellungen über den „Unterrichtsbetrieb“ in früheren Schulen erkennen lässt.

Direkte soziale Interaktionen in Verbindung mit ihren unmittelbaren zwischenmenschlichen Beziehungen sind wichtig für die Abgrenzung der Erziehung von technisch vermittelten Medieneinflüssen. Wenn man die „Direktheit“ als spezifisches Merkmal der Erziehung anerkennt, dann sind die absichtsvollen Einflüsse des Fernsehens keine Erziehungsprozesse im oben definierten Sinne - auch wenn sie oft wirkungsvoller sind als die erzieherischen Bemühungen von Eltern oder Berufserziehern. Aber auch die unbewussten und mehr oder weniger zufälligen wechselseitigen (direkten) Beeinflussungen im zwischenmenschlichen Kontakt sind noch nicht Erziehung im oben definierten Sinne, obgleich durch Nachahmungen sehr viel gelernt und in der Umgangssprache die z. T. unbewusste Vorbildwirkung von Eltern oft als Erziebungseinfluss bewertet wird.

Erst aus der Wirksamkeit einer bewussten Absicht zur Persönlichkeitsentwicklung in Verbindung mit pädagogischer Führung und persönlichen Lernbemühungen resultiert Erziiehung. Erzieherische Bewusstheit kann allerdings bei einem Menschen so entwickelt sein, dass er sich selbst führt und erzieht. Im Falle der Selbsterziehung sind gewissermaßen Erzieher und zu Erziehender in einer Person vereint (siehe auch S. 23). Aus dieser Sicht kann auch die Auffassung von Heinz-Hermann Krüger nicht akzeptiert werden, der meint:

„Da alle Lebensalter heute lernwillig und von Lernprozessen abhängig sind, hat der Erziehungsbegriff an Bedeutung eingebüßt“" (Krüger 2002, S. 280). 
Krüger übersieht, dass intensives und bewusstes Lernen seinem Wesen nach Bestandteil von Selbsterziehung sein kann, das innere Anstrengungen und Anregungen von außen benötigt. Außerdem sei darauf verwiesen, dass bereits Paul Natorp (1854-1924) einen wesentlichen Zusammenhang von Lernen und Erziehen wie folgt charakterisiert hat:

„Das theoretische Lernen kann auch in dem Sinne nur selbsteigene Leistung sein, daß es vom Wollen abhängt. [...] Also ist gewiß jeder wahre, nämlich freie Einsicht und nicht bloß autoritative Annahme wirkende Unterricht zugleich eine Erziehung, nicht als ob die bloße Verstandesbelehrung von selbst den Willen bewegte, sondern vielmehr umgekehrt, indem die Verstandesbelehrung ohne Willensentwicklung gar nicht erreicht würde“ (Natorp 1920, S. 92).

Da es viele Anregungen aus der Umwelt gibt, die nicht persönlichkeitsfördernder Natur sind, bedarf es im Entwicklungsprozess aller Altersgruppen gelegentlich auch „korrigierender Bemühungen“, so dass wir sagen können: Erziehung wird nicht überflüssig, sie verliert nicht grundsätzlich an Bedeutung; es verändern sich nur die Qualitäten und Intensitäten der Wirkungskräfte von Fremd- und Selbsterziehung in den Erziehungsprozessen. So wie es praktisch keine erfolgreiche Fremderziehung obne selbsterzieherische Bemühungen gibt, so gibt es umgekehrt auch keine Selbsterziehung ohne mehr oder weniger bewusste Anstöße von außen; niemand kann sich „,aus sich selbst heraus“ erziehen. Auch nach Natorp „,ist Selbsterziehung erst Resultat der Erziehung durch Andre“ (Natorp 1920, S. 5).

Im Erziehungsbegriff als Grundkategorie der Pädagogik sind also prinzipiell beide Komponenten enthalten, daher bleibt er in seiner Bedeutung bestehen. Gieseckes Behauptung vom „Ende der Erziehung“ ist wohl Ausdruck unzureichender begrifflicher Vorstellungen von Erziehung, in denen veraltete methodische Konzepte von Erziehung nicht klar vom Wesen der Erziehung unterschieden werden. Es ist zudem unlogisch, wenn einerseits der historische Charakter der Erziehung betont wird und die historischen Vorstellungen von Erziehung differenziert erörtert werden (vgl. z. B. Historisches Wörterbuch der Pädagogik 2004) und andererseits nicht die Bereitschaft besteht, die aktuellen Merkmale von Erziehung als solche anzuerkennen. Wenn Giesecke einen Paradigmen- oder Perspektivwechsel „von Erziehung zur Lernhilfe“ konstatiert (1992, S. 67), dann übersieht er offenbar, dass Lernhilfe schon immer ein Wesensmerkmal von Erziehung gewesen ist. Im Widerspruch zu dem auch „,werbespsychologisch“ formulierten Titel „Das Ende der Erziehung“ charakterisiert Giesecke selbst in seinem Buch u. a. die erzieherischen Aufgaben des Unterrichts in prägnanter und zutreffender Weise (vgl. 1996, S. 145). Und schließlich sollte nicht übersehen werden, dass jede Abwertung oder Geringschätzung von Erziehung die Gefahr in sich birgt, dass dann bei auftretenden Verhaltensschwierigkeiten von Kindern bzw. Schülern nach dem Therapeuten gerufen wird. Damit werden aber Erzieher und Zöglinge von ihrer jeweiligen Verantwortung entlastet und die Mängel in der Erziehung (Verwöhnung, Überbehütung, Vernachlässigung, Gleichgültigkeit usw.) u. U. unreflektiert fortgesetzt (vgl. S. 130f. und Seibert 1994, S. 811). 
In Anbetracht der Kompliziertheit und Mehrdeutigkeit des Entwicklungsbegriffs (vgl. Oerter/Montada 1998, S. 1-24) wird nunmehr der Begriff der psychischen und physischen Veränderungen des Menschen in der Tätigkeit als Gattungsbegriff für die folgende Definition gewählt - ausgenommen sind dabei jene Veränderungen, die durch physikalische, chemische und biologische Einwirkungen hervorgerufen werden und demzufolge als $V e r-$ letzungen oder Erkerankungen Gegenstand der Medizin sind. Die Veränderungen in der Tätigkeit erfolgen durch Erkenntnis-, Erlebnis- und Lernprozesse unterschiedlicher Art; sie lassen sich unter mehreren Aspekten charakterisieren, z. B. in Abhängigkeit

- von der Art der Einflussfaktoren (Naturerlebnisse, menschliche Kunstwerke, Menschengruppen, Medien) und ihrer Verarbeitung durch die Beeinflussten;

- von der Art und dem Grad der Bewusstheit und Aktivität aller Beteiligten;

- von der Art der Beziehungen zwischen den Beteiligten (direkte oder technisch vermittelte, freundliche oder feindliche, distanzierte oder vertrauliche usw.) und schließlich

- hinsichtlich der Qualität der Effekte bei den Tätigen (stimulierend oder niederdrückend, förderlich oder deformierend, nachhaltig oder flüchtig usw.).

Mit Hilfe der beiden artspezifischen Merkmale (vgl. S. 13) „Bewusstheit “ und „Direktheit" (oder besser: direkte soziale Interaktionen) lassen sich aus der Fülle von Prozessen der Persönlichkeitsveränderung (durch Tätigkeit) jene herausfinden, die als Erziehung bezeichnet und in folgender Definition zusammengefasst werden können:

Erziehung ist die bewusst geführte und in sozialen Interaktionen erfolgende nachhaltige Veränderung des Menschen durch Auseinandersetzung mit der Umwelt und sich selbst entsprechend Erfordernissen gesellschaftlicher Reproduktions- und Entwicklungsprozesse sowie kollektiver und individueller Welt- und Wertvorstellungen der prozessführenden Kräfte.

Dass es sich bei dieser Definition um eine Abstraktion von fließenden Übergängen und zugleich um eine idealisierende Abstraktion handelt, wird in folgenden Gesichtspunkten deutlich, die gewissermaßen immer mit bedacht werden müssen:

- In jedem realen Erziehungsprozess ist der Grad der Bewusstheit der prozessführenden Kräfte verschieden; es mischen sich immer bewusste Bemühungen mit spontanen Wirkfaktoren aus dem gesamten Lebenszusammenhang, deren sich die Prozessbeteiligten oft kaum oder gar nicht bewusst sind.

- Die zwischenmenschlichen Beziehungen in den sozialen Interaktionen sind jeweils unterschiedlich intensiv und vertrauensvoll, in jedem Falle aber durch 
wechselseitige Kommunikationen mit einem relativ kontinuierlichen wechselseitigen Feedback verknüpft. Über dieses Feedback kann ein Erzieher auch Wirkungen andersartiger erzieherischer und nichterzieherischer Einflïsse bemerken, um sie im weiteren Vorgehen zu berücksichtigen.

- Der minimale Grad an Bewusstheit bezüglich der Veränderung des Menschen und der minimale Intensitätsgrad der zwischenmenschlichen Beziehungen, die gegeben sein müssen, damit von Erziehung gesprochen werden kann, sind empirisch nicht bestimmbar, weil es dafür keine Maßeinheiten und Messmethoden gibt. Dennoch ist in dem ,heterogenen Kontinuum“ (vgl. Hassenstein 1954) zwischen unbewussten Beeinflussungen bei zufälligen Begegnungen und bewussten, planmäßigen erzieherischen Interaktionen ein Punkt anzunehmen, bei dem die Absicht zur Beeinflussung und ibre bewusste Realisierung im direkten Kontakt einen solchen Grad erreicht haben, dass von Erziehung gesprochen werden kann.

- Die Auseinandersetzungen mit der Umwelt und mit sich selbst erfolgen spielend, beobachtend-erkennend, kommunizierend und reflektierend, moralisch und ökonomisch bewertend, produktiv, praktisch und politisch handelnd, künstlerisch gestaltend bzw. rezipierend und schließen entsprechende Lernprozesse ein, deren Richtung maßgeblich durch die Führung gesellschaftlicher Kräfte (Eltern, Lehrer, Ausbilder, Sozialpädagogen usw.) bestimmt wird und deren Effiqienz wesentlich von den eigenen Bemühungen der Lernenden (insbesondere von der Selbsterziehung) abhängt. Pädagogisch zielgerichtete Auseinandersetzungen erfordern zweckmäßige Arrangements von Bedingungen und Mitteln, wofür die Erzieher verantwortlich sind. Auseinandersetzung mit sich selbst bedeutet vor allem Selbsterziehung, die Prange (2000, S. 75) als „,höchsten Punkt der Erziehung“ bezeichnet.

- Lernprozesse sichern die Nachbaltigkeit von Veränderungen und sind Gegenstand von Lerntheorien, mit denen sich auch Sozialpädagogen beschäftigen sollten. In dieser Schrift wird ein weiter Lernbegriff verwendet, der Verhaltensveränderungen des Menschen durch Aufnahme und Verarbeitung von Informationen in Verbindung mit geistigen und körperlichen Übungshandlungen sowie Umlernprozessen umfasst. In Diskussionen nach 1945 bzw. nach der Vernichtung des NS-Regimes wurde in der Erwachsenenbildung aus nahe liegenden Gründen auf die „Umerziehungsfunktion der Erwachsenenbildung“ orientiert, was Schaller veranlasste, von einer dialektischen Einheit von Neulernen und Umlernen zu sprechen. Es muss nämlich berücksichtigt werden, dass Lernprozesse immer mit bereits vorhandenen Verhaltensweisen und schon angeeigneten Bewusstseinsinhalten in Wechselwirkung stehen. Es ist jedoch ein Unterschied, ob unklare Vorstellungen und unsichere Verhaltensweisen durch Lernprozesse präzisiert bzw. stabilisiert werden oder ob Milieu abhängig erlernte und verfestigte 
inakzeptable Normen, Wertvorstellungen und Verhaltensweisen zu korrigieren sind, was ja in sozialpädagogischen Prozessen geschehen soll.

- Mit der Kennzeichnung der Erziehung als Bestandteil des gesellschaftlichen Reproduktionsprozesses über Generationen hinweg wird angedeutet, dass sie für die Existenzsicherung der Menschheit unentbehrlich ist und im System der gesellschaftlichen Triebkräfte eine große Rolle spielt, denn es geht nicht nur um eine einfache Reproduktion, sondern um eine erweiterte, die Innovationen mit einschließt und daher auch schöpferische Persönlichkeiten erfordert.

- Die Bezugnahme auf die Welt- und Wertvorstellungen der Prozessführenden soll einer unzulässigen Einengung auf „Erziehung von tauglichen Arbeitskräften" vorbeugen und zugleich einen allgemeinen Erziehungsbegriff kennzeichnen, der für Erziehung unter verschiedenen gesellschaftlichen Bedingungen mit ihren historisch-konkreten Ausprägungen durch entsprechende spezifische Merkmale angereichert werden kann. Wenn sich bspw. Baldur Kozdon eine Erziehung ohne jegliche Religion nicht recht vorzustellen vermag (vgl. 1994, S. 716), dann setzt er wohl in unzulässiger Weise Weltanschauung und Religion gleich; er berücksichtigt nicht, dass auch eine areligiöse Weltanschauung ihre Wertvorstellungen hat, die Erziehung erfordern und ermöglichen.

Die reale Erziehung, die mittels o. g. Merkmale erkennbar ist, wird in der vorliegenden Schrift als Gegenstand der Pädagogik betrachtet. Die Definition bestimmt den Grundbegriff als tragende Kategorie der Pädagogik. Die genannten Begriffsmerkmale sind persistent, d. h. beständig oder „erblich“ in dem Sinne, dass sie in unterschiedlicher Ausprägung und verknüpft mit weiteren Merkmalen in den sich historisch wandelnden Erziehungssytemen sowie ihren spezifischen Erziehungsbereichen durchgängig auftreten.

Die Rede von einer „Erziehung im weitesten Sinne“, womit auch zufällige und unbeabsichtigte Einflüsse mit ibren Wirkungen erfasst werden, behindert oder erschwert die Entwicklung der Erziehungswissenschaft. Zufällige und unbeabsichtigte Einflüsse auf Menschen und ihre Wirkungen - auch als funktionale Erziehung bezeichnet - sind zwar wegen ihrer förderlichen oder destruktiven Effekte in der Erziehungspraxis bedeutsam und für die Pädagogik von Interesse, aber nicht ihr eigentlicher Gegenstand! Für die Unterscheidung von intentionaler (absichtsvoller) und funktionaler Erziehung sind nicht allein der moralische Inhalt oder die Nachhaltigkeit der Wirkungen wesentlich, sondern die Struktur und Funktionsweise des Prozesses auf der Grundlage der in der Definition genannten spezifischen Bedingungen. So wirken beispielsweise die Erlebnisse, der Umgangston, die Normen in einer Peer-Gruppe auf einzelne ihrer Mitglieder oft nachhaltiger als die bewussten erzieherischen Bemühungen der Eltern, d. h., die sog. funktionale Erziehung kann - zumindest zeitweilig oder teilweise - stärker sein als die intentionale. Das ist jedoch kein Grund zur Erweiterung des Gegenstandes der Pädagogik, wohl aber 
ein Grund für Erzieher, ihre Erziehungsmethoden zu überprüfen, um möglichst ein Dominieren der intentionalen Erziehung zu sichern. Allerdings wäre es ein Fehler, die sog. funktionale Erziehung nur als destruktiven Prozess zu bewerten. In der Praxis kann zum Beispiel die Erfahrung mit einem noch glimpflich abgelaufenen Autounfall wirkungsvoller sein als ein mehrstündiger Lehrgang in Verkehrserziehung.

Die hier vorgestellte und im Vergleich zur Kurzfassung von Schaller (S. 13) differenziertere Erziehungsdefinition unterscheidet sich von der „hypothetischen Leitdefinition“ von Hans Bokelmann, die von Maximilian Buchka im Studienbuch für soziale Berufe „Pädagogik - Grundlagen und Arbeitsfelder“" wie folgt zitiert wird:

„Erziehung ist dasjenige Handeln, in dem die Älteren (Erzieher) den Jüngeren (Edukanden ${ }^{3}$ ) im Rahmen gewisser Lebensvorstellungen (Erziehungsnormen) und unter konkreten Umständen (Erziehungsbedingungen) sowie mit bestimmten Aufgaben (Erziehungsgehalten) und Maßnahmen (Erziehungsmethoden) in der Absicht einer Veränderung (Erziehungswirkungen) zu eigener Lebensführung verhelfen, und zwar so, daß die Jüngeren das erzieherische Handeln der Älteren als notwendigen Beistand für ihr eigenes Dasein erfahren, kritisch zu beurteilen und selbst fortzuführen lernen“(Badry, Buchka et al. 1994, S. 142; Bokelmann 1970, S. 185f.).

Bokelmann bindet Erziehung in traditioneller Weise an ein natürliches Merkmal, nämlich an den Altersunterschied zwischen Erziehern und Edukanden. Inzwischen setzt sich aber die Erkenntnis durch, dass nicht ein Generationsverhältnis oder Altersunterschied, sondern eine ziel- und prozessrelevante Kompetenzüberlegenheit im Sinne des jeweils geltenden Wertesystems den Erzieher auszeichnet, was die Rolle der Erziehung in der Generationsfolge natürlich nicht aufhebt.

Bokelmann betont in den Erläuterungen zu seiner „hypothetischen Leitdefinition“ mehrfach das „Zusammenhandeln zwischen Erzieher und Edukand“ (Bokelmann 1970, S. 179, S. 192ff.). Das ist fundamental, denn wenn ein Zögling nicht entsprechend einer Erzieherhandlung reagiert, so war sie allenfalls ein Versuch, einen Erziehungsprozess in Gang zu setzen. Selbst wenn ein Zögling auf die Maßnahme eines Erziehers widerwillig oder widerständig reagiert, handelt es sich um Erziehung, solange beide mit der Lösung des Widerspruchs ringen und der Zögling „,nicht aus dem Felde geht“.

Die Erläuterungen Bokelmanns zur Leitdefinition enthalten viele wertvolle Hinweise auf vermeidbare Erziehungsfehler und differenzierte Erörterungen zu methodologischen Problemen pädagogischer Theoriebildung. Er schließt auf Seite 191 auch eine bewusste Übernahme „,von pädagogischen Rollen“ durch den Edukanden nicht aus („,falls dieser dazu fähig ist“), aber er vermeidet das Wort „,Selbsterziebung“. Manche Autoren lehnen den Begriff der Selbsterziehung sogar explizit ab; nach Hobmair u. a. ist es

3 Edukand (aus dem Lateinischen: educandus) = zu Erziehender oder Zögling, ein in allgemeinen pädagogischen Abhandlungen vielfach verwendetes Wort, um den mit der umgangssprachlichen Bedeutung des Wortes „Z̈̈gling“ verbundenen negativen „Beigeschmack“ zu vermeiden. 
„logisch verwirrend, von Selbsterziehung zu sprechen“, weil Erziehung auf sozialer Interaktion beruht. „Was auch immer mit »Selbsterziehung" gemeint sein mag, dieser Sachverhalt sollte eher »intentionales Lernen«, »Selbststeuerung« oder »Selbstverwirklichung« genannt werden“ (Hobmair u. a. 1989, S. 83).

Abgesehen davon, dass „Selbststeuerung“ und „Selbstverwirklichung“ andere Dimensionen haben als Selbsterziehung, berücksichtigen die o. g. Vorschläge nicht, dass jener Prozess, den die Lernpsychologie als intentionales Lernen bezeichnet, aus pädagogischer Sicht auch Selbsterziehung genannt werden kann. Es geht dabei um die Planung von Lernprozessen, das Hinterfragen von Zielen bzw. Werten und Normen, um Entschlüsse und Entscheidungen, bestimmte Handlungen und Verhaltensweisen zu praktizieren oder zu unterlassen, also um Situationsanalysen, Lebensplanungen, Selbstreflexionen mit Selbstbewertungen, Selbstbeherrschung, Selbstüberwindung und Selbststeuerung als wesentliche Momente selbsterzieherischer Kompetenz. In diesem Sinne demonstriert z. B. jeder werdende Violinvirtuose oder Spitzensportler, was Selbsterziehung ist, wenn er sich entsprechend seiner selbsterzieherischen Kompetenz fast „,äglich schindet“! Außerdem ist Selbsterziehung grundsätzlich für die persönliche Überlebensoptimierung - speqiell bei Suchtgefährdeten - von großer Bedeutung.

Erziehung umfasst in der Regel die Einheit von Fremd- und Selbsterziehung, schließt aber auch eine relativ eigenständige Selbsterziehung nicht aus, die vor allem in Auseinandersetzungen mit problematischen und deformierenden Kräften der Gesellschaft notwendig ist! Sicherlich spielen bei Kindern die fremderzieherischen Einwirkungen eine größere Rolle als bei Erwachsenen, weil Letztere vielfach durch hohe Anforderungen ihres Arbeits- und Lebensalltags gezwungen werden, sich selbst zu erziehen. Übrigens weiß jeder Erzieher aus Erfahrung, dass ohne das eigene Wollen und Bemühen seines Zöglings kein nachhaltiger Erfolg zu erwarten ist. Andererseits ist Selbsterziehung bei einem Kleinkind erst keimhaft vorhanden und äußert sich z. B. im Bemühen, den Erwartungen der Erzieher zu entsprechen. Aber bei der grundlegenden Begriffsklärung geht es nicht um Anteile oder Wirkungsunterschiede von Fremd- und Selbsterziehung, sondern um die Erziehung in ihrer Ganzheit. Die Leistungsfähigkeit einer Erziehungsdefinition ist vor allem daran zu erkennen, dass und wie sie begründete Abgrenzungen zu ähnlichen und anderen Prozessen der Persönlichkeitsveränderung ermöglicht, z. B. zur Sozialisation, Enkulturation, Personalisation und Manipulation.

Erziehung kann auch als Hilfe für Sozialisationsprozesse betrachtet werden, wie es die Autoren des von Hobmair herausgegebenen Lehrbuchs tun (vgl. Hobmair u. a. 1989, S. 94). Aber deswegen werden Erziehung und Sozialisation insgesamt nicht identische Prozesse. Ferner kann die helfende Funktion der Erziehung betrachtet werden hinsichtlich der Entwicklungsprozesse von Menschen, die aspekthaft mit den Begriffen der Personalisation (Aufbau des Personseins), der Individuation (Entwicklung einer eigen- 
ständigen Individualität mit entsprechendem Verantwortungsbewusstsein) und der Enkulturation (Aneignung der menschlichen Kultur) erfasst werden. Für die Kulturanthropologie ist der Begriff der Enkulturation tragend und für die Entwicklung der Pädagogik können ihre Forschungsergebnisse nützlich sein, aber es ist zumindest problematisch zu schreiben:

„Das Lernen der Kultur ist der eigentümliche und ganze Gegenstand der Pädagogik, zu dessen Bezeichnung wir von der Kulturanthropologie den Terminus ,Enkulturation, übernehmen“ (Loch 1969, S. 126; zitiert nach Kron 1991, S. 48).

Indem Werner Loch das Lernen zwecks Aneignung der Kultur zum „eigentümlichen“ und ,ganzen“ Gegenstand der Pädagogik erklärt, werden auch alle unbeabsichtigten und zufälligen Prozesse des Erfahrungssammelns und Lernens im kulturellen Kontext in den Gegenstandsbereich der Pädagogik eingeordnet. Dadurch wird seine Spezifik verkannt und der Status der Pädagogik als eigenständige Wissenschaft beeinträchtigt. Wirksame Sozialisationsfaktoren und kulturelle Einflüsse obne erzieherische Absichten gehören zwar mit zu den Bedingungen erzieherischen Handelns, sind aber nicht der eigentliche Gegenstand der Pädagogik.

Die Wörter Erziehung und Bildung haben sich in unterschiedlichen Bedeutungen im deutschen Sprachraum eingebürgert. Mit Rücksicht auf die Absichten und Möglichkeiten dieses Buches sei nur darauf verwiesen, dass in der DDR-Pädagogik das Begriffspaar „Erziehung und Bildung“ verwendet wurde, um den ganzheitlichen Erziehungsprozesses unter zwei Aspekten zu betrachten, nämlich hinsichtlich

- der zielstrebigen Entwicklung von moralischen Qualitäten oder Verhaltenseigenschaften der Persönlichkeit (= Erziehung im engeren Sinne) und

- der Leistungseigenschaften (Wissen und Können) als Voraussetzungen erfolgreichen Handelns (= Bildung im engeren Sinne).

Aus der Ganzheitlichkeit der Persönlichkeitsentwicklung ergibt sich die Forderung nach der Einheit von Bildung und Erziehung (i. e. S.) als Prinzip pädagogischen Handelns, d. h., alle Leistungsanforderungen sollen zugleich mit humanistisch orientierten Verbaltensanforderungen verbunden werden und umgekehrt. Aber auch die Trennung von Bildung und Erziehung ist historisch und praktisch bedeutsam, ermöglicht doch Bildung (i. e. S.) die Übermittlung und Aneignung auch solcher Erkenntnisse, die bei strikter Einhaltung der offiziell geforderten Erziehung (i.e. S.) aus Sorge vor einem weltanschaulichen, politischen oder moralischen Tabubruch negiert würden (vgl. Prange 2000, S. 56f.).

Neben dem engen, auf Leistungseigenschaften bezogenen Bildungsbegriff werden in der deutschen Kulturgeschichte unterschiedlich weite und inhaltich verschieden akzentuierte Bildungsbegriffe verwendet. Alfred Langewand gibt zu den theologischen, philosophischen, soziologischen und pädagogischen Begründungen und Interpretationen 
von Bildungsbegriffen einen informativen Überblick (siehe Langewand bei Lenzen 1994, S. 69ff.). Zur Orientierung seien hier nur einige wichtige Verwendungsmöglichkeiten des weiten Bildungsbegriffs genannt:

Bildung umfasst die Prozesse und Resultate

- der allgemeinen Menschenbildung und der Persönlichkeitsbildung,

- der Allgemeinbildung im Sinne der Aneignung von Grundlagen der menschlichen Kultur und der Spezialbildung auf unterschiedlichen Niveaus (z. B. Berufsbildung),

- der Volksbildung und der Elitebildung,

- der Schulbildung, der Bildung in Freizeitgruppen und der Selbstbildung,

- der Bildung in bestimmten Lebensaltern (z. B. frühkindliche Bildung, Jugendbildung, Erwachsenenbildung),

- der Bildung für bestimmte Lebens- oder Handlungsbereiche (z. B. politische Bildung, polytechnische Bildung, musische Bildung, mathematische Bildung),

- der Bildung aller oder auch nur spezieller Persönlichkeitsbereiche (z. B. Persönlichkeitsbildung, Charakterbildung, intellektuelle Bildung).

Zu den Merkmalen fast aller Bildungsbegriffe gehört die Entwicklung vorhandener Anlagen durch möglichst selbsttätige geistige Aneignung der Welt mit dem Ziel der Vervollkommnung der Persönlichkeit entsprechend humanistischer Normen, was auch unter nichtpädagogischen Bedingungen geschehen kann, z. B. beim Reisen und Fernsehen! Die Resultate aller Bildungsprozesse hängen immer vom eigenen Bemühen der sich bildenden Subjekte ab. Aus dieser Sicht kann das Prinzip der Einheit von Erziehung und Bildung auch so verstanden werden, dass Erziehung darauf gerichtet sein muss, das eigene Streben der Lernenden zu aktivieren, zu unterstützen und zu fördern. Verstöße gegen dieses Prinzip äußern sich darin, dass

- Erziehung nur als Verhaltensdrill praktiziert wird, bei dem Bildungsprozesse vernachlässigt werden, oder

- durch bloße Materialangebote sowie mangelhafte pädagogische Führung die Lernenden nicht effizient und hinreichend auf die steigenden - speziell auch moralischen - Anforderungen in Schule und Gesellschaft vorbereitet werden.

In neueren Pädagogiklehrbüchern werden als Ziele und Merkmale von Bildung vor allem Mündigkeit, Emanzipation und Partizipation der Menschen angesehen (vgl. u. a. Kaiser/Kaiser 1991, S. 65). Dieser Bildungsbegriff berücksichtigt nicht jene Lernprozesse, auf die Jansen, Schreiber u. a. bei ihren sozialpädagogischen Bemühungen um jugendliche Straftäter gestoßen sind und auch als Bildung bezeichnen. Es handelt sich um Lernprozesse, die in asozialen Milieus ablaufen und außer moralischer Deformation beachtliche geistige und „soziale“ Fähigkeiten hervorbringen, die es den Lernenden ermöglichen, sich 
in destruktiven Milieus zu behaupten (vgl. Jansen u.a. 2006, S. 127ff.). Aus dem Dargelegten kann man schlussfolgern: Bildung ist primär eine Komponente der Individualentwicklung, die der Selbstentfaltung und Selbstbehauptung der Persönlichkeit dient. Erziehung ist wesentlich eine Komponente des gesellschaftlichen Reproduktions- und Entwicklungsprozesses, die einer optimalen Gestaltung von Natur und Gesellschaft dienen sollte. Beide im Lernen zusammenfallende Prozesse erfahren unter ihren Realisierungsbedingungen jeweils spezifische Ausprägungen, die sich in speziellen Begriffsmerkmalen und Bezeichnungen widerspiegeln (Arbeitserziehung, musische Bildung usw.).

Der Gebrauch des Wortes Bildung durch mehrere Wissenschaften ist vielfältig und lässt keinen eindeutigen Begriffsinhalt erkennen. Schon allein aus diesem Grunde kann der Bildungsbegriff nicht als tragende Kategorie für die weitere Entwicklung der Sozialpädagogik genutzt werden. Daher betrachten wir den Erziehungsbegriff - ungeachtet aller Definitionsprobleme - als basale Kategorie.

Auf die Grenzen relativ kurzer Definitionen hat übrigens schon Engels hingewiesen: „Alle Definitionen sind wissenschaftlich von geringem Wert. Um wirklich erschöpfend zu wissen, was Leben ist, müßten wir alle seine Erscheinungsformen durchgehen, von der niedrigsten bis zur höchsten. Für den Handgebrauch sind jedoch solche Definitionen (gemeint ist: Leben = Daseinsweise der Eiweißkörper usw.; W. N.) sehr bequem und stellenweise nicht gut zu ent behren; sie können auch nicht schaden, solange man ihre unvermeidlichen Mängel nicht vergißt“" (MEW, Bd. 20, S. 77).

Was Engels über die Definition des Lebens sagt, gilt auch für die Definition der Erziehung. Daher ist die Kritik von Bernhard Schwenk in Rowohlts Enzyklopädie „Pädagogische Grundbegriffe“ (1993, Bd. 1, S. 431) an der Erziehungsdefinition in der „Einführung in die Pädagogik“ (1975) von Naumann gegenstandslos. Schwenk beachtet nicht die Grenzen von Begriffsdefinitionen, wenn er verlangt, dass eine Definition des Erziehungsbegriffs die Merkmale der Erziehung früherer Epochen und außereuropäischer Kulturen konkret (also als Totalität vieler Bestimmungen) mit erfassen muss.

Engels verweist analog zu Georg W. F. Hegel (1770-1831) darauf, dass es für eine „erschöpfende“ wissenschaftliche Erkenntnis notwendig ist, alle Erscheinungsformen des zu Definierenden - „,von der niedrigsten bis zur höchsten“ - durchzugehen, denn

„daß das Wissen nur als Wissenschaft oder als System wirklich ist und dargestellt werden kann; daß ferner ein sogenannter Grundsatz oder Prinzip der Philosophie, wenn er wahr ist, schon darum auch falsch ist, insofern er nur als Grundsatz oder Prinzip ist. - Es ist deswegen leicht, ihn zu widerlegen. Die Widerlegung besteht darin, daß sein Mangel aufgezeigt wird; mangelhaft ist er, weil er nur das Allgemeine oder Prinzip, der Anfang ist" (Hegel 1964, S. 23).

Was Hegel hier über Prinzipien der Philosophie sagt, gilt auch für die Pädagogik, denn hinter dem Merkmal „Veränderung der Persönlichkeit“ steht die Gesetzeserkenntnis: 
Persönlichkeiten verändern sich in der Tätigkeit. Diese Erkenntnis hat im Prinzip der Selbsttätigkeit der Lernenden ihren Niederschlag gefunden. Aber Erziehung erschöpft sich nicht in der Anwendung eines Prinzips oder Beachtung einiger Wesensmerkmale.

Dass die hier vorgestellte Erziehungsdefinition trotz ihrer unvermeidlichen Mängel „nicht gut zu entbehren“ ist, zeigt sich bei der Bewertung umgangssprachlicher Wendungen und Vorurteile. Wenn z. B. gesagt wird: Arbeit erzieht, dann ist das, vom Standpunkt der o. g. Definition aus betrachtet, falsch, denn Arbeit (im Sinne des Stoffwechsels zwischen Mensch und Natur) ist bewusst auf die Herstellung von Produkten und nicht auf die Veränderung von Menschen gerichtet. Dass sich die Arbeitenden in diesem Prozess selbst auch verändern, ist klar; doch die Veränderungen erfolgen nicht immer im Sinne humaner Persönlichkeitsbildung oder pädagogischer Ziele, sondern leider auch im Sinne von Deformationen - denken wir nur an die inhumanen Effekte monotoner Fließbandarbeit. Natürlich können Arbeitsprozesse auch als Mittel der Eræiehung genutzt werden, aber dann erfordernt sie von ihren Organisatoren zusätzlich pädagogisch durchdachte Konzeptionen und pädagogisch geeignete Mitarbeiter als „Lehrmeister“.

Die hier vorgestellte und begründete Auffassung von Erziehung unterscheidet sich wesentlich von der, die Jürgen Oelkers wie folgt formuliert:

„Unter »Erziehung« kann allgemein die moralische Kommunikation zwischen Personen und Institutionen sowie mit und über Medien verstanden werden, soweit sie auf dauerhafte Einwirkungen abzielt und ein Gefälle voraussetzt“" (Benner/Oelkers 2004, S. 304).

Diese Begriffsbestimmung ruft folgende Einwände und Fragen hervor:

- Wenn Erziehung immer an eine „Kommunikation zwischen Personen und Institutionen“ gebunden wäre, dann gäbe es keine Selbsterziehung.

- Was ist mit „moralischer Kommunikation“ gemeint? Wenn es dabei nur um formulierte Moralnormen, moralische Anforderungen oder Bewertungen geht, fallen viele andere Kommunikationsinhalte - z. B. die der ästhetischen, intellektuellen und körperlichen Erziehung - aus dem Erziehungsbegriff heraus.

- Wo bleiben die zu jedem Erziehungsprozess gehörenden und für das Resultat entscheidenden Übungen, die nicht Bestandteil zwischenmenschlicher Kommunikation, sondern der individuellen Selbsttätigkeit oder Selbsterziehung sind?

- Wie ist die Formulierung „mit und über Medien“ gemeint? Das Schreiben und das Lesen eines Buches sind gesonderte Prozesse, deren Subjekte nur selten miteinander kommunizieren. Natürlich können Bücher, Filme, CDs usw. als Mittel der Erziehung genutzt werden, indem die Erzieher sie in die Kommunikationsprozesse mit ihren Zöglingen pädagogisch sinnvoll einordnen, um ihre Potenzen zu nutzen. Wenn man aber eine „Kommunikation“ über das Medium Fernsehen als Erziehung bezeichnet, dann werden zwei qualitativ verschiedenartige 
Prozesse in unzulässiger Weise gleichgesetzt. Es ist ein wesentlicher Unterschied, ob ein einseitiger Übermittlungsprozess oder ein auf wechselseitiger Kommunikation beruhender und daher durch wechselseitiges Feedback charakterisierter Prozess abläuft, der qielstrebige Individualisierungen ermöglicht.

- Wie „dauerhaft“ muss eine „Einwirkung“ sein, damit von Erziehung gesprochen werden kann? Oder sind vielleicht dauerhafte Effekte gemeint? Doch diese hängen weniger von Einwirkungen und auch nicht allein von Kommunikationsprozessen ab, sondern von den Tätigkeiten der Lernenden, insbesondere von den damit verbundenen Übungs-, Anwendungs- und Gewöhnungsprozessen.

- Ist der bildhafte Begriff „Gefälle“ für eine Definition geeignet?

Die analysierte Begriffsbestimmung lässt erkennen, wie schwierig es ist, eine eindeutige, relativ umfassende und leistungsfähige Erziehungsdefinition zu formulieren.

Auf der Grundlage der in Anlehnung an Schaller auf S. 19 erfolgten Definition lassen sich die wesentlichen Merkmale des Erziehungsbegriffs übersichtlich durch ein klassenlogisches Schema verdeutlichen, wobei der Erziehungsbegriff als Durchschnittsklasse erscheint:

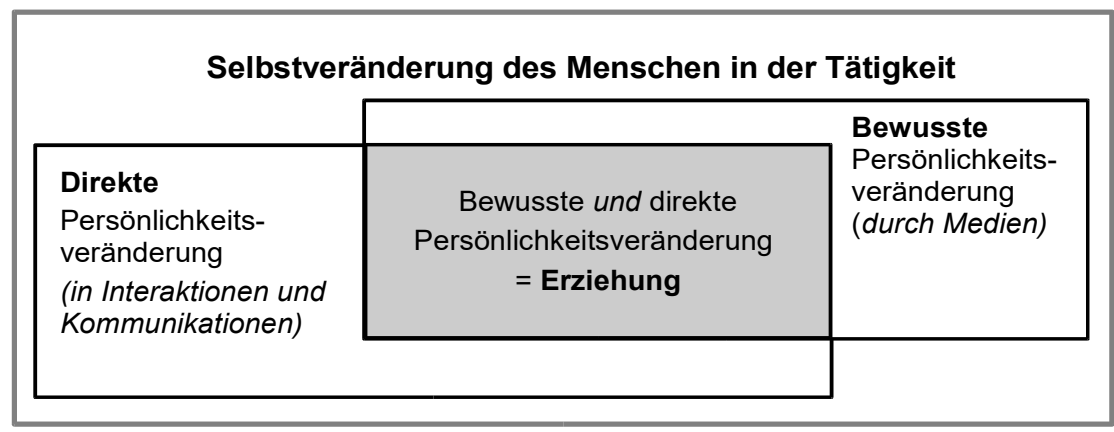

Schema 1

Die Kategorie Erziehung ist eine idealisierende Abstraktion von fließenden Übergängen und widerspiegelt in ihren invarianten Wesensmerkmalen das Zusammenwirken gesetzmäßiger Prozesse, Aktivitäten und Zusammenhänge, d. h.:

- Persönlichkeiten verändern sich in Tätigkeitsprozessen,

- wobei die Beziehungen zwischen den gemeinsam Tätigen die funktionale Wirksamkeit bewusster Bemühungen um Persönlichkeitsveränderung determinieren.

- Entscheidend für die Richtung der Veränderung ist die Führung der Aktivitäten

- und für die realen Eræiehungsresultate das eigene Bemühen der Lernenden. 


\subsection{Zur Fundierung eines Systems pädagogischer Erkenntnisse}

Die Geschichte der Pädagogik als Wissenschaft ist gekennzeichnet durch das Bemühen von Philosophen und Pädagogen, wesentliche und für das Handeln bedeutsame Zusammenhänge in den vielfältigen Erscheinungen der Erziehungswirklichkeit zu erkennen. Sie mussten daher die empirisch gewonnenen Vorstellungen analysieren, d. h. aus der Vielfalt der Erscheinungen durch isolierende Abstraktion wesentliche Momente herausheben, z. B. die Tatsache, dass in den beobachtbaren Erziehungsprozessen Eryieher und zu Erziehende anzutreffen sind, die sich mit bestimmten Methoden um die Realisierung bestimmter Ziele bemühen. Auf diese Weise ermittelten sie grundlegende Elemente des „lebendigen Ganzen“, die in „dünnen Abstraktionen“ (vgl. MEW, Bd. 42, S. 35f.) ihren Niederschlag fanden. Zweifellos handelt es sich bei dem Begriff „Ziel“ um eine solche dünne Abstraktion, solange wir nicht wissen, welchen Inhalt es hat, welche Struktur es besitzt, welche Funktionen es im Erziehungsprozess erfüllen soll usw. Zugleich galt es, die wesentlichen Relationen zwischen den bei der Analyse erkannten Elementen aufzudecken und auf ihrer Grundlage eine solche Synthese (= Zusammenfassung vieler Bestimmungen und Beziehungen) vorzunehmen, dass eine möglichst differenzierte Vorstellung von den konstitutiven Elementen und ibren Zusammenhängen entsteht.

Marx beschreibt den Erkenntnisprozess in Anlehnung an Hegel (1964, S. 79ff.):

„Das Konkrete ist konkret, weil es die Zusammenfassung vieler Bestimmungen ist, also Einheit des Mannigfaltigen. Im Denken erscheint es daher als Prozeß der Zusammenfassung, als Resultat, nicht als Ausgangspunkt, obgleich es der wirkliche Ausgangspunkt und daher auch der Ausgangspunkt der Anschauung und der Vorstellung ist. Im ersten Weg (= Analyse, W. N.) wurde die volle Vorstellung zu abstrakter Bestimmung verflüchtigt; im zweiten (= Synthese, W. N.) führen die abstrakten Bestimmungen zur Reproduktion des Konkreten im Wege des Denkens" (MEW, Bd. 42, S. 35).

Ein Erkenntnissystem ist demnach eine „Zusammenfassung vieler Bestimmungen oder Einheit des Mannigfaltigen", die durch Analyse und Synthese gewonnen worden ist. Da Erziehung eine dynamische gesellschaftliche Erscheinung ist, genügt es natürlich nicht, ihre gegenwärtigen strukturellen Zusammenhänge zu erkennen. Es muss vor allem ihre $D y$ namik, d. h. ihre Funktionsweise unter verschiedenen gesellschaftlichen Bedingungen und ihr bistorischer Wandel hinsichtlich ihrer Erscheinungsformen und Ursachen untersucht werden.

Die Erkenntnis Hegels, „daß das Wissen nur als Wissenschaft oder als System wirklich ist und dargestellt werden kann" (1964, S. 23) war es, die Schaller veranlasst hat, den Systemgedanken für die Entwicklung der Pädagogik als Wissenschaft in den Vordergrund zu stellen. 
Da die Erziehung als Teil unserer Welt nicht allein aus sich selbst heraus erklärt und wissenschaftlich begründet dargestellt werden kann, stellte Schaller bei der Entwicklung seines Systems folgende Fragen:

1. Durch welche Tatsachen des Seins wird Erziehung bestimmt?

2. Welches sind die tragenden Momente oder Elemente mit ihren Beziehungen in der Erziehung (Struktur)?

3. Wodurch sind innere Dynamik und historischer Wandel von Erziehung bedingt?

4. Welche Funktionen hat Erziehung zu erfüllen?

5. Was vermag Erziehung zu bewirken?

Die erste Frage zielte auf Bestimmungsfaktoren, Ursachenelemente (also Determinanten), die außerhalb der Erziehung liegen und die wir finden, wenn wir die Grenzen des Erziehungssystems überschreiten. Schaller nannte sie transgrediente Grundlagen (transgredi $=$ überschreiten), um zum Nachdenken zu provozieren, und meinte damit Natur und Gesellschaft (ohne Erziehung). Dabei betonte er die Unterscheidung von außermenschlicher und (gesellschaftlich modifizierter) menschlicher Natur als Determinanten für alles erzieherische Geschehen, die in ihrer konkreten Wirkungsweise und praktischen Bedeutung für erzieherisches Handeln untersucht und beachtet werden müssen, soweit das historisch, wissenschaftlich, gesellschaftlich und individuell möglich ist.

Es ist leicht einzusehen, dass außermenschliche Naturbedingungen (geografisches Milieu, klimatische Verhältnisse usw.) für Erziehungsprozesse bedeutsam sind, da sie ja immer mit der Natur des Menschen in Beziehung stehen und demzufolge praktisch berücksichtigt werden müssen, etwa beim Bau von Bildungseinrichtungen, die den jeweiligen klimatischen Bedingungen anzupassen sind, oder bei der Erarbeitung von Schulordnungen, die auf die physische und psychische Belastbarkeit der Lehrenden und Lernenden Rücksicht nehmen müssen (Unterrichtsbeginn und -ende, Pausen, „Hitzefrei““ usw.).

Die gesellschaftlich modifizierte Natur des Menschen begründet prinzipiell die Notwendigkeit (Bedürftigkeit) und Möglichkeit seiner Erziehung. Im Einzelnen jedoch ist die Bedeutung der menschlichen Natur für Erziehungsprozesse umstritten, und sie wird vielfach unterschätzt - nicht selten in der Absicht, biologistischen oder sozialdarwinistischen Tendenzen entgegenzutreten. Aber wer die Bedeutung der menschlichen Natur für Erziehung, speziell die biotische Beschaffenheit des Menschen nicht ernst nimmt, kann menschliches Verhalten nicht verstehen und läuft leicht Gefahr, besonders jenen nicht gerecht zu werden, die mit Behinderungen belastet sind. Behinderungen können nicht nur als gesellschaftliche Wertungsprobleme behandelt werden, sondern sind in der Regel ihrem Wesen nach physiologische oder neurologische Tatsachen - verbunden mit Behinderungen, deren Kompensation medizinisch begründete technische bzw. pädagogische Maßnahmen erfordern (z. B. bei Hörgeschädigten, Blinden, Taubstummen). 
In der Bundesrepublik sind die geisteswissenschaftlichen Traditionen der Pädagogik noch so wirksam, dass nicht immer ein richtiges Verständnis für die natürlichen Grundlagen der Erziehung besteht. Deshalb ist das Erscheinen des Buches „Biologische Grundlagen des Lernens“ (Cornelsen Verlag, Berlin 2001) von Annette Scheunpflug ein notwendiger Vorstoß zur naturwissenschaftlichen Fundierung der Pädagogik.

Bei den natürlichen Grundlagen der Erziehung geht es z. B. um die natürlichen Existenzbedingungen und um die Rolle von Erbanlagen in der Ontogenese des Menschen sowie um Auswirkungen von Medikamenten oder Drogen auf das sich entwickelnde Leben im Mutterleib, um den natürlichen Bewegungsbedarf von Kindern, Jugendlichen und Erwachsenen, um gesunde Lebensweise und Sexualität - kurz gesagt: um die Bedeutung der gesellschaftlich modifizierten Natur des Menschen für Erziehungsprozesse. Indem Schaller Natur und Gesellschaft zusammenfassend als transgrediente Grundlagen der Erziehung bestimmte, wollte er einer einseitigen ökonomischen und soziologischen Sicht auf Erziehung entgegentreten. Erst aus einem Geflecht von Wechselwirkungen zwischen allen gesellschaftlichen und natürlichen Faktoren resultiert ein Bedingungsgefüge, das je nach konkreter Ausprägung eine bestimmte Erziehung erfordert, ermöglicht oder auch erschwert und behindert.

\subsection{Struktur, Dynamik und Funktionen der Erziehung}

Um Erziehung zu bestimmen und zu erklären, genügt es nicht, das Kind oder einen Lernenden zu betrachten, vielmehr müssen zumindest ein Zögling und ein Erzieher in ihrem Geflecht von Wechselwirkungen mit ibren Wirkungsbedingungen untersucht werden. Wollen beide ein Ziel erreichen, gehen sie nach Schaller gemeinsam einen „Weg“ bzw. gestalten sie einen Prozess, der differenziert werden kann nach Inhalt und Form, wobei in Anlehnung an die pädagogische Tradition anstelle der Form Methode und Organisation stehen. Am relativen „Ende des Weges“ erscheint ein Resultat, das dem Ziel mehr oder weniger entspricht. Durch das nachfolgende, von Schaller entwickelte Schema werden einige wesentliche Zusammenhänge in den Verhältnissen von Ganzem und Teil sowie von System und Umwelt der Erziehung angedeutet (Vorlesungsmitschrift vom 17.12.1953; Archiv des Verfassers). Schallers Schema skizziert eine Antwort auf die für einen Theorieansatz zentrale Frage nach der grundlegenden Struktur der Erziehung, d. h.:

- Welches sind die konstitutiven Elemente jedes Erziehungsprozesses (unabhängig von seiner konkret historischen und individuellen Erscheinungsform)?

- Welche Relationen bestehen zwischen diesen Elementen?

- Wodurch werden Erziehungsprozesse dialektisch determiniert? 


\section{Immanente Momente}
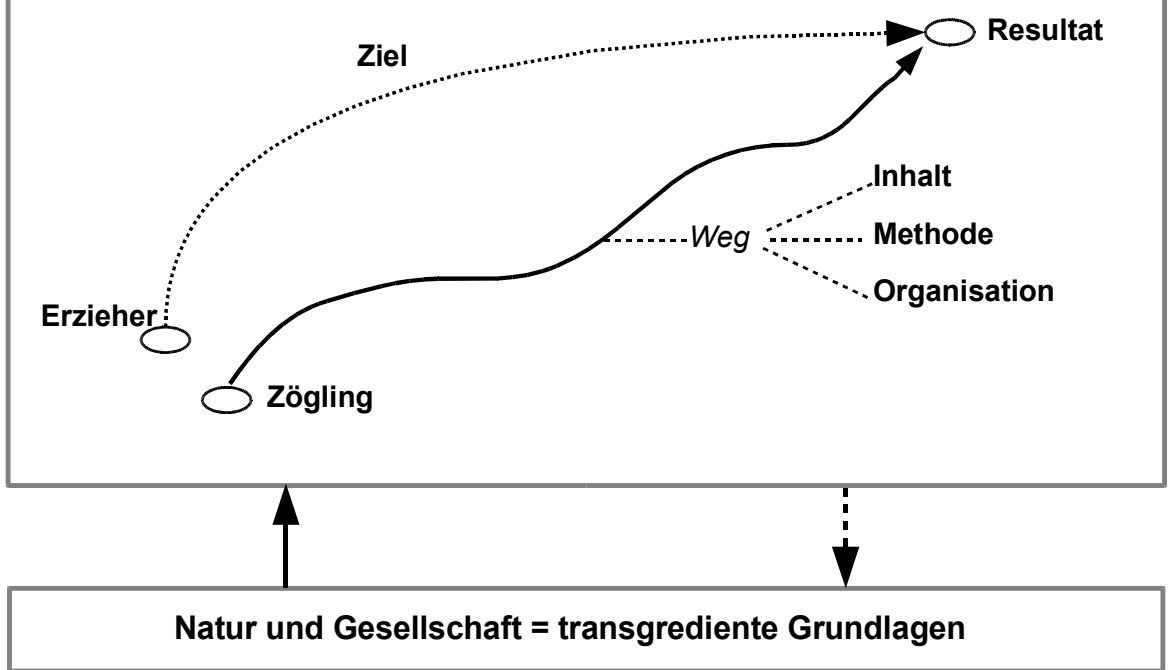

Schema 2

Da den immanenten Momenten der Erziehung jeweils noch ganze Kapitel oder Abschnitte gewidmet sind, sollen im Rahmen der Systemskizze nur die Kurzdefinitionen zum Zwecke einer ersten Verständigung vorgestellt werden, also:

Zwei personelle Momente ${ }^{4}$ :

- Der Erzieher ist das verantwortliche Subjekt des Erziehungsprozesses.

- Der Zögling ist das hilfebedürftige Objekt erzieherischer Einflüsse und zugleich das Subjekt des Lernprozesses.

Fünf sachliche Momente:

- Ein Ziel ist ein ideell vorweggenommenes Resultat und kennzeichnet zugleich die bewusst angestrebte Persönlichkeitsqualität des Zöglings.

- Der Inhalt im Erziehungsprozess ist ein zielgemäß ausgewählter Komplex mehr oder weniger adäquater Abbildungen der Realität und gedanklicher Konstrukte, die in Form von Informationen vom Zögling angeeignet werden.

4 In seiner Dissertation über „Grundlagenprobleme der Pädagogik in kybernetischer Sicht“ (Berlin 1967) hat W. Knöchel das System der immanenten Momente für eine kybernetische Betrachtung der Erziehung aufbereitet (siehe Schema 7) und die personellen Momente als aktive Elemente bezeichnet. Sicherlich ist es im Rahmen moderner Systembetrachtungen zweckmäßig, statt von immanenten Momenten von Elementen oder Subsystemen zu sprechen und die transgredienten Grundlagen als Supersysteme zu betrachten, um damit Erfordernissen einer wissenschaftlichen Systemanalyse im aktuellen materialistischen Verständnis zu entsprechen (vgl. Bunge/Mahner, S. 2004, S. 77f.). 
- Die Methode im Erziehungsprozess ist die Art und Weise der gemeinsamen Tätigkeit von Erziehern und Zöglingen, durch die Inhalte ausgewählt und strukturiert, übermittelt und angeeignet sowie Resultate kontrolliert und nachgewiesen, bewertet und ausgewertet werden.

- Die Organisation ist die räumliche und zeitliche Anordnung von Sachen und Personen, die differenziert werden kann nach relativ stabilen Organisationsstrukturen (soziale Gebilde oder institutionelle Organisation) und flexiblen organisatorischen Maßnahmen (= Organisationsweise oder instrumentelle Organisation);

- Das Resultat ist das realisierte Ziel bzw. der erzogene Zögling.

Schon Schallers Systemskizze lässt einige Probleme erkennen, die er selbst in seinem letzten Institutsseminar 1964 zur Diskussion gestellt hat, nämlich:

- das Verbältnis von Ziel und „Weg“ im System der immanenten Momente und

- die Zuordnung des Resultats zu den sachlichen Momenten.

Indem er in seiner Skizze den bildhaften Begriff des Weges verwendet, erzeugt er im Grunde genommen eine unnötige Hürde für die Definition der Momente selbst. Wenn man nämlich bei dem Bild bleibt, dann wäre eine Zielangabe sozusagen der Wegweiser. Aber das entspricht nicht der realen Prozessdialektik. Während Wegweiser relativ stabil an den Weg- oder Straßenrändern stehen bleiben, verändern sich pädagogische Ziele als Vorstellungen der Erzieher und der Zöglinge im Prozess fortgesetz̧t, zum einen, weil sie annähernd realisiert werden - d. h. in Resultate „umschlagen“ - und zum anderen, weil sie präzisiert oder korrigiert werden müssen, damit sie den Bedingungen entsprechen und realisierbar sind. Sie sind also auch Bestandteile des „Weges“.

Indem Schaller das pädagogische Resultat als erzogenen Zögling definiert, sieht er es natürlich auch als Prozess bzw. Prozessmoment oder „Durchgangsstadium“, das in den jeweils nächsten Stadien verändert wird und erst kurz vorm Tode eines Menschen auch als „Endresultat“ betrachtet werden kann. Damit wird die Zuordnung des Resultats zu den sachlichen Momenten fragwürdig, denn der (jeweils besser) erzogene und damit auch funktionstüchtigere Zögling ist und bleibt ein personelles Element im System. Vermutlich ist dieser Zuordnungsfehler dadurch bedingt, dass Schaller - wie in der Pädagogik üblich - nicht klar zwischen pädagogischen Resultaten und deren gesellschaftlichen Auswirkungen oder Ergebnissen unterschieden hat. Das Verhältnis von pädagogischen Resultaten und gesellschaftlich bedeutsamen Ergebnissen der Erziehung lässt sich dadurch klären, dass die Ergebnisse als Erscheinungsformen der Resultate gefasst werden, die uns in Gestalt gelöster Aufgaben und bewältigter Probleme begegnen. Solche wahrnehmbaren Ergebnisse tragen allerdings vielfach sachlichen Charakter, handelt es sich dabei doch um vergegenständlichte geistige bzw. physische Leistungen der erfolgreich Erzogenen in Form von schriftlich vorliegenden Kontrollarbeiten, künstlerischen Gebilden, materiellen 
Produkten, sozialen Hilfeleistungen usw. Entsprechend dieser Unterscheidung von Resultat und Ergebnis sollte auch zwischen pädagogischen Zielen (als angestrebten Persönlichkeitsveränderungen) und Zwecken der Erziehung als den mittels Erįiehung angestrebten Veränderungen in Natur und Gesellschaft differenziert werden (vgl. 4.1).

Doch ungeachtet dieser Schwächen in der ursprünglichen Ableitung des Systems der immanenten Momente ist es doch als Erkenntnissystem von theoretischem und methodologischem Wert, wie sich noch zeigen wird. Aus dem Systemverständnis bezüglich der immanenten Momente resultiert beispielsweise auch eine funktionale Betrachtungsweise und Begriffsbildung, die unser Erziehungsverständnis vertieft. Indem nämlich die Kategorien „Erzieher“ und „Zögling“ als Träger pädagogischer Funktionen betrachtet werden, ist es möglich, von Selbsterziehung zu sprechen: ein Mensch kann beide Funktionen in sich vereinen und realisieren, sofern er die dafür erforderlichen Kompetenzen erlangt (s. S. 23). Vermutlich resultiert die Ablehnung des Begriffs der Selbsterziehung aus einer mechanischen und starren Gegenüberstellung von Erwachsenen (als Erziehern) und Kindern (als Zöglingen). Ferner lässt sich auch die Frage beantworten, weshalb solche Kategorien wie beispielsweise Plan, Konzeption, Mittel, Medien nicht als immanente oder konstitutive Elemente der Erziehung betrachtet werden. Der Grund dafür ist, dass es sich bei diesen Bestandteilen des Erziehungsprozesses bereits um Verknüpfungen mehrerer immanenter Momente handelt. So enthält z. B. ein Erziehungsplan sowohl Zielbestimmungen als auch Inhaltsangaben und vielfach noch methodische und organisatorische Hinweise. Ähnlich verhält es sich mit den Mitteln (z. B. Bücher, Filme, Beratungsgespräche, Morgenkreise, Projekte), die sowohl Quellen von Inhalt sind als auch methodische sowie organisatorische Erfordernisse und Möglichkeiten ihrer pädagogischen Nutzung anbieten bzw. darstellen.

Abgesehen von der terminologischen Problematik, die mit dem Wort „Zögling“ verbunden ist, taucht hierbei die Frage nach dem Begriffsumfang auf: sind damit ausschließlich Individuen gemeint oder auch Menschengruppen? Schaller bezieht den Begriff Zögling auch auf Menschengruppen unterschiedlicher Dimension, die unter pädagogischer Führung an ihrer Entwicklung arbeiten. Am deutlichsten kommt die dialektische Sicht auf die immanenten Momente im Falle der Selbsterziehung zum Ausdruck, bei dem Erzieher und Zögling in einer Person vereinigt sind. Damit wird auch klar, dass diese Kategorien Funktionen von Personen und Personengruppen im Erziehungsprozess erfassen. Das Wort „Erzieher“ bezeichnet in allgemeinen pädagogischen Betrachtungen keine bestimmte Berufsgruppe, sondern eine Funktion, die jedem Menschen zukommt, sofern er sie praktisch ausführt. Das hat zugleich auch Bedeutung für ein richtiges Verständnis des pädagogischen Kollektivbegriffs bzw. des Begriffs der Erziehungsgemeinschaft: es handelt sich auch hierbei um eine spezifische Verknüpfung von immanenten Momenten, speziell von Zöglingen und Erziehern, da eine Erziehungsgemeinschaft in der Regel beide Funktionen realisiert - sie erzieht und lernt dabei insgesamt (vgl. Abschnitt 5.4). 
Für ein richtiges Verständnis der vorgestellten Erziehungsauffassung ist das Moment „Organisation“ von besonderer Bedeutung. Nach Auffassung von Anton S. Makarenko (1888-1939) stellt die Organisation von Lebens- und Entwicklungsbedingungen der Zöglinge eine wesentliche Komponente erzieherischen Handelns dar, denn diese Aktivitäten sind darauf gerichtet, die jeweiligen Kollektive als erzieherische Kräfte zu entwickeln (siehe S. 278ff.). Die Organisation von Erziehungsprozessen ist Bestandteil von Erziehung, die sich aber letztendlich immer in sozialen Interaktionen und/oder in der Selbsttätigkeit/Selbsterziehung der Zöglinge realisiert.

Die vorgestellte Auffassung von der Struktur des Erziehungsprozesses ist zugleich bedeutsam für erzieherische Bewusstheit. Eræieherische oder gar pädagogische Bewusstheit des Erziehers bezieht sich auf alle immanenten Momente; sie umfasst im unterschiedlichen Grad

- pädagogisches Selbstbewusstsein des Erziehers und Verantwortungsbewusstsein für seine Zöglinge,

- Kenntnisse und Reflexionen zu Eigenheiten der Zöglinge,

- Kenntnisse zu Zielen und Reflexionen zu ihren Realisierungsmöglichkeiten,

- Beherrschung potenzieller Inhalte,

- Methodenbewusstheit im erzieherischen Handeln,

- Kenntnisse bezüglich rationeller Möglichkeiten zur Organisation der Erziehung

- und schließlich auch Reflexionen zu den Resultaten.

Elemente erzieherischer Bewusstheit wirken auch in Selbsterziehungsprozessen (Tagesplanung, Trainingsprogramm, Selbstdisziplinierung u. Ä.). Pädagogische Bewusstheit der erzieberischen Kräfte entsteht in wissenschaftlichen Reflexionen zu den immanenten Momenten und transgredienten Grundlagen, was ein entsprechendes Studium voraussetzt.

Die Frage nach den Ursachen der inneren Dynamik und dem historischen Wandel der Erziehung lässt sich mit Hilfe der materialistischen Dialektik dadurch beantworten, dass die Zusammenhänge zwischen den immanenten Momenten als Wechselwirkungen verstanden werden, die aus Widersprüchen zwischen den aktiven Elementen resultieren, die letztendlich in den transgredienten Grundlagen ibre Wurzeln haben. Beispielsweise fordern technische Entwicklungen bestimmte Qualifikationen der Produzenten, die sich zunächst in pädagogischen Zielvorstellungen widerspiegeln und dann als Anforderungen vor den Auszubildenden stehen, um Lernprozesse zu stimulieren und zu orientieren.

Zur Charakterisierung wesentlicher Zusammenhänge zwischen den immanenten Momenten und transgredienten Grundlagen der Erziehung bediente sich Schaller einer Analogie, deren Grundlage die Marx'sche Analyse der Beziehungen zwischen Produktion, Distribution, Austausch und Konsumtion ist (vgl. MEW, Bd. 42, S. 34). Schaller schrieb:

„Die transgredienten Grundlagen wirken auf die Erziehung und umgekehrt (Wechselwirkung). Die transgredienten Grundlagen sind dabei das Übergreifende. Die 7 immanenten Momente 
bilden ein Ganzes, stehen als Glieder einer Totalität in allseitiger Wechselwirkung““ (Schaller 1960, S. 7).

Jedes immanente Moment „entstammt“ den transgredienten Grundlagen und ist Funktionsträger im erzieherischen Systemzusammenhang. Die immanenten Momente in ibrem Zusammenwirken bilden den Gegenstand der Pädagogik und konstituieren in Form davon abstrabierter und konstruktiv bearbeiteter Erkenntnisse (Aussagen und Gesetze, Normen, Prinzipien und Regeln, Begriffe und Modelle) den Inhalt der Pädagogik. Mit der Feststellung, dass die transgredienten Grundlagen im Wechselwirkungsgeschehen mit dem System der immanenten Momente von übergreifender Bedeutung sind, dokumentiert Schaller seine dialektisch-materialistische Position. Er betrachtet die immanenten Momente sowobl als Ganzheit wie im Einzelnen in ibren Beziehungen zu den natürlichen und gesellschaftlichen Grundlagen und liefert damit auch eine theoretische Basis für die Beantwortung der Fragen

- nach den Ursachen der historischen Dynamik und

- nach der funktionalen Wirkungskraft (den Möglichkeiten und Grenzen) der Erziehung.

Wenn die transgredienten Grundlagen von übergreifender Bedeutung sind gegenüber dem System der immanenten Momente, dann ist klar, dass gesellschaftliche Veränderungen gesetzmäßig zu Wandlungen des Erziehungssystems führen, was z. B. ehemaligen DDR-Bürgern mit ihrer Eingliederung in die Bundesrepublik und der Transformation des Bildungswesens nachhaltig bewusst wurde. Das Gesetz der transgredienten Determination der Erziehung muss im Sinne einer dialektischen Determination verstanden werden. Das bedeutet z. B., dass in den jeweiligen gesellschaftlichen Bedingungen stets auch solche enthalten sind, die Erfordernisse und Möglichkeiten einer besseren Zukunft repräsentieren. Daher ist es prinzipiell möglich, durch Erziehung auf eine Veränderung der Menschen und ibrer Lebensbedingungen binzuarbeiten, natürlich immer mit den Risiken, die durch den statistischen Charakter des Gesetzes der transgredienten Determination der Erziehung und die damit verbundenen Erfolgswahrscheinlichkeiten bzw. Unsicherheiten bedingt sind.

Die transgredienten Grundlagen sind nicht nur für die Eigenheiten der Struktur und des Charakters, sondern auch für die historische und funktionale Dynamik des Systems der immanenten Momente von Bedeutung. Die Erziehung hat es ja mit den Menschen zu tun, die durch vielfältige gesellschaftliche Faktoren und Kräfte sozialisiert werden und muss demzufolge diese Effekte berücksichtigen. Vor allem aber muss sie mit gesellschaftlich relevanten Zielstellungen, Inhalten und Methoden versuchen, ihren Beitrag zur Erhaltung und Entwicklung der Gesellschaft zu leisten. Das Gesetz der transgredienten Determination der Erziehung darf nicht so verstanden werden, als wären die immanenten Momente nur „,passive Reflexe“ von Natur und Gesellschaft. Im Gegenteil: der Systemcharakter der immanenten Momente besteht darin, dass sie sowohl in ihrer 
Gesamtheit als auch als Subsysteme bestimmte Eigengesetzlichkeiten aufweisen. Dank der Dynamik dieser Eigengesetzlichkeiten ${ }^{5}$ wirkt die Erziehung über ihre Resultate auf die transgredienten Grundlagen zurück. Vermittelt werden die Rückwirkungen beispielsweise durch befähigte Erfinder technischer Nenerungen und qualifizierte Arbeitskräfte, die diese Neuerungen praktisch umsetzen. Sie nehmen damit Einfluss auf ökonomische Entwicklungsprozesse und zugleich auch generell auf die natürlichen und gesellschaftlichen Lebensgrundlagen der Menschen. Analoges lässt sich im positiven wie im negativen Sinne bei Wirtschaftsmanagern, Bankern, Politikern usw. feststellen.

Bei der relativen Eigengesetzlichkeit der Erziehung handelt es sich um die Existenz spezifischer Struktur- und Funktionsgesetze der Erziehung bzw. des Systems der immanenten Momente (vgl. Naumann 1980, S. 155ff.) Die relative Eigengesetglichkeit des Systems der immanenten Momente begründet die relative Autonomie der Erziehung und ermöglicht die aktive Rückwirkung der Erziehung auf ihre natürlichen und vor allem gesellschaftlichen Grundlagen. Von einer relativen Autonomie muss deshalb gesprochen werden, weil ₹. B. Krisenerscheinungen einer Gesellschaft auch Erziehungsprozesse nachbaltig beeinträchtigen. So widerspiegelt sich die Massenarbeitslosigkeit als Ausdruck einer gesellschaftlichen Krise im schulaversiven Verhalten mancher Hauptschüler, die meinen, dass sie ohnehin keine Chancen auf dem Arbeitsmarkt haben und sich daher auch nicht sonderlich um hohe schulische Leistungen zu bemühen brauchen.

Die praktische Abhängigkeit der Erziehung von gesellschaftlichen Kräften (Parteien, Kirchen usw.) kann zum Problem werden, wenn diese die Erziehung für eigennützige Zwecke und nicht oder nur unzureichend im Interesse der Heranwachsenden nutzen (Nohl 1920, S. 124). Dieses Problem ist allerdings nicht dadurch zu lösen, dass eine Autonomie der Erziehung im Sinne völliger Unabhängigkeit von gesellschaftlichen Kräften gefordert wird, weil Erziehung ja gesetzmäßig durch ihre transgredienten Grundlagen determiniert wird. Dies erfolgt vor allem über die Ziele, die gestellt, und die Inhalte, die entsprechend ausgewählt und vermittelt werden, wobei jedoch die Erzieher als Vertreter oder Kritiker der Gesellschaft bzw. ihrer Gruppierungen von entscheidender Bedeutung sind. Das heißt: das Gesetz der transgredienten Determination der Erziehung kann nicht außer Kraft gesetzt, sondern bestenfalls im humanistischen Sinne genutzt werden. Dem Anliegen von Herman Nohl (1879-1960) ist dadurch Rechnung zu tragen, dass

- der Einfluss jener Kräfte zurückgedrängt wird, die versuchen, Erziehung in fragwürdiger oder gar inhumaner Weise für ibre eigennütrigen Zwecke zu missbrauchen,

- $\quad$ und verantwortungsbewusste Erzieher sich bemühen, eine humanistische Eræiehung unter Nutzung ihrer relativen Eigengesetzlichkeit zum Wohle ihrer Zöglinge zu realisieren.

5 Ob oder wie es wegen empirischer Strukturunterschiede möglich ist, obigen sozialen Sachverhalt mit dem biologisch begründeten Begriff der Autopoiesis adäquat zu erfassen, bedarf weiterer Untersuchungen (vgl. Schweizer 2012, S. 71 f.). 
Die Erörterung immanenter Momente oder konstitutiver Elemente der Erziehung durch Schaller war nicht neu, denn kein Pädagoge kann sich ohne die o. g. Kategorien über Erziehung äußern. Auch Versuche zur schematischen Darstellung „konstitutiver Momente des Pädagogischen“ (Badry u. a. 1994, S. 36) gab und gibt es mehrere.

Verwiesen sei hier z. B. auf das didaktische Dreieck

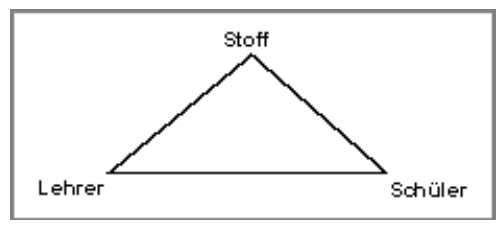

Schema 3

und auf das pädagogische Dreieck

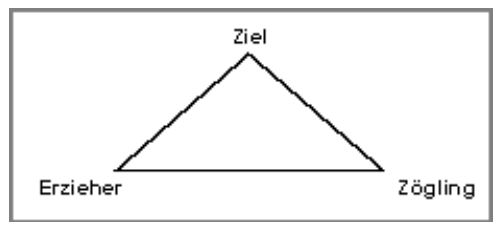

Schema 4

Beide Schemata oder ähnliche sind auch in neueren Lehrbüchern noch zu finden (vgl. Schilling 1993, S. 119 ff. und Badry u. a. 1994, S. 36).

Josef Derbolav (1912-1987) bietet eine Weiterentwicklung des pädagogischen Dreiecks mit seinem pädagogischen Kegel an (vgl. Badry u. a. 1994, S. 39). Er verwendet in dem Modell anstelle des „Zöglings“ das lateinische Wort „Educand“" und präsentiert - im Vergleich zum Strukturmodell von Schaller - weitere Kategorien bzw. Gesichtspunkte. Er lässt dabei aber zugleich ein Moment außer Acht, nämlich das Resultat, das - vom gesellschaftlichen Standpunkt aus betrachtet - das wichtigste ist.

Sein Hauptmangel gegenüber dem Schaller'schen Strukturmodell besteht jedoch darin, dass es aus der Fülle realer äußerer Determinanten nur den „politischen Ordnungswillen zwecks bildungspolitischer Normierung “ auswählt und auf den ,gesellschaftlichen Rahmen“ hinweist. Die Natur als fundamentale gesetzmäßige Determinante aller Erziehungsprozesse wird hierbei nicht explizit berücksichtigt. Die Einschränkung der gesellschaftlichen Grundlagen auf den politischen Ordnungswillen und der Verweis auf den metaphorischen Begriff des ,gesellschaftlichen Rahmens“ sind Ausdruck einer problematischen Reduktion der trangredienten Determinanten, denn Erziehung wird prinzipiell - und damit auch bildungspolitisch - von allen Gesellschaftsbereichen, also von der Ökonomie, Technik, Kultur, Justiz, Religion usw. mit determiniert. Einzelne

6 Eine Erörterung dieses terminologischen Problems erfolgt im Abschnitt 3.1. 
gesellschaftliche Kräfte können sogar im Widerspruch zum politischen Ordnungswillen der Herrschenden die Erziehung nachhaltig beeinflussen.

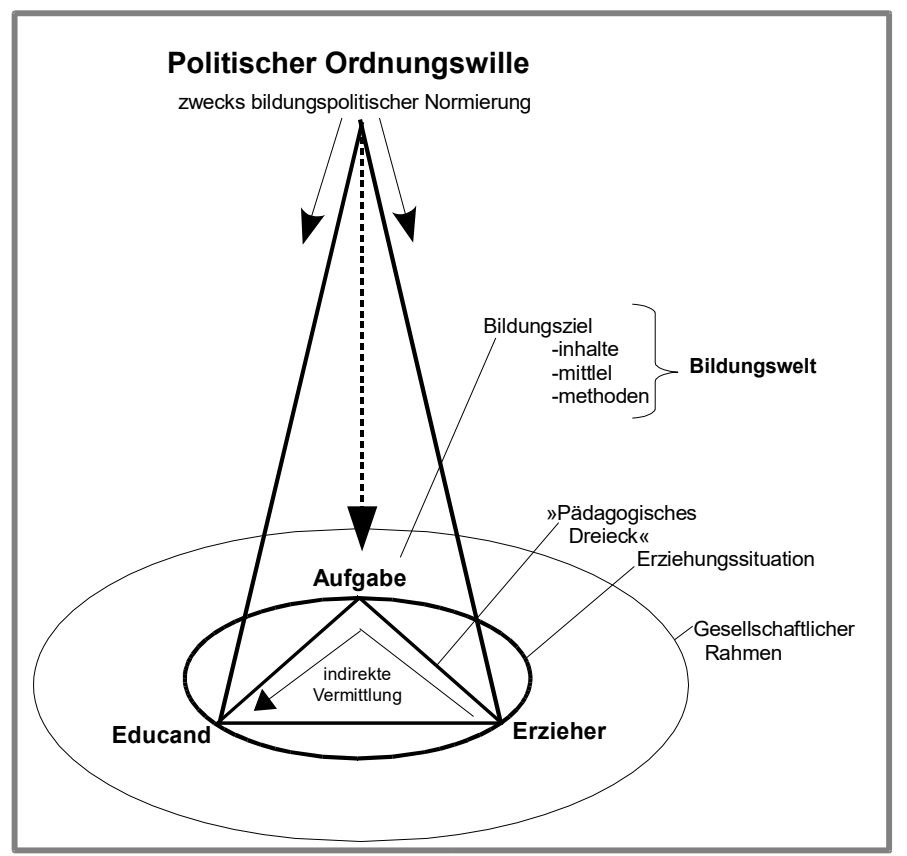

Schema 5

Hinzu kommt, dass es schon vor der Entstehung der Politik (d. h. vor der Entwicklung von Staaten) urgesellschaftliche Einflüsse auf Erziehung gegeben hat und dass die Wirkungen der Ökonomie - z. B. des Arbeitsmarktes und der Globalisierung der Wirtschaft - immer noch mächtiger und nachbaltiger sind als die der Politik. In zunehmendem Maße muss die Politik auch der Ökologie Rechnung tragen, was ihre Vermittlungsfunktion gegenüber Erziehung und anderen Gesellschaftsbereichen verdeutlicht.

Die gewichtige Rolle der Ökonomie in den Wechselwirkungen zwischen transgredienten Grundlagen und immanenten Momenten der Erziehung widerspiegelt sich auch in dem Argument von der Gefährdung des Wirtschaftsstandortes Deutschlands in der Diskussion um die beklagten und umstrittenen Leistungen deutscher Schüler bei den internationalen Schulleistungsvergleichen. Es ist klar, dass viele ökonomische Erfordernisse über den politischen Ordnungswillen vermittelt werden, aber eben auch recht unmittelbar erzieherische Anforderungen und Möglichkeiten bedingen; das merkt beispielsweise jede Fami- 
lie, die plötzlich von Arbeitslosigkeit betroffen wird und nunmehr auch verstärkt zur Sparsamkeit erziehen muss, wenn sie nicht in Schwierigkeiten geraten will. Mit der Betonung der Bedeutung der Ökonomie für die Erziehung vertrat Schaller eine bekannte dialektisch-materialistische Position in dem von Engels relativierten Sinn,

„daß alle juristischen, politischen, philosophischen, religiösen etc. Vorstellungen der Menschen in letzter Instanz aus ihren wirthschaftlichen Lebensbedingungen, aus ihrer Weise zu produzieren und die Produkte auszutauschen, abgeleitet sind“ (MEW, Bd. 31, S. 399).

In seinem Brief an J. Bloch vom 21./22. September 1890 vermerkt Engels außerdem, „daß von den Jüngeren zuweilen mehr Gewicht auf die ökonomische Seite gelegt wird, als ihr zukommt, haben Marx und ich teilweise selbst verschulden müssen. Wir hatten den Gegnern gegenüber das von diesen geleugnete Hauptprinzip zu betonen, und da war nicht immer Zeit, Ort und Gelegenheit, die übrigen an der Wechselwirkung beteiligten Momente zu ihrem Recht kommen zu lassen“" (Marx/Engels 1958, S. 223).

Schaller betonte in seinen Lehrveranstaltungen außerdem, dass bei allen allgemeinen Erörterungen über die Bedeutung der Ökonomie im Verhältnis zu anderen Gesellschaftsbereichen zu fragen und zu unterscheiden ist:

- Welche Bedeutung hat die Ökonomie als Quelle des gesellschaftlichen Seins?

- Welche Rolle spielt sie dann in bestimmten gesellschaftlichen Prozessen tatsächlich im Verhältnis zu bestimmten ideellen Triebkeräften?

Von diesen Fragestellungen ausgehend, muss die Bedeutung der Ökonomie jeweils konkret bestimmt werden, natürlich unter Beachtung ihrer fundamentalen Bedeutung als Quelle gesellschaftlichen Seins. Aus dieser Sicht kann Benners Position, dass „kein Bereich menschlicher Praxis einen Primat gegenüber anderen beansprucht“ (in: Roth 1991, S. 11) nicht akzeptiert werden. Mit der fehlenden Unterscheidung zwischen Quelle und Rolle der Ökonomie im Verhältnis zu anderen Bereichen menschlicher Praxis wird die Problemsicht unzulässig vereinfacht und letztendlich die Bedeutung der Ökonomie unterschätzt. Wie „primär“ beispielsweise die jeweiligen historisch-konkreten ökonomischen (und damit finanziellen) Verhältnisse eines Landes als notwendige Quelle für Bildungsreformen sind, widerspiegelt sich in den aktuellen Reformdiskussionen und Reformschwierigkeiten. Welch überragende Bedeutung die Politik den ökonomischen Verhältnissen zubilligt, belegen die Rettungsmaßnahmen zahlreicher Regierungen und Parlamente für die von Insolvenz bedrohten Banken und Konzerne in Krisensituationen.

Der Primat der Ökonomie als Quelle gesellschaftlicher Erscheinungen bedeutet z. B.: aus den jeweiligen ökonomischen Verhältnissen erwachsen einerseits bestimmte Anforderungen an das „Niveau der Erzogenen“ und andererseits auch die materiellen und personellen Ressourcen zur Realisierung dieser Erfordernisse. Eine andere Frage ist dann, welche Rolle die Ökonomie im System der Triebkeäfte gesellschaftlicher Ent- 
wicklungsprozesse spielt. Darauf kann keine für alle gesellschaftlichen Veränderungen allgemeingültige Antwort gegeben werden, weil die Wirksamkeit der Ökonomie vom Gesamtsystem der Wechselwirkungen aller beteiligten Bereiche, vor allem auch von der Qualität jener Erscheinung abhängt, auf die ökonomisch eingewirkt wird. Die Anerkennung der Ökonomie als Grundlage und Triebkraft gesellschaftlicher Entwicklungen bedeutet nicht, dass sie die Moral im System der Triebkräfte außer Kraft setzen darf, wie es in der „Marktgesellschaft“ (Michael J. Sandel) leider zunehmend geschieht.

So trivial also das Strukturschema von Schaller zunächst anmutet, so ist doch bei genaueren Betrachtungen zu erkennen, dass es eine beachtliche wissenschaftliche Substanz besitzt. Schaller hat den Ausdruck der „transgredienten Grundlagen“ nicht nur im Interesse der Entwicklung einer pädagogischen Fachsprache gewählt, sondern weil er mit diesem befremdlichen Wort zum Nachdenken anregen wollte. Dabei hat er heftige parteiinterne Kritiken in Kauf genommen, denn solche terminologischen Eigenwilligkeiten entsprachen in der DDR nicht den Bestrebungen der SED-Führung zum politisch-ideologisch geregelten Sprachgebrauch in den Gesellschaftswissenschaften.

Die Funktionen der Erziehung lassen sich unter zwei Aspekten betrachten: dem gesellschaftlichen und dem individuellen. Hinsichtlich des ersten Aspekts - der Existenz und Entwicklung der Gesellschaft - unterscheidet Artur Meier zwei Funktionen der Erziehung: die Überlieferungs- oder Tradierungsfunktion und die Vorlauf- oder Lokomotionsfunktion (Meier 1974, S. 31). Die Tradierungsfunktion ist darauf gerichtet, der jeweils nachfolgenden Generation jenes grundlegende Wissen und Können, jene Einstellungen und Verhaltensweisen zu übermitteln, die sie befähigt, die Gesellschaft zu reproduzieren. Da Natur und Gesellschaft sich ständig wandeln, muss Erziehung stets auch zu Innovationen im Interesse des gesellschaftlichen Fortschritts und zur Prävention im Hinblick auf die Abwebr existenzbedrobender Gefahren befähigen, möglichst sogar auf die Bewältigung von Ereignissen vorbereiten, die zwar noch nicht überall oder massenhaft erlebt werden, aber doch vorhersehbar sind - z. B. Folgen von Klimaveränderungen! Übrigens ist durch die Bestimmung „Auseinandersetzung mit der Umwelt“ in der Erziehungsdefinition der dialektischmaterialistischen Pädagogik ökologisches Denken vom Ansatz her mit angelegt.

Die gesellschaftlichen Funktionen widerspiegeln sich auch im Bereich der individuellen Wirksamkeit der Erziehung, d. h., Erziehung muss möglichst jedes Individuum befähigen, in der Gesellschaft zu leben und zu arbeiten, damit es ein kulturvolles und sinnerfülltes Leben führen kann. Was dabei unter einem kulturvollen und sinnerfüllten Leben verstanden wird, hängt von den jeweiligen Wertvorstellungen der erzieherischen Kräfte ab. Erziehung muss also über ibre ökonomische Funktion binaus zur möglichst vielseitigen Bildung der Persönlichkeit beitragen. Doch schon zur Realisierung existenzieller wirtschaftlicher Aufgaben, insbesondere zur selbständigen Bewältigung des Lebensalltags, sind beachtliche Fähigkeiten und soziale Verhaltensweisen notwendig, die erzieherisch 
vermittelt werden müssen und die von allen Menschen - abgesehen von hochgradig Geschädigten - auf unterschiedlichem Niveau erlernt werden können.

Auch die Präventionsfunktion der Erziehung muss in jedem individuellen Erziehungsprozess beachtet werden; je besser und erfolgreicher das geschieht, desto eher werden sozialpädagogische Interventionen überflüssig, um Fehlentwicklungen zu korrigieren. Mit der Förderung individueller Begabungen wird zugleich ein Beitrag zur Realisierung der Innovationsfunktion der Erziehung geleistet, da die Entwicklung individuellen Schöpfertums eine Grundlage für gesellschaftlichen Fortschritt ist.

Die gesellschaftlichen Funktionen der Erziehung widerspiegeln sich in jedem individuellen Erziehungsprozess, indem sie auch hier im Sinne von Tradierung, Innovation und Prävention wirken oder versagen. Daraus folgt, dass jede Art humanistischer Erziehung (also familiäre, schulische, außerschulische usw.) nicht nur tradierend oder integrierend (im Sinne notwendiger Anpassung), sondern auch innovativ (kritisch und progressiv-mobilisierend) und präventiv (vorbeugend gegenüber Gefährdungen in der Persönlichkeitsentwicklung) wirksam sein sollte!

Die vorgestellte Auffassung von den gesellschaftlichen Funktionen der Erziehung wendet sich zugleich auch gegen die im gesellschaftlichen Alltag anzutreffenden Bestrebungen zur Manipulation von Individuen und Menschengruppen zugunsten einzelner Personen oder gesellschaftlicher Interessengruppen und zum Nachteil der Manipulierten, z. B. durch wirtschaftliche Unternehmen, politische Parteien oder religiöse Gemeinschaften. Allerdings ist es manchmal schwierig, ehrlich gemeinte Erziehung im Interesse des Einzelnen und der Gesellschaft von eigennütziger Manipulation abzugrenzen.

Jede sich entwickelnde Persönlichkeit benötigt Orientierungshilfen, um die für ein selbständiges Leben notwendige Souveränität im Denken, Urteilen und Handeln zu erlangen. Sie ist damit auch auf die Übernahme von Wertvorstellungen und Erfahrungen anderer angewiesen. Manipulation zielt auf die Entwicklung von Einstellungen und Handlungsweisen, die primär den Manipulatoren oder ibren Auftraggebern nützen, wobei die Manipulierten zumeist nicht merken, dass und wie sie mit ibren durch Manipulation erzengten Vorstellungen, Einstellungen und Handlungen primär fremden Interessen dienen und sich letatendlich selbst schaden.

Die geistige (einschließlich moralische) Manipulation erfolgt wesentlich durch Vermittlung bestimmter Wertvorstellungen und Normen, wobei nicht nur Reklametricks, sondern auch Methoden der Indoktrination eine besondere Rolle spielen können, nämlich immer dann, wenn es sich um Glaubenssätze oder ideologisch geprägte Meinungen handelt. Die unkritische Übernahme eben dieser Meinungen erfolgt um so bedenkenloser, je stärker das zumeist mehrdimensionale Abhängigkeitsverhältnis der „Empfänger“ von den „Sendern“ ist. Dies gilt besonders für das Verhältnis von religiösen und politischen Führern und ihren Anhängern, spielt aber auch in Jugendcliquen und Banden eine 
große Rolle, zumal hier der psychische Druck mittels physischem Zwang durch den Boss und seine ihm ergebenen Anhänger noch verstärkt werden kann.

Humanistische Erzieher im Sinne der Aufklärung unterscheiden sich von Manipulatoren wesentlich dadurch, dass sie die zu Erziehenden bewusst zu kritischen Reflexionen über Welt- und Wertvorstellungen anregen und ihnen die erforderlichen sachlichen Informationen zum Abwägen des Für und Wider nicht vorenthalten. Sie sollten dabei jedwede Form der Verketzerung und Verunglimpfung ,abweichlerischer“ Meinungen vermeiden bzw. unterbinden, aber auch konsequent menschenverachtenden Auffassungen entgegentreten.

\subsection{Notwendigkeit und Möglichkeit, Kraft und Grenzen der Erziehung}

Während es im vorangegangen Abschnitt darum ging, festzustellen, welche Funktionen oder Wirkungsrichtungen - die Erziehung überhaupt realisieren sollte, geht es nunmehr um das Problem der Macht, d. h. der Kraft und Grenzen der Erziehung in den Prozessen der Gesellschafts- und Persönlichkeitsveränderung. In der Geschichte der Erziehung, insbesondere des pädagogischen Denkens, finden wir zwei extreme Auffassungen über die Macht der Erziehung: die Positionen von der Allmacht und der Ohnmacht der Erziehung, die wiederum unter zwei Blickrichtungen zu betrachten sind:

1. Welchen Einfluss haben Erziehungsprozesse auf die Veränderung und Entwicklung („Verbesserung“) der Gesellschaft?

2. Welchen Einfluss haben Erziehungsprozesse auf die Veränderung und Entwicklung (,Veredelung“) des Individuums?

Es ist ein charakteristisches Merkmal der meisten frühbürgerlichen Pädagogen, dass sie bei ihren Bemühungen von einem großen pädagogischen Optimismus getragen werden und vielfach meinen, nicht nur einzelne Individuen, sondern die ganze Gesellschaft durch Erziehung grundlegend verbessern zu können - es sei hier nur an Johann H. Pestalozzi (1746-1827) und Johann B. Basedow (1723-1790) mit ihren Anhängern erinnert. Diese Denktradition hält bis ins 19. Jahrhundert hinein an. Wir finden sie dann allerdings nicht mehr so sehr bei den Pädagogen, sondern bei deren sozialkritisch engagierten Zeitgenossen, die sich mit den Auswirkungen der industriellen Revolution und des Manchesterkapitalismus auf die Lebensverhältnisse der Arbeiter befasst haben.

Außer den französischen Aufklärern (z. B. d’ Holbach und Helvétius) und den utopischen Sozialisten (Saint Simon und Fourier) sei hier der englische Unternehmer Robert Owen (1771-1858) genannt, auf den sich Marx in seiner Kritik an der Auffassung von der Allmacht der Erziehung ausdrücklich bezieht. In der Festrede Owens aus dem Jahre 1812 zu Ehren Joseph Lancasters (1778-1838) - des Erfinders einer 
Organisation zur Unterrichtung sehr großer Schulklassen (Monitorensystem der Lancasterschen Schuleinrichtung) - heißt es u. a.:

„Viel ist über Erziehung gesagt und geschrieben worden; aber nur wenige sind sich über ihre wahre Bedeutung in der Gesellschaft im klaren, und sicherlich nimmt sie in unserer Einschätzung nicht jenen hervorragenden Platz ein, der ihr gebührt. Denn bei richtiger Untersuchung wird sich herausstellen, daß sie, wenigstens soweit es von unseren Maßnahmen abhängt, die Hauptquelle alles Guten und alles Übels, alles Elends und alles Glücks der Welt ist“" (Owen 1955, S. 63).

Owen geht es also nicht nur um das Wohl des Einzelnen, sondern um die Verbesserung der gesamten Gesellschaft. Den Ansatzpunkt dafür sieht er in einer Verbesserung der Erziehung und der Lebensbedingungen der Menschen, denn:

„Der Mensch wird ein grausamer Wilder, ein Kannibale, oder ein hochzivilisiertes und gütiges Wesen, je nach der Umwelt (circumstances), in die er geboren wird“ (a. a. O., S. 64).

Eben das ist genau jene milieutheoretische Position (die Erziehung einschließt), die Marx in der 3. These über Feuerbach zum Gegenstand seiner Kritik gemacht hat. Die von Engels redigierte Fassung dieser These lautet im ersten Teil:

„Die materialistische Lehre, daß die Menschen Produkte der Umstände und der Erziehung, veränderte Menschen also Produkte anderer Umstände und geänderter Erziehung sind, vergißt, daß die Umstände eben von den Menschen verändert werden und daß der Erzieher selbst erzogen werden muß. Sie kommt daher mit Notwendigkeit dahin, die Gesellschaft in zwei Teile zu sondern, von denen der eine über der Gesellschaft erhaben ist (z. B. bei Robert Owen)“ (MEW, Bd. 3, S. 533/534).

Die These des mechanischen Materialismus, dass „der Mensch Produkt seiner Verhältnisse ist", wird gelegentlich auch heute noch vertreten und verdient daher eine genauere Betrachtung. Sie hat ihre philosophische Grundlage in der Auffassung des Empirismus, nach der die Seele des Kindes bei seiner Geburt einem „unbeschriebenen Blatt" (= tabula rasa) gleicht, das erst durch die Sinneseindrücke im Verlaufe der individuellen Entwicklung „beschrieben“ wird, denn „,nichts ist im Verstande, was nicht

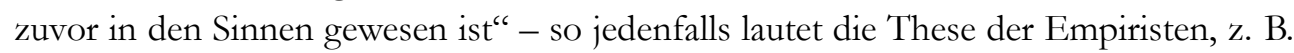
John Lockes (1632-1704). Wenn aber das „Seelenleben“ des Menschen so maßgeblich von den Einflüssen aus seiner Umwelt abhängt, liegt es nahe, dass man eine „gute Umwelt“ schaffen müsse, um „gute Menschen“ zu „erzeugen“. Diese Umwelt sollte nach Auffassung der Aufklärer des 18. Jahrhunderts vor allem durch eine entsprechend vernünftige Gesetzgebung und eine gute Erziehung aller Menschen herbeigeführt werden. Einen wichtigen Ansatz dazu sahen sie in einer vernünftigen Erziehung und Aufklärung der Herrscher. Daher schrieb z. B. Paul Th. d' Holbach (1723-1789):

„Fürsten, Gesetzgeber, Beherrscher der Welt! Euch kommt es zu, die Menschen zu erziehen [...] nur ihr könnt die Völker zur Vernunft bringen“ (d’ Holbach 1959, S. LV). 
Auch Owen appellierte an einflussreiche Leute, insbesondere an Fabrikanten, mehr für die Erziehung und Ausbildung der Arbeiter und ihrer Kinder zu tun, und zwar mit dem Argument,

„daß man die Menschen leicht ausbilden und verwenden kann, um den finanziellen Gewinn bedeutend zu vergrößern (Hervorhebung durch W. N.), während Sie diese gleichzeitig in hohem Maße glücklich machen können“ (Owen 1955, S. 71).

Das historische Scheitern der Bemühungen um die Realisierung dieser Theorie hängt damit zusammen, dass die ökonomischen Gesetze der Gesellschaft durch moralische Appelle nicht außer Kraft gesetat werden können; das musste schließlich auch der Unternehmer Owen einsehen, dessen edelmütige Projekte dem Konkurrenžkampf zum Opfer gefallen sind.

Marx hat in der 3. Feuerbachthese einen fundamentalen Mangel in der Gesellschaftstheorie der Aufklärung kritisiert; wenn es nämlich stimmen würde, dass eine schlechte Umwelt immer schlechte Menschen hervorbringt, dann ist nicht zu erklären, woher die guten Menschen kommen sollen, die eine „gute Umwelt“ schaffen und alle Menschen gut erziehen. Marx suchte einen Ausweg aus diesem Dilemma und formulierte:

„Das Zusammenfallen des Ändern(s) der Umstände und der menschlichen Tätigkeit oder Selbstveränderung kann nur als revolutionäre Praxis gefaßt und rationell verstanden werden“ (Originaltext von Marx in: MEW, Bd. 3, S. 6).

Fundamental in dieser These ist die Erkenntnis, dass die Menschen sich in ibrer umweltverändernden Tätigkeit zugleich selbst verändern. Praktisch bedeutet dies, dass die Menschen nicht nur Produkte, sondern zugleich auch Produzenten ibrer Verbältnisse und ibrer selbst sind. Die Teilung der Gesellschaft in gute bzw. aufgeklärte Menschen einerseits und erziehungsbedürftige andererseits ist für eine undialektische Betrachtungsweise der Gesellschaft charakteristisch. Die Annahme, auf dieser Grundlage die Gesellschaft „verbessern“ zu können, ist daher - schon aus theoretischer Sicht - ein Irrtum. Den praktischen Beleg für diesen Irrtum hat die historische Entwicklung geliefert.

Die Aussage im zweiten Teil der These, mit der Marx einen konstruktiven und realisierbaren Lösungsansatz zu formulieren versucht, bedarf allerdings noch weiterer Bearbeitung, denn sie wirft die Frage auf: Was heißt revolutionäre oder umwälzende Praxis? Eine gängige Interpretation im vergangenen Jahrhundert durch Vertreter des Marxismus-Leninismus lautete: Revolutionäre Praxis bedeutet eine proletarische Revolution zum Zwecke der Umgestaltung der Gesellschaft durch Aufhebung des Privateigentums an den Produktionsmitteln und die Errichtung der Diktatur des Proletariats als Übergangsphase zum Kommunismus. Marx und Engels formulierten ihre Erwartung in zugespitzter Form, indem sie 1845 in der „Deutschen Ideologie“ schrieben,

„daß also die Revolution nicht nur nötig ist, weil die herrschende Klasse auf keine andre Weise gestürzt werden kann, sondern auch, weil die stürzende Klasse nur in einer Revolution dahin 
kommen kann, sich den ganzen alten Dreck vom Halse zu schaffen und zu einer neuen Begründung der Gesellschaft befähigt zu werden“ (MEW, Bd. 3, S. 70).

Diese These widerspiegelt einen historisch begründeten Irrtum, der auch aus dem unzureichenden Entwicklungsstand der Psychologie vor Wilhelm Wundt (1832-1920) und Sigmund Freud (1856-1939) zu erklären ist. Zudem liegt es auf der Hand, dass mit dem Zusammenbruch der ehemaligen sozialistischen Staatengemeinschaft ein Versuch des Übergangs zum Kommunismus gescheitert ist. Die Ursachen dafür sind vielfältig. Entsprechend der historisch-materialistischen Gesellschaftstheorie müssten die Hauptursachen im Bereich der Ökonomie zu finden sein und das trifft auch tatsächlich zu, denn die sozialistische Planwirtschaft hat derart gegen elementare Gesetze der Ökonomie verstoßen (z. B. gegen das Wertgesetz durch voluntaristische Preisbildungen), dass es nicht verwunderlich ist, wenn dadurch die „natürlichen Triebkräfte“ und Regulationsmechanismen der Wirtschaft deformiert worden sind. Eine Mangelwirtschaft mit ihren Versorgungsschwierigkeiten war die unausbleibliche Folge; dagegen konnte 1961 auch keine Grenzschließung (zwecks Unterbindung des Abwanderungsstroms von DDR-Bürgern in die Bundesrepublik) auf die Dauer helfen. Zudem kann man wohl den Initiatoren des Mauerbaus vorwerfen, dass sie u. a. auch folgende Zeilen aus dem „Manifest der Kommunistischen Partei “ von 1848 missachtet haben:

„Die wohlfeilen Preise ihrer Waren sind die schwere Artillerie, mit der sie (die Bourgeoisie, W. N.) alle chinesischen Mauern in den Grund schießt, [...]“" (MEW, Bd. 4, 1980, S. 466).

Dieser Satz galt auch für die Berliner Mauer, für deren Fall allerdings nicht nur ökonomische Gründe bedeutsam waren, sondern auch der Protest gegen Menschenrechtsverletzungen. Inwieweit Engels 1888 mit der Umwandlung der Marx’schen Formulierung von „revolutionäre“ in „umwälzende“ Praxis bereits eine veränderte und realistischere Sicht auf das Problem andeuten wollte, können wir heute nicht mehr entscheiden. Auf jeden Fall besagen die Erfahrungen (sowohl aus der Großen Französischen Revolution von 1789 als auch aus der Russischen Oktoberrevolution von 1917), dass bewaffnete Aufstände mit gewaltsamen Umstürzen und der Niederhaltung des Widerstandes mit vielfach willk:ürlichen Mitteln offenbar nicht die von Marx erhoffte moralisch reinigende Rückwirkung auf die „stürzende Klasse“ haben. Sie laufen vielmehr in Gefahr, durch den Missbrauch bzw. die Usurpation der revolutionären Macht durch Einzelne ihrer Führer (Robespierre, Napoleon, Stalin, Mao Zedong u. a.) in ein diktatorisches Terrorsystem einzumünden - verbunden mit Verrat an erklärten Zielen der Revolution.

Das Problem der Entwicklung einer gerechten Gesellschaftsordnung ist vermutlich allein über gesellschaftliche Innovationsprozesse zu lösen, die in kritisch-konstruktiver Reflexion und Nutzung der Erkenntnisse und Methoden von Marx erforscht werden müssen. Reformprozesse im strengen Sinne des Wortes scheiden aus, denn Reform meint eigentlich die Wiederherstellung des aus der Form geratenen ursprünglichen und im Kern für 
gut gehaltenen Zustandes (vgl. Braun-Thürmann 2005, S. 29f.). Dieser Reformbegriff tauchte im alten Rom auf und zielte auf die Rückekehr der unter Nero degenerierten Monarchie zu den Verhältnissen unter Augustus. Der Innovationsbegriff dagegen meint

„die Abkehr vom vermeintlich guten Alten, um nach einem von seinem Ursprung losgelösten neuen Zustand zu streben, von dem angenommen wird, dieser entspräche den gegenwärtigen Bedürfnissen, Erkenntnissen und Erfahrungen“ (Braun-Thürmann 2005, S. 33 ).

Durch die bisherigen Ausführungen dürfte klar geworden sein, dass die Auffassung von der Allmacht der Erziehung bei der Gesellschaftsveränderung eine Illusion ist. Doch bezüglich der Wirkungskraft der Erziehung beim Individuum gab es bis in die Mitte des 20. Jahrhunderts hinein noch deutlich erkennbare Tendenzen zur Allmachtsposition. So schrieb der Vertreter des Behaviorismus John Broadus Watson (1878-1958):

„Geben Sie mir ein Dutzend gesunder Kinder und meine eigene besondere Welt, in der ich sie erziehe. Ich garantiere Ihnen, daß ich blindlings eines davon auswähle und es zum Vertreter irgendeines Berufes erziehe, sei es Arzt, Richter, Künstler, Kaufmann oder [...] Dieb ohne Rücksicht auf seine Talente, Neigungen, Fähigkeiten, Anlagen, Rasse oder Vorfahren“ (zitiert nach Hobmair u. a. 1989, S. 59).

Es soll nicht verkannt werden, dass die Vertreter des Behaviorimus bemüht waren, pädagogischen Optimismus zu fördern, ohne den wohl kein Erzieher seinen belastenden Beruf auf Dauer durchstehen kann. Ihre Auffassung richtete sich vor allem gegen die Vertreter des Nativismus ${ }^{7}$, die von der Position ausgehen, dass die Erbanlagen für die Entwicklung des Menschen entscheidend wären und Erziehung eben dadurch obnmächtig sei. Ebenso wie die Auffassung von der Allmacht der Erziehung reicht auch die Vorstellung von der Ohnmacht der Erziehung bis ins Altertum zurück.

In der Neuzeit hatte die Auffassung von der Ohnmacht der Erziehung vor allem zwei Fürsprecher: Vertreter der Philosophie Schopenhauers und nativistisch orientierte Psychologen. In seiner von der Königlich Norwegischen Societät der Wissenschaften zu Drontheim gekrönten Preisschrift behauptet Arthur Schopenhauer (1788-1860), dass der individuelle Charakter des Menschen angeboren und konstant sei (vgl. Schopenhauer 1988, S. 48ff.). Er begründet dies mit Alltagserfahrungen und sprichwörtlichen Redewendungen (z. B. ,Wer einmal stiehlt, ist sein Lebtag ein Dieb“). Die Frage nach der Wirksamkeit der Erziehung kann aber auf der Grundlage von Alltagserfahrungen nicht fundiert beantwortet werden. Daher ist die Wissenschaft gefordert. Als Vertreter der nativistisch orientierten Psychologie sei hier auf Cyril Burts (1883-1971) verwiesen, der mit angeblichen Forschungsergebnissen die Öffentlichkeit sehr beeindruckt hat. Diese „Forschungsergebnisse“ hat jedoch Leon Kamin 1974 als Fälschungen entlarvt (vgl. Hobmair u. a. 1989, S. 69f.).

7 Lateinisch: „natus“ - geboren, zu etwas geschaffen, von Natur zu etwas bestimmt, von Natur geartet. 
Die Versuche, die Bedeutung von Erbanlagen für die Entwicklung der individuellen Struktur von Persönlichkeiten zu bestimmen, stoßen auf große forschungsmethodische Schwierigkeiten. Selbst die Ergebnisse seriöser Familien- und Zwillingsforschungen, die mit Hilfe des sog. Erblichkeitskoeffizienten den Anteil von Erbanlagen an der geistigen Entwicklung mit $20 \%$ in der frühen Kindheit, mit $40 \%$ in der Kindheit und mit $60 \%$ in der Adoleszenz angeben (vgl. Oerter/Montada 1998, S. 42), erfassen damit nur Durchschnittswerte zu bestimmten Zeitpunkten der Entwicklung in relativ statischer Form, d. h., über die potenzielle Dynamik der individuellen Entwicklung geistiger Fähigkeiten wird damit noch nichts ausgesagt.

Für die Erblichkeitskoeffizienten anderer Persönlichkeitsmerkmale wurde eine ähnliche Tendenz wie bei der Intelligenzentwicklung - also eine stärkere Wirksamkeit von Umwelteinflüssen in der frühen Kindheit als in der Adoleszenz - festgestellt, allerdings auf einem niedrigeren Niveau (vgl. Oerter/Montada 1998, S. 42). Die Beobachtungsdaten stützen die Vermutung, dass die Plastiz̨ität der Anlagen bei jüngeren Kindern größer ist als bei älteren bzw. Erwachsenen.

Die bisher vorliegenden empirischen Untersuchungen behandeln aus forschungsmethodischen Gründen das Verhältnis von Anlagen (endogenen Faktoren) und Umwelteinflüssen (exogenen Faktoren) relativ statisch, d. h., sie können nicht die Mechanismen der Vermittlung zwischen exogenen und endogenen Faktoren exakt beschreiben oder erklären. Dass es solche Vermittlungen gibt, ist klar, denn irgendwie müssen ja die Wechselwirkungen realisiert werden. Dabei gibt es sicher eine Menge von spontanen Anpassungsleistungen des menschlichen Organismus an seine Umwelt; z. B. wird sich das nachts schreiende Kind an den Tages- und Nachtrhythmus der Familie gewöhnen, sobald es die Entwicklungsvoraussetzungen dafür erlangt hat und die Eltern zielstrebig darauf hinarbeiten. Für die Persönlichkeitsentwicklung des Kindes sind aber nicht so sehr diese Anpassungsleistungen des Organismus wesentlich, sondern jene Vermittlungen, die durch autogene Faktoren realisiert werden (vgl. Hobmair u. a. 1992, S. 190f.).

Der Begriff ,autogener Faktor“ taucht in Abhandlungen zur Erbe-Umwelt-Problematik relativ selten auf, obgleich er unter dem Aspekt der Vermittlungsagenzien sinnvoll ist. Denn tatsächlich werden die Wechselwirkungen zwischen endogenen und exogenen Faktoren im Verlaufe der Persönlichkeitsentwicklung in zunehmendem Maße durch autogene Faktoren vermittelt, nämlich durch Bedürfnisse, Neigungen, Interessen und schließlich auch durch Willenshandlungen, die das sich entwickelnde Subjekt in bestimmter Weise aktiv werden lassen, d. h., die autogenen Faktoren ermöglichen die Selbstorganisation der Persönlichkeit und ihre relativ eigenständige Entwicklung. Letztendlich entscheiden die Aktivitäten der Persönlichkeit durch ihre Erfolge oder Misserfolge auch über Entwicklungsresultate. Daher ist es berechtigt, in der Dialektik von endogenen, exogenen und autogenen Faktoren den autogenen - zumindest innerhalb eines bestimmten Schwankungsberei- 
ches - eine für das Entwicklungsresultat maßgebliche Bedeutung beizumessen. Die Herkunft der autogenen Faktoren bedarf weiterer Untersuchungen; vermutlich ,wurzeln“ sie in basalen invarianten Bedürfnissen (vgl. S. 218f.; S. 227) und erfahren durch vielfältige Lernprozesse ihre individuelle Ausprägung als wirksame Kräfte.

Mit der Anerkennung der Rolle von autogenen Faktoren ist auch die Verantwortung des Individuums für sein persönliches Handeln und Verhalten objektiv begründet. Wenn nämlich ein Mensch fähig ist, die Folgen seines Handelns zu bedenken, dann ist er auch dafür verantwortlich. Verminderte Schuldfähigkeit ist nur unter den Bedingungen der nachweislich eingeschränkten Leistungsfähigkeit der autogenen Kräfte gegeben. Bewusstes Handeln schließt ja Reflexionen über die Resultate des Handelns mit ein, so dass der Handelnde mit zunehmender Mündigkeit auch für die Richtungen seiner Bestrebungen und Neigungen, deren Risiken und möglichen Resultate verantwortlich ist. So kann z. B. die Neigung zum Jähzorn im geerbten Temperament als Risikofaktor vorhanden sein. Aber diese Anlage drängt nicht mechanisch-deterministisch zum Durchbruch, d. h., ob jemand tatsächlich jähzornig und aggressiv agiert, hängt davon ab, ob er sich „gehen lässt“ oder zu beherrschen lernt, was natürlich in einer „Spiel- und Spaßgesellschaft" vielen Kindern und Heranwachsenden schwer fällt.

Gelegentlich wird zur Begründung nativistischer Positionen auf Erkenntnisse der Hirnforschung hingewiesen. Tatsächlich sagt der Hirnforscher Hans Markowitsch in einem Interview:

„Wir identifizieren derzeit Mechanismen im Hirn, die ein Verhalten hervorbringen können, das wir moralisch als böse, juristisch als strafbar bewerten. Für Neurowissenschaftler sind das Defekte, für die ein Delinquent nichts kann, weil sie angeboren sind oder meist in früher Kindheit erworben wurden“ („Der Spiegel“ Nr. 31/2007, S. 117).

Aber er formuliert auch die Aussage:

„Jedes Gehirn ist plastisch, also veränderbar, zum Beispiel mit einer Therapie. Und wir können im Kernspin überprüfen, ob die Therapie erfolgreich war“ (a. a. O., S. 123).

Und am Ende er kommt zu der Schlussfolgerung:

„Meiner Ansicht nach muss man alle, die strafauffällig sind, zu Erziehungsmaßnahmen führen“ (a. a. O., S. 120).

Sinn und Zweck dieser Erziehungsmaßnahmen ist es, auch diese Menschen - sofern sie nicht sehr krank sind - als bildsame und mit Bewusstsein begabte gesellschaftliche Wesen so weit zu erziehen, dass sie mehr sind als blind Ausführende eines genetisch bedingten neurophysiologischen Mechanismus'. 


\subsection{Zur statistischen Gesetzeskonzeption in der Pädagogik}

\subsubsection{Problemlage und Ausgangspositionen}

In vielen modernen Standard- und Nachschlagewerken der Pädagogik sucht man in den Sachregistern vergeblich nach den Stichworten Gesetz (im Sinne von Seins-Gesetzen) und Gesetzmäßigkeiten, obgleich in den Darstellungen zu einzelnen Themen durchaus von Gesetzmäßigkeiten und Prinzipien die Rede ist. Vermutlich hängt diese Zurückhaltung in der theoretischen Erörterung der Gesetzes- und Prinzipienproblematik damit zusammen, dass Pädagogen, die in der geisteswissenschaftlichen Denktradition stehen, Hemmungen haben, öffentlich über Begriffe zu reflektieren, die inhaltlich vor allem von Erkenntnissen der Naturwissenschaften bestimmt worden sind. Möglicherweise sind aber auch veraltete, etwa aus der Mechanik stammende Auffassungen von Gesetzen im Spiel, die zur Verdrängung der Gesetzesproblematik aus der Pädagogik geführt haben. Hierdeis und Hug zitieren z. B. in ihrer Schrift „Pädagogische Alltagstheorien und erziehungswissenschaftliche Theorien“ eine von ihnen namentlich nicht genannte Pädagogin mit den Worten:

„Die Vorstellung des eher empirisch-analytischen Ansatzes, daß man zu irgendwelchen gesetzmäßigen Aussagen kommen könnte, [...] hat sich ja leider nicht einlösen lassen [...]“ (Hierdeis/Hug 1991, S. 23).

Diese Bewertung verdient es, überprüft zu werden, denn immerhin werden in der pädagogischen Literatur zumindest seit Jan Amos Komenský (1592-1670) explizit Regeln, Prinzipien und Gesetze formuliert, wenn sich auch die begrifflichen Vorstellungen davon bei den einzelnen Autoren unterscheiden. Dem Wesen nach ging es immer um Vorschriften oder Empfehlungen für Lehrende und Lernende, deren Einhaltung nach vorliegenden Erfahrungen mit einiger Wahrscheinlichkeit zu Erfolgen führten.

Bei der Verwendung des Wortes „Gesetz“ ist zu beachten, ob von Seinsgesetzen oder von „Sollensgesetzen“ (normativen Gesetzen) die Rede ist. Seinsgesetze sind objektive, wesentliche und unter bestimmten Bedingungen wiederholbare Zusammenhänge, ,weil die Dinge über konstant verbundene Eigenschaften [...] verfügen (Bunge/Mahner 2004, S. 49). Aussagen über diese Zusammenhänge - also Gesetzesaussagen - sind entweder wahr oder bypothetisch; im letzteren Fall können sie wahr oder falsch sein. Sie bedürfen daher der weiteren Überprüfung. Dagegen sind juristische Gesetze und Moralnormen unter relevanten Bedingungen gültige und verbindliche Vorschriften für das Handeln und Verhalten, die in Form von Aufforderungen bzw. Muss-, Soll-, Kann- oder Darf- Sätzen formuliert werden.

In der Erziehung bzw. Pädagogik treten Normen auf, die unterschiedlichen Charakter tragen, weil sie wissenschaftlich unterschiedlich fundiert sind. In Übereinstimmung mit Seiffert (1969, S. 71ff.) können wir soziale und nichtsoziale Normen unterscheiden. 
Zu den sozialen Normen gehören nach Seiffert die juristischen und moralischen. Juristische Normen in Form von Gesetzesvorschriften (Paragrafen) haben einen definierten Geltungsbereich und sind in einem solchen Maße verbindlich, dass ihre Nichtbeachtung bzw. Nichteinhaltung in der Regel auch juristisch definierte Sanktionen zur Folge haben. Ordnungswidrigkeiten z. B. werden mit Bußgeldern geahndet und Straftatbestände von Gerichten behandelt, die nach den geltenden Rechtsnormen ihr Urteil sprechen und damit auch die eventuell notwendigen Sanktionen festlegen. Moralnormen werden allgemein in Form von Soll- oder Darf-Sätz̧en formuliert. Sie sind durch die Moralvorstellungen der Gesellschaft, einer bestimmten sozialen Schicht oder Gemeinschaft begründet (siehe Abschnitt 4.3.1). Über die Sanktionen oder Konsequenzen bei Verstößen gegen Moralnormen entscheiden in der Regel die davon Betroffenen.

Nichtsoziale Normen gibt es in allen Handlungsbereichen im Sinne von Gebrauchsanweisungen oder technischen Vorschriften. Ihre Begründung finden sie - sofern sie nicht durch Vereinbarung festgelegt worden sind wie z. B. die Deutschen Industrienormen (DIN) - in objektiven Gesetzen der Natur und der Gesellschaft. Wenn etwa für die Reinigung eines technischen Gerätes vorgeschrieben wird, dass zuvor der Stecker der Strom zuführenden Verbindungsschnur heraus gezogen werden muss, dann deshalb, weil sonst die Gefahr eines Stromschlages oder einer Verletzung durch unbeabsichtigtes Einschalten des Gerätes besteht, d. h., physikalische Gesetze begründen in Verbindung mit der Wertvorstellung vom Leben und dem Menschenrecht auf Leben eine entsprechende Norm oder Vorschrift mit hohem Verbindlichkeitsgrad.

Es gibt nun allerdings Bereiche, in denen soziale und nichtsoziale Normen eigentümlich miteinander verbunden auftreten. Beispielsweise wird übermäßiger Alkoholgenuss vielfach als moralisches Problem betrachtet. In der Tat drückt sich darin auch eine Verantwortungslosigkeit des Trinkers gegenüber seinen Familienangehörigen aus, vor allem wenn durch Sucht bedingte Geldausgaben die Familie in Not gerät und/oder wenn der Alkoholiker seine Familienangehörigen misshandelt, wobei im letzteren Fall auch noch gegen Rechtsnormen verstoßen wird. Zugleich geht es aber auch um ein biologisches bzw. medizinisches Problem, denn durch übermäßigen Alkoholgenuss zerstört der Trinker seine eigene Gesundheit (gesetzmäßiges Auftreten von Leberschäden!). Je nach dem, wie man das Alkoholismus-Problem betrachtet, können die zu seiner Bewältigung gültigen Normen unterschiedlich begründet werden. Im Sinne der Moral lässt sich formulieren: Ein Trinker ist moralisch zu verurteilen, weil er verantwortungslos und rücksichtslos gegenüber seinen Familienmitgliedern und Mitmenschen handelt; daraus folgt: er soll den Alkoholgenuss meiden! Für den Fall, dass es wiederholt zu Rechtsverstößen kommt, lautet die Norm: der Alkoholkranke muss (auch aus juristischen Gründen) den Alkohol meiden. Aus medizinischer Sicht kann aber auch gesagt werden: übermäßiger Alkoholgenuss ist gesundheitsschädlich und lebensgefährlich. Daraus folgt 
allgemein die Vorschrift oder Empfehlung: Du sollst möglichst wenig Alkohol trinken! Unter spezielleren Bedingungen - etwa bei einer bereits bestehenden Alkoholkrankheit kann die „Empfehlung“ zu einem strikten Verbot verschärft werden (du darfst keinen Alkohol mehr trinken oder: du musst Alkohol unbedingt meiden!), weil nur dann die Chance besteht, noch einige Zeit länger zu leben. Damit wird deutlich, dass der Verbindlichkeitsgrad einer Handlungsvorschrift nicht allein vom Inhalt der Norm (etwa: Mäßigkeit im Alkoholkonsum), sondern auch von ibren Anwendungsbedingungen abhängt. Bei diesen Anwendungsbedingungen ist bedeutsam, in welchem Maße mit dem Verstoß gegen die Norm zugleich auch objektive Gesetzmäßigkeiten ignoriert werden. Ist dies über einen kritischen Punkt hinaus der Fall (etwa bei Gefahr einer Leberzirrhose), gilt die Norm im verschärften Sinne; sie sollte demzufolge auch in einem Muss-Satz ausdrückt werden, denn ihre Nichtbeachtung bedeutet Gefahr für Leib und Leben.

Der Unterschied zwischen Aussagesätzen und normativen Sätzen ist also beträchtlich, was im Alltagsdenken häufig übersehen wird. Eine Aussage ist wahr, falsch oder hypothetisch; eine normative Formulierung ist gültig, ungültig oder fragwürdig bzw. diskursbedürftig, aber nicht wahr oder falsch. Der Unterschied zwischen Aussagesätzen und normativen Sätzen oder Vorschriften wird so bewertet, dass logische Ableitungen von „Soll-Sätzen“ aus Aussagen wegen des damit verbundenen naturalistischen Fehlschlusses für unmöglich gehalten werden, was allerdings die Menschen nicht daran hindert, es dennoch mittels nichtdeduktiver Begründungen zu ihrem eigenen Wohle zu tun, wie die Erörterung zum Alkoholismusproblem erkennen lässt.

Die wissenschaftliche Ableitung von Forderungen bzw. Normen aus Aussagen ist tatsächlich ein kompliziertes philosophisches, erkenntnistheoretisches und logisches Problem. Um so erstaunlicher ist, dass in den bisherigen Diskussionen der Lösungsvorschlag von Franz Loeser aus dessen Buch „Deontik“ kaum aufgegriffen und kritisch geprüft worden ist. Er entwickelt den Begriff der „deontischen Äquivalenz“ und empfiehlt ein darauf basierendes Regelwerk für die Ableitung von Muss-, Soll-, Darf- und KannSätzen aus Aussagesätzen (1966, S. 124).

Für die Ableitung von pädagogischen Vorschriften aus Aussagen ist folgender Sachverhalt wesentlich: Es gibt pädagogische Vorschriften, die nicht nur auf moralischen Wertvorstellungen beruhen, sondern auch auf Gesetzmäßigkeiten des Organismus und der Psyche des Menschen. So kann z. B. gesagt werden: Um ein bestimmtes Ziel zu erreichen (z. B. einen Drogenabhängigen vor dem endgültigen Ruin zu bewahren), sind bestimmte therapeutische und sozialpädagogische Maßnahmen notwendig. Es wird damit zu einem Sachverhalt eine Aussage formuliert (es existiert eine lebensbedrohliche Notlage bezüglich x) und daran die Aufforderung geknüpft, die Not zu wenden. Dazu wird ein Muss-Satz formuliert, der speziell verlangt: ein Sozialpädagoge oder Therapeut muss versuchen, dem Drogensüchtigen zu helfen, was sich verallgemeinert im Rettungsprinzip widerspiegelt. 
Ähnlich verhält es sich auch bei anderen Prinzipien: Die Aussage „Persönlichkeiten entwickeln sich in der Tätigkeit" begründet zusammen mit dem Ziel der Selbständigkeit das Prinzip der Selbsttätigkeit, das ebenfalls als Muss-Satz formuliert werden kann: Erzieher müssen ihre Zöglinge zu anspruchsvollen entwicklungsfördernden Tätigkeiten anhalten, da sie sonst ihrer Verantwortung gegenüber dem Zögling und der Gesellschaft nicht gerecht werden. Natürlich gibt es unterschiedliche Arten und Grade des Notwendigen; nicht in jedem Falle geht es um die physische oder psychische Gesundheit bzw. um Leben oder Tod. Bedeutsam ist ferner die Tatsache, dass in manchen Fällen gleichzeitig mehrere Notwendigkeiten bestehen; so gibt es in dem oben angedeuteten Fall des Alkoholikers

- eine medizinische bzw. therapeutische Notwendigkeit wegen der Leberzirrhose,

- eine moralische Notwendigkeit wegen der Schädigung der Familie, insbesondere der Kinder (sofern solche bei ihm leben),

- eine juristische Notwendigkeit im Falle der Misshandlung von Familienmitgliedern und

- nicht zuletzt die pädagogische Notwendigkeit, das Verhalten des Alkoholikers auch in seinem eigenen Interesse zu verändern.

Diese Notwendigkeiten widerspiegeln sich generalisiert in Prinzipien oder Regeln, mit deren Hilfe Maßnahmen und Handlungsweisen begründet und empfohlen werden können.

Die Behauptung, dass es in der Pädagogik Handlungsvorschriften in Form von Prinzipien und Regeln gibt, die auf objektiven Gesetzmäßigkeiten beruben, stößt nun allerdings vielfach auf Ablehnung. Die Einmaligkeit jedes menschlichen Individuums und die Einmaligkeit seiner jeweiligen konkreten Lebenssituation scheint den Erfordernissen des Gesetzesbegriffes nach Allgemeinheit und Wiederholbarkeit entgegen zu stehen. Außerdem ist im Bereich der Erziehungswissenschaft vielfach noch die Denkweise der geisteswissenschaftlichen Pädagogik wirksam, die sich von Wilhelm Diltheys (1833-1911) Grundsatz leiten lässt: „Die Natur erklären wir, das Seelenleben verstehen wir“ (Dilthey 1990, S. 144). Wolfgang Brezinka kritisiert diese von Dilthey und seinen Anhängern vertretene Trennung zwischen Natur- und Geisteswissenschaften (Brezinka. 1989, S. 44) und weist mit Recht darauf hin, dass rationelles Verstehen eigentlich keine Methode, sondern ein Ergebnis ist, das auf dem Erklären als Methode basiert. Erklären bedeutet, die der Erscheinung zugrunde liegenden gesetzmäßigen Zusammenhänge aufzudecken. Aber auch das Verstehen im Sinne eines Sich-binein-Versetzens in die Lage anderer sollte in seiner methodischen und pädagogischen Bedeutung nicht unterschätzt werden. Es kann dies nämlich als Moment im methodischen Vorgehen bei der Gestaltung des Erziehungsprozesses interpretiert werden! Das Zeigen von Verständnis, das einem Klienten im Hilfeprozess ermutigt sich zu öffnen, ermöglicht Erkenntnisgewinn (für Praktiker und Theoretiker!) und weckt wahrscheinlich ein Vertrauen, das wiederum der Problemlösung dient. 
Unter dem Erklären versteht man inzwischen nicht nur in den Naturwissenschaften das Auffinden jener gesetzmäßigen Zusammenhänge, die eine beobachtete Erscheinung bedingen. Um zum Verständnis psychischer Prozesse - und demzufolge auch davon abhängiger Verhaltensweisen - zu gelangen, müssen nach geisteswissenschaftlicher Auffassung die Ziele der jeweiligen Person ermittelt und interpretiert werden. Diese teleologische Betrachtung menschlicher Verhaltensweisen (telos = Zweck) ist in der Pädagogik eine wertvolle Ergänzung zur kausalanalytischen, weil aus dem Verständnis für die Bestrebungen eines Menschen Erkenntnisse darüber gewonnen werden können, wie ihm zu helfen ist. Allerdings kann und muss man - ähnlich wie in den Naturwissenschaften - versuchen, eben auch zu erklären, wodurch die Ziele und Motive des jeweiligen Handelns und Verhaltens bedingt sind, d. h. nach den gesetzmäßigen Ursachen der Ziele und Motive fragen. Wenn beispielsweise ein fünfjähriges Kind die Erwachsenen in ihrem Gespräch stört, so kann mit an Sicherheit grenzender Wahrscheinlichkeit als Ursache dafür angenommen werden, dass es sich unbeachtet und damit abgewertet fühlt (kausale Beziehung) und zugleich den Zweck verfolgt, einbezogen bzw. beachtet qu werden (teleologische Beziehung). Die auf das Verstehen gerichtete hermeneutische Methode bereichert die kausalanalytische in der Sozialforschung. Kausalanalysen sind auch in den Sozialwissenschaften möglich und notwendig, auch hier zielen die Erklärungsversuche auf die Erkenntnis gesetzmäßiger Zusammenhänge. Letztendlich haben viele Zielvorstellungen der Menschen ihre Ursachen in ihren Bedürfnissen und Lebensbedingungen, die durch Gesetzmäßigkeiten dialektisch determiniert und deshalb erklärbar sind.

Die teleologische Betrachtungsweise ist nach dialektisch-materialistischer Auffassung für das wissenschaftliche Verständnis sozialer Erscheinungen nicht ausreichend. Aus diesem Grunde muss auch Alfred Adlers (1870-1937) Überbewertung der Finalität im menschlichen Handeln und der teleologischen Betrachtung bzw. hermeneutischen Methode in der psychologischen Erkenntnisgewinnung kritisch gesehen werden (vgl. Ansbacher/Ansbacher 1982, S. 104f.). Eine so strikte methodologische Unterscheidung von Natur- und Geisteswissenschaften, wie sie besonders von Dilthey vertreten wurde und mit der geisteswissenschaftlichen Pädagogik auch im 20. Jahrhundert noch üblich war, kann nicht mehr aufrecht erhalten werden. In diesem Punkte ist der Argumentation von Volker Gerhard zuzustimmen (2007, S. 12ff.).

\subsubsection{Wesensmerkmale objektiver Gesetzmäßigkeiten und wissenschaftlicher Gesetze}

Objektive Gesetzmäßigkeiten bilden eine reale Grundlage für den zielstrebigen und Erfolg versprechenden Umgang mit den Dingen, weil die Dinge über konstant verbundene Eigenschaften verfügen (vgl. Bunge/Mahner 2004, S. 41 und 49). Gesetresaussagen werden formuliert im Ergebnis von eingegrenzten Realitätsanalysen, isolierenden und idealisierenden Abstraktionen und deren annähernd realitätsadäquater konstruktiver Synthese. 
In den Sozialwissenschaften ist Gesetzeserkenntnis schwierig, weil beliebige Erscheinungen bzw. Prozessresultate niemals nur durch die Wirksamkeit eines einzigen Gesetzes erklärt werden können, denn sie resultieren aus dem komplizierten Zusammenwirken vieler Gesetze. Es ist bei sozialen Experimenten und ihren Analysen nicht möglich, die Wirkungen der jeweiligen Systemgesetze auszuschließen, die mit dem zu untersuchenden einzelnen Gesetz zusammenhängen. Man kann lediglich versuchen, ihre Wirksamkeit im Sinne stabiler Wirkungsbedingungen so relativ konstant zu halten, dass der jeweils untersuchte einzelne Gesetzeszusammenhang durch seine Effekte hinreichend deutlich wird.

Auch pädagogisches Handeln vollzieht sich in realen Systemzusammenhängen, die durch viele unterschiedliche Gesetze determiniert werden; Herbert Hörz schreibt:

„Unter Gesetzmäßigkeiten ist ein System von Gesetzen zu verstehen, das allgemeine und besondere, grundlegende und abgeleitete, einander bedingende und widersprechende sowie koexistierende Gesetze umfasst, die zum Teil erkannt sind oder weiter untersucht werden. Gesetzmäßige Prozesse - von der Sozialpädagogik untersucht - umfassen einen Komplex von natürlichen, gesellschaftlichen, technischen, psychischen, mentalen Prozessen mit spezifischen Gesetzen, für die es Systemgesetze gibt, die den sozialpädagogischen Prozess in seinem Ablauf bestimmen“ (Hörz 2004, S. 1).

Vielfach sind es beobachtete Regelmäßigkeiten in bestimmten Prozessen, welche die Frage nach möglichen gesetrmäßigen Zusammenhängen aufwerfen, um die empirisch festgestellten Regelmäßigkeiten erklären zu können. Dabei ist es zunächst einmal gleichgültig, in welcher Form eine objektive, relativ allgemeine und wesentliche relationale Eigenschaft widergespiegelt wird. So wurde beispielsweise der gesetzmäßige Zusammenhang zwischen Reibung und Wärme ursprünglich ganz praktisch erfasst und zur Entzündung von Feuer genutzt. Wann die qualitative Gesetzesaussage „Reibung erzengt Wärme“ formuliert worden ist, können wir nicht sagen.

Aussagen von ähnlicher Qualität wie im oben genannten Beispiel gibt es nicht nur im physikalischen, sondern auch im pädagogischen Bereich, z. B.: Übung macht den Meister. Die Übungseffekte unterscheiden sich natürlich in Abhängigkeit von den individuellen Voraussetzungen der Übenden, den Übungsmaterialien, der Übungsmethode usw. Aber Erfahrungen und Experimente belegen, dass unter sonst vergleichbaren Bedingungen die geübten Schüler besser sind als die ungeübten, was mit Gesetzmäßigkeiten des Lernprozesses zu tun hat, die von der Lernpsychologie und Neurologie im Einzelnen untersucht werden. Natürlich erscheint das in Gesetzesaussagen erfasste Allgemeine real in individuellen Ausprägungen; das aber hängt damit zusammen, dass ,je höher die Entwicklungsstufe der Materie, desto größer das Gewicht des Einzelnen, Individuellen gegenüber dem Allgemeinen“ ist (Klaus 1958, S. 371). Daher müssen wir im Erziehungsprozess dem Individuellen besondere Aufmerksamkeit schenken, was aber die Beachtung allgemeiner, also auch gesetzmäßiger Zusammenhänge mit einschließt. 
Jeder Lehrer weiß, dass trotz eines relativ gleichartigen Übungsaufwands die Lerneffekte bei den Schülern verschieden sind, was sich z. B. in den verschiedenen Noten von Kontrollarbeiten widerspiegelt. Diese Erfahrung verweist auf eine Eigentümlichkeit in der Wirksamkeit gesetzmäßiger Zusammenhänge im pädagogischen Bereich, nämlich auf ihren statistischen Charakter. Dabei handelt es sich aber nicht nur um eine Besonderheit der Erziehung und des Unterrichts, sondern um ein allgemeines Charakteristikum gesetzmäßiger Zusammenhänge in der Gesellschaft. Aus vielen Forschungen haben Hörz und andere die philosophische Schlussfolgerung abgeleitet, dass in hochkomplizierten und komplexen Systemen die statistische Gesetzeskonzeption gilt (vgl. H. Hörz 1962). In Anlehnung an Hörz/Wessel (1983, S. 108) können wir sagen: In der Erziehung wirken Gesetzmäßigkeiten statistischen Charakters, d. h.:

- Unter bestimmten Bedingungen treten im Erziehungsprozess mit Sicherheit bestimmte gesetzmäßige Wirkungen auf (dieser Sachverhalt entspricht dem sog. dynamischen Aspekt des Gesetzeszusammenhanges),

- deren Ausprägungen aber - bezogen auf eine bestimmte Zöglingsgruppe eine statistische Verteilung aufweisen (= stochastischer Aspekt),

- wobei für jedes einzelne Gruppenmitglied (als Element des Systems) eine bestimmte Wahrscheinlichkeit für den Ausprägungsgrad der zu erwartenden Wirkung besteht, die um einen Durchschnittswert schwankt (= probabilistischer Aspekt des Gesetzeszusammenhangs).

Der Begriff des dynamischen Aspekts rührt daher, dass die aus der klassischen Physik bekannten Gesetze auch als dynamische Gesetze bezeichnet werden, sozusagen im Unterschied zu statistischen Gesetzen, wie sie u. a. in der Physik der Elementarteilchen auftreten. Für dynamische Gesetze gilt, dass bei Kenntnis der Wirkungsbedingungen mit Hilfe der in Formeln gefassten Gesetzesaussage die Wirkungen relativ genau berechnet werden können. Als Beispiel sei hier auf das Gesetz des freien Falls verwiesen, das den Typ des dynamischen Gesetztes verdeutlicht. Der gesetzmäßige Zusammenhang wird bekanntlich durch die Formel $\mathrm{s}=1 / 2 \cdot \mathrm{g} \cdot \mathrm{t}^{2}$ ausgedrückt, wobei $\mathrm{g}=9,81 \mathrm{~m} / \mathrm{sec}^{2}$ für die Beschleunigung des frei fallenden Körpers auf der Erde steht und s die Strecke des freien Falls bezeichnet, z. B. die Höhe der Plattform eines Turmes, von der jemand einen Stein hinunterfallen lässt.

Will man die Fallzeit des Steins berechnen, der aus $90 \mathrm{~m}$ Höhe fällt, so ist das nach Umformung obiger Gleichung möglich, also

$$
\begin{aligned}
\mathrm{s} & =1 / 2 \cdot g \cdot \mathrm{t}^{2} \\
\mathrm{t}^{2} & =(2 \cdot \mathrm{s}): \mathrm{g}, \text { demzufolge ist } \\
\mathrm{t} & =\sqrt{(2 \cdot \mathrm{s}): \mathrm{g}}
\end{aligned}
$$


werden dann die bekannten Größen eingesetzt, ergibt sich:

$$
\begin{aligned}
& \mathrm{t}=\sqrt{(2 \cdot 90): 9,81} \\
& \mathrm{t}=\sqrt{180: 9,81} \\
& \mathrm{t}=\sqrt{18,35} \\
& \mathrm{t}=4,28 \mathrm{sec} .
\end{aligned}
$$

Mit der Formel des dynamischen Gesetzes kann der Zeitpunkt des Ereignisses „Auftreffen des Steins auf den Erdboden neben dem Turm“ relativ genau vorausberechnet werden, wobei in der Rechnung gewisse Begleitbedingungen des Vorgangs vernachlässigt werden - etwa der Luftwiderstand, der sich bei dem Gewicht eines faustgroßen Steins nur gering auswirken wird, oder die unterschiedlichen Werte für die Beschleunigung in verschiedenen Breiten der Erdoberfläche (am Äquator ist $\mathrm{g}=9,745 \mathrm{~m} / \mathrm{sec}^{2}$, an den Polen $\mathrm{g}=9,832 \mathrm{~m} / \mathrm{sec}^{2}$ ). Absolut genau ist also der errechnete Zeitpunkt für das Auftreffen des Steins nicht.

In komplizierten Systemen wirken viele Faktoren und damit verbundene GesetzmäBigkeiten zusammen bzw. gleichzeitig, so dass die Gesamtwirkungen in statistischen Effekten erkennbar werden, von denen Wolfgang Stegmüller (1923-1991) sagt:

"Statistische Gesetzmäßigkeiten [...] gestatten Voraussagen der Einzelzüge von Ereignissen nur mit einer bestimmten Wahrscheinlichkeit“ (Stegmüller 1960, S. 179; vgl. dazu auch Hörz/ Wessel 1983, S. 107ff.).

Der praktische Nutzen statistisch erfasster gesetzmäßiger Zusammenhänge ist dennoch für pädagogisches Handeln bedeutsam, wie z. B. die Übersicht 1 auf der Seite 58 erkennen lässt. Die statistischen Effekte sind nicht nur durch das gleichzeitige Wirken vieler Faktoren in einem bestimmten Systemzusammenhang bedingt, sondern vor allem auch durch die Wirksamkeit gesetzmäßig gegenläufiger Prozesse zu erklären - im vorgestellten Beispiel der Übersicht 1 durch die gesetzmäßigen Vergessensprozesse, die den Eimprägungsprozessen entgegenwirken. Doch so wie Wissenschaftler und Ingenieure in Anwendung physikalischer Gesetze Flugapparate entwickelt haben, die sich trotz der gesetzmäßigen Wirkungen der Gravitation vom Erdboden abheben, so können auch trotz gesetzmäßiger Vergessensprozesse hohe Behaltenseffekte erreicht werden, wenn die Gesetzmäßigkeiten des Lernprozesses hinreichende Beachtung finden.

Eine dieser Gesetzmäßigkeiten widerspiegelt sich in der Statistik der Übersicht 1.

Die erkennbaren Regelhaftigkeiten in der statistischen Verteilung bzw. die gesetzmäßigen Tendenzen im Auftreten der Lerneffekte formulieren Clauß und Hiebsch verallgemeinernd in einer ,gesetzesartigen Aussage“ (Bunge, 1968, S. 118) wie folgt:

„Der Behaltenseffekt ist gewöhnlich besser, wenn nach der Kenntnisaneignung geschlafen wird, als wenn ihr eine Wachperiode folgt“ (Clauß/Hiebsch 1961, S. 297). 


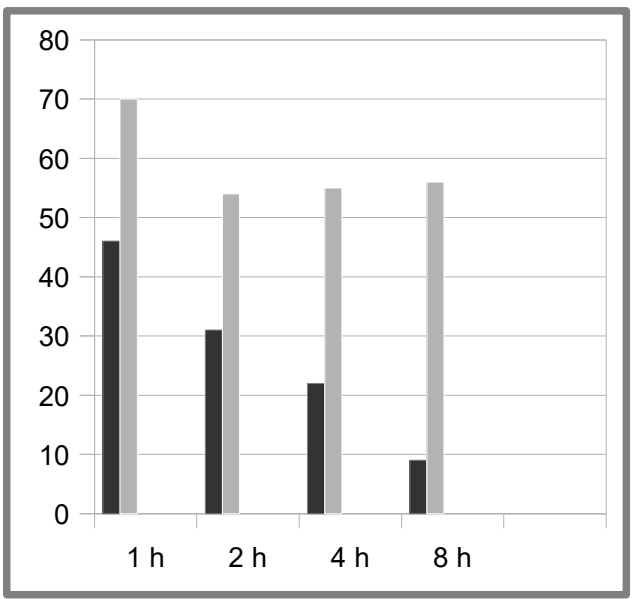

Effekte nach dem Wachzustand

Effekte nach dem Schlafen

Durchschnittliche Behaltenseffekte nach dem Wach- bzw. Schlafzustand laut Untersuchung von Jenkins/Dallenbach 1925 (zitiert nach Clauß/Hiebsch 1961, S. 297)

\section{Übersicht 1}

Die in den Untersuchungen ermittelten Lerneffekte streuen natürlich bei jeder einzelnen Versuchsperson um die angegebenen prozentualen Durchschnittswerte, die sich auf repräsentative Stichproben beziehen. Die mehr oder weniger starken Abweichungen der Einzelfälle von den Durchschnittswerten ändern aber nichts an der Erkenntnis, die diese Statistik vermittelt: der Behaltenseffekt nach dem achtstündigen Schlafzustand ist - bezogen auf die Gesamtheit - mit durchschnittlich $56 \%$ wesentlich günstiger als nach dem Wachzustand mit $9 \%$. Wegen des Unterschiedes zwischen $9 \%$ und $56 \%$ kann die Erkenntnis über die Wirksamkeit des statistischen Gesetzes auch als praktisch nützlich angesehen werden. So ist es z. B. für einen Abendschüler unzweckmäßig, frühmorgens vor der Tagesarbeit ein neues Lernprogramm zur Vorbereitung auf den Abendunterricht zu realisieren. Dagegen ist es zweckmäßig, das vor dem Einschlafen Gelernte und Eingeprägte frühmorgens zu wiederholen, um es zu festigen. Die oben angegebenen statistischen Werte haben sich als Durchschnitt aus den Lernergebnissen aller Mitglieder der untersuchten Lerngruppen ergeben und sind damit auch für jedes einzelne Mitglied relevant. Für jeden Einzelnen ist unter den angegebenen Bedingungen (8 Stunden Wachzustand oder 8 Stunden Schlafzustand) mit hoher Wahrscheinlichkeit jeweils ein relativ schlechtes bzw. ein wesentlich besseres Lernergebnis zu erwarten. Die Statistik repräsentiert zunächst einmal nur empirische Regelhaftigkeiten, die in der vorn (S. 57) formulierten gesetzesartigen Aussage verallgemeinernd erfasst wurden. Diese erklärt noch nicht, auf welchem Gesetz die Effekte beruhen. Erst auf der Grundlage 
der lernpsychologischen Theorie von den pro- und retroaktiven Hemmungen konnten Clauß und Hiebsch die Erklärung in Form einer komparativen Gesetæesaussage formulieren:

„Die Stabilisierung von Engrammen erfolgt umso leichter und besser, je weniger dieser Prozess durch nachfolgende kortikale Erregungen gestört wird“" (Clauß/Hiebsch 1961, S. 297).

Es ist klar, dass im Vergleich zum Schlafzustand im Wachzustand mehr äußere Einflüsse auch zu entsprechend intensiveren kortikalen Erregungen führen. Nach diesem Gesetz ist deshalb davon abzuraten, etwa nach einem abendlichen Lernprogramm noch eine Fernsehsendung zu sehen. Das Lernen sollte vielmehr unmittelbar vorm Einschlafen erfolgen, so dass danach „das Lehrbuch unterm Kopfkissen liegt“ - wie schon seit Jahrhunderten etwas scherzhaft empfohlen wird.

Lehrer erleben statistische Effekte bei Kontrollarbeiten in Form von Notenverteilungen und sie wissen auch bei einiger Kenntnis ihrer Schüler, wer voraussichtlich welche Note erreichen wird, d. h., sie können wahrscheinliche Resultate voraussagen. Ein empirisch belegter ungewollter Nebeneffekt solcher Voraussagen kann allerdings auftreten: die Lehrer übersehen bei leistungsstarken Schülern, von denen sie gute und sehr gute Arbeiten erwarten (z. B. bei Diktaten), relativ mehr Fehler als bei leistungsschwachen. Daraus folgt: Lehrer dürfen ihre Erfahrungswerte bezüglich der Lerneffekte einzelner Schüler nicht überschätzen und sich nicht zu flüchtigen Kontrollen verleiten lassen!

Da durch ein statistisches Gesetz nur eine „durchschnittliche Wahrscheinlichkeit“ des Übergangs von einem Zustand zu einem anderen angegeben wird, ist auch die Möglichkeit eines Misserfolges mit eingeschlossen. Einzelne Elemente der Gesamtheit, d. h., einzelne Lernende können ja so weit vom Durchschnitt entfernt sein, dass bei ihnen die allgemein erwartete Wirkung nicht oder nur unter Schaffung weiterer fördernder Lernbedingungen eintritt. Es muss nämlich - wie oben angedeutet - beachtet werden, dass in der Praxis kein Gesetz isoliert, sondern immer im Zusammenhang mit anderen wirkt; das bedeutet, dass andere gesetzmäßige Zusammenhänge zugleich als Wirkungsbedingungen des jeweils untersuchten auftreten. Beim angeführten Beispiel wird durch den Schlafzustand nach dem Einprägen die gesetzmäßige Wirkung retroaktiver Hemmungen reduziert, d. h., durch das Ausschalten neuer Eindrücke, die ja bei einem Wachzustand zwangsläufig auftreten würden, kann sich das Eingeprägte sozusagen ungestört festigen. Ferner besteht ein „Regime von Wechselwirkungen“ (vgl. Bellmann 1964) zwischen den Determinanten des Eimprägungsprozesses einerseits (z. B. Zahl und Rhythmus der Wiederholungen, persönliche Bedeutsamkeit des Lernstoffs usw.) und den Determinanten des Vergessensprozesses andererseits (Wirkungen von pro- und retroaktiven Hemmungen, zu großer Abstand zwischen den Wiederholungen usw.). Die reale Wirkung, die aus Regimes von Wechselwirkungen hervorgeht, ist von der Stärke der jeweils dominierenden Determinanten abhängig, die durch menschliches Handeln im Gefüge der Wirkungsbedingungen häufig auch bewusst beeinflusst werden kann. 
Wegen relativ hoher Erfolgsaussichten - und es finden sich durchaus noch gesetzmäBige Zusammenhänge mit höheren durchschnittlichen Erfolgsaussichten als 56 \% (es sei hier nur an den programmierten Unterricht erinnert!) - nutzen methodenbewusst handelnde Lehrer die wissenschaftlich erkannten oder praktisch erlebten Regelhaftigkeiten und damit die ihnen zugrunde liegenden gesetzmäßigen Zusammenhänge in ihrer Unterrichtsgestaltung, indem sie Bedingungen für eine möglichst starke Wirksamkeit jener Determinanten schaffen, die den Erfolg maßgeblich bestimmen. So war die alte Schulmeisterempfehlung „lerne das Gedicht abends vor dem Einschlafen“ eine empirisch begründete Regel, die nachträglich durch die oben formulierte Gesetzeserkenntnis erklärt und begründet wird. Dabei machen die unterschiedlichen Erfolge aber immer wieder deutlich, dass es sich eben um einen Zusammenhang im Sinne der statistischen Gesetzeskonzeption handelt, weil ein ganzes System gesetzmäßiger Beziehungen wirksam ist, deren Determinanten im Einzelnen oft nicht hinreichend genau einkalkuliert werden können. Diesem praktisch unvermeidbaren Risiko wird in gewissem Maße Rechnung getragen mittels der Beobachtung und Reflexion des Handlungserfolgs sowie seiner Bedingungen durch die am Prozess Beteiligten, um ihn nötigenfalls durch angemessenere Maßnahmen zu verbessern.

Von diesem Standpunkt aus betrachtet, ist es völlig abwegig, zu erwarten, dass in der Pädagogik „erfolgsgarantierende Gesetze pädagogischen Handelns“ „,aufgestellt“ werden könnten (vgl. Benner bei Roth 1991, S. 16). Wer von der Beachtung psychologischer Gesetze bzw. von der Anwendung darauf basierender pädagogischer Prinzipien „Erfolgsgarantie“ erwartet, „übersieht“ den statistischen Charakter sozialer GesetzmäBigkeiten, der sich in den Wahrscheinlichkeiten ihrer Wirkungen äußert, was mögliche Misserfolge einschließt.

„Mit statistischen Gesetzen können zwar Trends der Zukunft angegeben, aber keine exakten Prognosen aufgestellt werden“" ( Hörz 2004, S. 4).

Gesetze werden auch nicht als reine Gedankenkonstrukte „aufgestellt“, um etwas Ordnung in die chaotische Wirklichkeit zu bringen, sondern durch Analyse von Erscheinungen der Realität entdeckt, indem nämlich wesentliche und unwesentliche, einmalige und wiederholbare Zusammenhänge erkannt werden. Die erkannten wesentlichen, relativ allgemeinen und unter bestimmten Bedingungen wiederholbaren Zusammenhänge oder invarianten relationalen Eigenschaften von Dingen bzw. Prozessen können in verschiedenen Formen synthetisiert und sprachlich als Aussagen formuliert werden. Stegmüller (1960, S. 180/181) nennt drei Möglichkeiten, Gesetzeserkenntnisse zu formulieren, nämlich:

1. qualitative Gesetze - er meint damit Formulierungen, die sich darauf beschränken, die Qualität des objektiven gesetzmäßigen Zusammenhanges zu charakterisieren, z. B. „Reibung erzeugt Wärme“ oder „Persönlichkeiten verändern sich in der Tätigkeit"; 
2. komparative Gesetze, dabei handelt es sich um Aussagen, die mangels definierter Größen quantitative Gewichtungen oder „Wirkungsgrade“ in dem Gesetzeszusammenhang durch komparative Formulierungen zum Ausdruck bringen (z. B.: ,Je stärker sich der Zögling mit einem Menschen oder einer Gruppe gefühlsmäßig verbunden fühlt, desto größer ist deren verhaltensdeterminierender Einfluss.“ - Friedrich 1966, S. 61; oder: „Je kürzer die Erwerbslosigkeit, desto weniger psychische Beeinträchtigungen." - Staub-Bernasconi 2009, S. 140);

3. quantitative Gesetze, diese bedienen sich entweder definierter Größen beispielsweise in der Physik - oder statistischer Werte wie in dem o. g. Beispiel aus der Lernpsychologie.

Qualitative Gesetze können nicht nur in der oben angeführten sprachlichen Fassung formuliert werden, sondern auch als „Wenn-dann-Beziehung“, also z. B.: „Wenn sich eine Persönlichkeit betätigt, dann verändert sie sich in Abhängigkeit von Art und Umfang ihrer Tätigkeit“, wobei die Veränderungen selbst immer eine statistische Streuung aufweisen. Selbst bei gleichartigen Tätigkeiten sind deren persönlichkeitsbildenden Rückwirkungen verschieden, denn der Effekt der Rückwirkung hängt nicht nur ab von der Tätigkeit selbst und den dabei erfahrenen Einflüssen aus der Umwelt, sondern auch von den inneren Voraussetzungen des Tätigen, wobei die Vermittlung zwischen beiden - also die Verarbeitung der äußeren Einflüssen entsprechend den inneren Voraussetzungen über den realen Effekt in der Persönlichkeitsveränderung entscheidet.

Zweifellos ist es schwierig, die inneren Verarbeitungsprozesse erzieherisch zu beeinflussen, zumal stets auch noch vielfältige Umwelteinflüsse mit im Spiele sind. Um diese Schwierigkeiten im Interesse eines zielstrebigen Prozessverlaufs zu meistern, bedarf es vor allem der Kenntnis und Nutzung psychischer Gesetzmäßigkeiten und eines funktionierenden Feedbacks im Prozessverlauf.

Durch die „Wenn-dann-Formulierungen“ zur Charakterisierung der gesetzmäßigen Zusammenhänge werden die komplizierten Wechselwirkungen zwischen den Determinanten „vertuscht“ oder „überspielt". Es wird der Eindruck erweckt, als würde ein rein dynamischer Gesetzeszusammenhang oder gar eine lineare Kausalbeziehung vorliegen, was aber nicht gemeint ist. Es geht vielmehr nur um die Charakterisierung des dynamischen Aspekts des erkannten oder vermuteten gesetzmäßigen Zusammenhanges, auf den die jeweilige qualitative Gesetzesaussage hinweist. Außerdem muss zwischen realen Kausalbeziehungen und den Gesetzen, die sie begründen, unbedingt unterschieden werden. So wird z. B. das Handeln und Verhalten von Menschen nicht nur durch allgemein-notwendige und wesentliche Zusammenhänge bestimmt, es hängt auch von Begleitbedingungen und zufälligen Ereignissen ab, die seine Entscheidungen beeinflussen. Hinzu kommt: welcher Zusammenhang als wesentlich oder unwesentlich bewertet und beachtet wird, kann sich individuell sehr unterscheiden. 
Die statistische Gesetzeskonzeption ist keineswegs ein Notbehelf der Sozialwissenschaften, sondern wurde in den Naturwissenschaften erarbeitet und wird in vielen Wissenschaftsdisziplinen genutzt. Die Dialektik von Notwendigkeit und Zufall spielt außerhalb der Untersuchungsfelder der klassischen Physik eine solche Rolle, dass statistische Gesetze als Normalfall betrachtet und die dynamischen Gesetze als jene Sonderfälle der statistischen interpretiert werden, bei denen die Wahrscheinlichkeit des Eintreffens der vorausgesagten Wirkungen nahezu gleich 1 ist. Damit wird klar, dass die Skepsis der von Hierdeis und Hug zitierten Pädagogin (s. S. 50) gegenüber der Wirksamkeit von Gesetzmäßigkeiten in pädagogischen Prozessen vermutlich auf einer historisch überholten mechanisch-deterministischen Vorstellung beruht.

\subsubsection{Gesetze und ihre Wirkungsbedingungen}

Die Formulierung einer Gesetzesaussage ist $\mathrm{u}$. a. auch verbunden mit einer isolierenden Abstraktion, d. h. mit der Herauslösung des erkannten Gesetzeszusammenhangs aus seinem realen Wirkungszusammenhang, aus der Gesamtheit der Systembedingungen. Um jedoch über die Wirkungsweise von objektiven Gesetzen etwas aussagen zu können, müssen sie im Zusammenhang mit ibren Wirkungsbedingungen betrachtet und dargestellt werden. Hörz unterscheidet bei den Wirkungsbedingungen von Gesetzen:

- notwendige nichtspezifische Wirkungsbedingungen;

- spezifische Wirkungsbedingungen erster Ordnung, die „die im Gesetz enthaltene allgemein-notwendige und wesentliche Beziehung (bestimmen)“ (Hörz 1971, S. 132); sie wird annähernd in der Gesetzesaussage erfasst;

- spezifische Wirkungsbedingungen zweiter Ordnung, welche die Beziehungen zwischen den Variablen des Gesetzeszusammenhanges bestimmen und daher für seine reale Wirksamkeit wesentlich sind (vgl. Hörz 1971, S. 132/133);

- $\quad$ spezifische Wirkungsbedingungen dritter Ordnung usw. (vgl. a. a. O., S. 135);

- Begleitbedingungen.

Wenden wir nun diese Erkenntnisse in der Pädagogik an:

- In der Pädagogik sind die transgredienten Grundlagen als notwendige nichtspezifische Wirkungsbedingungen von gesetzmäßigen Zusammenhängen der Erziehung zu betrachten, denn natürliche Lebensbedingungen, gesellschaftliche Verhältnisse und erziehbare menschliche Individuen müssen notwendigerweise vorhanden sein, damit überhaupt Erziehungsprozesse stattfinden können.

- Spezifische Wirkungsbedingungen erster Ordnung im Gegenstandsbereich der Pädagogik sind die strukturellen und funktionalen Zusammenhänge zwischen bewusster Tätigkeit von Erziehern und Zöglingen im Rahmen sozialer Interaktionen und 
eigener Bemühungen mit dem Ziel der Persönlichkeitsveränderung, und zwar unter Einschluss von Wechselwirkungen mit den transgredienten Grundlagen.

- Wirkungsbedingungen zweiter bis n-ter Ordnung sind die unterschiedlichen historischen, soziokulturellen, institutionellen und individuellen Ausprägungen der immanenten Momente und ibrer Relationen (siehe S. 278). Um zu einer begründeten Differenzierung der Bedingungen hinsichtlich ihrer Ordnung und praktischen Bedeutung zu gelangen, bedarf es noch weiterer Untersuchungen.

Die prozessinternen dialektischen Determinationen und die zugleich auch wirksamen Einflüsse der transgredienten Grundlagen auf den Prozessverlauf erklären die statistischen Effekte und Verteilungen in den Resultaten mit ihren Vorzügen und Mängeln. Diese Feststellungen mögen manchen Leser, dessen Gesetzesvorstellungen durch Beispiele aus der klassischen Mechanik geprägt sind, enttäuschen, aber der wissenschaftliche und praktische Wert der statistischen Gesetzeskonzeption und der Gesetzeserkenntnisse wird dadurch auch in der Pädagogik nicht geschmälert. Im Gegenteil, „die statistische Gesetzeskonzeption wendet sich gegen jede Auffassung von einem Automatismus der Entwicklung des Sozialen und Individuellen ebenso wie gegen die Auffassung, in der überschaubaren Zukunft sei alles möglich. Der Mensch ist keineswegs nur Erfüllungsgehilfe objektiver Gesetze, denn es gibt kein solches Gesetz, das menschliches Verhalten eindeutig reguliert. Für jedes Ereignis existiert ein System von Gesetzen, aus dessen Möglichkeitsfeld eine der Möglichkeiten (mehr oder weniger! W. N. ) zufällig realisiert wird. Menschliches Verhalten hat verschiedene Determinanten. Als Naturwesen unterliegen Menschen den Naturgesetzen. Sie müssen ihre natürlichen Existenzbedingungen im Rahmen von Gesetzen gestalten und sind den genetischen, biotischen, hormonellen Mechanismen unterworfen.

Psychische Konstitution und soziale Organisation determinieren menschliches Verhalten, lassen dem Individuum seinen Willen zur freien Entscheidung. Jedes konkrete Ereignis, an dem Menschen beteiligt sind, ist als komplexe Erscheinung immer durch ein System von objektiven Gesetzen bestimmt, doch zugleich durch ein Parallelogramm von Natur- und Sozialkräften, deren Resultante das Ereignis ist. Menschen gestalten die Existenz- und Wirkungsbedingungen von Gesetzen mit. Sie schöpfen dabei die immer vorhandene und von Menschen beeinflussbare Varianzbreite des Elementverhaltens in einem System entsprechend ihren Zielen und ihrem Charakter mehr oder weniger aus. Wäre dem nicht so, könnte der Mensch wegen des Fallgesetzes keine Fluggeräte konstruieren, wegen der Strahlengesetze keine Laser bauen, wegen der genetischen Stabilität keine Haustiere züchten, wegen der biotischen Determination nicht sozial lernfähig sein. Freiheit ist nicht nur die Nutzung des vorhandenen Evolutionsraums in den sich selbst organisierenden sozialen Systemen, sondern auch die Gestaltung der Strukturen. Insofern sind die Menschen in der Lage, sich Normen unterzuordnen, sie inhaltlich zu gestalten und sie zu verändern“ (Hörz 2004, S. 3). 
Der statistische Charakter gesetzmäßiger Zusammenhänge ist aber auch insofern von Bedeutung, als er uns vor dem Irrtum bewahrt, den Sartre und andere Existenzialisten provozieren, indem sie dem menschlichen Handeln generell ein „Bewusstsein des Nichtdeterminiertseins“ unterstellen (vgl. Kamps 1992, S. 16), was dann verständlicherweise die Angst vor Misserfolgen erzeugt. Natürlich liegt in vielen freien Entscheidungen das Risiko einer Fehlentscheidung, die u. U. auch Angst hervorruft. Aber dieses Risiko resultiert nicht aus dem Nichtdeterminiertsein menschlicher Absichten und menschlichen Verhaltens, sondern aus der Tatsache, dass es sich immer um dialektische Determinationen handelt, in denen das angestrebte Resultat nur mit einer bestimmten Wahrscheinlichkeit eintrifft, die man in vielen Situationen schwer einschätzen kann. Im Verständnis der statistischen Gesetzesauffassung ist es falsch, das Ausbleiben mechanischer Determinationen als Indetermination zu interpretieren.

Die Erforschung gesetzmäßiger Zusammenhänge im Erziehungsprozess ist keine akademische Spielerei, sondern praktisch bedeutsam - vor allem aus zwei Gründen:

1. Die Pädagogik und ihre Nachbarwissenschaften benötigen die Kenntnis gesetzmäßiger Zusammenhänge und ihrer Wirkungsbedingungen für die Erkelärung ihrer Phänomene, also z. B. für kriminelles Handeln oder erzieherische Erfolge und Misserfolge.

2. Ähnlich wie in den technischen Wissenschaften die Kenntnisse über gesetzmäßige Beziehungen aus der Natur mit darauf berubenden Kausalbeziehungen praktisch genutzt werden, können auch in der Pädagogik die für den Erziehungsprozess relevanten gesetzmäßigen Beziehungen bei der Realisierung von Erziehungszielen Beachtung finden - allerdings immer unter Berücksichtigung ihres statistischen Charakters und der damit verbundenen Wabrscheinlichkeiten, die Risiken einschließen.

Aus dem gleichzeitigen Zusammenwirken vieler Gesetze in jeder Erziehungssituation resultiert eine Besonderheit pädagogischer Disziplinen in der Art der „Verwertung“ erzieherisch relevanter Gesetzeserkenntnisse, nämlich ibre Nutzung mittels pädagogischer Prinzipien und Regeln, und zwar sowohl bei Erklärungs- als auch bei Gestaltungsprozessen. Mit erzieherisch relevanten Gesetzen sind jene gemeint, die in den Bezugswissenschaften erforscht werden (also in der Biologie, Soziologie, Psychologie, Kommunikationswissenschaft usw.). Die Pädagogik nutzt erkannte Gesetze aus natürlichen, gesellschaftlichen und psychischen Zusammenhängen durch ibre Verknüpfung mit pädagogischen Zielen, indem sie daraus Prin₹ipien und Regeln für erzieherisches Handeln ableitet, wobei die Erforschung der gesetzmäßigen Zusammenhänge selbst die Aufgabe der zuständigen Wissenschaften ist. Pädagogische Prinzipien und Regeln sind also transdisqiplinär begründet und geben den erzieherischen Kräften Hinweise zur Gestaltung materieller und sozialer Bedingungen sowie zur Anregung persönlicher Handlungen und Stimulation innerer Vorgänge bei den Zöglingen, um so die Erfolgsaussichten des Erziehungsprozesses zu verbessern. 


\subsection{Prinzipien und Regeln - ihre Bedeutung für pädagogisches Handeln}

\subsubsection{Wesen und Funktionen pädagogischer Prinzipien und Regeln}

In der Pädagogik gibt es nicht nur Skeptiker gegenüber Prinzipien wie z. B. Grüntgens (2001), sondern auch Befürworter. Zu ihnen zählt Olaf-Axel Burow, wie sein Buch „Prinzipien erfolgreicher Erziehung“ belegt. Allerdings fällt bei Lesen des Buchs auf, dass Burow die Frage nach der Ableitung oder Begründung von Erziehungsprinzipien nicht gründlich untersucht oder doch zumindest nicht erörtert hat, denn er schreibt:

„Prinzipien sind Richtlinien für das Betragen des Menschen, die bewiesen haben, daß sie von anhaltendem, beständigem Wert sind. Sie sind fundamental. Man kann im Grunde nicht gegen sie argumentieren, da sie aus sich selbst heraus offensichtlich sind“ (Burow 2003, S. 67).

An anderer Stelle heißt es ergänzend dazu:

„Wenn ich also von der Entwicklung von Erziehungsprinzipien spreche, dann meine ich keinesfalls abgehobene Tugendkataloge, sondern Prinzipien, die zu Ihren persönlichen Voraussetzungen und den Anforderungen Ihrer spezifischen Situation passen“ (a. a. O., S. 68).

Zunächst ist einzuwenden, dass es sehr wohl Erziehungsprinzipien gibt, gegen die man argumentieren kann und die man u. U. sogar ablehnen muss. So ließe sich beispielsweise gegen das Prinzip der Freiwilligkeit in der Jugendarbeit (vgl. Hobmair u. a. 1989, S. 334) einwenden, dass es Situationen gibt, in denen man es nicht anwenden darf, weil dadurch der Problembelastete Schaden nehmen oder gar sein Leben verlieren würde. Deshalb kann auch - wie Peter Lüssi es tut - nur von einem Prinzip des Vorrangs der Freiwilligkeit gesprochen werden. Oder betrachten wir das von A. S. Neill formulierte „Prinzip der Selbstbestimmung“ des Kindes (1969, S. 114), das er verknüpfte mit den „Ideen der Nichteinmischung in das Heranwachsen des Kindes und des Verzichts auf jeglichen Druck" (Neill 1969, S. 103). Leider führten solche einseitigen Fassungen und absoluten Formulierungen in verschiedenen Erläuterungen zu bedauerlichen pädagogischen Fehlleistungen unter Neills Anhängern, wie etwa Susanne Gaschke in ihrem Buch „Die Erziehungskatastrophe" konstatiert. In Reflexionen über reale Erziehungskonflikte hat Neill die Unhaltbarkeit von einseitigen Interpretationen seines Prinzips selbst demonstriert (vgl. Abschnitt 5.3). Zudem hat er seine Aussagen relativiert, indem er erklärte „Freibeit ist nicht Zügellosigkeit" (a. a. O., S. 14) und protestierte, wenn z. B. repressionsfrei erziehende Eltern mit Stolz ihr Kind vorstellten, das mit Straßenschuhen auf seinem Konzertflügel herum spazierte. Man kann oder muss also gegen Neills einseitig formuliertes und leicht missverständliches Prinzip der Selbstbestimmung argumentieren.

Erziehungsprinzipien sind nicht „aus sich selbst offensichtlich“ - wie Burow meint - , sondern erfordern theoretische Begründungen und praktische Überprüfungen. Sie sind auch nicht allein durch ,persönliche Voraussetzungen“ und „Anforderungen der 
spezifischen Situation“ begründet, sondern primär durch objektive Gesetzmäßigkeiten, die aber in Burows Darstellung nicht erörtert werden.

Im Abschnitt 1.5.2 wurde herausgestellt, dass objektive Gesetze durch Aussagen widergespiegelt werden können. Aussagen stellen fest, was wahr oder falsch, möglich oder unmöglich, wahrscheinlich oder unwahrscheinlich ist. Im Vergleich dazu haben in der Pädagogik Prinzipien und Regeln eine andere Funktion: sie schreiben vor, was getan werden muss oder soll. Sie sind demzufolge auch nicht wahr oder falsch, sondern gültig oder ungültig, zweckmäßig oder unzweckmäßig. Das Wort „Prinzip“ wird allerdings in den verschiedenen Wissenschaften im unterschiedlichen Sinne verwendet. Darauf hat Wolfgang Wächter in seinem Artikel „Zur methodischen Funktion von Prinzipien in der Forschung“ (1978) hingewiesen, in dem er speziell die Prinzipienbegriffe der Naturwissenschaft, der Technik, der Pädagogik und Philosophie erörtert.

Wesentlich an Prinzipien in der Pädagogik ist, dass sie in dem betreffenden System allgemein gelten, für das sie erarbeitet worden sind. Diese allgemeine Gültigkeit drückt sich auch in der „Übersetzung“ des Wortes Prinzip aus, nämlich: Grundsatz, womit eine Beziehung zur lateinischen Wortwurzel - „pricipium“ = Ursprung, Grund - angedeutet wird. Die Grundsätzlichkeit der formulierten Handlungs- oder Verhaltensvorschrift ist je nach Art des Prinzips bedingt

a) durch besonders wichtige Wert- und Zielvorstellungen oder

b) durch Verknüpfungen wichtiger Zielvorstellungen mit gesetzmäßigen Zusammenbängen im Handlungsbereich,

die ihre Orientierungsfunktion begründen.

Die jeweils wichtigen Wert- und Zielvorstellungen resultieren aus allgemeinen gesellschaftlichen, klassen- oder schichtspezifischen, nationalen und/oder regionalen ökonomischen, politischen, sozialen, kulturellen, religiösen usw. Bedürfnissen und Interessen und werden im Abschnitt 4.3 noch näher erörtert.

In der Methodologie der wissenschaftlichen Forschung ist es üblich, aus wichtigen Zielvorstellungen Prinzipien abzuleiten. Sie werden als normative Prinzipien bezeichnet.

„Normative Prinzipien der Forschung bringen keine konkreten individuellen Erkenntnisziele zum Ausdruck, wie z. B. die Zielstellung, einen ganz bestimmten Sachverhalt zu klären, sondern Ziele, Orientierungen und Maßstäbe, die für die wissenschaftliche Forschung überhaupt, für bestimmte Wissenschaftsbereiche (z. B. empirische Wissenschaften) bzw. -disziplinen oder für bestimmte wissenschaftliche Verfahren (Erklärung, Prognose etc.) charakteristisch sind“ (Wächter 1978, S. 108/109).

In der Sozialen Arbeit können z. B. die von Friedrich Trost (1899-1965) zunächst für die Heimerziehung formulierten Prinzipien - das Rettungsprinzip, das Heilungsprinzip, das Prinzip der Ertüchtigung (vgl. Mollenhauer 1991, S. 118) - als solche durch 
Ziele begründete normative Prinzipien betrachtet werden. Da sie auch in Menschenrechtsnormen verankert sind (vgl. Artikel 3, 22 und 26 der Allgemeinen Erklärung der Menschenrechte), gelten sie nicht nur in der Heimerziehung, sondern in allen Bereichen der Sozialen Arbeit, und zwar in dem Sinne, dass sie als Entscheidungskriterien bei der Anwendung aller nachgeordneten Prinzipien und Regeln fungieren. So wird z. B. das Prinzip des Vorrangs der Freiwilligkeit bei der Wahrnehmung von Hilfen durch das Rettungsprinzip in seiner Anwendung näher bestimmt: wenn es nämlich um Leben und Gesundheit von Hilfebedürftigen geht, entfällt die Freiwilligkeit; dann muss und darf entsprechend des Rettungsprinzips auch gehandelt werden, weil die Bedingungen für die Freiwilligkeit nicht gegeben sind. In diesem Sinne tragen die Prinzipien von Trost tatsächlich den Charakter von Normen, die eingehalten werden müssen, weil sonst das Grundanliegen der Sozialen Arbeit (einschließlich der Sozialpädagogik) - Hilfe für die in Not Geratenen - verfehlt und eventuell sogar gegen die Pflicht zur Hilfeleistung bei Lebensgefahr verstoßen wird.

Dagegen liegt bei dem Prinzip der Selbsttätigkeit eine Verknüpfung von Zielvorstellungen und Gesetzeserkenntnissen vor, denn es richtet sich auf die Entwicklung von Selbständigkeit und Selbstbewusstsein (= Ziele), was nur in der Tätigkeit erfolgt (= Gesetz). Persönlichkeitsentwicklung vollzieht sich im Entscheiden für und im Ausfübren von Handlungen, die nicht nur entsprechendes Können erzeugen, sondern vor allem auch eine Stärkung von Selbstvertrauen und Selbstbewusstsein durch Handlungserfolge bewirken.

Die im Prinzip enthaltene Aufforderung, den Lernenden in Tätigkeit zu versetzen, zielt auf die Herstellung einer Wirkungsbedingung erster Ordnung. Die reale Wirksamkeit des Gesetzes (Persönlichkeiten verändern sich in der Tätigkeit) hängt wesentlich von den Wirkungsbedingungen zweiter Ordnung ab; so sind bekanntlich die persönlichkeitsbildenden Rückwirkungen schöpferischer Tätigkeiten bei Künstlern, Wissenschaftlern, Handwerkern o. Ä. recht verschieden von den Rückwirkungen einförmiger Verrichtungen von Fließbandarbeitern. Daher müssen Wirkungsbedingungen zweiter Ordnung auch bei der Anwendung des Prinzips der Selbsttätigkeit vom Lehrer beachtet werden, d. h., er muss die jeweils zweckmäßigen Wirkungsbedingungen zweiter Ordnung organisieren, indem er z. B. den Lernenden erfüllbare Aufgaben stellt und günstige Bedingungen für die Aufgabenbearbeitung sichert oder Probleme zwecks Entwicklung kreativer Fähigkeiten lösen lässt.

Ein anderes Beispiel ist das Prinzip der Ermutigung, das auf die Entwicklung eines gesunden Selbstbewusstseins (= Ziel) gerichtet ist und der psychologischen Erkenntnis Rechnung trägt, die besagt: Je erfolgreicher ein Mensch in einem ihm wichtig erscheinenden Lebensbereichen agiert, desto besser entwickeln sich in ihm Selbstvertrauen, Selbstwertgefühl und Selbstbewusstsein. Prinzipien o. g. Art widerspiegeln sowohl wichtige Ziele (denen Bedürfnisse und Werte zugrunde liegen) als auch objektive Gesetzmäßigkeiten der Prozesse ihrer Realisierung; sie sind Erkenntnisprodukte aus rationalen 
Abbildungen und Konstruktionen und resultieren aus teleologisch und kausalanalytisch gewonnenen Erkenntnissen (vgl. S. 54). Sie entsprechen mit ihrer spezifischen Struktur - der Verknüpfung von Zielen mit gesetzmäßigen Zusammenhängen - in besonderer Weise den Erfordernissen der Hauptaufgabe der Erziehungswissenschaft: Handlungsorientierungen zu erarbeiten für zielgemäße Veränderungen von Menschen. Pädagogische Prinzipien, die Zielvorstellungen mit Gesetzeserkenntnissen verbinden, stellen ihrem Wesen nach eine bedeutsame Form der Verknüpfung von Orientierungs- und Sachwissen dar. Dabei sind die Ziele der Zöglinge besonders wichtig, denn pädagogische Prinzipien werden in der Erziehungspraxis dann erfolgreich angewendet, wenn die Ziele in den Prinzipien mit den Zielen der Lernenden übereinstimmen bzw. von ihnen akzeptiert werden. So fordert und fördert die Anwendung des Prinzips der Selbsttätigkeit die Selbständigkeit des Lernenden gerade deshalb, weil das Streben nach Unabhängigkeit und Selbständigkeit eines ihrer Grundbedürfnisse ausdrückt, das unter Beachtung legitimer Ziele und humaner Normen befriedigt werden muss. Überbehütung und Verwöhnung widersprechen dem Prinzip der Selbsttätigkeit und führen daher gesetzmäßig zu Erziehungsschwierigkeiten.

Pädagogische Prinzipien sind keine Rezepte, die konkrete Handlungsschritte oder Operationen vorschreiben, sondern Kriterien zur Bestimmung zweckmäßiger Handlungen und Verhaltensweisen im Interesse der Erfolgssicherung des Prozesses. So meint z. B. das Prinzip der Selbsttätigkeit ein Handeln aus eigener oder zumindest zu eigen gemachter Motivation, das eine selbständige Handlungsregulation bewirkt, die sich in qielstrebigen und ausdauernden Bemühungen äußert. Gegen den Rezeptcharakter von Prinzipien hat sich auch Dieter Kirchhöfer ausgesprochen, indem er schrieb, dass Prinzipien „unbestimmte Aufforderungen sind“. Sie sind nicht durch einen einzigen notwendigen Handlungsablauf erfüllbar, sondern in der Beziehung Aufforderung - Handlungsfolge ein-mehrdeutig.

„Sie sind eindeutig in dem Sinn, daß die ausgewählte Menge der Handlungen Element der Menge von Handlungen zu sein hat, die für die Realisierung einer Zielsetzung von Bedeutung ist“" (Kirchhöfer 1974, S. 417).

Sie sind mehrdeutig in dem Sinne, dass bei der Anwendung der Prinzipien auf ein Spektrum möglicher Operationen, nicht aber nur auf eine bestimmte Handlung oder Handlungsfolge orientiert wird.

Die Unterscheidung zwischen Prinzipien und Regeln ist schwierig, weil Regeln Vorschriften für das Handeln bzw. Verhalten sind, die ebenfalls auf gesetzmäßigen Zusammenhängen beruhen und deren Anwendung auf die Realisierung bestimmter Ziele gerichtet ist. Wenn z. B. vom Lehrer gefordert wird, er soll den Unterricht mit einer Motivierung und Zielorientierung des Lernenden beginnen, dann entspricht das grundlegenden lernpsychologischen Erkenntnissen, die besagen, dass gut motivierte Schüler, die wissen, worauf es ankommt, unter sonst gleichartigen Bedingungen erfolgreicher lernen als unzureichend motivierte und orientierte (= komparative Gesetzesaussage). 
Das Beispiel Motivation lässt einen Unterschied zwischen Prinzipien und Regeln erkennen: Während Prinzipien für mindestens einen definierten oder gar institutionalisierten Handlungsbereich (z. B. für die Familienerziehung und/oder für die Schule und/oder für die Freizeitpädagogik) gelten, sind Regeln für die Bewältigung definierter Situationen formuliert. So gibt es z. B. unterschiedliche Regeln für den Einstieg in ein nenes Unterrichtsthema (siehe Motivierung) oder für die Gestaltung der Kontaktaufnahme mit Ratsuchenden in der Sozialen Arbeit (siehe S. 336f.), für die Bearbeitung eines physikalischen Problems im Unterricht oder für die Lösung von Konflikten, für die Auswertung einer Klassenarbeit oder für die Art der Ablösung von Klienten am Ende eines Betreuungsprozesses usw.

Die Tatsache, dass es pädagogische Prinzipien gibt, die in den verschiedensten pädagogischen Spezialdisziplinen immer wieder genannt oder in ähnlicher Weise formuliert werden (z. B. das Prinzip der Selbsttätigkeit, das Prinzip der Individualisierung, das Prinzip der Ermutigung), hängt damit zusammen, dass sie wegen der ihnen zugrunde liegenden allgemeinen Gesetze der Persönlichkeitsentwicklung persistent sind also durchgängig in allen Erziehungsbereichen gelten. Der im Vergleich zu den Prinzipien eingeschränkte Geltungsbereich von Regeln findet seinen Ausdruck darin, dass sie in Form von Soll- oder Darf-Sätzen bzw. als empfehlenswerte Operation oder Operationsfolge angegeben werden. Prinzipien dagegen werden zumeist als Muss-Sätze formuliert, was ihre systemberogene Gültigkeit unterstreicht, das heißt also:

Pädagogische Prinzipien sind verbindliche Vorschriften im Sinne von flexibel zu nutzenden Orientierungsgrundlagen für das Handeln und Verhalten von Erziehern und Zöglingen, die auf gesellschaftlichen Zielen (Werten) und gesetzmäßigen Zusammenhängen ihres Geltungsbereichs beruhen.

\subsubsection{Pädagogische Prinzipien, Regeln und Methoden}

Prinzipien und Regeln spielen in der Pädagogik seit Jahrhunderten eine beträchtliche Rolle, was damit zusammenhängt, dass ihnen eine spezifische methodische Funktion zukommt, und zwar im Sinne von Methodenvorschriften. So hat z. B. Kant Erkenntnismethoden der Philosophie definiert als

„Verfahren nach Prinzipien der Vernunft, wodurch das Mannigfaltige einer Erkenntnis allein ein System werden kann“ (Kant 1978, S. 179).

Diese Definition sagt aus, wodurch Verfahren eigentlich bestimmt werden, nämlich durch Prinzipien. Da in der Pädagogik seit alten Zeiten auch Regeln als Methodenvorschriften gebräuchlich sind, bedeutet das: reale Erziehungsmethoden ergeben sich durch die 
Auswahl und Verknüpfung der sich wechselseitig bedingenden Operationsfolgen von Erziehern und Zöglingen entsprechend pädagogischen Prinzipien und Regeln.

Die konkrete Erziehungsmethode resultiert zwar aus den in Wechselwirkung miteinander stehenden Operationsfolgen der Erzieher und Zöglinge, aber ihre Wirkungen hängen nicht allein ab von den beobachteten Operations- und/oder gesprochenen Wortfolgen (einschließlich Tonfall und Körpersprache), sondern auch von den individuell unterschiedlichen inneren Voraussetzungen der Lernenden, von den Inhalten, die sie vermitteln, und von den Beqiehungen zwischen den beteiligten Personen.

Es geht daher bei der Beschreibung und Realisierung von Methoden nicht nur um die Operationsfolgen, sondern auch um den emotionalen Kontext, in dem sie realisiert werden, z. B. ob im Rahmen freundschaftlicher und vertrauensvoller Beziehungen oder in einer von Misstrauen geprägten Konfrontation zwischen Erziehern und Zöglingen. Der pädagogische Methodenbegriff enthält demzufolge zwei wichtige Momente erzieherischen Handelns: die Art des Umgangs der Beteiligten miteinander (Interaktionen), die sich partiell in Erziehungsstilen widerspiegelt, und die Vorgehensweise, die sich in Operationsfolgen (bzw. Handlungen) und Kommunikationsabläufen ausdrückt. Mit dieser Bestimmung des Methodenbegriffs in der Pädagogik erhält die allgemein bekannte Auffassung von Methode als Art und Weise menschlichen Handelns eine fachspezifische Bedeutung. Erziehungsmethoden sind Operationsfolgen in Verbindung mit Kommunikationsabläufen zur Übermittlung und Aneignung von Inhalten und zur Entwicklung wertvoller Beqiehungen zwischen den Beteiligten entsprechend pädagogischen Prinzipien und Regeln.

Durch bestimmte, sich wechselseitig bedingende Operationsfolgen der Erzieher und Zöglinge werden nicht nur Gegenstände verändert (z. B. der Werkstoffe im Werkunterricht oder Texte im Sprachunterricht), sondern auch die Handelnden selbst. Ein wesentlicher Teil der Subjektveränderungen rührt daher, dass durch die methodischen Operationen (z. B. Beobachten, Analysieren, Vergleichen, Kombinieren, Synthetisieren, Konstruieren) vielfältige Abbilder der Wirklichkeit und gedankliche Konstrukte gewonnen bzw. sprachlich vermittelt werden, wodurch sich die Bewusstseinsinhalte und die emotionalen Befindlichkeiten der Beteiligten verändern. Die sinnlichen und rationalen Abbilder bzw. Konstrukte und ihre sprachlichen Formen sind Inhalte des Erziehungsprozesses. Dass es methodischer Operationen bedarf, um Inhalte zu bewegen, ist evident. Aus den Wechselwirkungen zwischen den methodisch übermittelten bzw. selbständig gewonnenen Inhalten mit den bisherigen Vorstellungen, Erkenntnissen, Gefühlen und Einstellungen des Lernenden entstehen die Resultate der Erziehung in Form veränderter Persönlichkeitsqualitäten. Prinzipien helfen bei der Auswahl von Handlungsarten bzw. Operationsfolgen sowie Verhaltensweisen in einem Handlungsbereich; Regeln empfehlen eine jeweils zweckmäßige, situationsabhängige Operationsfolge bzw. Verhaltensweise im Rahmen des durch Prinzipien bestimmten Handelns und Verhaltens. Doch bei aller Wertschätzung päd- 
agogischer Regeln ist zu beachten, was Gustav von Rohden (1855-1942) in seinem Artikel über Rettungsanstalten geschrieben hat:

„Die Erziehung zu Persönlichkeiten läßt sich nicht durch leblose Regeln bewirken, sondern muß von lebendigen Persönlichkeiten ausgehen“ (bei Rein u. a. 1898, Bd. V, S. 867).

Eine weitere Spezifik der Methoden im pädagogischen Bereich, die auch ihre systematische Darstellung erschwert, besteht darin, dass jede methodische Operation multifunktional wirkt, und zwar in Abhängigkeit von individuellen und situativen Momenten des Handlungsprozesses. Schon eine solch relativ einfache methodische Operation wie die Aufforderung ,Seht alle her!“ schließt zumindest drei Wirkungsmöglichkeiten ein:

- Sebt alle her, d. h., alle werden zur Aufmerksamkeit aufgefordert.

- Seht alle her, d. h., die Aufforderung richtet sich zwar an alle, meint aber eigentlich diejenigen, die sich unaufmerksam verhalten.

- Seht alle her, d. h., die Aufgeforderten sollen auf einen bestimmten „Punkt" hinschauen.

Aus der Wirkungsvielfalt methodischer Operationen folgt, dass Erzieher bemüht sein müssen, die tatsächlichen Wirkungen ihres Handelns (einschließlich ihrer sprachlichen Äußerungen) zu erfassen, und zwar über das sog. Feedback, das eine Grundlage ist für das weitere und möglichst präzisierte Vorgehen.

Ältere Darstellungen zu Methoden in der Sozialpädagogik nennen folgende:

- Einzelfallhilfe,

- Gruppenarbeit,

- Gemeinwesenarbeit.

Diese Wörter bezeichnen aber keine spezifischen Operationen von Erziehern und Zöglingen zwecks Übermittlung und Aneignung von Inbalten und der Gestaltung von Beziehungen (was ja das Wesen von Erziehungsmethoden ausmacht), sondern nur Organisationsformen des erzieherischen Geschehens, die durch vielgestaltige Operationsfolgen ,,ausgefüllt“ werden können. Versuche zur Gruppierung und Klassifizierung von Methoden und ihren Elementen in formalen Übersichten gehören zu den wenig nützlichen Kapiteln der Pädagogik, denn sie lassen nichts erkennen von der Dynamik des lebendigen methodischen Geschehens. Daher wird hier eine andere Darstellungsweise gewählt. Die methodische Seite des sozialpädagogischen Prozesses wird unter drei Aspekten betrachtet,

- dem grundsätə̧lichen Herangehen an sozialpädagogische Aufgaben und Probleme (Kapitel 4, insbesondere 4.6),

- der Gestaltung der Beziehungen zwischen den Prozessbeteiligten (Kapitel 5) und

- der Vorgehensweise bei der Lösung sozialpädagogischer Aufgaben und Probleme (Abschnitte 6.2 und 6.3). 


\section{Kapitel}

Historische Wurzeln, Gegenstand und Aufgaben der Sozialpädagogik als Wissenschaftsdisziplin 


\subsection{Das Wort „Pädagogik“ und seine Bedeutungswandlungen}

Um eine Vorstellung von der Bedeutung des Wortes Sozialpädagogik zu gewinnen, sind zunächst einige Ausführungen zum Wort und zum Begriff Pädagogik erforderlich. Das Wort „Pädagogik“" wurde als Bezeichnung für die Wissenschaft von der Erziehung in Deutschland um 1770 eingeführt. Bereits 1702 verwendete August H. Francke (16631728) das Wort „Paedagogium“ als Bezeichnung für eine höhere Schule (vgl. Schorn 1911, S. 187). Johann B. Basedow (1724-1790) und Johann H. Campe (1746-1818) vom Dessauer Philanthropinum gaben 1777 „Pädagogische Unterhandlungen“ heraus. 1779 wurde auf Betreiben des für Kirchen- und Schulfragen zuständigen Ministers Friedrichs II. von Preußen, des Freiherrn Karl A. von Zedlitz (1731-1793), an der Universität Halle die erste deutsche Professur für Pädagogik eingerichtet und mit einem bewährten Lehrer aus dem Dessauer Philanthropinum besetzt, nämlich mit Ernst Ch. Trapp (1745-1818), der 1780 ein Buch mit dem Titel „Versuch einer Pädagogik “veröffentlichte. Danach trat die Bezeichnung „Didaktik“ in den Hintergrund, die seit Wolfgang Ratke (1571-1635) und Jan A. Komenský (1592-1670) allgemein verwendet worden war, um systematisierte Erfahrungen und Vorstellungen über Erziehung und Bildung in einer Lehrartlehr - wie Ratke (1957, S. 147) zu sagen pflegte - zu erfassen.

Mit der Errichtung der Professur für Pädagogik an der Universität Halle wurde ein erster Schritt getan, um die Pädagogik - die bis dahin und auch noch später von Philosophieprofessoren mit gelehrt worden war - als selbständige Wissenschaft zu institutionalisieren. Mit der Professur war ein Institutum Paedagogicum (eine Art Universitätsübungs schule) für die Ausbildung von Lehrern verbunden, das Trapp leitete. Allerdings hat Trapp wegen verschiedener Querelen mit den Professoren der Philosophischen Fakultät die Universität Halle bereits nach vier Jahren wieder verlassen. Sein Nachfolger, der Professor für Philosophie Friedrich A. Wolf (1759-1824), beschäftigte sich besonders mit den Werken antiker Philosophen und Dichter und weigerte sich, das o. g. Erziehungsinstitut zu leiten, so dass der hoffnungsvolle Ansatz zur Entwicklung einer eigenständigen akademisch institutionalisierten Wissenschaftsdisziplin Pädagogik wieder erlosch (vgl. Theodor Fritzsch in: „E. Chr. Trapps Versuch einer Pädagogik“"1913, S. VII).

Nach Auffassung von Dieter Lenzen

„,ist das Jahr 1783 dasjenige, in dem der erste Lehrstuhl für Pädagogik eingerichtet und durch Friedrich August Wolf in Halle eingenommen worden ist" (Lenzen 1994, S. 22).

Wie jedoch die Darstellung von Fritzsch erkennen lässt, irrt sich Lenzen, und zwar nicht nur im Jahr der Institutionalisierung und im Namen des ersten Professors für Pädagogik, sondern auch im Vorgang: Durch Wolf wurde 1783 der erste Erfolg im Prozess der Institutionalisierung der Pädagogik zunichte gemacht! 
Das Wort „Pädagogik“ als Bezeichnung für jene Wissenschaft, die sich mit Erziehungs- und Bildungsfragen befasst, setzte sich dennoch allgemein durch. Das Wort stammt - wie das bei vielen Wissenschaftsnamen der Fall ist - aus dem Griechischen. Abgeleitet ist es von den Wörtern $\pi \alpha \iota \delta \varepsilon i \alpha=$ Erziehung bzw. $\pi \dot{\alpha} \iota \varsigma=$ Knabe und $\dot{\alpha} \gamma \omega \gamma \dot{\varsigma} \varsigma=$ Führer, in der Zusammensetzung also $\pi \alpha \iota \delta-\alpha \gamma \omega \gamma \dot{\varsigma} \varsigma$ (lateinisch: paedagogus) = Knabenführer. Allerdings war im antiken Griechenland dieser „Knabenführer“ zunächst kein Erzieher oder Lehrer, sondern jener Sklave, der die Söhne seines Herren ins Gymnasium begleitete. Auf die genannten griechischen Wörter griffen die Philanthropisten zurück, als sie das Wort „Pädagogik" zur Bezeichnung von systematisierten Erfahrungen bzw. Erkenntnissen und darauf basierenden Handlungsorientierungen für die Bildung und Erziehung der Menschen in Umlauf brachten. Es ist immerhin bemerkenswert, dass sich in Trapps „Versuch einer Pädagogik“ bereits eine erweiterte Vorstellung von Erziehung und Pädagogik andeutet, denn er schreibt,

„daß man Erziehung nicht in dem eingeschränkten Verstande nehmen muß, da es heißt, Kinder bis zu einem gewissen Alter in die Schule schicken, sondern in dem weiten Sinn, in welchem sie die ganze Bildung des Menschen zu einem gewissen Zweck bedeutet, sich auch über das männliche Alter noch erstreckt“ (Trapp 1913, S. 6).

Ferner fällt auf, dass die Philanthropisten die Notwendigkeit einer „Erziehungskunst“ betonten, womit sie ein qualifiziertes erzieherisches Handeln meinten, zu dem sie mit ihren Schriften Anleitung geben wollten. Damit unterschieden sie also recht deutlich zwischen Erziehungspraxis, Erziehungskunst oder Erziehungswirklichkeit einerseits und den Erkenntnissen, konzeptionellen Vorstellungen und Anleitungen zur Erziehung andererseits; letztere bilden den Inhalt der Pädagogik. Im Grunde genommen setzten sie mit anderen Worten eine durchaus vernünftige Betrachtungsweise fort, die wir schon bei Ratke antreffen, der auch zwischen der „Lehrart“ als Begriff für reales Unterrichtsgeschehen und der „Lehrartlehr“ als Lehre oder wissenschaftliche Widerspiegelung des realen Unterrichtsgeschehens differenziert hat. Ebenso heißt es in Schmids „Encyklopädie des gesammten Unterrichts- und Erziehungswesens":

„Wir verstehen hier unter Pädagogik [...] nicht die Erziehungskunst selbst in ihrer praktischen Wirklichkeit, sondern die wissenschaftliche Erfassung und Ausbildung der Idee derselben, wie diese letztere unter den Bedingungen des gegenwärtigen menschlichen Daseins realisirt werden kann und soll“ (Schmid 1883, Bd. 5, S. 497).

Um im Interesse besserer Verständigung diese Unterscheidung zwischen Erziehungswirklichkeit und ihrer gedanklichen Widerspiegelung aufrecht zu erhalten, wurde von Josef Dolch (1899-1942) und Heinrich Döpp-Vorwald (1902-1977) der vergebliche Versuch unternommen, zur Bezeichnung der Erziehungswirklichkeit das Wort „Pädagogie“ einzuführen (vgl. Tenorth 2004, S. 377). 
Es hat sich also ein Gebrauch der Wörter „Pädagogik“ und „pädagogisch“ entwickelt, in dem ihre Bedeutung im Sinne von Erziehungswirklichkeit oder Erziehungswissenschaft nur noch aus dem Kontext des Wortgebrauchs entnommen werden kann. Wenn z. B. von einem „pädagogischen Prozess“ die Rede ist, dann wird darunter ein realer Erziehungsvorgang und nicht ein Prozess pädagogischer Erkenntnisgewinnung (Forschung) verstanden. An den beschriebenen unlogischen und die Verständigung erschwerenden Zustand haben wir uns weitgehend gewöhnt, obgleich in anderen Wissenschaften in ähnlichen Fällen vielfach korrekt formuliert wird; so unterscheidet man beispielsweise in der Psychologie zwischen realen psychischen Erscheinungen im Gegenstandsbereich der Psychologie und psychologischen Erkenntnissen oder Fragestellungen im Sinne der Wissenschaft vom Psychischen.

Die Entwicklung der Pädagogik zu einer selbständigen Wissenschaft war im christlichen Europa historisch mit zwei Schwierigkeiten verbunden: Erziehung stand wesentlich im Dienste der Religion und der Kirche, und zwar sowohl hinsichtlich der Erziehung breiter Volksschichten im Sinne des Christentums als auch hinsichtlich der Heranbildung von Intellektuellen (z. B. von Beamten, Priestern, gelehrten Theologen und Juristen), wobei die Kirche vielfach als Bildungsträger fungierte und Geistliche in der Regel die Aufsicht über das Schulwesen ausübten. Demzufolge ist über Jahrhunderte hinweg das Nachdenken über Erziehung theologisch geprägt, wie u. a. die Ausführungen Oelkers zum Stichwort Erziehung im „Historischen Wörterbuch der Pädagogik“ (Benner/Oelkers 2004, S. 313-320) deutlich machen. Der Kampf fortschrittlicher Lehrer im 19. Jahrhundert unter der Führung von Friedrich A. W. Diesterweg (17901866) und Karl F. W. Wander (1803-1879) gegen eine Bevormundung durch die Kirchen belegt die Härte der Auseinandersetzungen.

Wissenschaftliches Nachdenken über Erziehung wurde mit der Emanzipation der Philosophie von der Theologie zum Bestandteil der Philosophie, insbesondere der aufklärerischen. Erziehung wurde wesentlich als angewandte Philosophie, speziell als angewandte Ethik betrachtet. Es können hier nicht die Bemühungen verschiedener Hochschullehrer des 18. und 19. Jahrhunderts um die Entwicklung der Pädagogik behandelt werden. Es sei nur darauf hingewiesen, dass erst Ende des 19. und zu Beginn es 20. Jahrhunderts an Universitäten im deutschsprachigen Raum Lehrstühle für Pädagogik eingerichtet worden sind, wobei Österreich-Ungarn vorangegangen ist.

Um die Entwicklung der Pädagogik und ihrer Praxis zu befördern, wurde von Nohl die Forderung nach „Autonomie der Pädagogik“ erhoben, indem er schrieb:

„Die Weltanschauungen oder eigentlich richtiger ihre Organisationen möchten die Pädagogik nur als ausführendes Organ gelten lassen. Der Erzieher ist dann einseitig der subalterne Beauftragte der Kirche oder des Staates oder gar einer Partei. Angesichts des grausamen Kampfes dieser Mächte und der Weltanschauungen, die hinter ihnen stehen, kommt es heute mehr als je 
darauf an, daß die Pädagogik den Ort findet, der sie in gewissem Sinne unabhängig von ihnen macht, ihr eine Arbeit aus eigenem Recht erlaubt und damit Selbstbewusstsein, Würde, aber auch Zusammenhang und Fortschritt ermöglicht“" (Nohl 1963, S. 124).

Er meinte also mit seiner Forderung nach Autonomie der Pädagogik primär eine Autonomie der Erziehung im Sinne ihrer Unabhängigkeit von den verschiedenen gesellschaftlichen Kräften (Staat, Kirche, Parteien, Wirtschaftsverbände usw.). Diese Forderung ist wegen der starken eigennütrigen Bemühungen o. g. Kräfte und im Interesse der Schüler und Lehrer, die sich nicht vereinnabmen lassen wollen und sollten, durchaus verständlich. In Anbetracht der Wirkungen des Gesetzes der transgredienten Determination der Erziehung ist aber nur eine relative Autonomie der Erziehung möglich, und zwar als Ergebnis fortgesetzter Auseinandersetzungen der Erzieher mit den vielfältigen Anforderungen der Gesellschaft an sie selbst und ihre Zöglinge. Aus dem Gesetz der transgredienten Determination von Erziehung folgt als Konsequenz für erzieherisches Handeln: Von der Gesellschaft ausgehen, auf den Zögling eingehen und ihn dabei dort abholen, wo er steht, was eine kritische Sicht auf gesellschaftliche Anforderungen und eine differenzierte Förderung von Selbstbildungsbestrebungen im humanistischen Sinne einschließt.

Als die Aufklärer des 18. Jahrhunderts bzw. die Philanthropisten die alte Bezeichnung „Didaktik“ durch das Wort „Pädagogik“ ersetzten und in den Hintergrund drängten, tauchte auch das Wort „Erziehungswissenschaft“ in der Literatur auf. Erstmalig wurde es 1766 im „Magazin für Schulen und die Erziehung überhaupt“ (vgl. Tenorth bei Benner/Oelkers 2004, S. 341) und danach 1785 von Johann H. Campe gebraucht (a. a. O., S. 342). Da beide Wörter von den Philanthropisten synonym verwendet wurden und Trapp nachdrücklich die Entwicklung einer wissenschaftlichen Pädagogik gefordert hatte, die sich auch auf empirische Untersuchungen und Experimente stützen sollte (vgl. Trapp 1913, S. 33-41), kann davon ausgegangen werden, dass beide Wörter zur Bezeichnung eines Begriffes dienten, d. h., das Wort „Erziehungswissenschaft“ war nur die Übersetzung des Wortes „Pädagogik“. In diesem Sinne wurde das Wort „Erziehungswissenschaft" noch 1826 von Friedrich W. A. Fröbel (1782-1852) in seinem Hauptwerk „Die Menschenerziehung“ benutzt (Reclam o. J., S. 31). Auch Wilhelm Harnisch (1787-1864), Direktor des preußischen Lehrerseminars in Weißenfels, schrieb 1839 in seinem „Handbuch für das Deutsche Volksschulwesen“:

„Die Erįiehungswissenschaft (Pädagogik) vereinigt Lehre und Kunst und kann vielfach mitgeteilt werden“ (Harnisch 1893, S. 15).

Allerdings bahnte sich mit der Wende vom 19. zum 20. Jahrhundert eine neue Sicht auf die Erscheinungen des sozialen Lebens und die Wissenschaft an, die zu einer betonten Unterscheidung zwischen Pädagogik und Erziehungswissenschaft führte. Ein exponierter Vertreter dieser Unterscheidung von Erziehungswissenschaft und Pädagogik, nämlich Rudolf Lochner (1895-1978), schrieb: 
„1. Unter Wissenschaft sei verstanden eine geordnete Zusammenstellung von Erkenntnissen (also ein »System«) aus einem engeren, besondere Zusammenhänge aufweisenden Bereich der menschlichen oder außermenschlichen Natur. Solche Erkenntnisse werden gewonnen durch denkende Betrachtung von Natur und Geisteswelt, durch ihre Anschauung, Beobachtung und durch Vergleich der Einzelheiten, darauf folgende Beschreibung, sowie Darstellung und, wenn möglich, Ableitung von Regelmäßigkeiten (Gesetzen). Wissenschaft dieser Art ist und bleibt also Tatsachenforschung. Ihre Methoden und Mittel sind beschreibender Art. Die eigentliche oder exakte Wissenschaft wird sich mit diesen Arbeitsweisen begnügen müssen. Wesentliches Merkmal dieses Wissenschaftscharakters ist die Deskription [...]. Beschreibung dieser Art ist der Absicht nach ein wertfreies Verfahren: [...]

2. Soweit Erziehungswissenschaft als strenge Wissenschaft gelten will, muß sie den in Ziffer 1. genannten Merkmalen entsprechen“ (Lochner 1947, S. 7).

Um nun Pädagogik von einer so verstandenen Erziehungswissenschaft zu unterscheiden, benutzt er den Begriff der Lehre:

„3. Unter Lehre sei verstanden eine geordnete Zusammenfassung von Ratschlägen, Empfehlungen oder Normen, wie ein Sachbereich engerer Zusammenhänge in Welt und Leben zu organisieren, zu beherrschen, zu verbessern sei. Jede Lehre erhebt Anspruch auf Normensetzung; sie ist nicht beherrscht vom Erkennen, sondern vom Drang, Ziele zu setzen; ihre Methode ist nicht das Beschreiben, sondern das Vorschreiben" (a. a. O.).

In Anwendung auf das vorliegende Gebiet kommt er zu der Schlussfolgerung:

„Es gibt also neben der Erziehungswissenschaft eine Erziebungslehre. Eine normative Erziehungs'wissenschaft' kann nicht anerkannt werden; denn indem ich ein Verhalten lehre, menschliches Tun zu verbessern beabsichtige, überschreite ich den Boden der Wissenschaft. Wissenschaft stellt Seiendes fest und versucht es zu erklären; Lehre will noch nicht Seiendem ins Dasein verhelfen“ (a. a. O., S. 8).

Da die Pädagogik offensichtlich bestrebt ist „menschliches Tun zu verbessern“, ist sie nach Lochners Auffassung eigentlich gar keine Wissenschaft, sondern nur eine Lehre.

„Das Verhältnis zwischen Erziehungswissenschaft und Erziehungslehre ist derart, daß die erstere der letzteren vorangehen soll, wenn die letztere nicht auf dem schwankenden und unsicheren Boden des Herkommens und der mehr oder weniger tiefen praktischen Einsicht verbleiben will“" (a. a. O., S. 9).

Das Anliegen, das Lochner in Anlehnung an Max Weber (1864-1920) mit seiner Konzeption verfolgt, ist historisch verständlich, hat er doch die Wirkungen der nationalsozialistischen Pädagogik, die den Charakter einer scheinwissenschaftlichen normativen Glaubenslehre besaß, mit ihren schlimmen Konsequenzen erlebt. Aber das Anliegen Lochners ist nicht realisierbar, indem eine Erziehungswissenschaft neben oder vor die Pädagogik gestellt wird. 
Wenn wir das von Lochner definierte Kriterium von Wissenschaftlichkeit - die Tatsachenforschung mit ihrer Deskription der feststellbaren realen Zusammenhänge - auf sein eigenes Wissenschaftskonzept anwenden, dann stellen wir fest, dass es - selbst bei ehrlicher Absicht - eine weltanschaulich neutrale oder wertfreie wissenschaftliche Forschung nicht gibt und auch nicht geben kann. Jede wissenschaftliche Fragestellung und ibre Beantwortung ist in eine von unterschiedlichen Interessen beherrschte Welt eingebunden; das ist eine Tatsache! Schon folgende unumgängliche Frage lässt die untrennbare Bindung jedweder Forschung an menschliche Interessen und damit an Wertvorstellungen erkennen: Welches Ziel wird mit einer wissenschaftlichen Fragestellung verfolgt oder warum und wozu ist eine Erkenntnis erstrebenswert? Wahre Erkenntnisse sind nicht wertfrei, sondern durch ihre Beziehungen zur Gesellschaft, ohne die sie nicht existieren würden, wertvoll. Sie können darum auch mehreren Interessen dienen. Selbst das sog. „,reine Erkenntnisinteresse“ in der Grundlagenforschung ist in letzter Instanz mit weltanschaulichen Positionen und Interessen der Gesellschaft oder einzelner ibrer Gruppen und Mitglieder verbunden. Die Gefahr des „EinflieBens" fragwürdiger Wertvorstellungen in die Forschung bzw. der Irreführung durch sie wird nicht durch den Ausschluss von Wertvorstellungen und Normen aus der wissenschaftlichen Arbeit gebannt, sondern eher durch das Bemühen um ihre wissenschaftlich fundierte Begründung und durch kritische Reflexionen von Normen im humanistischen Sinne. Das gilt auch für die Pädagogik mit ihren juristischen, moralischen, ästhetischen und spezifisch pädagogischen Werten und Vorschriften (Zielen, Prinzipien, Regeln).

Den Eindruck von Wertfreiheit oder Wertneutralität der Wissenschaft erwecken vereinzelt betrachtete Verfahren und theoretische Aussagen (z. B. Gesetzesaussagen); aber diese sind nicht identisch mit Wissenschaft, sondern nur Elemente derselben. Sie sind eingeordnet in die Wissenschaft als einem durch Arbeitsteilung bedingten Gesellschaftsbereich und daher untrennbar verbunden mit menschlichen Interessen und Werten.

Aus der Tatsache des unvermeidlich gesellschaftlichen Charakters menschlicher Tätigkeit folgt: Man kann nicht handeln (also auch nicht forschen), ohne irgendwelche Interessen in der Gesellschaft (und damit verbundene Werte) zu berühren. Selbst beabsichtigte Neutralität bedeutet u. U. eine verhängnisvolle Parteinahme, indem sie gefährliche Kräfte gewähren lässt. Offenbar fassen Lochner und seine Anhänger den Begriff der Wissenschaft zu eng. Wissenschaft umfasst mit ihren Erkenntnissystemen zugleich einen Bereich der gesellschaftlichen Arbeitsteilung, der diese methodisch erzengt; in ihm bilden Entstehungszusammenhang, Begründungszusammenhang und Wirkungszusammenhang eine dialektische Einheit.

Auch vom Standpunkt der von Lochner geforderten Tatsachenforschung aus betrachtet, ist eine Trennung von Erziehungswissenschaft und Pädagogik unter dem Aspekt der Werffreibeit oder Wertgebundenheit nicht gerechtfertigt, denn tatsächlich ist Wissenschaft ein historischer und damit werthaltiger Prozess. Natürlich haben Wertvorstellungen eine „normierende Wirkung“ auf das pädagogische Denken, daher beeinflussen sie 
die Erkenntnisgewinnung, was zu fehlerbaften Erkenntnisresultaten führen kann, durch die schließlich auch das dadurch gesteuerte Handeln fehlgeleitet wird. Aber dieses Problem wird nicht durch eine Trennung von Pädagogik und Erziehungswissenschaft gelöst. Die Pädagogik kann und muss sich bemühen, durch wissenschaftliche Begründung und Reflexion ihrer normativen Bestandteile zu gültigen Orientierungen zu gelangen. Im Interesse der Pädagogik als Wissenschaft sollten dabei spirituelle und irrationale Argumentationen unterbleiben. Übrigens verweist auch Pierre Bourdieu darauf, dass es unmöglich ist, eine wertfreie, interessenunabhängige und machtneutrale Erkenntnis mitzuteilen, schon weil jeder Sprechende und Schreibende in Beziehungen eingebunden ist, die mit Bedürfnissen, Interessen und Machtausübung zusammenhängen (vgl. Bourdieu 1989, S. 42ff.).

Ergänzend sei an dieser Stelle noch vermerkt, dass es in der DDR einen besonderen Grund zur Verwendung des Wortes „Erziehungswissenschaft“ gegeben hat, nämlich folgenden: Unter dem Einfluss der Sowjetpädagogik setzte sich nach dem IV. Pädagogischen Kongress (1949) an den Universitäten und Pädagogischen Instituten bzw. Hochschulen der DDR die Definition „Pädagogik ist die Wissenschaft von der Bildung und Erziehung der heranwachsenden Generation“ durch. (vgl. Pädagogische Enzyklopädie 1963, Bd. 2, S. 669) Mit dieser Definition beharrten DDR-Pädagogen auf einer Position der deutschen und russischen Pädagogik (und damit auch der Sowjetpädagogik), die im 19. und zu Beginn des 20. Jahrhunderts in Europa vorgeherrscht hatte. Theodor Waitz (1821-1864) schrieb:

„Der Erwachsene wird nicht leicht mehr innerlich so umgebildet, daß sein gesamter sittlicher Zustand dadurch ein anderer würde, und selbst wenn und wo es möglich wäre, setzen äußere Verhältnisse einer solchen Umbildung fast immer unüberwindliche Hindernisse entgegen“ (Waitz 1910, S. 6).

Dass äußere Verhältnisse den Menschen zwingen können, sich durch Erziehung und Selbsterziehung auch innerlich zu verändern, konnte sich ein Pädagoge vor den beiden Weltkriegen und den gesellschaftlichen Veränderungen des 20. Jahrhunderts sicher nicht vorstellen. Seiner Meinung nach „beschränkt sich die Pädagogik auf die Erziehung des werdenden, innerlich noch gestaltbaren Geschlechts" (Waitz 1910, S. 6).

Nach dem II. Weltkrieg war 1949 das erste deutsche Institut für Erwachsenenbildung an der Universität Leipzig unter Leitung von H. Schaller gegründet worden. Er verstand Erwachsenenbildung nicht nur im Sinne von Wissensvermittlung und Könnensentwicklung; ihm ging es immer um die Entwicklung der Persönlichkeit und Vervollkommnung des ganzen Menschen. In seiner Denkschrift zur Gründung des Instituts schrieb er:

„Innerhalb der Erziehung gewinnt Erwachsenenbildung ausschlaggebende Bedeutung, da die großen individuellen, weltanschaulichen, politischen und sexuellen Entscheidungen erst während der Reifezeit und später getroffen werden, da die schroffen Änderungen der gesellschaft- 
lichen Situationen immer neue Schulungen der Älteren nötig machen. [...] Fortschreitende Beherrschung der Natur und der Gesellschaft verlangen rationellste Arbeit mit dem Ziel des Optimums der Leistung. Die mannigfaltigen Probleme der Erwachsenenbildung müssen daher wissenschaftlich, kollektiv, total, dynamisch erforscht und gelehrt werden." ${ }^{\text {8 }}$

Schallers Konzept hätte aber eine prinzipielle Erweiterung des oben definierten engen Begriffs der Pädagogik erfordert und dagegen wandten sich viele Mitarbeiter der damaligen Pädagogischen Fakultät der Universität Leipzig (die sich mit Kinder- und Jugenderziehung befassten) ganz entschieden, und zwar nicht nur mit fachlichen Argumenten wie wir sie z. B. bei Johann F. Herbart (1776-1841) oder Theodor Waitz finden, sondern auch mit politischen; ging es doch um eine Position der Sowjetpädagogik, die Schaller infrage stellte; das war Häresie! Um dem damit verbundenen politisch-ideologischen Streit aus dem Wege zu gehen, benutzte er das Wort „Erziehungswissenschaft“.

Inzwischen hat sich das Verständnis vom Pädagogik-Begriff erweitert; bereits am Ende der DDR hatte sich auch das Wort „Erwachsenenpädagogik“ eingebürgert. Es veränderte sich die langwährende Wortbedeutung - nämlich „Wissenschaft von der Erziehung der heranwachsenden Generation“ - in Richtung „Wissenschaft von der Erziebung des Menschen“. Damit entfällt das oben skizzierte Problem auch für die Sozialpädagogik, die es ja ebenfalls mit Heranwachsenden und Erwachsenen zu tun hat. In dieser Schrift wird das Wort „Pädagogik“ gebraucht zur Bezeichnung der Wissenschaft von der Erziehung des Menschen und der Erziehungswirklichkeit, was sich auch in der Verwendung des Wortes „pädagogischer Prozess“ äußert. Mit dieser Bestimmung werden jedoch nur zwei grundlegende Verwendungen des Wortes „Pädagogik“ vorgestellt, eine allgemein anerkannte begriffliche Klarheit ist dadurch noch nicht gegeben, weil ja unterschiedliche Erziehungsauffassungen existieren (vgl. Abschnitt 1.1). Auf der Grundlage des vorn definierten Erziehungsbegriffs kann formuliert werden:

Pädagogik im Sinne von Erziehungswissenschaft hat die Erziehung des Menschen zum Gegenstand. Sie erforscht die Struktur, Funktionsweise und Entwicklung der Erziehung sowie ihre Wechselbeziehungen mit Natur und Gesellschaft, um Erkenntnisse zu gewinnen, zu systematisieren und in Form von Modellen und Konzepten, Prinzipien und Regeln als Orientierungsgrundlagen für erzieherisches Handeln zur Verfügung zu stellen.

Für ein richtiges Verständnis der Definition ist wichtig:

- Pädagogik wird in der oben formulierten Definition so weit gefasst, dass alle historisch-konkreten und individuell-einmaligen Erscheinungsformen von Erziehung zu ihrem Untersuchungsgegenstand gemacht werden können.

8 H. Schaller: Denkschrift. Sächsisches Hauptstaatsarchiv Dresden, M. f. V., Akte Nr. 1610, Blatt 60. 
- Die Pädagogik im definierten Sinne erfasst nicht nur das Handeln der Erzieher, sondern auch die dadurch beeinflussten Aktivitäten der Zöglinge; d. h., ein Erziehungsprozess hat erst dann stattgefunden, wenn der Zögling sich die zielgemäß ausgewählten Inhalte so weit angeeignet hat, dass dies im Resultatsnachweis - wenn auch auf unterschiedlichem Niveau - deutlich wird. Der Aneignungsprozess der Zöglinge ist wesentlicher Bestandteil von Erziehung (also auch des Gegenstands der Pädagogik) und nicht nur Wirkung von Erziehung.

- Der Systemzusammenhang der immanenten Momente begründet die Eigenständigkeit der Pädagogik als Wissenschaft; diese erfordert und ermöglicht auch eine eigenständige pädagogische Grundlagenforschung. Indem die Pädagogik Erkenntnisse und Methoden anderer Wissenschaften (z. B. Biologie, Psychologie, Soziologie, Ethik, Medizin, Wirtschaftswissenschaften, Rechtswissenschaften) und praktische Erfahrungen integriert, erhält sie einen transdisziplinären Charakter.

- Der Gegenstand der Pädagogik ist die in natürliche und gesellschaftliche Zusammenhänge eingeordnete dialektische Einheit von Erziehung und Selbsterziehung im vorn definierten Sinne (S. 23f.), wobei in der Kindererziehung die „Fremderziehung" eine größere Rolle spielt als in der Erwachsenenbildung.

- Im Falle der Selbsterziehung realisiert der Mensch eine pädagogische Führung gegenüber sich selbst, indem er sich bemüht, entsprechend seinen objektiven Möglichkeiten und subjektiven Fähigkeiten die Anforderungen des Lebens $q^{u}$ erkennen und sich entsprechend zu qualifizieren. Erziehung muss darauf gerichtet sein, adäquates Situationsbewusstsein zu fördern, zur Analyse und Bewertung der eigenen Lebensumstände und des persönlichen Lebensstils anzuregen und zur Selbsterziehung im Interesse eines gelingenden Lebens sowie erfolgreicher gesellschaftlicher Partizipation zu befähigen.

- Die Pädagogik steht vor der noch weitgehend ungelösten Aufgabe, wissenschaftliche Grundlagen für die Selbsterziehung zu erarbeiten. Hinweise zur Notwendigkeit einer Autodidaktik und vereinzelte Ratschläge dazu deuten das Problem an; aber es ist mehr erforderlich, wenn man bedenkt, welche hohen Anforderungen die sich wandelnden ökonomischen, technischen, sozialen und kulturellen Verhältnisse an jeden Menschen immer wieder erneut stellen.

- Erziehung wird nicht nur durch gesellschaftliche und individuelle Kräfte initiiert und gestaltet, sondern dient auch immer der Entwicklung individueller und sozialer Qualitäten der Persönlichkeit, sie ist also immer zugleich Individual- und Sozialerziehung (vgl. auch S. 99ff.), wobei die spezifischen Anteile und Effekte sozialerzieherischer Bemühungen in den verschiedenen „Erziehungsfeldern“ schwer einzuschätzen sind. Aber die Tatsache, dass jede Erz̧iehung - ganz gleich mit 
welcher spezifischen Zielstellung und in welcher personellen Konstellation oder Einrichtung - immer auch mehr oder weniger wirksame Sozialerziehung ist, lässt es als unlogisch erscheinen, eben diese zum Gegenstand einer besonderen Sozialpädagogik als einer Pädagogik ,für die Hinterhöfe der Menschbeit" zu erklären (vgl. Bornemann 1978, S. 26).

- Jede pädagogische Disziplin muss sich auf ihre Weise mit den individuellen und sozialen Werten und Wirkungen der Erziehung in ihrem Gegenstandsbereich beschäftigen - andernfalls würde sie das Wesen von Persönlichkeitsentwicklung verkennen. Diese Anforderung an jede pädagogische Disziplin schließt nicht aus, dass einzelne Aspekte pädagogischer Prozesse in speziellen Projekten erforscht und dargestellt werden. Wenn Pädagogen die Erziehung als Systemzusammenhang untersuchen und darstellen wollen, müssen sie einerseits eine sorgfältige Tatsachenforschung betreiben, um zu wissenschaftlich begründeten Verallgemeinerungen zu gelangen, und andererseits auch die jeweils erforderlichen und wirksamen Wertvorstellungen und Normen mit Hilfe der Ethik und anderer relevanter Wissenschaften aufklären. Vor allem müssen die pädagogischen Disziplinen die in ihrem Gegenstandsbereich geltenden Prinzipien, Regeln und sonstigen pädagogischen Vorschriften wissenschaftlich bearbeiten.

- So wie der Wahrheitsgehalt von Aussagen relativ ist, weil sie die Eigenheiten eines Gegenstandes im definierten Bereich nur annähernd adäquat erfassen, so sind auch Normen relativ gültig, was aber ihren Wert für den Bereich, in dem sie zur angegebenen Zeit gelten, keineswegs mindert. Unterschiede bestehen u. a. in den Methoden, mit denen der Wahrheitsgehalt von Aussagen und die Gültigkeit von Normen überprüfbar sind. Dass nun die Methoden für die Gültigkeitsüberprüfung von Normen weniger entwickelt sind als die zur Überprüfung des Wahrheitsgehalts von Aussagen, ist kein hinreichender Grund, Normen für wissenschaftlich unbegründbar zu halten (vgl. 4.3).

Auf der Grundlage der hier dargestellten Positionen erscheint ein synonymer Gebrauch der Wörter Erziehungswissenschaft und Pädagogik - wie er bereits im 19. Jahrhundert üblich war - als möglich und gerechtfertigt. Eine Reduzierung der Aufgaben der Erziehungswissenschaft auf empirische Untersuchungen von Erziehungsprozessen oder auf theoretische Reflexionen zur Pädagogik im Sinne einer Metatheorie entspricht nicht den gesellschaftlichen Funktionen und der moralischen Verantwortung einer Wissenschaft. Die dialektisch-materialistische Erziehungswissenschaft ist objektorientiert, sie arbeitet systemisch, empirisch-analytisch-abstrahierend und theoretisch-konstruktiv-synthetisierend; sie ist sozialkritisch, emanzipatorisch gerichtet und transdisziplinär begründet handlungsanleitend - zumindest ist das vorliegende Buch in diesem Sinne konzipiert. 


\subsection{Soziale Nöte als Auslöser für Sozialarbeit und Sozialpädagogik}

Im mittelalterlichen Europa wurden arme und Not leidende Menschen durch das Almosenwesen ,aufgefangen“ und elementar versorgt. Doch mit Beginn der kapitalistischen Entwicklung wuchs auch der Anteil der städtischen Bevölkerung durch landflüchtige Bauern, die nicht immer Arbeit fanden. Ferner hatte sich nach der Reformation ein neues Arbeitsethos entwickelt und im Zusammenhang damit eine neue Einstellung zur Armut. Es war nicht mehr möglich, das Problem der städtischen Armut auf der Grundlage des Almosenwesens zu regeln. Stattdessen wurden im 18. und 19. Jahrhundert sog. Armenordnungen entwickelt, die Regelungen zur Erlangung materieller oder finanzieller Mittel und zu ihrer Verteilung an Not leidende Mitglieder der Kommune umfassten. Zweck dieser Armenordnungen war es, den Notleidenden Erleichterung zu verschaffen und gesellschaftliche Konflikte zu reduzieren. Damit waren zwar auch verhaltenssteuernde Effekte bei den Betroffenen verbunden, aber es stand nicht die Erziehung der Bedürftigen im Vordergrund, sondern ihre Versorgung mit Lebensnotwendigem (Nahrung, Kleidung, Behausung).

Anders war es im 19. Jahrhundert in speziellen Erziehungseinrichtungen für Kinder und Jugendliche aus den unteren Sozialschichten, etwa in Kleinkinderbewahranstalten, Waisenhäusern und sog. Rettungsanstalten für verwahrloste Jugendliche, in denen mit Rücksicht auf das Alter erzieherische Momente eine wesentliche Rolle spielten. Allerdings gab es auch furchtbare Verhältnisse der Kinderarbeit und Kinderausbeutung in Verbindung mit Waisenhäusern. In vielen ging es nicht um die Persönlichkeitsentwicklung der Kinder, sondern um hohen Profit aus Kinderarbeit. Auch die Kleinkinderbewahranstalten waren zunächst primär zur Behebung drückender sozialer Nöte geschaffen worden und somit Erscheinungsformen der Armenpflege. Es ging darum, den Müttern in den ärmsten Kreisen der Bevölkerung eine Erwerbstätigkeit zu ermöglichen oder dort zur „wahrhaft menschlichen Entwicklung und Bildung“ beizutragen, wo die „Eltern durchaus unfähig sind, für ihre Kinder zu sorgen“ (Diesterweg 1959, Bd. III, S. 505). Diesterweg sah in den Bewahranstalten zunächst wirklich nur

„Notbehelfe, Surrogate für gute häusliche Erziehung. Nur da, wo die Kinder zu Hause verwahrlost werden, ist es ein preiswürdiges, segensreiches Werk, sie ins Leben zu rufen“(a. a. O.).

Diesterweg änderte allerdings diese Auffassung aus dem Jahre 1834 später zu Gunsten der Intentionen von Friedrich Fröbel. In seiner Rede zur Eröffnung des ersten Kindergartens in Berlin am 03.08.1851 erläuterte und unterstützte er Fröbels Konzeption (vgl. Quellen zur Geschichte der Vorschulerziehung 1971, S. 173-180), die durchaus auch auf Kinder aus normalen bürgerlichen bzw. mittelständischen Elternhäusern gerichtet war und deutlich der Schulvorbereitung diente, wie u. a. aus der „Nachricht und Rechenschaft von dem deutschen Kindergarten“ (1843) zu entnehmen ist, in der es heißt: 
„Sein Zweck ist also nach der einen Seite, Kinder des vorschulfähigen Alters nicht nur in Aufsicht zu nehmen, sondern ihnen eine ihrem ganzen Wesen entsprechende Bethätigung zu geben; ihren Körper zu kräftigen, ihre Sinne zu üben und den erwachenden Geist zu beschäftigen; sie sinnig mit der Natur und Menschenwelt bekannt zu machen; besonders Herz und Gemüth richtig zu leiten und zum Urgrunde alles Lebens, zur Einigkeit mit ihm hinzuführen. Im Spiele sollen sie freudig und allseitig, alle Kräfte übend und bildend, in schuldloser Heiterkeit, Einträchtigkeit und frommen Kindlichkeit sich darleben, für die Schule und kommenden Lebensstufen sich wahrhaft vorbereiten [...] (Hervorhebung durch W. N.).

Nach der anderen Seite ist sein Zweck, die Personen, namentlich junge Leute beiderlei Geschlechts, in der rechten Leitung und Beschäftigung der Kinder zu unterweisen, den Müttern gute Gehilfinnen in der Pflege der Kleinen, den Familien bessere Wärterinnen und Erzieherin nen, den Bewahranstalten und anderweitigen Kindergärten geschickte Kindermütter und einsichtige Kinderführer zu geben“ (Quellen zur Geschichte der Vorschulerziehung 1971, S. 166). Von einem bloßen sozialen „Notbehelf“ oder Ausgleich für versagende Familienerziehung kann bei Fröbels Kindergartenkonzeption keine Rede sein; vielmehr handelt es sich um eine Einrichtung zur vorschulischen und perspektivisch orientierten Bildung und Erziehung der Kinder und zur grundlegenden pädagogischen Ausbildung von jungen Leuten beiderlei Geschlechts, wobei natürlich auch präventive Momente gegenüber Verwöhnungs- und Verwahrlosungsgefahren mit bedacht worden sind. Übrigens findet sich auch in Fröbels Hauptwerk „Die Menschenerziehung“ keine Äußerung über Sozialpädagogik, Sozialerziehung, Erziehung von Verwahrlosten o. Ä. Fröbel ging es um Menschenerziehung mit nationalerzieherischem Einschlag, was dem Zeitgeist entsprach; er verstand sich als Menschenerzieher (mit dem Schwerpunkt Vorschulerziehung) und nicht als Sozialpädagoge. Es ist wohl einer historisch gewachsenen Fehldeutung von Fröbels Kindergartenkonzeption vermittelt durch Gertrud Bäumers (1873-1954) Bestimmung von Sozialpädagogik als drittem Erziehungsbereich neben Familie und Schule - zuzuschreiben, wenn z. B. Mühlum den Schöpfer des Kindergartens als Sozialpädagogen in eine Reihe stellt mit Pestalozzi, Johann H. Wichern (1808-1981) u. a. (Mühlum 2001, S. 58 und 63).

Das Wort „Socialpädagogik“ ist 1844 erstmals von Karl Mager (1810-1858) publiziert worden, denn ungeachtet der realen „Doppelwirkungen“ von Erziehungsprozessen haben in der Geschichte der Pädagogik die Praktiker und Theoretiker ibre Bemühungen unterschiedlich akzentuiert. So stand in frühgeschichtlichen Gesellschaften die Erziehung durch und für die Gemeinschaft oder den Staat deutlich im Vordergrund - aus verständlichen Motiven, weil dadurch Wesentliches für den Bestand der jeweiligen Gemeinschaft geleistet wurde. In dem Maße nun, wie mit der Verbreitung der christlichen Religion die „ewige Seligkeit des Individuums“ (vgl. z. B. Comenius 1957, S. 67ff.) oder im Zuge der Aufklärung die „Glückseligkeit des Menschen“ (vgl. Trapp 1913, S. 15ff.) als Eræiehungszwecke in den Vordergrund gerückt wurden, veränderten sich pädagogisches Denken 
und Handeln in Richtung Individualpädagogik, und zwar so sehr, dass dies wiederum Anlass zu Bedenken gab. Daher schrieb Karl Mager:

„Es ist gewiß, daß die neuere Pädagogik seit Locke, Rousseau, den Philanthropisten, Pestalozzi, Herbart, Benecke u. a. den Fehler hat, nur Individualpädagogik zu sein, und darum habe ich mehrmals darauf hingewiesen, daß jetzt die Wissenschaft weiter gefaßt, daß sie durch die Staats- oder Collektivpädagogik vervollständigt, auch der Gesichtspunkt des Platon und Aristoteles wieder genommen werden muß - freilich so, daß man sich in dieser Social-Pädagogik über die Ideen der Alten erhebt, nicht aber, wie unsre Radicale und Absolutisten sie nur wieder aufwärmt“ (Mager 1844, S. 396).

Aus weiteren Bemerkungen Magers geht hervor, dass ihn die unzureichend Erzogenen beunruhigten, denn er befürchtete,

„daß es wie jetzt die Welt fortgeht, mit der Zeit zu einem schmählichen Bankerott unsrer sogen. Civilisation kommen kann, daß uns ein täglich wachsender Pöbel bedroht“" (a. a. O.).

In seiner Abhandlung „Was ist Pädagogik“ verweist Mager ausdrücklich darauf, dass es nicht nur „Pädagogen von Profession“ - z. B. Lehrer - gibt, sondern Pfarrer, Exerziermeister beim Militär, Staatsbeamte, ja auch Vereine, offene Gerichte usw., die erżieherisch tätig sind, damit „das Collektiv-Individuum, Volk genannt, das Richtige einsehe und wolle“ (Mager 1846, S. 3). Damit wird einerseits ein Prozess der Vergesellschaftung der Erziehung durch Betonung gesellschaftlicher Ziele und Einbeqiehung vielfältiger gesellschaftlicher Kräfte als Erzieher erkennbar, andererseits deutet sich hier auch eine Reflexion der Tendenz zur Pädagogisierung der Gesellschaft an. Mager meint ja, dass soziale Probleme verstärkt mit den Mitteln der Pädagogik, die vielen gesellschaftlichen Kräften zur Verfügung stehen, gelöst werden sollten und könnten. Dieser Gedanke war allerdings nicht neu, denn schon Friedrich Schleiermacher (1768-1834) verfolgte eine „Strategie der Pädagogisierung der Jugendphase“ durch „eine Gestaltung der öffentlichen Erziehung und des Generationsverhältnisses, welche die Revolution entbehrlich macht" (Dudek 1997, S. 48).

Die „Angst vor dem Pöbel“ bzw. vor dem Aufbegehren der in Armut lebenden Proletarier ist wohl ein wesentliches Motiv für die Entwicklung sozialpädagogischen Denkens und Handelns in der Entwicklung des Kapitalismus. Die unübersehbaren sozialen Konflikte haben zur Ausarbeitung unterschiedlicher Auffassungen und Konzepte von Sozialpädagogik geführt. Auch Diesterweg bemerkte nach der Revolution von 1848 in seinem bekannten Werk „Wegweiser zur Bildung für deutsche Lehrer“:

„Die Erscheinungen dieses Jahres (weisen) auf keine Forderung dringender (hin), als auf die geregelte Fürsorge für die geistige und sittliche Reife der Nation; daß freie Staaten ohne allgemein durchgeführte Bildung für die Jugend und ohne Bildungsvereine die größte Gefahr laufen, in Pöbelherrschaft zugrundezugehen“ (Diesterweg 1850, S. 129). 
Nach dialektisch-materialistischer Auffassung können die ökonomischen und politischen Ursachen sozialen Elends nicht primär von Pädagogen bzw. mit pädagogischen Mitteln beseitigt werden! Aber Pädagogen können und müssen Menschen erziehen, die bereit und fähig sind, sich auch mit politischen Mitteln und Methoden für eine humanere Gesellschaft einzusetzen. Wenn also z. B. Hans-Uwe Otto sagt: „Wir leisten keine Nothilfe, sondern wir stellen Gerechtigkeit her“ (zitiert nach C. W. Müller 2000, S. 425), formuliert er zwar eine gute Absicht, aber keine realisierbare Losung für Sozialarbeiter. Sie können unter gegebenen Bedingungen durch ihre professionelle Tätigkeit nur Hilfen in individuellen und kollektiven Notlagen geben, was noch keine Gerechtigkeit herstellt, solange z. B. relativ wenige Menschen an den Finanzmärkten Millionen ,verdienen“ und zugleich Millionen Menschen verarmen.

Seit Mager hat das Wort „Sozialpädagogik“ mehrere Bedeutungswandlungen durchgemacht, die in zahlreichen Veröffentlichungen erörtert worden sind. Helga Marburger hat z. B. umfangreiche Analysen zum Wandel des Wortgebrauchs vorgenommen und ihre Ergebnisse in folgende Übersicht gebracht:

- „so bezeichnet Kurt Haase mit Sozialpädagogik die »Lehre von der Erriehung zum sittlichen Sozialverbalten «(1962, Sp. 374).

- „ „Sozialpädagogik ist Erziehung zur Gesellschaft [...], Volksbildungsarbeit im breitesten Sinne«, heißt es bei Erich Knirck (1963, S. 60).

- Klaus Mollenhauer (1964a, S. 12) bestimmt Sozialpädagogik als »denjenigen Bereich der Erziehungswirklichkeit, der im Zusammenhang (mit) der industriellen Entwicklung als ein System gesellschaftlicher Entwicklungshilfen notwendig geworden ist, sich erweitert und differenziert hat; Eingliederungshilfen, die gleichsam an den Konfliktstellen dieser Gesellschaft entstehen: im wesentlichen das, was das Jugendwohlfahrtsgesetz 'Jugendhilfe' nennt.«

- Theodor Wilhelm (1966, S. 30) schlägt vor, Sozialpädagogik lediglich als historischen Begriff zu verwenden, zur Kennzeichnung jenes geschichtlichen Zeitraumes zwischen den Weltkriegen, als Sozialpädagogik mit Jugendwohlfahrt gleichgesetzt wurde.

- »Sozialpädagogik ist die wissenschaftliche Theorie vom sozialpädagogischen Aspekt in den Erziehungsfeldern und reflektiert das pädagogische Handeln, das auf Integrationshilfe in die moderne Gesellschaft zielt«, sagt Lutz Rössner (1970, S. 477).

- Klaus Jürgen Tillmann (1972, S. 806) definiert »Sozialpädagogik als Theorie und Therapie von Sozialisationskonflikten«.

- Hans Pfaffenberger (1969, S. XVI) versteht unter Sozialpädagogik »psychosoziale Lebenshilfe in den Formen der Anpassungs-, Entwicklungs-, Reifungs- und Bildungshilfer.

- Für Siegfried Keil schließlich (1975, Sp. 969) ist Sozialpädagogik »als Theorie spezieller Sozialisationshilfen (...) die Wissenschaft von den Bewältigungsmöglichkeiten der So- 
zialerziehung und Sozialarbeit einschließlich der Jugend-(...) und Sozialhilfe (...) für die im Laufe der lebenslangen Sozialisation auftretenden Konflikte "“ (Marburger 1981, S. 9/10).

Die vorliegenden Versuche zur Begriffsbestimmung zeigen nicht nur eine Vielfalt von Auffassungen, sondern widerspiegeln z. T. auch ein unzureichendes wissenschaftstheoretisches und methodologisches Niveau im Herangehen:

- Es ist unverständlich, wenn Haase das Wort „Sozialpädagogik“ zur Bezeichnung einer Lehre verwenden will und nicht zugleich explizit betont, dass auch eine Forschung dazu gehört, ganz abgesehen von der Einengung auf „Erziehung zum sittlichen Sozialverhalten“; jeder sozialpädagogische Praktiker weiß, wie häufig auch praktisch-sachliches Wissen und Können zur Bewältigung des Lebensalltags den Hilfebedürftigen vermittelt werden muss.

- Indem Knirck Sozialpädagogik als „Erziehung zur Gesellschaft“ auffasst, übersieht er die gesellschaftliche Funktion jedweder Erziehung. Wenn Sozialpädagogik „Volksbildungsarbeit im breitesten Sinne“ ist, entsteht die Frage, warum es noch eine Volkshochschul- bzw. Erwachsenenpädagogik gibt.

- Mollenhauers „Eingliederungshilfen“ im Sinne des „Jugendwohlfahrtsgesetzes“ engen den Begriffsumfang einerseits unzulässig ein, denn sozialpädagogisches Handeln erfolgt auch außerhalb der Jugendhilfe bzw. des „Geltungsbereichs“ des JWG oder nunmehr KJHG. Andererseits „überdehnen“ sie den Gegenstandsbereich der Sozialpädagogik, weil so auch viele Beschaffungs- und Versorgungshandlungen als Elemente der Sozialarbeit der Pädagogik zugeordnet werden.

- Wilhelm bezweifelt die Notwendigkeit einer Sozialpädagogik nach dem II. Weltkrieg; aber man kann oder sollte die „Sozialpädagogik“ nicht abschaffen, solange ihre praktisch erlebbaren Problemfelder existieren.

- Der Definitionsvorschlag von Rössner ist logisch nicht haltbar, denn wenn man den Begriff oder Gegenstand der „Sozialpädagogik“ definieren will, dann darf man das entsprechende Wort nicht zugleich in gewandelter Form („sozialpädagogischer Aspekt“) als Mittel zur Definition verwenden.

- Tillmann sieht im Kern den Aufgabenbereich der Sozialpädagogik richtig nämlich die Hilfe für Problembelastete, die in vielen Fällen auch therapeutische Behandlungen mit einschließt, aber das rechtfertigt nicht die Subsumierung der therapeutischen Praxis unter den Begriff der Sozialpädagogik, weil dafür eigenständige Wissenschaftsdisziplinen existieren.

- Aus der zitierten Auffassung von Pfaffenberger geht nicht hervor, unter welchen Bedingungen die o. g. „psychosozialen Hilfen“ gegeben werden, um als 
Ausdruck sozialpädagogischen Handelns gelten zu können (vgl. S. 109 in diesem Buch). Auch Therapien können als psychosoziale Hilfen verstanden werden.

- Die Definition von Keil orientiert mit dem Hinweis auf die Bewältigung der „im Laufe der lebenslangen Sozialisation auftretenden Konflikte“ durchaus auf ein Kernstück der Wesensbestimmung, subsumiert aber die Sozialarbeit unter die Sozialpädagogik.

Eine zutreffende Einordnung der Sozialpädagogik in die Struktur der Erziehungswissenschaft nimmt H.-H. Krüger im Handbuch „Grundriss Soziale Arbeit“ vor (Thole u. a. 2002, S. 278f.). Leider „charakterisiert“ er die Sozialpädagogik zugleich „mit dem neueren Begriff der »Sozialen Arbeit «", was zu einer neuen Unschärfe der Begriffe führt.

\section{Struktur der Erziehungswissenschaft}

\begin{tabular}{|c|c|c|}
\hline \multicolumn{3}{|c|}{ Subdisziplinen (Auswahl) } \\
\hline \multirow{2}{*}{ Ebene 1} & $\left(\right.$ (a) ${ }^{*}$ Allgemeine Pädagogik & $\begin{array}{l}\text { Systematische Pädagogik } \\
\text { Historische Pädagogik } \\
\text { Vergleichende Pädagogik }\end{array}$ \\
\hline & (b) Spezielle Pädagogiken & $\begin{array}{l}\text { Schulpädagogik } \\
\text { Berufs- und Wirtschaftspädagogik } \\
\text { Erwachsenenbildung } \\
\text { Sozialpädagogik } \\
\text { Sonderpädagogik }\end{array}$ \\
\hline \multicolumn{3}{|c|}{$\begin{array}{c}\text { Verwandte Disziplinen: } \\
\text { Pädagogische Psychologie, pädagogische Soziologie, Fachdidaktiken } \\
\text { Fachrichtungen (Auswahl) }\end{array}$} \\
\hline Ebene 2 & $\begin{array}{l}\text { Interkulturelle Pädagogik } \\
\text { Frauenstudium } \\
\text { Medienpädagogik } \\
\text { Verkehrspädagogik } \\
\text { Betriebspädagogik }\end{array}$ & $\begin{array}{l}\text { Hochschulpädagogik } \\
\text { Altenbildung } \\
\text { Vorschulpädagogik } \\
\text { Kulturpädagogik } \\
\text { Freizeitpädagogik }\end{array}$ \\
\hline
\end{tabular}

Übersicht 2

Krügers Übersicht lässt erkennen, dass ganz verschiedene Aspekte des erzieherischen Geschehens zur Grundlage der Bildung von Subdisziplinen gemacht werden:

1(a): Aspekte des methodischen Herangehens an den zu untersuchenden Gegenstand „Erziehung“, also:

- systematisch,

- bistorisch oder

* Die Buchstaben sind im Original nicht enthalten, sie wurden zwecks Analyse der Übersicht vom Autor nachträglich eingefügt. 
- vergleichend, aber in jedem Falle auf allgemeine Erkenntnisse gerichtet. 1(b): Subdisziplinen unter den Aspekten von

- Institutionen oder Gesellschaftsbereichen: z. B. Schule, Hochschule, Wirtschaftssektor, Freizeitsektor;

- Besonderheiten der Zielgruppe: „Normalschüler“, Schüler mit besonderem Förderbedarf, Erwachsene;

in der 2. Ebene ferner:

- Spezielle Zielgruppen: Vorschulkinder, Hochschulstudierende, Frauen, Verkehrsteilnehmer, Betriebsangehörige, Senioren und freizeitaktive Personen;

- Mittel: Kultur, Verkehr, Medien.

Abgesehen davon, dass Krügers Gruppierungen keine einheitlichen Gliederungsprinzipien erkennen lassen, werden unter dem Aspekt des Inhalts solche wichtigen inhaltsabhängigen Disziplinen wie die Fachdidaktiken nicht mit genannt, da sie bei ihm eine Sonderstellung zwischen der jeweiligen Fachdisziplin und der Erziehungswissenschaft einnehmen. In der DDR waren die Fachmethodiken (wie hier die Fachdidaktiken bezeichnet wurden) allgemein als erziehungswissenschaftliche Spezialdisziplinen anerkannt, was keineswegs als Abwertung angesehen wurde und darüber hinaus zur Entwicklung dieser Disziplinen beigetragen hat, wie sich anhand der wissenschaftlichen Arbeiten, des beachtlichen Personalbesatzes der Fachmethodiken an den Universitäten und Hochschulen sowie der hohen Pflichtstundenzahl für Lehrerstudenten in diesen Disziplinen nachweisen lässt. Krügers Übersicht widerspiegelt also einen historischen Entwicklungsstand der in der Bundesrepublik institutionalisierten pädagogischen Disziplinen.

Vom Ringen um Klarheit hinsichtlich der Bestimmung von Sozialarbeit und Sozialpädagogik zeugen auch folgende Ausführungen:

„Sozialpädagogik und Sozialarbeit sind Teilfelder gesellschaftlicher Praxis, die zwar aus verschiedenen historischen Wurzeln und Ansätzen stammen, zwischenzeitlich aber zu einem integrierten Feld gesellschaftlicher Praxis zusammengewachsen sind oder zumindest auf dem Wege dahin sich entwickeln, zu einem Gesamtfeld, das schon wegen der sehr weiten Überschneidungen und des Fehlens eines durchgängigen logischen Unterscheidungs- und Abgrenzungsprinzips nicht mehr einfach zweiteilbar, sondern nur noch mehrdimensional aufgliederbar ist. Nach diesem sogenannten Konvergenz-Theorem (Pfaffenberger 1966; Tuggener 1971), also der These von der Entwicklung zweier Teilfelder zu einem umfassenden Gesamtfeld aus unterschiedlichen historischen Wurzeln, ist die traditionelle terminologische Zweiteilung, die zugleich historisch eine Zweiteilung der Berufe, der Berufsausbildungsgänge, der Berufsausbildungsstätten usw. war, historisch bedingt, aber zugleich heute und erst recht in Zukunft sachlich überholt“" (Pfaffenberger bei Roth 1991, S. 989). 
Wie nun die Wissenschaft aussehen soll, die die Zweiteilung überwindet und für das Ganze der Sozialen Arbeit zuständig ist, wird allerdings noch heftig diskutiert. Wollte man die Sozialpädagogik so erweitern, dass sie alle Bereiche der Sozialen Arbeit erfasst, würde sie die Grenzen einer erziehungswissenschaftlichen Disziplin weit überschreiten und hätte mit Pädagogik als Wissenschaft nur noch wenig zu tun. Es gibt ja nicht nur eine zunehmende und sich stets wandelnde Zahl von Arbeitsfeldern oder Problembereichen, um die sich Sozialarbeiter/Sozialpädagogen kümmern (vgl. Eyferth/Thiersch/Rauschenbach 1987, S. 998), es sind auch in jedem Bereich selbst vielschichtige zweckgerichtete Verknüpfungen von Elementen aus mehreren Wissens- und Handlungsbereichen zu beachten, z. B. aus:

- juristisch fundierten Analysen und Entscheidungen bzw. Maßnahmen,

- finanzökonomischen Planungen, Handlungen und Abrechnungen,

- Verwaltungshandeln und verwaltungstechnischen Arbeiten,

- Beratungen sowie Beschaffungs- und Versorgungshandlungen,

- pädagogischen Aktivitäten der Sozialpädagogen, Problembelasteten und Problembeteiligten (vgl. Lüssi 1992, S. 93f. und S. 144 dieses Buches),

- therapeutischen Maßnahmen.

Um Soziale Arbeit wissenschaftlich begründet und erfolgreich realisieren zu können, sind Erkenntnisse aus vielen relevanten Wissenschaften notwendig, die in ihrer Bedeutung für den jeweiligen Fall variieren, in jedem Fall aber ein transdisziplinäres Heranund Vorgehen bei der Problembearbeitung erfordern. Bezugswissenschaften sind:

- Anthropologie,

- Biologie (insbesondere Neurologie, Physiologie, Verhaltensbiologie)

- Philosophie (insbes. Wissenschaftstheorie, Erkenntnistheorie, Ethik)

- Soziologie (insbes. Kultursoziologie und Sozialstatistik - einschließlich sozialwissenschaftlicher Forschungsmethoden),

- Rechtswissenschaften (insbes. BSHG, KJHG) und Kriminologie,

- Wirtschaftswissenschaften (insbesondere Betriebswirtschaftslehre und Sozialwirtschaftslehre),

- medizinische Wissenschaften (bei physisch-psychischen Schädigungen, psychischen Erkrankungen und Suchtkrankheiten),

- Psychologie (Entwicklungspsychologie, Lernpsychologie, Psychopathologie, Forensische Psychologie usw.),

- Kommunikationswissenschaften (insbes. Kommunikationspsychologie)

- Psychotherapie, Arbeitstherapie, Spieltherapie usw. , 
- pädagogische Wissenschaften (insbes. Sozialpädagogik, Rehabilitationspädagogik und Freizeitpädagogik),

- Jugendkunde bzw. Jugendforschung,

- Forschungen zur Frauenbewegung,

- Ethnografie und Migrationsforschung

- Gerontologie und Geragogik,

- Politikwissenschaften (insbes. Sozialpolitikwissenschaft) und

- Medienwissenschaften.

Es ist einerseits möglich und notwendig, die juristischen, medizinischen bzw. therapeutischen, soziologischen, psychologischen, pädagogischen, sozial- und verwaltungsrechtlichen, finanzökonomischen usw. Momente der Sozialen Arbeit aus dem Gesamtprozess herauszulösen, um sie unter den Aspekten der jeweiligen Wissenschaftsdisziplinen zu erforschen und zu lehren. Und es ist andererseits möglich, notwendig und teilweise üblich, durch praktische Übungen die Studierenden zur ziel- und situationsgerechten Synthese und Anwendung der angeeigneten Wissenselemente aus den verschiedenen Disziplinen zu befähigen - angefangen mit Fallanalysen und Erörterungen über Problemlösungsmöglichkeiten in Seminaren bis hin zu praxisnahen Übungen unter Anleitung und in angeleiteten sowie ausgewerteten echten Praktikumseinsätzen.

Allerdings würde das vorgeschlagene Vorgehen für den Bereich der Sozialen Arbeit eine Sozialpädagogik erfordern, die das Allgemeine und Wesentliche sozialpädagogischer Prozesse im engeren und eigentlichen Sinne präsentiert. Eine solche Sozialpädagogik muss als echte erziehungswissenschaftliche Disziplin konzipiert werden. Deren Erkenntnisse könnten dann unter Beachtung der typischen Besonderheiten der verschiedenen Arbeitsfelder und unter Einbeziehung der relevanten Bezugswissenschaften konkretisiert und als sozialpädagogische Didaktiken der jeweiligen Arbeits- oder Handlungsfelder entwickelt werden. Für diese Didaktiken lassen sich auf der Grundlage der jeweils typischen Problemstrukturen in den Arbeitsfeldern auch Erkenntnisse aus den verschiedenen Bezugswissenschaften für eine feldzentrierte Synthese relevanter Erkenntnisse finden. Mit dem Wort „Didaktik“ ist hier eine arbeitsfeldbezogene transdisziplinäre sozialpädagogische Wissenschaftsdisziplin gemeint - analog zu den Fachdidaktiken der Schulpädagogik -, die sich mit der Spezifik des jeweiligen Feldes, mit seinen Ziel- und Inhaltsfragen, vor allem aber mit organisatorisch-methodischen Möglichkeiten der psychosozialen Intensiverziehung im jeweiligen Feld der Sozialen Arbeit befasst.

Für das Arbeitsfeld „Kampfzone Straße“ bieten Gaertner und Saad erprobte didaktische Konzepte an wie z. B. die Gefährderansprache (2012, S. 108ff.) oder das Kiezturnier (S. 42ff.), was einer Entwicklungstendenz entspricht, die Mühlum in seinen Betrachtungen ,zur überschaubaren Zukunft der Sozialen Arbeit“ konstatiert: 
„Angesichts der epochalen Umbrüche kann Einzelfallorientierung gewiss nicht die Lösung der Zukunftsprobleme sein. Es wird eine verstärkte Umstellung von der Fallarbeit zur Feldarbeit geben (Hervorhebung von W. N.), die die Lebensräume und sozialen Beziehungen zum Gegenstand hat, womit einmal mehr die Nähe zum systemischen und ökologischen Denken deutlich wird“ (Mühlum 2001, S. 233).

Zudem fordert Mühlum eine „sozial-humanitäre ganzheitliche Sicht“ auf die Soziale Arbeit (2001, S. 64), die sich auch in den Bemühungen um eine einheitliche Wissenschaft für die Soziale Arbeit widerspiegelt. Auf die Diskussionen dazu kann hier nicht näher eingegangen werden. Aber eine kurze Standpunkterklärung ist erforderlich, zumal darüber nachgedacht werden muss, welche Beziehung eine transdisziplinäre Sozialarbeitswissenschaft als Handlungswissenschaft, wie sie die Züricher Schule anstrebt, dann zur hier vorgestellten transdisziplinären Allgemeinen Sozialpädagogik haben könnte. Den führenden Vertretern dieser Schule, Silvia Staub-Bernasconi und Werner Obrecht, geht es bei ihren Bemühungen um das „Theorieideal" eines „Systems von meta-, objekt- und bandlungstheoretischen Theorien" (Obrecht 2009, S. 124). Es ist nicht möglich, alle Momente und Aspekte der Sozialen Arbeit auf all ihren verschiedenen Strukturebenen durch eine Objekttheorie zu erfassen. Aber es erscheint mir möglich und zweckmäßig, auf einer metatheoretischen Ebene eine Sozialarbeitswissenschaft im Sinne einer Methodologie für eine arbeitsfeld- und fallgerechte Integration von Erkenntnissen der Bezugswissenschaften zu entwickeln, um damit Forschungsorientierungen und praktische Handlungsorientierungen wissenschaftlich umfassend begründen zu können.

Verbunden mit einer eindrucksvollen Darstellung zur Geschichte der Sozialen Arbeit und ihrer internationalen Verbreitung bzw. Organisation sowie in kritischer Auseinandersetzung mit verschiedenen philosophischen und wissenschaftstheoretischen Positionen erarbeitete Staub-Bernasconi theoretische Grundlagen für ein Handlungskonzept in Gestalt eines „transformativen Dreischritts“ sozialarbeiterischen Handelns (2007, S. 204-209, 258ff. und 2009, S. 140-143). Die Fundierung besteht darin, dass

1. auf die Untersuchung der sozialen Wirklichkeit (im Sinne einer materialistischen Ontologie) und ihre gesetzmäßigen Zusammenhänge orientiert wird;

2. die gewonnenen Erkenntnisse als Grundlage für die Aufstellung handlungstheoretischer Hypothesen zur Problemlösung dienen, die dann ihrerseits

3. die Formulierung von Handlungsleitlinien ermöglichen.

Wegen ihres Allgemeinheitsgrades tragen die Orientierungshinweise des transformativen Dreischritts den Charakter heuristischer Regeln (oder einer Methodologie?); denn sie eröffnen die Möglichkeit zur differenzierten Nutzung spezieller Erkenntnisse der Bezugswissenschaften, die für die Probleme der Sozialen Arbeit relevant sind, was zugleich den transdisziplinären Charakter der Sozialarbeitswissenschaft begründet. 
Doch unabhängig von der Entwicklung einer Sozialarbeitswissenschaft als Handlungswissenschaft ist in der Praxis für arbeitsfeldübergreifende Fragen der sozialen Arbeit ein differenziertes Unterstützungsmanagement erforderlich. Daher gibt es Gremien und Personen, die auf der Grundlage fachspezifischer Analysen bzw. Diagnosen über den Einsatz der verschiedenen Fachkräfte zur Lösung des jeweiligen Problemfalls beraten bzw. entscheiden und damit Managementfunktionen erfüllen. Solche Gremien sichern, dass ein Fall den zuständigen Helfern zugeordnet wird.

Da sozialpädagogisches Handeln vielfach in Verwaltungshandeln eingebunden ist und die Frage der Zuständigkeit auch finanzielle Bedeutung hat, muss durch die Beschreibung der jeweiligen Problemsituation deutlich werden,

- um welchen Typus von Problemfall es sich handelt,

- welchen Fachleuten er zur Behandlung zugeordnet werden sollte und

- was mit welchem Problembelasteten brw. -beteiligten zweckmäßigerweise zu tun ist (vgl. B. Müller 1994, S. 28ff.).

Solche und ähnliche disziplinübergreifenden Aufgabenstrukturen im Zusammenhang mit allgemeinen Prinzipien für das Heran- und Vorgehen in Problemlösungsprozessen könnten Bestandteile einer Managementwissenschaft für die Soziale Arbeit sein, die in der Lage ist, Mühlums Forderung zu erfüllen, den Sozialarbeitern „,verstärkt sozialorganisatorische Kompetenzen“ zu vermitteln (Mühlum 2001, S. 234).

In der Ausbildung von Sozialarbeitern wird diesen Anforderungen z. T. schon im hohen Maße entsprochen. Das belegen z. B. die von der Berner Fachhochschule veröffentlichten „Aufgaben der Sozialen Arbeit“ zwecks Orientierung und Charakterisierung des Berufsprofils für den Studiengang „Bachelor in Sozialer Arbeit“ (vgl. S. 272f. in den Anlagen). Die dort vorgestellte Aufgabenübersicht macht deutlich, welchen Wert den Fähigkeiten zur Kommunikation und Information, zur Planung, Organisation, Koordinierung, Kooperation, Auswertung und Dokumentation von Hilfeprozessen beigemessen wird. Die in der Übersicht aufgelisteten Aufgaben, insbesondere auch die Managementaufgaben und die Aufgaben im Bereich der Öffentlichkeit, lassen ferner erkennen, wie umfassend und differenziert Soziale Arbeit gesehen wird.

Eine Managementwissenschaft von der Sozialen Arbeit ist zweifellos für den Praxisbereich in seiner Ganzheit notwendig. Die Ausführungen von Silvia Staub-Bernasconi zu den Aufgaben und Hauptmitteln des Sozialmanagements (2007, S. 286) präsentieren eine vielfach geforderte ganzheitliche Sicht auf die Soziale Arbeit, wenn diese Sicht auch primär ökonomisch und organisatorisch geartet ist. Die persönlichen Schwächen der Klienten werden dabei nicht gleichermaßen ganzheitlich und theoretisch differenziert betrachtet. Daher ist der Managementbegriff auch nicht geeignet, um als „Oberbegriff“ die „direkte Arbeit mit den Adressat(inn)en“" zu erfassen (vgl. Staub-Bernasconi 2007, S. 151). 


\subsection{Zur Neubestimmung der Sozialpädagogik}

$\mathrm{Zu}$ den Ausgangsbedingungen einer Neubestimmung der Sozialpädagogik und ihres Gegenstandes gehört zunächst einmal eine Charakteristik des bisher erreichten Klärungsprozesses. Werner Thole beschreibt ihn wie folgt:

„Die Identität der Sozialpädagogik scheint bis zum heutigen Tage ihre Nicht-Identität zu sein: Sie hat keinen eindeutigen, klar zu benennenden Ort in der Praxis, kein einheitliches Profil der Ausbildung, keine selbstverständliche, von allen ihren VertreterInnen geteilte disziplinäre Heimat, keine stabilen theoretischen, wissenschaftlichen und professionellen Grundannahmen. Im Kern scheint nicht einmal hinreichend geklärt, welcher Art die Theorie zu sein hat, die die Sozialpädagogik braucht" (Thole 2002, S. 26).

Einer von vielen Belegen für das Fehlen von „stabilen theoretischen, wissenschaftlichen Grundannahmen“ ist in der "Zeitschrift für pädagogische Historiographie“ Nr. 1/2005 zu finden, in der Carsten Müller unter der Überschrift „Sozialpädagogik als Bürgererziehungswissenschaft" auf Magers Auffassung von Sozialpädagogik zurückgreift. In Anbetracht der Tatsache, dass sich in der heutigen Gesellschaft die Tendenzen zum Individualismus im Vergleich zum 19. Jahrhundert eher noch verstärkt haben, erscheint es zunächst plausibel, Magers Idee einer Sozialpädagogik als „Gegenkraft" zur Individualpädagogik wieder aufzugreifen. Gegen die von Müller formulierte pädagogische Zielstellung, „Menschen zu Bürgern zu erziehen, welche die Angelegenheiten des Gemeinwesens in eigene und gemeinsame Hände nehmen“ (a. a. O., S. 5), ist auch nichts einzuwenden. Es ist nur die Frage, ob es dafür einer Sozialpädagogik im Sinne einer Bürgererziehungswissenschaft bedarf, weil es sich ja um Aufgaben handelt, für die schon mehrere Einrichtungen zuständig sind (allgemeinbildende Schulen, Jugendfreizeitzentren, Volkshochschulen usw.) und für die es entsprechende pädagogische Disziplinen gibt. Das bedeutet: Müllers Zielformulierung muss mehr oder weniger von jeder pädagogischen Disziplin und in allen Erziehungsbereichen beachtet werden; im Übrigen findet sie in bestimmten Praxisbereichen der Erziehung ohnehin schon schwerpunktmäßig Beachtung, z. B. in Veranstaltungen zur Politischen Bildung oder in Volkshochschulen, sofern sich diese auch noch ihrer ursprünglichen Funktion verpflichtet fühlen.

Müllers Vorschlag berücksichtigt nicht den Systemzusammenhang realer Erziehungsprozesse, der für die Bestimmung des Gegenstandes jeder einzelnen Disziplin bedeutsam ist, und lässt eine Reflexion über die Kriterien pädagogischer Disziplinbildungen vermissen, so dass die Hauptursachen für den von Thole beklagten Zustand fortbestehen.

Um einer Lösung des Problems näher zu kommen, ist ein Exkurs in die Konstituierungskriterien pädagogischer Disziplinen notwendig. Pädagogische Erkenntnisse lassen sich unter verschiedenen Aspekten zu Disziplinen strukturieren: 
1. entsprechend den weltanschaulichen und philosophisch-methodologischen Grundlagen ihrer Gewinnung und Interpretation,

2. entsprechend der Sichtweise im Herangehen an Erziehung und

3. entsprechend des interessierenden Ausschnitts aus dem Objektbereich Erziehung. Diese Möglichkeiten lassen sich auf Pädagogiken anwenden, die für einzelne Länder, Religionen, Konfessionen und politische Systeme entwickelt werden, und sie widerspiegeln sich zugleich - wenn auch in unterschiedlicher Weise - in den nachfolgend genannten pädagogischen Disziplinen. Als Beispiele für die 1. Gruppe seien hier nur genannt:

- Geisteswissenschaftliche Pädagogik,

- Neopositivistische Pädagogik,

- Rationalistische Pädagogik,

- Experimentelle Pädagogik,

- Phänomenologische Pädagogik,

- Existenzphilosophische Pädagogik,

- Anthropologische Pädagogik,

- Religionsphilosophische Pädagogik,

- Systemtheoretische Pädagogik,

- Praxeologische Pädagogik,

- Psychoanalytische Pädagogik,

- Dialektisch-materialistische Pädagogik.

Für die 2. Gruppe lassen sich folgende Beispiele angeben:

- Systematische Pädagogik,

- Historische Pädagogik,

- Vergleichende Pädagogik.

Für die 3. Gruppe lassen sich praktisch bedeutsame Ausschnitte aus der Erziehungswirklichkeit mittels verschiedener Konstituierungskriterien finden. So kann z. B. eine Disziplinbildung erfolgen in Abhängigkeit von

- der jeweiligen Organisationsform (Institution), in der Erziehung stattfindet:

- Familienpädagogik (in der Institution Familie),

- Kindergartenpädagogik,

- Schulpädagogik,

- Hochschulpädagogik,

- Militärpädagogik, 
- Betriebs- oder Wirtschaftspädagogik,

- Museumspädagogik,

- Vereinspädagogik

- $\quad$ oder den jeweils spezifischen Zielen und entsprechenden Inhalten, z. B.:

- Musikpädagogik,

- Ingenieurpädagogik,

- Fachdidaktiken für den Biologieunterricht, den Physikunterricht, den Deutschunterricht usw.,

- Religionspädagogik,

- Freizeitpädagogik

- oder den jeweils hauptsächlich genutzten Mitteln, z. B.:

- Arbeitspädagogik,

- Medienpädagogik,

- Erlebnispädagogik

- oder der jeweiligen Altersgruppe der Zöglinge, also:

- Pädagogik des Kindesalters,

- Pädagogik des Jugendalters,

- Erwachsenenpädagogik,

- Geragogik.

Außer den bisher genannten systembildenden Merkmalen pädagogischer Disziplinen gibt es noch weitere Möglichkeiten, um das System der Erziehungswissenschaften zu differenzieren und auszubauen. So kann z. B. auf systembildende Relationen der immanenten Momente zurückgegriffen werden, etwa auf die Zöglings-Ziel-Relation. Beispielsweise sind die Disziplinen der Rehabilitations- oder Behindertenpädagogik abhängig von den Behinderungen der Zöglinge (Blinde, Sehschwache Gehörlose, Schwerhörige, Taubstumme usw.) und mit dem Ziel ihrer weitgehenden Kompensation verknüpft. Entscheidend für die Konstituierung einer Pädagogik für Blinde und Sehschwache war also nicht eine Institution (Blindenanstalt oder Schule), sondern eine spezifische ZöglingsZiel-Relation. Darauf bezogene Erkenntnisse können auch von Hauslehrern oder Fachkräften in Blindenwerkstätten genutzt werden.

Verallgemeinernd lässt sich sagen: Jeweils spezifische Zöglings-Ziel-Relationen bedingen verschiedene pädagogische Disziplinen; so ergibt sich z. B.

- eine Vorschulpädagogik, die hilft, Vorschulkinder zur Schulreife zu führen, wobei natürlich auch weitergehende Ziele eine Rolle spielen, 
- $\quad$ eine Schulpädagogik, die hilft, Schülerinnen und Schülern eine grundlegende, wenn auch schulformspezifische Allgemeinbildung zu vermitteln,

- eine Berufspädagogik, die hilft, Auszubildenden eine berufliche Qualifikation zu vermitteln,

- $\quad$ eine Hochschulpädagogik, die hilft, Studierende (die als Voraussetzung über eine entsprechende Hochschulreife oder Studierfähigkeit verfügen) zu einem anerkannten Hochschulabschluss zu führen.

Es ist unter dem Gesichtspunkt der Zöglings-Ziel-Relation auch zu prüfen, ob es nicht notwendig und zweckmäßig ist, eine Migrations- oder Integrationspädagogik zu entwickeln. Hierbei geht es darum, einer definierten Zielgruppe (Einwanderungswillige und Asylsuchende) die erforderliche Sprachkompetenz zu vermitteln und sie mit notwendigen verfassungsrechtlichen und juristischen Kenntnissen, mit den kulturellen und ethischen Werten des Einwanderungslandes vertraut zu machen usw. Eine Übertragung dieser Aufgabenvielfalt an Sozialpädagogen ist nicht zweckmäßig, weil sie normalerweise nicht zugleich Lehrer für die zu erwerbende Landessprache, für Verfassungsund Sozialkunde, für Landesgeschichte, Kunst, Ethik usw. sind. Außerdem ist es für Migranten - vor allem für gebildete - sicherlich nicht angenehm, als Klient eines Sozialpädagogen betrachtet zu werden, der es im Prinzip mit sozial Auffälligen zu tun hat. Schon Hans Jochen Gamm stellte in einem anderen Zusammenhang kritisch fest:

„Der massenhafte Einzug ausländischer Arbeitskräfte in die Bundesrepublik ist zu keinem Zeitpunkt bildungspolitisch bearbeitet worden“ (Gamm 1997, S. 125).

Über praktische Erfahrungen mit den schwerwiegenden Auswirkungen dieses Mangels hat z. B. die ehemalige Direktorin der Rütli-Schule in Berlin-Neukölln, Brigitte Pick, in ihrem Buch 2007 eindrucksvoll berichtet.

Eine pädagogische Disziplin widerspiegelt und rekonstruiert ideell, d. h. mit Begriffen (in Form von Worten), Aussagen (bzw. Aussagesätzen) und Normen (bzw. Muss-, Soll-, Darf- und Kann-Sätzen) ein System der immanenten Momente mit ibren Funktionen aus der Erziehungswirklichkeit unter dem Aspekt einer spezifischen Zöglings-Ziel-Relation. Untersuchungen und Darstellungen zu jedem immanenten Moment und seiner Funktionsweise erfordern auch die Nutzung von Erkenntnissen anderer Wissenschaftsdisziplinen (z. B. der Biologie, Soziologie, Ethik, Psychologie und der Wissenschaften, die die Lerninhalte liefern). Daraus resultiert der transdis₹iplinäre Charakter pädagogischer Disziplinen, der bisher von der Allgemeinen Pädagogik kaum reflektiert worden ist.

Wenn wir die Zöglings-Ziel-Relation für die Bestimmung der Sozialpädagogik als erziehungswissenschaftliche Disziplin nutzen wollen, müssen wir geeignete gemeinsame und damit systembildende Merkmale der Zielgruppen bzw. Zöglinge finden, was wegen der Unterschiedlichkeit der Problembelasteten schwierig ist, denn es geht um 
- Kinder, die unter Deprivation leiden, also solche, denen die Befriedigung elementarer Bedürfnisse nach Pflege und sozialer Zuwendung versagt wird;

- Kinder in Kindertagesstätten, die bereits durch Vernachlässigung oder Verwöhnung in ihrer Familie große Schwierigkeiten haben im Umgang mit anderen Kindern bzw. mit der Einordnung in ein Gruppenleben;

- Schüler, die durch schulaversives Verhalten auffallen (z. B. fortgesetztes Stören des Unterrichts und Schulschwänzen);

- Kinder und Jugendliche, die durch auffälliges und dissoziales Verhalten (z. B. Diebstähle, Gewalttätigkeiten oder Suchtabhängigkeit) Schwierigkeiten haben;

- benachteiligte Jugendliche, die durch Schulversäumnisse und den Abbruch der Lehre Schwierigkeiten haben, eine Berufsausbildung erfolgreich abzuschließen;

- „entwurzelte“"Jugendliche im betreuten Wohnen bzw. in Wohngemeinschaften;

- Personen, die durch Überschuldung in Not geraten sind;

- Arbeits- und Obdachlose bzw. Nichtsesshafte unterschiedlichen Alters;

- suchtabhängige Personen, die nicht in der Lage sind, selbständig ein einigermaßen geordnetes und gelingendes Leben zu führen, vielfältige Schwierigkeiten haben und auch für ihre Angehörigen belastend geworden sind;

- straffällig gewordene Personen, die in Justizvollzugsanstalten sozialpädagogisch betreut werden oder Bewährungshilfe benötigen;

- Kinder und Frauen, die unter Misshandlungen und Gewalttätigkeiten durch Angehörige bzw. Partner leiden;

- Personen, die infolge ihrer physiologischen und/oder psychischen Beeinträchtigungen nicht in der Lage sind, ihren Alltag selbständig zu bewältigen, und demzufolge über eine rehabilitationspädagogische, juristische bzw. pflegerische Betreuung hinaus noch sozialpädagogische Lebens- und Integrationshilfe benötigen.

Diese Aufzählung kann sicherlich noch ergänzt werden. Sie lässt aber schon erkennen, dass es sich stets um Personen handelt, die in irgendeiner Weise mit ibrem Leben nicht zurechtkommen. Es sind also solche, die sich und/oder andere gefährden und schädigen und/oder gefährdet und geschädigt sind, deshalb auch nicht nur materielle, sondern vor allem psychosoziale Hilfe benötigen, auch wenn sie nicht immer aktiv als Hilfesuchende auftreten. Ausgehend von o. g. Erscheinungsbildern wurden Schwächen oder Defizite in der Sozialerziehung als wesentliche Gründe für die Entwicklung der Sozialpädagogik angesehen (vgl. Wollenweber 1978, S. 108; Mühlum 2001, S. 57 ff.).

Die sozialen Spannungen und Konflikte in der Entwicklung der Gesellschaft und im Zusammenleben der Menschen sollten nach verbreiteter Auffassung mit einer verstärkten Erziehung zu angepasstem sozialen Verhalten gelöst oder wenigstens gemildert werden. 
Sozialerziehung im Sinne der Erziehung für die Gemeinschaft und durch die Gemeinschaft war beispielsweise für Natorp ein Konstituierungskriterium und Wesensmerkmal der Sozialpädagogik.

Auch Nohl meinte, mit Hilfe der Sozialpädagogik und einem ihr zugeordneten dritten Bereich der Erziehung (neben der Familie und Schule) die sozialintegrativen Momente im gesellschaftlichen Erziehungsprozess stärken zu können - deshalb sein Engagement für sozialfürsorgerische und sozialpflegerische Einrichtungen und Regelungen, die 1922 grundlegend im Reichsjugendwohlfahrtsgesetz fixiert wurden. Auch bei jüngeren Autoren kreist die Diskussion um die Entwicklung der Sozialpädagogik immer wieder um die Sozialerziehung als die Disziplin bestimmende Erscheinung.

„Die Sozialpädagogik hat nach Röhrs die »sozialerzieherische Fragestellung als Kern der Erziehung zentraler in ihre kritischen Klärungsversuche (einzubeziehen). Ihre eigentlichen Aufgabenfelder liegen indes dort, wo diese aller Erziehung in Schule und Öffentlichkeit eigene sozialerzieherische Funktion aus den verschiedenen Gründen versagt«" (Wollenweber 1978, S. 109).

In diesem Zitat ist folgende Aussage bemerkenswert: Die „eigentlichen Aufgabenfelder“ der Sozialpädagogik liegen dort, wo die sozialerzieherische Funktion aller Erziehung versagt. Wirkungen des Versagens äußern sich in devianten Verhaltensweisen der Zöglinge. Aber deviante Verhaltensweisen sind keineswegs nur Folge versagender Sozialerziehung, sondern ebenso auch Folge unzureichender Individualerziehung. Wie sollte man sonst z. B. solche Erscheinungen wie Magersucht oder Selbstverletzungen durch sog. Ritzen erklären? Hierbei geht es offenbar darum, dass diesen Problembelasteten die notwendige Ich-Stärke oder Selbstkompeten₹, das notwendige Selbstwertgefühl und Selbstbewusstsein fehlen, so dass sie meinen, sich durch solche selbstschädigenden Handlungen gegenüber ihrer Umwelt als zuwendungsbedürftig ausweisen zu müssen. Dass individuelle Schädigungen im Zusammenhang stehen mit gestörten Sozialbeziehungen, ist bekannt (durch Selbstverletzungen fordern Personen mit Borderline-Syndrom auch fürsorgliche Zuwendung ein), aber gerade für die Normalisierung der Sozialbeziehungen ist allgemein die Stärkung des Selbstvertrauens und des Selbstwertgefühls der Problembelasteten durch eine Akzentuierung der Individualerziebung wichtig.

Eine Begründung der Sozialpädagogik mit Erfordernissen einer verstärkten Sozialerziehung läuft Gefahr, im Problembelasteten primär einen sozialen Störenfried zu sehen, und beachtet dabei zu wenig, dass dieser mit sich selbst Schwierigkeiten hat. Offenbar wird von manchen Vertretern der zitierten Auffassung nicht genügend bedacht, dass jeder Erziehungsprozess sozialerzieherische und individualerzieherische Wirkungen hat, d. h., Erziehung muss den ganzen Menschen als biopsychosoziokulturelle Einheit im Blick

9 Vgl.: lateinisch: devertere $=$ abkehren, abwenden; französisch: déviance $=$ auffällige oder von der Norm abweichende Verhaltensweise. 
haben und dabei berücksichtigen, dass seine autogenen Kräfte als vermittelnde Glieder in der Dialektik von endogenen und exogenen Faktoren den Gesamtprozess der Persönlichkeitsentwicklung wesentlich determinieren. Allerdings können diese autogenen Kräfte z. B. bei neurologischen Defekten - auch ausfallen oder unzureichend funktionieren. Diese Argumente machen deutlich, dass eine Wirkungsrichtung der Erziehung, die sog. Sozialerziehung, für die Begründung der pädagogischen Disziplin Sozialpädagogik ungeeignet ist. Auf diesen Sachverhalt hat bereits Buchka deutlich hingewiesen (vgl. Badry, Buchka, Knapp 1994, S. 140).

Bei näherer Betrachtung lassen sich in der oben angegebenen Aufzählung möglicher Klienten drei Gruppen unterscheiden:

1. Personen, die als Opfer ihrer Lebensumstände, Entwicklung und/oder Veranlagung in solche Schwierigkeiten geraten sind, dass sie sozialpädagogische Hilfe benötigen, z. B. unter Deprivation leidende Kinder, Misshandelte, physisch bzw. physiologisch oder psychisch Beeinträchtigte (Blinde, Taubstumme usw.), verlassene, vereinsamte und hilflose Singles - kurzum: Problembelastete;

2. Personen, die als Täter durch deviantes Handeln und Verhalten andere und sich selbst schädigen, also im Grunde genommen auch Problembelastete sind;

3. Personen, die als Problembeteiligte unter der Hilflosigkeit und/oder den abweichenden Verhaltensweisen ibrer Mitmenschen leiden, wobei im konkreten Fall zu prüfen ist, inwieweit sie auch Mitverursacher sind.

In der Praxis ist die Zuordnung der Hilfebedürftigen zu einer Gruppe oft nicht möglich, weil sich Opfer, Täter und Leidender häufig in ein und derselben Person vereinigen; z. B. gibt es die alleinerziehende Mutter aus dissozialen Familienverhältnissen (also als Opfer), die ihr Kleinkind vernachlässigt (also als Täterin) und zugleich von ihrem ehemaligen Lebenspartner misshandelt worden ist (abermals Opfer und Leidende), wobei Letztgenannter häufig auch nicht nur Täter ist, sondern seinerseits wiederum unter Arbeitslosigkeit mit ihren Folgen leidet. Jeder Problembelastete muss daher hinsichtlich seiner Rolle(n) in der jeweiligen sozialen oder sozialpädagogischen Problemsituation betrachtet werden. Für die Klienten von Sozialpädagogen ist charakteristisch, dass sie in irgendeiner Weise durch deviante Handlungs- und Verhaltensweisen belastet sind.

Wenn hier der Begriff des „devianten Verhaltens“ verwendet wird, dann deshalb, um das systembestimmende Merkmal zu nennen, das in unterschiedlicher Ausprägung und Konstellation eine Rolle spielt. Historisch betrachtet wurde der Begriff des devianten Verhaltens vielfach als Synonym für „delinquentes“ oder „kriminelles Verhalten“ verwendet, das zugleich zur Grundlage einer Kriminal- oder Devianzpädagogik ${ }^{10}$ gemacht wurde. Allerdings ist das in diesen Konzepten vertretene Begriffsverständnis

10 Vgl. Artikel zum Stichwort „Devianzpädagogik“von Hans-Joachim Plewig im „Lexikon der Sozialpädagogik und der Sozialarbeit.“ Hrsg.: Franz Stimmer. R. Oldenbourg Verlag. München/Wien 2000. 
von Devianz unscharf, denn es gibt auch Arten des sozialen und psychischen Verhaltens, die zwar deviant, aber nicht kriminell oder delinquent sind; z. B. Ess-Störungen, die zur Magersucht führen, Selbstverletzungen durch sog. Ritzen oder auch unzureichende Fähigkeiten im Umgang mit Geld bzw. Kaufsucht, was zur Überschuldung führen kann und dann existenzbedrohend wird. Aus diesen Gründen muss der Devianzbegriff wesentlich weiter gefasst werden als der Begriff der Delinquenz. Kriminologen beschäftigen sich mit dem Devianz- oder Delinquenzproblem unter dem Aspekt von Verstößen gegen Rechtsnormen und der Bekämpfung solcher Verstöße im Sinne der Verhinderung oder Reduzierung von Kriminalität. Sozialpädagogen dagegen interessiert vor allem die Frage: wie kann den Problembelasteten geholfen werden, damit sie mit den Folgen ibres abweichenden Handelns fertig werden und Wiederholungen vermeiden?

Die angedeuteten Beispiele lassen erkennen, dass Devianz nicht mit Verwahrlosung identisch ist. Verwahrlosung würde - wenn wir dieses Wort denn überhaupt verwenden würden - nur eine Variante von Devianz bezeichnen und wäre zudem mit dem Problem behaftet, generell diffamierend zu wirken; außerdem wird darunter recht Unterschiedliches verstanden, manchmal sogar ein berechtigtes Protestverhalten gegenüber repressiven und inhumanen Verhältnissen.

Die Soziologie unterscheidet zwischen progressiver (voranbringender) und regressiver (zerstörerischer) Devianz. Progressive Devianz zielt auf Veränderung historisch oder moralisch überholter Verhaltensweisen und Verhältnisse; denken wir z. B. an Luthers Ablehnung des Ablasshandels und die durch ihn initiierte Reformation oder an die Vertreter der 68er Bewegung, die mit ihrem devianten Auftreten konservative Denkweisen überwinden halfen, auch wenn nicht alle ihre Forderungen und Lebenspraktiken akzeptiert werden können. Regressive Devianz ist ihrem Wesen nach zerstörerisch; sie schädigt zumeist nicht nur die Gesellschaft oder Einzelne ihrer Mitglieder, sondern auch die Täter selbst, wie das beispielsweise bei beschaffungskriminellen Drogensüchtigen zu beobachten ist.

Weiterhin unterscheidet man zwischen primärer und sekundärer Devianz. Bei der primären Devianz handelt es sich um einmalige oder nur gelegentliche Abweichungen von anerkannten Normen. Sekundäre regressive Devianz liegt vor, wenn sich die betreffenden Personen allen andersartigen Orientierungen mehr oder weniger hartnäckig widersetzen und schwer zugänglich sind für Alternativen in ihrem praktizierten Verhalten und Handeln, so dass nicht nur von Unerfahrenheit, Gedankenlosigkeit oder Nachlässigkeit, sondern von schlechten Gewohnheiten, dissozialer Lebensweise, krankhaften Verhaltensstörungen, kriminellen Neigungen o. Ä. gesprochen werden muss, denen die jeweiligen Erzieher, Mitmenschen oder Vorgesetzten hilflos gegenüberstehen. Wenn in den nachfolgenden Darstellungen von Devianz gesprochen wird, so ist damit eine Form von sekundärer 
(relativ verfestigter) regressiver sozialer und psychischer Devianz gemeint, sofern nicht ausdrücklich etwas anderes vermerkt wird.

Die Verwendung des Begriffs der Abweichung - speziell der sekundären regressiven sozialen Devianz - ist natürlich mit der Frage verbunden: Welche Norm, von der abgewichen wird, liegt der Bewertung zugrunde? Wenn im sozialen Bereich von Normen die Rede ist, dann handelt es sich ja nicht um „messbare Größen“, sondern um soziokulturelle Forderungen und Erwartungen, die von den Mitgliedern der Gesellschaft, für die sie gelten, erfüllt werden sollen. Dabei ist zu beachten, dass je nach Charakter der Norm und dem Normenverständnis ihrer Verfechter unterschiedliche Toleranzen existieren. Damit deutet sich schon ein subjektiver Faktor an, der in dem, was eine soziokulturelle Norm fordert, enthalten ist. Eine wesentliche Ursache dafür liegt im jeweils verwendeten Normbegriff bzw. in der Auffassung darüber, was normgerecht oder normal ist. Drei mögliche Auffassungen lassen sich unterscheiden:

1. Als normal gilt, was die meisten Menschen regelmäßig tun und für zweckmäßig halten; es handelt sich dann um ein sog. durchschnittliches Verhalten in einer gegebenen Population, das auch die Abweichungen - die im vertretbaren Rahmen liegen - durch gewisse Toleranzgrenzen mit erfasst.

2. Als normal wird das betrachtet, was die Gesellschaft erwartet, weil es wünschenswert erscheint oder gesetzlich verlangt wird. Diese Erwartungen, die sich in soziokulturellen Normen ausdrücken, widerspiegeln die jeweiligen „historisch gewachsenen" und sich wandelnden Wertvorstellungen der Gesellschaft; sie liegen auch dem zugrunde, was die meisten Menschen „für richtig halten“, und begründen damit annähernd das o. g. durchschnittliche Verhalten der Gesellschaftsmitglieder.

3. Als normal kann auch ein übliches oder gewohnheitsmäßiges individuelles Verhalten angesehen werden und als unnormal demzufolge eine auftretende Abweichung, mit der man bei dem Betreffenden nicht gerechnet hat. Die individuellen Normen beruhen nicht nur auf Gewohnheiten, sondern bringen auch individuelle physiologische, kulturelle u. a. Bedürfnisse zum Ausdruck, z. B. Bedürfnisse nach Aktionen oder Ruhe, nach Unterhaltung, Abwechslung usw.

Die traditionelle Devianzforschung geht von einem „normativistischen Wirklichkeitsverständnis“ aus (Herriger 1979, S. 147), d. h., sie unterstellt ein in der Gesellschaft existierendes allgemeingültiges Normensystem im Sinne von Punkt 2, nach dem sich auch die Mehrheit richtet (Punkt 1), und wer dagegen verstößt, verhält sich deviant. Im 20. Jahrhundert wurde ein Herangehen an das Devianzproblem entwickelt, das von einem „subjektivistischen Bild sozialer Wirklichkeit“ (a. a. O., S. 149) ausgeht.

„Gemäß der ersten Strategie ist deviantes Verhalten ein Handeln, das objektiv eine Norm verletzt. Gemäß der zweiten Strategie ist deviantes Verhalten ein Handeln, das durch andere als 
eine Norm verletzend wabrgenommen wird“ (Wheeler 1966, S. 607; zitiert nach Herriger 1979, S. 149/150).

$\mathrm{Ob}$ ein Verhalten als deviant angesehen wird, hängt also von den Erwartungen und Wabrnehmungen der jeweiligen Gruppe oder Gemeinschaft bzw. ibren Kontrollinstanzen (und damit von deren Wertvorstellungen und Normen) ab. Daraus folgern die Vertreter der Labeling-Theorie (Etikettierungstheorie):

„Gesellschaftliche Gruppen (schaffen) abweichendes Verhalten dadurch (...), daß sie Regeln aufstellen, deren Verletzung abweichendes Verhalten konstituiert, und daß sie diese Regeln auf bestimmte Menschen anwenden, sie zu Außenseitern abstempeln“ (Becker 1973, S. 8; zitiert nach Herriger 1979, S. 153).

So interessant manche Ergebnisse von empirischen Untersuchungen der Etikettierungstheoretiker für die Entstehung und vor allem für die Verfestigung devianter Persönlichkeitsstrukturen sein mögen, so trifft wohl auch hier zu: das bloße Gegenteil von einem Fehler (dem unhistorischen normativen Wirklichkeitsverständnis) in Form des subjektivistischen Wirklichkeitsverständnisses ist wieder ein Fehler. Denn trotz der Wandelbarkeit und Relativität gesellschaftlicher Normen wegen ihres historischen Charakters und ihrer (oft unbewussten) Abhängigkeit von Klassen-, Schichten- und Gruppeninteressen kann bei vielen Normen eine objektive Grundlage in Gestalt existenzieller menschlicher Bedürfnisse gefunden werden (siehe Abschnitt 4.3). Es ist also jeweils zu prüfen, ob es sich um Normen handelt, deren Anwendung geeignet ist, die Existenz und die Entwicklung der Menschbeit und des Einzelnen zu fördern oder zu schädigen (vgl. S. 201f.).

Aber selbst dann, wenn eine Norm als allgemeingültig anerkannt wird, ist sie vielfach noch weiterhin ,aushandlungsbedürftig“, d. h., sie muss „problem- und situationsspezifisch ausgelegt werden“ (Herrig 1979, S. 148). Ein wesentliches Merkmal der Objektivität vieler gesellschaftlicher Normen besteht darin, dass im Falle ihrer Verletzung ein Schaden bei den Opfern deviant handelnder Täter und/oder bei diesen selbst feststellbar ist, so dass sie dann als Problembelastete erscheinen - siehe z. B. den beschaffungskriminellen Drogensüchtigen, der andere und sich selbst schädigt.

Es mag etwas befremdlich anmuten, dass recht unterschiedliche Personengruppen zu den Problembelasteten gehören, mit denen es Sozialpädagogen zu tun haben, z. B.:

a) Personen, die durch ihr regressives deviantes soziales Verhalten (z. B. Aggressivität, Diebstahl, Suchtverhalten, Schul- und Arbeitsbummelei, Vernachlässigung von Familienangehörigen, insbesondere von Kindern) andere und/oder sich selbst schädigen bzw. gefährden.

b) Personen, die sich wegen physisch-psychischer Schädigungen, geistiger Behinderung oder psychischer Erkrankung selbst gefährden könnten, daher zusätzlich zu rehabilitationspädagogischen Maßnahmen sozialpädagogisch betreut werden. 
Auf den ersten Blick scheint es außer den beobachtbaren Abweichungen oder Auffälligkeiten keine inneren oder psychischen Gemeinsamkeiten zwischen diesen Personen zu geben, die ihre Zuordnung zur Zielgruppe der psychosozialen Intensiverziehung rechtfertigen würden. Betrachten wir sie jedoch vom Standpunkt individualpsychologischer Erkenntnisse, dann finden wir bei den Vertretern beider Gruppen - wenn auch aus unterschiedlichen Ursachen resultierende und in unterschiedlicher Ausprägung auftretende - charakteristische psychische und soziale Besonderheiten, nämlich ein mehr oder weniger bewusstes Leiden und hilfloses Agieren unter dem Einfluss von Minderwertigkeitskomplexen - häufig auch in Verbindung mit einem problematischen Lebensstil und zumeist mit hohen Belastungen für sich und andere.

Bekanntlich sind kleine Kinder hilflos und daher auf die Pflege und Unterstützung von Erwachsenen angewiesen. Alfred Adler (1870-1937) beschreibt die psychische Situation von Kindern mit den Worten:

„Das Gefühl der Minderwertigkeit, der Unsicherheit, der Unzulänglichkeit ist es, das die Zielsetzung im Leben erzwingt und ausgestalten hilft. Bereits in den ersten Tagen der Kindheit macht sich der Zug bemerkbar, sich in den Vordergrund zu drängen, die Aufmerksamkeit der Eltern auf sich zu lenken, zu erzwingen. Das sind erste Anzeichen für das erwachende Geltungsstreben des Menschen, das sich unter der Einwirkung des Minderwertigkeitsgefühls entwickelt und das Kind dazu führt, sich ein Ziel zu setzen, bei dem es der Umwelt überlegen erscheint" (Adler 1991, S. 73).

Die unterschiedlich verursachten Minderwertigkeitsgefühle sind unvermeidlich und sogar nützlich, da sie als Triebkräfte für eigene Bemühungen und Anstrengungen wirken. Problematisch wird es nur dann, wenn das Kind keine Möglichkeit erhält, durch sozial akzeptierte erfolgreiche Bemühungen die jeweiligen Minderwertigkeitsgefühle zu überwinden. Adler meint:

„Jeder Mensch hat, wie wir gesagt haben, ein Minderwertigkeitsgefühl. Aber das Minderwertigkeitsgefühl ist keine Krankheit, es ist vielmehr ein Anreiz zu einem gesunden, normalen Streben und einer normalen Entwicklung. Es wird nur dann zu einem pathologischen Zustand, wenn das Gefühl der Unzulänglichkeit den Menschen überwältigt und, weit davon entfernt, ihn zu nützlicher Aktivität anzustacheln, ihn bedrückt und ihn zu einer Entwicklung unfähig macht. Der Minderwertigkeitskomplex bezeichnet die Stellungnahme eines Menschen, der dadurch ausdrückt, daß er nicht in der Lage ist, ein vorliegendes Problem zu lösen. Der Minderwertigkeitskomplex ist die Darstellung eines Menschen, aus der er sich und anderen erklärt, nicht stark genug zu sein, um ein bestimmtes Problem in sozial wertvoller Weise zu lösen“ (Ansbacher/Ansbacher 1982, S. 247).

Was Adler hier über die mit Minderwertigkeitskomplexen belasteten Menschen sagt nämlich die Unfähigkeit „ein bestimmtes Problem in sozial wertvoller Weise“ zu lösen -, 
ist jenes zentrale Merkmal, auf das Sozialpädagogen bei ihren Problembelasteten stoBen, und zwar sowohl bei manchen physisch oder psychisch Beeinträchtigten als auch bei sog. Normalen oder Gesunden. Dabei ist zu berücksichtigen, dass psychisch beeinträchtigten Personen selbst einfache Aufgaben als Probleme erscheinen, die sie nicht ohne fremde Hilfe lösen können. Es ist in der Regel ein kompliziertes Geflecht von biotischen, sozialen, psychischen und kulturellen Faktoren, das zur Entstehung von Minderwertigkeitskomplexen führt, die sich häufig in Hilflosigkeit und in regressiven devianten Verhaltensweisen äußern.

Diese Erkenntnisse der Individualpsychologie, die in der Humanistischen Psychologie aufgehoben sind und auch von der dialektisch-materialistischen Pädagogik aufgegriffen werden können, verweisen auf das gemeinsame psychologische Charakteristikum der Problembelasteten, mit denen es Sozialpädagogen zu tun haben: auf die Minderwertigkeitskomplexe mit ihren Folgen in der Entwicklung, im Lebensstil und im Verbalten der Betreffenden, also:

- Unsicherheit, Zaghaftigkeit, Überempfindlichkeit, Kontaktarmut, Hilflosigkeit, Ausweichverhalten, Neigung zu Depressionen oder

- Selbstüberschätzung, Macht- und Dominanzstreben, Gewaltbereitschaft und Neigung zu aggressivem Handeln.

Eine Sonderstellung nehmen hilflose Senioren ein, wenn sie denn ursprünglich ein selbständiges Leben geführt haben. Bei ihnen spielen spezifische Alterserscheinungen (soziale Isolierung, Senilität, Alzheimer) eine entscheidende Rolle für die Entstehung der Hilfebedürftigkeit. Es ist daher auch zu fragen, ob sie zurecht als Problembelastete der Sozialpädagogik zugeordnet werden können oder ob nicht die Geragogik für sie zuständig ist. Demzufolge kann und sollte auch in der Praxis ein eigenständiges, von der Sozialpädagogik zu unterscheidendes Konzept angewendet werden.

In der individuellen psychischen Struktur der Problembelasteten fällt also ein relativ einheitliches psychisches Strukturmerkmal auf: die Existenz von Minderwertigkeitskomplexen mit ibren unterschiedlichen nachteiligen Folgeerscheinungen für das Handeln und Verhalten.

Ein auffallendes Merkmal dieser Personengruppe ist, dass es ihr nicht gelingt, ihre Aufgaben und Probleme bei der Bewältigung des Lebensalltags selbständig oder mit den üblichen Methoden mitmenschlicher Hilfe und pädagogischer Unterstützung zu bewältigen, so dass eine psychosoziale Intensiverziehung notwendig wird. Mit dieser Gegenstandsbestimmung für Sozialpädagogik wird die von Rüdiger Wurr und Henning Trabandt formulierte Position konzeptionell weitergeführt, denn ihrer Auffassung nach

„läßt sich Abweichung als der entscheidende Gegenstand der sozialpädagogischen Arbeit bestimmen und Verhinderung, Abbruch oder Eindämmung von Dissoziationsprozessen als entscheidende Zielsetzung“ (Wurr/Trabandt 1993, S. 17).

Aus der Sicht einer ressourcenorientierten Sozialarbeit/Sozialpädagogik könnte nun der Einwand erhoben werden, dass mit dem Devianzphänomen als einem grundlegenden 
Konstituierungsfaktor der Sozialpädagogik ein Rückfall in ein Konzept der Defizitorientierung erfolgen würde. Eine solche Besorgnis ist unbegründet, denn

- kein Sozialpädagoge kommt daran vorbei, in der Problemanalyse auch die Defizite des Problembelasteten zu ermitteln, um sie überwinden zu können,

- er muss in der Analyse der Problemsituation seines Klienten nach den inneren und äußeren Ressourcen für die Problemlösung suchen, um z. B. bestimmte Stärken des Problembelasteten für die Problemlösung nutæen zu können;

- Defizit- und Ressourcenermittlung schließen sich nicht aus, sondern bedingen einander; entscheidend ist, dass im gesamten Problemlösungsprozess - also auch in der psychosozialen Intensiverziehung - die Ressourcen optimal genutzt werden.

Diese Ressourcennutzung bezieht sich aber nicht nur auf die Überwindung der festgestellten regressiven Devianz, sondern auch auf die materiellen und sozialen Möglichkeiten zur Verbesserung der Lebensbedingungen der Klienten. Unter den absehbaren Bedingungen der Globalisierung und fortschreitenden Automatisierung vieler Prozesse im Produktions- und Dienstleistungssektor ist mit einer Vollbeschäftigung aller Arbeitsfähigen auf dem ersten Arbeitsmarkt zu ausreichenden Löhnen für den Lebensunterhalt kaum zu rechnen. $\mathrm{Ob}$ und wann sich dieser Zustand wegen der rückgängigen Geburtenentwicklung und eines auch dadurch bedingten Arbeitskräftemangels ändert, ist schwer zu sagen. Aus diesem Grunde haben sich z. B. an verschiedenen Orten alternative Wohn- und Lebensgemeinschaften (auf Zeit) gebildet, die zwar auch von den herkömmlichen Normen abweichen, aber in innovativer und sozial verträglicher Weise.

Der Autor konnte sich selbst bei einem Besuch einer solchen Gruppe in einem abgelegenen und bereits aufgegebenen Bauernhof in Nordwestmecklenburg davon überzeugen, dass es Möglichkeiten der progressiven Devianz gibt. Leider hat sich dafür bisher kein Sozialpädagoge (mit Forschungskapazität!) interessiert, obgleich es hier interessante pädagogische und soziale Probleme und Lösungsversuche gibt. Es geht z. B. um Fragen der Verantwortlichkeiten und Aufgabenverteilung im Rahmen des Zusammenlebens - angefangen bei der Hausordnung und dem täglichen Küchendienst bis hin zur Regelung menschlicher Beziehungen und Konflikte unter den für ehemalige Stadtbewohner neuartigen Lebensbedingungen. Demzufolge müssen sie viel lernen, um unter den relativ primitiven Bedingungen zurechtzukommen, d. h. die alten Öfen zu heizen, den Garten zu bebauen usw. Hinzu kommt, dass es sich z. T. auch um Partnerschaften mit kleinen Kindern handelt, für deren Erziehung in der alternativ lebenden Gemeinschaft gesorgt werden muss. Sozialpädagogischer Beistand wäre bei den auftretenden Problem- und Konfliktsituationen in manchen Fällen gewiss hilfreich.

Es ist natürlich problematisch, solche alternativ lebenden Gruppen als Zielgruppen der Sozialpädagogik zu betrachten, weil sie sich dadurch diskriminiert fühlen könnten, 
zumal nicht selten nach ihrem Devianzverständnis eigentlich die „übrige Gesellschaft“ deviant im Sinne einer fundamentalen Abweichung von natürlichen Lebensbedingungen und Normen lebt, zu denen manche alternativen Gruppen eben gerade zurückfinden wollen. Werden jedoch Vertreter einer solchen Denkweise mit dem Begriff der progressiven Devianz konfrontiert, reagieren sie wahrscheinlich nicht beleidigt.

Die Einbeziehung progressiven devianten Verhaltens in den Gegenstandsbereich der Sozialpädagogik ermöglicht es auch, bestimmte Bedürfnisse der Problembelasteten aufzugreifen oder doch zumindest ihre Sichtweisen bei der Gestaltung des sozialpädagogischen Prozesses - so weit wie noch vertretbar - besser zu berücksichtigen. Dadurch würde auch einem Anliegen entsprochen, das in neueren Diskussionen zu Fragen der Devianzpädagogik eine Rolle spielt (vgl. Plewig bei Stimmer 2000, S.141f.).

Damit erfolgt eine Erweiterung des Gegenstandsbereichs und der Funktionen der Sozialpädagogik; sie geht über eine mehr oder weniger auf soziale Anpassung und Alltagsbewältigung zielende Defizitkompensation bei den Problembelasteten hinaus und erhält eine innovative Funktion, durch die neue Möglichkeiten für ein sinnvolles individuelles Leben und für die Lösung gesellschaftlicher Probleme erschlossen werden.

Der Begriff der psychosozialen Intensiverziehung wird von Buchka verwendet und damit begründet, dass die Allgemeine Pädagogik

„überfordert (ist) mit Zielgruppen, die ein unregelhaftes, defizitäres, abweichendes psycho-soziales Zustandsbild aufweisen. Hier sind spezielle Kenntnisse und Fähigkeiten nötig, um durch spezifische Forschungen und didaktisch-methodische (Be-)Handlungskonzepte angemessen helfen zu können. Für diese spezielle Forschung und Erziehung wird eine spezielle Pädagogik gebraucht, die wir als Sozialpädagogik definieren im Sinne einer Theorie und Praxis der psycho-sozialen Intensiverziehung (Hervorhebung durch W. N.). Eine solche Sozialpädagogik als psycho-soziale Intensiverziehung versteht sich als pädagogische Hilfe bei pathologischen Erziehungs- und Sozialisationsphänomenen. Sie bietet verschiedene Formen der Anpassungs-, Entwicklungs-, Reifungs- und Bildungshilfen (Pfaffenberger 1969: XVI) als pädagogische Hilfe an, die notwendig wird, wenn soziale und pädagogische »Gefährdung droht oder Schaden eingetreten ist (Fischer 1980: 8), [...]. Damit ist »Sozialpädagogik nichts anderes als der verschärfte, der radikale Fall von Erziehung« (v. Hentig). Die so verstandene Sozialpädagogik richtet sich nicht nur auf soziale, sondern auf psychische Fragestellungen hinsichtlich einer diagnostizierten Abweichung vom Regelfall und will mittels psycho-sozialer (Be-) Handlungskonzepte eine Intensiverziehung zum Zwecke der Prävention, Korrektion oder Kompensation bei pathologischen Erziehungs- und Sozialisationsphänomenen anbieten“ (Badry, Buchka, Knapp 1994, S. 140f.).

Aus dem zitierten Text von Buchka geht hervor, dass bei der gemeinten Zöglingsgruppe ein „abweichendes psycho-soziales Zustandsbild“ anzutreffen ist, womit auf 
die beiden miteinander verbundenen Determinanten und Erscheinungsformen des Zustandsbildes - auf die sozialen und psychischen Bedingungen und Verhaltensweisen der Problembelasteten - hingewiesen wird. Mit dem Begriff der psychosozialen Intensiverziehung, den wir hiermit aufgreifen, erfolgt zugleich eine Abkehr von der vorn kritisierten einseitigen Bindung der Sozialpädagogik an eine wie auch immer verstandene Sozialerziehung, denn es geht eben auch um Individualerziehung, und zwar um eine intensive! Ergänzend sei dazu bemerkt, dass mit dem Begriff der Intensiverziehung an eine optimale Nutzung der sozialen und psychischen Ressourcen der Problembelasteten und Problembeteiligten zu denken ist, aber natürlich auch an die Gestaltung entwicklungsfördernder sozialer Bedingungen. Das Hauptziel sozialpädagogischer Prozesse ist die Entwicklung der Bereitschaft und der Fähigkeiten zu selbständigem und verantwortungsbewusstem Handeln in der Gemeinschaft - soweit dies ein eventuell vorhandener Grad der Behinderung oder Erkrankung zulässt. Psychosoziale Intensiverziehung hat es vor allem mit Korrekturen und Umlernprozessen hinsichtlich der Lebensorientierung, der Einstellungen und Verhaltensweisen der Problembelasteten zu tun, was schwieriger oder zumindest anders ist als das Lernen in primären Sozialisationsprozessen.

Mit der oben formulierten Zielbestimmung sozialpädagogischen Handelns wird zugleich auch die sozialintegrative Funktion der Sozialpädagogik betont, die viele Theoretiker als ihre charakteristische und bestimmende betrachten. Psychosoziale Intensiverziehung richtet sich auf die Veränderung der Problembelasteten und erfordert zugleich relativ menschenwürdige Lebensbedingungen, die von den Klienten zum eigenen Wohle besser genutzt werden sollen. Das Merkmal der „menschenwürdigen Lebensbedingungen“ ist natürlich unscharf, da die Auffassungen darüber, was menschenwürdig ist, historisch und individuell variieren Daher bedarf es noch weiterer Untersuchungen dazu. Im Sinne einer ersten Orientierung sei darauf verwiesen, dass es sich dabei um Bedingungen handeln muss, die nicht nur ein Überleben des Menschen ermöglichen, sondern im Sinne des Förderungsprinzips (vgl. S. 206) auch eine solche Entwicklung und Nutzung seiner Fähigkeiten zum Wohle der Gesellschaft einschließen, dass er darin Befriedigung finden kann. Offen ist dabei, in welchem Maße Sozialarbeiter zur Schaffung menschenwürdiger gesellschaftlicher Bedingungen beitragen können. Der Auftrag im lokalen Bereich dafür ist ihnen durch den $\int 1$ Absatz 4 des Kinder- und Jugendhilfegesetzes gestellt, denn darin heißt es:

„(3) Jugendhilfe soll zur Verwirklichung des Rechts nach Absatz 1 insbesondere [...]

4. dazu beitragen, positive Lebensbedingungen für junge Menschen und ihre Familien sowie eine kinder- und familienfreundliche Umwelt zu erhalten oder zu schaffen.“

Beispielsweise sind Stadtteilprojekte im Rahmen von Gemeinwesenarbeit darauf gerichtet, im Wohngebiet die jeweiligen (mesosozialen) Lebensbedingungen menschenwürdig sowie kinder- und familienfreundlich zu gestalten, wobei es sich dem Wesen nach um kommunalpolitische Maßnahmen mit sozialen, kulturellen und medizinischen 
Akzenten handelt. Doch auch dann sind positive Wirkungen im hohen Maße an erzieherische Prozesse im vorn definierten Sinne gebunden, denn der Mensch ist nicht schlechthin Produkt seiner Lebensbedingungen (vgl. S. 45).

Aus der Sicht der oben formulierten Definition der Sozialpädagogik ist der Kindergarten keine sozialpädagogische Einrichtung, sondern eine vorschulische. Dass die Kindergärten durch Beschluss der Reichsschulkonferenz von 1920 nicht als Vorschuleinrichtungen den Schulämtern, sondern als „sozialpädagogische Institutionen“ der Jugendfürsorge unterstellt wurden, war nicht wissenschaftlich begründet, sondern eine Folge der kirchlich orientierten Mehrheit im Abstimmungsgremium der Reichsschulkonferenz, die ihre Kindergärten vor dem Zugriff einer weltlichen bzw. staatlichen Schulaufsicht bewahren wollte (vgl. Die Reichsschulkonferenz 1920, S. 692ff.) - ganz abgesehen von der Sorge um dann möglicherweise zu erwartende höhere Kosten für die Ausbildung und für die Entlohnung qualifizierter pädagogischer Fachkräfte in Kindergärten mit Vorschulcharakter und ausgeprägter Bildungsfunktion.

Natürlich hatten und haben Kindergärten auch eine sozialpädagogische Funktion im Sinne einer Primärprävention gegenüber devianten Verbaltensweisen. Aber diese präventive Funktion muss jeder Erziehungsbereich erfüllen und nicht nur der Kindergarten bzw. die Kindertagesstätte. Das ist also kein Argument für die Zuordnung. Unter diesem Aspekt betrachtet, ist auch die Freizeitpädagogik eine eigenständige und von der Sozialpädagogik abzugrenzende Disziplin, zumal ihr Gegenstandsbereich eine eigene Struktur und Dynamik sowie Funktionsmöglichkeiten aufweist, die zwar geeignet sind, aber viel weiter reichen als zur Überwindung devianten Verhaltens und zur Prävention (vgl. Opaschowski 1979 S. 196; 1981, S. 20f.; Badry u. a. 1994, S. 220f. und S. 351ff. dieses Buches).

Entsprechend der dominierenden Zöglingsvoraussetzungen und pädagogischen Zielstellungen sollte der Kindergartenbereich der Vorschulpädagogik zugeordnet werden, denn bei der Mehrzahl der Kinder im Kindergarten finden wir glücklicherweise noch kein „psychosoziales Zustandsbild“, dessen Überwindung eine psychosoziale Intensiverziehung erfordert. Kindergärten benötigen ein fundiertes vorschulpädagogisches Konzept mit spezifischen Bildungs- und Erziehungszielen. Diese beziehen sich auf die Entwicklung sozialer Verhaltensweisen in der Gruppe, die Förderung der sprachlichen Ausdrucksfäbigkeit, der Konzentrationsfähigkeit und der Feinmotorik (auch als Bedingungen für das Erlernen des Schreibens), auf die Entwicklung elementarer Mengenvorstellungen, eine gesunde körperliche Entwicklung durch sportliche Betätigungen usw. Wie jede ordentliche Erziehung schließt sie auch Prävention hinsichtlich devianten Verhaltens mit ein.

Immanente Bemühungen um Prävention hinsichtlich devianter Verhaltensweisen sind ein Qualitätsmerkmal aller guten Kindergärten, in manchen werden sie sogar explizit realisiert, z. B als Projekt „Suchtprävention“, wofür nicht nur bei naschhaften Kindern reale Voraussetzungen existieren. Ähnliche Projekte gibt es auch an manchen Schulen, 
ohne dass diese deshalb zu sozialpädagogischen Einrichtungen erklärt werden. Primärprävention im Sinne von „Vorsorge-Treffen“ sollte ein Wesensmerkmal jeder Erziehung und damit auch Inhalt jeder pädagogischen Disziplin sein. Anders verhält es sich mit der sekundären und tertiären Prävention. Im Falle der sekundären Prävention handelt es sich um

„Bemühungen und Maßnahmen, mit denen Kranke mit psychischen Störungen innerhalb einer Bevölkerung möglichst frühzeitig erfasst werden, um sie einer Behandlung zuzuführen, die Krankheitsdauer zu verkürzen, Rückfälle zu verbindern (Hervorhebung von W. N.) und weiteren Schaden für den Kranken und seine Umgebung zu verhindern“ (Peters 2004, S. 423).

Im Falle der tertiären Prävention geht es um den

„Versuch, durch geeignete Maßnahmen die Folgen einer psychischen Krankheit auszugleichen oder in Grenzen zu halten, ihre invalidisierenden Auswirkungen zu vermeiden oder zu mildern“ (Peters 2004, S. 423).

Psychosoziale Intensiverziehung ist darauf gerichtet, aktuelle deviante Handlungs- und Verbaltensweisen zu überwinden und im Sinne sekundärer und tertiärer Prävention zu wirken. Zusammenfassend kann man also sagen:

Psychosoziale Intensiverziehung ist darauf gerichtet, durch optimale Nutzung der sozialen und psychischen Ressourcen die mit Devianzproblemen Belasteten in einem solchen Maße zu persönlicher Selbständigkeit und Gemeinschaftsfähigkeit zu führen, dass sie ihr Leben auch unter schwierigen, aber menschenwürdigen Bedingungen auf akzeptable Weise bewältigen und am gesellschaftlichen Leben partizipieren.

Allerdings haben es Sozialpädagogen nicht nur mit Problembelasteten zu tun, die eine psychosoziale Intensiverziehung benötigen, sondern oft auch mit Problembeteiligten, die ebenfalls erzieherisch beeinflusst werden müssen, um sie z. B. zu mitwirkenden Helfern zu qualifizieren. Die psychosoziale Intensiverziehung ist gewissermaßen das „Kernstück“ sozialpädagogischer Prozesse, in die auch Problembeteiligte pädagogisch integriert sein können. Nach dem bisherigen Stand der Erkenntnis lässt sich daher formulieren:

Die Allgemeine Sozialpädagogik ist die Wissenschaft von der psychosozialen Intensiverziehung und sekundären erzieherischen Prävention von Personen mit regressiven devianten Handlungs- und Verhaltensweisen; sie erfasst auch die erzieherische Beeinflussung Problembeteiligter.

Eine weitere Prägisierung ist möglicherweise notwendig, wenn Probleme der progressiven Devianz. einbezogen werden, wobei dann die Frage nach der Notwendigkeit der psychosozialen Intensivererziehung bzw. Art der Erziehung zu prüfen sein wird. 
Sozialpädagogisches Handeln kann auch körperlich und psychisch Benachteiligte oder Geschädigte mit erfassen, wenn diese über die bereits erfolgenden rehabilitationspädagogischen und therapeutischen Maßnahmen hinaus und in Verbindung damit eine spezifisch sozialpädagogische Unterstützung benötigen (s. Fall „Sven“ auf S. 357f.).

Sozialpädagogische Prozesse können relativ selbständig (z. B. in der Erziehungsberatung) oder auch in Verbindung mit anderen Maßnahmen auftreten, die der Lösung sozialer Probleme und/oder der Prävention dienen, z. B. in Verbindung mit

- sozialarbeiterischen Prozessen (sozialpädagogische Familienhilfe, Jugendhilfe, Schuldnerberatung usw.),

- therapeutischen Prozessen (bei Suchtkranken, Personen mit Ess-Störungen, Personen, die unter einem Trauma oder einer Phobie leiden usw.),

- juristischen Prozessen (Jugendgerichtshilfe, Bewährungshilfe, sozialpädagogische Betreuung in Justizvollzugsanstalten),

- Bildungsprozessen (in Kindertagesstätten bei der Überwindung frühkindlicher Entwicklungsstörungen, in allgemeinbildenden Schulen beim Auftreten von Schulaversion und in überbetrieblichen Ausbildungseinrichtungen bei benachteiligten Jugendlichen oder bei der Unterrichtung von Analphabeten in der Erwachsenenbildung),

- freizeitpädagogischen Prozessen (besonders in solchen, die zur sekundären und tertiären Prävention geeignet sind).

Indem sozialpädagogisches Handeln auf die Überwindung devianten Verhaltens gerichtet ist und mit sekundärer Prävention verknüpft wird, lässt es sich von anderen Handlungsarten in der Sozialen Arbeit abgrenzen. Die Anerkennung der obigen Definition für Sozialpädagogik hängt davon ab, ob man eine spezielle erziehungswissenschaftliche Disziplin für die psychosoziale Intensiverziehung entwickeln möchte oder ob das Wort „Sozialpädagogik“ weiterhin als Synonym für „Soziale Arbeit mit Kindern und Jugendlichen“ in der Praxis und deren Theorie stehen soll.

Die theoretische Abgrenzung der Sozialpädagogik von ihren Nachbardisziplinen bzw. Bezugswissenschaften (also der Freizeitpädagogik, der Rehabilitationspädagogik, den Rechtswissenschaften, den Wirtschaftswissenschaften, der Soziologie usw.) ist durch eine wissenschaftliche Systembildung ebenso notwendig und möglich wie ihr Zusammenwirken im praktischen Handeln. Die Integration von Erkenntnissen aus verschiedenen Wissenschaften in der Anwendung wird durch eine transdisziplinär konzipierte Sozialpädagogik erleichtert und unterstützt. Wie auf der Grundlage einer strukturellen und dynamischfunktionalen Betrachtung realer Erziehungsprozesse in ihrem Systemzusammenhang eine adäquate Systematik für pädagogische Disziplinen entwickelt werden kann, wird mit dem vorliegenden Buch zumindest angedeutet. 


\subsection{Sozialarbeit und Sozialpädagogik in der Sozialen Arbeit}

Auch wenn wir den gesamten Wirkungsbereich von Sozialarbeitern und Sozialpädagogen mit dem Begriff der Sozialen Arbeit erfassen, bleibt doch die Frage nach dem Verhältnis von Sozialarbeit und Sozialpädagogik innerhalb dieses Bereiches bestehen. Ein Grund für die Schwierigkeiten bei der Klärung dieses Verhältnisses besteht wohl darin, dass an bestimmten historisch gewachsenen Vorstellungen festgehalten wird, da diese inzwischen auch in Rechtsvorschriften und Institutionen ihren Niederschlag gefunden haben. Um die Beziehungen zwischen Sozialarbeit und Sozialpädagogik auf theoretischer Ebene zu klären, müssen wir fragen: Worin besteht das jeweils Ursprüngliche und Wesentliche des sozialarbeiterischen und des sozialpädagogischen Handelns?

Dabei kann uns die Betrachtung der bistorischen Wurzeln der beiden Bereiche weiterhelfen, nämlich die eigentlich unpädagogische Armenhilfe des Mittelalters und die pädagogischen Bemühungen der sog. Rettungsanstalten für „verwahrloste "Kinder und Jugendliche in der Frühzeit des Kapitalismus. Die Armenhilfe im christlichen Mittelalter basierte wesentlich auf Almosen und war darauf gerichtet, den Bedürftigen das zum Überleben Notwendigste zu verschaffen: Nahrung, Kleidung, Versorgung bei Krankheit und Behausung, wenn es denn die Umstände erforderten. Mühlum ist gewiss zuzustimmen, wenn er meint, dass die kirchliche Armenpflege im Mittelalter ,auf höherer Stufe gestanden haben (mag), als gemeinhin angenommen wird“ (Mühlum 2001, S. 41). Allein die hohe Zahl der Bettler in den Städten lässt die Dimension des Problems erkennen. Almosen war als leibliche Hilfe und seelischer Trost gemeint, aber kaum mit erzieherischen Absichten gegenüber den Bedürftigen verbunden. Almosen gehörten zusammen mit den Gebeten und dem Fasten zu den drei Hauptbestandteilen der Buße des Spenders. Almosen kamen der Kirche - und über sie vermittelt auch den Armen - oder den Armen direkt zugute. Diese erhielten zur Linderung ihrer Not auf diese Weise Mittel, die Lüssi als Bedürfnisobjekte der Hilfebedürftigen oder Basisgegenstände der Sozialarbeit bezeichnet (vgl. Lüssi 1992, S. 81), nämlich:

- Unterkunft (Obdach, Wohnung),

- Nahrung,

- Gebrauchsgegenstände (Kleidung, Mobiliar, Fahrzeug und anderes),

- Geld,

- Betreuung (wegen Erkrankung oder anderer Notlagen)

Mit der Entwicklung des Kapitalismus entstand ein hoher Bedarf an Arbeitskräften in Werkstätten und Manufakturen. Zugleich aber drängte auch mit der Abschaffung feudaler Bindungen auf dem Lande eine dort überschüssige und arme Bevölkerung in die Städte, vielfach ohne andersartige als für Landarbeiten notwendige Arbeitsfähigkeiten 
zu besitzen, so dass weitere Basisgegenstände der Sozialarbeit zwecks Überwindung sozialer Notlagen hinzu kamen, nämlich:

- Erwerbsarbeit (Arbeitsplätze),

- Erziehung/Ausbildung,

- funktionelles Verhältnis zu notwendigen Bezugspersonen (da z. B. ländliche Sippen- und Nachbarschaftsbeziehungen reduziert waren).

Mit der Ausbreitung des Protestantismus und seines Arbeitsethos' wurde auch das im Mittelalter bestehende Recht auf Bettelei zunehmend verachtet und arbeitsfähigen Bettlern hart begegnet. Häufig wurden sie zwangsweise in Arbeitshäuser eingewiesen, wo sie unter unwürdigen Bedingungen leben und arbeiten mussten.

Lüssis Ansatz für die Bestimmung des Wesens der Sozialarbeit ist die klassische Armenpflege (zur Sicherstellung der lebensnotwendigen Bedarfsgüter), und die Hauptanfgabe des Sozialarbeiters ist die Lösung sozialer Probleme.

„Ein sozialer Sachverhalt ist für Sozialarbeiter dann ein soziales Problem, wenn ihm folgende Momente innewohnen:

- Not

- subjektive Belastung

- Lösungsschwierigkeit“" (Lüssi 1992, S. 84)

Das soziale Problem für den Hilfebedürftigen besteht also darin, dass er einen Notstandetwa den Mangel an Nahrung, Kleidung, Behausung, Arbeit usw. - als persönliche Belastung erlebt und selbst keinen Ausweg aus dieser Notlage findet. In diesen Fällen ist der Sozialarbeiter als Helfer bei der Problemlösung gefordert. Sozialarbeit ist nach Lüssis Auffassung wesentlich Sozialberatung (vgl. Lüssi 1992, S. 54), allerdings unter Einschluss von helfenden Aktivitäten bei der Beschaffung der notwendigen Basisgegenstände. Lüssi bestimmt den Kern oder das Wesen der Sozialarbeit als individuell gerichtete soziale Problemlösung durch Beschaffung der o. g. Basisgegenstände der Sozialarbeit. Der Prozess der Problemanalyse, Problembearbeitung und -lösung wird unter systemischen Gesichtspunkten behandelt, wobei Eriehung auch als Moment der Sozialarbeit auftreten kann. Es gelingt Lüssi nicht, das Verhältnis von Sozialarbeit und Sozialpädagogik klar zu bestimmen. Um Sozialarbeit von Sozialpädagogik abzugrenzen, führt er ein plausibel erscheinendes Unterscheidungskriterium ein: den Unterschied im räumlich-zeitlichen Zusammensein von professionellen Helfern und Hilfebedürftigen. Nach ihm besteht „der grundsätzliche Unterschied zwischen Sozialarbeit und Sozialpädagogik“ in Folgendem:

„Der Sozialpädagoge nimmt an der Lebenswelt seiner Klienten, ihrem Alltag teil und verfolgt das Ziel, mit der besonderen Art seiner Teilnahme, die Klienten persönlich so zu beeinflussen und die Lebenswelt so zu gestalten, dass sie sich sozial bestmöglich entwickeln können. Das 
hat im einen Falle (z. B. bei Kindern) einen überwiegend erzieherischen, im andern Falle (z. B. bei erwachsenen Geistigbehinderten) einen mehr betreuerischen Charakter“ (Lüssi 1996, S. 50). Der Sozialarbeiter ist ambulant tätig, und er beschäftigt sich nur mit Problemen der Leute. Er hat seinen Ort bzw. Sitz in einer Institution (»Sozialdienst«, »Beratungsstelle«, »Fürsorgeamt« etc.), nicht in der Lebenswelt der Klienten“ (Lüssi 1996, S. 51).

Diese mögliche (aber nicht notwendige und hinreichende) äußerliche Unterscheidung, die auch von anderen Autoren für zutreffend gehalten wird (z. B. von Bock - vgl. Mühlum 2001, S. 118), erfasst nicht das Wesen der jeweiligen Prozesse. Es wird übersehen,

- dass Erziehungsprozesse auch dort stattfinden, wo die beteiligten Personen nicht ständig zusammen leben, sondern in relativ regelmäßigen Begegnungen erzieherische Impulse gegeben werden können, die den Selbsterziehungsprozess stimulieren, der letztendlich über das Erziehungsresultat entscheidet;

- dass das Prinzip der Hilfe zur Selbsthilfe als allgemein anerkanntes Prinzip der Sozialarbeit vor allem mit pädagogischen Mitteln realisiert werden muss;

- dass die Sozialarbeit obne sozialpädagogische Komponente in der Regel aktuelle Notlagen nur vorübergehend lindern oder in erträglichen Grenzen halten kann.

Das an der Häufigkeit und Intensität der Begegnungen oder dem Zusammenleben von Helfern und Hilfebedürftigen orientierte Unterscheidungsmerkmal führt zu einer unscharfen Sicht auf das Verhältnis von Sozialarbeit und Sozialpädagogik auch in Lüssis eigener Theorie, d. h., sozialpädagogisches Handeln wird einerseits auf o. g. Weise von Sozialarbeit abgegrenzt und erscheint aber dann doch als Komponente der realen Sozialarbeit, was sich u. a. in manchen der von ihm formulierten Prinzipien der Sozialarbeit widerspiegelt, z. B. im „Prinzip der pädagogischen Verhaltensbeeinflussung“ als Bestandteil von Sozialarbeit (Lüssi 1992, S. 261f.). Im Unterschied zu Schilling (2005, S. 150) wirft Lüssi Rössner vor, dass dieser die „Sozialarbeitswissenschaft zur Subwissenschaft der Erziehungswissenschaft" erklärt (a. a. O., S. 31), aber er selbst subordiniert unter der Hand Sozialpädagogisches unter die Sozialarbeit und ihre Wissenschaft.

Allerdings kommen wir an einer Unterscheidung von Sozialarbeit und Sozialpädagogik im Rabmen der Sozialen Arbeit nicht vorbei. Soziale Probleme gehen stets von einer wie auch immer gearteten Dysfunktionalität im Sozialsystem aus (z. B. dem realen Mangel an Arbeitsplätzen); sie werden aber auch durch Defizite der Problembelasteten hervorgerufen. Die sozialarbeiterische Analyse fragt nach den feblenden Basisgegenständen, die zu beschaffen sind. Den Sozialarbeitern obliegt wesentlich die Funktion, die Problembelasteten zu beraten, um mit ihrer aktiven Mitwirkung im Rahmen der bestehenden Möglichkeiten die Basisgegenstände zu beschaffen. Für ihre Mitwirkung in diesem Beschaffungsprozess müssen die Problembelasteten aber vielfach motiviert, angeleitet und auch kontrolliert werden, was die sozialpädagogische Komponente in der Sozialen Arbeit ausmacht. Einige wichtige 
strukturelle und funktionale Zusammenhänge der Sozialarbeit verdeutlicht folgendes Schema aus kybernetisch-systemtheoretischer Sicht:

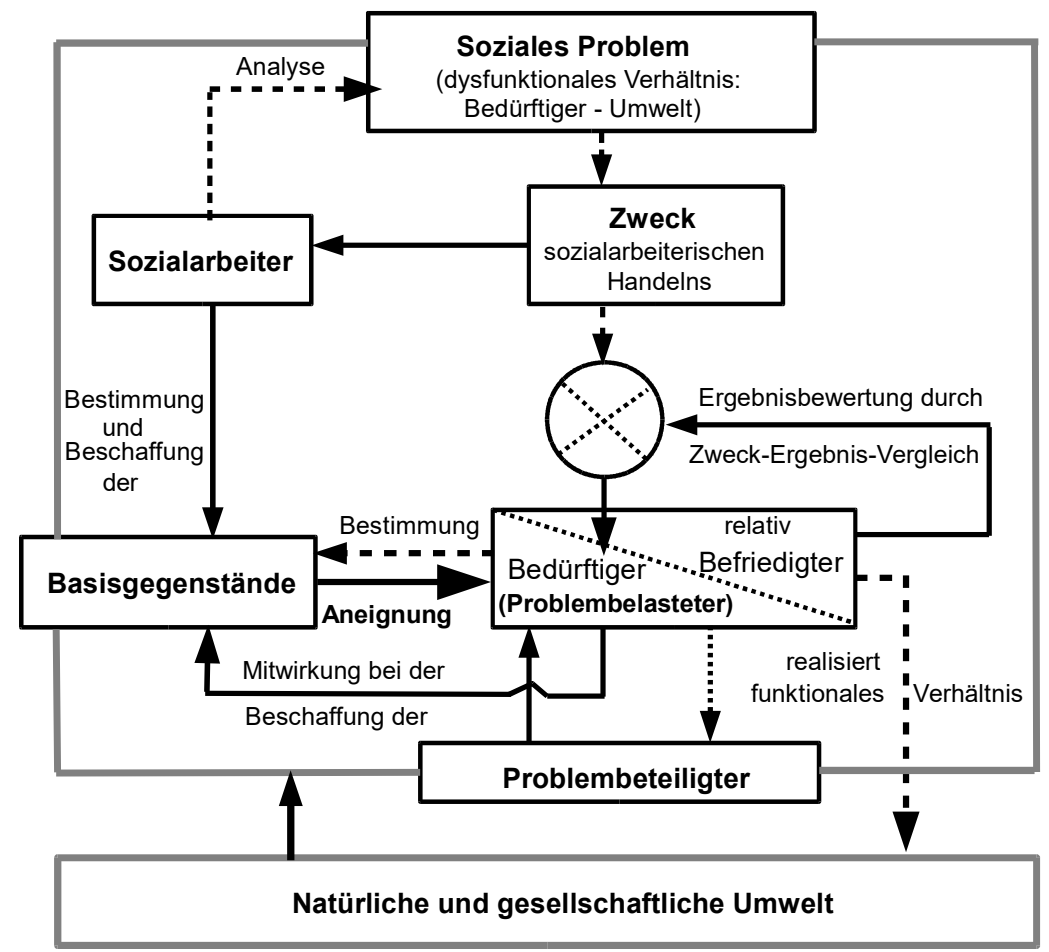

Schema 6

Erläuterung:

Sozialarbeiter werden in ihrer Praxis mit sozialen Problemen von Personen konfrontiert. Es ist die Aufgabe der Sozialarbeiter, mit dem Problembelasteten und eventuell unter Mitwirkung der Problembeteiligten (z. B. Familienangehörige, Freunde) die Problemsituation zu analysieren. Dabei sind die objektiven und subjektiven Bedingungen für die Entstehung des Problems bzw. Problembündels zu ermitteln, um herauszufinden, durch welche zweckmäßigen Handlungen das Problem gelöst werden kann. Die Analyse ergibt, welche Basisgegenstände beschafft werden müssen, die der Bedürftige zur Problemlösung oder Erleichterung benötigt. Der erkannte Zweck bestimmt die Beschaffung der Basisgegenstände, die sich der Bedürftige aneignet. In welchem Maße dadurch die Bedürfnisse befriedigt werden, zeigt sich beim Vergleich zwischen dem Zweck und dem Ergebnis. In Abhängigkeit von der Ergebnisbewertung werden jeweils weiterfübrende Maßnahmen vereinbart bzw. realisiert, um das dysfunktionale Verhältnis zugunsten eines funktionierenden zu 
überwinden. Die Analyse des Problems bzw. Problembündels erfordert methodisches Vorgehen, desgleichen die Bestimmung der Basisgegenstände, deren Beschaffung dann organisiert wird.

Betrachten wir im Vergleich dazu das von Knöchel entwickelte Struktur- und Funktionsmodell vom Erziehungsprozess (vgl. Knöchel 1967, S. 69):

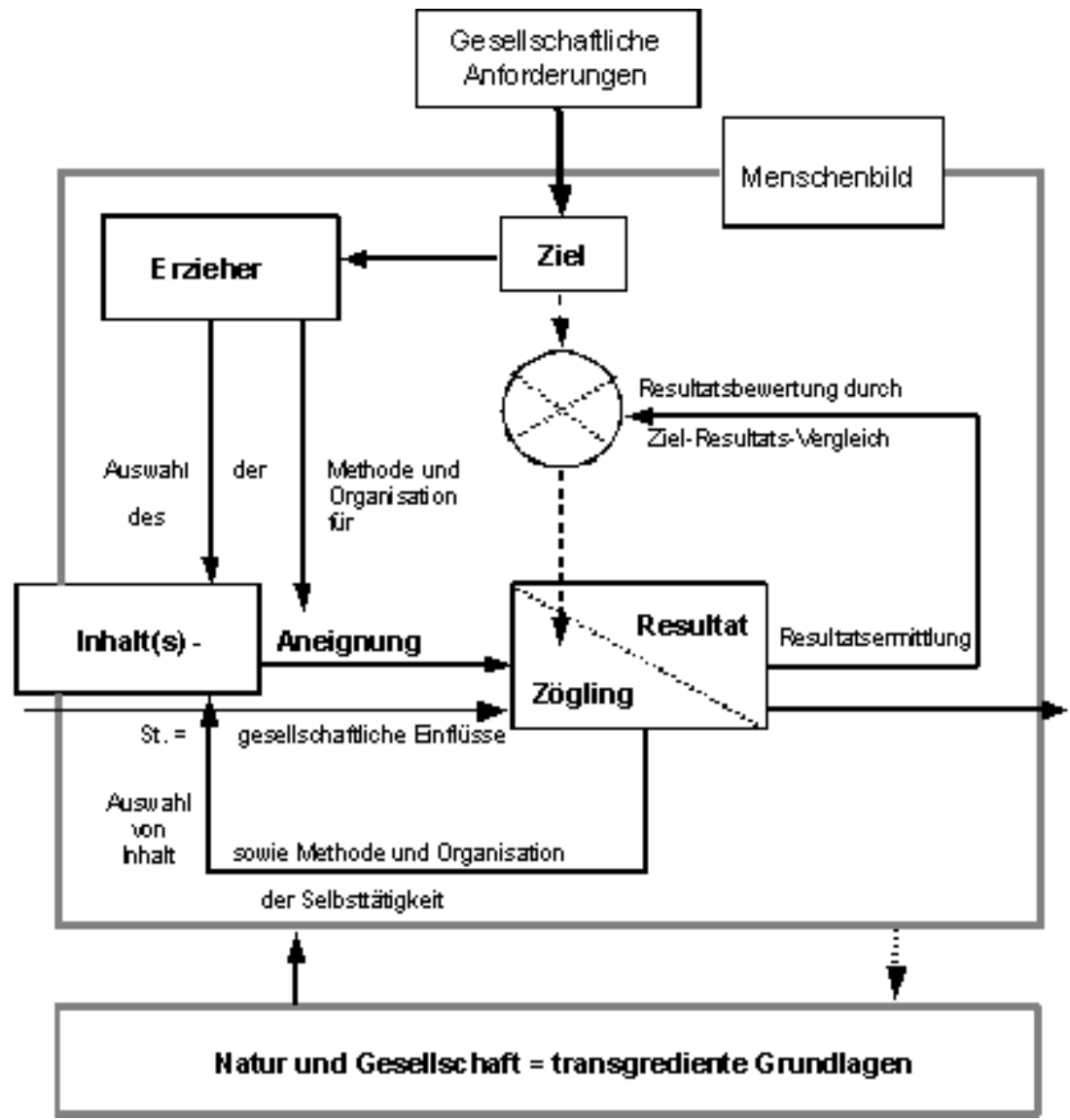

Schema 7

Erläuterung:

Gesellschaftliche Anforderungen determinieren in Verbindung mit dem jeweiligen Menschenbild die Ziele, die ihrerseits als Kriterien für die Auswahl von Erziehungsinhalten fungieren. Diese bestimmen unter Berücksichtigung der anderen immanenten Momente und der transgredienten Grundlagen die Organisation und das methodische Vorgehen bei der Übermittlung und der eigengeseţlichen Art der Aufnahme und Verarbeitung der Inhalte durch den Zögling. Die infolge der Verarbeitung entstandenen Resultate werden durch Ziel-Resultats-Vergleiche bewertet, streng genommen durch Vergleiche zwischen Zielvorstellungen und Resultatsabbildungen. Das bedeutet, dass auch in Abhängigkeit von den Kontrollmethoden die Bestandteile der realen Resultate mehr oder 
weniger adäquat erfasst werden. Da sich in der Resultatsbewertung der jeweils erreichte Entwicklungsstand des Zöglings annähernd widerspiegelt, kann dies - vermittelt über eine Zielkonkretisierung - beim weiteren inhaltlichen und methodisch-organisatorischen Vorgehen berücksichtigt werden (Feedback). Natürliche und gesellschaftliche Einflüsse werden wegen ihrer Systemfremdheit als Störgrößen (St.) bezeichnet; sie haben auch Einfluss auf die eigengesetzliche Inhaltsverarbeitung, wirken aber nicht in jedem Falle störend im Sinne von zielwidrig. Die transgredienten Grundlagen determinieren das Erziehungssystem; dieses wirkt durch Resultate verändernd auf Natur und Gesellschaft zurück (vgl. Knöchel 1967, S. 60-72). In der Realität sind - bezogen auf jeden Zöglingslebenslauf bzw. lang andauernden Erziehungsprozess - sehr viele Regelkreise miteinander ,vermascht“.

In Anlehnung an die Schallersche Terminologie hat Knöchel noch nicht zwischen dem Gegenstand und dem Inhalt pädagogischer Aneignungsprozesse unterschieden wie der Autor es im vorliegenden Buch und auch schon in früheren Arbeiten getan hat.

Ein Vergleich beider Schemata lässt sowohl hinsichtlich der Strukturmerkmale als auch der Funktionsweise der Prozesse gewisse Analogien erkennen, d. h., es treten analog auf:

- Zweck- und Zielbestimmungen,

- Auswahl von Basisgegenständen und Inhalten,

- organisatorisch und methodisch zu gestaltende Aneignungsprozesse,

- Ergebnis- und Resultatsermittlungen und -bewertungen.

- eine „Einbettung“ der Prozesse und ihrer Elemente in ihre Umwelt, verbunden mit Wechselwirkungen.

Bei der Realisierung der beiden miteinander verflochtenen Prozesse sind die jeweiligen sozialen (sozialökonomischen, sozialökologischen) und pädagogischen Systemzusammenhänge, in denen die Hilfebedürftigen leben, zu berücksichtigen, und zwar sowohl im Analyse- und Erklärungsprozess als auch im Planungs- und Problemlösungsprozess, da ja die sozialen und psychischen Ressourcen der Problembelasteten, Problembeteiligten und des Umfeldes genutzt werden sollen. Wie das konkret aussehen kann, lässt folgender Fall aus der Berufspraxis von Lothar Bunk und Sabine Ziegler erkennen:

Die Genannten wurden 1999 als Mitarbeiter einer Beratungsstelle des Deutschen Roten Kreuzes in Ostvorpommern mit den Problemen des von Obdachlosigkeit bedrohten fast 50-jährigen arbeitslosen Max konfrontiert. Max hatte über längere Zeit die Miete nicht bezahlt und sich auch durch die Bewirtung seiner Trinkkumpane bei den Mitbewohnern im Haus allgemein unbeliebt gemacht. Zudem wurde ihm die Wohnung wegen Mietschulden gekündigt. Schon im ersten Gespräch mit ihm wurde deutlich, dass ihn ein ganzes Bündel sozialer Probleme belastete, das auch Defizite in seiner Persönlichkeitsstruktur erkennen ließ.

Die Analyse ergab, dass Max 1951 als 2. Kind in einer Arbeiterfamilie in Vorpommern geboren worden war; sein Vater arbeitete bis zu seinem Tode 1961 als Tischler im Wohnort und seine 
Mutter als Küchenhilfe in der nahen Kreisstadt. Max besuchte den Kindergarten, wo er durch Clownerien auffiel, und hatte in der Schule solche Leistungsschwierigkeiten, dass er die 10-klassige Polytechnische Oberschule nach der neunten Klasse beendete. Dieser Abschluss ermöglichte es ihm aber, Melker zu werden und bis in die Wende hinein (1990) in einem Landwirtschaftsbetrieb zu arbeiten. Dann wurde er arbeitslos. Seine Mutter verstarb 1990 und seine Schwester verließ nach ihrer Heirat die relativ große elterliche Wohnung, in der Max nun allein verblieb. Jetzt wurden die Schnapsflaschen sein „Trostmittel“ und die Trinkkumpane vom Kiosk, die er früher geringschätzig betrachtet hatte, seine „Freunde“. Diese spielten als Problembeteiligte offensichtlich eine sehr negative Rolle im Prozess der Problementwicklung, zumal sie die Wohnung von Max als Asyl benutzten und sein Ansehen bei den Hausbewohnern ruinierten. Als notwendige Bedarfsobjekte oder Basisgegenstände ergaben sich bei Max also:

- eine kleinere, angemessene Wohnung,

- eine Erwerbsarbeit oder zumindest eine ABM,

- eine Entschuldung (einschließlich der Bezahlung der Mietrückstände) und die Sicherung einer Mindestsumme für den Lebensunterhalt,

- eine Suchttherapie und eine damit verbundene Betreuung,

- der Aufbau tragfähiger sozialer Beziehungen, um ihn aus der Isolierung bzw. aus dem „Freundeskreis“ herauszuführen.

Bei der Realisierung dieses Programms benötigte Max Unterstützung, und zwar speziell bei Verhandlungen mit den jeweils zuständigen Stellen und Ämtern (Schuldnerberatung, Hauseigentümer, Sozialamt, Arbeitsamt, Klinik für Suchtkranke usw.). Um diese Basisgegenstände zu erhalten, musste Max vor allem motiviert, ermutigt und angeleitet werden, die dafür notwendigen Schritte zunehmend selbständig zu gehen; d. h., im Sinne des Prinzips der Hilfe zur Selbsthilfe war auch im Rahmen der ambulanten Betreuung ein langfristiger sozialpädagogischer Prozess zu realisieren. Dieser basierte auf den Voraussetzungen, die Max in seiner bisherigen Entwicklung erworben hatte, und war verbunden mit den vielfältigen Maßnahmen zur Aneignung der Basisgegenstände. Max hatte einen Schulabschluss, der es ihm nach einiger Anleitung gestattete, den Schriftverkehr mit den jeweils zuständigen Ämtern selbständig zu führen. Es kam vor allem darauf an, ihm die Angst vor den Formularen und Ämtern zu nehmen, und zwar dadurch, dass er anfangs angeleitet und begleitet wurde. Aus der Art der Verhandlungsführung der Betreuer mit den Angestellten der Ämter lernte er, wie man seine Anliegen vertreten kann und muss.

Als Hauptschwierigkeit im Problemlösungsprozess erwies sich erwartungsgemäß die Alkoholabhängigkeit von Max. Als er jedoch wieder einmal mit einer schweren Alkoholvergiftung im Krankenhaus gelandet war, machten ihm die Ärzte klar, dass ein fortgesetzter Alkoholkonsum sein Leben in absehbarer Zeit beenden würde. Aber Max wollte leben und hatte am Beispiel eines seiner „alten Kumpel“ erfahren, wie schnell es zu Ende gehen kann. Die Autorität der Ärzte in Verbindung mit dem persönlich erlebten abschreckenden Beispiel bewirkten, dass er sich einer 
Therapie unterzog, sich nach einer Schlägerei wegen seiner Verweigerung des „Willkommenstrunks“ am Kiosk von seinen Trinkkumpanen trennte und danach tatsächlich abstinent lebte.

Dieser Prozess wurde nachhaltig unterstützt durch eine neue Wohnung in einer anderen Wohngegend und in einem Haus, dessen Mitbewohner ihn ohne Vorurteile aufnahmen, denen er sich durch Gartenarbeiten und Nachbarschaftshilfe als nützlich erwies, so dass sie sogar seinen Hund in Pflege nahmen, während er seiner Tätigkeit in einer $A B M$ nachging; d. h., es gelang auch, ein System sozialer Beziehungen aufzubauen, was wichtig war, weil sich seine Schwester von ihm, dem Trinker, distanziert hatte. Inwieweit diese gestörte bzw. abgebrochene soziale Beziehung nach der Therapie von Max wieder hergestellt werden konnte, war zum Zeitpunkt des Abschlusses der schriftlichen Hausarbeit noch nicht entschieden (vgl. Bunk/Ziegler 2003).

Es kann hier schon aus Platzgründen das Ineinandergreifen von sozialarbeiterischen, sozialpädagogischen und therapeutischen Aktivitäten nicht differenziert erörtert werden. Aber es dürfte deutlich geworden sein, dass die sozialarbeiterischen Maßnahmen stets mit Motivationen, Ermutigungen, Belehrungen, Bewertungen des jeweils Erreichten und auch mit Erfolgserlebnissen für Max selbst verbunden waren, die sein Selbstbewusstsein stärkten, so dass er zu dem Zeitpunkt des Abschlusses der Hausarbeit seiner Betreuer mit einer Wochenstunde Betreuung im funktionellen Gleichgewicht gebalten werden konnte. Verallgemeinernd kann man sagen:

- Sozialarbeiterische Aktivitäten erfordern und ermöglichen sozialpädagogisches Handeln und zudem akzeptieren Problembelastete in der Regel auch die Ratschläge von Menschen, die ihnen erfahrungsgemäß wirklich helfen.

- Sozialpädagogische Aktivitäten ermöglichen und befördern den sozialarbeiterischen Problemlösungsprozess, denn obne eigene Bemühungen des Problembelasteten sind nachhaltige Problemlösungen nicht zu erwarten.

- Sozialpädagogische Aktivitäten dienen nicht nur der Vorsorge im Sinne der Vorbereitung auf soziales, verantwortungsbewusstes und selbständiges Handeln, sondern erbringen mit den unmittelbaren Effekten der Beschaffung von Basisgegenständen der Sozialarbeit (Beziehungen der Nachbarschaftshilfe, ABM o. Ä.), auch Verbesserungen in der gesamten Lebenslage der Problembelasteten.

Alle Aktivitäten von Max - die Verhandlungen, die Wohnungssuche, der Umzug, seine Hilfsbereitschaft gegenüber den neuen Nachbarn, die Annahme einer ABM usw. verbesserten seine Lebensbedingungen und förderten seine Entwicklung. Zwischen praktischer Sozialarbeit und sozialpädagogischen Prozessen besteht also ein Wechselwirkungsverhältnis, das eingebettet ist in das System der Wechselwirkungen von transgredienten Grundlagen und immanenten Momenten der Erziehung. Dabei ist die Sozialarbeit zugleich Bestandteil der unmittelbaren transgredienten Grundlagen sozialpädagogischen Handelns. Allerdings sind nicht alle psychosozialen Intensiverziehungsprozesse mit Sozialarbeit im 
Sinne der Beschaffung materieller Basisgegenstände verbunden, wie etwa Eræiehungsberatungen erkennen lassen, die sich nur auf die Überwindung von Erziehungsschwierigkeiten bzw. devianten Handlungen richten. Umgekehrt gibt es auch Soziale Arbeit ohne Erziebung (z. B. mit Hochbetagten), die sich auf Beschaffung, Betreuung, bedingungsabhängige aktuelle Orientierungshilfen u. Ä. beschränkt.

Vergleichen wir das schematische Modell des pädagogischen Prozesses mit dem des sozialarbeiterischen, dann wird erkennbar: unter systemtheoretischem Aspekt betrachtet, weisen sozialarbeiterische und sozialpädagogische Prozesse analoge Strukturen und Funktionen auf, die die Verzahnung beider Komponenten im Prozess der Sozialen Arbeit bedingen und somit auch ibre Verknüpfung im praktischen Handeln erklären bzw. ermöglichen.

Sozialpädagogische Prozesse sind gerichtet auf die individuelle und kollektive Lösung sozialer Konflikte und Probleme, die sich aus krisenhaften Gesellschafts- und Lebenssituationen sowie aus den unzureichend entwickelten Fähigkeiten der Betroffenen zu einer sozial verträglichen Lösung dieser Konflikte ergeben. Sie sind aber nicht nur bei materiell Notleidenden erforderlich, sondern auch bei anderen: z. B. in wohlhabenden Familien, in Schulen und in Freizeitgruppen. Für die Sozialpädagogik als Wissenschaft bedeutet dies, dass sie keinen einheitlichen und eigenständigen institutionellen Wirkungsbereich besitzt; sozialpädagogisches Handeln ist eine personenabhängig notwendige Komponente verschiedenartiger gesellschaftlicher Prozesse, z. B.

- des Familienlebens (Familienberatung, sozialpäd. Familienhilfe),

- der Rechtspflege (Bewährungshilfe, SP in Justizvollzugsanstalten),

- des Bildungswesen (Schulsozialpädagoge, Sozialpädagoge in überbetrieblichen Ausbildungszentren für benachteiligte Jugendliche),

- der Jugendarbeit (z. B. in Kinder- und Jugendfreizeitzentren),

- der Straßensozialarbeit,

- der Arbeit mit Förderungsbedürftigen oder

- der Arbeit mit Betreuungsbedürftigen (Betreuungsgesetz vom 01. 01. 1992).

Grundsätzlich gilt: Sozialpädagogisches Handeln ist überall dort erforderlich, wo deviantes Handeln stereotyp auftritt, das wegen seiner schädlichen Wirkungen nicht toleriert werden kann.

Die hier vertretene Auffassung von sozialpädagogischem Handeln hat sprachliche Konsequenzen, beispielsweise für die sog. Schulsozialarbeiter, deren Aufgabe ja nicht die Beseitigung materieller oder finanzieller Nöte ist, sondern deren Handeln auf Probleme von Schülern im Bildungsprozess zielt, die mit devianten Verhaltensweisen verbunden sind (Schulangst, schulaversives Verhalten, Gewalttätigkeiten gegenüber Mitschülern usw.). Die Helfer sollten daher Sozialpädagogen heißen, wenn auch materielle Probleme der Herkunftsfamilien ihrer Klienten „,im Hintergrund“ eine Rolle spielen können. 


\subsection{Sozialpädagogik und Therapie}

In den bisherigen Darlegungen sind Zusammenhänge zwischen Therapien und Sozialpädagogik deutlich geworden. Es ist im Rahmen dieser Veröffentlichung nicht möglich und auch nicht notwendig, relevante Therapien im Einzelnen vorzustellen und hinsichtlich ihrer Wechselwirkungen mit sozialpädagogischen Handlungen differenziert zu untersuchen. Es geht lediglich darum, die hier vertretene Auffassung von Sozialpädagogik hinsichtlich einiger Konsequenzen für das Verbältnis von therapeutischem und sozialpädagogischem Handeln zu erörtern und darzustellen.

Unter Therapien verstehen wir die „Gesamtheit der Maßnahmen zur Behandlung einer Krankheit mit dem Ziel der Wiederherstellung der Gesundheit, der Linderung der Krankheitsbeschwerden und der Verhinderung von Rückfällen“ (Brockhaus 1993, Bd. 22, S. 87). Wir können unterscheiden:

- medizinische Therapien mittels Medikamenten und/oder cbirurgischer Eingriffe,

- Physiotherapien und

- Psychotherapien (einschließlich Sozialtherapie).

In der vorliegenden Darstellung geht es primär um eine Betrachtung des Verhältnisses von Psychotherapien und Sozialpädagogik, da es in der praktischen Arbeit von Sozialpädagogen eine große Rolle spielt. Dabei können wir von Erkenntnissen ausgehen, die Wolfgang Schumann in seinem Buch „Therapie und Erziehung" präsentiert: „Erziehung und Therapie unterscheiden sich in ihrer grundsätzlichen Absicht nicht. Beide sind am Idealbild eines gesunden, leidensfreien, lebensbejahenden, erlebnisfähigen, lernfähigen, handlungsfähigen und selbstverantwortlichen Menschen orientiert. Aber sie folgen dieser Absicht mit unterschiedlicher Zielsetzung. Während Therapie die Wiederherstellung physischer und psychischer Gesundheit zum Ziel hat, arbeitet Erziehung auf Bildung im umfassenden Sinne hin“ (Schumann 1993, S. 297).

Die unterschiedlichen Zielsetzungen sind verbunden mit den unterschiedlichen „Ausgangslagen der zu Behandelnden“ - vgl. dazu „Zöglings-Ziel-Relation“!

Abgesehen von vorbeugenden Schutzmaßnahmen (Prophylaxe) unterstellen Therapien als Ausgangslage das Vorbandensein von Krankheiten oder Beschwerden und Leiden, die geheilt oder gelindert werden sollen. Dabei ist allerdings schon der Begriff der Krankheit nicht unproblematisch, denn

„wo liegt z. B. die Grenze zwischen gesund und krank? Stellen wir uns die beiden Pole gesund/krank als Endpunkte einer Geraden vor, auf welchem Punkt der Geraden liegt dann 
wohl die momentane körperliche Mattigkeit? Ist sie näher an gesund oder an krank einzuordnen? Wie weit ist der Zustand eines depressiven Menschen schon vom gesunden entfernt oder wie nahe ist er der Marke krank?"“ (Schumann 1993, S. 281)

Während bei körperlichen Erkrankungen dem Arzt bei seiner Diagnose mittels moderner Diagnoseinstrumente und wissenschaftlicher Erkenntnisse auch in komplizierten Fällen wirksam geholfen werden kann, ist die Diagnose und Entscheidung über die angemessene Therapie bei psychischen Beschwerden und Leiden oftmals schwieriger.

Pädagogik unterstellt als Ausgangslage zunächst einen physisch und psychisch gesunden Zögling mit einer mehr oder weniger entwickelten Bildsamkeit, die zu seinem eigenen Wohle und dem der Gesellschaft möglichst optimal genutzt werden soll. Auf der begrifflichen bzw. abstrakten Ebene ist daher zunächst eine deutliche Unterscheidung zwischen den beiden „Handlungsfeldern“ möglich:

- Erzieherisches Handeln ist unter Nutzung der Bildsamkeit und Erziehbarkeit der Zöglinge auf deren Persönlichkeitsentwicklung gerichtet, ist also pädagogisch begründet und nutzt vor allem die Erkenntnisse und Erfahrungen der Pädagogik, der Psychologie und Soziologie für die Prozessgestaltung.

- Therapeutische Handlungen sind auf die Wiederherstellung verlorener Gesundheit oder Linderung krankhafter Erscheinungen gerichtet; sie sind medizinisch begründet und bedienen sich der Erkenntnisse und Erfahrungen der Medizin und im Falle psychischer Störungen oder Erkrankungen vor allem der Erkenntnisse der Neurologie, Psychiatrie und Psychotherapie.

Zwecks Unterscheidung beider Handlungssysteme verweist Schumann auf die jeweils unterschiedlichen Kontexte, in die die entsprechenden Handlungen einzuordnen sind. Mit Berufung auf Klenner (1980, S. 42) schreibt er:

„Pädagogik/Erziehen ist immer dem anthropologischen Kontext zugeordnet, Therapie/Behandeln dem technologischen. Der anthropologische Kontext ist von der ganzheitlichen Sichtweise des Menschen getragen. Dem steht eine Sichtweise gegenüber, die den Menschen eher unter Teilaspekten betrachtet. Das Defizit, der Defekt tritt in den Vordergrund. Während Erziehung allgemein notwendig ist, geschieht Therapie aufgrund eines Befundes, einer Indikation in Hinblick auf ein solches Defizit. [...] Die pädagogische Orientierung wird final gesehen, die therapeutische kausal. Das Erwachsenwerden ist Anliegen der Erziehung, die Wiederherstellung eines Normalzustandes das der Therapie“" (Schumann 1993, S. 309).

Hierzu müssten sicherlich die Therapeuten noch ihre Stellungnahme abgeben. Auch sie bemühen sich vielfach um eine ganzheitliche Sichtweise auf ihre Klienten und lassen sich bei ihrer Diagnose und Therapie nicht nur von kausalen Zusammenhängen, sondern auch von teleologischen leiten, wie am Beispiel der Individualpsychologie und der 
darauf beruhenden Psychotherapie erkennbar ist. Umgekehrt fragen auch Pädagogen nach den Ursachen erzieherischer Misserfolge bzw. von Erziehungsschwierigkeiten. Für die Abgrenzung von Sozialpädagogik und Psychotherapie ist das behauptete Unterscheidungsmerkmal Defizit oder Defekt, das bei der Therapie ,in den Vordergrund tritt", ungeeignet, solange die Ursachen dafür und die Möglichkeiten für ihre Überwindung nicht geklärt sind.

Schumann untersucht das Verhältnis von Erziehung und Therapie in der Schule und gelangt dabei auch zu allgemeingültigen Bestimmungen dieses Verhältnisses, die in der oben angegebenen Literatur nachgelesen werden können und die bei der nachfolgenden Erörterung des Verhältnisses von Sozialpädagogik und Psychotherapie mit berücksichtigt werden. Zu Schumanns fundamentalen Formulierungen gehört:

„Die Problematik einer Begriffsbeschreibung von Erziehung und Therapie ist eine doppelte. Einerseits sind die Begriffe Erziehung und Therapie und das Verständnis von diesen selbst ständigem Wandel unterworfen. Andererseits zeigt das Handlungsfeld keine klaren Grenzen“ (Schumann 1993, S. 313, Hervorhebung durch W. N.).

Damit wird gesagt, dass auch die theoretischen Begriffsbestimmungen bezüglich Therapie und Erziehung nur eine historisch begrenzte Klarheit erbringen können, denn es wandeln sich Realität und Erkenntnisse darüber.

Auf der abstrakten Ebene der Begriffe ist es also noch möglich, zu einer historisch bedingten relativen Klarbeit im Sinne einer Unterscheidung zu gelangen. Wendet man sich jedoch der realen Praxis zu, so stellt man fest, dass die Grenzen fließend und daher schwer bestimmbar sind. Das gilt für das Verhältnis von erzieherischem und therapeutischem Handeln allgemein und geht beim sozialpädagogischen und psychotherapeutischen Handeln so weit, dass es fast zu einer Identität der Operationen von Therapeuten und Sozialpädagogen kommt, das heißt: in der Praxis gehen beide Handlungsarten vielfach ineinander über! Das ist sicher auch ein verständlicher Grund für Tillmanns vorn (S. 87) zitierte Auffassung von Sozialpädagogik.

Die Gründe für das Ineinanderübergehen beider Handlungsarten sind in folgenden Gemeinsamkeiten beider Handlungssysteme zu suchen: Entsprechend der Definition von Seite 112 beschäftigen sich Sozialpädagogen mit der psychosozialen Intensiverziehung von Personen mit devianten Verbaltensweisen, die aus deren dysfunktionalen biologischen, sozialen, psychischen und kulturellen Strukturen sowie den damit verbundenen Störungen ihrer Beziehungen zur Umwelt und zu sich selbst resultieren. Diese Merkmale treffen auch auf Klienten von Psychotherapeuten zu, wobei für die praktische Zuordnung der einzelnen Problembelasteten zu Therapeuten oder Sozialpädagogen die Ursachen sowie Art und Ausprägungsgrade der Dysfunktionalitäten von entscheidender Bedeutung sind. 
Für das Handeln von Psychotherapeuten und Sozialpädagogen lassen sich folgende Gemeinsamkeiten formulieren:

- Psychotherapeuten und Sozialpädagogen haben die Aufgabe, ihren Klienten mittels spezieller Lernarrangements zu helfen, ihre persönlichen Ängste und Schwierigkeiten (Unsicherheiten, Selbstzweifel, Labilität, Niedergeschlagenheit, Depressionen, aber auch ihre Selbstüberschätzung) sowie ihren problematischen oder gar selbstzerstörerischen Lebensstil zu überwinden; ihre interpersonalen Beziehungen normgerecht und/oder zumindest erträglich zu gestalten sowie ihre Aufgaben und Probleme im Lebensalltag zu bewältigen.

- Psychotherapeuten und Sozialpädagogen bedienen sich der Erkenntnisse gemeinsamer Basis- bzw. Bezugswissenschaften (der Verhaltensforschung, der Lernpsychologie, der Tiefenpsychologie, der Individualpsychologie, der Sozialpsychologie usw.) bei der Entwicklung von individuellen und problemadäquaten Lernarrangements, die im Rahmen ihrer Interventionen eingesetzt werden; sie nutzen die psychischen Kräfte der Helfer (Therapeuten und Sozialpädagogen), der Problembelasteten sowie Problembeteiligten und wenden zum Teil gleiche oder ähnliche Methoden und Verfahren in der Arbeit mit den Problembelasteten an.

- Psychotherapeuten und Sozialpädagogen verstehen sich als Helfer für problembelastete Personen und dienen mit ihren Leistungen zugleich der individuellen und gesellschaftlichen Konfliktbewältigung bzw. -reduzierung.

Hompesch-Cornetz und Hompesch kommen bei ihren Analysen zu der Feststellung:

„Die Dimensionierungen interpersonalen Handelns machen deutlich, daß es keine generelle Trennung der beiden Handlungssysteme Sozialpädagogik und Therapie geben kann, daß sie sich vielmehr unter dem Oberbegriff »Organisation sozialen Lernens« zusammenfassen lassen“" (Hompesch-Cornetz und Hompesch 1987, S. 1040).

Dem ersten Teil der Aussage („keine generelle Trennung“) kann zugestimmt werden. Ob allerdings die „Organisation sozialen Lernens“ ein geeigneter Oberbegriff ist, um Sozialpädagogik und Therapie zu erfassen, hängt davon ab, was man unter sozialem Lernen versteht. Immerhin ist der Mensch ein biopsychosoziokulturelles Wesen: an seinen Lernprozessen sind alle vier „Komponenten“ beteiligt und „,nichtsoziale“ Lernprozesse gibt es nicht. Das Soziale in Lernprozessen existiert immer als Wesensmerkmal der Lernziele, der Lernenden als soziale Wesen, der Lernbedingungen und der Mittel der Zielrealisierung. Offenbar meinen die Autoren Lernprozesse, die auf den Erwerb von Sozialkompetenz gerichtet sind, doch dann entsteht die Frage, wie man solche von jenen Lernprozessen klar abgrenzen kann, die auf die Aneignung von Selbstkompetenz und kulturellen Sachkompetenzen zielen. Hinzu kommt, dass es bei deviant handelnden Personen nicht genügt, nur ihr soziales Verhalten verändern zu wollen, denn 
auch dieses resultiert aus einer Gesamtstruktur der Persönlichkeit, die in der Erziehung berücksichtigt werden muss.

Mögliche Unterschiede zwischen beiden Handlungssystemen lassen sich - wie schon angedeutet - an bestimmten äußerlichen Merkmalen festmachen, etwa am Handlungsort (Therapeuten arbeiten in Kliniken oder Praxen und Sozialpädagogen in Ämtern, bei freien Trägern, in Heimen unterschiedlicher Trägerschaft usw.), und Therapeuten haben in der öffentlichen Meinung einen höheren Status als Sozialarbeiter. Es lassen sich aber auch noch innere Unterschiede in den Handlungssystemen finden, z. B.:

- Akzentuierungen in der Zielstellung - also: Wiederherstellung eines verloren gegangenen Gesundheitszustandes oder Zuwachs an Persönlichkeitsentwicklung;

- Ansatzpunkte der „(Be)handlungsmaßnahmen“ - also Konzentration auf die intrapersonale psychische Struktur der Persönlichkeit (gilt besonders unter klinischen Bedingungen) oder auf die Handlungsziele und Verbaltensweisen des Problembelasteten, und zwar möglichst unter verbesserten lebensweltlichen Verhältnissen des Zusammenlebens, z. B. unter den Bedingungen der kollektiven Arbeitserziehung in den Kolonien von Makarenko oder in Gruppen der Erlebnispädagogik von Kurt Hahn (1886-1974) oder in einer Pflegefamilie usw.;

- Akzente bei der Auswabl und Kombination der Methoden und Verfahren in Abhängigkeit von Art und Grad der zu behandelnden Dysfunktionalitäten.

Allerdings dürfen diese Unterschiede nicht verabsolutiert werden, weil nämlich einerseits die Sozialpädagogen verstärkt auf Erkenntnisse der Psychotherapie zurückgreifen, um sie im Rahmen ihrer Möglichkeiten mit zu nutzen, und andererseits die Psychotherapeuten auch die Beziehungen zwischen den inneren psychischen Problemen und deren äußeren Determinanten im sozialen Umfeld ihrer Klienten berücksichtigen, um sie im Interesse des Erfolgs mit zu beeinflussen, was beispielsweise in Soziotherapien seinen Ausdruck findet.

Psychotherapeuten und Sozialpädagogen können sich in ihren Bemühungen praktisch erfordern und befördern. Es gibt ja Personen mit devianten Verhaltensweisen, die nicht allein mit den Mitteln der Sozialpädagogik erfolgreich behandelt werden können, weil eine echte Erkrankung vorliegt, die therapiert werden muss (z. B. ADHS, Spielsucht, Drogensucht usw.), und es gibt umgekehrt auch kranke bzw. psychisch beeinträchtigte Personen mit devianten Verhaltensweisen, bei denen gezielte Therapien allein nicht ausreichen, um ihre Persönlichkeit so zu fördern, dass sie ein selbständiges Leben führen können; daher sind zusätzlich sozialpädagogische (möglicherweise auch noch fürsorgerische) Aktivitäten notwendig. Die soz̧ialpädagogische Betreuung verfolgt dabei das Ziel, bestimmte Sachkompetenzen sowie die Selbständigkeit, das Selbstwertgefühl und die Gemeinschaftsfähigkeit der Betreuungsbedürftigen zu verbessern; sie ist von 
Pflege- und sozialen sowie juristischen Unterstützungsmaßnahmen wegen des Schweregrades bei manchen Beeinträchtigungen bzw. Behinderungen zu unterscheiden.

Da diese „Übergangsfelder“ und Wechselwirkungen allgemein bekannt sind, ist man bei der Hilfeplanung für Klienten mit multiplen Problembelastungen bemüht, mittels eines Fall-Managements eine möglichst zweckmäßige Abfolge und Kombination von therapeutischen und sozialpädagogischen Maßnahmen zu erreichen. Allerdings ist das nicht immer möglich, weil z. B. für die Durchführung einer Suchttherapie das Einverständnis des Süchtigen erforderlich ist, wozu der Betreffende nicht gezwungen werden kann und auch nicht gezwungen, sondern überzeugt werden sollte. Ohne ernsthafte eigene Bemühungen bestehen ohnehin keine Erfolgsaussichten.

Aus diesen Erkenntnissen und Erörterungen folgt, dass bei Hilfen für Personen mit schweren multiplen Problembelastungen ein Management erforderlich ist, das darauf abzielt, die jeweiligen Therapien mit sozialpädagogischen Maßnahmen so zu koordinieren, dass ein optimales Resultat erreicht wird (siehe Fall Max im Abschnitt 2.4). Allerdings sind bei schwerwiegenden Devianzen wegen krankhafter Persönlichkeitsstörungen wie sie etwa Werner Schreiber bei Strafgefangenen beschreibt (siehe Jansen u. a. 2006, S. 109ff.) - Diagnosen notwendig, die nach der hier vorgenommen Grenzziehung in den Bereich der Psychiatrie gehören. Was Schreiber an diagnostischer Problematik der „wissenschaftlichen Sozialpädagogik“ (a. a. O., S. 111) zuordnet, geht über den Gegenstandsbereich der Sozialpädagogik hinaus, gehört zur Psychiatrie/Psychotherapie.

Doch abgesehen von dem Verknüpfungs- oder Koordinierungsproblem bezüglich sozialpädagogischen und therapeutischen Handelns, das jeweils auf den Fall bezogen gelöst werden muss, gibt es auch den möglichen Effekt der unbeabsichtigten therapeutischen $\mathrm{Ne}$ benwirkung in der pädagogischen Arbeit, wie folgendes von Schumann geschildertes Beispiel erkennen lässt:

„Ein Lehrer unterrichtet im Fach Biologie der 6. Jahrgangsstufe über Amphibien. Er bringt dazu einen Frosch in die Klasse. Man baut ein Terrarium, füttert und hegt das Tier, setzt es schon mal auf die Hand, streicht mit dem Finger über seine Haut, spricht über Frösche, schreibt und zeichnet, lernt Wissenswertes und bei alle dem bleibt unentdeckt, dass sich ein Schüler vor solchen Tieren fürchtet. Die Furcht ist so groß, daß er sich scheut, das Tier zu berühren, sich vom Terrarium fernhält, sich wenn möglich mit dem Rücken dazu setzt. Selbst wenn der Lehrer solche Anzeichen bemerkt, wird er nicht sofort eine Phobie dahinter vermuten. Er wird darauf achten, daß der Schüler das unterrichtlich Notwendige lernt. Anschließend wendet man sich einem anderen Inhalt zu.

Einige Zeit später, anlässlich eines Elternsprechtages, äußert die Mutter des Schülers dem Lehrer gegenüber ihre Verwunderung. Ihr Sohn fange an, ein Terrarium zu bauen, Frösche zu be- 
obachten, besorge sich Literatur, sucht Tierhandlungen auf und hätte so gar keine Scheu mehr vor den Tieren, vor denen er zuvor jedes Mal mit Entsetzensschrei davon gerannt sei oder deren bloße Erwähnung bei ihm schon ein Gruseln hervorgerufen habe. Was war geschehen? Die Beschäftigung mit dem Inhalt hatte dazu beigetragen, dass der Schüler seine Abneigung und Angst im Umgang mit diesen Tieren überwunden hatte. Diese Wirkung stellte sich unbeabsichtigt, eher zufällig, ungeplant ein. Man wußte weder um die Ängste des Schülers, noch hätte man zuvor die »therapeutische« Wirkung des Inhalts für ihn vermutet" (Schumann 1993, S. 303/304).

Im Anschluss an dieses reale Beispiel konstruiert Schumann den denkbaren Fall, dass ein Therapeut in seiner Praxis den Jungen nach der Diagnose der Phobie systematisch behandelt, so dass dieser seine Angst vor Amphibien überwindet. In seiner Interpretation zum realen pädagogischen Fall und zur konstruierten Therapie schreibt er:

„An beiden Szenarien, ersteres real selbst erlebt, letzteres theoretisch konstruiert, aber im Ablauf so vorstellbar, arbeiten die »Akteure« (Ergänzung durch W. N.) mit dem gleichen Inhalt. Im Unterricht wären diese zunächst erzieherisch, in der therapeutischen Behandlungssituation bekommen sie therapeutische Qualität. Hier liegen in der Sache beide Möglichkeiten vor. Die »Neutralität« des Inhalts wird in der Verwendung verlassen“ (a. a. O., S. 304/305).

Dieses Beispiel belegt die therapeutische Wirkung von pädagogischen Aktivitäten eines Lehrenden bei Lernenden. Es kann daraus auch auf die prinzipielle Möglichkeit therapeutischer Effekte in sozialpädagogischen Prozessen geschlossen werden.

Auf ein theoretisches Problem in der Darstellung des Beispiels sei hier jedoch hingewiesen: Schumanns Interpretation liegt eine unzulässige Gleichsetzung von Gegenstand und Inhalt von Lernprozessen zugrunde, wodurch der eigentliche Veränderungsvorgang im Denken und Fühlen des Schülers eher verdunkelt als erhellt wird. Nach der im Abschnitt 1.2 dargestellten Auffassung vom Wesen des Inhalts erzieherischer Prozesse verhält es sich wie folgt: Im Unterricht wird der Schüler zunächst mit dem Frosch als Gegenstand des Unterrichts konfrontiert. Was er davon wabrnimmt und an Vorstellungen entwickelt, ist der Inhalt, und dessen Wirkung hängt offensichtlich nicht nur vom realen Frosch, sondern auch von den inneren Voraussetzungen des Schülers ab. Zu diesen gehört im oben geschilderten Fall die Phobie; sie fließt gewissermaßen mit ein in den Unterrichtsinhalt, den der Schüler erlebt. So gesehen, ist also nicht der Inhalt, sondern der Gegenstand neutral, was sich in Schumanns Formulierung äußert, dass ,in der Sache beide Möglichkeiten“" (des unterrichtlichen Bildungserwerbs und der Psychotherapie) liegen.

Der therapeutische Effekt ist nur dadurch zu erklären, dass es dem Lehrer unbewusst und zufällig gelungen ist, was ein Therapeut mit seinen Methoden bewusst anstrebt: nämlich die Herstellung einer wesentlich veränderten intellektuellen und emotionalen Beziehung 
zum Gegenstand durch die Veränderung der Sichtweise und Einstellung dazu, um Angst- und Ekelgefüble zu überwinden. Im Verlaufe der Beschäftigung mit dem Frosch als Gegenstand der Aneignung veränderte sich der Inhalt im Bewusstsein des Lernenden dank des methodischen Umgangs mit ihm - im ersten Fall relativ spontan und im zweiten Fall durch den bewussten Einsatz zweckmäßiger Methoden der intellektuellen und emotionalen Auseinandersetzung mit dem Inhalt, also den emotional bedeutsamen sinnlichen und rationalen Abbildungen sowie konstruierten Vorstellungen vom Frosch im Bewusstsein des Schülers. Im Ergebnis dieser Auseinandersetzung werden Angst- und Ekelgefühle, die der Anblick des Gegenstandes zunächst erzeugt hat, überwunden, weil als unbegründet erkannt und ,erfühlt“.

Eine anregende Darstellung zum Verhältnis von Erziehern und Therapeuten findet sich in dem Sammelband „Bildung und Erziehung an der Schwelle zum dritten Jahrtausend“ (München 1994) von Norbert Seibert (ebenda S. 801-828). Er hat zwar vorwiegend das Verhältnis von schulischer Erziehung und Psychotherapie im Auge, aber wesentliche Erkenntnisse etwa zu den spezifischen personellen Ausgangslagen und Zielen bei zu Erziehenden und zu Therapierenden hat er recht differenziert zusammengestellt. Dabei muss beachtet werden, dass Soz̧ialpädagogen noch „viel dichter“ bei den Psychotherapeuten ,angesiedelt“ sind als Lehrer von allgemeinbildenden Schulen, an die sich der Artikel richtet. Seibert weist darauf hin, dass folgende Handlungselemente, die Roger dem Therapeuten zuordnet, in abgeschwächter Form auch für den Lehrer wichtig und realisierbar sind, nämlich:

- „Echtheit oder Kongruenz des Therapeuten;

- das vollständige und bedingungslose Akzeptieren des Klienten seitens des Therapeuten und

- $\quad$ ein sensibles und präzises einfühlendes Verstehen des Klienten seitens des Therapeuten“ (Rogers zitiert nach Seibert 1994, S. 812).

Natürlich kann ein Lehrer, der seinen gesellschaftlichen Auftrag mit relativ großen Schulklassen zu erfüllen hat, solchen Anforderungen nicht voll entsprechen. Jedoch sollte er sich um die individuelle Förderung, die mit Rogers Programm verbunden ist, redlich bemühen. Erst recht aber ist ein Sozialpädagoge dazu verpflichtet. Zwischen seinem Herangehen an einen Klienten und dem, das Roger beschrieben hat, sollte es keine wesentlichen Unterschiede geben, so dass man sagen kann: die wesentlichen Unterschiede zwischen Erziehen und Therapieren lassen sich nur auf der theoretischen Ebene durch Kennzeichnung der unterschiedlichen Ausgangslagen (krank oder gesund) und den damit zusammenhängenden Zielen bestimmen. In der Praxis bedarf es stets einer sorgfältigen Analyse der Ausgangslage und einer differenzierten Diagnose. Die Analyse sollte nicht durch eine voreilige „Krankschreibung“ ersetzt werden, weil das leicht zu einer ungerechtfertigten „Pathologisierung des Täters“ führt und damit die 
Gefahr des Therapismus bedeutet, vor der Hartmut v. Hentig mit folgenden Worten warnt:

„Eine der schlimmsten Verführungen in unserer bedrohlichen und bedrohten Welt ist der uns allenthalben angebotene Status des Patienten. Die Schwierigkeiten sind zu groß für uns, wir fühlen uns überfordert und suchen nicht etwa jemanden, der uns stärkt, sondern jemanden, der uns behandelt. Wir überantworten unser Versagen einem anderen, der uns in der Regel bestätigt, unsere Schwäche sei durch dieses oder jenes Ereignis verschuldet. [...] Wir lassen uns moralisch entschuldigen. Der moderne Therapismus verspricht Heilung um den Preis, daß man sich für krank erklärt. [...] Ein menschenstärkendes Prinzip ist die Psychotherapie nicht, sie ist eine Nothilfe“" (zitiert nach Seibert 1994, S. 821).

Therapien finden Anwendung im Krankheitsfalle; psychosoziale Intensiverziehung erfolgt bei vorliegendem devianten Verhaltensweisen. Dementsprechend gibt es Prophylaxen im medizinischen und Präventionen im pädagogischen Bereich. Zu dieser Problematik schreiben Hompesch-Cornetz und Hompesch:

„Die gesellschaftliche Regulierung sozialer Probleme wird vermehrt durch präventive Sozialisationsangebote vorgenommen. Die Bestimmung sozialpädagogischen und therapeutischen Handelns macht sich damit an der Sozialisationsbedürftigkeit fest, nicht erst an der Abweichung von Sozialisationszielen“ (1987, S. 1030).

Der erste Satz ist richtig, aber was bedeutet die These, dass sich die „Bestimmung sozialpädagogischen und therapeutischen Handelns" an der Sozialisationsbedürftigkeit festmachen lasse? Grundsätzlich ist festzustellen, dass jedes neugeborene Menschenkind sozialisationsbedürftig ist - eben deshalb muss es erzogen werden, und zwar als individuelle Persönlichkeit und als Gemeinschaftsmitglied. Bedarf es deshalb aber schon von Anfang an therapeutischer oder sozialpädagogischer Maßnahmen? Sicher werden diese erst dann erwogen und eingesetzt, wenn es dafür hinreichende Gründe gibt. Und wann sind hinreichende Gründe erkennbar? Doch wohl erst bei auftretenden Krankheiten bzw. Devianzen, deren „Behandlungen“ professionelle Hilfen erfordern.

Außerdem ist die Frage zu stellen, ob für die Prävention bzw. Prophylaxe hinsichtlich devianten Verhaltens tatsächlich nur Sozialpädagogen und Therapeuten zuständig sind. Ist das nicht vielmehr Aufgabe aller erzieherischen und auch medizinischen Kräfte der Gesellschaft? Es müssten doch eigentlich alle Erzieher und Mediziner im Rahmen ihrer fachspezifischen Arbeit auch die jeweils relevanten präventiven bzw. prophylaktischen Aufgaben mit im Auge haben. Ist das nicht auch schon vielfach der Fall? Aber gewiss müssen diese Bemühungen gefördert und forciert werden durch eine entsprechende Orientierung und inhaltliche Komponente in der Ausbildung pädagogischer Fachkräfte, insbesondere im Bereich der Lehrerbildung! 


\subsection{Sozialpädagogik im Ensemble der Wissenschaften von der Sozialen Arbeit}

Nachdem eine spezifische Zöglings-Ziel-Relation als Konstituierungsgrundlage für eine Sozialpädagogik als erziehungswissenschaftliche Disziplin gewählt worden ist, sollen einige wichtige Konsequenzen dieser Entscheidung für die Erforschung und Darstellung der Struktur und Funktionsweise der psychosozialen Intensiverziehung aufgezeigt werden.

Nach der Bestimmung des Gegenstandes der Sozialpädagogik ist es nunmehr möglich, die spezifischen Phänomene im Gegenstandsbereich zu untersuchen und zu erklären, wobei die Sozialpädagogik auf Erkenntnisse ihrer Nachbarwissenschaften zurückgreifen kann und muss, also auf die Anthropologie, Soziologie, Psychologie usw. Da die Sozialpädagogik ihrem Charakter nach eine Handlungswissenschaft ist, geht es vor allem darum, möglichst fundierte und praktikable Handlungskonzepte zu erarbeiten, wozu die Untersuchung folgender Themenkreise gehört:

- Besonderheiten des Zöglings in der psychosozialen Intensiverziehung und Ansatzpunkte zur Überwindung devianten Handelns und Verhaltens (Kapitel 3);

- spezielle Probleme der Zielbestimmung in der psychosozialen Intensiverziehung und die Arbeit mit Zielen und Inhalten im Erziehungsprozess (Kapitel 4);

- Besonderheiten in den Eræieher-Zöglings-Beziehungen, die für eine erfolgreiche psychosoziale Intensiverziehung bedeutsam sind (Kapitel 5);

- Besonderheiten der inhaltlich-methodischen und organisatorischen Gestaltung der psychosozialen Intensiverziehung auf der Ebene einer Allgemeinen Sozialpädagogik (Kapitel 6).

Diese konzeptionelle Orientierung für das weitere Vorgehen lässt erkennen, dass und wie versucht wird, ausgehend von allgemeinen und grundlegenden Abstraktionen System, Element, Struktur, Funktionen, Erziehung, Sozialpädagogik, Therapie, Gesetze, Prinzipien usw. - etwas Konkretes im Sinne einer „reichen Totalität von vielen Bestimmungen und Beziehungen" (vgl. MEW, Bd. 42, S. 35) in Gestalt der Wissenschaftsdisziplin „Allgemeine Sozialpädagogik" zu erarbeiten. Für die Darstellung ist wesentlich, dass sie nicht nur Kategorien und Begriffe, empirische Feststellungen und Gesetzesaussagen, sondern auch Ziele und Normen sowie Prinzipien und Regeln als allgemeine Handlungsorientierungen anbietet. Damit wird aus der unendlichen Vielfalt von Erscheinungen und Vorgängen der Praxis das Allgemeine und Wesentliche abstrahiert und bewusst gemacht, das für erfolgreiches praktisches Handeln bedeutsam ist. Aus dialektisch-materialistischer Sicht betrachtet, irrt sich Bleidick, wenn er schreibt:

„Das Wesen der Theorie ist Abstraktion. [...] Praxis dagegen ist singulär, nicht übertragbar, auf die jeweils konkrete, einzigartige Situation bezogen“ (Bleidick 2001, S. 163). 
Nach Hegel und Marx ist auch eine Theorie konkret, nämlich als „,reiche Totalität von vielen Bestimmungen und Beziehungen“ (Marx, a. a. O.) oder Synthese vieler Abstraktionen. Umgekehrt ist auch in der Praxis das Allgemeine (im Sinne des „allen Fällen Gemeinsamen") zu finden, das der Mensch erkennen und z. B. in Begriffen und Prinzipien erfassen kann. Wenn Bleidick behauptet, die Praxis sei singulär, dann identifiziert er in unzulässiger Weise die Praxis (als Bewegungsform der Gesellschaft) mit dem einzelnen praktischen Fall. Singulär ist natürlich jeder einzelne Fall in seiner realen Ganzheit. Aber er enthält immer auch etwas Allgemeines, etwas, was auch in anderen praktischen Fällen auftritt, nämlich invariante Eigenschaften realer Gegebenheiten und ähnliche Anwendungsbedingungen für Prinzipien und Regeln, die theoretisch erfasst und praktisch genutzt werden können. Einerseits ist jeder praktische Fall reicher an Fakten und Zusammenhängen als das System der zu seiner Lösung verfügbaren theoretischen Erkenntnisse - andererseits bietet jede entwickelte Theorie wiederum mehr Erkenntnisse an als jeweils für den einzelnen Fall benötigt werden.

Aus der objektiven Existenz des Allgemeinen (im Sinne des ,allen Fällen Gemeinsamen") und des Einmaligen oder Individuellen in Erziehungsprozessen resultiert, dass Prinzipien und Regeln keine Rezepte sind, die mechanisch angewendet werden können. Vielmehr stellen sie relativ allgemeine Handlungsorientierungen dar, die einer schöpferischen Umsetzung durch die Agierenden bedürfen. Doch gerade für dieses bewusste schöpferische Handeln benötigen sie theoretische Erkenntnisse, die bereits ihre Wahrnehmung der Realität lenken, zur Analyse anleiten und rational begründete - also nicht nur gefühlsmäBige - Entscheidungen ermöglichen. Dabei wird auch dem Gefübl für das, was angemessen erscheint, eine Berechtigung zuerkannt; es gehört mit zum schöpferischen Handeln im einzelnen Fall, bei dessen Erklärungsversuche auch neue Probleme auftreten können.

Damit die Sozialpädagogik ihre Hauptaufgabe als Handlungswissenschaft - nämlich die Anleitung der in ihrem Gegenstandsbereich praktisch Agierenden - erfüllen kann, genügt es nicht, dass sie Bedingungen und Verlaufsqualitäten der psychosozialen Intensiverziehung untersucht und beschreibt, sie muss auch in möglichst rationeller Weise Handlungsanleitung zur Prozessgestaltung geben, wofür entsprechend den Ausführungen im Abschnitt 1.6 Prinzipien und Regeln geeignet und wichtig sind. Damit kommen wir zu einem Kernproblem der Sozialpädagogik als Handlungswissenschaft, zur Frage nach dem System und der zweckmäßigen Darstellung ibrer Prinzipien für die Prozessgestaltung.

Lüssis bestimmt in seinem Buch „Systemische Sozialarbeit“ (1992) die formale Struktur seiner Methodenlehre für Sozialarbeiter durch zwei fundamentale Kategorien, durch »methodische Prinzipien« und durch »Handlungsarten« der Sozialarbeit (Lüssi 1992, S. 209). Er unterscheidet sechs Handlungsarten: Beratung, Verhandlung, Intervention, Vertretung, Beschaffung und Betreuung. Diese Handlungsarten sind auf die Lösung sozialer Probleme gerichtet und erfordern die Beachtung von Prinzipien. Zwar hat Lüssi seine 
Prinzipien unter dem Aspekt der Entwicklung einer systemischen Sozialarbeit formuliert, doch ist bei den meisten Prinzipien ihre sozialpädagogische Relevanz unverkennbar gegeben. Das ist verständlich, wenn wir bedenken, dass moderne Sozialarbeit auf der Grundlage des Prinzips der Hilfe zur Selbsthilfe erfolgt, dessen Realisierung unbedingt auch pädagogische Aktivitäten erfordert.

Die Motivierung zur Mitwirkung am Problemlösungsprozess, die Lenkung von Lernprozessen einschließlich der Bewertung des Erreichten und der eigenen Anstrengungen sind wichtige sozialpädagogische Momente in der Sozialen Arbeit. Auf diese Momente in den Problemlösungsprozessen richten sich Lüssis methodische Prinzipien, die er wie folgt bestimmt:

„Die methodischen Prinzipien sind Denk- und Handlungsmaximen des Sozialarbeiters. In ihrem umfassenden, relativ abstrakt formulierten Sinn haben sie allgemeine Bedeutung und Gültigkeit für das sozialarbeiterische Problemlösungshandeln [... ]“ (Lüssi 1992, S. 209).

In der weiteren Erläuterung betont er den Systemcharakter der Prinzipien:

„Wir haben uns allerdings darüber klar zu sein, dass sich im konkreten methodischen Handeln des Sozialarbeiters stets mehrere Prinzipien zugleich realisieren. Es geht also in der Sozialarbeitspraxis nie um das einzelne methodische Prinzip an-sich, wie es die theoretische Analyse herausarbeitet. Und entsprechend setzt auch die sozialarbeiterische Methodenlehre die Prinzipien keineswegs absolut, sondern versteht sie als Teilaspekte eines zusammenhängenden Ganzen. Dieses Ganze ist die sozialarbeiterische Methode. [...] Das einzelne Prinzip bringt einen methodischen Gedanken, eine praktische Maxime prägnant zum Ausdruck, aber es darf nicht isoliert, für sich allein verstanden werden“ (a. a. O., S. 211; Hervorhebung im Original).

In seinen Erläuterungen zur Methode der Sozialarbeit betont Lüssi die Begründung der Prinzipien durch praktische Erfahrungen, ihren Systemcharakter und die Notwendigkeit ihrer flexiblen und schöpferischen Anwendung. Dass er damit eine herausragende wissenschaftliche Leistung vollbracht hat, steht außer Frage, auch wenn sie in einigen Punkten zur Kritik herausfordert. So untersucht er z. B. nicht den Zusammenhang von Prinzipien der Sozialarbeit mit ihren Zielen und Gesetzmäßigkeiten. Auch der Begriff des Prinzips selbst wird nicht eindeutig definiert, so dass das Verhältnis von Prinzipien, Subprinzipien und Regeln unklar bleibt.

Aus Gründen einer lebendigen Darstellung verzichtet Lüssi bewusst auf eine präskriptive (vorschreibende) Formulierung der Prinzipien zugunsten einer deskriptiven (beschreibenden), betont aber, „dass in derartigen, auf ein Ideal bezogenen deskriptiven Ist-Aussagen gleichzeitig eine präskriptive Soll-Meinung steckt, [...]“(a.a. O., S. 212). Lüssi stellt folgende Gruppen methodischer Prinzipien der Sozialarbeit vor:

1. Konzeptprinzipien

2. Handlungsprinzipien allgemeiner Art 
3. Handlungsprinzipien betreffend das Verhältnis zwischen Sozialarbeiter und Problembeteiligten

4. Handlungsprinzipien betreffend das Problemlösungsvorgehen

5. Akzeptanzfördernde methodische Prinzipien

Lüssi hat vorliegende Erfahrungen und Erkenntnisse aus der Sozialarbeit in entwickelten Industrieländern ausgewertet und die Prinzipien offenbar unter dem Aspekt der Hauptwirkungsrichtung von Handlungen gruppiert. Dabei ist er auf 33 Prinzipien und 26 Subprinzipien gekommen, die zwar ein differenziertes Anleitungsinstrumentarium darstellen, aber für den Lernenden bzw. Praktiker schwer zu überschauen und zu merken sind (vgl. Lüssis Prinzipienübersicht in der Anlage II dieses Buches). Darüber hinaus beachtet er nicht, dass es in der Philosophie und Pädagogik eine Reihe von Erkenntnissen zur Struktur gesetzmäßiger Beziehungen gibt, die auch bei der Formulierung von Prinzipien genutzt werden können. Gemeint ist damit, dass Gesetzmäßigkeiten in Natur und Gesellschaft als Regimes von Wechselwirkungen auftreten (vgl. S. 59f. und S. 277).

Eine Zusammenfassung oder Bündelung einiger Prinzipien von Lüssi ist daher nicht nur aus lernpsychologischen bzw. hochschuldidaktischen Gründen ratsam, sondern auch auf Grund folgender theoretischer Überlegungen möglich und zweckmäßig:

Erstens gibt es bei Lüssi einige Prinzipien bzw. Subprinzipien, deren Forderungen inhaltlich so eng zusammenhängen, dass sich eine Zusammenfassung geradezu anbietet. Es liegt z. B. nahe, das Prinzip der Handlungsherrschaft des Sozialarbeiters (a. a. O., S. 250) mit dem Prinzip der Selbständigkeitsförderung des Problembelasteten (a. a. O., S. 267) zu verknüpfen und als zu realisierende dialektische Einheit zu behandeln. Oder: das „systemische Prinzip" - also das systemische Herangehen an alle soziale Probleme - sollte zweckmäßigerweise mit dem „Prinzip des problemindividuellen Verstehens“ verbunden werden, damit die jeweilige individuelle Problematik bewusst in ihren natürlichen und gesellschaftlichen Zusammenhängen betrachtet und behandelt werden kann.

Zweitens enthält die Prinzipienliste von Lüssi einige Subprinzipien, die nach vorliegender Darstellung im Abschnitt 1.6.2 wohl eher als Regeln aufgefasst werden sollten, da es sich um situationsabbängige bzw. situationsbezogene Vorschriften handelt. Ob dem „Prinzip der Zeitrichtigkeit" zum Beispiel durch die Subprinzipen „rasches Handeln“ oder „Zuwarten" entsprochen wird, hängt offensichtlich von der jeweiligen Situation ab. Auch die von ihm genannten Arten und Möglichkeiten der Verhandlung sind situationsabhängig. Aber es stebt außer Frage, dass verhandelt werden muss, weil ohne Verhandlungen Soziale Arbeit nicht funktioniert.

Eine dritte Begründung für die Zusammenfassung ergibt sich aus den inneren Zusammenhängen zwischen den Prinzipien, auf die Lüssi selbst hinweist. Es ist eine alte Tradition in pädagogischen Methodenlehren, innere Zusammenhänge zwischen methodischen 
Forderungen auch in entsprechend formulierten Prinzipien zusammenzufassen. Beispiele dafür sind Herbarts Forderungen nach „Vertiefung“ und „Besinnung“ im Unterrichtsprozess oder nach Verbindung von analytischem und synthetischem Vorgehen, die auch als Prinzipien gelten. Mit der Verknüpfung polarer Forderungen im Rahmen eines Prinzips (z. B. beim Prinzip der Einheit von Konkretem und Abstraktem im didaktisch geführten Erkenntnisprozess) soll bewusst möglichen Einseitigkeiten in der Prozessgestaltung vorgebeugt und auf die als Triebkräfte wirkenden inneren Widersprüche des Prozesses hingewiesen werden.

Viertens schließlich hat es in der Geschichte der Pädagogik schon kompliziertere Verknüpfungen von Forderungen in einem Prinzip gegeben als die polaren. So hat beispielsweise August H. Niemeyer (1754-1828) vier „höchste Grundsätze aller Erziehung“ formuliert, von denen der dritte lautet:

„Richte die erweckte Kraft auf alles, was der Vernunft des Menschen würdig erscheint, durch jedes Mittel, das mit den Rechten des Zöglings als Vernunftwesen verträglich ist" (Niemeyer 1888, S. 65).

An dem „höchsten Grundsatz“ ist außer dem Forderungscharakter erkennbar, dass er im Sinne der Aufklärung ein Kriterium für gültige Ziele der Zöglingstätigkeit und für die Auswabl der Mittel angibt, nämlich die „Rechte des Zöglings als Vernunftwesen“.

Doch abgesehen von dem Problem der theoretischen Fundierung und zweckmäßigen Formulierung der einzelnen Prinzipien durch Lüssi, sind vor allem ihre Vielzabl und Gruppierungen kritisch zu prüfen. Dabei kann zunächst einmal festgestellt werden, dass Lüssis Herausarbeitung von Konzeptprinzipien originell, zweckmäßig und überzeugend ist, denn

„Die Konzeptprinzipien beziehen sich zur Hauptsache auf die konzeptionelle Strukturierung der sozialen Problemlösung: darauf, wie der Sozialarbeiter dieselbe grundsätzlich sieht, auffasst, versteht. Es drückt sich in ihnen das geistige Konzept aus, mit welchem der Sozialarbeiter an seine Aufgabe herantritt, [...]“ (Lüssi 1992, S. 213).

Für das Herangehen der Sozialarbeiter/Sozialpädagogen an ihre Aufgaben werden also allgemeine Prinzipien formuliert, die besonders bei der Planung zu beachten und zugleich persistent sind, d. h. möglichst auch während der gesamten Prozessgestaltung also in der prozessimmanenten und interaktiven Planung durch alle Beteiligten - mit berücksichtigt werden müssen. Allerdings ist zu prüfen, inwieweit die von Lüssi erarbeitete nachfolgende Liste von Konzeptprinzipien, nämlich

- das Prinzip des problemindividuellen Verstehens,

- das Prinzip der Wechselwirkung von Verstehen und Handeln,

- das systemische Prinzip,

- das Prinzip des soziallogischen Denkens, 
- das sozialethische Prinzip und

- das Kreativitätsprinzip

mit weiteren prinzipiellen Forderungen angereichert werden kann oder muss (vgl. 4.6). Lüssis Aufgliederung der Handlungsprinzipien in allgemeine und in spezielle „betreffend das Problemlösungsvorgehen“ ist kaum verständlich, weil auch unter pragmatischen Gesichtspunkten nicht hinreichend begründet. Beispielweise besteht zwischen den allgemeinen Handlungsprinzipien der Zielsetzung oder Flexibilität und dem speziellen sog. Verbandlungsprinzip oder dem Tatsachenprinzip hinsichtlich des Allgemeinheitsgrades kein Unterschied; außerdem dienen sie alle dem Problemlösungsvorgehen. Ähnlich verhält es sich mit den „Handlungsprinzipien betreffend das Verhältnis zwischen Sozialarbeitern und Problembeteiligten“ und den „akzeptanzfördernden methodischen Prinzipien“, denn bei dem Verbältnis, das zwischen beiden Seiten entwickelt werden soll, geht es wesentlich um Akzeptanz und Vertrauen. Rechtfertigt die Teil-Ganzes-Beziehung (Akzeptanz als Moment des ganzen Verhältnisses) die Bildung von zwei Prinzipiengruppen?

Hinzu kommt, dass die Einordnung der einzelnen Prinzipien in die jeweilige Gruppe vielfach fragwürdig ist. Aus welchen Gründen wird z. B. das Kommunikationsprinzip den „Handlungsprinzipien betreffend das Verhältnis zwischen Sozialarbeitern und Problembeteiligten“ zugeordnet und das Verhandlungsprinzip den „Handlungsprinzipien betreffend das Problemlösungsvorgehen"? Verhandlungen ohne Kommunikation gibt es nicht. Kommunizieren und Verhandeln sind zwar nicht identische Begriffe, aber doch so eng verwandt, dass Lüssis unterschiedliche Eingruppierung nicht einleuchtet.

Ferner erscheinen Lüssis „Handlungsprinzipien allgemeiner Art“ (vom Standpunkt des Einteilungskriteriums „Hauptwirkungsrichtung“ aus betrachtet) als fragwürdiger Gruppierungsversuch. Sicherlich könnten in Anwendung von Wächters Kriterien zur Prinzipienklassifikation manche Prinzipien von Lüssi den normativen Prinzipien zugeordnet werden. Einige von seinen allgemeinen Handlungsprinzipien (z. B. das der „Lösungszentriertheit" mit den zugeordneten Subprinzipien „Zielsetzung“ und „Effizienz") oder sein „Kreativitätsprinzip“ aus der Reihe der Konzeptprinzipien sind gültige Normen für die Gestaltung vieler gesellschaftlicher Prozesse und daher auch für die Soziale Arbeit relevant. Sie können deshalb auch nicht als spezifische Prinzipien der Sozialarbeit/Sozialpädagogik betrachtet werden, obgleich sie wegen der Persistenz vieler Prinzipien menschlichen Handelns auch in diesem Bereich gelten.

Das eigentliche Problem, das hier sichtbar wird, besteht in den Fragen,

- ob es wirklich spezifische normative Prinzipien der Sozialen Arbeit und damit auch der Sozialpädagogik gibt und - wenn ja -

- welche es denn sein könnten. 
Die bereits von Trost formulierten Prinzipien - das Rettungsprinzip, das Heilungsprinzip, das Prinzip der Ertüchtigung oder modern formuliert: das Förderungsprinzip - orientieren auf allgemeine Ziele der Sozialen Arbeit und charakterisieren zugleich ihr humanistisches Anliegen, dem so weit wie möglich alle Handlungen und Operationen der Sozialpädagogen entsprechen müssen. Da normative Prinzipien aus der Eigenart des jeweiligen Handlungsbereiches abgeleitet werden (also: Wissenschaft, Soziale Arbeit, Wirtschaft usw.), erfolgt ihre weitere Erörterung an geeigneter Stelle, d. h. nach der Klärung wesentlicher Besonderbeiten des Gegenstands der Sozialpädagogik am Ende des 3. Kapitels.

Ausgehend von diesen Überlegungen werden in den nachfolgenden Kapiteln in Anlehnung an Lüssi seine sozialpädagogisch relevanten Prinzipien in der traditionellen Form von Forderungen formuliert. Außerdem wird nicht nur die Darstellungsform, sondern auch der Schwerpunkt in der Betrachtungsweise gewechselt. Während Lüssi primär die Sozialarbeit betrachtet (wobei Sozialpädagogik als untergeordnete Komponente auftritt), steht nunmehr die sozialpädagogische Betrachtungsweise im Vordergrund.

Es werden hier auch nur jene grundlegenden Handlungsorientierungen als Prinzipien aufgenommen, die den dargestellten Kriterien entsprechen, d. h., Formulierungen Lüssis, die sich bei genauerer Prüfung als Regeln erweisen, werden von der Prinzipienliste gestrichen. Die Forderung nach Präsumtion (Voraussetzung, Annahme) des guten Willens ist beispielsweise eine solche Regel, die eben nur im Umgang mit manchen Klienten und nicht bei allen gilt, weil es beim begründeten Verdacht von Hinterhältigkeit des Klienten dem Prinzip der Echtheit widersprechen würde, ihm dennoch guten Willen zu unterstellen. Übrigens fehlt das Prinzip der Echtheit, das für die Vertrauensentwicklung wichtig ist, bei Lüssi, und es ist mit der Akzeptanz eines vorgetäuschten guten Willens unvereinbar. Die Nichtbeschuldigung dagegen, das Anknüpfen an persönliche Stärken des Klienten und der Glaube an „einen guten Kern in ihm“ in Übereinstimmung mit der Echtheit im Verhalten des Sozialpädagogen können als allgemeine, wesentliche und notwendige Forderungen in der Sozialarbeit und damit auch in der praktischen Sozialpädagogik angesehen werden, da sie nicht nur in manchen Situationen, sondern allgemein gelten.

In der bisherigen Erörterung wurde auf die innere Verflechtung der Prinzipien, den pragmatischen Charakter der Gruppierungen und auf die Kompliziertheit der Systemzusammenhänge in der Sozialen Arbeit verwiesen. Aber gerade deshalb ist zu prüfen, ob es nicht doch eine theoretisch begründete oder zumindest hochschuldidaktisch zweckmäßigere Lösung des Gruppierungsproblems gibt. Für eine begründete Systematisierung von sozialpädagogischen Prinzipien werden analog jene Gesichtspunkte genutzt, die der Autor bereits für die Darstellung von Prinzipien der Didaktik entwickelt hat (vgl. Liimets/Naumann 1982 und 1985), so dass sich nunmehr folgende Gruppierung ergibt:

1. Normative Prinzipien, die den humanistischen Sinn und das Wesen sozialpädagogischen Handelns bestimmen und der Grundorientierung dienen; 
2. Konzeptprinzipien, die das Herangehen an sozialpädagogische Aufgaben und Probleme betreffen und auch für die prozessimmanente bzw. interaktive Planung gelten;

3. Strukturprinzipien für das Miteinander-Umgehen, d. h. für die Gestaltung der Beziehungen zwischen Sozialpädagogen und Klienten zwecks Sicherung der Funktionstüchtigkeit des Prozesses;

4. Funktionsprinzipien für das gemeinsame Vorgehen im Problemlösungsprozess durch die Prozessbeteiligten.

Zugleich wird in den nachfolgenden Darstellungen außer der Prinzipienbezeichnung der jeweilige Muss-Satz. formuliert, der die gemeinten Forderungen klar ausdrückt. Ein Muss-Satz erscheint deshalb, weil es sich bei echten Handlungsprinzipien auch um Erfordernisse objektiver Gesetzmäßigkeiten handelt und nicht nur um etwas moralisch Wünchenswertes, das gewöhnlich in Soll-Sätzen formuliert wird.

Unter Lüssis Prinzipien, die als Grundlage für die hier vorgenommene Zusammenfassung von 14 Prinzipien dient, fehlt außer dem Prinzip der Echtheit ein von Makarenko angewendetes und wiederholt betontes, das auch gegenwärtig noch (oder wieder!) aktuell ist:

„Möglichst hohe Forderungen an den Menschen und möglichst hohe Achtung vor ihm“ (Makarenko 1969, Bd. V, S. 155, S. 238).

Da es hinreichend viele praktische Erfahrungen bezüglich der Zweckmäßigkeit dieses Prinzips gibt und sich auch eine theoretische Begründung dafür finden lässt (vgl. Abschnitt 4.6.5), wird es als fünftes in die Reihe der Konzeptprinzipien eingefügt, so dass sich insgesamt 15 Prinzipien ergeben (siehe Anlage III). Bei der Begründung der einzelnen Prinzipien in den entsprechenden Kapiteln dieses Buches wird erläutert, dass und wie die Sozialpädagogik auf Erkenntnisse - besonders gesetzmäßiger Zusammenhänge ihrer Bezugswissenschaften zurückgreift. Auch das verdeutlicht dann noch einmal die Stellung und die Funktion der Sozialpädagogik im Ensemble der relevanten Wissenschaften: Einerseits ist die Sozialpädagogik von ibren Bezugswissenschaften in hohem Maße abhängig und andererseits verbilft sie deren Erkenntnisse vermittels eigenständig formulierter Prinzipien zu praktischer Wirksamkeit. Zugleich dokumentiert sie damit ibren transdiszipinären Charakter.

Diese Aussage über das Verhältnis von Sozialpädagogik zu ihren Bezugswissenschaften gilt generell für das Verhältnis der Pädagogik zu ihren relevanten Nachbarwissenschaften. Sie ist auch für das Verständnis des Wesens und der Wirksamkeit der Pädagogik als Wissenschaft überhaupt bedeutsam, denn trotz ihrer relativen Eigenständigkeit als Erkenntnissystem stützt sie sich bei der Formulierung ihrer Prinzipien auf die Forschungsergebnisse eben dieser Wissenschaften, also der Biologie, Medizin, Ökonomie, Soziologie, Psychologie usw. Deren Erkenntnisse gesetzmäßiger Zusammenhänge werden berücksichtigt bei der Formulierung pädagogischer Prinzipien und Regeln. 
Da Prinzipien keine eineindeutigen oder starren Handlungsvorschriften darstellen, können und müssen sie in modifizierter Weise - also möglichst situationsgerecht - zur Bewältigung erzieherischer Aufgaben oder Probleme genutzt werden. Um sie aber situationsgerecht nutzen zu können, ist jeweils eine sorgfältige Einzelfallanalyse notwendig, und eben dazu können die auf Seite 92f. gekennzeichneten Didaktiken der Arbeitsfelder hilfreich sein, denn sie würden die jeweils problemspezifischen Analysegesichtspunkte und Handlungskonzepte für die Feldarbeit mit ihren Einzelfällen liefern.

Grundsätzlich jedoch bedarf es einer differenzierten Vorstellung von den wesentlichen Momenten des Prozessverlaufs, um die formulierten Prinzipien im Erziehungsprozess auf den Einzelfall anwenden zu können. Diese Prozesselemente aufzudecken und praktikabel darzustellen, ist eine Kernaufgabe der Pädagogik, die ihr keine andere Wissenschaft abnehmen kann und der wir uns im 6. Kapitel besonders zuwenden. Darin werden die Grundzüge des Verlaufs sozialpädagogischer Prozesse mit Hilfe eines Funktionsmodells (s. S. 321) dargestellt. In der zweckmäßigen Verknüpfung der einzelnen Funktionseinheiten und Funktionen mit den jeweils relevanten Prinzipien auf der Grundlage der Erkenntnisse aus der Feld- und Fallanalyse besteht dann die schöpferische Leistung des Erziehers bzw. Sozialpädagogen, die allerdings auch bei Beachtung aller wissenschaftlichen Gesichtspunkte keine Erfolgsgarantie einschließt, weil die in den Prinzipien widergespiegelten gesetzmäßigen Zusammenhänge probabilistischen Charakter tragen.

Die speziellen Sozialpädagogiken für die verschiedenen Arbeitsfelder oder Didaktiken - die zweckmäßige Bezeichnung müsste noch geklärt werden - beschäftigen sich mit spezifischen Erscheinungsformen, typischen Kombinationen und Entstehungsbedingungen für das jeweils charakteristische deviante Handeln und Verhalten im betreffenden Arbeitsfeld (Gewalttätigkeiten, Diebstahl, Arbeitsbummelei, Drogensucht, Ess-Störungen usw.); sie erarbeiten zugleich methodische Hilfen (Analyse- und Handlungskonzepte) für die Feldarbeit und den Einzelfall. Dabei spielen biologische, soziologische, psychologische, medizinische und weitere Erkenntnisse eine Rolle, die im nächsten Kapitel zur Verdeutlichung des transdisziplinäre Charakters der Sozialpädagogik partiell vorgestellt werden. Speziell der Abschnitt 3.2 vermittelt Erkenntnisse ausgewählter Theorien zur Erklärung devianten Verhaltens.

In Verbindung mit den bisherigen Ausführungen zu den transgredienten Grundlagen pädagogischen Denkens und Handelns (unter besonderer Berücksichtigung philosophischer, wissenschaftstheoretischer und methodologischer Probleme) bieten die nachfolgenden Kapitel zu den immanenten Momenten der Erziehung und ihrer Funktionsweise auch eine Variante zur Strukturierung der Sozialpädagogik als transdisziplinäre Wissenschaftsdisziplin an. Die Systematik der Sozialpädagogik als Wissenschaftsdisziplin orientiert sich damit an der Struktur und Funktionsweise realer Erziehungsprozesse in ihrem Gegenstandsbereich. 


\section{Kapitel}

\section{Besonderheiten der Zielgruppen in sozialpädagogischen Prozessen}




\subsection{Zöglingsbegriff und Devianz in neuerer Zeit}

Wenn es um die Bezeichnung der zu Erziehenden in der Pädagogik geht, stoßen wohl alle Pädagogen auf das Problem der zweckmäßigen Wortwahl. Aus der Sicht unserer wissenschaftlichen Vorfahren (z. B. Herbarts) war das kein Problem, da der zu Erziehende wegen seiner - nach allgemeiner Auffassung - offensichtlichen Hilfebedürftigkeit und mangelnden Reife üblicherweise als Zögling bezeichnet wurde, ohne dass damit der Gedanke einer Diskriminierung verbunden war. Das Wort „Zögling“ ist in der deutschen Sprache zunächst einfach nur das sprachlich korrekte Pendant zum Wort „Erzieher" und wurde z. B. im 19. Jahrhundert durchaus nicht in einem abwertenden Sinne verstanden, sondern bezeichnete das pädagogisch geführte Subjekt seiner Selbsterziehung und Selbstbildung. So schrieb beispielsweise der Direktor des Weißenfelser Lehrerseminars Wilhelm Harnisch schon 1839:

„Der Ervieher helfe dem Zögling in seiner gesamten Selbstbildung und suche durch Erwärmung, Leitung und Förderung alle seine guten Anlagen zur vollen Entwicklung, alle seine bösen Triebe aber bierdurch, so wie durch ernstes Entgegentreten zum Absterben zu bringen "(Harnisch 1893, S. 22; Hervorhebung im Original) In der 1. Auflage des Buches hieß es an dieser Stelle: „Hilf dem Zögling in der eigenen Bildung, aber richte ihn nicht ab“ (Fußnote a. a. O.).

In einer Erläuterung fügte Harnisch hinzu:

„Der Erzieher ist nur ein Helfer in der Selbstbildung, er ist daher fern von Herrschsucht und Selbstsucht, er geht der guten Natur des Zöglings nach, und sein Ziel ist, dem Zögling zur Selbständigkeit zu verhelfen“ (a. a. O., S. 23).

Aber nicht nur im Volksschulbereich wurde der Zöglingsbegriff in diesem positiven Sinne verwendet, sondern auch im Hochschulwesen, denn Karl Mager, der bekanntlich als erster in Publikationen das Wort „Socialpädagogik“ verwendet hat, schrieb:

„[...] unter hundert Zuhörern geben zehn oder zwölf Hoffnung, sie könnten einmal die Wissenschaft fortpflanzen und fördern, sie könnten einmal Meister (magistri, doctores) werden. Die Lehrer einer Wissenschaft vereinigen sich nun, um diese zehn oder zwölf unter ihre Obhut zu nehmen, die bloßen Zubörer verwandeln sich jetzt in Zöglinge (Hervorhebung durch W. N.), es entsteht ein Verhältnis der Meister- und Jüngerschaft" (Mager 1844, S. 397).

Die „Verwandlung“ eines bloßen Zuhörers in einen Zögling - oder modern ausgedrückt: die Übernahme der Zöglingsfunktion durch einen Menschen - erfolgt durch seine Bemühungen um die Entwicklung seiner Anlagen unter Anleitung eines Erriehers. Daher lautet der erste Grundsatz der Erziehung von August H. Niemeyer:

„Wecke und bilde jede dem Zögling als Mensch und Individuum gegebene Anlage und Fäbigkeit" (Niemeyer 1888, S. 62). 
Aus der Bildsamkeit des Menschen und seinem Streben nach Vervollkommnung erwächst also seine Zöglingsfunktion, sobald er in Beziehung tritt zu einem Erzieher. Herbart versuchte zudem schon die Bildsamkeit von Menschen einzuschätzen, indem er schrieb:

„Die Pädagogik darf jedoch auch keine unbegrenzte Bildsamkeit voraussetzen; [...]. Die Unbestimmtheit des Kindes ist beschränkt durch dessen Individualität. Die Bestimmbarkeit durch Erziehung wird überdies beschränkt durch Umstände der Lage und der Zeit. Die Festigkeit des Erwachsenen bildet sich innerlich fort und wird dem Erzieher unerreichbar“ (Herbart 1922, Bd. 1, S. 300).

Bemerkenswert an diesen Aussagen ist, dass Herbart die Wirkungsmöglichkeiten des Erziehers sowohl von der Individualität des Kindes als auch von seinen Umständen der Lebenslage und der Zeit abhängig macht, was sicher heute noch gilt, wobei Sozialpädagogen besonders an „schwierige Kinder“ in „schwierigen Lebenslagen“ denken. Auch die „Festigkeit des Erwachsenen“ meint jedermann zu kennen, obgleich bei der Bewertung dieses Phänomens Vorsicht geboten ist. Immerhin ist durch lernpsychologische Untersuchungen die Lernfähigkeit von Erwachsenen hinreichend belegt. Sogar was die Veränderbarkeit von Meinungen, Überzeugungen und Einstellungen betrifft, sei nur daran erinnert, in welch außerordentlich hohem Maße gerade in der Gegenwart die Medien auch Erwachsene beeinflussen. Selbst in grundlegenden Fragen der Weltsicht und der Lebensgestaltung haben z. B. politische Umbrüche - besonders auch in Deutschland gezeigt, dass Erwachsene einfach gezwungen sind, sich veränderten Lebensbedingungen lernend anzupassen, was wohl nicht ganz ohne Erziehung (und vor allem Selbsterziehung!) im vorn definierten Sinne geht. Außerdem ist Erwachsenenbildung auch deshalb so bedeutsam, weil lebensbestimmende Anforderungen und Entscheidungen gerade vor dem jugendlichen Erwachsenen stehen (Wahl des Wohnsitzes bzw. Arbeitsortes, Partnerwahl, Familiengründung usw.) und er auch erst in diesem Alter über einige notwendige Voraussetzungen zur differenzierten Problemsicht verfügt, was aber wiederum seinen Bildungsbedarf erhöht. Herbarts Auffassung resultiert aus einer Zeit, in der die Menschen mit ihren in der Kindheit und früben Jugend erworbenen Fähigkeiten und Einstellungen unter relativ gleichbleibenden Bedingungen ihr Leben meistern konnten; daher ist sein Standpunkt verständlich.

Im 20. Jahrhundert erfuhr der Zöglingsbegriff aus dem 19. Jahrhundert im Rahmen des pädagogischen Systems von Schaller eine Wandlung. Er bezieht sich nicht mehr nur auf eine Funktion einer bestimmten sozialen Gruppe - also der Heranwachsenden - , sondern erfasst eine Funktion des Menschen im gesellschaftlichen Reproduktionsgeschehen und im persönlichen Entwicklungsprozess in Abhängigkeit von unterschiedlichen erzieherischen Kräften. Doch ungeachtet dieser wissenschaftlich begründeten Bedeutungswandlungen haftet dem Wort „Z̈̈gling“ immer noch das Merkmal der Unmündigkeit des so Bezeichneten oder gar der Makel von ,jugendlichen Rechtsverletzern“ an - wie etwa in den übersetzten 
Schriften Makarenkos. Das mögen Gründe dafür sein, dass häufig das Wort „zu Erziehender" verwendet wird, obgleich es in die entsprechenden Texte eine spürbare sprachliche Schwerfälligkeit hinein bringt und formal ein bedürftiges und passives Moment betont. Um dem zu begegnen, greifen manche Erziehungswissenschaftler auf das lateinische Wort „educandus“ zurück, was vornehmer klingt, aber entsprechend der grammatischen Form des Lateinischen auch eine Person bezeichnet, die erzogen werden soll oder muss. Ansonsten bieten sich natürlich je nach dem Erziehungs- oder Bildungsbereich die jeweils üblichen speziellen Bezeichnungen an: Schüler, Student, Auszubildender, Hörer usw. Eine Allgemeine Erziehungswissenschaft kann allerdings nicht auf einen allgemeinen Begriff und seine fachsprachliche Bezeichnung verzichten.

Bei der Bestimmung des Gegenstandes der Sozialpädagogik im Abschnitt 2.3 wurden bereits die Zielgruppen der Sozialpädagogen genannt. Es sind zum einen die Problembelasteten, die mit der Umwelt und sich selbst nicht klar kommen, und zum anderen die Angehörigen oder andere Problembeteiligte, die unter den Verhaltensweisen der Problembelasteten leiden, obgleich sie nicht selten zu den Mitverursachern der Probleme gehören - wie das z. B. bei überforderten Eltern der Fall sein kann. Bei vorliegender regressiver Devianz ist die Personengruppe der Zöglinge oder Problembelasteten durch ein unterschiedlich ausgeprägtes Auftreten folgender Merkmale gekennzeichnet.

\section{Existenzielle Benachteiligung, Gefährdung oder Schädigung der Person durch}

- erlittene physische und psychische Misshandlungen,

- Vernachlässigungen und/oder Verwöhnung

- physisch-psychische Schädigung bzw. Erkrankung oder geistige Behinderung,

wodurch Hilflosigkeit und unzureichende Integrationsfähigkeit bedingt sind, verbunden mit

- anhaltendem regressivem deviantem Verhalten zum eigenen Schaden und/oder zum Nachteil anderer,

- wobei die Betreffenden selbst und ihre Mitmenschen allein mit den Problemen der devianten Verhaltensweisen nicht fertig werden.

Für alle Zielgruppen, denen Sozialpädagogen in ihrer Berufstätigkeit begegnen, ist charakteristisch, dass sie problembelastet oder zumindest problembeteiligt sind, wenn auch aus unterschiedlichen Gründen. In Anlehnung an Lüssis Terminologie ist es auch in der Sozialpädagogik zweckmäßig, von Problembelasteten und Problembeteiligten zu sprechen. Problembelastete heißen dann diejenigen, auf die sich die sozialpädagogischen Maßnahmen konzentrieren; Problembeteiligte sind diejenigen, die unter den Verhaltensweisen und Handlungen der Problembelasteten leiden, obgleich sie häufig auch Mitverursacher der Probleme sind und daher im Problemlösungsprozess ebenfalls pädagogisch mit „erfasst“ werden (sollten). 
Ein wesentlicher Vorzug dieser Wörter ist, dass sie die betreffenden Personen, die sich in der Rolle von Hilfebedürftigen befinden, sprachlich nicht diskriminieren; es ist ja offen, woher die Probleme stammen. Da Problembelastete und Problembeteiligte als Hilfebedürftige bzw. Hilfesuchende auftreten, können sie auch so bezeichnet werden. Wenn sie dann ihren professionellen Helfer finden, entsteht zu diesem eine Beziehung, die sich in dem Begriff des Klienten oder der Klientel widerspiegelt. Diese Beziehung enthält eine durch das zu lösende Problem bedingte wechselseitige Abhängigkeit, begründet durch die reale Hilfebedürftigkeit des Klienten und die - vielfach auch gesetzlich geforderte - Pflicht des Sozialpädagogen zur Hilfe.

Sozialpädagogen benötigen eine möglichst genaue Kenntnis der Erscheinungsformen und Wesensmerkmale devianten sozialen Verhaltens sowie ihrer ursächlichen Bedingungen - sozusagen als Orientierungsgrundlage für das Erkennen der konkereten Problemsituation in jedem einzelnen Fall. Auf Schwierigkeiten bei Problemanalysen wurde im Abschnitt 2.3 bereits hingewiesen. Daraus ergibt sich für den Sozialpädagogen zunächst die Pflicht, vor jeder sozialpädagogischen Intervention zu prüfen, ob überhaupt ein Fall für ihn vorliegt, d. h., er muss erst einmal im Rahmen einer Problemanalyse die Frage nach den gültigen Normen und dem Grad der Abweichung davon für den jeweiligen Fall klären, und zwar unter Einbeziehung der Beteiligten und nötigenfalls von Experten. In der Praxis werden nämlich auch sog. Grenzfälle auftreten, d. h.: Normenverstöße sind bei vielen Menschen alltäglich und werden nicht automatisch zu Anlässen für sozialpädagogische Interventionen. Erst bei einem bestimmten Schweregrad, der den Verdacht auf ein vorliegendes sekundäres regressives deviantes Verhalten weckt, sind Sozialpädagogen gefordert. Sekundäres regressives deviantes Verhalten liegt vor,

- wenn es von anerkannten Normen und berechtigten Erwartungen der Umwelt so abweicht, dass es als belastend erlebt wird,

- weil es zerstörerisch ist und daher dem handelnden Subjekt selbst oder seiner Umwelt persönliches Leid und/oder sachlichen Schaden zufügt,

- wobei es nicht gelingt, allein mit den üblichen pädagogischen Mitteln und Maßnahmen bestehende Defizite in der Persönlichkeitsstruktur der Problembelasteten zu beheben.

Damit werden auch subjektive Momente - die individuelle Bewertung der Schwere und Häufigkeit der Abweichungen und der Entwicklungsstand pädagogischer Fähigkeiten bei den Leidtragenden bzw. Erziehern - bei der Entscheidung der Frage „deviant oder nicht deviant" wirksam. In der Praxis ist eine anfängliche Unsicherheit in der Beurteilung eines Falles zunächst kein Problem, denn es ist mit der Berufsehre eines Sozialpädagogen unvereinbar, einen Fall als Bagatelle abzuweisen, weil vielleicht keine „echte regressive Devianz" vorliegt. Wer wegen bedenklicher Verhaltensweisen einer Person, die er 
als abweichend und schädlich empfindet, Rat und Hilfe bei Professionellen sucht, muss diese erhalten. Wenn die Analyse ergibt, dass es sich um einen relativ harmlosen Fall handelt, um so besser! Allerdings sollte immer ernsthaft geprüft werden, ob es sich um Signale einer sich anbabnenden Feblentwicklung handelt; dann gilt die Regel: je früher die psychosoziale Intensiverziehung einsetzt, desto größer ist die Aussicht auf Erfolg!

Natürlich ist der Begriff „deviantes“ oder „abweichendes Verhalten“ von Persönlichkeiten in einer liberalen, pluralistischen und multikulturellen Gesellschaft mit starken Tendenzen zur Individualisierung problematisch, weil sich drei Fragen stellen:

- Von welcher Norm wird abgewichen?

- Wie stark oder häufig muss der Normenverstoß sein, um berechtigt von einem relativ verfestigten devianten Verhalten sprechen zu können?

- Handelt es sich bei dem abweichenden Verhalten eines Beklagten wirklich um deviantes Verhalten, das eine sozialpädagogische Intervention erfordert, oder verhält sich vielleicht der „Kläger“ deviant?

Beginnen wir mit der letzten Frage: Es ist ja möglich, dass eine junge Muslimin in Mitteleuropa Verhaltensweisen an den Tag legt, die von den traditionellen Normen und Erwartungen ihrer Familienangehörigen abweichen. Diese Devianz erzeugt bei den Familienmitgliedern solch heftigen Kummer und Zorn, dass sie durch einen „Ehrenmord“ die „Abweichlerin bestrafen“" wollen, was bei dieser begründete Angst auslöst. Die Familienangehörigen erkennen und akzeptieren in solchen Fällen ja nicht, dass es sich bei dem Verhalten der „Abweichlerin“ möglicherweise um eine progressive Devianz. handelt, die mit den Menschenrechtsnormen übereinstimmt.

Ein weiteres Problem des Devianzbegriffs besteht darin, dass viele Menschen ihr Ansehen und ihren individuellen Wert dadurch erhöhen möchten, dass sie sich von anderen auffällig zu unterscheiden trachten, d. h. also Abweichungen bewusst produzieren. Sie hoffen, gerade durch ihre Abweichungen vom Normalen oder Üblichen besonderen Eindruck erwecken zu können. Wenn es sich dabei aber nur um ein auffälliges Outfit handelt, dann fällt das nicht unter den hier gemeinten Devianzbegriff, denn auffällige Äußerlichkeiten in der Kleidung, im Schmuck, in der Haarfrisur usw. sind für niemanden bedrohlich. Außerdem werden durch betonte Ablehnungen und überflüssige Kritiken solcher Äußerlichkeiten zumeist erst Spannungen und Konflikte erzengt, die dann u. U. sozialpädagogisches Handeln erfordern. Der Begriff der Abweichung oder Devianz erzeugt also die Frage: Abweichung wovon? Mit der Antwort: von der Norm oder vom sog. Normalen entsteht zugleich die Frage: Was ist in einer pluralistischen Gesellschaft normal?

In der Vergangenheit wurde die sog. Normalbiografie als Maßstab für Normalitätsvorstellungen verwendet - also regulärer Schulbesuch, Ausbildung oder Studium, Berufstätigkeit, Ruhestand (vgl. Münchmeier in Vahsen 1992, S. 39). Abgesehen davon, dass 
mangels bezahlbarer Arbeitsplätze in der gegenwärtigen Gesellschaft immer mehr Menschen eine solche „Normalbiografie“ nicht mehr durchlaufen können, haben sich im Entwicklungsprozess der Jugendlichen und auch bei den nicht arbeitslosen Erwachsenen beträchtliche Veränderungen vollzogen, etwa hinsichtlich Dauer, Wechsel und Unterbrechungen der Ausbildungswege, der Arbeitsstellen usw. (vgl. Münchmeier bei Vahsen 1992, S. 34f.). Doch nicht nur die Biografien differenzieren sich immer mehr, auch die Normen und Werte in den verschiedenen sozialen Schichten, Berufs- und Altersgruppen unterscheiden sich in einem solchen Maße, dass sich nur noch ganz allgemeine und fundamentale soziale Normen nennen lassen, die für alle als verbindlich angesehen werden können. Die „Normenbündel“, wie sie sich in den sog. Normalbiografien widerspiegeln, können also nicht mehr als Bezugssystem dienen, wenn es um die Frage nach der „Abweichung wovon“ geht. Vielmehr sind für Sozialpädagogen nur noch relativ fundamentale Werte und Normen als Orientierungsgrundlagen verbindlich.

Wenn sich also eine Mutter über das unaufgeräumte Zimmer ihres Teenagers beschwert, ist das zwar verständlich, aber noch nicht unbedingt als regressive Devianz zu behandeln, denn es müssen bei Verstößen gegen bisher gültige und anerkannte Normen die veränderten Toleranz̧renz̧en berücksichtigt werden, die allerdings auch nicht beliebig dehnbar sind. Wo z. B. Ladendiebstähle zum „normalen Alltag“ gehören, können Kinder oder Jugendliche darin keine Abweichung mehr erkennen. Daher werden heutrutage Ladendiebstäble bei Kindern trotz des beträchtlichen Schadens für den Handel ${ }^{11}$ anders - in der Regel viel milder - bewertet als vor hundert Jahren. Viele sog. Bagatelldelikte werden gar nicht mehr angezeigt und erscheinen daher auch in keiner Statistik. Diese Erscheinung ist sicher einzuordnen in jene fatale Verschiebung der „Wertmaßstäbe immer weiter nach unten“, die Winterhoff allgemein konstatiert (2009, S. 51). Allerdings muss beachtet werden, ob es sich bei einem Ladendiebstahl um eine gelegentliche (primäre) Normabweichung oder um ein bereits verfestigtes Verhalten handelt (das möglicherweise den Einstieg in eine kriminelle Karriere signalisiert) oder gar um bandenmäßig organisierten Diebstabl, zu dem manchmal auch Kinder von ibren Verwandten gezwungen werden (vgl. dazu Ulrich 2006, S. 54). Polizei und Justiz sind diesen Dieben gegenüber ziemlich hilflos, weil sie nicht strafmündig sind und in der Bundesrepublik eine historisch verständliche Abneigung gegen Heimerziehung besteht (vgl. Wensierski 2006, Kuhlmann 2008), obgleich man Heime u. U. auch zum Schutze der von ibren Angehörigen zu Dieben degradierten und missbrauchten Kinder benötigt.

Wie bei den meisten Definitionen, die gesellschaftliche Erscheinungen betreffen, handelt es sich auch bei der o. g. Definition von „deviantem Verhalten“ um eine Abgrenzung auf der Basis fließender Übergänge, so dass es immer Fälle gibt, die nicht sofort klar

11 Laut Schweriner Volkszeitung vom 25. 05. 2004 (S. 6) fügen unehrliche Kunden dem deutschen Einzelhandel jährlich einen Schaden von schätzungsweise 2,1 Milliarden Euro zu; die Inventurprüfungen haben einen Verlust von nahezu 4,5 Mrd. € ergeben. 
zugeordnet werden können. $\mathrm{Ob}$ es sich bei beklagten ungewöhnlichen Handlungen und Verhaltensweisen um Abweichungen im Sinne von relativ harmlosen „Ungehörigkeiten“ oder um echte regressive Devianzen handelt, wird ein Praktiker in der Regel aber nicht über theoretische Diskussionen zur Normenfrage klären, sondern in Abhängigkeit von der Dauer beobachteter Auffälligkeiten und den bereits erkennbaren persönlichen Leiden und/oder sachlichen Schäden.

Ein weiteres Problem in der Definition ist mit dem Begriff der „Defizite in der Persönlichkeitsentwicklung"verbunden, da es sich hier ebenfalls um eine Bewertung handelt. Welche persönliche Eigenheit eines Menschen nämlich als defizitär bewertet wird, hängt von historisch wandelbaren und individuellen subjektiven Maßstäben ab. So konnte z. B. ein Volksschulabsolvent der 6. Klasse im 19. Jahrhundert unter den überschaubaren Verhältnissen seines Heimatdorfes als Landarbeiter durchaus noch seinen Lebensunterhalt verdienen und sein Leben sinnvoll gestalten, zumindest mit etwas familiärer Unterstützung. Ein Mensch mit ähnlichen persönlichen Voraussetzungen ist in der Gegenwart vermutlich überfordert und gerät in Anbetracht der höheren Anforderungen des großstädtischen Lebensalltags und moderner Bürokeratien in ernste Schwierigkeiten.

Es sind also nicht schlechthin irgendwelche Defizite in der Persönlichkeitsentwicklung (z. B. Analphabetismus, Dyskalkulie, Konzentrationsschwäche, Unbeherrschtheit, moralische Labilität), die aus einem Menschen einen Problembelasteten machen, sondern es ist sein Verbältnis zu den aktuellen Erfordernissen seines Lebens, die er entweder bewältigt oder nicht. Es gibt daher Gemeinsamkeiten in der Lebenssituation aller Problembelasteten, die sich darin äußern, dass sie in Schwierigkeiten und Nöte geraten sind, weil sie mit ibren Lebensbedingungen im weitesten Sinne des Wortes nicht zurechtkommen. Die Ursachen dafür sind vielfältig und sowohl objektiver als auch subjektiver Natur, d. h., die Notlage kann durch einen krisenhaften Zustand der Gesellschaft hervorgerufen - objektiv so groß sein, dass es manchen Menschen trotz gut entwickelter subjektiver Fähigkeiten zur Lebensbewältigung (unter „,normalen“ Bedingungen!) nun nicht mehr gelingt, damit fertig zu werden. Es sei hier nur darauf verwiesen, dass es Sozialpädagogen auch mit Problembelasteten zu tun haben können, die nicht wegen biografisch bedingter persönlicher Defizite, sondern durch neuartige gesellschaftliche Umstände in Not geraten sind, z. B. durch die „Wendefolgen“ im Osten Deutschlands. Es ist sogar möglich, dass erst unter den Bedingungen einer entstandenen vermeintlichen Ausweglosigkeit kriminelle Energien geweckt werden. Dafür gibt es historische Beispiele - darunter allerdings auch solche, die zeigen, dass selbst unter extremen sozialen Bedingungen sozialpädagogisches Handeln erfolgreich sein kann, wie etwa Makarenkos Wirken in den zwanziger Jahren des 20. Jahrhunderts in der Sowjetukraine belegt.

Doch unabhängig von besonderen gesellschaftlichen Katastrophensituationen gilt im Prinzip das, was Mollenhauer über die kapitalistische Gesellschaft geschrieben hat: 
„Es scheint zu den Merkmalen unserer Gesellschaft zu gehören, daß die Zahl derer groß ist, die auffällig werden, denen es nicht gelingt, mit ihrer Lebensführung in einer von allen akzeptierten Weise fertig zu werden, die auf Abwegen ihre Bedürfnisse zu befriedigen suchen oder gar überhaupt abwegige Bedürfnisse haben. Jedenfalls ist es der industriellen Gesellschaft bis her nicht gelungen, dasjenige einzudämmen, was sie den Anstieg von Verwahrlosung und Kriminalität oder auch die Gefährdung des Heranwachsenden nennt“ (Mollenhauer 1991, S. 42).

Was Mollenhauer hier systemkritisch beschreibt, ist aber kein „Schein“, sondern bittere Tatsache, wie die Kriminalstatistiken und alltäglichen Erfahrungen, insbesondere in den neuen Bundesländern, belegen. Manche Journalisten, Politiker und Wissenschaftler bemühen sich seit dem Zusammenbruch der DDR intensiv darum, das Rechts-, Sozial- und Bildungssystem der DDR pauschal als inhuman, verwerflich oder ineffizient darzustellen, häufig in der Annahme, einer vermeintlichen (N)ostalgie entgegenwirken zu müssen. So schrieb z. B. Arnulf Baring in seinem Buch „Deutschland, was nun?“:

„Die heutige Lage in der ehemaligen DDR ist in der Tat vollkommen anders als bei uns nach 1945. Das Regime hat fast ein halbes Jahrhundert die Menschen verzwergt, ihre Ausbildung verhunzt. Jeder sollte nur noch ein hirnloses Rädchen im Getriebe sein, ein willenloser Gehilfe. Ob sich heute einer dort Jurist nennt oder Ökonom, Pädagoge, Psychologe, Soziologe, selbst Arzt oder Ingenieur, das ist völlig egal: Sein Wissen ist auf weiten Strecken völlig unbrauchbar (Hervorhebung durch W. N.). [...] Wir können den politisch und charakterlich Belasteten ihre Sünden vergeben, alles verzeihen und vergessen. Es wird nichts nützen; denn viele Menschen sind wegen ihrer fehlenden Fachkenntnisse nicht weiter verwendbar“ (Baring 1991, S. 59).

Wenn sich der Professor für Zeitgeschichte Arnulf Baring einmal dafür interessiert hätte, wie viele ehemalige junge DDR-Bürger vor und nach der Wende in internationalen Schülerolympiaden und Sportwettkämpfen Medaillen (zuletzt auch für die Bundesrepublik) erkämpft haben, wäre er vielleicht zu anderen Schlussfolgerungen gekommen. Dass einmal eine Bundeskanzlerin und ein Bundespräsident aus den Reihen angeblich „verzwergter Menschen“ mit ihrer „verhunzten Ausbildung“ hervorgehen würden, konnte er 1991 natürlich nicht ahnen. Aber es war allgemein bekannt, dass sowohl vor dem Mauerbau als auch nach dem Mauerfall die gut ausgebildeten Fachkeräfte aus der DDR in bundesdeutschen Unternehmen recht willkommen gewesen sind. Auch die Leistungen von DDRBürgern in der Kriminalitätsbekämpfung und -prävention (als Bestandteile des Erziehungssystems und der Rechtsordnung) lassen erkennen, dass Barings pauschale Abwertung unhaltbar ist. Laut Untersuchungen von Robert Northoff

„fühlten sich im Jahre 1985 rund 58 Prozent der Befragten vor strafbaren Handlungen privater Personen in der DDR ziemlich sicher, weitere 34 Prozent fühlten sich sogar sehr sicher. Im Jahre 1988 fühlten sich ebenfalls rund 58 Prozent der so Befragten in der DDR ziemlich sicher und immerhin weitere 22 Prozent fühlten sich sehr sicher. Im Jahre 1993, also drei Jahre nach 
der Einigung, fühlten sich nur 6 Prozent der Befragten in den neuen Bundesländern ziemlich sicher und weniger als 1 Prozent sehr sicher" (Northoff 1995, S. 52).

Der Verdacht, dass die Befragungsergebnisse durch nostalgische Bewertungen gefärbt seien, ist in Anbetracht der Datenlage unbegründet, denn:

„Geht man von den statistischen Daten zur Rechtspflege der DDR aus, so ergibt sich für das Jahr [...] 1988 eine Quote von 715 Straftaten/100 000 der Bevölkerung. [...] Für die BRD ergibt sich ausweislich des statistischen Jahrbuchs 1991 [...] für 1988 eine Quote von 7114 bekannt gewordenen Straftaten/100 000 Einwohner" (Northoff 1995, S. 51).

Der niedrigeren Krimanalitätsquote in der DDR entsprach übrigens auch ein geringeres „Gewaltausmaß“ an Schulen - z. B. in Thüringen und Sachsen einerseits und im Vergleich dazu in Hessen und Baden-Württemberg andererseits. Zugleich wurde auch eine sich verstärkende negative Entwicklung in den neuen Bundesländern wenige Jahre nach dem Beitritt der DDR zur Bundesrepublik festgestellt (vgl. Melzer 2000, S. 90).

Dass es sich bei der Bewertung des Sicherheitsgefühls nach der Wende nicht um ein rein subjektives oder mediengeschürtes Angstgefühl der Ostdeutschen, sondern um ein im Kern begründetes Abbild der Realität handelt, belegt die nach 1990 im Osten Deutschlands beträchtlich angestiegene Kriminalitätsquote. Northoff schreibt:

„Vergleicht man nun die Kriminalitätsentwicklung in den alten und den neuen Bundesländern, so ergibt sich ausweislich der Ende Mai 1994 vorgestellten Polizeilichen Kriminalstatistik, daß im Jahre 1993 die Straftaten von 6,3 auf 6,7 Millionen angestiegen sind. Dahinter verbirgt sich ein Zuwachs von 2,7 Prozent in den alten Bundesländern und ein Zuwachs von etwa 30 Prozent in den neuen Bundesländern“ (a. a. O., S. 52).

Wenn auch die Zahlen in den neuen Bundesländern zwischen 1990 und 1993 mit denen der alten wegen unterschiedlicher Erhebungsverfabren nicht ganz vergleichbar sind, zeigen sie doch eine Tendenz, die 1998 klar bestätigt wurde: die neuen Bundesländer haben die alten in der Kriminalitätsentwicklung nicht nur eingeholt, sondern überholt, wobei sich allerdings seit 1999 ein Rückgang der Häufigkeitsquote in den neuen Bundesländern und eine Annäherung zwischen West und Ost in diesem Bereich abzeichnet.

\begin{tabular}{|c|c|c|}
\hline Jahr & Alte Bundesländer & DDR/Neue Bundesländer \\
\hline 1988 & 7114 & 715 \\
\hline 1998 & 7576 & $\mathbf{9 2 8 1}$ \\
\hline 2008 & 7401 & 7622 \\
\hline
\end{tabular}

Übersicht 3

(Quellen: Siehe oben und PKS, Berichtsjahre 1998 und 2008, zu finden unter: [online] http://www.bka.de/pks/pks1998/rg004.html, Gesamtüberblick, S. 1; und http://www.bka.de/pks/pks2008/download/pks-jb_2008_bka.pdf, S. 49. (Zugriff: 17.12.2009) 
Die Vorschläge von Northoff zur vorurteilsfreien Auswertung der DDR-Erfahrungen im Bereich der Kriminalprävention sind zu begrüßen. Er beklagte „die politische Unerwünschtheit und Tabuisierung einer gesamtdeutschen Diskussion“, weil „alle positiven (kriminalpräventiven) Ansätze der DDR ideologisch belastet und damit pauschalen Wertungen ausgeliefert sind.“ Er kommt zu der Schlussfolgerung:

„So darf die Überlegung, daß eine ausgeprägte Kriminalität auch als Preis der Freiheit verstanden werden kann, nicht dazu verleiten, resignativ das zu verlassen, was gleichwohl an präventiven Maßnahmen möglich ist. Bei genauerer Betrachtung ergibt sich nämlich, daß in den ideologisch verbrämten Ansätzen der DDR zahlreiche gemeinschaftsfördernde und das Verantwortungsbewußtsein des einzelnen stärkende Maßnahmen (Hervorhebung durch W. N.) enthalten sind. Sie herauszuarbeiten, auf ihre kriminalpräventive Brauchbarkeit zu überprüfen und gegebenenfalls ideologiefrei zu vermitteln, ist eine wichtige Herausforderung“ (Northoff 1995, S. 133).

Die vorliegenden Statistiken belegen, dass es in der DDR prozentual viel weniger Kriminelle gegeben hat als in der Bundesrepublik, was auch darauf hindeutet, dass nicht jede Kollektiverziehung und Wertschätzung von Kollektiven zwangsläufig zur Entmündigung und Verrohung seiner Mitglieder führen muss. Dies ist bei der sicher berechtigten Kritik Adornos (1903-1969) an Kollektive (allerdings bestimmter Typen) zu berücksichtigen (vgl. Adorno: Erziehung nach Auschwitz. 1965).

In den nachfolgenden Betrachtungen werden soziale Bedingungen unterstellt, wie wir sie gegenwärtig etwa in Nord-, Mittel und Westeuropa vorfinden. Auch unter diesen Lebensbedingungen gelingt es nicht allen geistig und körperlich gesunden Menschen, ein sinnerfülltes und erfolgreiches Leben zu führen. Sie leiden unter materieller Not, geistig-kultureller Verarmung und moralischer Deformation. Um diesen Menschen zu helfen, bedarf es sowohl verbesserter gesellschaftlicher „Rahmenbedingungen“ (z. B. mehr Ausbildungs- und Arbeitsplätze mit Existenz sichernden Löhnen) als auch gezielter Maßnahmen zur individuellen Befähigung der Menschen, vorhandene gesellschaftliche Bedingungen und Möglichkeiten für sich sinnvoll zu nutzen.

Für die objektiven gesellschaftlichen Bedingungen ist die Politik, insbesondere die Wirtschafts- und Sozialpolitik verantwortlich; allerdings fällt es den Politikern offensichtlich schwer, sich gegenüber den Inhabern der wirtschaftlichen Macht durchzusetzen, um die ökonomischen Ursachen sozialer Nöte wirkungsvoll zu bekämpfen - es sei nur an die Hilflosigkeit von Regierungen gegenüber Steuerbetrügern erinnert. Dem Staat gehen jährlich Milliarden durch Steuerhinterziehung, Subventionsbetrug und Schattenwirtschaft verloren (vgl. www.rentenreform-alternative.de/steuerungerechtigkeit.htm).

Die Entwicklung der subjektiven Voraussetzungen zur sinnvollen Nutzung der gesellschaftlichen Möglichkeiten obliegt den bildungspolitischen, familienpolitischen und erzieherischen Kräften der Gesellschaft, wobei Sozialpädagogen vielfach „Nachhilfe“ erteilen. 


\subsection{Theorien über die Entstehung devianten Verhaltens}

Im Interesse einer optimalen Gestaltung sozialpädagogischer Prozesse ist es notwendig, bei jedem Problembelasteten oder Hilfesuchenden nach den Ursachen zu fragen, durch die gerade er in die jeweilige Notlage gekommen ist. Eine fundierte Antwort wird immer eine individuelle Konstellation ursächlicher Bedingungen enthalten, aber zugleich auch Faktoren, die als allgemeine Bedingungen für die Entstehung abweichenden Verbaltens von verschiedenen Theorien erkannt worden sind. Das Problem devianter Verhaltensweisen ist im Grunde genommen uralt, ebenso sind es auch die Versuche zu seiner Klärung. Wissenschaftlich wertvolle Erkenntnisse hat z. B. Norbert Herriger in seinem Buch „Verwahrlosung - Eine Einführung in Theorien sozialer Auffälligkeit“ (Juventa Verlag. München 1979) dargestellt. Er informiert über die Leistungen von drei (in sich zu differenzierenden) Erklärungskonzepten: den biologisch-medizinischen, den sozialisationstheoretischen Theorien und dem Erklärungsmodell der Labeling-Perspektive (Etikettierungsmodell). Dabei zeigt er die Leistungen und Grenzen der jeweiligen Konzepte auf, die für den Praktiker auch heute noch wissenswert sind. In seiner Kritik der einzelnen Konzepte vertritt er die Meinung, dass die vielfältig bedingten Devianzprobleme nicht mit einer Theorie binreichend erklärt werden können (vgl. S. 66ff.) - einen Standpunkt also, dem sich der Autor der vorliegenden „Sozialpädagogik“ anschließt.

Siegfried Lamnek stellt in seinem Buch "Neue Theorien abweichenden Verhaltens“ (1994) eine ganze Palette soziologischer Theorien zur Erklärung abweichenden Verhaltens vor. Dabei konzentriert er sich auf die Darstellung neuerer kriminalsoziologischer Theorien. Diese verhalten sich gegenüber älteren ätiologischen Theorien der traditionellen Kriminologie recht kritisch, weil diese etwas einseitig die psychologischen Ursachen abweichenden Verhaltens untersuchen, dabei die soziologischen Bedingungen für die Entstebung devianter Verhaltensweisen nicht gebübrend berücksichtigen und obendrein zur Pathologisierung der Täter neigen (vgl. Lamnek 1994, S. 25ff.). Im Ergebnis von Lamneks differenzierter und instruktiver Darstellung der verschiedenen Strömungen oder wissenschaftlichen Schulen wird allerdings auch deutlich, dass es keine bündige und allgemein anerkannte kriminalsoziologische Theorie zur Erklärung abweichenden Verhaltens gibt.

Aus der Sicht der Sozialpädagogik sind die kriminalsoziologischen Konzepte zur Erklärung devianten Verhaltens zwar interessant, aber pädagogisch nicht ausreichend, denn der Sozialpädagoge hat es immer mit individuellen Fällen devianten Verhaltens zu tun und auch mit solchen, die nicht unbedingt in den Bereich der Kriminologie fallen. Er soll und will dem Einzelnen oder der Gruppe helfen. Dazu braucht er einen Überblick über wichtige also auch, aber nicht nur kriminalsoziologische - Erkenntnisse bə̧w. Theorien, die über den Entstehungsprozess devianten Verhaltens Aufschluss geben. 
Um Einseitigkeiten in den Erklärungsbemühungen durch Überbetonung biologischer, ökonomischer, soziologischer oder psychologischer Faktoren im Bedingungsgefüge vorzubeugen, werden in den folgenden Abschnitten einige wichtige theoretische Ansätze mit ihren Thesen und/oder Hypothesen zu ursächlichen Bedingungen und Wirkfaktoren bei der Entstehung und Stabilisierung devianter Verhaltensweisen ,aufgelistet" und in knapper Form erörtert - also nicht mit dem Anspruch auf Vollständigkeit. In der angegebenen Literatur kann jede Theorie gründlicher studiert werden.

\subsubsection{Biologische und medizinische Erkenntnisse zur Erklärung devianten Verhaltens}

Aus seiner stammesgeschichtlichen Entwicklung bringt der Mensch spezifische organische und psychische Voraussetzungen mit, die ihm ein selbständiges Leben unter relativ normalen natürlichen und gesellschaftlichen Bedingungen erlauben, wenn es ihm gelingt, den dafür erforderlichen Lern- bzw. Sozialisationsprozess zu realisieren. Zu den organischen Voraussetzungen gehört auch ein stammesgeschichtlich und historisch erworbenes Aktivitätspotenzial. Über die Bedeutung verschiedener Erbanlagen wird seit Jahrzehnten gestritten - auch über eine angeblich vererbte Neigung zur Kriminalität. Das Problem möglicher vererbter Dispositionen kann hier nicht tiefgründig erörtert werden; es geht nur um einige relativ gesicherte Erkenntnisse zu den genetischen Grundlagen devianter Verhaltensweisen. Dazu gehört z. B. das Streben jedes normalen Menschen zur Selbstbehauptung und das, was Felix v. Cube als „Störung des verhaltensökologischen Gleichgewichts“ vieler Menschen in der modernen Gesellschaft bezeichnet. Was heißt das?

Jeder Mensch hat normalerweise den Wunsch und den Willen zu leben; Anatol Rapoport bezeichnet dies auch als „invariantes Bedürfnis“ (Rapoport 1970, S. 155ff.). Das Bestreben, sich zu erhalten, ist verbunden mit einem bereits vererbten Aktivitätspotenzial, das entsprechend den jeweils entwickelten Fähigkeiten und angeeigneten Wertvorstellungen genutzt wird, um sich unter den gegebenen Umständen zu behaupten. $\mathrm{Ob}$ dies immer auch in aggressiver Weise geschieht, wird noch diskutiert unter der Fragestellung, ob es wegen der Notwendigkeit zur Selbstbehauptung eine generell vererbte $A g$ gressivität gibt. Fakt ist, dass in Situationen der Bedrängnis viele Menschen physisch und/oder verbal aggressiv werden und dass sie grundsätəlich befähigt werden müssen, mit ihren aggressiven Regungen so umzugehen, dass sie nicht durch unverhältnismäßige Aktionen oder Abwehrreaktionen andere oder sich selbst schädigen. An dieser Notwendigkeit ändert sich auch nichts, wenn man den Standpunkt von einer angeborenen Disposition zur Aggressivität vertritt, denn auch deren Äußerungsformen werden erlernt und sind daher durch Lernprozesse zu beeinflussen. Im Übrigen bedarf es bei jeder Aggression nach den Erkenntnissen von Konrad Lorenz (1903-1989) außer der Wirksamkeit eines Triebs auch eines sog. Appetenzuerhaltens (d. h. das Aufsuchen auslösender Reize bei steigender Triebstärke) und einer

Triebhandlung mit Lustempfindung. Im Unterschied zum Tier kann ein geistig gesunder 
Mensch die Fähigkeit erwerben, sein Verhalten zu reflektieren (z. B. auch sein Sexualleben) und bewusst zu steuern, also nötigenfalls auch auslösenden Reizen auszuweichen. Aus dieser Fähigkeit und seiner Einbindung in die Gesellschaft erwächst ihm zugleich die Verantwortung, es u. U. auch zu tun. Andernfalls muss er die jeweiligen Konsequenzen ertragen. In jedem Falle muss er lernen, seine Bedürfnisse in bumaner Weise zu befriedigen.

Aus den Ergebnissen ethologischer Forschungen von Konrad Lorenz, Irenäus EiblEibesfeldt, Nikolaas Tinbergen (1907-1988) u. a. resultiert die Erkenntnis, dass es angeborene Verbaltensweisen gibt, die bereits in den Genen festgelegt sind und nicht erlernt werden müssen, sondern in normalen Entwicklungsverläufen menschlicher Individuen bei entsprechenden Reizen auftreten (z. B. Reflexe).

Doch damit ist noch nicht viel gewonnen für die Klärung der Ursachen für die Realisierung oder Nichtrealisierung anspruchsvoller moralischer Verhaltensweisen. Es gilt als gesicherte Erkenntnis, dass sich in den Erbanlagen jedes Neugeborenen vieles von dem widerspiegelt, was in der Evolution und Anthropogenese bedeutsam war. Das Potenzial des gesunden neugeborenen Menschen enthält - mit dem animalischen vor allem auch das spezifisch menschliche Anlagenpotenzial, das relativ plastisch ist und durch Sozialisation, Enkulturation und insbesondere Erziehung so entwickelt werden kann und muss, dass wirklich ein Mensch mit bumanen Verbaltensweisen und Fähigkeiten entsteht; das ist - aus humanistischer Sicht - letztendlich das allgemeinste Ziel der Erziehung, und eben auch deshalb verwendete Schaller den Begriff der Menschenformung.

Die Formulierung „ein Mensch mit humanen Verhaltensweisen und Fähigkeiten“ abstrahiert allerdings von evolutionär bedingten Schwierigkeiten, auf die Hans Mohr aufmerksam macht:

„Unsere moralische Insuffizienz - der Umstand, daß wir in und an der modernen Welt immer bedenklicher versagen - wird von der Evolutionären Ethik darauf zurückgeführt, daß wir genetisch auch heute noch auf ein Leben unter den Rahmenbedingungen des Pleistozän und Neolithikum eingestellt sind und nicht auf ein Leben in der modernen Welt. Im Vordergrund des Interesses stehen derzeit die Fragen, warum es keine kulturelle Überformung bislang vermochte, die Menschen vom Krieg abzuhalten, und warum uns der gesittete, vernünftige Umgang mit der Natur und mit der technischen Zivilisation nicht gelingen will“" (Mohr 1990, S. 557).

Hans Mohr skizziert in dem zitierten Artikel einige Erkenntnisse der Evolutionären Ethik, erörtert dabei besonders die aus der Evolution des Menschen herrührenden Ursachen für die Schwierigkeiten in seiner Erziehung zu vernünftigem Handeln und kommt letztlich zu dem Schluss, dass uns nichts anderes übrig bleibt, als auf Vernunft zu setzen, an ihrer Verbreitung zu arbeiten und die Hoffnung darauf, dass dies gelingen möge, nicht aufzugeben (vgl. a. a. O., S. 562). 
Allein schon die Erkenntnisse der Evolutionären Ethik erklären, dass und warum die Menschen Schwierigkeiten haben, ihr Verhalten unter den modernen Lebensbedingungen stets vernünftig zu steuern. Darüber hinaus gibt es spezifische Entwicklungsstörungen im menschlichen Organismus, z. B. die sog. Aufmerksamkeits-Defizit-Hyperaktivitäts-Störung (ADHS). Dabei handelt es sich um „eine angeborene, meist ererbte Störung in der Hirnchemie“ (Skrodzki 2001), die etwa bei $5 \%$ der Kinder und $2 \%$ der Erwachsenen zu beobachten ist.

„Von Geburt an unterscheiden sich diese Kinder von normalen temperamentvollen, lebhaften Kindern. Sie sind dauernd in Bewegung, ablenkbar, erregbar, redselig und ungebremst. Einige sind Träumer und immer abwesend [...]. Sie können weder stillsitzen noch zuhören, nicht folgen, nicht warten, nicht aufhören, nicht verlieren und sich nicht einfügen. Und sie erkennen Grenzen und Gefahren nicht. Deshalb sind sie Klassenclown und Außenseiter und finden keine bleibenden Freunde. Weil ihre Interessen und Fähigkeiten nicht zum schulischen Alltag pas sen und auf Unverständnis und Ablehnung stoßen, sind diese Kinder trotz großer Phantasie, Kreativität und unerschöpflicher Ideen meist unglücklich“ (Skrodzki 2001).

Klaus Skrodzki fordert in seinem Beitrag eine medizinische und psychologische sowie pädagogische Behandlung der Betroffenen, u. a. mit dem Hinweis darauf, dass niederländische und amerikanische Studien belegen: 35-50 \% der Jugendlichen im Jugendstrafvollzug sind unbehandelte ADHS-Kinder.

Dass sowohl für die Entstehung als auch für die Behandlung von ADHS die jeweiligen „natürlichen (oder eben unnatürlichen) Lebensbedingungen“ eine beträchtliche Rolle spielen, geht aus den Darlegungen von A. Schätz in einer Experten- und Diskussionsrunde des Bayrischen Landtages vom 22.11.2001 hervor; er verweist darauf, dass Kinder in einem Waldkindergarten nach wenigen Tagen deutlich ruhiger und umgänglicher in ihrem Verhalten waren als zuvor. Offensichtlich resultieren aus zunehmender Urbanisierung, Reizüberflutung und sonstigen Überforderungen in der modernen Gesellschaft für viele Kinder Anpassungsschwierigkeiten mit krankhaften Folgeerscheinungen. Über Jahrmillionen verliefen kindliche Entwicklungsprozesse bei unseren Vorfahren ja in vieler Hinsicht ganz anders als gegenwärtig, und eben diese andersartigen Sozialisationsbedingungen erschweren in mancher Hinsicht auch die Individualentwicklung für Kinder bzw. Heranwachsende.

Zwar können wir nicht genau sagen, was von „den alten Programmen“ in welcher Weise noch wirkt, aber es ist doch bemerkenswert, dass es von der sog. „Hackordnung“ und dem „Revierverhalten“ offenbar auch bei den Menschen noch Reste gibt. Versuchen nicht manche Leute ihren Rangplatz mit Methoden des Mobbings zu verteidigen? Genügt manchen nicht schon der Verdacht einer Bedrängnis, um gegenüber Fremden mit Ablehnung zu reagieren? Beispiele gibt es dafür leider auch in neuerer Zeit - etwa in der Meinung, „dass Ausländer raus müssen, weil sie uns Arbeitsplätze wegnehmen“, 
was ja so ganz allgemein nicht zutrifft, wenn man die gesetzlichen Regelungen für die Arbeitserlaubnis für Ausländer und Asylbewerber sowie den Bedarf an qualifizierten Arbeitskräften berücksichtigt. Vor allem aber kann aggressive Ausländerfeindlichkeit nicht mit dem Hinweis auf mögliche Vererbungsprozesse entschuldigt werden, denn im Verlaufe der Humangenese und Menschheitsgeschichte wurden spezifisch menschliche Formen der Konfliktregelung und Solidarität entwickelt.

Störungen in entwicklungs- und lebensnotwendigen Wechselwirkungen zwischen Organismus und Umwelt sind als krankheitserregende Faktoren bekannt. Es sei hier nur an die Entstehung des Hospitalismus bei unzureichenden Wechselwirkungen zwischen den Sinnesorganen des Säuglings mit seiner Umwelt im Falle großer Abschirmung bzw. Isolation erinnert. Offensichtlich benötigen heranwachsende Menschen - wie übrigens auch andere Lebewesen - zu ihrer Entwicklung den ständigen Kontakt mit einem entwicklungsfördernden Umfeld, mit dem sie sich physisch, physiologisch und psychisch bzw. geistig auseinandersetzen, um ihre Anlagen zu entwickeln. Werden diese Wechselwirkungen beeinträchtigt oder gar verhindert, treten gesetzmäßig Entwicklungsstörungen auf. Diese bekannten Erscheinungen lassen sich in einen größeren Entwicklungszusammenhang einordnen, auf den v. Cube in seinem Artikel „Verhaltensbiologie und Pädagogik " (bei Roth: Pädagogik 1991) näher eingeht.

Aus der Fülle verhaltensbiologischer Erkenntnisse interessiert im vorliegenden Zusammenhang vor allem folgender Sachverhalt: Um zu überleben, mussten die Menschen - und auch schon ihre tierischen Vorfahren - ein beträchtliches Maß an Aktivitäten aufbringen, z. B. um sich ihre Nahrung zu suchen oder zu erjagen oder um sich vor natürlichen Feinden zu schützen. Bedenkt man allein die rund 2 Millionen Jahre dauernde urgeschichtliche Entwicklung des Menschen seit dem Auftreten des homo habilis und homo ergaster, in deren Verlauf vor allem die Männer vieler Generationen häufig und ausdauernd lange Strecken bei ihrer Suche nach bereits toten oder jagdbaren Tieren laufen mussten, dann wird verständlich, dass sich die Menschen in ihrer körperlichen Konstitution und Leistungsfähigkeit eben diesen lebensnotwendigen Anstrengungen angepasst haben und über ein dafür erforderliches erbliches Aktivitätspotenzial verfügen, das sicherlich bis ins Tierreich zurück reicht. Dieses wird auch heute noch weiter vererbt, obgleich es der Mensch in der modernen Zivilgesellschaft zur Sicherung seines Lebensunterhalts nicht mehr in dem Maße wie früher benötigt. Hinzu kommt eine verbreitete Neigung, körperliche Anstrengungen zu vermeiden, wenn sie denn nicht durch besonderen Ehrgeiz bzw. durch Hobbys (z. B. Bergsteigen) motiviert sind oder Vorteile in Gestalt von Sportlergehältern, Startgeldern, Olympiamedaillen oder Weltmeistertiteln versprechen. Aber ansonsten besteht doch sehr ein Hang zur Bequemlichkeit, etwa die zumeist selbstverständliche Nutzung von Fahrstühlen und Kraftfahrzeugen (auch schon bei relativ kurzen Strecken). 
Die Folgen der Ignoranz gegenüber dem ererbten Aktivitätspotenzial durch eine ungesunde brw. bewegungsarme Lebensweise sind unübersehbar, denn sie äußern sich in weit verbreiteten sog. Zivilisationskrankheiten. Nicht erst bei Erwachsenen, sondern zunehmend auch bei Kindern werden die Folgen erlebt und wahrgenommen als Übergewichtigkeit, Stoffwechsel- und Kreislauferkrankungen. So hat z. B. der übermäßige Genuss von Süßigkeiten und das lange Sitzen vor Bildschirmen zur Folge, dass in neuerer Zeit schon bei Jugendlichen sog. Altersdiabetes auftritt. Auswertungsergebnisse des bundesweiten Kinder- und Jugendgesundheitssurveys über die Verbreitung von Übergewicht und Adipositas bei Kindern und Jugendlichen in einem Tagungsbericht von Kurth besagen:

„Insgesamt sind $15 \%$ der Kinder und Jugendlichen von 3-17 Jahren übergewichtig, und 6,3 \% leiden unter Adipositas. Der Anteil der Übergewichtigen steigt von $9 \%$ bei den 3- bis 6-Jährigen über $15 \%$ bei den 7- bis 10-Jährigen bis hin zu $17 \%$ bei den 14- bis 17-Jährigen. Die Verbreitung von Adipositas beträgt bei den 3- bis 6-Jährigen 2,9 \% und steigt über 6,4 \% bei den 7- bis 10-Jährigen bis auf $8,5 \%$ bei den 14- bis 17-Jährigen. Klare Unterschiede zwischen Jungen und Mädchen oder zwischen alten und neuen Bundesländern sind nicht zu erkennen. Ein höheres Risiko für Übergewicht und Adipositas besteht bei Kindern aus sozial benachteiligten Schichten, bei Kindern mit Migrationshintergrund, bei Kindern, die nicht gestillt wurden und bei Kindern, deren Eltern ebenfalls übergewichtig sind“ (A. Schaffrath-Rosario; B.-M. Kurth; bei Kurth 2006, S. 1051).

Die jeweils steigenden Tendenzen zum Übergewicht mit zunehmendem Alter lassen vor allem auch auf eine fehlerhafte Ernährungs- und Bewegungsweise der Betroffenen schließen. Diese steigende Tendenz zum Übergewicht geht in bemerkenswerter Weise einher mit zunehmenden Schwächen in der Motorik der Kinder und Jugendlichen in den letzten Jahrzehnten, wie die Untersuchungsergebnisse zu „Sport und Bewegung bei Kindern und Jugendlichen in Deutschland“ von T. Lampert; A. Starker und G. B. M. Mensink im gleichen Tagungsbericht erkennen lassen:

„Im Bereich der Motorik zeigt sich, dass über ein Drittel der Kinder und Jugendlichen nicht in der Lage ist, 2 oder mehr Schritte auf einem $3 \mathrm{~cm}$ breiten Balken rückwärts zu balancieren. Bei der Rumpfbeuge erreichen $43 \%$ nicht das Fußsohlenniveau. Die Ergebnisse im Standweitsprung deuten einen Rückgang der Kraftfähigkeit um 14 \% seit 1976 an“ (Bös, Oberger et al. bei Kurth 2006, S. 1056).

Langes Sitzen vorm Bildschirm bringt Kinder nicht nur in gesundheitliche Schwierigkeiten, sondern beeinträchtigt durch das erzeugte Übergewicht ihr Aussehen und ihre Leistungsfähigkeit (z. B. im Sportunterricht), was wiederum zu Minderwertigkeitskomplexen führt - häufig verstärkt durch Hänseleien Gleichaltriger. Die Duldung grober Abweichungen von begründeten Normen einer gesunden Lebensweise bei Kindern muss daher auch als deviantes Verhalten und Handeln der Eltern und Erzieher gewertet werden. 
Doch es gibt offenbar noch weitere Auswirkungen der aktivitätsarmen Lebensweise unter den Bedingungen sozialer Verwöhnung und technischer „Entlastung“: die Entstehung sog. aggressiver Langeweile (v. Cube bei Roth 1991, S. 126). Wenn also arbeitslose Jugendliche an Buswartehäuschen „herumhängen“ und obendrein ihr Gefühl der Leere und Langeweile mit Alkohol „wegzuspülen“ versuchen, ist es kein Wunder, dass dann die „überschüssigen Aktivitätspotenziale“ eingesetzt werden, um das Buswartehäuschen, die vielleicht noch daneben stehende Telefonzelle oder die nächste Parkbank zu zerstören. Bei dem nicht selten unterbreiteten Vorschlag, das nicht sinnvoll ausgeschöpfte Aktivitätspotenzial im Sport zu nutzen, um dadurch Aggressivität abzubauen, muss das komplizierte und vielfältige Bedingungsgefüge für die Entstehung von Aggressivität beachtet werden. Uwe Füllgrabe schreibt:

„Man baut durch Gewalt (z. B. im Boxsport, W. N.) keine irgendwie vorhandene Aggression ab, sondern erzeugt sie erst, lebt eine aggressive Fantasie aus usw. Derartige Vorschläge können sogar gewaltfördernd sein [...]“ (Füllgrabe 2002, S. 731).

Sicherlich ist hierbei auch die Sportart und das Klima im Sportlerteam bedeutsam; es liegt auf der Hand, dass es hinsichtlich der Gewalt- und Teamproblematik große Unterschiede gibt, z. B. zwischen dem Box- und dem Volleyballsport.

Es ist evident, dass es für eine normale Entwicklung eines gewissen Gleichgewichts in den Wechselwirkungen zwischen dem menschlichen Organismus und seiner Umwelt bedarf. Dazu gehört nicht nur die Luft zum Atmen, sondern die gesamte Ernährungs-, Bewegungs- und Lebensweise der Menschen. Wird nun durch erzwungenes, leichtfertiges oder auch unwissentlich unangepasstes Verhalten dieses System der Wechselwirkungen zwischen dem menschlichen Organismus und seiner Umwelt gestört, ist der Sachverhalt gegeben, den v. Cube als Störung des verhaltensökologischen Gleichgewichts bezeichnet.

Außer der oben gekennzeichneten ungesunden oder unnatürlichen Lebensweise als Ursache für Störungen des Gleichgewichts zwischen Organismus und Umwelt gibt es auch noch andere, nämlich Drogen und Medikamente mit ihren nicht immer hinreichend bekannten Nebenwirkungen. So berichtet z. B. Zimbardo in seinem Standardwerk „Psychologie“ davon, dass in den 60er-Jahren des 20. Jahrhunderts in den USA manchen Frauen Progesteron verschrieben worden war, um Fehlgeburten zu verhindern. Nachträgliche Untersuchungen haben dann allerdings ergeben,

„daß sowohl männliche als auch weibliche Kinder, die in ihrem Embryonalstadium geringe Mengen dieses Hormons aufgenommen hatten, eine signifikant höhere Bereitschaft für körperliche Aggression zeigten als ihre Geschwister, die diese Behandlung nicht erhalten hatten“ (Zimbardo 1992, S. 365).

Er nennt Untersuchungen, die belegen, dass etwa 10 Millionen der in den USA lebenden Menschen während kritischer Perioden ihrer Entwicklung derartige Medikamente 
erhalten haben. Außerdem ist auch Alkoholgenuss während der Schwangerschaft auBerordentlich schädlich für das sich entwickelnde Kind.

Es wirken also biologische und psychosoziale Risikofaktoren während der Schwangerschaft von Müttern, während der Geburtsphase und in den ersten Lebensmonaten und Lebensjahren der Kinder, die zu Entwicklungsstörungen führen können. Dazu gibt es seit langem umfangreiche Spezialuntersuchungen, deren Ergebnisse hier nicht referiert werden können; es sei daher nur auf eine fundierte Veröffentlichung von Bernhard Meyer-Probst/Helfried Teichmann und Mitarbeitern verwiesen: „Risiken für die Persönlichkeitsentwicklung im Kindesalter“ (Leipzig 1984).

Aber unabhängig von den konkreten Ursachen auftretender Aggressivität steht die Gesellschaft vor der Aufgabe, dass sie etwas dagegen tun muss und mit Hilfe der modernen Medizin und wegen der grundsätzlichen Lernfähigkeit des Menschen auch tun kann. Die Frage ist nur: was? Aus den Erkenntnissen der Verhaltensbiologie hat F. v. Cube im angegebenen Artikel ein Konzept zur anerischen Erziehung ${ }^{12}$ abgeleitet, das auf dem evolutionären (der Entwicklungsgeschichte des Menschen Rechnung tragenden) Erziehungsprinzip „Fordern und Selbstfordern “ beruht. Jedem Kenner der Pädagogik Makarenkos wird bei dieser Formulierung dessen Prinzip der Verbindung von „möglichst hohen Forderungen an den Menschen und möglichst hoher Achtung vor ihm“ einfallen (Makarenko 1969, Bd. V, S. 155) und dazu seine Ergänzung:

„Wir müssen Forderungen stellen, doch nur solche, die den Kräften entsprechen (...) Jede Überforderung kann nur Schaden anrichten“ (a. a. O., S. 467).

Die von Makarenko beeinflusste DDR-Pädagogik hat diesem Prinzip stets große Bedeutung beigemessen, sie wurde aber in der sog. Wendezeit oft pauschal als „Kommandopädagogik“ diffamiert. Doch nachdem nun die Früchte antiautoritärer Erziehung und offenkundiger Verwöhnungstendenzen in der bundesdeutschen Erziehungspraxis unübersehbar geworden sind, bestehen Chancen dafür, dass die Vorschläge F. v. Cubes ernst genommen und die Auffassungen Makarenkos besser verstanden werden. Füllgrabe verweist in seiner Ursachenerörterung von Gewaltverbrechen auch auf die negativen Auswirkungen fehlerhafter Freiheitsauffassungen in der Erziehung, indem er formuliert:

„Zimbardo (1970) hatte schon damals mit Besorgnis auf die Auswirkungen einer Entwicklung hingewiesen, die durch nicht kognitiv orientierte, sondern emotionsorientierte Therapien, Betonung des spontanen, freien Äußerns von Gefühlen usw. eine breite gesellschaftliche Förderung und Legitimation bekam. Und es entwickelte sich eine weitverbreitete hedonistische Haltung: Handle anderen gegenüber so, wie es dir beliebt“ (Füllgrabe 2002, S. 731f.).

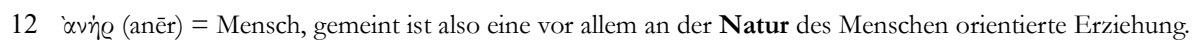


Meiner Meinung nach beachtet auch die Diskussion um die PISA-Ergebnisse der deutschen Schüler und die Mängel im deutschen Schulsystem zu wenig jene wichtigen Ursachen der beklagten Leistungsmängel, die im Sozialisations- und Erziehungssystem liegen. Wenn angeblich alles gut ist, was Spaß macht, braucht man sich nicht zu wundern, wenn Kinder und Jugendliche ein Ausweichverhalten gegenüber schulischen Anforderungen und Anstrengungen entwickeln, die eben nicht immer Spaß machen. Außerdem fördert diese praktizierte Norm die Zahl jener Gewalttäter, die ihre Brutalitäten einfach wegen des „Kicks“ begehen, den sie dabei empfinden. Das bedeutet: nicht alles, was notwendig ist, macht Spaß, und nicht alles, was Spaß macht, ist erlaubt!

\subsubsection{Verhaltenstheorische soziologische Erkenntnisse von Georg Caspar Homans zur Erklärung devianten Verhaltens}

Die Erkenntnisse der Biologie - speziell der Verhaltensbiologie - bezüglich möglicher Ursachen devianten Verhaltens erfassen das komplizierte Phänomen nur unter einem Aspekt. Auf einen weiteren verweist die verhaltenstheoretische Soziologie von Georg C. Homans (1910-1989). Er fordert von der Soziologie, dass sie die empirisch beobachtbaren Erscheinungen auch erklärt und meint, dass dies mit Hilfe allgemeiner Gesetze der verhaltenstheoretischen Psychologie möglich sei. Es können hier nicht die Auseinandersetzungen Homans mit der strukturfunktionalistischen Theorie in der Soziologie referiert werden, die Tamás Meleghy (1989, S. 31-50) skizziert. Es werden nur die grundlegenden Thesen der verhaltenstheoretischen Soziologie von Homans vorgestellt, die für die Erklärung abweichenden Verhaltens geeignet sind - aber nicht in dem Sinne, dass mit ihrer Hilfe bereits eine binreichende Erklärung möglich sei. Vielmehr handelt es sich auch hier nur um einen zu beachtenden Aspekt bei der Betrachtung des Ursachenkomplexes devianter Verhaltensweisen.

Homans geht davon aus, „dass das menschliche Verhalten universellen Gesetzmäßigkeiten folgt" (Meleghy 1989, S. 38). Ferner gibt es seiner Meinung nach

„,in den Sozialwissenschaften nur eine Art von Erklärung, nämlich die Zurückfübrung der Handlung von menschlichen Individuen bzw. der Resultate der Handlungen von Individuen [...] auf Sätze der behavioristischen Psychologie [...]. Die Sätze der behavioristischen Lerntheorie sind damit die allgemeinen erklärenden Hypothesen nicht nur in der Soziologie, sondern in allen Sozialwissenschaften " (Meleghy 1989, S. 39).

Meleghy formuliert mit Berufung auf Homans: „Die psychologische Erklärung ist zudem die einzig kausale sozialwissenschaftliche Erklärung" (a. a. O.). Ergänzend bemerkt er, „dass es einen eindentigen Beweis für die Zurückführbarkeit aller soziologischen Makrophänomene (Beziehungen zwischen verschiedenen Merkmalen von Gruppen oder Gesellschaften) auf die verhaltenstheoretische Lerntheorie nicht gibt und auch nicht geben kann“ (a. a. O., S. 47). 
Damit wird seine Behauptung zur Hypothese; sie mag manchen plausibel erscheinen, weil ja alles menschliche Handeln untrennbar mit der menschlichen Psyche, die sich lernend entwickelt, verbunden ist, aber das ändert nichts daran, dass er die Anlagenausstattung in ihrer Bedeutung für menschliches Verhalten unterschätzt.

Außerdem wird nicht beachtet, dass die psychischen Grundlagen des Handelns bzw. Lernens ihrerseits Ursachen haben. Diese sind nach dialektisch-materialistischer Auffassung in letzter Instanz in den natürlichen Bedürfnissen des Menschen nach Nahrung, Kleidung, Wohnung u. dgl. zu suchen. Natürlich „lebt der Mensch nicht vom Brot allein“, aber seine kulturellen, geistigen und auch weltanschaulichen bzw. religiösen Bedürfnisse und Interessen kann er nur im Zusammenhang mit einer zumindest elementaren Befriedigung seiner leiblichen Bedürfnisse entwickeln. Wenn oben die organischen Bedürfnisse als ursächliche Bedingungen menschlichen Handelns mit der Einschränkung „,in letzter Instanz" versehen wurde, so ist das eine globale und generalisierende Aus sage, die auf die Gesellschaft im Ganzen zutrifft. Das Individuum dagegen besitzt seine individuelle Bedürfnis- und Wertestruktur, die sein Handeln bestimmt, und dabei können z. B. ideelle - speziell religiöse - Motive wirksamer sein als der Hunger (etwa in einer Fastenzeit) oder als der Lebensdrang, wie z. B. islamistische Selbstmordattentäter zeigen. Allerdings ist bei den Letztgenannten mit der Erwartungshaltung „Belohnung des Opfertodes mit dem Einzug ins Paradies“ ein „quasimaterielles“ Motiv im Spiel - zumal, wenn man die Vorstellungen der Islamisten vom Paradies in Rechnung stellt.

Hinzu kommt, dass große gesellschaftliche Zusammenhänge und Veränderungsprozesse überhaupt nicht hinreichend mit einer Summe individueller Handlungen erklärt werden können, sondern dass hierbei gesellschaftliche Systemgesetze zu beachten sind, denen das individuelle Handeln seinerseits - wenn auch in großer Variationsbreite - unterworfen ist. Worum es sich bei diesen gesellschaftlichen Systemgesetzen handelt, kann z. B. bei Karl Marx nachgelesen werden, und wem dies zu mühselig ist, der vergegenwärtige sich nur einmal die Kämpfe um die Rohstoff- und Energieressourcen in der Welt sowie die Handlungsweisen profitgieriger Banker.

In diesem Buch geht es nicht um die Ursachen weltgeschichtlicher Ereignisse oder aggressiver Handlungen von Regierungen, sondern um die Erklärung devianten Handelns und Verhaltens von Personen, die in individuelle Notlagen oder Schwierigkeiten geraten sind und denen von Sozialpädagogen geholfen werden soll. Und in diesem Bereich können die Hypothesen der verhaltenspsychologischen Lerntheorie durchaus hilfreich sein, wenn man bei ihrer Anwendung nicht vergisst, dass jede Persönlichkeit so vielschichtig ist, dass ihr Verhalten nicht mit einer Theorie allein erklärt werden kann.

Allen Hypothesen voran stellt Homans die sog. Rationalitätshypothese, da er davon ausgeht, dass menschliches Handeln seinem Wesen nach rational ist. Da das im Einzelfall nicht immer zutrifft, sah sich Homans veranlasst, auf die Einschätzungsfähigkeit des 
Handelnden zum jeweiligen Zeitpunkt hinzuweisen und die prognostizierte gesetzmäßige Handlungsweise stets als eine wahrscheinliche zu betrachten. Die Rationalitätshypothese lautet:

„Jeder Mensch wird, wenn er zwischen alternativen Handlungen zu wählen hat, wahrscheinlich diejenige wählen, für die - entsprechend seiner Einschätzung zum gegebenen Zeitpunkt - das Produkt aus dem Wert (w) des Ergebnisses und der Wahrscheinlichkeit (p), das Ergebnis zu erzielen, größer ist; und je höher der Wert p mal w für die Handlung im Vergleich zu ihrer Alter native ist, um so eher wird er die erste Handlung wählen“ (zitiert nach Meleghy 1989, S. 37).

Wenn zwischen einem Ziel mit relativ geringer Wertigkeit (sagen wir $\mathrm{w}=4$ ) und großer Realisierungschance (sagen wir $\mathrm{p}=75 \%$ ) und einem Ziel mit der böheren Wertigkeit $\mathrm{w}=6$ und der geringen Realisierungswahrscheinlichkeit von $\mathrm{p}=25 \%$ entschieden werden soll, ergeben sich folgende Rechnungen: $4 \cdot 0,75=3$ und $6 \cdot 0,25=1,5$. Im Volksmund heißt das schlicht: der Spatz in der Hand ist besser als die Taube auf dem Dach.

Aber auch das ist für viele Akteure keine absolut gültige Maxime, nämlich dann, wenn sie in einer Entscheidungssituation affektiv handeln und nicht abwägend entscheiden oder „es einfach riskieren“ - wohl wissend, wie gering die Erfolgsaussichten sind. Dennoch kann ein Rückgriff auf die Rationalitätshypothese im konkreten Fall bei einer Problemanalyse zweckmäßig sein, nämlich dann, wenn abwägendes Handeln vorlag und möglicherweise gerade Fehleinschätæungen der Situation von Bedeutung waren, z. B. bei Kreditaufnahmen, deren Folgen in Schuldnerberatungen eine Rolle spielen.

Auf der Grundlage der behavioristischen Lerntheorie formuliert Homans schließlich folgende Hypothesen zur Erklärung menschlichen Handelns und Verhaltens:

- Erfolgshypothese: ,Je häufiger die Aktivität einer Person belohnt wird, mit um so größerer Wahrscheinlichkeit wird diese Person die Aktivität ausführen“ (zitiert nach Meleghy 1989, S. 41).

- Reizhypothese: „Wenn in der Vergangenheit eine Aktivität, die von einem bestimmten Reiz oder von einer Menge von Reizen begleitet wurde, belohnt worden ist, dann wird eine Person um so eher diese oder eine ähnliche Aktivität ausführen, je ähnlicher die gegenwärtigen Reize den vergangenen sind“ (a. a. O., S. 41/42).

- Werthypothese: ,Je wertvoller die Belohnung einer Aktivität für eine Person ist, desto eher wird sie die Aktivität ausführen“ (a. a. O., S. 43).

- Entbehrungs-Sättigungs-Hypothese: ,Je öfter eine Person in der nahen Vergangenheit eine bestimmte Belohnung erhalten hat, desto weniger wertvoll wird für sie jede zusätzliche Belohnungseinheit"( a. a. O., S. 44).

- Frustrations-Aggressions-Hypothese: „Wenn die Aktivität einer Person nicht wie erwartet belohnt oder unerwartet bestraft wird, wird die Person ärgerlich, und im Ärger sind die Ergebnisse aggressiven Verhaltens belohnend“ (a. a. O., S. 45). 
Beachten wir die Vielschichtigkeit jeder Persönlichkeit, so wird verständlich, warum Homans bei den ersten 4 Hypothesen die für komparative Gesetzesaussagen mit Wahrscheinlichkeitscharakter typischen Komparative (häufiger, größer, eher, weniger, öfter, ähnlicher) verwendet. Die Frage ist: wodurch sind die Wahrscheinlichkeiten begründet? Sind dafür unzureichende Einsichten des „Entscheidungsträgers“ in die Handlungsbedingungen maßgebend oder gibt es Kräfte, die sozusagen „von innen heraus“ den von Behavioristen erwarteten Entscheidungen und Verhaltensweisen entgegenwirken? Bei den endogenen Faktoren handelt es sich um angeborene Dispositionen, z. B. um invariante Bedürfnisse (siehe S. 218ff. und S. 227), bei den autogenen u. a. auch um erworbene und verfestigte Überzeugungen oder starre Gewohnheiten, so dass irgendwelche Belohnungen oder mögliche tragische Konsequenzen weniger beachtet werden. Dies gilt besonders in Krisensituationen, in denen häufig alle bisherigen Erfahrungen vernachlässigt werden und gerade nicht nach einem erlernten und prognostizierten Reiz-Reaktions-Schema gehandelt wird.

Auch die Frustrations-Aggressions-Hypothese gilt nicht immer. Bei gefestigten Persönlichkeiten, die Frustrationstoleranz entwickelt haben und das Leben kennen, spielt sie sicher keine große Rolle. Aber gerade bei Problembelasteten, die uns in der Sozialarbeit und Sozialpädagogik begegnen, mangelt es häufig an Frustrationstoleran₹, an realistischer Situationsbewertung und an Selbstbeherrschung; daher sollte diese Hypothese bei Problemanalysen unbedingt beachtet werden - zumal häufig das zerstörerische Handeln, die Randale und der Vandalismus Jugendlicher nur Ausdruck von Aggressionen gegen Ersatzobjekte sind, die mit der Ursache der Frustration nichts zu tun haben. Die durch irgendwelche Enttäuschungen hervorgerufene und angestaute ohnmächtige Wut wird an wehrlosen Ersatzobjekten abreagiert.

Für die Betrachtungsweise des Behaviorismus und aller darauf basierenden Theorien ist charakteristisch, dass die Erfahrungen der Individuen mit äußeren Reizen (unter dem Aspekt ihrer angenehmen oder entlastenden Wirkungen) als Regulationsinstanz für das Handeln und Verhalten betrachtet werden. Eine entgegengesetzte Sichtweise finden wir bei Konzepten, die von tiefen- oder individualpsychologischen Erkenntnissen ausgeben. Hier werden innere Triebe und Bestrebungen als primäre Regulationsinstanzen für Aktionen und Reaktionen betrachtet und daher auch für die Erklärung abweichenden Verhaltens bevorzugt. Sicherlich geht es bei beiden Sichtweisen auch um die Wechselwirkung von endogenen und exogenen Faktoren, wobei aber die Rolle der autogenen Faktoren (z. B. des Verantwortungsbewusstseins, der Wertvorstellungen und Willensqualitäten der Persönlichkeit) unterschiedlich bewertet wird. Behavioristische Theorien lassen den exogenen Faktoren größere Bedeutung zukommen als tiefenpsychologisch orientierte Konzepte, welche den endogenen Faktoren der Persönlichkeit größeres Gewicht im Antriebs- und Regulationssystem beimessen. 


\subsubsection{Sozialpsychologische Erkenntnisse von Erich Fromm zur Erklärung devianten Verbaltens}

Während Homans bemüht ist, soziales Handeln und Verhalten von Menschen durch konsequente Nutzung des Reiz-Reaktions-Mechanismus der behavioristischen Psychologie zu erklären und dabei sowohl die endogenen Voraussetzungen des Individuums als auch den bistorischen und strukturellen Charakter der Umweltbedingungen vernachlässigt, finden wir bei Erich Fromm (1900-1980) den Versuch, die „Bedürfnisse der menschlichen Natur" in ihren konkreten Wechselwirkungen mit den historischen speziell auch sozialökonomischen - Verhältnissen für die Erklärung menschlichen Verhaltens und Handelns zu nutzen.

„Für Freud stehen Gesellschaftsleben und Zivilisation ihrem Wesen nach im Gegensatz zu den Bedürfnissen der menschlichen Natur, so wie er sie sieht. Der Mensch sieht sich vor die tragische Alternative gestellt, zwischen einem Glück, das sich auf die uneingeschränkte Befriedigung seiner Triebe gründet, und der Sicherheit und den kulturellen Leistungen zu wählen, die auf Triebverzicht basieren und daher zur Neurose und allen anderen Formen seelischer Erkrankung führen“ (Fromm 1981, S. 79).

Fromm hält sowohl eine genauere Bestimmung dessen, was „,menschliche Natur“ ist, für notwendig als auch eine gründlichere Analyse der Wechselwirkungen zwischen der sich historisch wandelnden menschlichen Natur und den jeweiligen gesellschaftlichen Verhältnissen, unter denen sie sich äußert und entwickelt. Und um diese Zusammenhänge aufzuklären, nutzt er u. a. Erkenntnisse von Marx zum Wesen und zur Funktionsweise des Kapitalismus einschließlich seiner Auswirkungen auf die Arbeits- und Lebensweise der Menschen und ihre Persönlichkeitsentwicklung.

Da es hier nicht möglich ist, das Erkenntnissystem Fromms umfassend zu referieren, sollen nur einige seiner grundlegenden Erkenntnisse zu den gesellschaftlichen Bedingungen für die Entstehung devianter Verhaltensweisen vorgestellt werden. Dies ist gegenwärtig besonders wichtig, weil unter dem Einfluss neoliberaler Wirtschaftspolitik die These von der „Selbstverschuldung" der in Not Geratenen vehement vertreten wird zum einen, um die Verantwortung der Zuständigen für Wirtschaft und Politik an den wirtschaftlichen und sozialen Problemen herabzuspielen, und zum anderen, um den Notleidenden ein schlechtes Gewissen einzureden, das ihren Protestwillen schwächt.

In Anlehnung an Auffassungen von Marx, die er in den „Ökonomisch-philosophischen Manuskripten“ (MEW, Bd. 40) zur Problematik der Entfremdung dargestellt hat, kommt Fromm „zu dem zentralen Problem der Auswirkungen des Kapitalismus auf die Persönlichkeit: zum Phänomen der Entfremdung“ (Fromm 1981, S. 120ff.):

„Die Entfremdung in unserer modernen Gesellschaft ist fast total. Sie kennzeichnet die Beziehung des Menschen zu seiner Arbeit, zu den Dingen, die er konsumiert, zum Staat, zu seinen Mitmenschen und zu sich selbst“" (Fromm 1981, S. 123). 
Entfremdung als Folge einer - nach Auffassung von Fromm - als normal betrachteten pathologischen Wirtschaftsweise drückt sich vor allem darin aus, dass alle die genannten Phänomene (Arbeitsprozess, Arbeitsprodukte, Arbeitsverwaltung bzw. Staat und Bürokratie, Arbeitskollegen bzw. Mitmenschen) dem Menschen fremd und feindlich gegenüberstehen. Obgleich er sie mit gestaltet, wird er letztlich von ihnen in einer Weise beherrscht, dass er Schaden nimmt an seinem Charakter. Fromm versucht sogar einen allgemeinen Gesellschaftscharakter als Wesenszug aller individuellen Charaktere zu bestimmen, der dem jeweiligen Entwicklungsstand der sozialökonomischen Verhältnisse und der damit verbundenen Arbeits- und Lebensweise entspricht.

Um den Gesellschaftscharakter von Menschen in der modernen Industrie- und Konsumgesellschaft zu kennzeichnen, benutzt er das Wort Marketing-Charakter:

„Ich habe die Bezeichnung »Marketing-Charakter« gewählt, weil der einzelne sich selbst als Ware und den eigenen Wert nicht als »Gebrauchswert«, sondern als »Tauschwert« erlebt. Der Mensch wird zur Ware auf dem »Persönlichkeitsmarkt«" (Fromm 2000, S. 141).

Daraus resultiert ein Selbstbewusstsein, das er wie folgt beschreibt:

„Des Menschen Wertgefühl hängt von seinem Erfolg ab, ob er sich gewinnbringend verkaufen kann, ob er mehr aus sich zu machen weiß als er zu Anfang seiner Laufbahn war, kurz, ob er »ein Erfolg ist«. Sein Körper, sein Geist und seine Seele sind sein Kapital, und seine Lebensaufgabe besteht darin, dieses vorteilhaft zu investieren, einen Profit aus sich zu ziehen. Menschliche Eigenschaften wie Freundlichkeit, Höflichkeit und Güte werden zu Gebrauchswerten, zu Aktivposten des »Persönlichkeitspakets«, die zu einem höheren Preis auf dem Personenmarkt verhelfen“ (Fromm 1981, S. 139).

Als eine schwerwiegende Folge dieser Sicht- und Verhaltensweise beklagt er:

„Man kann das Wesen der Entfremdung nicht ganz verstehen, wenn man einen speziellen Aspekt unseres modernen Lebens außer acht läßt: die Routinisierung und die Verdrängung der Grundprobleme menschlicher Existenz aus dem Bewußtsein" (Fromm 1981, S. 141).

Mit der zitierten Charakterisierung erfasst Fromm wesentliche Momente der Selbstentfremdung des Menschen im Hinblick auf den Schaffenden (hier verstanden als Funktion) - sei es ein Arbeiter oder ein Manager.

Im Hinblick auf den Konsumierenden beschreibt Fromm eine andere Erscheinungsform der Selbstentfremdung, für die er den Begriff des homo consumens definiert:

„Der homo consumens ist der Mensch, dessen Hauptziel es nicht ist, Dinge zu besitzen, sondern immer mehr zu konsumieren, um auf diese Weise seine innere Leere, Passivität und Angst zu kompensieren. In einer Gesellschaft, die durch Großunternehmen und durch riesige Bürokratien in Industrie, Verwaltung und Gewerkschaften gekennzeichnet ist, fühlt sich der einzelne, der seine Arbeitsbedingungen nicht mehr selbst unter Kontrolle hat, ohnmächtig, einsam, gelangweilt und von Angst erfüllt. Gleichzeitig verwandelt ihn das Profitstreben der großen 
Konsumindustrien durch das Medium der Werbung in ein unersättliches Wesen, in einen ewigen Säugling, der immer mehr konsumieren möchte und für den alles zu einem Konsumartikel wird: Zigaretten, Alkohol, Sex, Kino, Fernsehen, Reisen, ja sogar Bildung, Bücher und Vorträge. Neue künstliche Bedürfnisse werden erzeugt, und der Geschmack der Menschen wird manipuliert. (In seinen extremeren Formen ist der Charakter des homo consumens ein wohlbekanntes psycho-pathologisches Phänomen. Man findet es häufig bei depressiven oder angsterfüllten Menschen, die sich in übermäßiges Essen und Einkaufen oder in den Alkoholismus flüchten, um ihre heimliche Depression und Angst zu kompensieren.) Die Konsumgier [...] wird in der gegenwärtigen Industriegesellschaft zur dominierenden psychischen Kraft. Der homo consumens lebt in der Illusion, glücklich zu sein, während er unbewußt unter Langeweile und Passivität leidet. Je mehr Macht er über Maschinen besitzt, um so machtloser wird er als menschliches Wesen; je mehr er konsumiert, um so mehr wird er zum Sklaven der ständig wachsenden Bedürfnisse, die das Industriesystem erzeugt und manipuliert. Er verwechselt Sensationslust und aufregende Erlebnisse mit Freude und Glück und materiellen Komfort mit Lebendigkeit. Die Befriedigung seiner Gier wird zum Sinn seines Lebens, das Streben danach wird zu einer neuen Religion. Die Freiheit zu konsumieren wird zum Wesen der menschlichen Freiheit“ (1990, S. 28).

Konkret erleben Menschen die Entfremdung als Gefübl der Obnmacht gegenüber den gesellschaftlichen Verhältnissen und Prozessen, die ihr Leben bestimmen, ein Gefühl, das jeder Arbeitssuchende kennt, dem es ernst ist mit seinem Anliegen, und das auch dem kleinen Unternehmer vertraut ist, der im harten Konkurrenzkampf unterliegt. Das Gefübl der Ohnmacht und Hilflosigkeit in existenziellen Fragen ist oft ein Grund für deviante Verhaltensweisen, z. B. für Gewalttätigkeit in der Familie oder Aggressionen in den Agenturen für Arbeitsvermittlung. Ohnmacht in Kombination mit menschlicher Leere und Langeweile bilden außerdem einen Nährboden für die Entstehung devianter Verhaltensweisen, die sogar bis hin zum Foltern und Töten ,aus Spaß“ reichen.

Als Psychotherapeut hat sich Fromm aber nicht nur mit den soziologischen, sondern auch mit den psychologischen Grundlagen devianter Verhaltensweisen auseinander gesetzt, speziell mit der Auffassungen vom Destruktionstrieb oder Todestrieb.

„Die Diskussion über die Frage eines angeborenen oder instinktiven Destruktionstriebes spitzt sich oft zu folgender Alternative zu: Auf der einen Seite stehen Forscher wie Freud, Lorenz und andere, die sagen: ja es gibt diese instinktive Destruktivität; und auf der anderen Seite stehen viele, besonders amerikanische Forscher, die sagen: nein, das gibt es überhaupt nicht, die Destruktivität ist immer nur die Folge der Frustration, oder sie ist gelernt; auf alle Fälle ist sie nichts, was nicht einfach aus den Einflüssen der Gesellschaft und der Umwelt erklärt werden kann, und sie ist nichts, was im Organismus des Menschen selbst begründet liegt. Die letztere Position ist auch unhaltbar, denn wir wissen, dass es in der Tat im Gehirn Zentren gibt, die wenn sie gereizt, z. B. elektrisch stimuliert werden - tatsächlich Aggressionsreaktionen hervor- 
rufen. [...] Ich glaube, daß es eine andere Lösung des Dilemmas gibt: entweder angeborener Destruktionstrieb oder nur gelernte oder aus der Umgebung erzeugte Destruktivität. Diese Lösung besteht in der Annahme, daß in der menschlichen Physiologie eine Bereitschaft zur Aggression vorliegt, die aber nicht [...] spontan und ständig wachsend von selbst wirkt wie Sexualität, sondern die erst mobilisiert werden muß durch bestimmte Stimuli; wenn diese Stimuli nicht vorhanden sind, entsteht Aggressivität gar nicht, weil sie immer in Schach gehalten wird von der gleichzeitig wirkenden Hemmungstendenz, die - neurophysiologisch gesehen - ihr eigenes Hirnzentrum hat. Das heißt also auch, daß es keinen Destruktionstrieb gibt, der ständig kontrolliert werden muß, sondern eine Destruktionsbereitschaft, die ständig bereit ist, auf bestimmte Anlässe zu reagieren“ (Fromm 1990, S. 141/142).

Fromm sieht in der Bedrohung vitaler Interessen solche Anlässe, die Aggressivität auslösen, wobei er folgende wesentliche Unterschiede zwischen der Aggressionsbereitschaft von Tieren und Menschen sieht: Tiere reagieren aggressiv, wenn sie ihre vitalen Interessen unmittelbar bedroht sehen, also ihr eigenes Leben oder das ihres Nachwuchses in Gefahr ist. Menschen dagegen können auf Grund ihres vorausschauenden Denkens schon mögliche künftige Gefahren erkennen und reagieren u. U. vorbengend aggressiv, was natürlich Irrtümer einschließt und daher auch unnötige Aggressivität bedeuten kann.

„Der Mensch schafft Symbole und Werte, die für ihn identisch werden mit seinem Selbst, mit seiner ganzen Existenz. Angriffe auf diese Symbole sind Angriffe auf seine vitalen Interessen, die es beim Tier in dieser Sphäre natürlich nicht gibt. Der Mensch schafft sich Götzen, an die er versklavt ist, ohne die er aber auf einem bestimmten Stand der Entwicklung nicht leben kann, ohne verrückt zu werden oder innerlich zusammenzubrechen. Die Versklavung an die Götzen auf einer bestimmten Stufe ist die Bedingung seines seelischen Gleichgewichts. Jeder Angriff auf diese Götzen wird als Angriff auf seine vitalen Interessen empfunden“ (a. a. O., S. 143).

Fromm meint mit den „Götzen“ nicht nur irgendwelche nichtjüdischen oder unchristlichen Gottesvorstellungen, sondern alles, was heute angebetet wird: Ideologien, Staatssouveränität, Nation, Rasse, Freiheit, maximaler Konsum usw.

„Es gibt vielleicht keine Bedrohung, die mehr Feindseligkeit und Destruktivität in der Geschichte des Menschen hervorgerufen hat, als die Bedrohung seiner Götzen; nur daß sich die Menschen immer darüber täuschen, indem sie glauben, die eigenen Götzen seien die wahren Götter, und die Götter der anderen seien die wahren Götzen“ (Fromm 1990, S. 144).

Damit wird erklärt, weshalb Menschen aggressiver und brutaler sind als Tiere, was z. B. durch die Grausamkeiten von Rassisten, Nationalisten, politischen Extremisten, ideologischen und religiösen Fundamentalisten seit Jahrhunderten demonstriert wird.

Außer der reaktiven Aggressivität oder Destruktivität, deren Auftreten an tatsächliche oder vermeintliche Bedrohungen vitaler Interessen gebunden ist, unterscheidet er 
noch einen zweiten Typ, den er „sadistisch-grausame Destruktivität“ nennt (vgl. Fromm 1990, S. 145). Sie resultiert aus der bereits erwähnten Ohnmacht und Hilflosigkeit des Menschen gegenüber undurchschaubaren und unbeherrschbaren gesellschaftlichen Verhältnissen; sie stellt eine Art von Kompensation dar.

„Ihr Ziel ist das Erlebnis der Allmacht über Menschen und Dinge, das sich in der absoluten Kontrolle über Menschen und Dinge bis zur Zerstörung, zur Quälerei und Tortur ausdrückt. [...] Dieses Gefühl muß nicht bewußt sein, denn es gibt genügend Mittel, sich darüber zu täuschen, da es unbequem ist, sich bewußt ohnmächtig zu fühlen. Offenbar will der Mensch, wenn er sich ohnmächtig fühlt, Lebendiges zu schaffen, wenigstens das Lebendige zerstören“ (a. a. O., S. 145).

Fromm verweist auf historische Beispiele und bemerkt anschließend,

„daß Menschen, die auf Grund ihrer realen Situation am ärmsten an Freude und Schöpferkraft sind, auch häufiger als in anderen Schichten diese sadistische Destruktivität zeigen“" (a. a. O., S. 146).

Zusammenfassend kann daher festgestellt werden, dass Fromms sozialpsychologische Theorie unter Nutzung kritisch weiterentwickelter Erkenntnisse der Tiefenpsychologie und des Marxismus reale Quellen für die mögliche Entstehung devianter Verhaltensweisen und delinquenten Handelns aufzeigt. Indem Fromm die determinierende Wirkung sozialökonomischer Lebensbedingungen auf die Charakterentwicklung der Menschen herausarbeitet, macht er diese aber nicht zu passiven Produkten ihrer Lebensbedingungen, vielmehr sah er sie auch als Produzenten ibrer Verbältnisse. Daher hat er sich um die Entwicklung konzeptioneller Vorstellungen für gesellschaftliche Veränderungen bemüht und sie unter den Begriff des demokratischen oder humanistischen Sozialismus gefasst (vgl. 1990, S. 87ff.). Um eine neue und humanistische Gesellschaft zu schaffen, sind nach seiner Überzeugung große wissenschaftliche Anstrengungen notwendig, deren Ziel es ist, die Herrschaft zu erlangen „über die Technik und über irrationale gesellschaftliche Kräfte und Institutionen, die das Überleben der westlichen Gesellschaft, wenn nicht gar der Menschheit bedrohen“ (2000, S. 168).

\subsubsection{Sozialökonomische Erkenntnisse von Robert K. Merton zur Erklärung devianten Verhaltens}

In Weiterführung der Erkenntnisse von Emile Durkheim (1858-1917) und Talcott Parsons (1902-1979) zur strukturfunktionalistischen Handlungstheorie hat Robert King Merton (1910-2003) eine Klassifizierung von Anpassungstypen vorgenommen, die erkennen lässt, welche Möglichkeiten die Menschen haben, um auf sog. anome Verhältnisse zu reagieren. Da widersprüchliche und krisenhafte gesellschaftliche Verhältnisse zu Lebensbedingungen führen, die viele Menschen verunsichern und überfordern, kommt es zu unterschiedlichen Reaktionsweisen in der Anpassung an diese Verhältnisse. Merton hat auf empirischer Grundlage folgende Anpassungstypen gefunden: 


\begin{tabular}{|lcc|}
\hline Anpassungstypen & $\begin{array}{c}\text { Einstellungen zu } \\
\text { kulturellen Zielen }\end{array}$ & $\begin{array}{c}\text { Einstellungen zu } \\
\text { zugelassenen Mitteln }\end{array}$ \\
Konformität & + & + \\
Innovation & + & - \\
Ritualismus & - & + \\
Sozialer Rückzug & - & - \\
Rebellion & $-(+)$ & $-(+)$ \\
\hline
\end{tabular}

$+=$ Akzeptierung; $-=$ Ablehnung ; $-(+)=$ Substitution (zitiert nach Grohall in: Biermann u. a. 1992, S. 156)

Übersicht 4

Für devianztheoretische Betrachtungen sind die beiden Anpassungstypen „Innovation“ und „Rebellion“ von besonderem Interesse. Wer nämlich die allgemein anerkannten und verbreiteten kulturellen Ziele verbissen anstrebt, wird mit allen Mitteln versuchen, sie auch für sich zu realisieren, und sei es mit unzulässigen Mitteln, die er sich dafür ausdenkt (Innovation!). Wer mit dem sog. Anomiestress nicht klar kommt, entwickelt seine eigenen kulturellen Ziele und Wertvorstellung und rebelliert gegen angeblich allgemeingültige Ziele $-z$. T. auch mit verwerflichen Mitteln.

Als psychologischer Hintergrund dieser Klassifikation können folgende Erfahrungen bzw. Überlegungen gelten: Jeder sog. normale Bürger in der kapitalistischen Gesellschaft weiß, dass sein Ansehen wesentlich davon bestimmt wird, ob er es zu etwas gebracht hat, was in der Öffentlichkeit oder zumindest in seiner Bezugsgruppe etwas zählt, der also ein winner ist. Verbunden ist diese Vorstellung zumeist mit dem Glauben, dass ,jeder seines Glückes Schmied ist" und dass es daher seiner Tüchtigkeit oder Geschicklichkeit unterliegt, sich die „Zeichen des Erfolgs“ zu beschaffen. Dass überhaupt ein solches Streben nach Anerkennung und Wertschätzung im Menschen steckt, kann die Soziologie und Sozialökonomie nicht hinreichend erklären; dazu müssen die Erkenntnisse der Psychologie und Anthropologie mit herangezogen werden (siehe 3.2.5 und 4.3.1).

Um sich das allgemein als erstrebenswert Geltende (z. B. modische Markenkleidung, schnelle Autos usw.) zu beschaffen, bedarf es z. T. erheblicher finanzieller Mittel, über die jedoch schon allein wegen ihrer sozialen Herkunft nicht alle Menschen verfügen. Es besteht also für eine nicht geringe Zahl von Kindern und Jugendlichen eine Diskrepanz zwischen den Werten, die sie erstreben, und den Mitteln, um das Erstrebte zu erlangen. Da aber in der Regel keiner gewillt sind, als Versager oder loser dazustehen, versuchen sie das Erstrebenswerte dennoch zu erlangen - und sei es mit ungesetzlichen Mitteln, d. h., sie erpressen sich das Geld für Markenkleidung oder stehlen das Auto. Es kommt zu abweichenden bzw. kriminellen Verhaltensweisen, um die Diskrepanz zwischen den erstrebten Werten und den unzureichenden Mitteln zu „überwinden“. 
Wurr und Trabandt gelangen entsprechend Mertons Theorie zu der Schlussfolgerung: „Ursache abweichenden Verhaltens ist der Widerspruch zwischen Erfolgsidee und sozialer Ungleichbeit" (1993, S. 24).

Die Wert-Mittel-Diskrepanz-Theorie besitzt für die Erklärung der Jugenddelinquenz in den Industriestaaten besondere Bedeutung. Für diese Länder ist charakteristisch, dass die individuelle persönliche Reife und die ökonomische Selbständigkeit wegen der langen Schul- und Ausbildungszeiten (und wegen noch hinzutretender Schwierigkeiten beim Einstieg ins Erwerbsleben) zeitlich sehr weit auseinander liegen. Der Jugendliche aber hat das Bedürfnis als Erwachsener angesehen zu werden und auch teilzuhaben an deren „Privilegien“, so dass er oft nur die Möglichkeit sieht, sich diese auf illegale Weise $\mathrm{zu}$ verschaffen.

Zweifellos ist dieser Widerspruch zwischen erstrebten Werten und verfügbaren Mitteln eine fundamentale Erklärung für abweichendes Verhalten - wenn auch keine Entschuldigung! Allerdings zeigen sich hier auch die schädlichen Auswirkungen des ökonomisch erzeugten Konkurrenzdenkens in seiner Übertragung auf die Sphäre des persönlichen Strebens nach Anerkennung, das zudem von aggressiven Werbungen der Wirtschaft und der Medien in unverantwortlicher Weise unterstützt und gefördert wird. Zwar wird immer wieder auf die erzieherische Verantwortung der Eltern verwiesen, die hier gegensteuern müssten, aber bisher hat niemand genau aufzeigen können, welche Erfolgsaussichten dafür eigentlich bestehen. Und so ist es kein Wunder, dass - beginnend mit kleinen Ladendiebstählen bis hin zu Raub- und Banküberfällen - ein breites Spektrum von Praktiken zur Überwindung der Wert-Mittel-Diskrepanz im materiellen Bereich entstanden ist. Eine andere Variante zur „Bewältigung“ der Wert-MittelDiskrepanz besonders auch durch Jugendliche ist die Überschuldung (Zahlungsprobleme bei der Telekommunikationsbranche und bei Versandhäusern), die den Kreis der Problembelasteten erweitern.

Es ist ein Verdienst von Wurr und Trabandt, dass sie die Wert-Mittel-Diskrepanz-Betrachtung auch auf den außerökonomischen Bereich anwenden und mit Recht von einer „soziokulturellen Wert-Mittel-Diskrepanz“ sprechen (a. a. O., S. 24). Als Beispiel führen sie den oftmals von Eltern für ihre Kinder erwünschten höheren Schulabschluss an, für den aber manchen Kindern die geeigneten Mittel in Form intellektueller Fähigkeiten, geistiger Interessen und Lernfleiß fehlen. Für den Fall, dass das Kind entsprechend den Wertvorstellung seiner Eltern eine höhere Schule besuchen muss, kann es auf verschiedene Weise reagieren, nämlich

- durch eine sog. deviante Innovation (auch wenn sie nicht immer neu ist) - zum Beispiel durch die Bewältigung anspruchsvoller Hausaufgaben mit Hilfe des Internets -, um auf diese Weise zu versuchen, das geforderte Ziel zu erreichen; 
- $\quad$ durch Rückzug aus der als unangenehm erlebten Diskrepanz zwischen den hohen Anforderungen, die mit der Wertvorstellung der Eltern verbunden sind, und den eigenen Kräften (Mitteln) hinsichtlich der Erfüllung dieser Anforderungen, und zwar durch Schwänzen bestimmter Unterrichtsstunden oder der Schule überhaupt;

- $\quad$ durch Rebellion in der Schule, z. B. Störungen des Unterrichts, Ärgern der Lehrer, Sachbeschädigungen in der Schule - möglicherweise in der Hoffnung, deshalb ,gefeuert zu werden“;

- durch - oft auch nur zeitweilige - Scheinanpassung an die unangenehme Situation, um schlimmere Bedrohungen und Belastungen zu vermeiden oder zu verkürzen, was allerdings dazu führen kann, dass sie schließlich als unerträglich empfunden werden und daher in eine Rebellion oder Katastrophe umschlagen, z. B. Suizid oder Amoklauf;

- durch Konformität, was in der Regel die wünschenswerte Reaktion ist, die aber mit Resignation verbunden sein kann. Dieser Nachteil ist vermeidbar, wenn die Diskrepanz wesentlich gemildert wird, z. B. hinsichtlich des Schulabschlusses durch geeignete pädagogische Hilfen oder ein realisierbar erscheinendes Ziel, was leider eine Abstufung im Schulsystem bedeuten kann.

Auch die erweiterte Wert-Mittel-Diskrepanz-Hypothese erklärt deviantes Verhalten nur aus einem - wenn auch praktisch bedeutsamen - Blickwinkel, so dass wir uns weiteren Theorien zuwenden müssen.

\subsubsection{Individualpsychologische Erkenntnisse von Alfred Adler zur Erklärung devianten Verhaltens}

In der kritischen Auseinandersetzung mit seinem ehemaligen Lehrer und Freund Sigmund Freud (1856-1939) hat Adler eine Theorie von den Triebkräften menschlichen Handelns und Verhaltens entwickelt, die durch Klarheit, Verständlichkeit und Leistungsfähigkeit beeindruckt. Hinzu kommt, dass sich wichtige theoretische Auffassungen von ihm in die hier vorgestellte dialektisch-materialistische Sichtweise einfügen.

Aus vorliegenden anthropologischen Erkenntnissen ist allgemein bekannt, dass der Mensch nach Arnold K. F. Gehlen (1904-1976) bei seiner Geburt ein „,biologisches Mängelwesen“, nach Nikolaas Tinbergen (1907-1988) ein „instinktreduziertes“ und nach Jakob J. v. Uexküll (1864-1944) ein ,weltoffenes Wesen“ist, das erst durch einen komplizierten Lernprozess zu jenem gesellschaftlichen Wesen wird, das über sich selbst, seine Vergangenheit und Zukunft nachdenken kann und sein Leben mehr oder weniger bewusst und schöpferisch gestaltet (vgl. Ilse 1994, S. 12f.). Gehlens These vom „biologischen Mängelwesens" muss nicht unbedingt mit jenen konservativen Konsequenzen verbunden werden, die berechtigte Kritik hervorgerufen haben; aber dass jedes menschliche 
Individuum seine Mängel selbst durchlebt, ist evident und hat nach Adler auch entwicklungsfördernde Bedeutung:

„Jeder Mensch hat, wie wir gesagt haben, ein Minderwertigkeitsgefühl. Aber das Minderwertigkeitsgefühl ist keine Krankheit, es ist vielmehr ein Anreiz zu einem gesunden, normalen Streben und einer normalen Entwicklung. Es wird nur dann zu einem pathologischen Zustand, wenn das Gefühl der Unzulänglichkeit den Menschen überwältigt und, weit davon entfernt, ihn zu nützlicher Aktivität anzustacheln, ihn bedrückt und ihn zu einer Entwicklung unfähig macht. Der Minderwertigkeitskomplex bezeichnet die Stellungnahme eines Menschen, der dadurch ausdrückt, daß er nicht in der Lage ist, ein vorliegendes Problem zu lösen. Der Minderwertigkeitskomplex ist die Darstellung eines Menschen, aus der er sich und anderen erklärt, nicht stark genug zu sein, um ein bestimmtes Problem in sozial wertvoller Weise (Hervorhebung durch W. N.) zu lösen“ (Ansbacher/Ansbacher 1982, S. 247).

Was Adler hier über die von Minderwertigkeitskomplexen belasteten Menschen sagt nämlich die Unfähigkeit ,ein bestimmtes Problem in sozial wertvoller Weise“ zu lösen - , ist genau jenes zentrale Merkmal, auf das Sozialpädagogen bei ihrer Klientel stoßen.

Die Folgen der Minderwertigkeitskomplexe sind schon bei Kindern zu beobachten. Adler beschreibt sie - allerdings im Hinblick auf Kinder mit angeborenen Organschäden - wie folgt:

„Dem Minderwertigkeitsgefühl ${ }^{13}$ entsprechen Züge wie Ängstlichkeit, Zweifel, Unsicherheit, Schüchternheit, Feigheit und verstärkte Züge von Anlehnungsbedürfnis und unterwürfigem Gehorsam. Daneben finden sich Phantasien, ja auch Wünsche, die man als Kleinheitsideen oder masochistische Regungen zusammenfassen kann. Über diesem Gewebe von Charakterzügen finden sich regelmäßig - in abweisender und ausgleichender Absicht - Frechheit, Mut und Übermut, Hang zur Auflehnung, Starrköpfigkeit und Trotz, begleitet von Phantasien und Wünschen nach einer Helden-, Krieger-, Räuberrolle, kurz von Größenideen und sadistischen Regungen“ (Ansbacher/Ansbacher 1982, S. 70/71).

Fragt man nach den Ursachen für die Entstehung dieser anschaulich beschriebenen Verhaltensweisen, die auch bei Kindern obne angeborene Organschäden auftreten können, dann lassen sich diese im „unpädagogischen“ Umgang von Eltern mit ihren Kindern relativ leicht finden: Die Neigung von zwei- und dreijährigen Kindern nach Mitwirkung im Familienalltag, das damit verbundene Streben nach Anerkennung und Selbständigkeit äußert sich z. B. in ihrem „Helfen-Wollen“ bei alltäglichen Verrichtungen (z. B. beim Tischdecken) oder auch in der Ablehnung von Hilfestellungen durch Erwachsene (,,ich kann das schon allein“). Natürlich erleben gerade aktive Kinder bei ihren Bemühungen zu helfen nicht wenige Missgeschicke (z. B. das Zerbrechen eines Tellers), was

13 Gemeint ist hier ein ,gesteigertes Minderwertigkeitsgefühl“, das später auch als Minderwertigkeitskomplex bezeichnet worden ist. Erklärungen zur Entwicklung der Terminologie sind zu finden bei Ansbacher/Ansbacher 1982, S. 63 f., S. 70 , S. $245 \mathrm{ff}$. 
verständlicherweise Mindervertigkeitsgefüble hervorruft. Das ist - wie oben gesagt - nicht von vorn herein schädlich, sondern im Gegenteil eher eine Triebkraft für größeres Bemühen, denn das Kind möchte ja dieses Gefühl mittels gelungener Handlungen überwinden oder künftig vermeiden. Wenn sich allerdings die Misserfolge häufen und jeder Fehlschlag von den Erziehern zum Anlass genommen wird, dem Kind seine Unfähigkeiten vorzuwerfen oder die Mithilfe zu verbieten (was ja leider geschieht), dann bilden sich eben jene Minderwertigkeitskomplexe, die sich als schwerwiegende Entwicklungsstörung bemerkbar machen und so äußern, wie Adler sie beschrieben hat.

Eine Bekräftigung der Minderwertigkeitsgefühle im Umgang mit dem Kind sollte unbedingt vermieden werden, denn

„Kein Mensch kann ein Minderwertigkeitsgefühl lange Zeit ertragen; er wird in eine Spannung versetzt, die irgendeine Art von Handlung notwendig macht“ (Ansbacher/Ansbacher 1982, S. 247).

Wie diese Handlungen, die eine Entspannung herbeiführen, jeweils aktuell aussehen können, ist bekannt (z. B. Ablehnung und Abwertung der Überforderung, Ausweichverhalten). Doch laut Adler reichen die Wirkungen dieser Spannungen weiter:

„Aber angenommen, ein Individuum ist entmutigt; angenommen, es kann sich nicht vorstellen, daß es durch realistische Anstrengungen die Situation verbessern kann. Es wird trotzdem unfähig sein, sein Minderwertigkeitsgefühl zu ertragen; es wird doch darum kämpfen, es los zu werden; aber es wird Methoden anwenden, die es nicht weiter vorwärts bringen. Sein Ziel ist es noch, »Schwierigkeiten überlegen zu sein«, aber anstatt die Hindernisse zu überwinden, wird es versuchen, sich selbst zu hypnotisieren oder sich selbst zu betäuben, und zwar mit einem Überlegenheitsgefühl“ (Ansbacher/Ansbacher 1982, S. 247). Denn: „Als normale Gefühle sind das Streben nach Überlegenheit und das Gefühl der Minderwertigkeit von Natur aus komplementär“" (a. a. O., S. 249).

Sobald also ein gesteigertes Minderwertigkeitsgefühl oder ein Minderwertigkeitsgefühlskomplex entsteht, entwickelt sich bei manchen Personen zugleich auch ein Überlegenheitskomplex als Kompensation, d. h.:

„Wir sollten nicht überrascht sein, wenn wir in den Fällen, wo wir einen Minderwertigkeits(gefühl)-komplex sehen, mehr oder weniger versteckt einen Überlegenheitskomplex finden“ (a. a. O., S. 248).

Aus den Gefühlen der Minderwertigkeit und der Ohnmacht erwächst ein entsprechender individueller Lebensstil, der auf eine Kompensation eben dieser Gefühle orientiert ist. Außer der realen Überwindung individueller Schwächen in gemeinschaftlichen Lern- und Arbeitsprozessen gibt es verschiedene Möglichkeiten zur Kompensation, z. B. ein Streben nach Überlegenheit, zu deren Erlangung man sich aller möglichen Mittel bedienen kann. 
Adler charakterisiert die Erscheinungsformen des Überlegenheitskomplexes in sehr differenzierter Weise. Sie reichen von auffälliger Kleidung, hochnäsigem Verhalten und prahlerischem Auftreten bis hin zu tyrannischen Verhaltensweisen, zum Bestreben über Schwache und Kranke zu gebieten sowie zu Affektsteigerungen wie Zorn, Rachsucht und Bestrebungen, andere Menschen zu entwerten (vgl. Ansbacher/Ansbacher 1982, S. 250). Allerdings warnt Adler ausdrücklich davor,

„diese Idee zu einem Überwertigkeitskomplex [...] unbesonnen jedermann an den Kopf zu werfen. Dasselbe gilt von der Kenntnis des Minderwertigkeitskomplexes [...]“ (a. a. O.).

Mit der Entwicklung von Verhaltensweisen des „Überwertigkeitskomplexes“ entsteht eine Art von Teufelskreis, denn mit den „minderwertigen Verhaltensweisen“ in Form von unkontrollierten Aggressionen, beleidigenden Ausfällen oder auch schlimmeren Bösartigkeiten werden Abwertungen provoziert, was den Minderwertigkeitskomplex verstärkt. Es ist schwierig, aber notwendig, diesen Teufelskreis zu durchbrechen, indem der Betreffende über den Grundirrtum in seinem Kommunikations- und Lebensstil aufgeklärt wird. Nur ein Erzieher, zu dem der Problembelastete wirklich Vertrauen hat und dem er ehrliche Absichten zubilligt, vermag mit viel Geschick in solchen Fällen etwas auszurichten. Erscheinungsformen von Minderwertigkeitskomplexen sind mangelndes Selbstvertrauen, Schüchternheit und die Neigung zur Resignation.

Bei manchen Menschen tritt ein Minderwertigkeitskomplex besonders in den Affekten in Erscheinung, mit deren Hilfe sie ihn zu kompensieren versuchen.

„Die Affekte sind Steigerungen jener Erscheinungen, die wir als Charakterzüge bezeichnet haben. [...] (Wir unterscheiden zwischen sozial trennenden und sozial verbindenden Affekten.) Die trennenden Affekte, wie Wut, Sorge oder Furcht, sind keine rätselhaften, undeutbaren Erscheinungen; sie treten immer dort auf, wo sie einen Sinn haben, wo sie der Lebensmethode, der Leitlinie eines Menschen entsprechen. Auch sie haben zum Ziel, eine Änderung herbeizuführen, um die Situation eines Menschen zu seinem Gunsten zu ändern. [...] Durch eine erhöhte Kraftanstrengung soll die eigene Person in den Vordergrund gestellt und siegreich gemacht werden. [...] Es gäbe viel weniger Zornausbrüche, wenn nicht die Möglichkeit gegeben wäre, sich auf diesem Weg Geltung zu verschaffen. Durch einen Zornausbruch wünscht das Individuum, seine Unvollkommenheit so schnell wie möglich zu überwinden. Einen Mitmenschen zu schlagen, zu beschuldigen oder anzugreifen scheint der beste Weg zu sein“ (Ansbacher/Ansbacher 1982, S. 221).

In aggressiven Gewalttätigkeiten erleben diejenigen, die sonst häufig das Gefühl der Verlierer haben, dass sie oben sind und über andere bestimmen - unter Umständen sogar über deren Leben und Sterben, wie es in tragischer Weise die Amokschützen demonstrieren. Außerdem besteht bei Menschen, die unter einem Minderwertigkeitskomplex leiden, eine große Neigung, ,starke Persönlichkeiten“ zu suchen, zu verehren 
und sich ihnen anzuschließen, um gewissermaßen teilzuhaben an deren vermeintlicher oder realer Stärke. Das erklärt auch den Zulauf, den sog. „starke Männer“ politischer und religiöser Strömungen vor allem in krisenhaften Zeiten erfahren (z. B. Hitler in Deutschland, Khomeini im Iran). Doch hier gibt es dann in der Regel eine deformierende Rückwirkung dergestalt, dass autoritäre Persönlichkeiten das Verantwortungsbewusstsein ihrer Gefolgschaft reduzieren, etwa nach der Losung: Führer befiehl, wir folgen dir!

Wenn allerdings autoritäre Regime nicht oder nicht mehr die Unterstützung der Untergebenen haben und diese die autoritären Maßnahmen als Unterdrückung ihrer berechtigten Ansprüche und Bestrebungen erleben, kann es geschehen, dass gerade dadurch der Drang zum gewaltsamen Widerstand, zur Befreiung von dem Druck erzeugt wird, d. h., es kommt zum Aufruhr. Diesen allerdings kann man nicht in die Kategorie regressiven devianten Handelns einordnen, sondern in ein durch Menschenrechtsnormen begründetes revolutionäres Handeln bzw. in den Bereich der progressiven Devianz.

Generell ist für sozialpädagogische Interventionen wichtig, im Beratungsgespräch eben genau jene Irrtümer, die infolge fehlerhafter Verarbeitung von Misserfolgserlebnissen im Bewusstsein der Problembelasteten entstanden sind, aufzudecken oder zu enthüllen. Denn sie sind es, die relativ stark den Lebensstil der Persönlichkeit beeinflussen und damit auch deviante Verhaltensweisen erklären helfen (vgl. Ansbacher/Ansbacher 1982, S. 174ff. und Birnbaum 1931 und 1932).

Welche Rolle Minderwertigkeitskomplexe im Leben der Menschen spielen können, lässt sich besonders deutlich an ihren Auswirkungen auf das Verhalten von Arbeitslosen erkennen: Der unverschuldete Verlust des Arbeitsplatzes bedeutet für den Betroffenen, dass seine Arbeitskraft nicht mehr gebraucht und gewürdigt wird. Es bedarf nunmehr einiger Anstrengungen, um nach anderen Möglichkeiten Ausschau zu halten und sich zu bewerben. Erfährt der Arbeitssuchende jetzt wiederholt Ablehnungen, so entsteht ein motivationaler Teufelskreis, d. h., jede Motivation erweist sich sozusagen als sinnlos, und jeder neue Entschluss fällt schwerer. Die wiederholten Absagen erzeugen im Betroffenen den begründeten Eindruck, dass er seine aktuelle Lebenssituation nicht wirklich gestalten kann und seine Zukunft ungewiss ist. Wer immer wieder die Erfahrung macht, dass er sein Geschick nicht in die Hand nehmen kann, generalisiert diesen Kontrollverlust und gerät damit in einen kognitiven Teufelskreis, d. h., er sieht keine Möglichkeiten mehr, aus seiner Lage herauszukommen, fühlt sich ohnmächtig und bemüht sich daher auch noch weniger. Es zeigen sich damit Symptome erlernter Hilflosigkeit, die mit Apathie und Depressivität verbunden sind. Die wiederholten Fehlschläge bei den Bewerbungen führen in einen aktionalen Teufelskreis, d. h., die Betroffenen unternehmen schließlich nichts mehr - sie geben auf! 
Auch für die Erklärung von Tötungsverbrechen wird die Erkenntnis über die Rolle von Minderwertigkeitskomplexen mit herangezogen. So schreibt z. B. Hans Joachim Schneider in seinen Erklärungsanalysen zum Verhalten jugendlicher Mörder:

„Aus ihrem unzulänglichen Selbstwertgefühl erwächst ihr mächtiger Wunsch nach Domination, der durch die Tötung erfüllt wird“ (Schneider 2002, S. 612).

Da Menschen mit geringem Selbstwertgefühl dazu neigen, es durch Überlegenheitsgefühle kompensieren zu wollen, kann über diesen Mechanismus auch der sog. Caligulaeffekt $^{14}$ erklärt werden: die Ausübung unberechenbarer Gewaltakte (z. B. bei Serienmördern) erzeugt allgemeine Angst in der Gesellschaft, die den Urhebern das Gefühl verleiht, Macht über Leben und Tod anderer Menschen zu haben. Die Realisierung solcher Ambitionen wird noch dadurch begünstigt, dass sie über Distanzdelikte erfolgt, d. h. ohne persönliche Beziehung zu den Opfern - etwa durch Schüsse auf unbekannte Passanten (vgl. Füllgrabe 2002, S. 730).

Diese Erkenntnisse können Sozialpädagogen bei der Problemanalyse helfen, Erklärungen zu finden, die dann Grundlage für die Intervention bzw. den Hilfeplan sind. Ein Grundsatz, der aus diesen Erkenntnissen abgeleitet worden ist und der jede sozialpädagogische Maßnahme bestimmen sollte, ist der Grundsatz der Ermutigung, der sich aber nicht im ,guten Zureden“ erschöpfen darf, sondern vor allem darauf gerichtet sein muss, dem Entmutigten sozial wertvolle Erfolge zu verschaffen.

Wichtige Erkenntnisse Adlers sind von der Humanistischen Psychologie aufgegriffen und weiterentwickelt worden. Sie widerspiegeln sich z. B. in der Rolle, die Selbstbewertungen und das Selbstwertbewusstsein, das Streben nach Selbstverwirklichung und die prinzipiell positive Wertschätzung von Klienten in der Theorie Carl R. Rogers (19081987) spielen. Es ist hier nicht möglich, diese Weiterentwicklung und die damit verbundenen Unterschiede zu referieren, die vor allem für darauf basierende Therapiekonzepte bedeutsam sind. Es ging zunächst um einige fundamentale psychologische Erkenntnisse zur Erklärung devianter Verhaltensweisen, die Alfred Adler gewonnen hat.

\subsubsection{Lernpsychologische Erklärungen devianten Verhaltens}

Über die Rolle der Vererbung und der Lernprozesse bei der Entstehung aggressiver Verhaltensweisen wird zwar immer noch gestritten, aber dass an der Entstehung devianter (einschließlich aggressiver und krimineller) Verhaltensweisen und Handlungen Lernprozesse beteiligt sind, steht außer Frage. In welchem Maße jedoch bei einem bestimmten Individuum die feststellbaren devianten Verhaltensweisen kreative Eigenleistungen, Ergebnisse von Probierhandlungen oder ausschließlich Nachahmungen sind,

14 Benannt nach dem römischen Kaiser Gaius Julius Caesar Germanicus (37-41 n. Chr.), genannt Caligula (=Stiefelchen), der durch seinen unberechenbaren und grausamen Despotismus die Öffentlichkeit in Angst und Schrecken versetzte bis er von der Prätorianergarde ermordet wurde. 
kann nicht mit Sicherheit gesagt werden. Kinder machen Fehler sowohl bei ihren nachahmenden als auch bei ihren schöpferischen Handlungen. Das ist normal und so lange nicht problematisch, wie sie bereit sind, aus den Fehlern zu lernen. Sozialpädagogisch relevant werden solche Fehler erst dann, wenn sie sich trotz entsprechender Belehrungen verfestigen oder wenn fortgesetzt demoralisierende und kriminalisierende Lernprozesse stimuliert werden. Selbstverständlich muss ein Kind erst einmal einzuhaltende Normen kennen und respektieren lernen, und dazu bedarf es vieler Übungen in unterschiedlichen Situationen. Von Bandura und anderen sind psychologische Untersuchungen durchgeführt worden, die erkennen lassen, dass und wie z. B. Kindergartenkinder aggressives Handeln nachahmend erlernen (vgl. Zimbardo 1992, S. 368).

Untersuchungen von Edwin H. Sutherland (1883-1950) belegen, dass delinquentes Handeln speziell in Gruppen (Assoziationen) mit kriminellem Charakter auf intensive und nachhaltige Weise erlernt wird. Hans Hartwig Bohle referiert den genannten Begründer der „Theorie der differentiellen Kontakte (oder Assoziationen)“ mit den Worten,

„daß eine Person dann delinquent wird, wenn Gesetzesverletzungen begünstigende Einstellungen gegenüber den solche Handlungen negativ bewertenden Einstellungen überwiegen, wobei Bedingungen wie Häufigkeit, Dauer, Abfolge und Intensität der differentiellen Kontakte maßgeblich sind“" (Bohle 1987, S. 3).

Wenn also Kinder in einem Milieu aufwachsen, in dem Diebstahl in der Regel keine negative Bewertung erfährt, weil er sozusagen zum normalen Alltag gehört, wird er entsprechend bedenkenlos nachgeahmt. Wurr und Trabandt meinen:

„Der kriminalisierende Lernprozess unterscheidet sich in nichts von anderen Lernprozessen, außer in den Inhalten“ (1993, S. 31).

Wesentlich an kriminalisierenden Lernprozessen ist, dass sie nicht nur im Erwerb technischer Fertigkeiten (etwa für das „Autoknacken“) bestehen, sondern die ganze Persönlichkeit erfassen, also ihre Motivstruktur („Ich will den anderen zeigen und beweisen, was ich alles erreiche!"), ihr mangelndes Mitgefübl für die Be- oder Geschädigten, die Fähigkeit, den Unschuldigen und Harmlosen zu spielen usw. Kriminalisierende Lernprozesse umfassen auch die Erfindung von Rechtfertigungsgründen und die Fähigkeit zu Vertuschungsmanövern bei deviantem Handeln. Effizienz und Nachhaltigkeit kriminalisierender Lernprozesse hängen oft damit zusammen, dass die Kinder und Heranwachsenden in einem Milieu leben, in dem rücksichtsloses, aggressives, gewalttätiges und kriminelles Handeln üblich ist und sie sich darin behaupten wollen. Hinzu kommt: wenn Kinder kein Mitgefübl erfahren haben, können sie auch selbst keines für andere entwickeln. Ferner besitzen kriminalisierende Lernprozesse eine gewisse Eigendynamik: erfolgreiche kleine Diebstähle „ermutigen“ auf der Basis wachsender Wünsche zu kühneren Plänen, erzeugen wachsende Risikobereitschaft und zunehmende Rücksichtslosigkeit. 
Welche Rolle speziell die Bezugspersonen in kriminalisierenden Lernprozessen spielen, lassen die Untersuchungen amerikanischer Psychologen in Armenvierteln von Großstädten erkennen. Es ist nicht so, dass in solchen Wohnvierteln mit hoher Kriminalität automatisch alle Heranwachsenden kriminelles Verhalten aus ihrer Umgebung nachahmen. Vielmehr werden Jugendliche kaum kriminell, wenn in ihren Familien die Eltern geregelter Arbeit nachgehen, ordentliche häusliche Verbältnisse bestehen und die Kinder selbst frübzeitig in den Prozess der legalen Sicherung des Lebensunterhalts mitverantwortlich einbezogen werden (vgl. Oerter/Montada 1998, S. 1029 und 1033f.). Daraus schlussfolgert Leo Montada:

„Ansatzpunkte für eine primäre Prävention in der Kindheit liefern Untersuchungen, die zeigen, daß Armut kombiniert mit chaotischen Familienverhältnissen und problematischen familiären Interaktionsformen und Erziehungsstilen antisoziale Auffälligkeiten generieren oder stabilisie-ren. Folglich hat man Elterntraining in solchen Familien versucht. Das konsistenteste Ergebnis war, daß es sehr schwierig war, Eltern, die es am nötigsten hätten, für eine kontinuierliche Mitarbeit zu gewinnen“ (a. a. O., S. 1033f.).

Wenn deviantes Verhalten in hohem Maße durch Lernprozesse bedingt ist, folgt daraus, dass es auch durch Lernprozesse wieder verändert werden kann. Doch jeder erfahrene Erzieher weiß, dass Umlernen schwieriger ist als Neulernen, wobei u. a. auch entwicklungspsychologische Bedingungen eine Rolle spielen.

\subsubsection{Entwicklungspsychologische Erklärungen devianten Verhaltens}

Zwar gehen wir davon aus, „dass Lernfähigkeit, und somit auch Plastizität, nicht ein Privileg allein der frühen Kindheit ist, sondern die gesamte Lebensspanne des Menschen charakterisiert" (Oerter/Montada 1998, S. 182), aber durch entwicklungspsychologische Untersuchungen ist auch belegt, dass sich Kinder und Heranwachsende in verschiedenen Stadien ihrer Entwicklung verschiedene Lerninhalte unterschiedlich leicht oder schnell aneignen. Entwicklungsabschnitte, ,in denen im Vergleich zu vorangehenden oder nachfolgenden Perioden spezifische Erfahrungen maximale positive oder negative Wirkungen haben“, werden als sensible Perioden bezeichnet (Oerter/Montada 1998, S. 53). Wenn auch der Nachweis solch sensibler Perioden für die Aneignung einzelner Persönlichkeitsqualitäten methodisch schwierig ist und noch weitgehend aussteht, so müssen doch die bisherigen Erkenntnisse in ihrer Bedeutung für das Auftreten devianten Verhaltens stärker beachtet werden.

Eroggene Eltern, die sich wirklich um ihre Kinder kümmern, sind die wichtigste entwicklungspsychologische Voraussetzung für das Gedeihen der Kinder. Welche weitreichenden Wirkungen die Mängel in dieser Hinsicht haben, wird in den Forschungsergebnissen der Entwicklungspsychologie deutlich. Dabei darf allerdings nicht übersehen werden, dass andere 
Sozialisationsfaktoren stärker wirken können als die Eltern, weshalb es auch falsch ist, immer nur den Eltern die Schuld zu geben für ihre „missratenen Kinder“; dies entlastet nämlich sowohl die Medien als auch die Jugendlichen selbst in u. U. unangemessener Weise von ihrer Verantwortung. Elterliche Erziehungsbemühungen oder -versäumnisse müssen immer konkret geprüft und bewertet werden.

Aber auch diese Überprüfung hat in einer pluralistischen Gesellschaft ihre spezifischen Probleme, weil die Auffassungen darüber, „was richtige Erziehung ist“, weit auseinander gehen. Das erzieherische Handeln in den Familien und auch in den Kindertagesstätten ist derart unterschiedlich, dass es häufig schwer fällt, herauszufinden, woran es nun eigentlich liegt, dass bestimmte deviante Verhaltensweisen auftreten.

Als Hauptfehler in der Kindererziehung erweisen sich vor allem

- Verwöhnungen und Vernachlässigungen - oftmals sogar in Kombination - oder

- $\quad$ ein falsches Verständnis vom Kind, indem

- $\quad$ es trotz fehlender Reife als Partner betrachtet und dadurch überfordert wird (vgl. Winterhoff 2009, S. 18 und S. 37ff.) oder

- nicht mehr als eigenständiges Subjekt behandelt wird, sondern sich als „Teil des Erziehers"so verhalten muss wie der Erzieher selbst (a. a. O., S. 139ff.).

Einerseits werden die Kinder mit materiellen Werten (Spielsachen, eigenem Fernsehgerät usw.) überhäuft und andererseits entbehren sie persönliche Zuwendung und zielstrebige Förderung. Durch die Behandlung eines Kindes als gleichberechtigter Partner lernt es nicht, eine erzieherische Autorität und die durch sie gesetzten Grenzen zu respektieren. Aber eine unzureichende Anerkennung des Kindes als eigenständiges Subjekt wiederum führt zu unersprießlichen Machtk:ämpfen, denn ein jedes Kind möchte selbständig werden. Erzieher müssen also im täglichen Umgang mit dem heranwachsenden Kind das dem jeweiligen Entwicklungsstand entsprechende Maß an Zuwendung und Zutrauen finden, sozusagen aus der individuellen Situation heraus „erspüren“.

Die Plastizität und Beeinflussbarkeit der kindlichen Psyche bedeutet, dass sie durch ungünstige Faktoren in armen Familien in ihrer Entwicklung beeinträchtigt werden kann, vor allem wenn die materielle Armut verbunden ist mit soziokulturellen Schwächen der Familie und psychosozialer Vernachlässigung der Kinder durch die Eltern. Die bekannte Tatsache jedoch, dass auch Kinder aus armen Familien nicht notwendig abweichende Verhaltensweisen entwickeln, haben Psychologen zum Anlass genommen, die ursächlichen Bedingungen für dieses erstaunliche und erfreuliche Phänomen zu erforschen, das als Resilienz bezeichnet wird.

„Der Begriff Resilienz leitet sich von dem engl. Wort »resilience« ab und bezeichnet allgemein die Fähigkeit, erfolgreich mit belastenden Lebenssituationen umzugehen. Mit anderen Worten: Es geht um die Fähigkeit, sich von einer schwierigen Lebenssituation »nicht unterkriegen zu 
lassen« bzw. »nicht daran zu zerbrechen«. Resilienz kann damit verstanden werden als eine psychische Widerstandsfähigkeit von Kindern und Jugendlichen gegenüber biologischen, psychologischen und psychosozialen Entwicklungsrisiken [...]. In der Fachdiskussion werden auch häufig die Begriffe »Stressresistenz«, »psychische Robustheit«, »psychische Elastizität« synonym für Resilienz verwendet" (Wustmann 2006, S. 6).

Das negative Gegenteil von Resilienz wird als Vulnerabilität bezeichnet und meint die Verwundbarkeit, Verletzbarkeit oder Empfindlichkeit von Menschen gegenüber äußeren Einflussfaktoren, was sich dann nicht nur in einer erhöhten Anfälligkeit für psychische Erkrankungen, sondern auch in devianten Verhaltensweisen äußern kann.

Die psychologische Resilienzforschung untersucht die Wirkungen von Risikofaktoren auf die Entwicklung von Kindern, insbesondere in problembelasteten Familien, um Möglichkeiten zur Förderung der Resilienz zu finden und pädagogisch nutzen zu können.

„Im Mittelpunkt der Resilienzforschung stehen dabei folgende drei Erscheinungsformen:

- die positive, gesunde Entwicklung trotz hohem Risikostatus, wie beispielsweise bei chronischer Armut, elterlicher Psychopathologie oder sehr junger Elternschaft (gemeint sind damit auch sog. Multiproblemmilieus);

- die beständige Kompetenz unter extremen Stressbedingungen, wie elterlicher Trennung und Scheidung oder Wiederverheiratung eines Elternteils (sog. kritische Lebensereignisse);

- die positive bzw. schnelle Erholung von traumatischen Erlebnissen wie Tod eines Elternteils, Gewalterfahrungen, Naturkatastrophen oder Kriegs- und Terrorerlebnisse“ (Wustmann 2006, S. 6).

Dem Wesen nach handelt es sich also um die Entwicklung wissenschaftlicher Grundlagen für eine rationelle und erfolgreiche Prävention gegenüber möglichen psychischen und sozialen Fehlentwicklungen bei Kindern und Jugendlichen. Allerdings können im Rahmen dieses Buches die Ergebnisse der Resilienzforschung nicht ausführlich referiert werden, obgleich es für alle Pädagogen und speziell auch für Sozialpädagogen notwendig ist, sie zur Kenntnis zunehmen und in der Praxis zu beachten. Daher sei an dieser Stelle wenigsten auf die Veröffentlichungen von Corinna Wustmann (2004, 2005), Emmy Werner (1997) sowie die Dokumentation der Fachtagung „Resilienz - Was Kinder aus armen Familien stark macht“ (2006) verwiesen.

Speziell für Sozialpädagogische Familienberater, Erzieherinnen in Kindertagesstätten und Grundschullehrer sind die Erkenntnisse und Konzepte zur Resilienzförderung bedeutsam. Als Beleg dafür seien hier einige „schütz̨ende Faktoren“ genannt, die sich in empirischen Untersuchungen als bedeutsam herausgestellt haben und die auch in der Sozialen Arbeit berücksichtigt werden sollten und können: 
1. Personale Ressourcen des Kindes, die von Erziehern besonders gefördert werden sollten:

- positives Selbstkonzept und Kommunikationsfähigkeiten des Kindes;

- Selbstwirksamkeitsüberzeugungen (gemeint ist der Glaube, durch eigenes Handeln tatsächlich etwas bewirken zu können);

- hohe Sozialkompetenz und wertvolle Hobbys, die Trost spenden können.

2. Schutzfaktoren in der Familie:

- Aufbau einer engen, positiv-emotionalen und stabilen Beziehung zu mindestens einer Bezugsperson;

- Wertschätzung, Respekt und Akzeptanz des Kindes.

3. Schutzfaktoren im Umfeld:

- Verwandte, Nachbarin, Erzieherin, Lehrer oder Sozialpädagoge;

- Freunde, Peer-Gruppe (vgl. Wustmann 2006, S. 10ff.).

Als recht wirksam im Rahmen der Prävention haben sich verschiedene Programme erwiesen, die speziell zur Resilienzförderung entwickelt und in Grundschulen und Bildungsmaßnahmen für Eltern eingesetzt worden sind (vgl. Bohn 2006).

Eine alarmierende Analyse und Beschreibung der „Erziehungskatastrophe“ in der bundesdeutschen Gesellschaft hat Susanne Gaschke 2003 vorgelegt, wenngleich ihre konservativen Lösungsvorschläge zur Überwindung der Erziehungsprobleme nicht ungeteilte Zustimmung finden können. So ist z. B. ihre ablehnende Haltung gegenüber Kindertagesstätten in Anbetracht der von ihr selbst kritisierten Erziehungsschwächen vieler Elternhäuser ungereimt. Unter den Bedingungen einer offenbar zunehmend „erodierenden Erziehungskompetenz" in der Elternschaft kann in vielen Fällen auf die qualifizierte Arbeit gut ausgebildeter Erzieherinnen (und möglichst auch Erzieher!) nicht verzichtet werden! Hinzu kommt, dass Kinder im Vorschulalter die Gemeinschaft von Gleichaltrigen als Entwicklungsbedingung dringend benötigen, so dass gerade für die „Einzelkinder“ in vielen heutigen Familien ein Kindergartenbesuch sehr wichtig ist.

Ein deutlicher Ausdruck anwachsender Erziehungsprobleme ist die zunehmende Jugendkriminalität, die sich in der Übersicht 5 widerspiegelt. In dieser Statistik sind bis einschließlich 2006 nicht die verurteilten Deutschen aus den neuen Bundesländern mit enthalten. Außerdem wird mit der Statistik nicht die Zabl der realen Verbrechen und Vergehen, sondern nur die Zabl der deutschen Täter für die aufgeklärten Straftaten dokumentiert. Hinzu kommen auch noch die Täter nichtdeutscher Herkunft, so dass die Steigerungsquoten lediglich als Ausdruck für Tendenzen in der Bundesrepublik (unter Einschluss von Ostberlin ab 1995 und der neuen Bundesländer ab 2007) betrachtet werden können. 
Über Erscheinungsformen jugendlicher Gewaltdelikte und Täterprofile informieren Gaertner und Saad in ihrem Buch (2012, S. 49-70; 99-102).

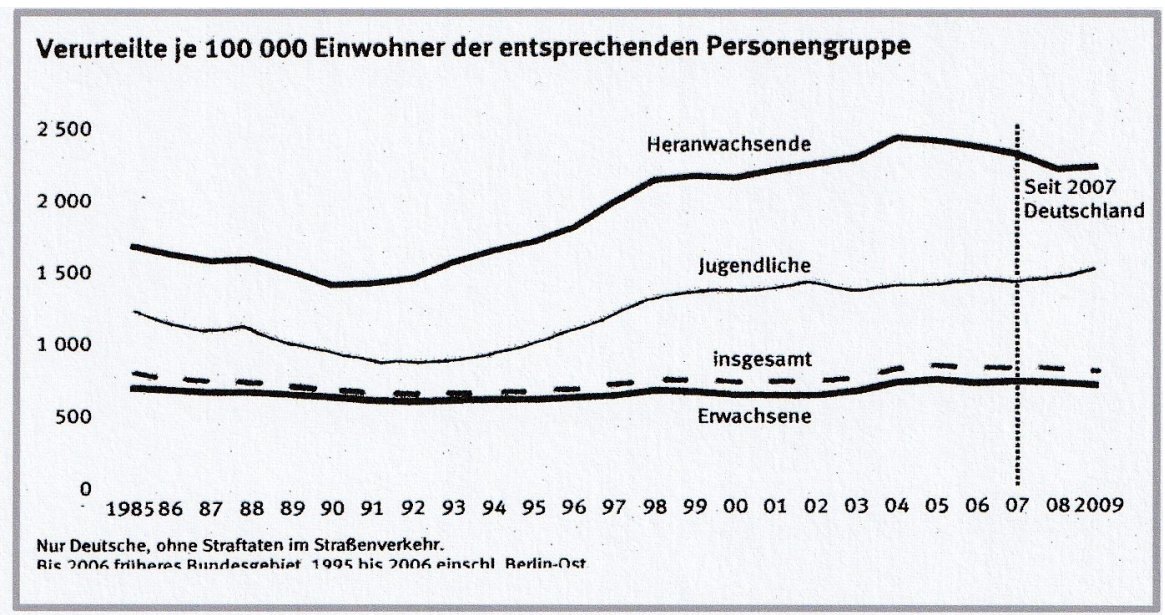

Übersicht 5

Quelle: [online] https://www.destatis.de/DE/Publikationen/Thematisch/Rechtspflege/Querschnitt/BroschuereJustizBlick0100001099004.pdf?_blob=publicationFile, d.h.: Justiz auf einen Blick, Ausgabe 2011, Statistisches Bundesamt, S. 19 (Zugriff: 11.06.12)

Laut Informationen des „Spiegel“ (Nr. 8/2007, S. 42) hat sich die Zahl der „einsitzenden“ 14- bis 18-Jährigen seit 1993 mehr als verdoppelt, womit der aus der obigen Statistik ersichtliche Trend durch neuere Daten bestätigt wird. Ohne das Problem zu dramatisieren, formuliert Melzer :

„Die Polizeiliche Kriminalstatistik (PKS) weist in den letzten Jahren regelmäßig einen überproportionalen Anteil von Kindern und Jugendlichen an den bekannt gewordenen Straftaten aus, während in der Gesamtbevölkerung eine Konstanz auf hohem Niveau, z. T. sogar geringer Rückgang zu verzeichnen ist. Nach den aktuellen verfügbaren Daten (1998) wurden 152.774 Kinder (bis unter 14 Jahre) als Tatverdächtige ermittelt - das sind 5,9 \% mehr als 1997. Bei den Jugendlichen (14 bis unter 18 Jahre) sind es 302.413 Tatverdächtige; dies entspricht einer Steigerungsrate um 3,4 \% (vgl. PKS 1998, S. 285)“ (Melzer 2000, S. 79).

Bei der Bewertung der offiziellen Daten über die Zahl von jugendlichen Gewalttätern ist speziell von Sozialpädagogen folgende Merkwürdigkeit zu berücksichtigen:

„Laut dem Bericht, der Mitte April auf der Innenministerkonferenz in Brandenburg vorgestellt werden soll, werden die meisten Verfahren gegen junge Gewalttäter eingestellt. Nur etwa 28 \% 
der Tatverdächtigen zwischen 14 und 21 Jahren erfahren überhaupt eine staatliche Reaktion nach dem Jugendgerichtsgesetz. In 16000 Fällen erfolgt eine Jugendstrafe, die meistens zur Bewährung ausgesetzt wird. Ins Gefängnis wandern weniger als 6500 der Verurteilten“ („Der Spiegel“" Nr. 14/2008, S. 16).

Über schwerwiegende Folgen einer teilweise unverständlichen Nachsicht der Justizorgane gegenüber jugendlichen Straf- und speziell Wiederholungstätern berichten Gaertner und Saad in ihrem Erfahrungsbericht „Kampfzone Straße“ (2012, S. 70, 182ff.).

Das Phänomen "Jugenddelinquenz" ist zunächst als ein besonderes quantitatives erkennbar. Was allerdings die Kriminalstatistiken nicht aussagen (können), betrifft den Charakter der Jugenddelinquenz, bei der nach Auffassung von Moffitt (siehe Oerter/ Montada 1998, S. 1027ff.) zu unterscheiden ist zwischen „normaler“ Jugenddelinquenz und einer Jugenddelinquenz, die auf einem persistenten antisozialen Verbalten beruht, das sich in frühen Kinderjahren entwickelt hat.

Bei der Darstellung der Wert-Mittel-Diskrepanz-Theorie wurde schon darauf hingewiesen, dass durch das Auseinanderfallen der biologischen und sozialen Reife (vor allem durch das Erlangen ökonomischer Selbständigkeit zu einem späteren Zeitpunkt) ein Widerspruch entstanden ist, der von manchen Jugendlichen mit devianten bzw. ungesetzlichen Mitteln „gelöst“ wird. Diese Art von Delinquenz ist natürlich gesellschaftsschädigend und auch für die Täter nachteilig. Aber es zeigt sich, dass solche ,jugendaltersbedingte "Delinquenz im Allgemeinen vorübergehender Natur ist und die Betreffenden zu normalen Lebens- und Verhaltensweisen zurückfinden, sobald sie berufliche und familiäre Bindungen von sich aus eingehen, entsprechende Verantwortung übernehmen und ihnen dabei geholfen wird (vgl. Oerter/Montada 1998, S. 1029f.).

Anders ist die Jugenddelinquenz zu erklären und zu bewerten, die aus persistentem antisozialem Verhalten resultiert. In empirischen Untersuchungen wurde nachgewiesen,

„daß persistentes antisoziales Verhalten häufig mit Störungen assoziiert ist, die bis in die früheste Kindheit zurückzuverfolgen sind: Hirnschädigungen [...] mit unterschiedlichen Ursachen, Aufmerksamkeitsstörungen, Störungen der motorischen Koordination, Hyperaktivität und Impulsivität, die zu Lernstörungen führen [...], unterdurchschnittliche kognitive Leistungen [...]. Eine Attention Deficit Disorder with Hyperactivity (ADDH) ist sowohl in der Kindheit mit hoher Aggressivität als auch mit persistenten antisozialen Tendenzen korreliert" (Oerter/ Montada 1998, S. 1031).

Empirische Untersuchungen belegen ebenso wie zahlreiche Erfahrungsberichte von Sozialpädagogen, dass delinquente Jugendliche bereits in ihrer frühen Kindheit unter chaotischen Familienverhältnissen, Vernachlässigungen und Misshandlungen, also unter sozialer Deprivation (Nichtbefriedigung elementarer kindlicher Bedürfnisse) gelitten haben. Soziale Deprivation in der für den Aufbau sozialer Beziehungen wichtigen und 
sensiblen Kleinkindphase führt gesetzmäßig (im Sinne der statistischen Gesetzeskonzeption!) zu Entwicklungs- und Verhaltensstörungen. Die vernachlässigten Kinder reagieren verständlicherweise mit andauerndem Schreien, „Ungehorsam“ und sonstigen Störungen ihrer Mitmenschen, die ihrerseits oft wieder recht unpädagogisch auf den „kleinen Störenfried einwirken“. Die Folge davon ist, dass diese Kinder ihrer Umwelt gegenüber Sicht- und Verhaltensweisen entwickeln, die von Misstrauen, Minderwertigkeitsgefühlen und devianten Methoden der Selbstbehauptung bestimmt sind. Es fehlt ihnen gerade das, was für eine normale Entwicklung und erfolgreiche Integration des Heranwachsenden wesentlich ist: das sog. Urvertrauen, für dessen Entwicklung eine enge und herzliche Beziehung des Säuglings bzw. Kleinkindes zu einem mütterlichen Wesen die Grundlage bildet. Fehlt dieses, dann sind wesentliche Bedingungen für den Teufelskreis gegeben, der in die persistente Delinquenz führen kann: es entsteht Misstrauen, das deviantes Verhalten erzeugt, deviantes Verhalten wiederum provoziert Reaktionen der Umwelt, die das Misstrauen bestätigen und erhöhen, bis die Aktionen des Verunsicherten schließlich in Delinquenz umschlagen.

„Da persistente Delinquenz mit Schulversagen, Schuldropout und dem Abbruch von Berufsausbildung korreliert ist, sind kompensatorische vorschulische und schulische Programme auch als Möglichkeiten der Primärprävention von Delinquenz her anzusehen“ (Oerter/Montada 1998, S. 1034).

In der zitierten Literatur werden ferner Belege für erfolgreiche sekundäre Präventionen bei Schul- und Ausbildungsabbrechern aufgeführt, die ihrerseits den Wert von lernpsychologischen Konzepten in der Überwindung auch von persistenter Delinquenz belegen. Montada stellt mit Berufung auf Gordon \& Arbuthnot fest:

„Gegenüber solchen fertigkeits- und verhaltenszentrierten Programmen erwiesen sich analytische und psychodynamische sowie klientenzentrierte Programme als wenig effektiv“ (Oerter/ Montada 1998, S. 1034).

Diese Erkenntnis ist wichtig, da es in der psychosozialen Intensiverziehung darum geht, durch neue Einsichten und Erfahrungen einen Einstellungswandel herbeizuführen und durch entsprechende Übungen neue Gewohnheiten zu entwickeln, also ein verhaltenszentriertes Programm zu realisieren.

Abschließend sei zu der zunehmenden Zahl von verdächtigen Kindern und Jugendlichen - die sich in der oben zitierten Statistik nur unvollkommen widerspiegelt - vermerkt, dass die verbreitete Auffassung, die Jugend bedrohe mit ihrer Kriminalität die Gesellschaft, einseitig ist; denn ebenso könnte man sagen: die Gesellschaft bedrobt Jugendliche mit Verwahrlosung und Kriminalität. Doch beide einseitigen Behauptungen abstrahieren von der Erkenntnis, dass der Mensch nicht nur Produkt, sondern auch Produzent seiner Verhältnisse ist; es muss also von beiden Seiten aus an das Problem herangegangen werden. 
Das Jugendalter ist natürlich nicht nur unter dem Aspekt möglicher delinquenter Verhaltensweisen als Problem für Sozialpädagogen bedeutsam. Wenn sich Heranwachsende vom Elternhaus ablösen und nach eigener Identität suchen, ist das naturgemäß schwierig und nicht selten mit devianten Verhaltensweisen der Jugendlichen verbunden. Gemeint sind damit nicht nur Probleme, die aus der ökonomischen Abhängigkeit und Unselbständigkeit der Jugendlichen resultieren und bereits im Zusammenhang mit der Wert-Mittel-Diskrepanz-Problematik erörtert worden sind, sondern auch Probleme, die vom frühzeitigen Nikotin- und Alkoholmissbrauch ${ }^{15}$ bzw. Tilidinmissbrauch jugendlicher Muslime (vgl. Gaertner/Saad 2012, S. 62ff.) über die Spiel- und Computersucht, die Einnahme von illegalen Drogen bis hin zu Ess-Störungen reichen. Unter dem Eindruck der Medien und der öffentlichen Meinung versuchen nicht wenige Mädchen (Statistiken sprechen z. B. von einem Drittel aller Gymnasiastinnen) den propagierten Idealvorstellungen auch um den Preis ihrer Gesundheit zu entsprechen, indem sie nicht nur alle möglichen Diäten zum Schlankwerden erproben, sondern Ess-Störungen verfallen, nämlich der Anorexia nervosa (Magersucht), der Bulimia nervosa (Ess-/Brechtsucht) oder der Binge Eating Disorder (Episoden von Heißhungeranfällen, verbunden mit hastigem Schlingen, Verlust des Völlegefühls und des Bestrebens einer Gewichtszunahme gegenzusteuern). Laut Auswertung des bundesweiten Kinder- und Jugendgesundheitssurveys (KiGGS) von Mai 2003 bis Mai 2006 wurden 21,9\% der befragten Kinder und Jugendlichen in ihrem Essverhaltens als auffällig identifiziert - bei Mädchen 28,9 \%, bei Jungen 15,2 \% - (vgl. Kurth 2006, S. 1052).

Es wäre eine unzulässige Vereinfachung, diese Gefahren nur als Folge von Modeströmungen und Medienwirkungen zu betrachten; auch hier sind die wesentlich durch familiäre Sozialisation bedingten inneren Kräfte bzw. Schwächen der Jugendlichen bedeutsam. Eine Jugendberaterin, die sich besonders mit Essstörungen bei Mädchen beschäftigt hat, schreibt dazu:

„Sie (die Mädchen) versuchen Hungern als Waffe gegen mangelndes Selbstwertgefühl, Versagensängste und gegen das Gefühl, machtlos zu sein, einzusetzen. Eltern verstärken die Situation, indem sie die Kinder voll in Besitz nehmen und kontrollieren. Durch ihre Sorge um den Erfolg greifen sie so stark in die Persönlichkeit ein, daß die Jugendlichen selbstzerstörerische Möglichkeiten nutzen, um ihre Person abzugrenzen und über ihren Körper selbst zu bestimmen“ (Kleiß 2004, S. 2).

Eine weitere entwicklungspsychologisch bedeutsame Erscheinung devianten Verhaltens von Kindern und Jugendlichen ist die Schulaversion, die sich äußert im Abwenden vom eigentlichen Unterrichtgeschehen im Klassenzimmer, in Störungen und im spontanen Verlassen des Unterrichts bzw. im Schwänzen einzelner Unterrichtsstunden, im

15 „Die Zahl der mit Alkoholvergiftung ins Krankenhaus eingelieferten Kinder und Jugendlichen verdoppelte sich seit 2000 auf zuletzt 19500 Patienten im Jahr" (Schweriner Volkszeitung vom 06.05.2008, S. 6). 
unentschuldigten Fernbleiben von der Schule an mehreren Tagen oder über Wochen und Monate hinweg. H. Bauer und N. Westphalen schreiben in ihrer Internet-Veröffentlichung „Hilfen für schulaversive Kinder und deren Eltern“:

„9,2\% aller Abgänger eines Jahres verlassen nach Erfüllung der Schulpflicht die Hauptschule ohne Abschluss (Statistisches Bundesamt, Stand 2000, zitiert nach Schreiber-Kittl/Schröpfer 2002, S. 19; in: [online] Bauer/Westphalen: Hilfen für schulaversive Kinder und deren Eltern, S. 1 ; Zugriff: 27.01.2010).

In Deutschland gibt es keine bundesweiten repräsentativen Untersuchungen zum Umfang von Schulverweigerung. Man schätzt jedoch, dass ca. 5-10\% aller schulpflichtigen Kinder regelmäBig aus verschiedenen Gründen den Schulbesuch verweigern [...].

Schulschwänzen in Hessen: Studie von 1995, Schülerbefragung mit 3.540 Schülerinnen und Schülern der Sek. I: 20 \% der Mädchen bzw. $24 \%$ der Jungen gaben an, innerhalb der letzten 12 Monate mindestens alle paar Monate unentschuldigt gefehlt zu haben, 4 \% sogar wöchentlich oder mehrwöchentlich“ (Tillmann u. a. 1999, zitiert nach Schreiber-Kittl/Schröpfer 2002, S. 67; in: Bauer/Westphalen: Hilfen für schulaversive Kinder und deren Eltern, S. 1, [online] Zugriff: 27.01.2010).

Thimm kommt im Ergebnis seiner Analyse zu der Schlussfolgerung:

„Soziale Desintegration ist eine reale Gefahr für 15 oder $20 \%$ der Schülerschaft, für die die Wissens- und Informationsgesellschaft nicht unbedingt Plätze vorhält“ (Thimm 2007, S. 13).

Die Koalitionsparteien der deutschen Bundesregierung stellten in ihrem Koalitionsvertrag vom 11. 11. 2005 fest,

„155.000 bzw. 17,1 \% der 25-Jährigen haben keinen Abschluss der Sekundarstufe II, d. h. sie haben weder eine Berufsausbildung abgeschlossen noch Abitur“ (Gemeinsam für Deutschland. Mit Mut und Menschlichkeit. Koalitionsvertrag von CDU, CSU und SPD. [online] pdf , S. 42).

Die Ursachen für die Schulverweigerung sind vielfältig: Sie reichen von unzureichender Vorbereitung auf die Anforderungen der Schule in geistiger und sozialer Hinsicht (Mängel in der Familienerziehung und in der vorschulischen Erziehung der Kindertagesstätten) über die Mängel speziell im deutschen Schulsystem selbst (frühe Selektion, überhöhte Lehrplananforderungen, pädagogisch unzureichend ausgebildete Lehrer und entsprechend schlechter Unterricht) bis hin zu den Auswirkungen krisenhafter Verhältnisse in der Wirtschaft auf die realen Erfahrungen und Denkweisen der Schüler.

„Verunsicherungen angesichts der Zukunftserwartungen an traditionell geregelte Lebensverläufe als Folge der Globalisierung tragen insbesondere unterhalb des Gymnasiums zu einer spürbaren Schulverdrossenheit bei. Bei [...] wachsender Konkurrenz auf dem Arbeitsmarkt lockert sich der Zusammenhang zwischen Bildungsabschlüssen und Berufskarrieren immer mehr: Einerseits bilden hohe Abschlüsse nach wie vor eine wesentliche Voraussetzung dafür, überhaupt konkurrenzfähig zu sein; andererseits garantieren sie aber nichts mehr. Dadurch ver- 
liert die schulische Arbeit vor allem für die am wenigsten privilegierten Schüler häufig ihre disziplinierende und motivierende Kraft. Gerade die antisoziale Rebellion bietet den unter Anerkennungsmangel leidenden Jugendlichen Erfahrungen eigener Wirksamkeit, welche die Schule ihnen versagt. Die sozialen und sozialpsychologischen Erfahrungen der »Wende« treten in Ostdeutschland kohortenspezifisch hinzu. ${ }^{16}[\ldots]$ In empirischen Studien hat sich gezeigt, daß das rechtsextreme gewaltbereite Potential sich nicht zuletzt aus dem schulverdrossenen Teil der Schüler der Sekundarstufe I und der berufsbildenden Schule rekrutiert. Diese Schüler erleben die Schule als negativ - und nicht nur diese: beispielsweise leiden $40 \%$ der Schüler in Sachsen unter Schulangst, $50 \%$ unter Leistungsdruck, nur $18 \%$ gehen überhaupt gern zur Schule [...]. Lernen wird häufig als sinnlos und ohne Nutzen für das Leben bewertet“ (Fauser 2003, S. 6f.).

Unter der Überschrift „neue Lernkultur“ werden vielfältige Forderungen und Vorschläge für eine moderne Unterrichtsgestaltung unterbreitet, und zwar mit der Absicht, den Unterricht für die Schüler interessanter zu machen und der vielfach beklagten Schulaversion zu begegnen. Bemühungen dieser Art sind zweifellos berechtigt. Aber es ist ein Irrtum zu glauben, dass vor allem durch eine „lockere Unterrichtsführung“, z. B. durch den sog. offenen Unterricht bei allen Schülern die Freude am Lernen und die Lernerfolge gesteigert werden könnten. In seinem Artikel „Zuwendung ist der wichtigste Erzieher" schreibt Gerald Hüther gerade über jene Kinder, die Schwierigkeiten in der Schule haben:

„Wonach diese Kinder suchen und worauf sie ihre ganze Aufmerksamkeit richten, ist nicht das gebotene Wissen, die vermittelten Fähigkeiten und Fertigkeiten, sondern ein Gefühl: das Bedürfnis nach Halt und Sicherheit, nach Anerkennung und Orientierung. Diese Kinder brauchen nicht immer bessere Unterrichtsformen und Lehrmethoden, sondern authentische, begeisterungsfähige, einfühlsame und Sicherheit bietende, also psychosozial kompetente [...]. Erzieher und Lehrer. [...] Bei offenem Unterricht ohne klare Führung werden problemanzeigende Kinder besonders anfällig für störende Verhaltensweisen, während dieselben Kinder bei konventionellen Lehrern, die gut strukturiert unterrichten und klar anleiten, oft ruhiger und konzentrierter arbeiten können“ (in: Mogge-Stubbe 2002, S. 44/45).

Prinzipiell muss Unterricht so gestaltet werden, dass auch leistungsschwache Schüler die Hoffnung auf Erfolge nicht verlieren oder aus Furcht vor Misserfolgen ausweichen. Schulaversives Verhalten hat ja nicht nur Lerndefizite der betreffenden Schüler zur Folge, sondern ist nach Berichten von Gaertner und Saad vielfach mit anderen devianten Verhaltensweisen dieser Schüler verbunden, z. B. mit Spielsucht und mit Hass auf fleißige Mitschüler, die gehänselt oder gar überfallen, misshandelt und ausgeraubt werden (vgl. Gaertner/Saad 2012, S. 128ff.).

16 Da Fauser diese Wendeerfahrungen nicht näher bestimmt, sei hier nur auf die massenhafte Entwertung der Berufsbiografien in der Eltern- und Großelterngeneration vieler Jugendlicher verwiesen sowie auf die Massenarbeitslosigkeit und den Lehrstellenmangel zur angegebenen Zeit speziell in Ostdeutschland, was auch demotivierend gewirkt hat. 


\subsubsection{Erklärung devianten Verhaltens aus der Sicht der Theorie der jugendlichen Bande}

Wurr und Trabandt greifen in ihrer Darstellung zur Erklärung devianten Verhaltens auch auf die Theorie der jugendlichen Bande bzw. der „delinquenten jugendlichen Subkultur" von Albert K. Cohen zurück (vgl. a. a. O., S. 32ff.) und verweisen darauf, dass in diesem Rahmen die Erkenntnisse der Wert-Mittel-Diskrepanz-Theorie in spezifischer Weise zur Geltung kommen. Aber es ist nicht nur der Widerspruch zwischen den Wünschen der Jugendlichen und ihren unzureichenden Mitteln zu deren Erfüllung, der sie zusammenführt. Es gibt viele Gemeinsamkeiten in den Biografien der Kinder und Jugendlichen, die sie miteinander verbinden, z. B.:

- Das Streben nach Anerkennung und Geborgenheit, nach Stärkung ibres Selbstwertgefübls, das sie in ihrem familiären und schulischen Umfeld nicht verwirklichen können;

- die Möglichkeit, die eigene Protesthaltung gegenüber der etablierten Gesellschaft, deren Erwartungen sie nicht erfüllen können, zu artikulieren, indem sie ibre aggressive Langeweile und ibren Frust gemeinsam abreagieren (Gewalttätigkeiten gegen Sachen und Personen);

- das Erleben von Kameradschaftlichkeit auch in Notsituationen in der Bande - wobei es sich bei genauerer Betrachtung um eine Art von Pseudokameradschaft handelt, die oft unbarmherzigen Terror gegenüber „Feiglingen“ und Aussteigern einschließt;

- das Interesse an „neuen Möglichkeiten“, sich vermeintliche und reale, vor allem materielle Vorteile im Hinblick auf die eigene Lebensweise zu verschaffen.

Schon diese Aufzählung lässt erkennen, dass einige der bisher erörterten Bedingungen für die Entstehung devianter Verhaltensweisen in Banden in besonders konzentrierter Weise auftreten, wie bspw. Rockerbanden erkennen lassen (vgl. „Bruderschaften der Gewalt“, in: „,Welt am Sonntag“, Nr. 31 vom 29.07.2012, S. B 2). Daher ist es berechtigt, dieses spezifische Bedingungsgefüge gesondert zu betrachten, in dem durch gruppendynamische Prozesse Delinquenz fördernde Impulse verstärkt wirksam sind.

Auch für jugendliche Banden gilt: „,Gruppennormen haben einen starken Einfluss auf das individuelle Verhalten eines Gruppenmitgliedes, solange es die betreffende Gruppe schätzt“" (Zimbardo 1992, S. 597) und Angehöriger der Gruppe bleiben will. Empirische Untersuchungen belegen, dass die unter dem Einfluss von Gruppen angeeigneten Denk- und Verhaltensweisen so verinnerlicht werden, dass sie auch dann noch wirksam sind, wenn sich die Gruppe aufgelöst hat (vgl. Zimbardo 1992, S. 597). Ein Grund für die Wirksamkeit der Gruppennormen besteht darin, dass eine Gruppe gerade deshalb aufgesucht wird, um das Gefübl der Zugebörigkeit zu erlangen. Ein Verstoß gegen die Gruppennormen oder gegen die öffentliche Meinung in der Gruppe hat un- 
weigerlich zur Folge, dass der „Normenbrecher“ in eine Außenseiterposition gerät, die er gerade nicht wünscht, also passt er sich an - sogar unter Zurückstellung eigener Skrupel, wenn es z. B. um eine geplante kriminelle Aktion geht, die bisher gewohnte Dimensionen devianten Handelns übersteigt.

Aber es ist nicht nur aktueller Druck der öffentlichen Meinung, der Anpassung erzwingt: „oft verläuft der Prozess der Beeinflussung durch Gruppennormen so allmählich und so subtil, daß ein Individuum nicht wahrnimmt, was geschieht. Selten kommt es vor, daß sich ein Gruppenmitglied dem Gruppeneinfluss entziehen kann“" (Zimbardo 1992, S. 597).

Welche Entwicklung eine Person nimmt, hängt wesentlich von den Werten, Normen und Verhaltensweisen ab, die das Zusammenleben in der Gruppe bestimmen, der sie angehört. Das wirkt sich natürlich in Banden auf jeden Einzelnen nachteilig aus und erklärt u. a. auch, warum mancher Jugendliche in der Gruppe etwas tut, was man von ihm zunächst nicht erwartet hätte. Außerdem gibt es auch noch andere Effekte in Gruppenaktionen, die zur Erklärung devianten Handelns beitragen.

\subsubsection{Erklärungen devianten Verhaltens aus der Sicht psychologischer Theorien der Deindividuation und der Debumanisierung}

Wohl jedem ist bekannt, dass Gruppen jugendlicher Randalierer besonders gewalttätig auftreten und gemeinsam Handlungen vollziehen, die man dem Einzelnen nicht zutrauen würde. Dieses Phänomen wurde schon seit langem bei jugendlichen Banden oder auch in Zusammenrottungen größerer Menschenmengen beobachtet. Nach dem II. Weltkrieg hat es aber besonders die Psychologen beschäftigt, die sich fragten, wie es möglich ist, dass die im Zivilleben normal agierenden ehemaligen Angehörigen der SS in der Vergangenheit schwere Verbrechen begehen konnten. Mit Berufung auf Arbeiten von Steven Prentice-Dunn und Rogers beantwortet Zimbardo diese Frage

- mit der Wirksamkeit der sog. Deindividuation des Einzelnen in seiner Gruppe und

- $\quad$ mit der sog. Dehumanisierung des Gegners bzw. Opfers durch die Tätergruppe.

„Als Deindividuation werden bei einer Person der Zustand und der Prozeß, die der Individuation entgegengesetzt sind, bezeichnet, also die Reduzierung der Selbst-Identifizierbarkeit und Selbstaufmerksamkeit. Im Zustand der Deindividuation können Handlungen (z. B. aggressive Verhaltensweisen) freigesetzt werden, die normalerweise unterdrückt werden. Die Einflüsse, die zur Deindividuation führen, lassen sich in zwei Variablenklassen einteilen: Verantwortlichkeitshinweise und Veränderungen der Aufmerksamkeit“" (Zimbardo 1992, S. 588).

Statt der ersten Variablenklasse „Verantwortlichkeitshinweise“ wäre in diesem Kontext das englische accountability cues wohl besser mit Verantwortlichkeitsverweise zu übersetzen, denn es geht darum, dass eine Person die Verantwortung für ihr eigenes Tun 
ablehnt und auf andere verweist oder delegiert. Jeder Erzieher kennt bei ertappten kleinen Sündern den Satz zur Selbstverteidigung, der da lautet: „die anderen haben doch auch ..." Offenbar tritt dieses Verhalten auch in viel schwerwiegenderen Fällen auf, wie die Beobachtungen und Untersuchungen bei „Verbrechen aus der Menge heraus“ zeigen. Zimbardo benennt als Beispiel dafür die extreme Aggressivität von Menschenmassen im Falle der Lynchjustiz. Der Grund für dieses Verhalten besteht wohl darin, dass - wie bei Kindern ja noch verständlich - auch in Massenaktionen der Erwachsenen die Verantwortlichkeit für das Geschehen nicht klar erkennbar ist, potenzielle Opfer nicht zurückschlagen und Autoritäten (z. B. Polizisten) den Straftäter nicht bestimmen können (vgl. Zimbardo 1992, S. 588). Damit ist die Gefahr, zur Verantwortung gezogen zu werden, natürlich gering. Dass Anonymität die Bereitschaft zu aggressiven Verhaltensweisen begünstigt, weil offenbar das Bewusstsein persönlicher Verantwortung reduziert wird, wurde in mehreren psychologischen Versuchen nachgewiesen, die Zimbardo anführt.

„Bei der zweiten Variablenklasse geht es um die Herbeiführung eines Zustandes der Deindividuation durch die Veränderung der Aufmerksamkeits- und Wahrnehmungsprozesse. Die übliche kognitive Verarbeitung von Informationen, die für eigene Maßstäbe, moralische Werte, persönliche Verpflichtungen und die projizierte Nützlichkeit alternativer Handlungsabläufe relevant sind, wird außer Kraft gesetzt. Wenn das geschieht, ist das geäußerte Verhalten sehr intensiv, gegenwartsorientiert, auf die Situation konzentriert und obne innengeleitete Hemmungen (Hervorhebung durch W.N.). Hervorgerufen werden können die Änderungen durch Reizüberflutung, Drogen, starke Emotionen oder physische Aktivität" (Zimbardo 1992, S. 588).

Prozesse der durch beide Variablen begünstigten Deindividuation lassen sich bei Krawallen und Ausschreitungen im Zusammenhang mit schlecht organisierten Demonstrationen und Sportveranstaltungen beobachten, wobei hinzu kommt, dass diejenigen, die sich durch besondere Brutalität hervorgetan haben, von ihren Parteigängern oder Kumpanen als Helden angesehen werden. Es entstehen also in diesen Gewaltaktionen auch entsprechend brutale Normen, die wiederum das Verhalten der Akteure in künftigen ähnlichen Situationen bestimmen.

Der Prozess der Deindividuation kann verbunden sein mit einem Prozess der Dehumanisierung, d. h. mit einer Aberkennung menschlicher Qualitäten bei den potenziellen und tatsächlichen Opfern antisozialen Handelns. Zu den geschichtlich extremsten und verbrecherischsten Vorgängen dieser Art gehört zum Beispiel die Bezeichnung (und Behandlung!) von Bürgern der ehemaligen Sowjetunion als „bolschewistische Untermenschen“, denen die ,arischen Herrenmenschen“ gegenübergestellt wurden. Die Verneinung menschlicher Qualitäten beim Gegner diente offensichtlich dazu, den Tätern (SS-Angehörige, Wehrmachtsangehörige) eventuell vorhandene Skrupel bei der Ausführung verbrecherischer Befehle zu nehmen und sie „moralisch zu entlasten“. 
Außerdem wurde den Mittätern der Aggressoren z. T. mit Erfolg eingeredet, dass die Gegner ja selbst Schuld seien an ihrer Vernichtung, weil sie irgendetwas getan oder unterlassen haben, was nach Ansicht der Aggressoren unverzeihlich sei.

Aber im Grunde wird hier nur am extremen Beispiel deutlich, was sich in der Weltgeschichte - sowohl in kriegerischen als auch zivilen Auseinandersetzungen - millionenfach zugetragen hat und immer noch zuträgt. Es sei nur an die Rolle von Feindbildern erinnert: sie alle haben die Aufgabe, den Feind als gefährlichen Bedroher von nationaler Sicherheit, Freiheit, Menschenwürde, des eigenen religiösen Glaubens o. Ä. darzustellen. Beim letztgenannten Beispiel entspricht seine Vernichtung angeblich sogar dem Willen Gottes und damit erscheinen fast alle Brutalitäten als gerechtfertigt. Was in den Konflikten zwischen Völkern und Staaten mit den Mitteln der psychologischen Kriegsführung sowie politischer, weltanschaulicher und religiöser Indoktrination betrieben wird, vollzieht sich ähnlich auch in kleineren Maßstäben zwischen verschiedenen Menschengruppen unterhalb kriegerischer Auseinandersetzungen.

Es ist hier nicht möglich, die verschiedenen Arten der Dehumanisierung mit ihren psychologischen Mechanismen zu erklären. Für Sozialpädagogen ist wichtig, dass sie das Phänomen der Aberkennung menschlicher Qualitäten kennen und gegebenenfalls erkennen, damit sie den Problembelasteten helfen können, diesen Grundirrtum in ihrem Menschenbild zu überwinden, was in der Regel sehr schwierig ist, weil es sich dabei um die Veränderung relativ verfestigter Einstellungen und Überzeugungen handelt.

\subsubsection{Politischer Extremismus und religiöser Fundamentalismus als Basis devianten Handelns}

Die Gruppenideologie und die Gruppennormen politischer und religiöser Extremistenvereinigungen bilden die Basis für den Zusammenschluss von Menschen, die nach innerem und äußerem Halt, nach Anerkennung und Wirkungsmöglichkeiten entsprechend ihren bereits vorgebildeten Neigungen und Verhaltensweisen suchen (z. B. Neigung zur Gewalttätigkeit oder zu intolerantem missionarischen Eifer). Wenn Konflikte mit diesem Hintergrund auftreten, können sie nicht allein von Sozialpädagogen gelöst werden. Hier müssen politische und juristische Kräfte wirksam werden. Sozialpädagogen können aber den Opfern solcher Konflikte und auch Sympathisanten oder Aussteigern der betreffenden Gruppe individuell helfen, sofern diese bereit sind, sich auf eine Hilfe einzulassen. Die Hilfeleistung erfordert dann allerdings von den Sozialpädagogen eine gründliche Kenntnis der Ideenwelt bzw. Glaubensvorstellungen und der psychosozialen Besonderheiten solcher Gruppen. Um diese Ideen bzw. Glaubensvorstellungen kennen zu lernen, bedarf es spezieller Studien im Bereich der Politik- und Religionswissenschaften. Aber auf einige typische psychosoziale Besonderheiten solcher Gruppen sei hier kurz verwiesen. 
In politischen Extremistenvereinigungen treffen sich in der Regel Menschen,

- die an Minderwertigkeitskomplexen leiden und eben deshalb zum Überlegenheitskomplex tendieren, den sie in einer „starken Truppe“ gemeinsam realisieren können;

- die unter mindestens einer Wert-Mittel-Diskrepanz leiden;

- für deren Verhalten offenbar die Frustrations-Aggressions-Hypothese besonders deutsam ist und

- die durch Mangel an sinnvoller Beschäftigung unter aggressiver Langeweile leiden, was z. B. bei rechtsextremen Gruppen dazu führt, dass sie aus „,purem Spaß“ und Fremdenfeindlichkeit „Ausländer klatschen“ gehen.

Das Zusammenwirken zumindest einiger dieser Ursachen für aggressive und deviante Verhaltensweisen in extremen politischen Gruppierungen wird dadurch verstärkt, dass solche Gruppen eine Ideologie haben, mit deren Hilfe das deviante Verhalten und Handeln gerechtfertigt erscheint (jedenfalls in den Augen ihrer Anhänger), was beim Einzelnen mögliche moralische Hemmungen im devianten Handeln beseitigt. Mehr noch: die Ideologie gebietet im angeblichen Interesse einer „höheren Idee“ verbrecherisches Handeln - z. B. die Unterdrückung, Vertreibung und/oder gar Vernichtung „,minderwertiger Rassen“ oder Ausländer. Deviante Handlungen werden mit Hilfe der „höheren Ziele“ der Gruppe quasi legitimiert; die Täter fühlen sich dadurch nicht nur moralisch entlastet, sondern geradezu ibren Zielen verpflichtet. Außerdem wirken in solchen Gruppen - wie schon erwähnt - auch die Mechanismen der Deindividuation und Dehumanisierung sowie recht rigide Gruppennormen, die jeden Abweichler bedrohen und jeden „Feigling“ ächten. Aus dem Zusammenwirken all dieser Faktoren resultiert das besonders hohe Aggressions- und Gewaltpotenzial, das für viele politisch extremistische Gruppierungen ein Hauptmerkmal ist.

Unter dem Aspekt verübter Gewalttaten (Landfriedensbruch und schwere Körperverletzungen) sind gegenwärtig besonders rechtsextreme Gruppierungen in der Bundesrepublik auffällig. Daher sollen die von Wurr und Trabandt zusammengestellten Merkmale zitiert werden, die in unterschiedlichen Ausprägungen in diesen Gruppen auftreten:

• „nationalistische bzw. völkische Selbstüberhöhung,

- Rassismus,

- Unterscheidung von lebenswertem und -unwertem Leben,

- Behauptung natürlicher Hierarchien unter Menschen und Völkern,

- Betonung des Rechts des Stärkeren,

- Auffassung des Lebens als andauernder Kampf ums Dasein,

- Normenrigidität,

- männerbündlerisches Gruppenverständnis,

- Gewaltanwendung als Normalform der Konfliktregelung“" (1993, S. 44). 
Es ist nicht Aufgabe dieses Abschnitts, spezifische konzeptionelle Überlegungen und Erfahrungen aus Bemühungen zur Überwindung politisch extremistischer Vereinigungen darzustellen. Es geht um Erklärungswissen und damit um die Kennzeichnung jener inneren Ansatzpunkte bei Anhängern solcher Gruppen, die beispielsweise als hilfesuchende Aussteiger oder „Störenfriede" im Freizeitzentrum oder in der Schule auftreten. Natürlich ist das Problem nicht allein sozialpädagogisch zu lösen, sondern nur im Zusammenwirken ökonomischer, politischer, pädagogischer und juristischer Aktivitäten.

Der religiöse Fundamentalismus spielt in der Gegenwart eine große, vermutlich sogar zunehmende Rolle. Im Vordergrund steht dabei der islamische Fundamentalismus - allerdings gibt es weltweit auch einen nicht unproblematischen mit Macht und Einfluss verbundenen christlichen und jüdischen Fundamentalismus. Die Probleme, die aus den Konfrontationen verschiedener religiöser Fundamentalisten erwachsen, sind nicht Gegenstand der Sozialpädagogik, sondern anderer Wissenschaften. Ihre Lösung ist auch nicht Aufgabe von Sozialpädagogen, sondern vor allem der Politik und der gemäßigten Kräfte in den religiösen Gruppierungen selbst. Für den Umgang mit jungen Islamisten - etwa jenen britischen Staatsbürgern, die sich an Terrorakten beteiligten bedarf es anderer Konzepte als solcher, die die Sozialpädagogik zu bieten vermag.

Grundsätzlich ist aber zunächst einmal Verständnis für religiöse Gemeinschaften und kulturelle Identitäten notwendig, das offenbar manchen Politikern und Journalisten der westlichen Demokratien fehlt. Ein angeblich aufgeklärter Bürger der freien Welt kann sich nicht auf den Standpunkt stellen, Millionen Andersdenkender mögen bitte schön die westlichen Vorstellungen von Presse- und Meinungsfreiheit unwidersprochen akzeptieren, wie z. B. im Falle der Karikaturen zu Mohammed. Ein wirklich aufgeklärter Künstler oder Journalist weiß um die Bedeutung religiöser Glaubensvorstellungen, der dadurch begründeten Normen und der mit hoher Wahrscheinlichkeit zu erwartenden Reaktionen bei der Verletzung religiöser Gefühle.

Hinzu kommt: nach traditionellen und konservativen islamischen Wertvorstellungen und Normen verhalten sich nämlich gerade diejenigen deviant, die einen westlichen Lebensstil pflegen. Wenn nun solche „unmoralischen Menschen“ oder „Ungläubige“ ihnen gegenüber anmaßend auftreten und ihre religiösen Gefühle verletzen, wehren sie sich auf ihre Weise und mit den Mitteln, die nach ibrer Überzengung legitim sind - und ein Märtyrertod ist nach ihren Normen legitim. Daher wird ein wirklich Aufgeklärter - der z. B. weiß, dass auch Ideen zur materiellen Gewalt werden, wenn sie die Massen ergreifen (vgl. MEW, Bd. 1, S. 385) - aus verantwortungsethischen Gründen (vgl. S. 229) solche Provokationen vermeiden, durch die sich Massen gläubiger Muslime beleidigt fühlen, schon um nicht weitere Fundamentalisten in die Trainingslager der Terroristen zu treiben.

Islamische Fundamentalisten sind zwar in der Minderheit unter den Mohammedanern, aber die aggressive Politik des Westens provozierte offenbar immer stärkeren Zulauf - 
sogar aus jenen Kreisen angeblich gut integrierter Muslime wie etwa in Großbritannien. Diese jungen Männer wurden gerade deshalb zu Terroristen, weil sie meinten, dass auch die westlichen Wertmaßstäbe im Umgang mit ihren islamischen Glaubensbrüdern nicht hinreichend beachtet wurden. Sie fühlten sich mit jenen Muslimen verbunden, die z. B. durch die Kriegshandlungen westlicher Armeen in Afghanistan und im Irak leiden, und ließen sich deshalb als „heilige Krieger“ anwerben. Ein fanatischer Glaube kann in Verbindung mit Rachegefüblen junge Leute zu verbrecherische Handlungen motivieren, weil sie sich dem Kampf für das ,einzig Gute“ und den wahren Glauben verpflichtet fühlen.

Ähnlich verhält es sich bei Sekten mit fundamentalistischen und inhumanen Tendenzen, die gerade bei Orientierung suchenden Jugendlichen Anklang finden können. Hier sind Aktivitäten von Sozialpädagogen zwar prinzipiell möglich - vor allem bei Kindern bzw. Jugendlichen, die sich von Sektenwerbern bedrängt füblen, und bei Aussteigern, die Hilfe suchen - allerdings sind dafür spezifische Kenntnisse bezüglich des Charakters und der Wirksamkeit religiöser Sekten erforderlich. Das gilt z. B. speziell bei Aussteigern oder „Verrätern“ von Satansanbetern, denn diese bedrohen gefährliche Mitwisser bzw. Opfer ihrer scheußlichen Rituale mit Racheakten, die tödlich ausgehen können. Das Spektrum devianter Verbaltensweisen, das durch Aktivitäten von Sekten erzeugt wird, ist breit und vielgestaltig. Es umfasst z. B.:

- gefäbrliche Selbstüberschätzung von Individuen und Gruppen auf sozialdarwinistischer Grundlage (z. B. PET ${ }^{17}$ Constant AG in Murten und EMT-Programmanbieter in Bad Münster und Bad Kreuznach);

- Bereitschaft, sich ausbeuten zu lassen (z. B. Scientologie, Mun Sekte);

- Rituelle Morde und Selbstmorde (z. B. Satansanbeter, Sonnentempler).

Wirksamkeit und Erfolge vieler Sekten beruhen darauf, dass sie an feststellbare Unsicherheiten und Minderwertigkeitskomplexe von Menschen, an ihren Mangel an Zuwendung und Geborgenheit in einer stabilen Gemeinschaft sowie der Suche nach einem sie befriedigenden Lebensstil und Lebensinhalt anknüpfen. Sie machen die so Angeworbenen von sich abhängig, indem sie diesen Bedürfnissen weitgehend entsprechen und verführerische Erfolgs- und Heilsversprechen anbieten, die angeblich dann eingelöst werden, wenn sich die Betreffenden den Ritualen sowie den Glaubenssätzen und Verhaltensregeln der Sekte bedingungslos unterwerfen.

\subsubsection{Medienwissenschaftliche Erkenntnisse zur Erklärung devianten Verhaltens}

Zur Erklärung devianter Verhaltensweisen bei Kindern und Jugendlichen wird in Diskussionen vielfach auf eine schädliche Rolle der Medien, insbesondere von Fernsehund Computerprogrammen verwiesen. Dabei geht es vor allem um zwei Fragen:

17 PET $=$ Persönliches Erfolgs-Training; EMT $=$ Erfolgs- und Motivations-Training. 
- Wie schädlich ist das Sitzen vor dem Bildschirm überhaupt?

- Unter welchen Bedingungen ist das Sitzen vor dem Bildschirm für die Persönlichkeitsentwicklung schädlich?

Auf die erste Frage gibt der Ulmer Hirnforscher Manfred Spitzer eine relativ klare Antwort. Er fordert auf der Grundlage umfangreicher empirischer Untersuchungen, dass Kleinkinder grundsätzlich nicht vor Bildschirmen sitz̧en sollten:

„Bildschirme liefern dem kleinen Kind weniger Struktur als wirkliche Realität. Man kann daher annehmen, dass ein substantieller Konsum von Bildschirmmedien (d. h. ein Konsum von Bildschirm-Medien über einen substantiellen Zeitraum im Vergleich zur Gesamtzeit der kindlichen Erfahrung) eine geringere bzw. unklarere Strukturierung des kindlichen Gehirns und damit wiederum der kindlichen Erfahrungswelt nach sich zieht. Damit sind Bildschirme bei den ganz Kleinen aus ganz grundsätzlichen Überlegungen heraus schädlich“ (Spitzer 2006, S. 90f.).

Bei den Vorschulkindern, die viel fernsehen, lassen sich ernsthafte Konzentrationsschwächen und Leistungsrückstände in der Grundschule nachweisen (Spitzer 2006, S. 134ff.), aber auch Mängel in der Sozialkompetenz: Letztere wird eben nicht durch Fernsehfilme und Computerspiele, sondern primär in sozialen Interaktionen und Kommunikationen in unmittelbaren zwischenmenschlichen Beqiehungen erworben.

Bei der zweiten Frage geht es um die Inhalte und die Menge des Fernsehkonsums und der Computerspiele. Als Belege für die Schädlichkeit von „Bildschirmleistungen“ dienen Handlungen von Kindern, die sich als Nachahmungen von devianten Handlungsweisen aus Fernsehsendungen interpretieren lassen - etwa wenn ein dreizehnjähriger Junge seine Nachbarin mit einem Beil so erschlägt, wie er es am Tage zuvor auf dem Bildschirm gesehen hat. Dabei werden allerdings die vielfältigen Faktoren im Entwicklungsprozess des Jungen außer Acht gelassen, die erst erklären können, weshalb er überhaupt zu einer solchen Tat fähig gewesen ist. Es ist nicht das einzelne schlechte Vorbild im Fernsehen, das ein solches Handeln provoziert und erklärt, sondern immer ein ganz konkretes individuelles Bedingungsgefüge, das zur Erklärung herangezogen werden muss, denn die reale Wirkung des Fernsehens hängt nicht allein von der Art der Sendung, sondern auch von der Art der Rezeption durch den Fernsebkonsumenten ab. Bei näherer Prüfung zeigt sich in der Regel, dass schon der einseitige und umfangreiche Fernsehkonsum Ausdruck von sozialen (einschließlich pädagogischen) Defiziterscheinungen ist, z. B. als kompensatorisches Handeln für ungenügende pädagogisch sinnvolle Anregungen und Zuwendungen interpretiert werden kann. Dennoch ist die Frage nach dem Anteil des Fernsehens bzw. der Medien an der Entstehung und/oder Stabilisierung devianter Verhaltensweisen berechtigt.

Grundsätzlich kann davon ausgegangen werden, dass die Medien im Prozess der Meinungsbildung und Verhaltenssteuerung vieler Menschen eine große Rolle spielen. Da- 
von sind zumindest diejenigen überzeugt, die viel Geld für Fernsehwerbesendungen ausgeben, und davon kann man leicht eine Vorstellung erlangen, wenn man das Bemühen vieler Menschen beobachtet, unbedingt mit den Moden mitgehen zu wollen, die durch Medien bzw. Reklamesendungen propagiert werden. Medien erzeugen ja nicht nur Vorbilder, Muster usw., die nachgeahmt werden, sondern auch einen gewissen Druck zur Nachahmung über die öffentliche Meinung. Besonders deutlich wird das an dem hohen Prozentsatz von 21,9\% der im Rahmen des Kinder- und Jugendgesundheitssurveys befragten Heranwachsenden im Alter von 11-17 Jahren, die an Ess-Störungen erkrankt sind (vgl. Hölling und Schlack bei B.-M. Kurth 2006, S. 1052) Es sind immerhin über eine halbe Millionen Mädchen und junger Frauen in Deutschland, die als magersüchtige und bulimistische Patientinnen unter dem propagierten Schönheitsideal leiden. Dabei betrifft es vor allem Menschen, die der Überbewertung äußerer Erscheinungsbilder anhängen und deren Selbstwertgefühl vorwiegend davon abhängt, inwieweit sie sich diesem Erscheinungsbild nähern. Betrachten wir die Wirksamkeit der Medien unter dem vorn erläuterten Aspekt der „Bedeutung von Minderwertigkeitskomplexen“ für die Verhaltenssteuerung, dann wird deutlich, warum Medien auf viele Menschen nachhaltig wirken können. Indem sie sich den jeweils modischen Trends in den verschiedenen Lebensbereichen (Kleidung, Wohnung, Kraftfahrzeuge, Musik usw.) anpassen, dokumentieren sie ihre Zugehörigkeit zu denen, die „etwas gelten“.

Über den Zusammenhang von Gewaltdarstellungen in den Medien und menschlichem Verhalten gibt es verschiedene Hypothesen, nämlich:

- „Die Stimulationsthese: Gewaltdarstellungen (zum Beispiel in Kinofilmen, Comics, Fernsehen [...] enthemmen menschliches Verhalten und regen zum Nachahmen an.

- Die Katharsisthese: Durch das Betrachten von Aggressionen und Gewaltszenen leben sich unterdrückte Triebregungen aus; beim Betrachten wird Aggressivität während der Beobachtung der Gewaltszene abgebaut.

- Die Habitualisierungsthese: Betrachtet der Rezipient häufiger Gewaltdarstellungen, dann führt dies zu Gleichgültigkeit gegenüber den Opfern in den Medien (und im Alltag), und der Rezipient sieht die Gewaltanwendung selbst als ein Mittel, um einen möglichen Konflikt lösen zu können.

- Die Inhibitionsthese: In Medien dargestellte Gewalt dämpft Aggression, da Gewalt in modernen Industriegesellschaften nicht gebilligt wird“" (Hobmair u. a. 1989, S. 290).

Die Thesen (eigentlich Hypothesen) erscheinen bei kritischer Betrachtung auf dem Hintergrund vorliegender Erfahrungen zumindest nicht als gleichwahrscheinlich. So ist die Behauptung der Inhibitionsthese sicherlich problematisch. Allein die kriegerischen Aktionen der vergangenen Jahrzehnte belegen dies. Es sei hier nur erinnert an den gewaltsamen Sturz des demokratisch gewählten sozialistischen Präsidenten Salvador Allende in 
Chile 1973 oder an die angebliche Bedrohung durch Massenvernichtungswaffen Sadam Husseins als Vorwand für den Überfall auf den Irak 2002. Die vielfach wirksame strukturelle systemimmanente Gewalt, wie sie sich u. a. in rücksichtslosen Massenentlassungen durch große Unternehmen äußert, repräsentiert ebenfalls ,gebilligte Gewalt“. Zudem ist fraglich, ob ein Rezipient in den Gewaltdarstellungen der Medien etwas nicht zu Billigendes erkennt!

Auch bei der Katharsis- oder „Reinigungshypothese“ ist unter den gegebenen historischen Bedingungen und angesichts des Umfangs und der Art brutalster Gewaltdarstellungen in manchen Filmen oder Computerspielen zumindest Skepsis angebracht, denn diese Darstellungen sind nicht mehr vergleichbar mit den Tragödien der alten Griechen oder Shakespeares, für deren Betrachtung die Katharsisthese wahrscheinlich gelten konnte. E. Fromm spricht auch den heutigen Menschen

„ein tiefes Verlangen nach einer Dramatisierung der letzten Dinge im Menschenleben“ zu, „,nämlich von Leben und Tod, von Verbrechen und Strafe, von Kampf zwischen Mensch und Natur. Aber während das griechische Drama diese Probleme auf einem hohen künstlerischen Niveau behandelte, sind unser modernes Drama und Ritual von roher Art und haben daher keinerlei kathartische Wirkung (Hervorhebung von W. N.). Diese ganze Faszination durch Sportwettkämpfe, Verbrechen und Leidenschaft zeugt von dem Bedürfnis, die routinemäßige Oberfläche zu durchbrechen, aber aus der Art, wie dies geschieht, spricht die klägliche Armut unserer Lösung“" (Fromm 1981, S. 142/143).

Außerdem haben psychologische Untersuchungen ergeben, dass der Ausdruck aggressiver Impulse oder die Beobachtung von Aggressionen die Wahrscheinlichkeit künftiger Aggression erhöht, es sei denn bei dem Ausdrücken der Gefühle handelt es sich nicht um Zornesausbrüche, sondern um Weinen und Reden darüber (vgl. Zimbardo 1992, S. 369). Alltägliche Erfahrungen - z. B. schon in Kindergärten - belegen, dass viele Kinder dazu neigen, bestimmte Fernsehfilmhandlungen (z. B. die Kämpfe und Methoden der Konfliktregelung ihrer Fernsehhelden) nachzuspielen, so dass wir nicht umhin kommen, die Stimulationsthese ernst zu nehmen - auch wenn beispielsweise Tilmann P. Gangloff gegenteiliger Auffassung ist. Er behauptet:

„Kinder, die ihre Freizeit bevorzugt mit gewalttätigen Computerspielen oder Videofilmen verbringen und dann aggressiv werden, wären auch ohne diese Medien verhaltensauffällig geworden“ (zitiert nach Mogge-Stubbe 2002, S. 78).

Diese Behauptung ist nicht beweisbar, weil kein Kind zugleich mit und obne Gewaltdarstellungen aufwachsen kann. Sie weckt daher den Verdacht, gewalttätige Medien in ihrer Wirkung auf Heranwachsende zu verharmlosen. Gegen Gangloffs Auffassung sprechen auch die inzwischen vorliegenden Befunde empirischer Untersuchungen. So berichtet z. B. Christian Pfeiffer, Direktor des Kriminologischen Instituts in Nieder- 
sachsen, über Untersuchungsergebnisse amerikanischer Wissenschaftler der StanfordUniversity, die an zwei Schulen ein interessantes Feldexperiment durchgeführt haben:

„In einer Koppelung von schriftlichen Informationen für die Eltern und sorgfältig vorbereiteten Unterrichtseinheiten in der Schule werden dort neunjährige Schüler selber dazu angehalten, freiwillig ihren Fernsehkonsum einzuschränken. Daneben gibt es eine gleichgroße Kontrollgruppe von Neunjährigen an anderen Schulen, die in keiner Weise an dem medienpädagogischen Experiment beteiligt sind. Bereits nach einem halben Jahr konnte bei der erstgenannten Gruppe eine deutliche Reduzierung des Fernsehkonsums sowie eine signifikant geringere Aggressivität der Schüler festgestellt werden. In der Kontrollgruppe war dagegen alles beim Alten geblieben“ (Pfeiffer 2003, S. 38).

Hinzu kommt, dass ein Abbau des menschlichen Mitgefübls Folge und Voraussetzung für den Konsum immer brutalerer Filme und Computerspiele ist, was zu der vielfach beklagten wachsenden Brutalität führt, mit der manche Jugendliche bei ihren aggressiven Handlungen vorgehen; und das spricht offensichtlich für die Habitualisierungsthese.

Auf der Grundlage kriminalpsychologischer Forschungsergebnisse formuliert H. J. Schneider eine klare und eindeutige Position zum Streit um die Rolle der Medien im Prozess der Desorientierung und Deformation von Kindern und Jugendlichen, indem er über Erklärungsversuche zum Verhalten jugendlicher Mörder schreibt:

„Durch Gewalt im Fernsehen, durch Videospiele und durch Veranschaulichungen im Internet wird seine (gemeint ist der potentielle Mörder, W. N.) Phantasie unterstützt. Hierbei ist es weniger die passive Unterhaltung durch gewaltsame Fernsehspiele und Filme, die ihn fasziniert. Er hat vielmehr an der aktiven Teilnahme an Videospielen Freude. Durch diese Teilnahme lernt er das Töten, und er lernt auch Spaß dabei zu haben. [...] Dreißig Jahre kriminalpsychologische Forschung haben eindeutig die schädlichen Folgen der Gewaltdarstellungen im Fernsehen und in Filmen nachgewiesen. Die Massenmedien setzen ihre ganze Macht ein, um diese eindeutigen Forschungsergebnisse zu unterdrücken und um den falschen Eindruck zu erzeugen und aufrechtzuerhalten, die Medienforschung sei in der Frage der unheilvollen Auswirkungen ihrer Gewaltdarstellungen gespalten. Der angebliche Wissenschaftsstreit zu diesem Problem ist ein Mythos, der künstlich am Leben erhalten wird“ (Schneider 2000, S. 613).

Im Rahmen der Diskussionen um die Schwierigkeiten in der Wertevermittlung an Heranwachsende verweist Horst Petri auf das verantwortungslose Handeln der profitorientierten Medienindustrie, indem er schreibt:

„Eine nicht zu unterschätzende Gefahr geht ferner von einer Medienindustrie aus, die durch die schonungslose Triebentfesselung der Gewalt und die Pansexualisierung und Pervertierung menschlicher Beziehungen unsere Schuld- und Schamkultur radikal hinwegfegt. Damit werden speziell die Moralschranken junger Menschen skrupellos durchbrochen und der Anarchie überantwortet" (Petri 2002, S. 24). 
Es ist nicht möglich, die vielfältigen Erkenntnisse der Medienpädagogik zur vorliegenden Problematik zu referieren. Es sei nur noch darauf hingewiesen, dass die modernen Medien nicht nur oder primär unter dem Aspekt von „Gefahrenquellen“ betrachtet werden dürfen. Ihre positiven Wirkungen im Prozess der Information, Bildung, Aufklärung und Unterhaltung sind unbestritten und auch den digitalen Spielen und Spielkulturen werden Bildungspotentiale zugebilligt ${ }^{18}$, woraus folgt: Die Befähigung der heranwachsenden Generation zum vernünftigen Umgang mit den Medien ist in einer Mediengesellschaft eine unvermeidliche und zentrale Aufgabe aller erzieherischen Kräfte, was übrigens auch gegen ein „Ende der Erįiehung“ spricht. Allerdings machen es sich die Produzenten von Gewaltdarstellungen zu leicht, wenn sie die Verantwortung für die Wirkungen ihrer Produkte grundsätzlich an die Eltern (die ihre Kinder nicht zum richtigen Verständnis der Medien erziehen) oder an die Rezipienten abschieben. Wie verantwortungslos zudem die Filmwirtschaft mit geltenden Kinder- und Jugendschutzbestimmungen umgeht, verdeutlichen Gaertner und Saad in ihrem Buch (2012, S. 152f.).

Solange Profitinteressen die Produktion im Medienbereich relativ uneingeschränkt bestimmen können und sich Gewaltdarstellungen besonders profitabel verkaufen lassen, ist die psychische und moralische Entwicklung jugendlicher Rezipienten bedroht. Von einer Verantwortung für das Wohl der Gemeinschaft kann da nicht mehr die Rede sein. Es ist unmöglich, durch Gesetzgebungen und Kontrollen zur Einhaltung der Gesetze den Medienmarkt von schädlichen Produkten zu säubern. Auch der Vorschlag Pfeiffers auf dem Deutschen Lehrertag 2003, die Ausstrablung der wegen ihrer Gewaltdarstellungen unter Jugendschutz, stehenden Filme über die Fernsehsender auch für die Zeit nach 22.00 Uhr zu verbieten (vgl. Pfeiffer 2003, S. 40), wird nicht viel bewirken. Er ist gut gemeint und soll der Gefahr der Medienverwahrlosung begegnen. Aber es bleiben ja immer noch die Möglichkeiten des käuflichen Erwerbs der entsprechenden Filme (Videos bzw. DVD) sowie von Ego-Shooter-Spielen für Computer durch Erwachsene, so dass auch Kinder und Jugendliche über Umwege den Zugang dazu erhalten.

Erfahrungsgemäß greift ein Rechtsstaat ein, wenn Unternehmer Pflanzenschutzmittel oder Tierfutter produzieren, deren Verwendung nachweislich zu schweren Gesundheitsschäden bei den Konsumenten der mit Gift- und Schadstoffen belasteten Pflanzenund Fleischerzeugnisse führt. Auch bei illegalen Drogen bemühen sich die Regierungen zivilisierter Länder um die Unterbindung ihrer Produktion. Das führt zur Frage: Warum werden wir nicht in gleicher Weise vor nachweislich moralischen Giften geschützt, indem bereits die Herstellung ,giftiger Produkte" verboten wird? Muss sich eine Demokratie nicht auch vor dem Missbrauch der Freiheiten im Medienbereich schützen? Wenn die Ware erst auf dem Markt ist, versagen erfahrungsgemäß alle Kontrollen, weil es immer Wege gibt, auf denen sich Interessenten die produzierten Filme und

18 Vgl. [online] http://www.medienpaed.com/15/fromme0812.pdf. (Zugriff: 28.06.2012) 
Computerspiele beschaffen können; im Übrigen reizt der Konsum des Verbotenen besonders. Ein Verbot zur Herstellung solcher ,giftigen Produkte“ wäre der einzige Weg einer radikalen Problemlösung. Aber das müsste weltweit geschehen und das ist unter den Bedingungen des Weltmarktes und in Anbetracht der Macht der Medienindustrie offenbar nicht möglich, daher bleiben Eltern, Erzieher, Sozialpädagogen und Therapeuten auch künftig weiterhin hart gefordert.

Es wäre sicher überzogen, wenn behauptet würde, dass schon allein die medialen Darstellungen von brutalen und kriminellen Handlungen deviantes und delinquentes Verhalten erzengen. Auf manche Menschen wirken solche Darstellungen ja auch abstoBend! Aber es muss in Rechnung gestellt werden, dass von solchen Darstellungen eine große Faszination ausgeht, besonders für Kinder und Jugendliche, so dass sie vom Fernseher oder Smartphone nicht mehr wegkommen. Der durch faszinierende und brutale Filme oder Spiele stimulierte überböhte Medienkonsum kann außerdem zur Sucht werden. Wenn auch exzessiver Medienkonsum noch nicht als „Mediensucht“ und damit auch nicht als psychische Krankheit anerkannt ist, an seinen faktischen Folgen ändert das nichts. Es ist inzwischen erwiesen, dass Gewalt verherrlichende Fernsehbilder bei acht- bis zwölfjährigen Kindern tiefe Schädigungen ihres moralischen Bewusstseins hervorrufen und mehr als zweistündiges Fernsehen täglich auch schulische Lernprozesse nachteilig beeinflusst (Spitzer 2006, S. 122-139, S. 168-188).

Als Schlussfolgerung für Sozialpädagogen (natürlich nicht nur für diese!) ergibt sich daraus, dass sie sich um die Entwicklung humaner Interessen und Neigungen bei allen Kindern und um deren Fähigkeit zum kritischen Umgang mit den Medien bemühen müssen, da sie nun einmal in einer Mediengesellschaft leben. Ein kritischer und zeitlich vernünftiger Umgang mit den Medien ist auch aus lernpsychologischen Gründen dringend erforderlich: Es ist durch lernpsychologische Untersuchungen belegt, dass intensives Fernsehen und spannende Computerspiele nach dem Schulunterricht oder auch nach der Erledigung von Hausaufgaben dazu beitragen, das „soeben Gelernte “im Gedächtnis zu „l̈̈schen“ oder wieder „zu verschütten“ (vgl. S. 58). Tägliches längeres Fernsehen führt allgemein zur Reduzierung des häuslichen Lernens „für den Unterricht“, was vielfach Misserfolge in der Schule nach sich zieht, so dass es kein Wunder ist, wenn diese Schüler eine Abneigung gegen schulisches Lernen entwickeln.

Mit zunehmender Nutzung des Internets durch Kinder und Jugendliche hat sich auch eine neue Möglichkeit des Mobbings entwickelt: das sog. Cyber-Mobbing oder „Cyber-Bullying“. Durch Handys oder Internetseiten werden Filme, Fotos oder verbale Äußerungen über Mitschüler, Lehrkräfte oder andere „missliebige Personen“ weltweit in Umlauf gebracht, die verletzen und diffamieren. Hier stehen Medienerziehung bezüglich der Prävention und psychosoziale Intensiverziehung im Sinne korrigierender Erziehung vor weiteren anspruchsvollen Aufgaben. 


\subsubsection{Zur Rolle der negativen Etikettierung im Entstehungsprozess devianten Verhaltens}

Bei der Darstellung von Erklärungsversuchen zur Entstehung und Verfestigung devianter Verhaltensweisen wird vielfach von der verbreiteten Vorstellung ausgegangen, dass es in jeder Gesellschaft ein System von sozialen Normen und kulturellen Übereinkünften gibt, die zwar einen unterschiedlichen Verbindlichkeitsgrad und Geltungsbereich besitzen, aber doch als gültige Maßstäbe zu betrachten und zu handhaben sind. Deviant ist danach jedes Handeln und Verhalten, das von diesen Maßstäben abweicht. Mit dieser Sichtweise wird das Augenmerk ausschließlich auf die Abweichler gelenkt. Unberücksichtigt im Prozess der Entstehung und Verfestigung devianten Verhaltens bleibt bei dieser Betrachtung die Rolle der „Normensetzer“ und vor allem der Kontrolleure (Erzieher, Polizisten, Juristen usw.).

Die Vertreter der Etikettierungstheorie meinen, dass

„,wir erst dann wissen können, ob eine Handlung als abweichend einzuordnen ist, wenn die Reaktion anderer darauf erfolgt ist. Abweichendes Verhalten ist keine Qualität, die im Verhalten selbst liegt, sondern in der Interaktion zwischen einem Menschen, der eine Handlung begeht, und Menschen, die darauf reagieren“ (Becker 1981, zitiert nach: Bohle 1987, S. 6).

Diese Position unterstellt, dass nur durch eine Fremdbewertung (Reaktion anderer Menschen in der Interaktion) die Qualität einer Handlung bestimmt werden kann. Dieser Standpunkt vernachlässigt die Tatsache, dass sich die Qualität einer Handlung in ihren realen Effekten offenbart, und wenn diese schädlicher Natur sind, kann das häufig auch der Täter feststellen. Jede Bewertung berücksichtigt normalerweise die realen Effekte von Handlungen und greift zudem auf ein historisch entstandenes Wertesystem zurück, das die Normen als Bewertungsmaßstäbe liefert.

Die soziale Qualität einer Handlung oder eines Verhaltens wird deutlich in dem Grad ihrer Übereinstimmung oder Nichtübereinstimmung mit soziokulturellen Normen, deren sich die Reagierenden bei der Beurteilung beliebiger Handlungen und Verhaltensweisen bedienen. Wenn es Abweichungen zwischen Fremd- und Selbstbeurteilungen gibt, so kann das nicht nur an der Interaktion, sondern auch an den Normen liegen, die von den verschiedenen Beurteilern als gültig angesehen und angewendet werden.

Wertungen können nicht allgemein als Willkürakte irgendeines die Normen setzenden Interaktionspartners betrachtet werden. So ist z. B. das Rauchen bei großer Trockenheit im Wald ein deviantes Verhalten, und zwar nicht, weil ein Interaktionspartner das behauptet, sondern weil ein durch Raucher verursachter Waldbrand ökologischen und ökonomischen Schaden verursacht. Desgleichen sind menschliche Wertvorstellungen und Gefühle sowie zwischenmenschliche Beziehungen empfindlich und verletzlich. Sie können beschädigt oder zerstört werden, ohne dass jemand das durch ein Werturteil nachträglich feststellt. Diese realistischen Beispiele machen deutlich, dass die Ausgangsposition 
der Labeling-Theorie unhaltbar ist. Die Qualität des Devianten erlangt ein Verhalten eben nicht erst dadurch, dass es als solches bewertet brw. bezeichnet wird, sondern es wird so bewertet und bezeichnet, weil es sich - gemessen an den tatsächlichen bzw. voraussebbaren Folgen - als ein solches erweist. Dass es manchmal schwierig ist, die Gültigkeit einer Norm zu begründen, wurde bereits an anderer Stelle erörtert, wenn aber durch bestimmte Handlungsweisen ein persönlicher oder gesellschaftlicher Schaden zu erwarten oder entstanden ist, der zu vermeiden gewesen wäre, liegt in der Regel ein Normenversto $\beta$ vor. Allerdings ist bei einem Normenverstoß stets zu beachten, ob er wissentlich bzw. absichtlich oder aus Normenunkenntnis bzw. aus Versehen erfolgt ist, weil das für die Reaktion - also auch für pädagogisches Handeln Bedeutung hat.

In pluralistischen und multikulturellen Gesellschaften gehen die Auffassungen darüber, was ein moralischer Schaden ist, oft weit auseinander ( z. B. Zwangsverheiratung, Ehrenmord, Beschneidung von Mädchen). In solchen Fällen ist ein Diskurs zur Gültigkeit einer umstrittenen Norm auf der Grundlage der Menschenrechtsnormen erforderlich und auch die Frage nach einer progressiven Devianz zu prüfen. In Anbetracht der Festigkeit traditioneller Wertvorstellungen und Normen ist es aber zumeist sehr schwierig, ihre Vertreter von der Berechtigung oder gar Notwendigkeit progressiver Normen zu überzeugen, so dass u. U. eine juristische Klärung notwendig ist - z. B. bei Diskriminierungen.

Trotz der oben formulierten Einwände enthält die Etikettierungstheorie eine sozialpädagogisch bedeutsame Erkenntnis: Wenn nämlich nach dem ersten Auftreten devianter Verhaltensweisen bei einem Kind (das vielleicht noch nicht einmal die Tragweite seines Handelns übersieht) von unverständigen Mitmenschen dem Kind wiederholt gesagt wird, es sei von ihm ohnehin nichts Gutes zu erwarten und es würde ,gewiss noch im Gefängnis landen“ usw., besteht die Gefahr, dass dieses Kind sich dieser Erwartung anpasst und eine sich selbst erfüllende Prophezeiung wirksam wird. Diese Entwicklung hat Lemert ,anschaulich in folgender Stufenfolge zusammengefasst: 1. primäre Abweichung; 2. soziale Strafen; 3. weitere primäre Abweichung; 4. härtere Strafen und Ablehnung; 5. weitere Abweichung, begleitet von Feindseligkeit und Ressentiments gegenüber dem Strafenden; 6. Überschreiten der Toleranzgrenze, gekennzeichnet durch formelle Aktivitäten der Stigmatisierung des Devianten durch die Öffentlichkeit; 7. Verstärkung des abweichenden Verhaltens als eine negative Reaktion auf Stigmatisierung und Bestrafung; 8. schließlich Übernahme des abweichenden sozialen Status und Anpassung an die damit verknüpfte Rolle“ (zitiert nach Herriger 1979, S. 159).

Moralisches Etikettieren ist also ein gefährliches und kritikwürdiges Moment im mitmenschlichen Umgang, da es deviante Verhaltensweisen verstärkt und verfestigt; es muss deshalb unbedingt vermieden werden. Die zitierte Stufenfolge ist ein nützliches Hilfsmittel, um eine sich anbahnende „Devianzkarriere“ zu erkennen und nach Möglichkeiten zu suchen, sie zu verhindern, wozu auch schon Anteil nehmendes Zubören beitragen kann. 


\subsection{Zur Bedeutung der vorgestellten Theorien über deviantes Verhalten für Sozialpädagogen}

Der Zweck der vorangegangenen Darstellung bestand darin, jene theoretischen Ansätze und Konzepte vorzustellen und zu erläutern, die dem Sozialpädagogen die Möglichkeit erschließen,

- das Handeln und Verhalten seiner Klienten besser zu verstehen,

- dieses sich selbst und so weit wie erforderlich bzw. möglich auch ibnen zu erklären,

- $\quad$ m zugleich auch Ansatzpunkte zur Überwindung abweichenden Verhaltens und Handelns zu finden.

Die in den Theorien erörterten Bedingungen für die Entstehung devianter Verhaltensweisen machen deutlich, wie kompliziert die Sozialisationsbedingungen für die heranwachsenden Generationen geworden sind. Mit jeder weiteren technischen Errungenschaft erlangen wir nicht nur Erleichterungen in unserem täglichen Leben; es wachsen auch die realen Anforderungen zur Bewältigung des Alltags - das ist ein dialektischer Grundzug der gesellschaftlichen Entwicklung, mit dessen Folgen Sozialpädagogen in besonderer Weise konfrontiert sind. Außerdem wirken die von den vorgestellten Theorien erarbeiteten einzelnen Faktoren oder Bedingungen für die Entstehung devianter Verhaltensweisen im Rahmen tief greifender und beschleunigter gesellschaftlicher Veränderungen, aus denen gewissermaßen eine Gesamtwirkung auf jeden einzelnen Menschen resultiert, die theoretisch kaum erfassbar ist. Petri gibt in seinem Buch ,Jugend auf der Suche“ (2006) einen interessanten Einblick in das Geflecht dieser Wirkungsbedingungen, das bei der Analyse jedes Falles und bei jedem Rückgriff auf einzelne Theorien zur Erklärung des Falles mit beachtet werden muss. Dieses komplizierte gesellschaftliche Bedingungsgefüge ist zu berücksichtigen, weil damit der Sozialpädagoge sich selbst vor kurzschlüssigen Selbstbeschuldigungen bewahren kann und im Falle des Scheiterns seiner Bemühungen nicht an sich selbst zu verzweifeln braucht. Auch für die psychosoziale Intensiverziehung gilt das Gesetz der transgredienten Determination der Erziehung, das den Bemühungen des Einzelnen objektive Möglichkeiten bietet, aber zugleich auch Grenzen setzt.

Bevor wir uns den Möglichkeiten der Behandlung von Problembelasteten zuwenden, stellt sich die Frage, inwieweit es die in den Theorien genannten gesellschaftlichen Bedingungen in Verbindung mit den anthropologischen Voraussetzungen jedes Menschen erlauben, den Problembelasteten für sein deviantes Verhalten verantwortlich qu machen oder ihm die Schuld an seiner Problembelastung zu geben, unter der andere und häufig auch er selbst leiden. Es gibt wohl keinen Zweifel daran, dass die Menschen schon allein durch ihre soziale Herkunft sowie durch Ort und Zeitpunkt ihrer Geburt unterschiedlich 
bevorzugt oder benachteiligt werden, d. h., sie verfügen über unterschiedliche soziale und individuelle Voraussetzungen für ihren Start ins Leben und haben es demzufolge leichter oder schwerer, ihr Leben zu gestalten.

Doch die individuellen Unterschiede ändern nichts daran, dass sie Menschen sind, die sich u. a. gerade dadurch von Tieren unterscheiden, dass sie kraft ihrer Vernunft über sich und ibr Tun reflektieren können - sofern sie nicht geistig schwer beeinträchtigt sind. Diese Fähigkeit in Verbindung mit der Erfahrung, dass jeder Mensch die Leistungen anderer zu seiner eigenen Existenz benötigt, verpflichtet ihn zur Gegenleistung; das Mindeste ist also, dass er sich so verbält, dass andere diese Leistungen (auch für ihn!) unbeeinträchtigt (also ohne Störungen durch deviante Verhaltensweisen) erbringen können. Schon allein aus diesem Grunde ist jeder psychisch nicht beeinträchtigte Mensch für sein Tun und Lassen verantwortlich. Gerade bei Problembelasteten muss an dieser Erkenntnis gearbeitet werden, da sie Grundlage ist für Einstellungswandlungen und Umgewöhnungsprozesse, die für dauerhafte Verhaltens- und Persönlichkeitsveränderungen notwendig sind.

Es ist nun die Frage, welche Möglichkeiten Sozialpädagogen haben, solche Prozesse der Persönlichkeitsveränderung in Gang zu setzen, und wodurch ihre Erfolgschancen begründet sind. Grundlegende Antworten zur Entwicklungsfähigkeit und Veränderbarkeit der Menschen in den verschiedenen Lebensaltern gibt die Psychologie. Jeder Mensch ist Schöpfer seiner Persönlichkeit - allerdings unter Berücksichtigung der Dialektik der endogenen und exogenen Faktoren, wobei die autogenen als relativ bewusste und vermittelnde Glieder in diesem Prozess von ausschlaggebender Bedeutung sind. Unter dem Aspekt der endogenen Faktoren sind die sensiblen oder sensitiven Perioden in der Entwicklung von Kindern und Heranwachsenden von besonderer Bedeutung. Gemeint ist damit, dass „,im Vergleich zu vorangehenden oder nachfolgenden Perioden spezifische Erfahrungen maximale positive oder negative Wirkungen haben“ (Oerter/Montada 1998, S. 53). So ist bekannt, dass für den Spracherwerb die frühe Kindheit genutzt werden muss. Geschieht dies nicht, weil das Kind bei einer taubstummen Mutter und relativ isoliert aufwächst, kann das Versäumte nur mit sehr hohem Aufwand nachgeholt werden.

Es ist ethisch problematisch, das Phänomen der sensitiven Perioden experimentell zu erforschen. Schon Experimente, in denen Kleinkinder hinsichtlich ihrer Entwicklungsfortschritte unter verschiedenen pädagogischen Bedingungen untersucht werden, enthalten die Gefahr, dass eine „Kontrollgruppe“ vernachlässigt oder eine „Versuchsgruppe “ überfordert wird. Außerdem ist immer zu berücksichtigen:

„Die Annahme sensitiver Perioden des Lernens bedeutet nicht, dass die Aufgaben zu einem früheren oder späteren Zeitpunkt nicht auch in Angriff genommen werden könnten, wohl aber, daß der Lernprozess dann größeren Aufwand mit sich bringt und externe Hilfestellungen einen geringeren Erfolg erwarten lassen“ (Oerter/Montada 1998, S. 327). 
Interessant in diesem Zusammenhang sind Experimente zur Sensibilität von Sänglingen, die zeigten, dass diese sich von drei Puppen, von denen eine bilfebedürftig, eine andere bilfsbereit und eine weitere ,böse“ agierte, danach am häufigsten die hilfsbereite Puppe zum Spielen auswählten, sich von dieser also angezogen fühlten (vgl. „TV Hören und Sehen“, Nr. 22/2008, S. 17). Rolf Degen verweist auf weitere Experimente mit Säuglingen und Tieren, die belegen, dass es für Empathie und Mitleid bei Menschen und höher entwickelten Tieren genetische Grundlagen gibt (vgl. 2007, S. 142-153).

Da es Sozialpädagogen vielfach erst dann mit Problembelasteten zu tun bekommen, wenn die sensitiven Perioden für bedeutsame Entwicklungsprozesse nur unzureichend genutzt worden sind, stellt sich die Frage: wie kann man die nunmehr wirksamen autogenen Faktoren (Bedürfnisse, Interessen, Neigungen, Willen usw.) im Interesse der Problembelasteten und ihrer progressiven Veränderung „mobilisieren“? Entscheidend ist ja letztendlich das eigene Bemühen um Selbstveränderung! Einige Hinweise bzw. Ansatzpunkte dafür enthält die nachfolgende Übersicht:

\section{Ansatzpunkte für Erziehung in der Bedürfnisstruktur der Persönlichkeit}

\begin{tabular}{|l|l|l|}
\hline \multicolumn{1}{|c|}{ Dispositionen } & \multicolumn{1}{c|}{ Entwicklungsresultate } & \multicolumn{1}{c|}{ Deformationen } \\
\hline Aktivitätspotenziale & Produktives und soziales Handeln & Zerstörungswut, Aggressivität \\
\hline Erholungsbedürfnis & Entspannung, Wohlbefinden & „Herumhängen“, „Gammeln“ \\
\hline Nahrungsbedürfnis & gesunde Ernährung & Esssucht, Trunksucht \\
\hline Neugier & Erkenntnisstreben, Forscherdrang & Sensationsgier \\
\hline Sicherheitsbedürfnis & Vorsicht, Umsicht & Ängstlichkeit \\
\hline Bedürfnis nach Geborgenheit & Vertrauen & Misstrauen \\
\hline $\begin{array}{l}\text { Bedürfnis nach Abenteuern } \\
\text { und auch (kollektiven) Risiken }\end{array}$ & $\begin{array}{l}\text { Selbstvertrauen, } \\
\text { Kameradschaftlichkeit }\end{array}$ & $\begin{array}{l}\text { Leichtsinn, } \\
\text { Rücksichtslosigkeit }\end{array}$ \\
\hline Bedürfnis nach Gemeinschaft & Gemeinschaftsfähigkeit & Cliquenhörigkeit \\
\hline Autonomiestreben & Souveränität & Überheblichkeit \\
\hline Streben nach Anerkennung & Gesunder Ehrgeiz & Herrschsucht, Machtgier \\
\hline Natürliches Mitgefühl & Nächstenliebe, Solidarität & prinzipienlose Gutmütigkeit \\
\hline Streben nach Wohlergehen & Fleiß, Erwerbsstreben & Egoismus, Raffgier \\
\hline
\end{tabular}

Übersicht 6

Die erste Spalte in der Übersicht enthält ein Spektrum endogener Faktoren und die zweite Spalte entsprechende Entwicklungsresultate, die auch als autogene Faktoren wirken können. Beide Faktorengruppen verweisen auf wesentliche innere Voraussetzungen für die relative Autonomie der Persönlichkeit und auf Ansatzpunkte für die psychosoziale Intensiverziehung, die praktisch genutzt werden sollten. 
In sozialpädagogischen Problemanalysen erfolgt allgemein eine Reduktion der Merkmalsfülle auf die für wesentlich gehaltenen Merkmale und Bedingungen. Es ist jedoch möglich, dass dabei Erscheinungen übersehen werden, die im konkreten Falle wichtig sind, weil ein Sozialpädagoge nicht immer alle binreichend genau wahrnehmen kann oder weil die angebotenen Theorien selbst noch unzureichend sind, daher auch noch nicht genügend Analysegesichtspunkte anbieten. Hinzu kommt, dass wegen des probabilistischen Charakters der wirkenden Gesetzmäßigkeiten auch die Risikowahrscheinlichkeiten im gegeben Fall falsch bewertet werden. Das sind jedoch keine Gründe zur Ablehnung wissenschaftlicher Erkenntnisse oder zu prinzipiellen Zweifeln an der Möglichkeit, Devianzprobleme auch genauer erkennen zu können, um jene Veränderungsmöglichkeiten in ihren inneren und äußeren Entstehungsbedingungen entsprechend der vorgestellten Theorien aufzudecken, die im Problemlösungsprozess zu nutzen sind.

Diese Veränderungsprozesse zielen entsprechend unserem humanistischen Menschenbild grundsätzlich auf die Rettung des Hilfebedürftigen. Das bedeutet: durch ökonomische, medizinische, soziale und pädagogische Hilfen muss nach Möglichkeit die physische, psychische und soziokulturelle Existenz der Problembelasteten gewährleistet werden. Wenn bereits Schädigungen der physischen und/oder psychischen Gesundheit eingetreten sind, müssen diese entsprechend dem Heilungsprinzip auch therapeutisch behandelt werden. Doch unabhängig davon, wie weit der Heilungsprozess geführt werden kann, muss der Problembelastete im Interesse seiner Lebensqualität und Selbständigkeit individuell und intensiv gefördert werden. Damit ergibt sich folgende Liste normativer Prinzipien:

- das Rettungsprinzip,

- das Heilungsprinzip und

- das Förderungsprinzip.

In der Sozialen Arbeit umfasst Förderung alle finanziellen, verwaltungstechnischen, juristischen sowie technisch-organisatorischen Unterstützungsmaßnahmen; ihr sozialpädagogischer „Kern“ aber ist die Hilfe zur Selbsthilfe und darüber hinaus die Förderung von Mündigkeit und Souveränität. Diese Forderung ist so fundamental, dass sie noch einmal explizit im Rahmen des 1. Konzeptprinzips (vgl. S. 250f.) erscheint.

Die normativen Prinzipien der Sozialen Arbeit sind allgemeingültig und persistent. Sie gelten demzufolge in der Sozialarbeit, in der Therapie und in der psychosozialen Intensiverziebung. Sie dienen als Entscheidungshilfen bei der Anwendung aller anderen Prinzipien und haben in diesem Sinne eine normierende Funktion. Das bedeutet: sozialpädagogische Maßnahmen müssen den o. g. normativen Prinzipien entsprechen, wobei die aufgeführte Reihenfolge der Prinzipien zugleich eine Rangfolge darstellt.

Abschließend werden noch einmal einige wichtige Erkenntnisse über die Entstehung devianten Handelns und Verhaltens in einer Übersicht zusammengefasst: 


\section{Zusammenfassende Übersicht}

\section{über wichtige Erklärungsmöglichkeiten für deviantes Verhalten}

(von unten nach oben zu lesen)

\begin{tabular}{|c|c|}
\hline \multicolumn{2}{|c|}{ und einige ihrer $\quad$ Argumente } \\
\hline Negative Etikettierung & führt zu sich selbst erfüllenden Prophezeiungen \\
\hline Medienwissenschaftliche Erkenntnisse & $\begin{array}{l}\text { Stimulationsthese und Habitualisierungsthese: } \\
\text { Brutale Darstellungen regen zur Nachahmung an } \\
\text { und erscheinen dem Konsumenten als Normalität }\end{array}$ \\
\hline $\begin{array}{l}\text { Politischer und/oder religiöser } \\
\text { Extremismus bzw. Fundamentalismus }\end{array}$ & $\begin{array}{l}\text { Hass auf Fremde, anders Denkende u. Gläubige; } \\
\text { rechtfertigt Verbrechen durch „,höhere Werte“ }\end{array}$ \\
\hline $\begin{array}{l}\text { Theorie der Deindividuation und } \\
\text { Dehumanisierung } \\
\text { (S. Prentice-Dunn) }\end{array}$ & $\begin{array}{l}\text { „Delegierung“ persönlicher Verantwortung an an- } \\
\text { dere; Verneinung menschlicher Qualitäten bei an- } \\
\text { deren Personen (z. B. „,rassisch Minderwertige“) }\end{array}$ \\
\hline Theorie der jugendlichen Bande & Handeln nach Normen der Subkultur \\
\hline Entwicklungs & $\begin{array}{l}\text { frühkindliche Prägungen und sensible Perioden } \\
\text { werden nicht genügend beachtet; Jugenddelin- } \\
\text { quenz und persistente Delinquenz unterscheiden! }\end{array}$ \\
\hline $\begin{array}{l}\text { Lernpsychologie, Theorie der differen- } \\
\text { tiellen Kontakte oder Assoziationen } \\
\text { (E. H. Sutherland) }\end{array}$ & $\begin{array}{l}\text { kriminalisierende Lernprozesse durch Nachah- } \\
\text { mung krimineller Vorbilder in Assoziationen }\end{array}$ \\
\hline $\begin{array}{l}\text { Individualpsychologie und Humanis- } \\
\text { tische Psychologie } \\
\text { (A. Adler, C. R. Rogers) }\end{array}$ & $\begin{array}{l}\text { Kompensation von Minderwertigkeitskomplexen, } \\
\text { falsch verstandenes Selbstverwirklichungsstreben }\end{array}$ \\
\hline $\begin{array}{l}\text { Sozialökonomische Theorie } \\
\text { (R. K. Merton) }\end{array}$ & $\begin{array}{l}\text { Wert-Mittel-Diskrepanz-Hypothese verweist auf } \\
\text { illegale bzw. unsittliche Mittel zur Überwindung } \\
\text { von Diskrepanzen zwischen erstrebten Werten } \\
\text { und dafür erforderlichen persönlichen Mitteln }\end{array}$ \\
\hline $\begin{array}{l}\text { Sozialpsychologie } \\
\text { (E. Fromm) }\end{array}$ & $\begin{array}{l}\text { „Pathologisch-normales“ Wirtschaften führt zu } \\
\text { Entfremdungserscheinungen, z. B.: „homo consu- } \\
\text { mens, ,reaktive Aggressivität“ und „sadistische } \\
\text { Destruktivität““ }\end{array}$ \\
\hline Verhaltenstheorie (G. C. Homans) & Frustrations-Aggressions-Hypothese \\
\hline $\begin{array}{l}\text { Biologie (insbes. Ethologie) u. Medizin } \\
\text { (K. Lorenz, F. v. Cube) }\end{array}$ & $\begin{array}{l}\text { Bestreben zur Selbstbehauptung; Störung des } \\
\text { verhaltensökologischen Gleichgewichts }\end{array}$ \\
\hline
\end{tabular}




\section{Kapitel}

Ziele und Inhalte der psychosozialen Intensiverziehung 


\subsection{Begriff und Erscheinungsformen des pädagogischen Ziels}

Bereits im Abschnitt 1.3 wurde der Begriff des pädagogischen Ziels definiert als ideell vorweggenommenes Resultat. Hobmair u. a. verstehen unter Erziehungszielen „die in der Erziehung ausdrücklich und bewusst gesetzten Wert- und Normvorstellungen“ (Hobmair u. a. 1989, S. 204). Schilling formuliert in Anlehnung an Brezinka: „Erziehungsziele sind Normen" (Schilling 1993, S. 131f.). Das ist ungenau, zwar fungieren pädagogische Ziele im Erziehungsprozess auch als Normen, aber Erziehungsziele müssen immer den ganzen Menschen im Auge behalten und sind demzufolge mebr als eine Art Bündelung von Normen; sie baben eine wesentlich kompliziertere Struktur: sie umfassen eine Vorstellung von jenen wesentlichen Persönlichkeitsqualitäten, über die der Erzogene schließlich verfügen soll und will.

Erziehungsziele lassen sich in Teilziele aufgliedern, mit deren Hilfe die angestrebten Persönlichkeitsqualitäten differenziert beschrieben werden können. Die Reduzierung von Zielen auf Normen birgt die Gefahr in sich, dass ihre Realisierung auf das Bestreben zur Normierung von Menschen hinausläuft. Die Praxis der Notengebung (Zensierung) in unseren Schulen enthält in der Tat diese Tendenz, da ja die Leistungen ungleicher Scbüler mit Hilfe (angeblich) gleicher Maßstäbe (Normen) bewertet werden. Hier schlägt die Vorstellung von Leistung und Leistungsbewertung entsprechend vorgegebener Normen aus dem Wirtschaftsleben durch, was verständlich ist, weil die Schüler auch auf die Arbeitswelt vorbereitet werden sollen, sich also an die Anwendung relativ gleicher Maßstäbe auf ungleiche Menschen gewöhnen müssen.

Sozialpädagogen sind nicht gehalten, Resultatsbewertungen primär unter dem Aspekt des Leistungswettbewerbs und der Konkurrenz vornehmen zu müssen. Für sie ist nicht wesentlich, in welchem Verhältnis die gezeigten Leistungen und Verhaltensweisen seines Klienten A zu dem von B stehen. Für sie ist wesentlich, inwieweit sich der einzelne Problembelastete im Prozess der Problemlösung dem vereinbarten pädagogischen Ziel „individuell genähert" hat. Gegenstand sozialpädagogischer Resultatskontrolle und -bewertung ist also der Entwicklungszuwachs eines Zöglings vom Zeitpunkt $\mathrm{t}_{1}$ zum Zeitpunkt $\mathrm{t}_{2}$, wobei das als gültig betrachtete Ziel als Maßstab dient und das festgestellte Handeln und Verhalten bei der Bewertung nicht mit dem eines anderen Zöglings verglichen wird.

Je nach Modellvorstellung von der Struktur der menschlichen Persönlichkeit lassen sich die angestrebten Persönlichkeitsqualitäten in Form von Eigenschaften formulieren, also:

1. Wissen, Können und Verhalten bezogen auf unterschiedliche Lebensbereiche (z. B. politisches Wissen, berufliches Können, soziales Verhalten) - oder - 
2. Kenntnisse, Fähigkeiten, Fertigkeiten, Interessen, Neigungen, Gewohnheiten, Einstellungen, Überzeugungen und Haltungen, die jeweils auf bestimmte Inhalte bezogen sind, z. B. musische Interessen, physikalische Kenntnisse, mathematische Fähigkeiten, handwerkliche Fertigkeiten, sportliche Neigungen, soziale Gewohnheiten, moralische Einstellungen, politische Überzeugungen, Arbeitshaltungen.

Es ist aber auch möglich, pädagogische Ziele als qu beherrschende Handlungen und zu realisierende Verhaltensweisen, d. h. als operationale Ziele zu formulieren; z. B. soll der Lernende „am Ende“ des Prozesses fähig sein, einen Antrag auf Hilfe in besonderen Lebenslagen zu stellen, ein Bewerbungsschreiben zu formulieren, sich in einem Bewerbungsgespräch richtig vorzustellen, mit Hilfebedürftigen verständnisvoll umzugehen usw. Allerdings sind nicht alle Ziele operationalisierbar; Einstellungen und Überzeugungen z. B. treten nur als Motive und Charakteristika bestimmter Handlungs- und Verhaltensweisen auf, wobei in manchen Fällen auch Verhaltensweisen gezeigt werden, die über die wirklich angestrebten Ziele und eigentlichen Motive hinwegtäuschen. Daher bedarf es diagnostischer Fähigkeiten, um die realen Einstellungen oder Überzeugungen zu erkennen.

Ungeachtet dieser methodischen Schwierigkeiten in der Resultatskontrolle und -bewertung ist aber für ein richtiges Verständnis pädagogischer Ziele wesentlich, dass es sich dabei immer um angestrebte Qualitätsmerkmale der Persönlichkeit handelt, die sich mittels bestimmter Inhalte und Methoden des Lehrens und Lernens - vor allem durch die damit verbundenen eigenen Bemühungen der Lernenden - entwickeln und äußern. Die Resultate besitzen daher auch kein streng normiertes, sondern jeweils ein individuell variables Realisierungsniveau, das den Zielen mehr oder weniger entspricht.

Hobmair u. a. meinen, „der Begriff Erziehungsziel ist genau von Lehr- und Lernzielen abzugrenzen“ (1989, S. 204). Das ist richtig, wenn man dabei beachtet, dass Lehrund Lernziele Aspekte von Erziehungszielen sind und in diesem Sinne von diesen abgegrenzt werden können. Erfolgreiche Lehrtätigkeit schließt aber immer auch Erziehung mit ein und normalerweise auch eine entsprechende Vorstellung beim Lehrenden von den angestrebten Persönlichkeitsqualitäten des Lernenden in Form von Teilzielen. Lernziele können ebenso als angestrebte Persönlichkeitsqualitäten gefasst werden (z. B. Kenntnis der Geografie des Landes x, Fähigkeit im Umgang mit gemeinen Brüchen, bejahende Einstellung zur parlamentarischen Demokratie, zweckmäßige Gewohnheiten bezüglich einer gesunden Ernährung und Lebensweise usw.).

Von den oben aufgeführten Möglichkeiten zur Aufgliederung pädagogischer Ziele wird vorwiegend in älteren pädagogischen Schriften Gebrauch gemacht. In neuerer Zeit haben sich gerade auch in der Sozialpädagogik Schwerpunktziele als praktisch zweckmäBig und nützlich erwiesen, die mit dem Begriff der Kompetenz erfasst werden. Es handelt sich dabei um zweckdienliche Kombinationen von Kenntnissen, Fähigkeiten, Fertigkeiten und 
Gewohnheiten, aber auch Einstellungen und Überzengungen, die zur Bewältigung wichtiger Aufgaben im täglichen Leben in einer demokratischen, pluralistischen, multikulturellen und hochtechnisierten Gesellschaft erforderlich sind (siehe S. 236).

Im Rahmen dieser Schrift wird deutlich zwischen pädagogischen Zielen und gesellschaftlichen Zwecken der Erziehung unterschieden, obgleich das in der Pädagogik nicht allgemein üblich ist. So schreibt z. B. Herbart: „Tugend ist der Name für das Ganze des pädagogischen Zwecks“ (Herbart 1922, S. 303). Damit wird der Begriff des Zwecks eindeutig zur Kennzeichnung der Persönlichkeitsqualität Tugend verwendet. In seiner „Allgemeinen Pädagogik“ erörtert er das Problem der Bestimmung des „Zwecks der Erziehung überhaupt" und schreibt:

„Der Erzieher vertritt den künftigen Mann beim Knaben; folglich, welche Zwecke der Zögling künftig als Erwachsener sich selbst setzen wird, muss der Erzieher seinen Bemühungen jetzt setzen; ihnen muß er die innere Leichtigkeit im voraus bereiten“ (Herbart 1922, Bd. 1, S. 157).

Herbart erwartet vom Erzieher, dass er den Zögling auf die Verwirklichung eben jener Zwecke vorbereitet, die sich dieser später einmal als Erwachsener setzen wird. Dabei hat er allerdings Zwecke auf sehr hohem Abstraktionsniveau im Auge: Tugend, Vielseitigkeit des Interesse, Charakterstärke der Sittlichkeit u. Ä. - und er fügt hinzu:

„Also schwebt uns hier nicht eine gewisse Anzahl einzelner Zwecke, (die wir überall nicht vorher wissen können,) sondern die Aktivität des heranwachsenden Menschen überhaupt vor“ (a. a. O., S. 158).

Auf dem hohen Abstraktionsniveau der Herbartschen Darstellung fallen Ziel und Zweck der Erziehung im Sinne von Idealen zusammen, denn „Tugend“ kann sowohl als eine anzustrebende Persönlichkeitsqualität (also Ziel) als auch als gesellschaftlich wertvolle Lebensäußerung betrachtet werden, die dann etwas bezweckt. Geht es aber um konkrete Zwecke, dann gilt, was Herbart oben über die „Anzahl einzelner Zwecke“ geschrieben hat. Sie sind nicht vorauszusehen, denn sie resultieren aus verschiedenen Erfahrungswelten bzw. Lebensbedingungen und aus unterschiedlichen Systemzusammenhängen. Der Erzieher entwickelt seine Vorstellungen vom Zweck der Erziehung aus seinem Menschenbild und seiner Lebenssituation heraus im Hinblick auf seine Zöglinge. Die durch ihn Erzogenen aber werden danach unter anderen Lebensbedingungen ibre Zwecke wählen müssen, wobei die vom Erzieher vermittelten Wertvorstellungen, Normen und Kompetenzen als Orientierungsgrundlagen dienen - ergänzt durch eigene Erfahrungen.

Mit Rücksicht auf die praktische Erziehungsarbeit ist es sinnvoll, zwischen pädagogischen Zielen und gesellschaftlichen Zwecken der Erziehung zu unterscheiden. Diese Unterscheidung ist prinzipiell und sozialpädagogisch bedeutsam: Erziehung hat ihrem Wesen nach eine wie auch immer geartete Vervollkommnung der Persönlichkeit zum Ziel, aber eine Persönlichkeit kann ihre Fähigkeiten nur so weit entfalten und nutzen, wie es die Gesellschaft zulässt. 
Daher muss Erziehung danach trachten, jeden Menschen nicht nur als individuelles, sondern als soziales Wesen, d. b. als Mitgestalter humaner gesellschaftlicher Lebensbedingungen zu entwickeln - eben das ist ibr allgemeiner Zweck. Eine sog. zweckfreie Erziehung oder Bildung ist eine Illusion, die hinsichtlich ihrer realen Absichten und Wirkungen hinterfragt werden sollte.

Grundsätzlich ist es möglich, pädagogische Zielvorstellungen nach verschiedenen Gesichtspunkten zu ordnen. So können Ziele z. B. inhaltlich differenziert werden nach

1. ihrem Allgemeinheitsgrad und Umfang (Leit-, Richt-, Grob- und Feinziele bzw. Teil- und Etappenziele),

2. ihrer Bindung an bestimmte Bereiche und Sachverhalte der Realität, mit denen sich die Zöglinge auseinandersetzen (Ziele der moralischen, der politischen, der ästhetischen, der polytechnischen Erziehung usw.),

3. ihrer Verknüpfung mit bestimmten Persönlichkeitsstrukturen (Wissensziele, Könnensziele, Verhaltensziele usw.),

4. ihrer Wichtigkeit oder Bedeutsamkeit (Grundqualifikationen, Schlüsselqualifikationen).

Unter formalem Aspekt betrachtet, lassen sich Ziele formulieren

- in Form der Kennzeichnung einzelner angestrebter Persönlichkeitseigenschaften mit Hilfe entsprechender psychologischer Kategorien (siehe oben Punkt 3) oder

- durch Zielbündelungen in Form sog. Kompetenzen oder

- als operationale Ziele durch die Angabe auszuführender bzw. zu beherrschender Handlungen, wodurch auch die Lernenden effektiv orientiert werden.

Die Diskussion um die Frage nach einem möglichen oder eher unmöglichen universellen inhaltichen Zielsystem der Erziehung (oder Bildung) rechtfertigt nicht einen Verzicht auf Anstrengungen um die Realisierung von Erziehungszielen im humanistischen Sinne.

Da es keine allgemein anerkannte Zieltaxonomie in der Pädagogik gibt, kann auch in diesem Buch nur eine Gruppierungsvariante angeboten werden, die begründet ist durch fundamentale menschliche Bedürfnisse und aktuelle gesellschaftliche Erfordernisse unter besonderer Berücksichtigung sozialpädagogischer Aufgaben.

Das vorliegende Buch beschränkt sich im Abschnitt 4.4 auf die Kennzeichnung einiger pädagogischer Leitziele, die zugleich Ausdruck von Persönlichkeitsidealen sind. Weitere Konkretisierungen durch dazugehörige Grob- und Feinziele können und müssen dann mit Rücksicht auf die Spezifik des jeweiligen Problemfalls der Sozialen Arbeit bzw. Sozialpädagogik vom Pädagogen unter Mitwirkung der Problembelasteten und Problembeteiligten selbständig erarbeitet und formuliert werden, denn erst relativ konkrete Ziele können die unter 4.5 vorgestellten Funktionen erfüllen. 


\subsection{Legitimation und Bestimmung pädagogischer Ziele}

\subsubsection{Möglichkeiten der Legitimation pädagogischer Ziele}

Erziehen bedeutet, dass Erzieher ihre Zöglinge zu bestimmten Verhaltensweisen und Handlungen bewegen und befähigen wollen, und zwar nicht nur situationsgebunden, sondern nachhaltig. Doch wodurch ist das Recht eines Erziehers zur zielstrebigen Beeinflussung eines anderen Menschen eigentlich begründet - oder anders formuliert: wodurch sind seine Ziele und die damit verbundenen zielstrebigen Maßnahmen als Ausdruck pädagogischer Führungstätigkeit legitimiert?

Plausible Antworten dazu finden wir bei Friedrich W. Kron (1991, S. 199). Er unterscheidet in Anlehnung an Max Weber (1864-1920) vier Möglichkeiten zur Legitimation von Führungstätigkeiten, die ja stets auf Ziele gerichtet sind:

- die traditionelle Legitimation,

- die legale Legitimation,

- die charismatische Legitimation,

- die prozedurale Legitimation.

Ein Sozialpädagoge sollte diese Möglichkeiten zur Legitimation oder Rechtfertigung pädagogischer Aktivitäten kennen, weil er dann auch besser versteht, wodurch die Erziehungseinflüsse begründet sind, denen seine Klienten unterliegen.

Im Falle der traditionellen Legitimation orientieren sich die erzieherischen Kräfte sowohl bei den Zielen als auch in der Prozessgestaltung an althergebrachten Vorstellungen („Schon Oma musste sich vorm Essen die Hände waschen“ usw.). Die legale Legitimation stützt sich auf gesetzliche Bestimmungen unterschiedlicher Art (z. B. Schulgesetze oder Heimordnungen), in denen ja auch pädagogische Ziele formuliert sind.

Eine charismatische Legitimation liegt vor, wenn die jeweiligen Ziele und damit verbundenen Vorgehensweisen durch die „Lehren“ bzw. Autorität und Ausstrahlung einer herausragenden Persönlichkeit als gerechtfertigt erscheinen, z. B. bei Religionsstiftern oder Parteiführern.

„4. In der neueren Literatur (Strzelewicz 1972) findet man schließlich die prozedurale Legitimation. Sie bedeutet, dass über gemeinsames Nachdenken und gemeinsame Diskussionen und Gespräche Vereinbarungen getroffen werden, auf deren Grundlage zukünftig gemeinsam gehandelt wird“" (Kron 1991, S. 199).

Diese prozedurale Legitimation wird in der praktischen Sozialpädagogik allgemein genutzt und bedarf ihrerseits natürlich einer besonderen methodischen Gestaltung, die an späterer Stelle (siehe Abschnitt 4.5) noch erläutert wird.

Die interessante und instruktive Darstellung von Kron enthält aber zwei Mängel: 
1. Sie lässt offen, wodurch denn nun die - wenn auch unterschiedlich legitimierten Zielinhalte tatsächlich begründet sind.

2. Sie lässt die für Sozialpädagogen wichtigste Art der Legitimation außer Acht, nämlich die Notlage der Hilfebedürftigen, zu deren Behebung ein staatlich anerkannter Sozialpädagoge/Sozialarbeiter im Prinzip fachlich befähigt und juristisch befugt ist.

Im erzieherischen Handeln wird bei der Bestimmung von Erziehungszielen auf die in der jeweiligen Gemeinschaft gültigen „Vorgaben“ und Normen zurückgegriffen. Das entbindet jedoch einen wissenschaftlich ausgebildeten Sozialpädagogen nicht von der Pflicht, über die Begründung und damit auch über die Gültigkeit der Normen seines pädagogischen Handelns nachzudenken, wozu die Abschnitte 4.2.2 und 4.3 einige Grundlagen bieten.

\subsubsection{Zur Begründung pädagogischer Ziele}

Realer Ausgangspunkt von Zielbestimmungen in der Pädagogik ist aus dialektisch-materialistischer Sicht der gesellschaftliche Hauptzweck der Erziehung: die Sicherung der Existenz und Entwicklung der Gesellschaft oder - in idealisierter Fassung die optimale Gestaltung von Natur und Gesellschaft. Dieser Hauptzweck lässt sich in viele einz̧elne Zwecke aufgliedern, zu deren Erfüllung die Menschen die dafür entsprechenden Persönlichkeitsqualitäten erwerben müssen. Das geschieht wesentlich auf der Grundlage von Erziehungskonzepten durch Erzieher, die diese Persönlichkeitsqualitäten in ihren Zielvorstellungen ideell vorweg nehmen und praktisch anstreben. Gesellschaftliche und individuelle Zwecke menschlichen Handelns und Verhaltens müssen daher in legitime und pädagogisch realisierbare Ziele „übersetzt“ werden. Im Rahmen von Bildungssystemen ist das ein besonderer erziehungswissenschaftlicher Arbeitsbereich (Curriculum- oder Lehrplanentwicklung), der hier nicht näher betrachtet werden kann. Aber es gibt einige grundlegende Verfahrenselemente der Zielgewinnung und Zielbestimmung, die in spezifischer Weise auch für die Sozialpädagogik gelten: Im Hinblick auf die jeweilige Problemsituation werden Ziele abgeleitet

- aus den Erfordernissen der transgredienten Grundlagen und unter Berücksichtigung der in einer pluralistischen Gesellschaft gültigen und anerkannten Menschenbilder, die in der Regel weltanschaulich begründet sind und historisch gewachsene Wertvorstellungen sowie Widersprüche miteinander einschließen,

- aus Entwicklungsbedürfnissen und -möglichkeiten des jeweiligen Zöglings bzw. der Zöglingsgruppe und

- berücksichtigen dabei - leider nicht immer ausreichend - die Leistungsfähigkeit des geplanten pädagogischen Prozesses (also das System der immanenten Momente in seiner konkreten historischen, regionalen, lokalen und 
möglichst auch situativen Ausprägung), weil nur dann realisierbare Ziele gewonnen werden können.

Mit der ersten Aussage wird auf erkennbare aktuelle und zukünftige Erfordernisse des Lebens in der Gesellschaft orientiert und keineswegs nur auf traditionelle Vorstellungen und Normen, die von Generation zu Generation weitergegeben werden sollen. Gesellschaftsprognosen sind daher wichtige Quellen für Zielableitungen, die allerdings mit erheblichen methodischen Schwierigkeiten verbunden sind.

Ferner machen die Aussagen unter 2. und 3. deutlich, wie wichtig es ist, bei der Zielbestimmung auf den Zögling einzugehen, seinen individuellen Möglichkeiten und berechtigten Ansprüchen differenziert Rechnung zu tragen. Eine humanistische Erziehung muss sich im Interesse des Zöglings um seine optimale Entwicklung bemühen; sie darf nicht nur seine Tauglichkeit für die Gesellschaft im Auge haben, aber auch nicht nur seinen möglicherweise recht einseitigen Bedürfnissen nach Spiel und Spaß nachgeben. Erziehung muss immer auch der Vorbereitung auf die Anstrengungen des Lebens dienen.

An der Transformation gesellschaftlicher Erfordernisse in pädagogische Ziele beteiligen sich viele gesellschaftliche Kräfte mit unterschiedlicher Intensität und unterschiedlichen Auffassungen darüber, was nun wirklich unabdingbar und wichtig ist für die heranwachsende Generation und das lebenslange Lernen der Erwachsenen. Es ist hier nicht der Ort, um die Probleme der Curriculumforschung oder der Erarbeitung von Ausbildungsunterlagen für die Berufsausbildung zu erörtern, denn in der Sozialpädagogik geht es ja nicht um die Bestimmung des Inhalts und Umfangs von Allgemein- oder Spezialbildung, sondern vor allem um die Überwindung devianter Verbaltens- und Handlungsweisen. Dafür aber sind Werte und Normen menschlichen Handelns und Verhaltens bedeutsam, die als Bestandteile von Zielen und als Inhalte sozialpädagogischer Prozesse erscheinen. Dass allerdings oft auch schwerwiegende Lücken in der Allgemeinbildung im kausalen Bedingungsgefüge devianten Verhaltens Einzelner eine Rolle spielen, ist bereits angedeutet worden und vielfach zu beobachten.

\subsection{Werte und Normen als Grundlagen von Zielbestimmungen und Er- ziehungsinhalten}

\subsubsection{Zur Begründung menschlicher Werte und soziokultureller Normen}

Werte und Normen sind noch keine pädagogischen Ziele, sondern liefern die fundamentalen Inhalte für pädagogische Zielvorstellungen; sie bilden aber zugleich auch die Substanz anzueignender Inhalte in Erziehungsprozessen und sollten durch das Vorbild der Erzieher praktisch repräsentiert werden. Wir wissen, 
„dass Werte durch die Identifikation mit Vorbildern vermittelt und verinnerlicht werden und den unverzichtbaren Kern unserer Persönlichkeit bilden; sie formen unseren Charakter, unsere Haltungen, unsere Moralität und unsere persönliche Integrität. Ohne Werte kann der Mensch nicht leben oder er verfällt der Asozialität“ (Petri 2002, S. 24).

Die Werte und Normen selbst bedürfen der Begründung und damit kommen wir zu einem der umstrittensten Probleme im Vorfeld der Pädagogik. Die Pädagogik selbst ist nicht für die Frage nach der Gültigkeit von Normen und Werten zuständig, sondern „übernimmt“ sie gewissermaßen aus dem von der jeweiligen Gesellschaft für gültig gehaltenen Fundus, der von der Moraltheorie bzw. Ethik wissenschaftlich bearbeitet wird. Pädagogen müssen sich darüber im Klaren sein, was Sutter zum Entwicklungsstand der Moraltheorie schreibt:

„Was Moraltheorie zunächst konzedieren muß, ist die Einsicht, daß die Diskussion um einen wissenschaftlich gültigen Ansatz von Moraltheorie noch nicht entschieden ist" (Sutter 1990, S. 10).

Zugleich verweist er auf eine fundamentale Forderung, die bei allen Versuchen zur Begründung moralischer Normen zu beachten ist:

„eine Moraltheorie, die die genetischen Bedingungen der Moral rekonstruieren will, darf nichts an Moral vorgeben, will sie nicht den zirkulären Erklärungsstrategien der Moralphilosophie verfallen" (Sutter 1990, S. 16).

Das bedeutet: man kann Moral nicht aus sich selbst heraus erklären, sondern muss auf die realen nichtmoralischen Grundlagen der Moral zurückgreifen, um sie erklären und begründen zu können. Etwa im Sinne von Schaller verweist auch Sutter auf „transgrediente Grundlagen“ der Moral mit den Worten:

„die Ausbildung der Erkenntnisstrukturen und der soziokulturellen Lebensformen des Menschen steht unter naturgeschichtlich entwickelten Bedingungen; was immer an Geist, Vernunft, Sinn und Moral sich entwickelt hat, ist aus ihnen heraus zu erklären [...]“ (Sutter 1990, S. 15f.).

Einen Erklärungsansatz für Moral in den „naturgeschichtlich entwickelten Bedingungen “ des Menschen und damit in der Anthropogenese finden wir bei Anatol Rapoport in seinem Buch „Philosophie heute und morgen - Einführung ins operationale Denken“ (3. Auflage, Darmstadt 1970). Dieser wird hier aufgegriffen, da er sich für eine dialektisch-materialistische Begründung soziokultureller Werte und moralischer Normen eignet, denn es handelt sich bei Rapoports Vorgehensweise um eine Differenzierung von primären menschlichen Bedürfnissen, die Marx zur Begründung des historischen Materialismus mit herangezogen hat, nämlich um die

„einfache Tatsache, daß die Menschen vor allen Dingen zuerst essen, trinken, wohnen und sich kleiden müssen, ehe sie Politik, Wissenschaft, Kunst, Religion usw. treiben können; [...]“ (MEW, Bd. 19, S. 335). 
Ohne explizite Bezugnahme auf einen geschichtsphilosophischen Hintergrund sucht Rapoport nach einer Begründung für moralisches Handeln, indem er davon ausgeht, „daß wir selbst angesichts der Verschiedenheit und der Gegensätzlichkeit der Bestrebungen menschlicher Gruppen doch vielleicht einige Bestrebungen finden können, die allen Gruppen gemeinsam sind“ (a. a. O., S. 155).

Er sieht in bestimmten Bestrebungen den Ausdruck invarianter Bedürfnisse und begnügt sich bei ihrer Begründung mit Hinweisen auf anthropogenetische Zusammenhänge und beobachtbare Fakten. Nach seiner Auffassung gibt es folgende invariante Bedürfnisse, die bei allen Menschen vorhanden sind - unabhängig von Rasse und Kultur, Alter und Geschlecht, sozialer Herkunft und Beruf:

- das Bedürfnis nach Erhaltung des Lebens - sowohl der Art als auch des Individuums (was Essen, Trinken, Wohnen usw. erfordert!),

- das Bedürfnis nach Zugehörigkeit zur Gemeinschaft,

- das Bedürfnis nach Ordnung und

- das Bedürfnis nach Sicherheit (vgl. a. a. O., S. 156-158).

In den invarianten Bedürfnissen sieht er eine objektive Grundlage von Wertesystemen, zumal ihre Befriedigung Lust, Wohlbehagen o. Ä. erzeugt. Er fügt der Aufzählung eine sog. Ich-Erweiterung als invariantes Bedürfnis hinzu (S. 161), nachdem er festgestellt hat:

„Die Liste kann erweitert werden, wenn sich zeigt, daß es noch mehr invariante Bedürfnisse gibt, oder sie kann gekürzt werden, wenn sich herausstellt, daß eines der hier aufgeführten Bedürfnisse nur eine Variation oder ein Sonderfall eines anderen ist“" (a. a. O., S. 158).

Prüfen wir die Liste, ob es sich hierbei wirklich immer um invariante Bedürfnisse handelt und ob nicht eventuell wichtige fehlen, dann zeigt sich, dass ein invariantes Bedürfnis nach Ordnung - das ja bei allen Menschen spontan wirksam sein müsste - vermutlich nicht existiert. Es ist nämlich fraglich, ob es sich bei dem Streben nach Ordnung wirklich um ein invariantes Bedürfnis handelt oder vielmehr um eine Fähigkeit bzw.

„Funktionsweise jedes Gehirns, des primitivsten ebenso wie des komplexesten“, das „einem alles bestimmenden Prinzip unterliegt: der Erkennung eines Musters, das den sich ständig wandelnden Reizen zugrunde liegt, [...]“(Fouts/Mills 1998, S. 204/205).

Rapoports Hinweise auf regelmäßige Muster und Verzierungen bei der Herstellung von Keramiktöpfen in urgeschichtlichen Kulturen sind zwar ein Ausdruck dieser Fähigkeit, verweisen aber wohl eher auf ein ästhetisches Bedürfnis und weniger auf ein invariantes Bedürfnis nach Ordnung. Desgleichen entspringen wissenschaftliche Strukturbildungen der Fähigkeit des Gehirns, Muster und Regelmäßigkeiten zu erkennen. Darüber hinaus könnte die Erfahrung, dass systematisiertes Wissen im Allgemeinen besser verfügbar ist und geordnete praktische Verhältnisse und Gegenstände in der Regel besser 
beherrschbar sind als ungeordnete, das Streben nach Ordnung erklären. Ob nämlich ein Künstler oder Wissenschaftler in ähnlicher Weise außerbalb seines professionellen Handelns nach Ordnung strebt, ist ja nicht gesagt. Zudem weiß jeder sozialpädagogische Familienhelfer, wie wenig vielfach das Bedürfnis nach Ordnung bei Problembelasteten entwickelt ist! Oft reicht es nicht einmal aus, um im eigenen Zimmer Ordnung herzustellen.

Auch das Beispiel des rhythmischen Tanzes, das als spontanes Bedürfnis schon bei Kindern und Naturvölkern beobachtet werden kann, ist als Beleg für ein invariantes Ordnungsbedürfnis - wie Rapoport annimmt - ungeeignet. Er übersieht nämlich ein echtes und fundamentales invariantes Bedürfnis: das aus dem geerbten Aktivitätspotenzial resultierende Bedürfnis nach Bewegung (vgl. Abschnitt 3.2.1). Gerade diesem Bedürfnis wird im Tanzen entsprochen, und wenn das nach Musikelängen und Rhythmen in der Gruppe geschieht, erlebt vermutlich jede Tänzerin und jeder Tänzer auch noch das von Rapoport genannte invariante Bedürfnis nach Zugehörigkeit zur Gemeinschaft. Das ist ein so bedeutsames und wirkungsvolles Erlebnis, dass es gegenwärtig in sozialpädagogischen Prozessen, die der Entwicklung von Gemeinschaftsfähigkeit dienen sollen, erfolgreich genutzt wird.

Allerdings wollen wir nicht übersehen, dass praktische Ordnungen oder Strukturierungen in Raum und Zeit für den Menschen bedeutsam sind, weil sie ihm ein Gefühl der Sicherheit aus Berechenbarkeit verleihen und die Möglichkeit zu Erfolg versprechenden Planungen seiner Handlungen eröffnen. Damit kann aber noch nicht die Frage entschieden werden, ob es sich beim sog. Ordnungssinn um ein angeborenes invariantes Bedürfnis oder um ein aus Menschbeitserfahrungen herrührendes Bemühen handelt. Angeborene Bedürfnisse setzen sich relativ spontan und ,eigenmächtig“ durch, was man vom Ordnungssinn wohl kaum sagen kann. Der Ordnungssinn der Menschen basiert auf der Fähigkeit des Gehirns, ähnliche Strukturen und Regelmäßigkeiten sowie deren praktischen Nutzen zu erkennen. In welchem Maße daraus ein gewohnheitsmäßiges Ordnungsstreben wird, ist eine Frage der Erziehung bzw. der Verarbeitung praktischer Erfahrungen.

Die Bedürfnisse nach Zugehörigkeit und Sicherheit sind zweifellos invariante Bedürfnisse, denn sie resultieren aus der Anthropogenese. Sie äußerten bzw. äußern sich bei Tieren als Herdentrieb und sind zudem mit dem Bedürfnis nach individuellem Leben und Überleben verbunden. Das Bedürfnis nach „Ich-Erweiterung“, das sich u. a. im Streben nach Erkennen und Beherrschen der Umwelt äußert, stößt natürlich auf Grenzen in Verbindung mit dem Erleben der Abhängigkeit vom ,größeren Ich“ der Familie, des Stammes usw. Rapoport spricht von Modellen der Ich-Erweiterung in den verschiedenen Kulturen; aber damit wird dieser Begriff eher noch verschwommener, so dass es geraten erscheint, stattdessen beim Individuum von einem invarianten Bedürfnis nach Autonomie zu sprechen - natürlich im Sinne von relativer Autonomie. Das Bestreben von Kindern, etwas selbständig zu machen und allein ₹и bewältigen, ist so unübersehbar und 
fundamental, dass es auch Wertvorstellungen mit begründet. Das ursprüngliche und invariante Bedürfnis nach Selbständigkeit und Unabhängigkeit findet schließlich in dem gesellschaftlichen Grundwert der Freiheit seinen höchst entwickelten Ausdruck.

Eine Erweiterung von Rapoports Liste der invarianten Bedürfnisse ist also tatsächlich notwendig. Ebenso bedeutsam wie das Bedürfnis nach Zugehörigkeit zur Gemeinschaft ist nämlich auch das Bedürfnis nach Anerkennung durch die Gemeinschaft bzw. Partizipation und nach gerechter Behandlung. Auf der Grundlage der Erkenntnisse von Adler erscheint es gerechtfertigt, das Bedürnis nach Anerkennung und Wertschätzung als ein invariantes zu betrachten; sein spontanes Auftreten beim Kleinkind und die schwerwiegenden Folgen seiner Geringschätzung in Form der vorn erörterten Minderwertigkeitskomplexe sprechen dafür. Ähnliches lässt sich von dem Bedürfnis nach gerechter Behandlung sagen. „Ungerechte“ Behandlungen - z. B. bei der Nahrungszuteilung - lösen bei Kindern, ja sogar schon bei Schimpansen und anderen Tieren Protest aus, was zumindest auf eine evolutionär bedingte genetische Grundlage des „Verlangens nach einem Anteil“" verweist (vgl. Degen 2007, S. 90ff.).

Die Verhaltensbiologie spricht von instinktiven Verhaltensdispositionen und rechnet dazu den Nahrungstrieb und den Sexualtrieb, die im Zusammenhang stehen mit dem invarianten Bedürfnis zu leben. Ferner konstatiert sie einen Nengiertrieb (v. Cube 1991, S. 123), der Grundlage ist für das Erkenntnisstreben des Menschen als einem weiteren invarianten Bedürfnis, das zusammen mit dem Aktivitätspotenzial und dem Bedürfnis nach Leben wirksam ist - führen doch die von Erkenntnissen geleiteten Aktivitäten zu einer zunehmenden (relativen) Beherrschung der eigenen Lebensverbältnisse.

Fouts und Mills stellten in Untersuchungen zur Kommunikationsfähigkeit von Tieren - speziell von Schimpansen beim erfolgreichen Gebrauch der Gebärdensprache - fest: „Das einzige obligatorische Verhalten, das sämtliche Spezies miteinander gemein haben, ist ihr Kommunikationsbedürfnis. Die Fähigkeit, Botschaften auszusenden und zu empfangen, ist entscheidend für die Organisation und das Überleben jeder tierischen und menschlichen Gemeinschaft“" (Fouts/Mills 1998, S. 109).

Dass dieses Kommunikationsbedürfnis invariant ist und einen hoch geschätzten Wert in der menschlichen Gesellschaft begründet - nämlich die Kommunikationsfreiheit -, ist evident, da sie sogar über Tod und Leben entscheiden kann.

Da es Rapoport um die Begründung ethischer Werte geht, schließt er die in seiner Liste genannten invarianten Bedürfnisse aus dem ethischen Wertesystem aus, denn „ethische Fragen lassen sich nur stellen, wo die Freiheit der Wahl besteht“" (a. a. O., S. 151). Bezüglich der Bedürfnisse nach Lebenserhaltung, nach Zughörigkeit und Sicherheit haben wir seiner Meinung nach keine Wahl oder alternative Entscheidungsmöglichkeit (vgl. a. a. O., S. 209). Diese Bedürfnisse existieren einfach, und die Frage der Wabl stellt sich 
erst, wenn es um die Mittel geht, um diese Bedürfnisse zu befriedigen. So steht z. B. ein Notleidender in seinem Bestreben, sein individuelles Leben zu erhalten, vor der Wabl,

- für seinen Lebensunterhalt zu arbeiten (sofern er Arbeit findet!),

- Anträge auf Unterstützung bei zuständigen Ämtern einzureichen,

- zu betteln oder

- zu stehlen.

Das angedeutete Beispiel soll nur zeigen, dass es zur Befriedigung invarianter Bedürfnisse ein Spektrum von Wahlmöglichkeiten in den Handlungen gibt und die konkrete tatsächliche Entscheidung für ein bestimmtes Mittel die ethischen Wertvorstellungen des Handelnden erkennen lässt, zumindest partiell. Wenn sich z. B. jemand im Falle eines zumutbaren Arbeitsangebotes dennoch für das Betteln oder den Diebstahl entscheidet, dann äußert er damit etwas von seinen ethischen Wertvorstellungen.

Zur Entstehung von materiellen, sozialen und kulturellen Werten bzw. Wertesystemen und entsprechenden Wertvorstellungen kam bzw. kommt es vermutlich dadurch, dass die Menschen in ihrem praktischen Handeln herausfinden, durch welche Mittel sie sowohl ihre invarianten Bedürfnisse als auch ihre sonstigen Interessen befriedigen können. So erkannte der urzeitliche Jäger in dem jagdbaren Wild und den Jagdwaffen sicher jene gegenständlichen oder materiellen Werte, die generell der Lebenserhaltung dienen. In der realen Hilfeleistung des Jagdgenossen „erfühlte“ er zugleich einen moralischen Wert, da ihm diese nicht nur den Jagderfolg sichern half, sondern vielleicht sogar das Leben rettete. Diese Hilfeleistung lag in der Entscheidungsmöglichkeit des anderen - er hätte ja aus Furcht vor dem wilden Tier auch flüchten können. Aber die genetisch bedingte Bereitschaft wechselseitiger Hilfe zwischen Verwandten (vgl. Degen 2007, S. 37ff.) und die Erfahrung, dass der Jagdgefährte nicht weggelaufen ist, sondern Beistand unter Lebensgefahr gewährte, repräsentierte faktisch einen moralischen Wert, der zugleich zur Norm für alle Mitglieder einer Jagdgemeinschaft bzw. Menschengruppe wurde, um das Überleben der Horde zu sichern. Die nicht beherrschbaren Risiken der Jagd (z. B. das Jagdglück) versuchten die urzeitlichen Jäger mit dem magischen Mittel des Jagdzaubers zu bewältigen, wobei allein schon der Glaube daran sie so sehr zur Ausdauer ermutigt haben mag, dass in vielen Fällen der gewünschte Erfolg eintrat.

Die zur Befriedigung grundlegender Bedürfnisse notwendigen Mittel erfahren verständlicherweise eine hohe Wertschätzung und erhalten - sofern ihre Herstellung auch als Ziel selbständiger Handlungen auftritt - zugleich einen eigenständigen Wert. So wurde z. B. der Bogen, der als Jagdwaffe diente, zu einem erstrebten Wertgegenstand oder materiellen Wert durch seine Bedeutung für den Menschen und die Beqiehung des Menschen zu ihm. Ein geschickter Bogenhersteller war demzufolge eine wertvolle Person für die Gemeinschaft und den Einzelnen. Der Wert eines beliebigen Gegenstandes, einer Person oder einer 
Idee liegt also nicht allein in den Objekten selbst, sondern resultiert aus den Objekten der Wertschätzung und ibren Beziehungen zu den Werte erlebenden Subjekten. Abgesehen von der historisch gewachsenen bumanistischen Vorstellung und Überzeugung vom Eigenwert jedes Menschen resultiert der individuelle Wert einer Persönlichkeit aus seinen Beziehungen zu seinen Mitmenschen. Das hat für moralische Werte große Bedeutung; so zeigte sich vermutlich, dass Ehrlichkeit als Ausdruck einer Beziehung zu den Mitmenschen zugleich ein Mittel ist, um die Zugehörigkeit zur Gemeinschaft zu fördern und zu festigen. Da die Stabilität einer Gemeinschaft auch vom ehrlichen Umgang der Mitglieder untereinander abhängt, wurde Ehrlichkeit zur Verhaltensnorm und ihre Tradierung ein wichtiges Anliegen der Erziehung. Die Transformation von Werten in Normen und wertvolle Erziehungsziele im Leben von Gemeinschaften seit ihrer urgeschichtlichen Entwicklung, die Fixierung wichtiger Werte und damit verbundener Handlungs- und Verhaltensvorschriften durch ungeschriebene Gruppennormen im Gemeinschaftsbewusstsein und schließlich auch in Form von Geboten heiliger Schriften oder juristischer Gesetze markiert den historischen Entwicklungsprozess sozialer, moralischer und rechtlicher Wertvorstellungen und Normen, die das menschliche Leben und Sterben im hohen Maße determinieren.

Die Kodifizierung von Normen in Gesetzen und ihre Erhebung zu göttlichen Geboten verlieh ihnen einen besonders hohen Grad von Verbindlichkeit. Ein Verstoß gegen die göttlichen Gebote war zugleich eine Form des Ungehorsams gegen einen mächtigen oder allmächtigen und strafenden Gott. Da die Furcht vor allen möglichen Gefahren im risikoreichen Lebensalltag mit vielen noch undurchschaubaren Naturereignissen sicher eine weit verbreitete Erscheinung bei den Menschen auf frühen Stufen ihrer historischen Entwicklung gewesen ist, war die Androhung von Rache oder eines Strafgerichts durch ein göttliches Wesen gewiss ein wirkungsvolles Mittel, den offiziellen Normen Geltung zu verschaffen. Außerdem bestand bei Verstößen gegen geltende Normen auch die Möglichkeit der Bestrafung durch die Gemeinschaft selbst. So heißt es in der Bibel bezüglich des Gebots der Sabbatfeier:

„..haltet meinen Sabbat, denn er soll euch heilig sein. Wer ihn entheiligt, der soll des Todes sterben. Denn wer eine Arbeit am Sabbat tut, der soll ausgerottet werden aus seinem Volk“" (2. Buch Mose; Kapitel 31, Verse 13/14).

Die Durchsetzung dieses Gebots wird dann u. a. wie folgt beschrieben:

„Als nun die Israeliten in der Wüste waren, fanden sie einen Mann, der Holz auflas am Sabbattag. Und die ihn dabei gefunden hatten, wie er Holz auflas, brachten ihn zu Mose und Aaron und vor die ganze Gemeinde. Und sie legten ihn gefangen, denn es war nicht klar bestimmt, was man mit ihm tun sollte. Der HERR aber sprach zu Mose: Der Mann soll des Todes sterben; die ganze Gemeinde soll ihn steinigen draußen vor dem Lager. Da führte die ganze Gemeinde ihn hinaus vor das Lager und steinigte ihn, so dass er starb, wie der HERR dem Mose geboten hatte“ (4. Buch Mose; Kapitel 15, Verse 32-36). 
Die Durchsetzung soziokultureller Normen auf der Basis von Glaubensgründen funktioniert aber nur innerbalb der jeweiligen Religionsgemeinschaft (einigermaßen). Grundsätzlich aber bedarf es einer wissenschaftlichen Begründung zumindest jener Normen, die für alle Menschen gelten sollen, was speziell beim Sabbat-Gebot ja nicht der Fall ist, obgleich es dem invarianten Bedürfnis nach Erholung entspricht (siehe S. 226).

Wenn die Urmenschen ihre Werteerlebnisse auch noch nicht theoretisch reflektierten, so haben sie in Verbindung mit der Befriedigung invarianter Bedürfnisse und damit in Abhängigkeit von etwas Erstrebenswertem gewiss schon relativ früh Wertgefüble entwickelt.

„Die Inhalte oder Gegenstände gerichteter Gefühle nennen wir »Werte«. Der Wertgehalt der Wirklichkeit (der aber nicht an sich existiert, sondern aus den Beziehungen der Menschen zu den entsprechenden Erscheinungen der Wirklichkeit resultiert, W. N.) erschließt sich uns in Akten der Freude und Trauer, der Verehrung, der Verachtung, der Liebe, des Hasses, der Furcht und der Hoffnung“" (Spaemann 1999, S. 37f.).

Wertgefühle sind durch ihre Beziehungen zu invarianten Bedürfnissen ,genetisch verankert" und entwickeln sich beim Individuum entsprechend seinen Lebensbedingungen. Das betrifft z. B. die Liebe zu den Eltern und die Verbundenheit mit Geschwistern, in deren Kreis man sich geborgen fühlt. Inhalt und Stärke der Wertgefüble, die sich in den frühen Kindheitsjahren entwickeln, werden wesentlich determiniert durch den förderlichen oder destruktiven Charakter der Entwicklungsbedingungen (vgl. S. 177ff.).

\subsubsection{Merkmale menschlicher Werte und soziokultureller Normen}

Historisch gesehen ist bedeutsam, dass die Fähigkeit des Menschen zum Abstrahieren die Entstehung allgemeiner menschlicher Wertvorstellungen ermöglicht, d. h., die vielfach im konkreten Lebensprozess gewonnenen Werteerfahrungen werden auf ähnliche Situationen übertragen und zunehmend verallgemeinert, wodurch sie teilweise sogar universellen Charakter annehmen. So gelangte die Menschheit von der Wertschätzung konkreter situationsabhängiger Unterstützungs- und Hilfsmaßnahmen für Familienangehörige oder Jagdgenossen zu einer immer weiter ausgreifenden Vorstellung von der Notwendigkeit mitmenschlicher Hilfe bis hin zur allgemeinen weltweiten Solidarität für Not leidende Menschen.

Auf analoger Grundlage lassen sich viele Werte und Wertvorstellungen erklären, wobei mit fortschreitender Kulturentwicklung in keativ-konstruktiver Weise unterschiedliche Wertesysteme entwickelt worden sind, die aber in letzter Instanz ihre Grundlage im realen Lebensprozess der Menschen haben, speziell in ihren invarianten Bedürfnissen und in ihrem Zusammenleben. Zumindest für fundamentale Werte gilt, dass sie sich nicht nur „aus Wünschbarkeiten konstituieren“ - wie Schilling in Anlehnung an Maag meint (vgl. Schilling 1993, S. 128). Sie resultieren vielmehr in letzter Instanz aus elementaren Lebensnotwendigkeiten, denen basale invariante Bedürfnisse zugrunde liegen. 
Man darf ferner nicht übersehen, dass sich manche Wertvorstellungen zu heiligen Dogmen verfestigt haben, die dann keine Rücksicht nehmen auf berechtigte Bedürfnisse und Wünsche derjenigen, die damit indoktriniert werden. Wenn sich z. B. Mädchen aus islamischen Familien emanzipieren wollen, stößt das häufig auf den Widerstand der religiös gestützten patriarchalischen Wertvorstellungen ihrer Herkunftsfamilien und erzeugt demzufolge Wertekonflikte, die bis zum sog. Ehrenmord führen können. Die generelle Bewältigung solcher Wertekonflikte ist sicher nur in längerfristigen Prozessen der Aufklärung und Veränderung der Lebensbedingungen der traditionsgebundenen Familien möglich und dauert Generationen. Im Einzelfall muss versucht werden, den familiären Konflikt mit friedlichen, d. h. mit pädagogischen oder juristischen Mitteln zu lösen. Wenn konservative oder islamische Eltern einen Werteverfall unter ihren Kindern beklagen, dann ist zu prüfen, ob es sich nicht eigentlich um einen aus emanzipatorischer Sicht begründeten und notwendigen Wandel bistorisch überlebter Wertvorstellungen handelt und welche Werte an die Stelle der alten treten. Man muss also sorgfältig zwischen einem gelegentlich beklagten Werteverfall und einem notwendigen und progressiven Wertewandel unterscheiden, der mit allen Mitteln der Erziehung und Aufklärung unterstützt werden sollte.

Rapoport konzentriert sich in seiner Darstellung der Werteproblematik auf die Begründung ethischer Werte und Normen, die er mit der Bedingung einer relativ freien Wabl der Mittel zur Realisierung bestimmter Ziele verknüpft. Wörtlich heißt es bei ihm:

„[...] es ist vernünftig, die ethischen Auswirkungen der bei der Verfolgung der Ziele angewandten Mittel zu bewerten, nicht aber die Ziele selbst“ (Rapoport 1970, S. 159).

Er berücksichtigt dabei nicht, dass die invarianten Bedürfnisse nach Selbst- und Arterhaltung, nach Zugehörigkeit und Sicherheit usw. gerade wegen ibrer existenziellen Bedeutung für die Menschen auch als Handlungsziele bewusst und bewertet werden. Im Ergebnis des Bewertungsprozesses nehmen sie sogar einen Spitzenplatz unter den Werten ein. Ähnliches lässt sich von der Selbständigkeit der Persönlichkeit und ihrer Aktivität sagen, vor allem wenn es sich um schöpferische Tätigkeiten handelt. Hierbei geht es um fundamentale und existenzielle Werte der Menschheit, für die anders als bei ethischen Werten die Wählbarkeit kein notwendiges Kriterium ist. Zwar hat der Mensch auch in diesen Bezügen eine gewisse Wahlfreiheit, denn er kann sich u. U. auch für den Tod, z. B. für einen Opfertod oder für einen Suizid entscheiden. Aber dann handelt es sich schon wieder um ethische Entscheidungen. Im Falle eines Opfertodes geht es in der Regel um eine ethische Entscheidung zu Gunsten eines höheren Wertes - zumindest sieht es der sich Opfernde so. Auch im Falle eines Suizids spielen ethische Gesichtspunkte eine Rolle. Zwar gibt es die Auffassung, dass der Mensch das Recht habe, über sein Leben selbst zu bestimmen, aber dabei darf nicht außer Acht gelassen werden, dass jeder Mensch im Rahmen seiner sozialen Beziehungen auch Pflichten und Verantwortung gegenüber anderen hat, also gegenüber seinen Eltern, seinem Partner und/oder seinen Kindern. 
Die Erhaltung des Lebens ist ein basales und invariantes Bedürfnis und der natürliche Tod eine traurige Selbstverständlichkeit. Mord ist ein schwerer Verstoß gegen den Grundwert Leben, gegen das Streben nach Lebenserhaltung und daher ein Verbrechen. Der Begriff des Selbstmordes ist fragwürdig, da derjenige, der sich selbst umbringt, nicht mehr leben will; das Streben nach Lebenserhaltung als Bedürfnis und Motiv entfällt also. Der Suizid ist kein Mord, sondern - sofern nicht durch die Verhältnisse „erpresst“ ein Verzicht, so gesehen auch kein Verstoß gegen das Bedürfnis nach Leben, wohl aber eine schwere ethische Entscheidung im Hinblick auf die Mitmenschen, wie die oben angedeuteten Überlegungen erkennen lassen. In jedem Falle ist zu prüfen, ob krankhafte psychische Zustände den „Verzicht motivieren“; trifft dies zu, muss die Krankheit behandelt werden, um dem „Lebensmüden“ zu helfen - was sehr schwierig ist! $\mathrm{Zu}$ einer dialektischen Betrachtungsweise der Werteproblematik gehört auch, dass wir nicht nur lebenspraktisch bedeutsame reale Beqiehungen des Menschen zu den Bewertungsobjekten als Werte auffassen, sondern berücksichtigen, dass die entsprechenden Wertvorstellungen einer geistigen Be- und Verarbeitung und damit vielfach einem beachtlichen Wandel unterliegen, wodurch Wertvorstellungen entstehen, die höhere Werte konstituieren. Am Beispiel des Wertes Leben lässt sich das verdeutlichen: Die Wertvorstellung vom Leben dient ja nicht nur als Orientierung für lebensnotwendige Handlungen, sondern durchdringt das Denken und Fühlen des Menschen so sehr, dass er es grundsätzlich nicht verlieren möchte. Die Folge davon ist, dass durch Abstraktion und Idealisierung unterschiedliche Vorstellungen von einem ewigen Leben entwickelt worden sind, z. B. von einem Weiterleben nach dem Tode im Jenseits oder im Paradies, von einer Wiederauferstehung von den Toten am Jüngsten Tag oder von der Seelenwanderung. Solche Wertvorstellungen finden Eingang in die jeweiligen Wertesysteme und bestimmen diese nachhaltig, etwa indem die Gläubigen das von ihnen erwartete ewige Leben höher schätzen als das irdische, was tiefgreifende Auswirkungen auf ihre persönliche Moral hat.

Die makabere Dialektik dieser idealisierenden Abstraktion als Bestandteil eines fanatischen religiösen Glaubens besteht nun darin, dass sie als ermutigender Stimulus zur Selbsttötung und Ermordung anderer Menschen wirksam werden kann, wie islamistische Selbstmordattentäter demonstrieren, die glauben, für ihren Opfertod im Paradies eine Belohnung zu erhalten. Für Wertvorstellungen gilt allgemein, dass ihnen - relativ unabhängig von ihrer Begründung - im praktischen Leben eine nachbaltige Orientierungsfunktion in der Lebensgestaltung zukommt (bis hin zum Verzicht auf ein weiteres irdisches Leben).

In Weiterführung des theoretischen Ansatzes von Rapoport lassen sich folgende basale und invariante Bedürfnisse feststellen, die entsprechend der Widersprüchlichkeit des Menschen zugleich auch dialektisch und in individueller Ausprägung in Erscheinung treten:

- das Bedürfnis zu leben, sich zu entwickeln und sich fortzupflanzen, 
- das Bedürfnis nach Aktivität und Entspannung (Erholung),

- das Bedürfnis nach Sicherheit und Abentenern (mit kalkulierbaren Risiken),

- das Bedürfnis nach Zugehörigkeit und Selbständigkeit,

- das Bedürfnis nach Anerkennung bzw. gerechter Behandlung und Partizipation,

- das Bedürfnis nach Erkenntnis und Beherrschung der eigenen Verhältnisse,

- das Bedürfnis nach Kommunikation und Selbstbesinnung.

Ihre Befriedigung - verbunden mit Gefühlen der Lust, der Freude, des Wohlbehagens usw. - widerspiegelt die Beziehungen der Menschen zu den Bedürfnisobjekten und stabilisiert Wertgefühle. So entstehen Grundwerte von existenzieller Bedeutung. Auch die erweiterte Liste von invarianten Bedürfnissen ist sicher noch überprüfungsbedürftig und kann korrigiert werden. Hier geht es nicht darum, eine umfassende Theorie der Wertebegründung und der Wertesysteme vorzustellen, sondern nur darum, zu verdeutlichen,

- was Werte und Wertvorstellungen sind,

- welche warum als besonders wichtig angesehen werden und

- worin ihre praktische Bedeutung besteht,

weil ihre Übermittlung und Aneignung sowie die Erziehung zu unbedingter Respektierung von Werten unverzichtbare Bestandteile pädagogischer Prozesse sind.

Auf der Grundlage des bisher Erörterten lässt sich sagen:

Werte sind Ausdruck bedeutsamer Beziehungen des Menschen zu seiner natürlichen und gesellschaftlichen Umwelt und zu sich selbst; sie werden reflektiert in Wertvorstellungen und Wertgefühlen, die bei normal entwickelten Persönlichkeiten relativ konstant sind, ihr Handeln und Verhalten nachhaltig stimulieren bzw. lenken, wodurch sie relativ berechenbar sind.

„Wertsysteme sind die Grundpfeiler von Kultur; sie vermitteln zwischen den Menschen und schützen zugleich den einen vor der Willkür des anderen“ (Höhler 1994, S. 119).

Die invarianten Bedürfnisse existieren nicht nur auf elementarer Ebene, sondern haben qualitativ höhere Ausprägungen entwickelt, die sich in eigenen Werten widerspiegeln. So begegnet uns das Bedürfnis nach Aktivität auch als Wert in Form der schöpferischen Arbeit. Der Verlust von Arbeit wird als fundamentaler Werteverlust empfunden, auch wenn durch das bestehende soziale Netz nicht mehr die Gefahr des Verhungerns besteht. Das Bedürfnis nach Selbständigkeit oder Autonomie widerspiegelt sich im Wert der Freiheit, die Bedürfnisse nach Sicherheit und Zugehörigkeit im Wert der Familie oder in dem Wert eines Freundeskreises, in dem man Geborgenheit, Zuwendung und Anerkennung erfährt. Das Bedürfnis nach Anerkennung findet zugleich seinen Ausdruck in der Erwartung, 
als Gleichberechtigter in der Gemeinschaft zu leben und Gerechtigkeit zu erfahren, die sich in gleichberechtigter Teilhabe (Partizipation!) an Willensbildungs- und Entscheidungsprozessen in der Gesellschaft äußert. Das Kommunikationsbedürfnis schließlich äußert sich nicht nur im Aufsuchen eines Kommunikationspartners, sondern findet im Zusammenhang mit den Bedürfnissen nach Selbständigkeit und Freiheit seine höchst entwickelte Ausprägung in dem Grundrecht auf freie Meinungsäußerung.

Auf elementarer Ebene kann die Frage, ob ein Verhalten normgerecht oder deviant, gut oder böse ist, durch Rückgriffe auf die o. g. relativ invarianten Bedürfnisse beantwortet werden, denn es erscheint evident zu sagen, dass diejenigen Handlungen und Verhaltensweisen moralisch gut sind, die sich richten auf

- die Erhaltung des Lebens und seine Entwicklung,

- $\quad$ eine möglichst schöpferische Aktivität und die dann auch erforderliche Erholung,

- $\quad$ eine allgemeine und persönliche Sicherheit sowie kalkulierbare Risiken,

- die Zugehörigkeit zu Entwicklung fördernden und Selbständigkeit fordernden Gemeinschaften,

- das Engagement für die Gemeinschaft und die Anerkennung durch sie, was eine gerechte Behandlung und Partizipation einschließt,

- die Erkenntnis und Beherrschung der eigenen Verhältnisse sowie

- Meinungsfreibeit und eine der Verständigung dienenden Kommunikation.

Wenn man sich bei der Beantwortung der Frage nach dem moralisch Guten von diesen Kriterien leiten lässt, dann wird deutlich, dass es in vielen Fällen keine streng normierten oder normierbaren Handlungs- bzw. Verhaltensweisen gibt, sondern jeweils ein Spektrum erforderlicher und erlaubter Möglichkeiten mit Toleranzgrenzen, von denen jeder entsprechend seiner Individualität so weit Gebrauch machen kann, wie er anderen oder sich selbst keinen materiellen, physischen oder psychischen Schaden zufügt. Dabei müssen auch die jeweils vertretbaren Maßverhältnisse gefunden und eingehalten werden, damit nicht aus Aktivität Hektik, aus dem Bestreben nach Erholung Trägheit oder gar Faulheit wird usw.

Für die Erziehung im „Zeitalter der Individualisierung“ erscheint ein Herangehen an die Formulierung von Erziehungszielen und damit verbundener moralischer Forderungen als realistisch, das nicht so sehr die Normen in Form schlichter Sollsätze, sondern als Spektrum erforderlicher und zulässiger Möglichkeiten in den Vordergrund stellt. Es ist daher vielfach praktikabel, wenn die Grenzen des Zulässigen durch „Darf-nicht-Sätze“ deutlich markiert werden.

Aus dem Alltagsleben wissen wir, dass es Entscheidungssituationen gibt, die nicht durch einen einfachen Rückgriff auf eine Norm bewältigt werden können, vielmehr sind die jeweils relevanten allgemeinen Normen noch aushandlungsbedürftig, d. h., sie 
müssen ,problem- und situationsspezifisch ausgelegt werden“ (Herrig 1979, S. 148), damit sie der Wahrung geltender Werte dienen, denn darin besteht eine wichtige Funktion der Normen. Deshalb erfolgt in der sozialpädagogischen Praxis auch vielfach eine prozedurale Legitimation der konkreten Ziele und Normen durch Diskurse zwischen den Prozessbeteiligten (vgl. S. 234f.).

Die Tatsache, dass die Norm vor ihrer Realisierung im konkreten Fall existiert, bedeutet nicht, dass sie nur Vorschrift oder Leitbild und nicht auch Abbild ist. Abbild ist eine Norm insofern, als sie Erfahrungen der Menschheit, der Gruppe oder der Persönlichkeit in spezifischer Form widerspiegelt und gerade deshalb als empirisch fundiertes Leitbild eines moralisch guten und persönlich vertretbaren bzw. sinnvollen Handelns und Verhaltens dienen kann.

Soziokulturelle Normen (einschließlich moralischer) sind ihrem Wesen nach Vorschriften und Maßstäbe für das Handeln und Verhalten der Menschen, die dazu dienen, einen bestimmten, dringend notwendigen oder erwünschten Zustand in der Realität zu erhalten oder herbeizuführen, um damit die Wertvorstellungen der Gesellschaft oder einer Gruppe zu realisieren.

Ob die Befolgung einer Norm tatsächlich Gutes bewirkt, hängt allerdings davon ab, ob sie dem Handlungsziel und den Handlungsbedingungen - also der realen Situation - angemessen oder adäquat ist. So können z. B. die Aktivitäten eines Kindes, die zeitweilig abwesenden Eltern bei ihrer Rückkehr mit einer guten Tat zu überraschen, indem es normgemäß aufräumt, u. U. von den Eltern als recht unzweckmäßige Eigenmächtigkeit bewertet werden, weil ein vom Kind nicht vorhersehbarer schädlicher Nebeneffekt der gut gemeinten Aufräumungsaktion mit aufgetreten ist. An anderer Stelle wurde bereits darauf hingewiesen, dass jede Handlung mehrere Wirkungen und Auswirkungen hat, darunter auch ungewollte oder nicht vorhergesehene Nebenwirkungen. Daher ist es problematisch, die moralische Qualität einer bestimmten Handlung oder Verhaltensweise nur an den Wirkungen ,ablesen“ zu wollen. Vielmehr müssen bei der Bewertung von Handlungen zunächst einmal die Motive und Absichten auf ihre moralische Qualität hin überprüft und bewertet werden, etwa die löbliche Absicht des Kindes mit einer Aufräumaktion den Eltern eine Freude zu bereiten, auch wenn die Eltern über das Ergebnis der kindlichen Bemühungen vielleicht entsetzt sind. Um also zu einer einigermaBen zutreffenden oder gerechten Bewertung zu gelangen, muss stets geprüft werden:

- Welches waren die Motive und Absichten der Handlung bzw. Verhaltensweise oder: welche Normen lagen ihr zugrunde?

- Welches sind die feststellbaren unmittelbaren Wirkungen und möglichen Spätfolgen, wobei die letztgenannten zumeist schwer abzuschätzen sind! 
Da es oft schwierig ist, die sog. wahren oder eigentlichen Absichten und Motive zu erkennen und auch bei den Wirkungen häufig nicht alle - vor allem nicht alle Fernwirkungen - ermittelt werden können, zeigt sich in der Praxis bei komplizierten Fällen ein eigentümliches Dilemma: Welche der beiden möglichen Begründungen für die moralische Qualität des Handelns und Verhaltens gebührt der Vorrang in der Bewertung?

In der Entwicklung der Ethik werden die beiden Herangehensweisen seit Max Weber unter den Begriffen der Verantwortungsethik und der Gesinnungsethik erörtert. Weber

„verstand unter Verantwortungsethik die Einstellung eines Menschen, der bei seinen Handlungen die Gesamtheit der voraussichtlichen Folgen in Betracht zieht, der also fragt, welche Folgen insgesamt unter dem Aspekt des Wertgehaltes der Wirklichkeit die besten sind und dementsprechend handelt, und zwar auch dann, wenn er dabei etwas tun muß, was, wenn man es isoliert betrachtet, schlecht genannt werden müßte“ (Spaemann 1999, S. 63).

„Ein Gesinnungsethiker beurteilt bei einer Handlung immer nur, ob diese selbst der reinen Gesinnung entspricht, also aufgrund ihres innermoralischen Wertes, ihre Folgen sind ohne Bedeutung. Er muß jede Handlung verurteilen, die sittlich bedenkliche Mittel anwendet, auch wenn dies die einzige Möglichkeit zur Realisierung eines moralischen Wertes ist" (Schülerduden Philosophie 2002, S. 406).

„Gesinnungsethisch [...] handelt der Pazifist, der unter keinen Umständen bereit ist, zu töten, sogar dann nicht, wenn die Ausbreitung des Pazifismus auf einer Seite die Kriegsgefahr erhöht. Er argumentiert, daß es keinen Krieg gäbe, wenn alle Pazifisten wären und daß schließlich einmal einige damit anfangen müßten“ (Spaemann 1999, S. 63f.).

Der Streit um die Berechtigung zur Veröffentlichung der sog. Mohammed-Karikaturen erzeugt z. B. die Frage: Soll im Interesse der Meinungs- und Pressefreiheit deren Veröffentlichung aus gesinnungsethischen Gründen bejaht oder aus verantwortungsethischen Gründen also mit Rücksicht auf die Folgen - lieber unterlassen werden?

Wegen gesinnungsethischer Bedenken (mit Bezug auf Artikel 6 Absatz 2 des Grundgesetzes) scheuen sich möglicherweise auch manche Sozialarbeiter, rechtzeitig und massiv einzugreifen, wenn Kinder von ihren Eltern vernachlässigt werden. Wie könnte es sonst geschehen, dass Kinder in Deutschland in der Wohnung ihrer Eltern verhungern (wie z. B. Lea-Sophie in Schwerin), obwohl es eigens für Problemfamilien Betreuer gibt, die beauftragt sind, in kritischen Fällen die Wächterfunktion der staatlichen Gemeinschaft wahrzunehmen? Dazu sind in dem angegebenen Handlungsbereich sicher verstärkt verantwortungsethische Entscheidungen erforderlich, bei denen man die möglichen Folgen von zu großer Rücksichtnahme auf das Elternrecht in den Vordergrund rückt. Komplizierte moralische Probleme sind weder allein auf der Grundlage der Verantwortungsethik noch der Gesinnungsethik zu lösen. Es müssen immer beide Herangehensweisen gegeneinander abgewogen und praktiziert werden, also: 
1. Wird im Falle einer verantwortungsethischen Entscheidung gegen eine fundamentale Norm im Sinne der Menschenrechte verstoßen? Wenn ja, dann muss sie unterbleiben, denn ,zu erwartende gute Folgen “ rechtfertigen nicht jedes Mittel!

2. Sind bei einer gesinnungsethischen Entscheidung die Folgen so schwerwiegend, dass die geltende Norm (z. B. der Verfassungsartikel des Elternrechts) relativiert werden muss? Wenn ja, dann müssen verantwortungsethische Momente stärker berücksichtigt werden, um den nachteiligen Folgen einer Handlung oder Unterlassung (z. B. einer Nichteinmischung) vorzubeugen.

Probleme der moralischen Entscheidung treten in der Sozialen Arbeit vor allem bei der Hilfeplanung auf, denn dabei geht es oft nicht nur um helfende Maßnahmen im Sinne materieller Unterstützung, sondern um die Verständigung über Handlungen und Verhaltensweisen der Problembelasteten und Problembeteiligten, d. h., es werden auch pädagogische Ziele und einzubaltende Normen des Handelns und Verhaltens vereinbart.

\subsection{Leitziele der Erziehung}

In der Geschichte der Pädagogik hat es in Abhängigkeit von den materiellen und sozialen Lebensbedingungen und den soziokulturellen Verhältnissen - insbesondere auch von weltanschaulichen Auffassungen - unterschiedliche Menschenbilder und dadurch bedingte allgemeine pädagogische Zielvorstellungen gegeben, die den Charakter von Leitzielen tragen. Bei den Leitzielen handelt es sich um eine Art „Kurzcharakteristik“ jener Persönlichkeitsqualitäten, die unter den aktuellen und zukünftigen Bedingungen für eine erfolgreiche persönliche Lebensgestaltung und Mitwirkung an gesellschaftlichen Entwicklungs- und Emanzipationsprozessen erforderlich sind. In Auswertung aktueller Darstellungen zur Zielproblematik in der pädagogischen Literatur lassen sich folgende Leitziele nennen:

- Souveränität,

- Vielseitigkeit,

- Mündigkeit,

- Gemeinschaftsfähigkeit,

- Toleranz.

Ihre Begründung erhalten diese Ziele durch invariante Bedürfnisse und Entwicklungspotenzen der Zöglinge selbst sowie durch die Anforderungen der transgredienten Grundlagen:

- Souveränität entspringt dem invarianten Bedürfnis nach Selbständigkeit und äußert sich im „Akt der Beherrschung seiner eigenen Angelegenheiten“ (Wessel 2005, 
S. 5). Sie basiert auf einem Spektrum von Kompetenzen und erfordert bzw. ermöglicht:

- Vielseitigkeit im Erkennen und Beherrschen der natürlichen und gesellschaftlichen Lebensbedingungen mittels Grundqualifikationen (s. Übersicht 8), die möglichst auch zur Bewältigung unvorbersebbarer Anforderungen befähigen sollen, also zur alltäglichen Flexibilität und beruflichen Disponibilität, die aus gesellschaftlichen Erschütterungen und Entwicklungen der Produktions-, Dienstleistungs-,Verkehrs- und Kommunikationsverhältnisse resultieren. Vielseitiges Erkennen und kritisches Denken begründen schließlich

- Mündigkeit im Sinne der Aufklärung (Kant 1912, S. 35ff.), um selbständig denkend und verantwortungsbewusst handelnd am gesellschaftlichen Leben möglichst gleichberechtigt zu partizipieren und es progressiv zu verändern.

- Die Gemeinschaftsfähigkeit beruht auf den invarianten Bedürfnissen nach Zugehörigkeit und Sicherheit bzw. Geborgenheit, nach Kommunikation und Partizipation; die genetisch bedingten Anlagen dafür benötigen zu ihrer Entwicklung entsprechende soziokulturelle Beqiehungen in einer Gemeinschaft sowie erfolgreiche kooperative Handlungen und konfliktlösende Kommunikationen.

- Toleranz in humanistisch definierten Grenzen ist eine Grundlage für die existenzielle Sicherheit des Einzelnen und der Gemeinschaft; aber das ist eine Einsicht, zu der bisher nur ein Teil der Menschheit durch Auswertung der Erfahrungen mit den Folgen von Intoleranz gelangt ist. Die Überzeugung mancher Personen und Gruppen von ,ihrer einzig wahren Sicht" auf Natur und Gesellschaft trübt den Blick auf die traurigen Folgen von Intoleranz. Hinzu kommt, dass Wertesysteme eine beachtliche Resisten z gegen Innovationen entwickeln (vgl. Höhler 1994, S. 119), was sich u. a. darin äußert, dass manche Menschen dazu neigen, ihre Werte auch recht aggressiv zu vertreten.

Brezinka (1994, S. 628) meint, dass die Toleranz allgemein als „Teilideal“ des Ideals „Gemeinschaftsfähigkeit“ zu betrachten ist. Das erscheint fraglich, denn er übersieht, dass Gemeinschaftsfähigkeit und Toleranz aus ganz unterschiedlichen emotionalen und rationalen Grundlagen erwachsen und daher als relativ selbständige Ideale betrachtet werden müssen. Während nämlich die Gemeinschaftsfähigkeit eine „natürliche Wurzel“ im invarianten Bedürfnis nach Zugehörigkeit hat, ist die Toleranz ein Produkt der menschlichen Vernunft. Das aus dem Überlebensbedürfnis resultierende ursprüngliche Misstrauen gegenüber dem Unbekannten und möglicherweise Feindlichen sowohl bei vielen Tieren als auch bei Menschen äußert sich in spontaner Ablehnung und in $A b$ wehrhaltungen gegenüber dem Fremden. Wird dieses gar als bedrohlich empfunden, schlägt die Abwehrhaltung leicht in Intoleranz oder gar Aggressivität um. 
Erziehung zur Toleranz ist deshalb so schwierig, weil sie die Überwindung der ursprünglichen spontanen Abwehrhaltungen gegenüber dem Fremden und möglicherweise Feindlichen bedeutet, was eine beachtliche intellektuelle und emotionale Leistung erfordert (vgl. v. Hentig 2001, Schorlemmer 2004).

Grundsätzlich kann davon ausgegangen werden, dass Kinder im täglichen Leben vieldurch Nachahmung von Handlungen und Verhaltensweisen ihrer Eltern, ihrer Mitmenschen und Fernsehlieblinge erlernen. Dabei machen sie die Erfahrung, dass nicht alles gelingt, was sie nachahmend erstreben. Die Ursache dafür kann sein, dass sie im nachahmenden Handeln nicht erkennen, ob ihre Handlungsweise tatsächlich situationsgerecht ist, weil sie schematische Übertragungen von Handlungsmustern vornehmen. Misserfolge führen naturgemäß nicht selten zu Protesten und Beschwerden, vielfach aber auch zu Verunsicherungen oder gar zur Resignation. Damit stehen die Heranwachsenden immer wieder vor der Frage: Wie sollen sie ihre persönlichen Misserfolge oder die von ihrem Handeln relativ unabhängigen Missgeschicke bewerten und verarbeiten?

Mit dieser aus vielen praktischen Lebenssituationen erwachsenden philosophischen Frage setzt sich jedes Kind, jeder Heranwachsende und jeder Erwachsenen auf seine Weise mehr oder weniger intensiv auseinander. Auf der Grundlage einer offenbar individuell angelegten Gemütsverfassung und unter dem Einfluss von Vorbildern entwickeln sich im Ergebnis dieser geistigen Auseinandersetzung bestimmte Einstellungen zum Leben, zu den Mitmenschen und zur Gesellschaft überhaupt, die sich äußern in zupackendem Optimismus oder verzagender Ängstlichkeit - um nur die beiden Extreme eines Spektrums von Positionen zu nennen, zwischen denen der Einzelne auch noch schwanken kann. Um sich die in den bisher erörterten Leitzielen genannten Persönlichkeitsqualitäten aneignen zu können, müssen die Heranwachsenden zu einer Weltsicht geführt werden, die es ihnen ermöglicht, an der Realisierung der Leitziele mitzuwirken. Es liegt auf der Hand, dass weder naiver Optimismus noch grüblerischer Pessimismus die Basis für jene anstrengenden Lernprozesse sein können, die die Leitziele erfordern. Daraus folgt: die Erzieher müssen dem Zögling bei der Beantwortung der oben formulierten philosophischen Fragen helfen, indem sie illusionäre Wunschvorstellungen kritisch reflektieren lassen, realisierbare Aufgaben stellen und Erfolgserlebnisse organisieren. Als Leitziel könnte diese Aufgabe des Erziehers mit den Begriffen Erziehung zu realistischer Lebenssicht und tatkräftiger Zuversicht umschrieben und den o. g. Leitzielen hinzugefügt werden. Die Realisierung dieses Zieles unterscheidet sich erheblich von Lernprozessen beim Erwerb physikalischen Wissens, mathematischer Fertigkeiten oder sprachlicher Fähigkeiten, denn es handelt sich um Einsichten in die Struktur und die Bedingungen des menschlichen Daseins, die oft nur unter Schmerzen - psychischen oder auch physischen - gewonnen werden können und die zudem ein ernsthaftes Ringen mit sich selbst erfordern, um auch die angemessene praktische Haltung zu 
Desillusionierungen und Enttäuschungen zu gewinnen. Es geht dabei um solche Fragen:

- Wie erkenne ich die Risiken, die nahezu bei jeder lebensbedeutsamen Entscheidung im Spiele sind?

- Wie reagiere ich auf Schicksalsschläge, die allen Risikoabschätzungen zum Trotz dennoch überraschend eintreten können?

- Was muss ich in meiner Lebensgestaltung grundsätzlich beachten und unbedingt sichern - soweit es in meinen Kräften steht - damit ich nicht in tiefes Unglück gerate?

Auf diese und ähnliche Fragen gibt es keine rezeptartigen Antworten, weil sie entsprechend ihres philosophischen Charakters auch von verschiedenen weltanschaulichen Standpunkten aus behandelt werden können. Ein religiöser Mensch wird sich in der Regel auf sein Gottvertrauen stützen, um mit Risikogefahren oder Folgen von Schicksalsschlägen fertig zu werden. Ein atheistisch bzw. philosophisch-materialistisch gesonnener Mensch wird sich vor allem selbst fragen: was kann ich mir zumuten bzw. selbst machen und was kann ich von anderen Menschen erwarten? Eine nüchterne und realistische Sicht auf bestimmte Trends in der Entwicklung von Natur und Gesellschaft sind gegenwärtig geeignet, eine pessimistische Grundstimmung oder ein Verhalten nach dem Motto „nach uns die Sintflut“ zu erzeugen. Aber solche Einstellungen und Stimmungen sind keine Grundlage für eine aktive und zielstrebige Lebensgestaltung. In diesem Punkte kann wohl nur die Position von Bloch weiterhelfen: „Es kommt darauf an, das Hoffen zu lernen. Seine Arbeit entsagt nicht, sie ist ins Gelingen verliebt statt ins Scheitern.“ (Bloch 1954, S. 13) Im Übrigen sei an dieser Stelle auf die Erörterung des Problems der positiven Perspektiven verwiesen, die im Abschnitt 5.4.2 folgt.

Gerade für Sozialpädagogen ist es wichtig, ihren Klienten zu realistischer Weltsicht und tatkräftiger Zuversicht zu verhelfen, weil sie nur dann ihre Probleme lösen können; ja mehr noch: viele ihrer Probleme resultieren gerade aus ihrer Unfähigkeit, Bedingungen und Anforderungen ihres Lebens klar zu erkennen und im Handeln zweckmäßig zu entsprechen. Oft wird die Frage gestellt: wie ist es möglich, dass ausgerechnet dieser Junge aus einem sog. guten und stabilen Elternhaus eine schwerwiegende kriminelle Handlung begeht, zum Amokschützen wird o. Ä.? Wahrscheinlich liegt gerade in der wohlbehüteten Kindheit mit mehr oder weniger starken Verwöhnungstendenzen eine wesentliche Bedingung für das deviante Handeln. Der Betreffende konnte unter seinen Entwicklungsbedingungen nicht lernen, dass nicht alle Wünsche erfüllbar sind, dass man Risiken realistisch einschätz̧en und Enttäuschungen ertragen können muss, will man sein Leben meistern. Krisen und Aufraffen zu einem Neubeginn gehören zum 
normalen menschlichen Leben und das lernt man nicht primär im Bildungssystem, sondern im realen Leben in der menschlichen Gemeinschaft.

Bollnow bietet im Rahmen seiner anthropologischen Pädagogik (1983, S. 78 ff.) einige wichtige allgemeine Anregungen und Hinweise, deren Beachtung zur Realisierung des fundamentalen Leitzieles - Realitätssinn und Zuversicht - beitragen können. Es geht dabei um die Herstellung zweckmäßiger Beziehungen zu einigen elementaren Konstituanten menschlichen Daseins, nämlich zu Raum, Zeit und Sprache.

Betrachten wir zunächst die Beziehungen des Menschen zum Raum, und zwar nicht im geometrischen Sinne, sondern im Sinne des von ibm zu erlebenden Raumes. Normalerweise wird in Europa ein Kind in einen wie auch immer gearteten familiären Raum hinein geboren, in dem es Schutz und Geborgenbeit findet; damit wird zugleich eines seiner elementarsten invarianten Bedürfnisse befriedigt. Das Kind erkundet seinen unmittelbaren Lebensraum und gewinnt dadurch Vertrauen zu ihm. Es weiß nachgerade, wo sich was befindet, d. h., es kennt die Struktur des Raumes, seine gemütlichen Ecken usw. Aus der Erkenntnis seiner Umwelt gewinnt es Vertrauen zu den Dingen, die ihm nützen. Dies erscheint zunächst banal, zumal es in einem strukturierten, d. h. „ordentlichen Raum" für ein Kind relativ einfach ist, verhaltenssteuernde Erfahrungen zu gewinnen, die das Gefühl der Sicherheit mit begründen.

Doch mit dem Übergang in ein spezielles Kinderzimmer ändert sich die Lage des Kindes: es soll lernen, auch dieses in Ordnung zu halten! Diese Forderung entspringt keineswegs nur dem Wunsch der Eltern nach Entlastung von zusätzlichen Aufräumarbeiten, sondern eigentlich einem Entwicklungserfordernis des Kindes selbst. Wenn man allerdings die Kinderzimmer vieler deutscher Familien betrachtet, kommt man nicht umhin, festzustellen, dass die Kinder in den meisten Fällen mit der Herstellung von Ordnung durch Aufräumen schlichtweg überfordert sind. Die Menge der aufzuräumenden Spielsachen kann es einfach nicht bewältigen - und das gilt auch in vielen Familien mit geringem Einkommen. Gerade deren Kinder werden nicht selten mit einer Fülle von kitschigem Billigkram überhäuft. Diese Situation ist neu und ungewöhnlich, weil sich die Mehrzahl aller Kinder über Jahrtausende hinweg mit relativ wenigen $G e$ genständen aus ihrer Umwelt ihr Spiel organisiert haben und eigens produziertes Spielzeug zumeist nur in sehr begrenzter und zu bewältigender Menge zur Verfügung stand.

Um einem Kind „Ordnung beizubringen“, muss es vor allem echte Chancen dafür bekommen, indem z. B. die Menge des Spielzeugs überschaubar und beherrschbar bleibt, was natürlich schwer fällt, weil das Angebot auf dem Markt groß ist und das Kind immer wieder etwas Neues haben möchte. Das kann im vertretbaren Maße auch geschehen, wenn dafür etwas von dem alten Spielzeug zumindest zeitweilig in einem Nebengelass aufbewahrt wird. 
Jeder Mensch braucht einen „Rückzugsraum“, in dem er sich wirklich erholen kann und sich wohl fühlt. Wenn er aber nicht gelernt hat, sich einen solchen Raum zu schaffen oder zu erhalten, wird er nicht jenen Ausgleich zu den Turbulenzen des normalen Lebensalltags finden, den er im Interesse seiner psychischen Gesundheit benötigt. Dabei geht es in der Regel nicht nur um einen einzelnen Raum, sondern um eine Wohnung oder ein Haus, in der mehrere Personen ihre Ruhe finden wollen. Bollnow bewertet die anthropologische Funktion des Hauses (hier als Synonym für eigene Wohnstätte) dahingehend,

„dass menschliches Leben nur dann gesund bleiben kann, wenn es einen solchen Raum der Geborgenheit hat, in dem der Mensch mit den Seinen, aber abgesondert von den Fremden, in Frieden und Sicherheit leben kann, in den er sich von dem »Sturm der Welt« zurückziehen und wieder zur Ruhe kommen kann, wenn er sich in den Geschäften der Außenwelt aufgerieben hat. Das Haus, so betont darum der französische Philosoph Bachelard, »hält den Menschen aufrecht alle Gewitter des Himmels und des Lebens hindurch« [...] Das Haus »ist ein Werkzeug, dem Kosmos die Stirn zubieten«. Das ist kein falscher Überrest einer vergangenen »bürgerlichen« Lebenshaltung, sondern ist im bleibenden Wesen des Menschen begründet. Es ist darum auch für die Erziehung von größter Bedeutung.[...] Die Sicherheit des Lebens beruht darauf, dass der Mensch auch im übertragenen Sinn über eine unverletzte »Intimsphäre« verfügt, die dem Blick der fremden Welt entzogen ist" (Bollnow 1983, S. 81).

Allerdings benötigt der Mensch auch der äußeren Ordnung gegenüber eine flexible oder dialektische Einstellung, denn jede totale Ordnung ist tot und das fortgesetzte oder ausschließliche Streben danach raubt die Zeit für schöpferisches Tun und Handeln, ferner gilt Bollnows Feststellung:

„Jede freie Betätigung des Lebens aber (schon im einfachsten Sinn im Gebrauch der Werkzeuge, die man nach Gebrauch schnell wieder aus der Hand legt, um für eine neue Tätigkeit frei zu sein) schafft Unordnung. Und wo diese Überhand nimmt, wird das menschliche Leben eingeengt und droht schließlich zu ersticken. Darum muss der Mensch immer wieder im Kampf mit der Unordnung die verloren gegangene Ordnung wiederherstellen; er muss »aufräumen«, weil er nur in einer aufgeräumten Welt zu leben vermag.“ (a. a. O. S. 82).

An der Richtigkeit der letzten Aussage mag man zweifeln, weil es viele Menschen gibt, die sich an ihre Unordnung gewöhnt haben oder sie lieber ertragen als aufzuräumen. Doch wäre zu prüfen, ob in Bollnows Aussage nicht doch ein wahrer Kern steckt, denn viele erfahrene Sozialpädagogen können bestätigen, dass problembelastete Familien und auch einzelne ihrer Klienten mit devianten Verhaltensweisen in sog. liederlichen oder unordentlichen Wohnungen leben, was natürlich umgekehrt nicht bedeutet, dass alle Leute, die Probleme mit ihrer äußeren Ordnung haben, deviant sind.

Wenn sich allerdings räumliche Unordnung mit ,zeitlichem Chaos“ mischt, d. h. die Unfähigkeit, den eigenen Tagesablauf zweckmäßig zu strukturieren, hinzukommt, dann 
wird es in der Regel tatsächlich bedenklich. Oerter/Montada referieren eindrucksvolle Untersuchungsergebnisse von Mulvey, Arthur \& Reppucci (1993) bezüglich der Bedeutung chaotischer Familienverhältnisse für die Entstehung von Jugenddelinquenz. (1998, S. 1033 f.). Aus diesem Grunde erscheint es zumindest bedenklich, die vielfach verbreitete Neigung von Kindern und Jugendlichen zum gedankenlosen Umgang mit der Zeit und zu Nachlässigkeiten hinsichtlich äußerer Ordnung einfach hinzunehmen. Im Grunde genommen wird diesen Heranwachsenden dadurch die eigene, selbständige Lebensgestaltung erschwert; sie bleiben in elementaren Lebensbereichen unselbständig und verharren dann am liebsten im Hotel „Mama“, in dem für sie alles geordnet wird.

Der Mensch hat aber nicht nur das Bedürfnis nach einem „Rückzugsraum“, sondern überhaupt nach einem ,vertrauten Platz im Raum“, dem ihn niemand streitig macht. Man beobachte nur einmal eine beliebige Gemeinschaft, die sich öfters trifft - sei es ein kleiner Verein, ein Lesezirkel, ein Lehrerkollegium oder eine Jugendgruppe. Man wird beobachten können, dass die Beteiligten in der Regel bestrebt sind, immer wieder „ibren Platz im Raum“ einzunehmen. Eine Veränderung erfolgt nur aus besonderem Grunde und eine versehentliche Platzbelegung durch einen anderen wird selten unkommentiert hingenommen. Offenbar ist die Befriedigung eines solchen Raumbedürfnisses, das übrigens in der Regel auch unvereinbar ist mit unzumutbarer Enge - es sei denn es gibt dafür einen besonderes emotionales Bedürfnis - für das Wohlbefinden des Menschen bedeutsam; dem sollte daher auch im Umgang miteinander Rechnung getragen werden.

Erziehung muss natürlich nicht nur zur Bewältigung der Aufgaben im eigenen Hause befähigen, sondern auch zur Bewältigung des öffentlichen Raumes. Das wird manchem Leser banal erscheinen, aber wer die Schwierigkeiten von manchen ALG II-Empfängern im Umgang mit Behörden und Ämtern kennt - vor allem jener in den neuen Bundes ländern, die auf die Eigenheiten der bundesdeutschen Bürokratie nicht gezielt vorbereitet werden konnten - weiß, wovon hier die Rede ist. Die allgemeine Schulbildung und Berufsausbildung sind nur ein Teil der Vorbereitung auf das Leben ,im öffentlichen Raum des gemeinsamen Handelns" (Bollnow) und sie erfassen nicht alles von dem, was der Bürger zur Alltagsbewältigung benötigt. Das beginnt mit der Einrichtung und Führung eines Girokontos und geht bis zum Ausfüllen einer Steuererklärung, was selbst studierte Leute lieber den Experten überlassen. Es geht um die vielfältigen juristisch geregelten Vorgänge des Alltags, die man in der Praxis erlernen muss und kann, wenn man denn nicht von vorn herein davor zurückschreckt oder davon fern gehalten wird.

Der entscheidende Bereich des Handelns im öffentlichen Raum aber ist neben der Arbeitsstelle zweifellos das weite Feld der Politik - angefangen von der Kommunalpolitik bis zur Landes-, Bundes- und Weltpolitik, von der jeder betroffen ist und an der deshalb jeder nach Maßgabe seiner Fähigkeiten auch teilnehmen sollte - sei es als Wähler 
oder Gewählter. In diesem Bereich wird wesentlich über die Lebensbedingungen jedes Einzelnen mit entschieden und daher sollte auch ein Kind schon frühzeitig daran gewöhnt und vor allem ermutigt werden, seine Anliegen und seine Meinung auch in der Öffentlichkeit - also auch fremden Menschen gegenüber - in gehöriger Form zur Sprache zu bringen. Kein Mensch kann hinsichtlich aller Anforderungen der Öffentlichkeit vorbereitend trainiert werden, aber er muss lernen, sich die notwendigen Informationen zu beschaffen und sich in seinem Selbstbewusstsein so weit stärken, dass er seine berechtigten Ansprüche gegen andere - auch möglichen Widerständen zum Trotz - vertreten kann und durchzusetzen versucht. Kurz gesagt: es muss Zivilcourage erwerben, um mit den Anforderungen des „Außenraumes“ (Bollnow) klar zu kommen.

Der Außenraum des öffentlichen Lebens umfasst jedoch den Lebensraum des Menschen noch nicht vollständig:

„[...] hinter dem öffentlichen Raum des gemeinsamen Handelns tut sich, ohne dass sich eine feste Grenze angeben ließe, noch ein neuer Raum auf: die weite Welt der fremden Gegenden und fernen Länder, die ganze lockende Ferne, die den Menschen mit unwiderstehlicher Gewalt anzieht. Auch dieser Bereich gehört als konstituierender Bestandteil mit zum konkreten menschlichen Raum und fordert vom Menschen die Erfüllung seiner Ansprüche. Hier entwickelt sich wiederum eine ganz andre Haltung, eine ganz neue innere Verfassung des Menschen, und mit ihr wieder neue Tugenden: die Kühnheit des Ausgreifens in die unendliche Weite des Raums, die fröhliche Zuversicht und das Vertrauen in die eigenen Kraft. War der politische Einsatz durch die Schwere der Verantwortung bestimmt, die der Mensch zu tragen hatte, so genießt er hier das Ausbrechen aus den gewohnten Bahnen“ (Bollnow a. a. O. S. 86)-

In diesen Zeilen werden die Grenzen der von Bollnow vertretenen anthropologischen Sichtweise auf „den Vorstoß ins Weite“ deutlich: Bezugspunkt seiner Betrachtung bildet ausschließlich das Bedürfnis der Menschen, das „mit unwiderstehlicher Gewalt“ in die Ferne drängt - die Folgen für die Natur, d. h., die menschheitsbedrohlichen Umweltschäden, die aus den $\mathrm{CO}_{2}$-Emissionen der vielen Flugreisen resultieren, werden überhaupt noch nicht gesehen; sie waren zur Zeit der Abfassung seiner Schrift wohl auch noch nicht hinreichend in das öffentliche Bewusstsein gedrungen. Die neuere dialektisch-materialistische Sichtweise dagegen sieht zwar auch den Menschen mit seinem „Fernweh“ und schätzt den Wert von Vorstößen in die Räume des Unerforschten aber immer unter dem Aspekt der natürlichen Grundlagen der Gesellschaft; sie versucht dieses Problem einzuordnen in das Gesamtsystem der menschlichen Existenz-bedingungen und ihrer Bewahrung, d. h., Erziehung zur realistischen Lebenssicht fordert verstärkt die Entwicklung ökologischen Bewusstseins, das mit der Bereitschaft zumVerzicht verknüpft ist. Die Befriedigung des Fernwehs muss mit umweltverträglichen Mitteln erfolgen, auch wenn das den Fluglinien-Unternehmen nicht gefällt und die Er- 
folgsaussichten der Pädagogik vorläufig nicht sonderlich hoch sind. Aber wenn die Gesellschaft nicht zur Zucht und Selbstzucht zurückfindet, wird die Natur sie „zü̈htigen“.

In seiner abschließenden Erörterung zur Wichtigkeit der drei Raumdimensionen - Innenraum, Außenraum und Weite - betont Bollnow die Notwendigkeit eines Gleichgewichts im Verhältnis der Besetzung dieser Räume durch den Menschen in seiner Bedeutung für eine gesunde Persönlichkeitsentwicklung. Dabei verweist er auf die historischen Schwankungen in der Sichtweise und Wertschätzung der einzelnen Räume:

„War es seinerzeit, als der Wandervogel aus der Enge des häuslichen Lebens ausbrach, die unendliche Weite, die dem Bewusstsein verlorengegangen war, so scheint heute eine entgegengesetzte Gefahr zu drohen: dass das Bewusstsein der Wichtigkeit des Hauses und der Würde des privaten Raumes in einer verhängnislosen Weise verloren gegangen ist. Darum gilt es heute, das Recht des privaten häuslichen Lebens wieder zu betonen, weil hier allein die Wurzeln zu suchen sind, die dem Menschen einen Halt geben gegenüber dem Versinken im Massendasein“ (a. a. O. S. 88).

Dabei übersieht er keineswegs, das auch dieser private Raum des Hauses keine vollständige Sicherheit gewähren kann in einer von Kriegen und Krisen geschüttelten Welt. Aber die Geschichte zeigt, dass nach allen Katastrophen die Menschen sich immer wieder aufgerafft und ihr Haus neu erbaut haben, worin sich zweifellos die im Abschnitt 4.3.1 erörterten invarianten Bedürfnisse äußern.

Das Erleben von Zeit und das Erkennen ihrer Bedeutung für das eigene Leben ist mit vielfältigen Erziehungsaufgaben verbunden. Die Bedeutung von Zeit für die Entstehung devianter Verhaltensweisen wurde bereits an verschiedenen Stellen sichtbar, etwa wenn von ,aggressiver Langeweile“ (3.2.1) oder von gestressten und von ihrer Arbeit total beherrschten Arbeitern und Managern (3.2.3) die Rede war. Langeweile oder Zeitnot und Zeitdruck sind nur einige Begriffe, die auf den anthropologíschen Aspekt des Zeitproblems verweisen. Darüber hinaus gibt es das, was umgangssprachlich mit „,innerer Uhr“ des Menschen angedeutet wird und hinter dem das auch humanbiologisch bedeutsame Forschungsgebiet der Chronobiologie steht, die sich mit dem zeitlichen Verlauf bzw. den Rhythmen der verschiedenen Lebensprozesse beschäftigt.

Aus anthropologischer Sicht erscheinen folgende Erziehungsaufgaben bedeutsam, die darauf abzielen, ein ,richtiges Verhältnis zur Zeit““ zu entwickeln:

1. Zum Umgang mit er Zeit:

- Zweckmäßiger Gebrauch der Zeit und sinnvolle Zeiteinteilungen im Tages- und Wochenverlauf, möglichst aber auch darüber hinaus,

- Intensive Nutrung günstiger Zeiten und Zeitgewinn durch vernünftige Planung,

- möglichst Zeitverschwendung vermeiden, 
- Eile und Geduld je nach den objektiven Erfordernissen der jeweiligen Situation,

- den richtigen Zeitpunkt erkennen und etwas zur rechten Zeit tun, wobei sowohl die objektiven Handlungsbedingungen als auch die Erkenntnisse der Chronobiologie berücksichtigt werden sollten.

2. Zum Verhältnis zur Vergangenheit:

- Sich nicht von der Last der Vergangenheit erdrücken lassen.

- das Positive aus der Vergangenheit aufwerten, ohne die Lehren aus den negativen Erfahrungen zu vergessen,

- die Vergangenheit in ibrer Bedeutung für die Gegenwart und den persönlichen Entwicklungsfortschritt betrachten und bewerten.

3. Zur Verhältnis zur Zukunft:

- Zukunftsbewusstsein in dem Sinne entwickeln, dass nicht bloß, ,in den Tag hinein gelebt" wird, auch wenn Zukunftsplanungen objektiv schwierig sind, weil der Einzelne nicht beliebig die Realisierungsbedingungen seiner Pläne bestimmen kann,

- Bemühungen um realisierbare Zukunftspläne initiieren,

- Lernen, mit Unsicherheiten ž leben - auch bei „Fehlplanungen“ nicht den Mut verlieren oder die Hoffnung aufgeben.

Eines der offenbar schwierigsten Probleme in der Zeitnutzung besteht darin, dass die Erkenntnisse der Chronobiologie beispielsweise bezüglich des Schlafbedarfs von Kindern und Jugendlichen oder der optimalen Leistungszeiten entweder gar nicht bekannt sind oder z. B. von den verantwortlichen Schul- und Unterrichtsplanern schlichtweg ignoriert werden. So ist erwiesen, dass erst gegen neun Uhr die Schulkinder die für einen erfolgreichen Unterricht erforderliche Wachheit und geistige Konzentrationsfähigkeit besitzen - auch wenn sie abends zu normaler Zeit zu Bett gegangen sind; aber das hindert die Schulplaner nicht daran, den Unterricht zuweilen schon vor 8 Uhr beginnen zu lassen, wobei hinzukommt, dass die Kinder auf dem Lande schon seit 7 Uhr oder noch früher mit dem Schulbus unterwegs gewesen sind. Hier zeigt sich die absolute Dominanz ökonomischer Faktoren gegenüber pädagogischen und lernpsychologischen Erfordernissen oder die übergreifende Wirkung der transgredienten Grundlagen zum Nachteil der Erziehung.

Andererseits kann nicht übersehen werden, dass durch das Fernsehen bis tief in die Nacht hinein die innere Uhr der Betreffenden zusätzlich belastet wird, was zu Schlafstörungen und damit verbundenen Minderungen in der Leistungsfähigkeit führt. Auch an diesen weit verbreiteten Lebensgewohnheiten wird deutlich, dass die Erziehung zu einem richtigen Verhältnis zur Zeit von großer Bedeutung ist. 
Das Erlernen der Muttersprache ist ein alltäglicher Prozess, der vielfach keine besondere Beachtung erfährt, sofern er sich ohne besondere Auffälligkeiten und Schwierigkeiten vollzieht. Im Kindergarten und vor allem in der Schule wird sodann dem grammatisch richtigem Sprechen die erforderliche Aufmerksamkeit geschenkt und natürlich dem Erlernen der schriftlichen Kommunikation. Kommt dann ein Fremdsprachenunterricht dazu, steigen die Anforderungen im Sprechen Lernen. Aber die Erziehungsaufgaben, die sich aus den allgemeinen Funktionen der Sprache und dem verantwortlichen Umgang mit ihr ergeben, bleiben vielfach unberücksichtigt bei jenen Kindern und Jugendlichen, die viel vor Bildschirmen hocken und daher wenig direkte, differenzierte, mündliche Kommunikationen üben.

$\mathrm{Zu}$ den allgemeinen Funktionen der Sprache gehört zunächst und vor allem, dass sie ein Mittel der Verständigung ist. Aber was heißt das? Zunächst geht es darum, dass das heranwachsende Kind, mit Hilfe sprachlicher Laute seine Wünsche gegenüber seinen Pflegern, Erziehern und Mitmenschen zum Ausdruck bringt und dabei zugleich jene Gegenstände benennt, die es haben möchte. Benennen der Umwelt (der umgebenden Personen und Sachen) und Herstellung von kommunikativen Beziehungen mit all ihren Wirkungen und Folgen - das sind wohl die beiden Hauptfunktionen, auf deren Bewältigung das Erlernen des Sprechens orientiert sein muss.

Zwar nimmt ein Kind verschiedene Seiten seiner Umwelt mit seinen Sinnen wahr, aber was es wahrnimmt, wird mit den Wörtern der Sprache, die es erlernt, bezeichnet und vielfach lernt es Wörter, deren objektives Korrelat es kaum oder gar nicht kennt. Die Wortbedeutung erschließt sich dem Kind bzw. Heranwachsenden erst nach und nach. Die Wortbedeutungen, die es aus dem Wortgebrauch im täglichen Umgang erschließt, prägen dann auch seine Vorstellungen von den Personen und Dingen, über die es spricht. Das bedeutet: die Vorstellungswelt und das „Erkenntnissystem“ des Menschen wird wesentlich bestimmt vom Inhalt der Sprache bzw. den Bedeutungen der Wörter, die er lernt und nicht unbedingt von dem, was er wahrnimmt oder auch gar nicht wahrnehmen kann. So lernt er über Gott und Engel oder über Atome und elektromagnetische Wellen zu reden, ohne sie je mit seinen Sinnen wahrgenommen zu haben. Aber nicht nur dass er darüber spricht, ist wesentlich, sondern dass viele solche Wörter und damit verbundene Reden sein Denken und Handeln bestimmen. Mit Hilfe der Sprache wird die Welt also nicht nur benannt und mehr oder weniger adäquat erkannt, sondern zugleich gedeutet. Das heißt: mit Hilfe der Sprache schafft sich der Mensch sein Weltbild. Das allein lässt schon etwas von der „Macht es Wortes“ ahnen. Betrachten wir nun noch die Macht des gesprochenen Wortes im Hinblick auf zwischenmenschliche Beziebungen, um deren Gestaltung es ja in der Erziehung und im gesellschaftlichen Leben wesentlich geht, dann werden folgende erziehungsrelevante Aufgaben deutlich: 
Sprache und Sprechen bestimmen wesentlich Qualität und Charakter der zwischenmenschlichen Beziehungen, denn im Sprechen und Schweigen äußert oder verbirgt der Mensch seine Meinung, je nachdem, ob er offen oder verschlossen ist und die Wahrheit sagt oder nicht. Auch eine Schweigen kann etwas Aussagen, denn „man kann nicht nicht kommunizieren" lautet das erste Axiom der Kommunikationspsychologie von Watzlawick (vgl. Altenthan u. a. 1992, S. 316). Von seiner Offenheit und dem Wahrbeitsgehalt seiner Äußerungen hängt die Berechenbarkeit eines Menschen ab und damit auch im hohen Maße seine Vertrauenswürdigkeit. Natürlich macht sich ein Mensch durch sein Sprechen angreifbar und verwundbar, weil er möglicherweise eine abweichende Meinung äußert oder eine Handlung offenbart, die dann kritisiert wird. Daher wird er mit Rücksicht auf den Wert der Beqiehung seine Worte wählen und zugleich zu vermeiden suchen, dass sie andererseits durch Heuchelei oder Heimlichkeiten belastet wird.

1. Ferner bestimmen Rede- und Kommunikationsstil ganz wesentlich den Charakter zwischenmenschlicher Beziehungen, d. h., ob jemand in einem Tonfall spricht, der keinen Widerspruch duldet und durch ständige Kontrollfragen seine Herrschaft über seine Gesprächspartner zu sichern trachtet oder ob jemand mit seinen Vorschlägen dem anderen Möglichkeiten zu eigener Meinungsbildung und Entschließung zugesteht, ist praktisch höchst bedeutsam. Ein zweckmäßiger partnerschaftlicher Stil soll und kann im täglichen (erzieherischen) Umgang geübt werden, ohne dass man dazu unbedingt alle Erkenntnisse der Kommunikationspsychologie heranziehen muss. Ein Sozialpädagoge sollte sie natürlich kennen und in seiner Tätigkeit beherzigen.

2. Durch die Sprache kann man andere beglücken oder verletzen, deshalb muss jeder Mensch zur zweckmäßigen bzw. angemessenen Wortwahl befähigt werden. Gespräche werden im Allgemeinen dann als bereichernd und beglückend empfunden, wenn sie wertvolle Mitteilungen enthalten und/oder positive Bewertungen der Gesprächspartner einschließen. Beglückende Gespräche fördern zwischenmenschliche Beziehungen, und zwar in einem solchen Maße, dass dann in der Regel auch kritische Worte von dem Kritisierten mit Gewinn verkraftet werden. In jedem Falle aber sollte man verletzende Äußerungen vermeiden - selbst dann, wenn kritische Wertungen im Interesse der Beziehungen und des Gelingens eines gemeinsamen Vorhabens notwendig sind. Auch im Zorne ausgesprochene Beleidigungen sind im Allgemeinen eine schwere Belastung für die jeweilige Beziehung und den Beleidigten selbst - gerade darin zeigt sich die zerstörerische Macht des Wortes.

3. Durch Reden offenbart und verpflichtet sich der Mensch, d. h., so lange er in Gedanken abwägt, was er zu tun und zu lassen gedenkt, verbleibt er noch im Unbestimmten. Bollnow bemerkt dazu:

„Aber auch der Mensch selber wandelt sich unter dem Einfluss des von ihm ausgesprochenen Worts. Was unausgesprochen in der Seele des Menschen geschieht, ist noch nicht im 
vollen Sinne da; es ist noch unbestimmt und ungegliedert, ist noch beliebiger Umdeutungen und Verfälschungen fähig. Erst wenn es vor einem andern ausgesprochen wird, ist es da, ist es wirklich, und kann nicht mehr aus der Welt geschaffen werden. Der Mensch kann bei seinem Wort genommen werden und muss zu seinem Wort stehen. Dieser Vorgang, durch den der Mensch durch sein Wort festgelegt wird, hat eine entscheidende Bedeutung für die Aus bildung der sittlichen Persönlichkeit, des Selbst im strengen Sinn des Worts: erst durch die Leistung der sprachlichen Fixierung gewinnt der Mensch die Festigkeit eines verantwortlichen Selbst“ (a. a. O. S. 105).

4. Hat ein Mensch sich erklärt, muss er zu seinem Wort stehen, wenn er ernst genommen werden will. Damit steht er besonders bei Versprechen vor der Frage: kann ich das Versprechen halten, das ich jetrt abgebe? Bollnow weist aber auch darauf hin:

„Über seine eigenen Stimmungen und Gefühle z. B., aber auch über seine Meinung darf der Mensch keine Versprechungen für die Zukunft abgeben; denn er weiß nicht, ob er zu einem späteren Zeitpunkt anders fühlt oder eine bessere Erkenntnis gewonnen hat. Aber hinsichtlich dessen, was der Mensch tun oder nicht tun kann, darf er Versprechungen geben und muss sie dann erfüllen, weil das (sofern er nicht durch »höhere Gewalt« verhindert ist) in seiner Macht steht“" (a. a. O. S. 107).

5. Der Mensch äußert sich nicht nur in Gesprächen - er verinnerlicht dabei auch zugleich etwas aus der Welt: nämlich die Erfahrungen, Erkenntnisse, Probleme und Meinungen bzw. Werturteile seiner Gesprächspartner - vorausgesetzt allerdings, er vermag zuzuhören. Das Zuhören-Können und das Vertreten der eigenen Meinung sind daher höchst wichtig für den Erkenntnis bereichernden und beziehungsfördernden Wert von Gesprächen und damit für das Zusammenleben überhaupt. Der Wert von echten Dialogen im Erkenntnisprozess und im Prozess der Gestaltung friedlicher Beziehungen zwischen den Menschen kann kaum überschätzt werden und eben deshalb kommt der sprachlichen Befähigung des Menschen im Erziehungsprozess enorme Bedeutung zu. Oft ist es gerade die Unfähigkeit zur verbalen Bearbeitung von Konflikten, die sich dann in aggressiven Gewalttätigkeiten äußert.

Mit diesen Hinweisen zu den Leitzielen der Erziehung soll dieses Kapitel abgeschlossen werden, obgleich es damit keineswegs erschöpfend behandelt worden ist. Auch kann man über die Zweckmäßigkeit der Systematisierung streiten, da die im letzten Abschnitt behandelten Ziele wegen ihrer fundamentalen Bedeutung für die weitere Existenz der Menschheit (z.B. Klimakatastrophe) und die „zweite Geburt des Menschen" ebenso gut an die Spitze oder den Anfang der Leitziele gerückt werden könnten. Doch entscheidend ist in diesem Falle nicht die Position der Problematik in der Gliederung, sondern ihre Berücksichtigung in der Praxis, und das dürfte aus der Art der Darstellung deutlich geworden sein. 


\subsection{Zur Erarbeitung und Nutzung konkreter Erziehungsziele}

Bei der Durchsicht pädagogischer Schriften zur Zielproblematik fällt auf, dass von allen Autoren pädagogische Ziele als Orientierungshilfen für die Gestaltung von Erziehungs- und Unterrichtsprozessen betrachtet werden. Unterschiede gibt es allerdings hinsichtlich der Gewinnung dieser Orientierungshilfen und ihrer Nutzung im Prozessverlauf. Die Zielbestimmung erfolgt in Abhängigkeit vom Charakter des zu gestaltenden Prozesses auf unterschiedliche Weise. Im Bildungssystem ist es üblich, ganze Systeme von fachbezogenen und klassenstufenbezogenen Teilzielen $\mathrm{zu}$ formulieren und den sog. Stoffplänen in Rahmenrichtlinien oder Lehrplänen voran zu stellen. Es wird dabei von gesellschaftlich notwendigen oder für notwendig erachteten „Soll-Vorstellungen“ ausgegangen und eine bestimmte Lernfähigkeit der Lernenden bzw. eine Leistungsfähigkeit der schulischen Institutionen unterstellt. Eine unzureichende praktische Erprobung der Pläne führt vielfach zu Überforderungen mit entsprechenden Folgen.

In der sozialpädagogischen Praxis erfolgt keine weit vorausschauende und dem Prozess vorgelagerte Planung, wie sie für das Bildungssystem charakteristisch ist, obgleich angesichts der Geschwindigkeit gesellschaftlicher Veränderungsprozesse die Frage auftaucht, was das denn konkret bedeutet? (vgl. v. Hentig 2001, S. 21ff.). Angesichts der „Offenheit der Zukunft" und eines unübersehbaren Wertewandels wird es zunehmend schwieriger, Ziele zu formulieren, die den zukünftigen Anforderungen an die Absolventen der verschiedenen Bildungseinrichtungen tatsächlich entsprechen.

In der Sozialpädagogik sind psychosoziale Notlagen der Ausgangspunkt aller pädagogischen Überlegungen und damit steht eine oder gar die Grundfrage der persönlichen Lebensgestaltung im Zentrum aller Bemühungen: Wie kann ich auf legale Weise und hinreichendem Niveau meine materiellen und sozialen Lebensgrundlagen sichern, um mir damit günstige Möglichkeiten meiner geistig-kulturellen Entwicklung und Lebensweise zu eröffnen? Es geht darum,

- die Problembelasteten so zu motivieren und zu befäbigen, dass sie relativ selbständig die materiellen und sozialen Bedingungen ibrer individuellen Existenz sichern und

- zugleich entsprechend ihren Möglichkeiten ihre Bildung vervollkommnen

- sowie einen Beitrag zur Reproduktion und progressiven Veränderung der Gesellschaft im Sinne von Humanität und sozialer Gerechtigkeit leisten können.

Ausgangspunkt sozialpädagogischer Zielüberlegungen sind also soziale Probleme, die zweckmäßig gelöst werden müssen. So muss z. B. einer überschuldeten und von Exmittierung bedrohten Familie zunächst einmal geholfen werden, die Wohnung zu behalten, weil vor allem die Kinder ibre Häuslichkeit benötigen; aus diesem Grunde sind Verhandlungen mit dem Vermieter und den Gläubigern notwendig. Dabei lässt sich der 
Sozialarbeiter von sozialen Zwecken leiten, die sowohl ihre gesellschaftlichen als auch individuellen Aspekte besitzen.

Aber natürlich müssen die Ursachen der Überschuldung bzw. der versäumten Mietzahlungen ermittelt werden und diese haben unter den Bedingungen des sozialen Netzes in Deutschland in der Regel etwas mit einem unbedachten oder gar chaotischen Umgang mit dem verfügbaren Geld zu tun, also mit spezifischen menschlichen Schwächen, zu deren Überwindung es gezielter sozialpädagogischer Maßnahmen bedarf, angefangen von der Anleitung zur Haushaltsplanung über die Fübrung eines Haushaltsbuches bis zur Selbstüberwindung beim Zurückstellen von Wünschen, um auch die vereinbarten Ratenzahlungen zwecks Schuldentilgung zu gewährleisten.

Dabei müssen alle an Geldausgaben aktiv beteiligte Familienmitglieder in den sozialpädagogischen Prozess einbezogen werden. Jeder muss seine individuellen Grenzen für Geldausgaben kennen, die vereinbart und hinsichtlich ihrer Verwirklichung zumindest über die Zweckrealisierung kontrolliert werden. Das schließt u.a. eine bestimmte Qualität der Kommunikation und der sozialen Beziehungen ein, die Gegenstand sozialpädagogischer Bemühungen sind. Sozialpädagogische Erfolge bei der Entwicklung einer rationellen Wirtschafts- und Lebensweise der Familie sind nicht nur für jedes Familienmitglied individuell bedeutsam, sondern haben gesellschaftliche Auswirkungen, auch wenn sie gering erscheinen mögen. Die Zweckerfüllung - also die Schuldentilgung bzw. -vermeidung und die Regelmäßigkeit der Mietzahlungen - ist zugleich ein Gradmesser der Zielrealisierung, allerdings kein absolut zuverlässiger, denn es könnte die Schuldentilgung ja durch begünstigende Zufälle realisiert worden sein (z. B. Lottogewinn).

Im Aufgabenbereich der Sozialpädagogik werden den Akteuren also nicht wie im Bildungswesen langfristig konzipierte Zielsysteme vorgegeben - vielmehr müssen sie diese im Prozessverlauf selbst konkret ermitteln und formulieren. Das geschieht im Zusammenhang mit der Analyse der Problemsituation, d. h. in den Funktionseinheiten Aufschließen und Aufklären (siehe Abschnitte 6.3.1 und 6.3.2), und zwar durch die Ermittlung der persönlichen Defizite im Handeln und Verhalten der Hilfebedürftigen, die als „,subjektive Seite“ der festgestellten Probleme angesehen werden können. Als solche persönliche Schwächen oder Formen regressiven devianten Verhaltens treten u. a. folgende Normenverstöße auf:

- Anmaßendes, rücksichtsloses und gewalttätiges Verhalten gegenüber Schwächeren oder Jüngeren (einschließlich Erpressungen);

- Ausweichverhalten gegenüber schulischen Lernanforderungen oder Arbeitsanforderungen (Bummelei);

- Diebstahl in Kaufhallen, Handtaschenraub usw.;

- exzessives Spielen am Computer; 
- Aggressivität und Gewalttätigkeit gegen Fremde bzw. „Andersartige“;

- übermäßiger und schließlich süchtiger Genuss von Drogen;

- Unfähigkeit, rationell mit Geld umzugehen.

Aus den jeweiligen „Fehlleistungen“ kann auf jene Mängel und Schwächen in der Persönlichkeitsentwicklung geschlossen werden, die es ₹u überwinden gilt. Dazu ist es erforderlich, dass die mit den Defiziten korrespondierenden Teilziele ermittelt werden, deren Realisierung zur Überwindung der erkannten Schwächen beitragen. In Anbetracht der komplizierten Struktur und Determination der Defizite sind bestimmte Persönlichkeitsqualitäten und die sie bedingenden äußeren Faktoren zu verändern. Nach Möglichkeit sind durch geeignete Maßnahmen die Entstehungsbedingungen für deviantes Verhalten zu beseitigen oder zumindest in ihrer Wirksamkeit zu reduzieren. Unter dem Aspekt der jeweiligen Erscheinungsformen der Devianzen müssen aber auch arbeitsfeldspezifische pädagogische Ziele anvisiert werden. So sind etwa bei allen Formen und Anzeichen von Suchtkrankheiten entsprechende Abstinenzziele zu formulieren, bei der Neigung zu Gewalttätigkeiten Ziele im Bereich der Konfliktfähigkeit und Selbstbeherrschung usw.

Im Unterschied zu Unterrichtsprozessen ist für die Planung und Gestaltung sozialpädagogischer Prozesse wesentlich, dass es kein vorgegebenes Zielsystem und keinen darauf basierenden Stoffplan gibt, der „umgesetzt“ werden muss. Das Vorgehen in sozialpädagogischen Prozessen weist Besonderheiten auf, die sich im Funktionsmodell (siehe Abschnitt 6.3) widerspiegeln und die sich in der prozessimmanenten Planung mit der darin eingeschlossenen Zielbestimmung, Zielpräzisierung oder auch Zielkorrektur ausdrücken.

Der allgemeine Charakter soziokultureller Normen, die historische Tatsache des Normenwandels und die Einmaligkeit jeder moralischen Entscheidungssituation erfordern von dem Sozialpädagogen, dem Problembelasteten, den Problembeteiligten und hinzugezogenen Experten, dass sie über die Ziele (und über die in ihnen enthaltenen Normen!) eine gründliche Beratung im Sinne eines Diskurses durchführen. Diese dienen dazu, dass sich die Beteiligten über die Problemsituation und den Problemlösungsprozess verständigen, d. h.:

1. Klarbeit über die Probleme und ihre möglichen Ursachen erlangen,

2. die Ressourcen für die Problemlösung ermitteln,

3. die konkreten realisierbaren Ziele vereinbaren,

4. die wichtigsten Maßnahmen für die Zielrealisierung bestimmen und

5. Festlegungen treffen zu den Kontrollterminen im Problemlösungsprozess.

Bei der Erarbeitung der spęiellen pädagogischen Ziele für die Problemlösung dienen die Ergebnisse der Problem- und Situationsanalyse, speziell die ermittelten Defizite, und die allgemeinen pädagogischen Zielvorstellungen als Grundlagen der konkreten Zielbestimmung. Es werden durch Vergleich zwischen den festgestellten Persönlichkeitsqualitäten und den zur Pro- 
blemlösung eigentlich notwendigen eben jene noch fehlenden oder unzureichend entwickelten ermittelt, die dann als Teil- und Etappenziele (ausgedrückt in notwendigen Verhaltens- und Handlungsweisen bzw. entsprechenden Normen) im Hilfeplan ihren Niederschlag finden. Auf diese Weise erfolgt auch eine prozedurale Legitimation, die sich von den anderen wesentlich dadurch unterscheidet, dass die Beteiligten in einer Beratungsprozedur bedingungsadäquate und realisierbare Ziele finden, vereinbaren und nötigenfalls auch irreale Zielvorstellungen korrigieren. Bei der Ermittlung gültiger und verbindlicher moralischer Normen und Ziele in sozialpädagogischen Hilfeplanungen kann (unabhängig von der Diskussion um das Wahrheitskriterium für wissenschaftliche Aussagen) auf die Regeln zurückgegriffen werden, die Jürgen Habermas für den „herrschaftsfreien Diskurs"bzw. für die ,ideale Sprechsituation" formuliert hat:

„1. Teilnahmeberechtigt an einem Diskurs ist jeder Sprachfähige in völliger Gleichberechtigung mit allen anderen Diskursteilnehmern. 2. Weder von außen noch von innen darf auf den Verständigungsprozess irgendein Zwang ausgeübt werden, zugelassen im »herrschaftsfreien Diskurs« ist allein der "zwanglose Zwang des besseren Arguments« (Habermas). 3. Die Diskursteilnehmer dürfen sich demgemäß allein von dem Motiv der kooperativen und der argumentativen Konsensfindung leiten lassen; vorauszusetzen sind also Gutwilligkeit (d. h. Anerkennung des besseren Arguments) und Wahrhaftigkeit (d. h. Übereinstimmung der Äußerungen mit der eigenen Überzeugung). 4. Die Diskursbeiträge unterliegen der Forderung nach sprachlicher Verständlichkeit und logisch-pragmatischer Richtigkeit (d. h. Übereinstimmung mit den traditionellen Regeln der Logik und den kontextuellen Regeln der Kommunikation)“ (Schülerduden „Philosophie“ 2002, S. 97).

Ein sozialpädagogisches Beratungsgespräch ist kein „herrschaftsfreier Diskurs“, weil die beteiligten Experten mit ihrer Kompetenzüberlegenheit als Autoritäten gelten. Ihre Auffassungen haben gegenüber denen der Problemblasteten und Problembeteiligten von vorn herein ein größeres Gewicht. Dennoch sollten die Regeln so weit wie möglich beachtet werden, denn entscheidend ist, dass die Klienten ihre Meinung in den Beratungs- und Entscheidungsprozess einbringen, weil von ihrem Einverständnis im hohen Maße ihr Engagement für die Problembewältigung abhängt.

Für die Erarbeitung gültiger und realisierbarer Normen psychosozialer Intensiverziehung gilt auch das Universalisierungsprinzip (aber unter Berücksichtigung individueller Kompromisse): „Eine strittige Norm kann unter den Diskursteilnehmern nur dann Zustimmung finden, wenn diese zu einem begründeten Konsens darüber gelangen, daß das ihr zugrunde liegende Interes se verallgemeinerungsfähig ist (Hervorhebung durch W. N.). Nicht konsensfähig sind daher Normen, die nur partikulare Interessen betreffen. Hinsichtlich einander widerstreitender partikularer Interessen kann lediglich ein Kompromiss durch kluges Verhandeln erzielt werden“ (Schülerduden „Philosophie“ 2002, S. 98). 
Als methodische Hilfe für ein systematisches Vorgehen bei der konkreten Zielbestimmung kann die nachfolgende Übersicht zu Grundqualifikationen dienen, deren Angaben vor allem auch auf die Überwindung feststellbarer Defizite bei Problembelasteten orientieren:

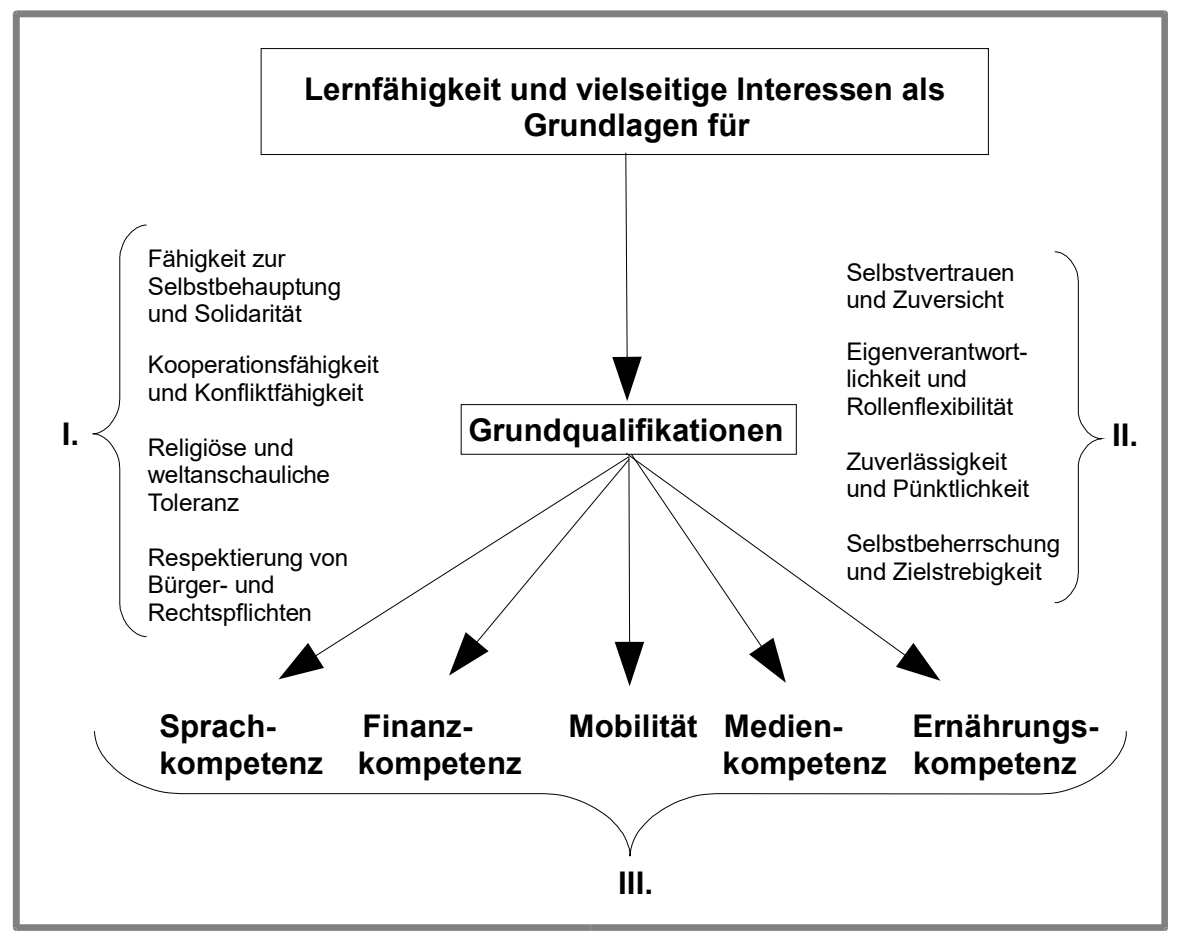

Übersicht 8

\section{Erläuterungen:}

I. Ziele im Bereich der Entwicklung von Sozialkompetenz.

II. Ziele im Bereich der Entwicklung von Selbstkompetenz.

III. Ziele im Bereich der Entwicklung von Sachkompetenzen

Zu den grundlegenden Sachkompetenzen gehören:

Sprachkompetenz umfasst für deutsche Staatsbürger die Fähigkeit zur Kommunikation sowie zum Lesen und Schreiben in der deutschen Landessprache und außerdem die Beherrschung der betreffenden nichtdeutschen Muttersprache bei nationalen Minderheiten in der Bundesrepublik (dänisch. sorbisch, türkisch usw.).

Finanzkompetenz umfasst die Fähigkeiten zum Rechnen, zum haushälterischen Wirtschaften, zur Kontenführung und Bedienung von Geldautomaten sowie ein elementares Verständnis für Kredit- und Steuerangelegenheiten. 
Mobilität umfasst im vorliegenden Zusammenhang die Fähigkeiten zum Lesen von Fahrplänen, zur Bedienung von Fahrkartenautomaten sowie zum Radfahren und möglichst auch zum Autofahren.

Medienkompetenz umfasst die Fähigkeiten zur Bedienung von Rundfunk- und Fernsehgeräten sowie Recordern, zur Bedienung von Handys und Personalcomputern sowie zum verantwortungsbewussten Umgang mit Medienangeboten.

Ernährungskompetenz zielt vor allem auf eine gesunde Ernährung und den vernünftigen Umgang mit Genuss- und Rauschmitteln - schließt also eine diesbezügliche Risikokompetenz mit ein.

Natürlich bedarf es außer diesen allgemeinen Sachkompetenzen zahlreiche spezielle, die für die Lebensgestaltung, insbesondere für das Berufsleben nötig sind.

Das auf Seite 117 dargestellte Funktionsmodell (Schema 7) ist geeignet, funktionale Zusammenhänge zwischen den immanenten Momenten zu verdeutlichen, wobei besonders die Rolle des Ziels als „Führungsgröße“ oder Orientierungshilfe im Erziehungsprozess erkennbar wird. Demnach lässt sich sagen: pädagogische Ziele dienen

- der Vermittlung von Erfordernissen der transgredienten Grundlagen an den pädagogischen Prozess, d. h., die erzieherischen Kräften müssen wesentliche und auch widersprüchliche Anforderungen der gesellschaftlichen Praxis an jeden ihrer Zöglinge unter Berücksichtigung von deren berechtigten Bedürfnissen und Interessen sowie realen Möglichkeiten in Form von Zielvorstellungen erfassen, damit sie erkennen, welche Qualitätsmerkmale die Resultate ihrer Erziehung aufweisen sollen;

- als Mittel zur Auswabl geeigneter Erziehungs- bzw. Bildungsinhalte sowie geeigneter Methoden und Organisationsformen der Prozessgestaltung;

- als Motive für den angestrebten Lernprozess, wozu es notwendig ist, dass sie entsprechende sprachliche Fassungen erhalten und so in reale Lebenskontexte bzw. Anforderungssituationen eingebettet werden, dass sie dem Lernenden als erstrebenswert erscheinen;

- als Maßstäbe im Prozess der Resultatsbewertung (= Ziel-Resultats-Vergleich), deshalb müssen die Leitziele in überschaubare Grob- und Feinziele bzw. Teilund Etappenziele aufgegliedert oder durch Beispielhandlungen so verdeutlicht werden, dass sie als Maßstäbe praktikabel sind.

Zielbestimmung ist nur ein „Schritt“ oder Moment der Prozessplanung, wobei Planung verstanden wird als ideelle Vorwegnahme wesentlicher Momente des künftigen Prozessverlaufs, verbunden mit dem Bewusstsein situationsabhängig notwendiger Präzisierungen und Plankorrekturen. In der sozialpädagogischen Praxis sind erst dann die notwendigen Voraussetzungen bzw. Informationen für eine Prozessplanung gegeben, wenn im Ergebnis der Problemanalyse deutlich geworden ist, um welche individuellen Schwierigkeiten es geht und 
wodurch sie bedingt sind. Um diese besondere Anforderungssituation zu bewältigen, benötigt der Sozialpädagoge ein Konzept für sein Herangehen an die Planung, das so allgemein ist, dass es auf jeden Problemfall angewendet werden kann. Für dieses Herangehen ist die von Lüssi (1992) formulierte Liste der Konzeptprinzipien hilfreich, die in diesem Buch unter sozialpädagogischem Aspekt etwas verändert bzw. ergänzt worden ist.

Konzeptprinzipien dienen auf der Grundlage o. g. normativer Prinzipien und gesetzmäßiger Zusammenhänge der Sozialen Arbeit als Entscheidungshilfen für das Herangehen an Problemlösungsprozesse, insbesondere bei der Bestimmung realisierbarer Ziele sowie bei der Wabl geeigneter und zulässiger Mittel und Methoden. Die Konzeptprinzipien sind auch bei der Anwendung der Struktur- und Funktionsprinzipien zu beachten.

\subsection{Konzeptprinzipien als Grundlage konzeptioneller und prozessimma- nenter Planung}

Wie schon erwähnt, erfolgt in der sozialpädagogischen Praxis eine prozessimmanente Planung. Das bedeutet jedoch nicht, dass der Sozialpädagoge ohne Vorstellungen von der künftigen Prozessgestaltung an den jeweiligen Fall herangeht. Er sollte sich nämlich während seiner Ausbildung konzeptionelle Vorstellungen vom Prozessverlauf, d. h. grundlegende Erkenntnisse zur Struktur und Dynamik sozialpädagogischer Prozesse sowie zu Prinzipien des Herangehens an einen beliebigen Fall angeeignet haben. Wesentliche Momente der funktionalen Dynamik sozialpädagogischer Prozesse widerspiegeln sich in dem Funktionsmodell des Abschnitts 6.1.3, das im Zusammenhang mit den Struktur- und Funktionsprinzipien betrachtet werden muss.

Mit dem Funktionsmodell und den Prinzipien erwirbt der Sozialpädagoge eine kon₹eptionelle Vorstellung von sozialpädagogischen Prozessen, die hilft, einen fundierten Plan für den jeweiligen Fall zu erarbeiten und als flexibles Instrument zu nutzen. Es ist ja möglich, dass die nach der ersten Problemanalyse vereinbarten Maßnahmen im weiteren Prozessverlauf präzisiert oder korrigiert werden müssen, und zwar in Abhängigkeit von den im Prozess sich vertiefenden Erkenntnissen in die Schwierigkeiten des Problembelasteten und die Wirksamkeit der vereinbarten Maßnahmen. Dabei ist wichtig, dass solche Korrekturen nicht stillschweigend (also im Sinne von Verstößen gegen die Vereinbarung) erfolgen, sondern bewusst und begründet vorgenommen werden.

Wie im Abschnitt 2.4 dargestellt, treten sozialpädagogische Probleme bäufig in Verbindung mit der Sozialarbeit auf. Sozialarbeit ist zunächst immer darauf gerichtet, durch Beschaffungsmaßnahmen hinsichtlich personeller, sachlicher und finanzieller Hilfen einen sozialen Notstand zu beheben oder zu lindern. Damit werden aber in der Regel nicht die subjektiven Bedingungen „im Klienten“ selbst verändert, die an der Entstehung des sozialen 
Notstandes beteiligt waren, was zur Folge hat, dass der Hilfesuchende ,am Tropf hängen bleibt.“ Das ist nur im Falle völliger Unselbständigkeit wegen schwerer oder schwerster psychischer Beeinträchtigungen des Klienten zu verantworten.

Die nachfolgende Darstellung der Konzeptprinzipien orientiert sich an der Liste von Lüssi und wurde ergänzt, nämlich durch das Prinzip der Verbindung von persönlicher Achtung mit angemessen hohen und steigenden Forderungen an die Problembelasteten (vgl. Makarenko 1969, Bd. V, S. 155 und S. 239). Ansonsten gelten für die Soziale Arbeit und das darin eingeschlossene sozialpädagogische Handeln als strategische Grundorientierung für die Prozessgestaltung zumindest folgende fünf Prinzipien:

\subsubsection{Das Prinzip der Verbindung von sozialer Hilfe mit direkter und indirekter pädagogischer Einflussnahme durch Anleitung zur Selbsthilfe}

Sozialarbeiter müssen soziale Hilfemaßnahmen (materielle Unterstützungen, Schutzgewährung usw.) mit pädagogischen Handlungen (z. B. Ermutigung, Anleitung, Kontrolle und Bewertung) verbinden, damit die Problembelasteten zur selbständigen juristisch, medizinisch und moralisch vertretbaren Lebensgestaltung aktiviert und befähigt werden.

\section{Begründung:}

Das gemeinsame Ziel der Problemlösung ist nachhaltig nur erreichbar, wenn der Sozialarbeiter über unmittelbare Beschaffungsmaßnahmen hinaus den Hilfebedürftigen zu eigenen Anstrengungen veranlasst, die zunehmend selbständig aufgebracht werden. In diesem Prinzip widerspiegelt sich der gesetzmäßige Zusammenhang, der in der progressiven Veränderung des Notleidenden durch eigene Anstrengungen bei der Problemlösung besteht, wobei er sowohl durch den Sozialpädagogen als auch durch andere an der Problemlösung beteiligte Personen ermutigt und unterstütat werden muss.

Sozialpädagogische Bemühungen sind immanenter Bestandteil jeder Hilfe, wenn der soziale Basisgegenstand nicht als Almosen, sondern als Ergebnis gemeinsamer Anstrengungen erlangt wird. Nur wenn auch ein sozialpädagogischer Erfolg erreicht wird, ist künftig mit einer dauerhaften Lösung, Reduzierung oder Vermeidung des sozialen Problems zu rechnen. Dabei sind bei der Betreuung von Personen mit physisch-psychischen Beeinträchtigungen deren spezifische physischen und psychischen Grenzen zu beachten.

\section{Handlungshinweise}

Besonders wirkungsvoll kann dieses Prinzip im Rahmen von Gruppenerziehungsprozessen realisiert werden, was Lothar Böhnisch offenbar veranlasst hat, von einem speziellen „Gruppenprinzip“ in der Sozialpädagogik des Kindes- und Jugendalters zu sprechen (vgl. Böhnisch 1993, S. 251). In pädagogisch geführten Institutionen kann sowohl eine Sicherung der materiellen Lebensbedingungen als auch eine direkte und indirekte erzieherische Einflussnahme auf den Einzelnen erfolgen, was entsprechend 
den Erfahrungen von Makarenko und anderen (siehe Abschnitte 5.3 und 5.4) besonders zu empfehlen ist. Allerdings erfordert dieses Vorgehen nicht schlechthin die Beachtung der Besonderheiten von Gruppen mit Zöglingen gleichen und unterschiedlichen Alters, sondern ein begründetes Konzept sowie die materiellen und juristischen Voraussetzungen zur Organisation von Entwicklungs-Gemeinschaften. In Entwicklungs-Gemeinschaften können nämlich jene Prinzipien angewendet werden, die Makarenko im Rahmen seiner Pädagogik der Kollektiverziehung entwickelt hat, d. h., die indirekte pädagogische Einflussnahme des Sozialpädagogen kann durch paralleles pädagogisches Vorgehen in der Entwicklungs-Gemeinschaft realisiert werden (siehe S. 293). Die indirekte pädagogische Einflussnahme durch den ,hauptberuflichen Erzieher“ oder das „parallele pädagogische Vorgehen“"19 wird von Makarenko wie folgt begründet:

„Der Erzieher muß folgendes stets richtig bedenken: Wenn auch alle Zöglinge begreifen, daß sie im Kinderheim belehrt und erzogen werden, so lieben sie es doch nicht sehr, wenn sie speziellen pädagogischen Prozeduren unterworfen werden, und erst recht nicht, wenn mit ihnen unendliche Gespräche über den Nutzen der Erziehung geführt werden und mit jeder Bemerkung eine moralische Belehrung verbunden ist. [...]. Ein Erzieher, der seine Zöglinge ewig mit ausgesprochen lehrhaften Gesprächen verfolgt, fällt ihnen auf die Nerven und stößt fast immer auf Widerstand“ (1969, Bd. V, S. 96).

An die Stelle der direkten „Einwirkungsversuche“ durch den Erzieher setzt Makarenko die im normalen Lebensprozess der Gemeinschaft erfolgenden erzieherischen Impulse auf jeden Einzelnen und jede Gruppierung durch die aktivsten und fortgeschrittensten Gemeinschaftsmitglieder, und zwar durch jene Forderungen, kritischen Hinweise und Kontrollen, die aus den Erfordernissen des Lebensalltags in der Gemeinschaft resultieren. Diese pädagogischen Aktivitäten laufen gewissermaßen parallel zu den Bestrebungen der Erzieher und haben ihre Grundlage in den Bedürfnissen und Interessen der Gemeinschaft, die die differenzierten Lebens-, Lern- und Arbeitsprozesse in der Einrichtung bestimmen und bei deren Realisierung auch wirksam sind.

\subsubsection{Das Prinzip der Verbindung von systemischem Herangehen mit problemindividuellem Verste- ben und Vorgehen}

Sozialpädagogen müssen die gesellschaftlichen und individuellen Determinanten der Problemlagen von Klienten in ihren Systemzusammenhängen, ihrer Widersprüchlichkeit und Eigenart erkunden, um unter Berücksichtigung problemverschärfender Faktoren und lösungsfördernder Bedingungen möglichst optimale Lösungen zu finden und realisieren zu können.

19 E. Günther-Schellheimer hat darauf hingewiesen, dass es sich bei Makarenkos Prinzip der sog. ,parallelen-pädagogischen Einwirkung“ (vgl. z. B. Makarenko 1969, Bd. V, S. 96) um eine fehlerhafte Übersetzung handelt. Die korrekte Übersetzung des russischen Wortes „dejstvie“ (Аействие) ist „Handlung“ und im vorliegenden Zusammenhang im Sinne von „Vorgehen“ zu verstehen (vgl. Günther-Schellheimer 2005, S. 25f.). 


\section{Begründung:}

Die Forderung nach Erklärung und Verständnis der Problemlage der Klienten liegt sowohl im Interesse des Problembelasteten und Problembeteiligten als auch des Sozialpädagogen und zielt auf eine Grundvoraussetzung für erfolgreiches sozialpädagogisches Handeln. Problemindividuelles Verstehen und Vorgehen erfordern differenzierte Einsichten in die Persönlichkeitsstruktur und in die Lebenswelt der Problembelasteten und Problembeteiligten, da jedes Problem nur im Rahmen der vielfältigen - darunter auch gesetəmäßigen Wechselwirkungen von Individuum und Gesellschaft erklärt und gelöst werden kann. Sozialpädagogisches Handeln ist dann effektiv, wenn die individuellen Schwierigkeiten der Klienten unter Berücksichtigung der belastenden und lösungsfördernden Lebensbedingungen (insbesondere der Ressourcen aus der Umwelt) „,bearbeitet“ werden.

\section{Handlungshinweise:}

Die individuelle Problemlage jedes Klienten ist zwar objektiv bedingt, oftmals aber auch mit das Ergebnis seiner unzureichend entwickelten Fähigkeiten, sich mit seinen Lebensbedingungen so auseinanderzusetzen, dass er dadurch seine physische und psychische Existenz und Entwicklung in menschenwürdiger Weise sichert. Da für die Entstehung sozialer Probleme sowohl objektive Überforderungen aus der Lebenssituation heraus als auch subjektive Defizite bezüglich ihrer Bewältigung eine Rolle spielen, muss der Sozialpädagoge stets beide Seiten ins Auge fassen, um herauszufinden, wo die günstigen Ansatzpunkte zur Problemlösung liegen. Dabei bedeutet problemindividuelles Verstehen nicht das Einverständnis mit all dem, was der Problembelastete getan oder versäumt hat. Vielmehr geht es darum, ihm mit Verständnis für seine Sichtweisen in der Problemsituation zu begegnen und dabei zugleich zu erklären, worin mögliche Fehler dieser Sichtweisen bestehen. Dem Klienten mit Verständnis begegnen bedeutet nicht, alle seine Handlungs- und Verhaltensweisen zu billigen. Speziell die Funktion „Enthüllung“ (siehe S. 328, S. 361ff.) dient dazu, dem Problembelasteten seine Irrtümer und Mängel im Lebensstil und die Bedeutung negativer Einflüsse aus seiner Umwelt bewusst zu machen. Dabei muss er begreifen, dass er nur dann eine „gerechte Behandlung“ erwarten kann, wenn er seinerseits berechtigte Erwartungen seiner Mitmenschen erfüllt.

Da dialektisches brw. systemisches Herangehen eine möglichst weitgehende Berücksichtigung des sozialen Lebenszusammenhangs der Problembelasteten und Problembeteiligten fordert, genügt es nicht, sich nur der Individualität der Klienten zuzuwenden; vielmehr muss geprüft werden, welche sozialen Bedingungen so verändert werden können, dass die Bemühungen des Problembelasteten insgesamt gefördert werden. Lüssi fordert eine „systemische Problemkonzeption“ (Lüssi 1992, S. 220) für die Problemlösung, die darauf gerichtet ist, das vorhandene dysfunktionelle System durch Veränderungen in den Lebensbedingungen und zwischenmenschlichen Bęiehungen zu überwinden. Es sei hier nur an den Fall Max im Abschnitt 2.4 erinnert, in dem die Betreuer durch Unterstützung 
beim Wohnungswechsel und bei der Beschaffung einer ABM-Stelle (also durch neue Nachbarn und neue Aufgaben!) ihrem Klienten in seinen Bemühungen so wirkungsvoll helfen konnten, dass der angestrebte Erfolg im Sinne der Einheit von sozialem Ergebnis und sozialpädagogischem Resultat erreicht wurde.

In einer ersten Begegnung des Sozialpädagogen mit dem Problembelasteten und der dabei erfolgenden Information über die Probleme ist es in der Regel nicht möglich, alle wesentlichen Momente einer Problemsituation zu erfahren. Es bedarf nämlich eines entwickelten Vertrauensverhältnisses, bis der Klient bereit ist, auch jene Informationen preiszugeben, die ihn in einem seiner Meinung nach „schlechten Licht“ erscheinen lassen. Aber gerade diese Informationen können für das Erkennen der Problemursachen besonders wichtig sein. So ist der Sozialpädagoge zunächst auch auf Vermutungen angewiesen, die noch keine hinreichende Grundlage für eine solide Prozessplanung sind. Zur Überwindung dieser Schwierigkeit dient daher besonders:

\subsubsection{Das Prinzip der Wechselwirkung von Verstehen und Handeln}

Sozialpädagogen müssen sich auf der Grundlage ihrer Einsichten in die Problemlage, die sie in Gesprächen schrittweise gewinnen, zu begründetem Handeln entschließen, an der Problemlösung arbeiten und durch sorgfältige Auswertung der erzielten Handlungseffekte ihr Problemverständnis vertiefen, um ihre Maßnahmen zu präzisieren oder auch zu korrigieren.

\section{Begründung:}

Verständnis für die Problemlage des Klienten und seine aus der Biografie erwachsenen Nöte ist Voraussetzung für erfolgreiches Handeln. Daher formuliert Böhnisch auch ein „Biographieprinzip“ (Böhnisch 1993, S. 264), das vor allem darauf gerichtet ist, mögliche Ressourcen zur Problemlösung unter Berücksichtigung der Biografie des Klienten zu finden. Die notwendigen Informationen für eine Problembearbeitung sind vor und während der Kontaktaufnabme nur begrenzt zu erfahren; dennoch muss zumeist umgehend gehandelt werden, weil der Problembelastete und die Problembeteiligten in der Regel sofortige Hilfe erwarten oder der Leidensdruck, den das soziale Problem ausgelöst hat, kein langes Zögern erlaubt.

\section{Handlungshinweise}

Das helfende Handeln erfolgt auf der Grundlage der jeweiligen Einsicht in die Problemlage. Da sich diese Einsichten durch kritische Reflexionen im Handlungsprozess, speziell der Verhaltensweisen des Problembelasteten, und durch weitere Offenbarungen der Problembeteiligten erweitern und vertiefen, können oder müssen die anfangs geplanten und vereinbarten Maßnahmen prozessimmanent präzisiert oder gar korrigiert werden; d. h., das Verständnis aller Beteiligten entwickelt sich im Handeln und das Handeln 
selbst wird effizienter mit dem wachsenden Problemverständnis, wenn der Sozialpädagoge professionell arbeitet.

In jeder Problemanalyse und ihrer weiteren Vertiefung bei der Problembearbeitung rücken mögliche Maßnabmen zur Problemlösung ins Blickfeld. Welche dieser denkbaren Maßnahmen nun aber tatsächlich Bestandteil der Vereinbarung werden, ist nicht allein von den inneren Voraussetzungen der Problembelasteten oder von dem abhängig, was der Sozialpädagoge auf Grund seiner Erfahrungen für wünschenswert hält. Vielmehr gibt es fallübergreifende Gesichtspunkte, die von großer Bedeutung sind für jede Entscheidung und die sich in folgendem Prinzip widerspiegeln:

\subsubsection{Das Prinzip der Verknüpfung von sozialethischen und sozialökologischen Positionen bei der Bestimmung des vertretbaren Aufwands an materiellen und personellen Mitteln zur Problem- lösung}

Sozialarbeiter und Sozialpädagogen müssen sich grundsätzlich von sozialethischen Prinzipien (Achtung der Menschenwürde, soziale Gerechtigkeit, soziale Solidarität, persönliche Selbstbestimmung, Ehrlichkeit, Diskretion) leiten lassen, die Ressourcen des sozialen Umfeldes (Nachbarn, Verwandte, Freunde und soziale Einrichtungen in der Region) einbeziehen und versuchen, mit kleinstmöglichen Eingriffen zu helfen, damit die Problembeteiligten möglichst nicht in neue Schwierigkeiten geraten und der personelle bzw. materielle Aufwand vertretbar und bezablbar bleibt.

\section{Begründung:}

Sozialethische Normen sind allgemeingültig und verbindlich für die Soziale Arbeit, ihre Einhaltung durch den Sozialpädagogen wird von den Klienten erwartet. Sie sollte aber auch von den Problembelasteten gefordert werden, denn auch deren Normenverstöße wirken erfolgsmindernd. Wenn es gelingt, die sozialethischen Normen in ihrer Gesamtheit angemessen zu berücksichtigen und die materiellen und personellen Ressourcen aus dem Umfeld des Klienten sowie den gesellschaftlichen Fonds zu nutzen, dann kann wahrscheinlich auch das jeweilige Problem entsprechend den gesellschaftlichen Möglichkeiten gelöst werden. Allerdings ist der Sozialarbeiter auch moralisch verpflichtet, durch sein fachlich fundiertes sozialpolitisches Engagement zur Verbesserung dieser Möglichkeiten beizutragen.

\section{Handlungshinweise:}

Unterschiedliche Auffassungen der Problembelasteten und Sozialpädagogen bei der Anwendung sozialethischer Normen können zu Widersprüchen führen, die eine humane Lösung erschweren oder gar verhindern. Ein Beharren auf persönlichen Vorstellungen seitens der Klienten kann überhöhte Forderungen hinsichtlich finanzieller Unterstützungen hervorrufen, die im Rahmen der verfügbaren Ressourcen nicht zu befriedigen sind. Die materiellen und personellen Ressourcen in der Sozialarbeit sind nun 
einmal begrenzt. Den Erwartungen kann nicht immer optimal entsprochen werden, weil der vertretbare Aufwand in jedem Einzelfall eine ökonomische Grenze hat, was zu Gratwanderungen in der Ressourcenzuteilung führt, die den Bedürftigen verständlich gemacht werden müssen, damit sie sich nicht ungerecht behandelt fühlen und mutlos werden.

Das Prinzip berücksichtigt zwei Schwierigkeiten, vor denen Sozialpädagogen stehen:

- Sie müssen ihrem sog. Doppelmandat ${ }^{20}$ entsprechen, d. h. die Interessen ihrer Klienten und der Gesellschaft wahrnehmen, was „bei schwieriger Kassenlage“ nicht immer zur allseitigen Zufriedenheit gelingen kann, und

- sie müssen mit Widerstand gegenüber den Hilfsangeboten rechnen, weil manche Problembelastete sich von illusionären Erwartungen leiten lassen, die aus ökonomischen und/oder ethischen Gründen vom Maßnahmeträger als Vertreter der Gesellschaft nicht akzeptiert werden können.

Das Prinzip markiert aus zwei Blickrichtungen die Grenzen der Sozialen Arbeit und damit auch der Sozialpädagogik: Zum einen kann vom potenziellen Klienten die Hilfeannahme trotz der Bemühungen des Sozialpädagogen verweigert werden, was u. U. mit Rücksicht auf das Selbstbestimmungsrecht der Persönlichkeit (= sozialethische Norm) respektiert werden muss und respektiert werden kann, wenn dadurch nicht gegen das Rettungsprinzip verstoßen wird. Zum anderen reichen die verfügbaren materiellen Ressourcen im Umfeld des Klienten und in den gesellschaftlichen Fonds zur optimalen Problemlösung nicht aus. Oft ist dann nur eine Linderung der Belastungen in der Problemsituation möglich. Allerdings gehört es zum Berufsethos von Sozialpädagogen, dass sie auch durch ihr politisches Engagement auf eine Verbesserung ihrer Arbeitsbedingungen hinwirken.

Mit der Forderung nach Berücksichtigung sozialökologischer Positionen wird zugleich auf die Lebenswelt der Problembelasteten mit ihren prägenden Wirkungen und begrenzten Ressourcen verwiesen. Es ist wichtig, die Spezifik der Lebenswelt der Problembelasteten bei der Problemanalyse zu erkennen und zu berücksichtigen, und zwar sowohl wegen ihrer hemmenden als auch ihrer möglichen fördernden Wirkungen im Problemlösungsprozess. Dabei darf nie übersehen werden, dass krisenhafte oder katastrophale Zustände in der Lebenswelt zu den wesentlichen Entstehungsbedingungen devianter Verhaltensweisen gehören.

Hinzu kommt, dass die lebensweltabhängigen Eigenheiten der Klienten - beispielsweise das Desinteresse an Bildung oder gesunder Lebensweise - den allgemeinen Entwicklungstrends und Erwartungen in der Gesellschaft so entgegenstehen, dass nur ibre Überwindung eine Problemlösung möglich macht. Daher bleibt es dem Sozialpädagogen nicht

20 Es ist problematisch, von einem Tripelmandat zu sprechen, weil der Kodex der Sozialen Arbeit mit wissenschaftlichen Erkenntnissen über sie (als dritte Bezugsgröße) kein aktives Subjekt ist, das ein Mandat erteilen oder entziehen kann. Erkenntnisse, Berufskodex und Menschenrechtsnormen bilden kein Mandat, sondern ein System (oder Bündel) von normativen und konzeptionellen, strukturellen und funktionalen Prinzipien, das für alle an der Sozialen Arbeit beteiligten Kräfte und Klienten gilt und strikt beachtet werden muss. Die Verpflichtung zum korrekten berufsethischen und professionellen Handeln hat übrigens eine lange Tradition, wie z. B. der hippokratische Eid belegt. 
erspart, mit hohem persönlichen Einsatz gegen destruktive und deformierende Kräfte im Umfeld des Klienten anzugehen, wenn es nicht gelingt, ihm eine „,neue Umwelt zu organisieren“ - etwa in Form einer Pflegefamilie oder eines Heims. Bezüglich der Veränderungen des Wohnumfeldes sollte sich ein Sozialarbeiter/Sozialpädagoge nicht zu hohe Ziele stellen; es gibt nun einmal unterschiedliche Vorstellungen und Gewohnheiten beispielsweise hinsichtlich äußerer Ordnung und Sauberkeit im Haushalt bzw. in der Wohnung. Sofern nicht Gefahren für die Gesundheit - insbesondere von Kindern bestehen, sollte ein Sozialpädagoge im Interesse der Lösung lebenswichtiger Probleme in Fragen der äußeren Ordnung etwas nachsichtig sein und versuchen, mit kleinstmöglichen notwendigen Eingriffen die wirklich schwerwiegenden Probleme zu lösen.

In der Jugendhilfe der DDR galt die „Organisierung des gesellschaftlichen Einflusses “ auf die Hilfebedürftigen als Leit- oder Konzeptprinzip (vgl. Mannschatz 1998, S. 15f.). Vermutlich ist seine relativ umfassende Realisierung auch eine wesentliche Bedingung für die bereits im Abschnitt 3.1 erwähnte Tatsache, dass 1988 die Kriminalitätsquote in der DDR nur ca. $10 \%$ von der in der damaligen Bundesrepublik Deutschland betrug.

Problembelastete erfahren infolge ihres Fehlverhaltens fortgesetzt Geringschätzungen und Abwertungen, was ihre Minderwertigkeitskomplexe verstärkt. Oft ist daher schon das Erlebnis, angehört und ernst genommen zu werden, für den Problemlösungsprozess förderlich. Makarenko hat mit viel psychologischem Verständnis für ,jugendliche Rechtsverletzer" genau diesen wichtigen Punkt im Umgang mit ihnen erkannt und daher ein Prinzip formuliert, das in Lüssis Prinzipienliste fehlt und modifiziert lautet:

\subsubsection{Das Prinzip der Verbindung von persönlicher Achtung mit angemessen bohen und steigenden} Forderungen

Sozialpädagogen müssen den Problembelasteten mit Achtung begegnen und angemessen hohe sowie steigende Forderungen an sie stellen, damit sie zur aktiven Mitwirkung am Problemlösungsprozess angeregt und herausgefordert werden.

\section{Begründung:}

Das in der Regel ,angeschlagene“ bzw. unzureichende Selbstwertgefühl der Hilfebedürftigen kann nur dann entwickelt werden, wenn ihnen mit Achtung begegnet wird und sie die Chance erhalten, durch die Erfüllung hoher und angemessener baw. steigender $A n$ forderungen ihr Selbstvertrauen zu stärken und ibre Kompetenzen zu entwickeln.

\section{Handlungshinweise:}

Sozialpädagogen begegnen dem Problembelasteten dann achtungsvoll, wenn sie ihn nicht mit Vorwürfen überbäufen oder als Person verurteilen. Sie bewerten das kritikwürdige Handeln und Verhalten (im Sinne der Echtheit - siehe Prinzip 5.5.2.) und vermeiden dabei moralisierende Belehrungen. Wenn sie angemessen hohe und steigende Anforde- 
rungen stellen, signalisieren sie Zutrauen, geben sie gewissermaßen Vertrauensvorschuss. Indem die Hilfebedürftigen diese Anforderungen - und sei es auch nur annähernd erfüllen, rechtfertigen sie die achtungsvolle Behandlung, haben sie Erfolgserlebnisse, die zugleich ihr Selbstvertrauen stärken. Damit wird deutlich, dass dieses Prinzip in Verbindung mit den Prinzipien 5.5.2 (unvoreingenommene Problemannahme) und 5.5.3 (Nichtbeschuldigung) auch die Forderungen des von Böhnisch formulierten „Selbstwertprinzips“ mit einschließt (vgl. Böhnisch 1993, S. 247).

Es ist oft schwierig, das rechte Maß in der Höhe der Anforderungen zu finden. Bereits Makarenko als Vertreter einer konsequenten „Anforderungspädagogik“ bemerkte dazu:

„Wir müssen Forderungen stellen, doch nur solche, die den Kräften entsprechen (...) Jede Überforderung kann nur Schaden anrichten“ (Makarenko 1969, Bd. V, S. 467).

Aus diesem Grunde ist es wichtig, mit den Problembelasteten und Problembeteiligten die Vereinbarungen zur Problemlösung sorgfältig auszuarbeiten und sie im Falle von „Fehlkalkulationen“ - d. h. von Über- oder Unterforderungen - bewusst und möglichst im wechselseitigen Einvernehmen zu korrigieren. Mit den Forderungen des Prinzips erfolgt zugleich auch eine Abgrenzung zum autoritären Erziehungsstil und zum „Laissez-faire-Stil““ wie sie Kurt Lewin (1890-1947) genannt und untersucht hat. Autoritäres oder autokratisches Verhalten eines Erziehers bzw. eines Lehrers oder Betriebsleiters basiert im Grunde genommen auf einer fehlenden oder unzureichenden Wertschätzung der Meinungen und Initiativen der zu Leitenden. Der Laissez-faire-Stil drückt sich darin aus, dass keine klaren und steigenden Anforderungen gestellt werden. Die in der Sozialpsychologie und in der Pädagogischen Psychologie erforschten Zusammenhänge zwischen dem Führungsverhalten von Vorgesetzten, Lehrern usw. und Unterstellten bzw. Schülern (vgl. Lewin, Lippit \& White 1939; A.-M. Tausch u. R. Tausch 1971; W. Kessel und G. Hentschel 1988) geben eine fundierte Orientierung auf die Notwendigkeit und die Merkmale des demokratischen oder sozialintegrativen Erziehungsstils (vgl. Hobmair u. a. 1989, S. 234ff.).

Das praktische Problem bei der Nutzung dieser Erkenntnisse besteht jedoch darin, dass für die Realisierung aller Merkmale des demokratischen Führungsstils speziell in der Arbeit mit devianten Zöglingen zunächst einmal die dafür notwendigen Voraussetzungen geschaffen werden müssen. Wenn z. B. Harald Rasmussen beim Empfang seiner jugendlichen Rechtsverletzer eine Diskussion über die Hausordnung o. Ä. begonnen hätte (vgl. Rasmussen 1993, S. 112f. und Abschnitt 5.4.2), dann wären die Jugendlichen wahrscheinlich irgendwann in der Nacht zu Bett gegangen und morgens nicht zur geplanten Zeit aufgestanden, um den Unterricht in der Schule oder die Arbeit in den Werkstätten aufzunehmen. Offenbar ist es nicht möglich, eine Liste von Merkmalen des „besten Führungs- oder Erziehungsstils“ abzuarbeiten. Vielmehr muss der augenblicklich praktizierte Stil auch den situativen Bedingungen - speziell den Voraus- 
setzungen der Zöglinge - entsprechen. Das heißt: es gibt Situationen, in denen der Erzieher unabdingbare Forderungen stellen muss - und zwar ohne Diskussion - und zu deren Durchsetzung er erforderlichenfalls auch zulässige Zwangsmittel einsetzt.

Zusammenfassend zum Kapitel 4 lässt sich sagen:

Der Widerspiegelungs- und Orientierungscharakter von pädagogischen Zielen begründet ihre Vermittlungsfunktion, d. h., mit Hilfe von Zielen werden die Anforderungen, die das Leben in der Gesellschaft an die Menschen stellt, pädagogisch bewusst gemacht, zunächst dem Erzieher, aber auch dem zu Erziehenden. Die akzeptierten Zielvorstellungen wiederum dienen als Kriterien bei der Festlegung von Inhalten und Methoden und haben damit wesentlichen Einfluss auf den Verlauf pädagogischer Prozesse und ihre Resultate, deren Qualität nach entsprechenden Resultatsermittlungen im alltäglichen Lebensprozess und/oder in besonderen Rechenschaftslegungen durch Ziel-Resultats-Vergleiche bewertet wird. Da sozialpädagogische Prozesse nicht langfristig im voraus geplant werden können, sondern aus sozialen Notlagen und Konfliktsituationen heraus erwachsen, werden sie auf der Basis einer prozessimmanenten und interaktiven Planung gestaltet, wozu die Konzeptprinzipien grundlegende Handlungsorientierungen vermitteln, wie folgendes Fallbeispiel erkennen lässt.

\subsection{Fallbeispiel zur Anwendung der Konzeptprinzipien}

\section{Vorbemerkung}

Die nachfolgende Fallanalyse wurde aus der schriftlichen Hausarbeit von Marianne Nitz - eingereicht 2003 für die Abschlussprüfung zur „Sozialpädagogischen Jugendund Familienberaterin“" am Bildungszentrum Dessau (Schulungsort Güstrow) - in gekürzter und redaktionell bearbeiteter Fassung übernommen, wobei die „Wir-Position“ in der Darstellung der Autorin an entsprechenden Stellen beibehalten wurde.

\section{Zur Vorgeschicbte}

Im Sommer 1999 wandte sich ein alleinerziehender Vater an das Jugendamt G. und beantragte Hilfe zur Erziehung seiner beiden Kinder, für die neunjährige Beate und ihren etwas jüngeren Bruder. Er wohnte mit den Kindern in einem ca. 10 km entfernten Dorf, von dem aus Beate täglich mit dem Schulbus zur Allgemeinen Förderschule nach G. fuhr. Beate zeigte ein auffälliges, zum Teil aggressives Verhalten gegenüber den mitfahrenden Schülern und Erwachsenen; sie tobte im Bus, ärgerte andere Kinder verbal und wurde häufig handgreiflich, indem sie diese kniff, trat und biss. 


\section{Darstellung der Problembearbeitung}

In dem Beratungsgespräch auf dem Jugendamt kam zur Sprache, dass Beate mit etwa drei Jahren in ein Kinderheim eingewiesen worden war, weil die Kindesmutter die Familie verlassen hatte. Beate war glücklich, dass sie nun wieder mit ihrem Bruder beim Vater wohnen konnte, bereitete aber ihm und anderen beträchtliche Schwierigkeiten. Vom Heim sprach sie nicht gern, da es ihr dort nicht gefallen hatte. Es bestand eine soziale Notlage in dem Sinne, dass sich der Vater mit der Erziehung - speziell der Tochter - überfordert fühlte. Als unmittelbare Hilfe kam die Eingliederung von Beate in eine Tagesgruppe entsprechend $\int 32$ des KJHG in Frage, denn mit einer solchen Entscheidung konnte sowohl dem Prinzip der Verbindung von sozialer Hilfe mit pädagogischer Einflussnahme durch Anleitung zur Selbsthilfe als auch dem Prinzip der Verknüpfung von sozialethischen und sozialökologischen Positionen auf der Grundlage eines vertretbaren Aufwands an materiellen und personellen Mitteln zur Problemlösung am ehesten entsprochen werden. Die sozialpädagogischen Aktivitäten richteten sich zwar primär auf Beate wegen ihrer devianten Verhaltensweisen, doch nach \32 des KJHG ist ja mit der Erziehung in einer Tagesgruppe eine „Begleitung der schulischen Förderung und Elternarbeit" (Hervorhebung durch W.N.) verbunden und der „Verbleib des Kindes [...] in seiner Familie“" gesichert, d. h.:

- Der sozialethischen Forderung nach Zusammensein von Beate mit dem Vater und dem Bruder wurde entsprochen;

- Beate konnte auf diese Weise in der von ihr sehnlich gewünschten und für ihre gesamte Entwicklung bedeutsamen sozialen Umgebung bleiben, was der sozialökologischen Forderung entsprach;

- die Unterbringung in einer Tagesgruppe ist wegen des materiellen und personellen Aufwands günstiger als eine Heimunterbringung.

Aus erkennbaren Defiziten in Beates Verhalten ließen sich folgende Teilziele ableiten:

- Stärkung ihres Selbstbewusstseins und allmähliche Entwicklung von Frustrationstoleranz und Empathie,

- Entwicklung von Konflikt- und Kooperationsfähigkeit.

Die Erzieherinnen beschäftigten sich in ihrer Erziehungsarbeit mit den fünf Mädchen und vier Jungen der Tagesgruppe, speziell auch mit den Auffälligkeiten und Schwierigkeiten von Beate. Sie wurde - wie allgemein üblich - in den Tagesablauf eingeordnet, was für sie schon eine beachtliche Anforderung darstellte. Es handelte sich um Lernangebote zur Förderung der Musikalität, der körperlichen Bewegung und Handgeschicklichkeit sowie des bildnerischen Gestaltens. Das Spielangebot umfasste Rollenspiele, das freie Spielen in der Natur mit Naturmaterialien, Spiele zur Förderung der Feinmotorik sowie Kreis- und Bewegungsspiele. 
Auch in der Tagesgruppe zeigten sich Beates Neigungen zu verbalen und körperlichen Aggressionen. In den Beschäftigungen und Gesprächen mit Beate vertieften die Erzieherinnen ihr problemindividuelles Verstehen. Sie erkannten, dass Beate sich während ihres Heimaufenthaltes daran gewöhnt hatte, sich durch Beschimpfungen anderer Kinder sowie mit Treten und Beißen durchzusetzen! Diese Gewohnheiten zur Selbstbehauptung galt es ebenso zu überwinden wie die Kompensationshandlungen zur Überwindung ihrer Minderwertigkeitsgefühle, die sich in ihrem Spielverhalten wie folgt äußerten:

1. Beate möchte immer das Spiel bestimmen,

2. Beate möchte die Spielregeln festlegen,

3. Beate möchte während des Spiels im Mittelpunkt stehen.

Werden diese Erwartungen nicht erfüllt, dann

- möchte Beate ein neues Spiel beginnen,

- verlässt sie den Spielkreis und spielt für sich allein oder

- sucht sie sich neue Spielgefährten.

Es erfolgte daher eine Präzisierung o. g. Maßnahmen dahingehend, dass eine Einübung und Erböhung der Selbstkontrolle in Verbindung mit einem zielstrebigen Umgewöhnungsprozess realisiert wurden. Am Ende jedes Tages erfolgte eine Auswertung ihres Verhaltens nach dem Punktsystem der Gruppe. Unter Berücksichtigung des Punktebewertungssystems hat sich Beate für den Zeitraum von vier Wochen folgende Ziele gesteckt:

- „Keine schlechten Wörter zu anderen Kindern sagen.“

- „Kein Treten und Beißen, wenn ich mit dem Verhalten eines anderen Kindes nicht einverstanden bin."

Beate konnte täglich 2 Punkte erreichen, im Verlauf einer Woche also 10 Punkte. Sie hat diese angestrebte Punktzahl für sich im Gespräch selbst festgelegt, machte aber auch deutlich, dass sie Hilfe und Unterstützung braucht, um sie zu erreichen. Besonders am Wochenbeginn fiel es ihr schwer, ihre Vorsätze zu verwirklichen. Sie suchte in Konfliketsituationen oft Blickkontakt zur Erzieherin, um sich für ihre Handlungsweise positive oder negative Rückmeldung zu holen, um eventuell ihre Position zu behaupten oder den Prozess der Konfliktzuspitzung abzubrechen (vgl. Nitz 2003, S. 8).

Es ging in der Tagesgruppe nicht nur um verstärkte Zuwendungen, die Beate oft entbehrt hatte, sondern auch um die Realisierung angemessen hoher und steigender Anforderungen. In dem Bestreben, alles bestimmen zu wollen und im Mittelpunkt zu stehen, zeigt sich ein typisches kompensatorisches Verhalten eines Kindes, das offensichtlich von frühester Kindheit an das notwendige Maß an Zuwendung entbehrt hat. Daher begegneten wir dem Kind stets mit Achtung. Es wurde seinem Wunsch entsprochen, 
mit Vater und Bruder zusammen zu leben, und es wurde auch in die Planung erzieherischer Maßnahmen mit einbezogen, indem es z. B. seine „Punktziele“ festlegen konnte. Nach 10 Monaten drohten unsere Bemühungen um Beate zu scheitern: Der Vater hatte zweimal hintereinander Beate und ihren Bruder tagelang ohne Aufsicht gelassen, so dass das Jugendamt G. eingreifen und eine Heimunterbringung für beide Kinder nach $\int 34 \mathrm{KJHG}$ arrangieren musste. Diese Maßnahme widersprach zwar dem Wunsch der Kinder, trug aber dem Prinzip der Verbindung von sozialethischen und sozialökologischen Positionen insofern Rechnung, als es ja nicht zu vertreten war, die Kinder im Falle des verantwortungslosen Verhaltens des Vaters sich selbst zu überlassen. Es wurde festgelegt, dass sie zum Jahresende wieder zum Vater zurückkehren, wenn er die gerichtlichen Auflagen erfüllt.

\section{Kommentar}

Die Darstellung lässt erkennen, dass dem Prinzip der Verbindung von sozialer Hilfe mit pädagogischer Einflussnahme als Anleitung zur Selbsthilfe im Hinblick auf den Vater nicht genügend Aufmerksamkeit geschenkt worden war. Ferner lässt die vorliegende Darstellung offen, in welchem Maße die verschiedenen Systemzusammenhänge in ihrer Widersprüchlichkeit und in ihren Wechselwirkungen bei der Gestaltung des vielschichtigen sozialpädagogischen Prozesses berücksichtigt werden konnten. Es ging ja eigentlich nicht nur um den pädagogischen Umgang mit Beate in der Familie, in der Schule und in der Tagesgruppe, sondern auch um die Erziehung ihres Bruders und um seinen Einfluss auf Beate sowie um den Vater. Von diesem wird berichtet, dass er Beate zwar streng behandelte, aber selbst auch seine Probleme hatte, wie seine Versäumnisse und die Gerichtsverhandlung zeigten. Gerade diese Ereignisse lassen die Bedeutung des Prinzips der Wechselwirkung von Verstehen und Handeln und damit verbundene Konsequenzen für die prozessimmanente flexible Planung erkennen, die im oben geschilderten Fall auf eine Ausweitung der Betreuungsmaßnahmen hinausgelaufen wären. Diese würden dann aber sicherlich die Möglichkeiten von Erzieherinnen einer Tagesgruppe übersteigen 


\section{Kapitel}

\section{Erzieherische Verhältnisse in der psychosozialen Intensiverziehung}




\subsection{Gesellschaft, Gemeinschaft und Individuum}

Die Ergebnisse wissenschaftlicher Untersuchungen und Diskussionen zu den komplizierten Beziehungen zwischen Gesellschaft und Persönlichkeiten bzw. Gemeinschaften und Individuen füllen seit Jahrhunderten die Bände vieler Bibliotheken und dennoch gehen die Meinungen darüber immer noch weit auseinander. Im Bereich der Pädagogik widerspiegelt sich dieser Streit in der Frage nach dem Übergreifenden oder Dominierenden in der Dialektik von Individuum und Gemeinschaft. Die Vertreter des Individualismus sehen in der Gemeinschaftserziehung die Gefahr der Vermassung, der Nivellierung und Entmündigung des Individuums. Die Vertreter des Kollektivismus sehen in der Individualerziehung die Gefahr der Entwicklung von Egoisten, die das Gemeinschaftsleben zerstören. In realen Diskussionen und im praktischen Handeln treten diese hier charakterisierten extremen Positionen zwar nur als mehr oder weniger ausgeprägte Tendenzen auf, aber eine Standpunktbildung dazu ist notwendig.

Die Frage nach dem Übergreifenden oder Bestimmenden in der Dialektik von Gesellschaft und Individuum kann nur beantwortet werden, wenn man nicht bloß die Beziehungen zwischen Menschheit oder regionalen Gesellschaften (insbesondere in Staaten bzw. Staatenbündnissen) und Individuen betrachtet, sondern die Kontakt-Gemeinschaften unterschiedlichen Charakters mit berücksichtigt, denen das Individuum jeweils angehört. Solchen Gemeinschaften kommt eine Vermittlerrolle in der Sicherung der Existenz und der Entwicklungsbedingungen des Individuums und der Gesellschaft zu. Ohne diese Vermittlerrolle der Gemeinschaften (also der Familie, der Spiel-, Lern- oder Arbeitsgruppen) wäre das Individuum in der Gesellschaft gar nicht lebensfähig und würde sich auch keine Gesellschaft organisieren können. Der Verzicht auf organisierte Gemeinschaftserziehung riskiert spontanes Wachstum von u. U. problematischen Cliquen, weil ein basales und invariantes Bedürnis nach sozialer Organisation wirkt (vgl. S. 305). Das bedeutet zugleich: ohne die Fähigkeit in der Gemeinschaft zu leben, sich einzuordnen und nach Möglichkeit auch durch Leistungen einzubringen, kann sich kein Individuum zur Persönlichkeit entwickeln. Darum ist die vom Individualpsychologen Adler für unabdingbar gehaltene Gemeinschaftsfähigkeit des Individuums und das damit verbundene Gemeinschaftsgefühl von existenzieller und übergreifender Bedeutung. Etwas zugespitzt formuliert Adler:

„Alle Versager - Neurotiker, Psychotiker, Verbrecher, Alkoholiker, schwer erziehbare Kinder, Selbstmörder, Perverse und Prostituierte - sind Versager, weil es ihnen an Gemeinschaftsgefühl fehlt. Sie nähern sich den Problemen des Berufs, der Freundschaft und der Liebe ohne das Vertrauen, daß diese Probleme durch Zusammenarbeit gelöst werden könnten. Die Ansicht, die sie vom Leben haben, ist eine private Ansicht“ (Ansbacher/Ansbacher 1982, S. 160). 
Die fundamentale Bedeutung des Gemeinschaftsgefühls für die Entwicklung der Persönlichkeit und damit auch für die Erkenntnis der Qualität dieser Entwicklung kommt in folgendem Satz Adlers zum Ausdruck:

„Das Gemeinschaftsgefühl ist das Barometer dafür, ob ein Kind normal ist oder nicht. Der Grad des Gemeinschaftsgefühls, den das Kind oder das Individuum offenbart, ist das Kriterium, das vom Psychologen und von den Eltern beobachtet werden muss. [...]

Wenn das Gemeinschaftsgefühl vom ersten Tage an dem nach oben gerichteten Streben der Psyche eingeflößt worden ist, wirkt es mit automatischer Sicherheit und färbt jeden Gedanken und jede Handlung. Wo dieses automatische Gemeinschaftsgefühl fehlt, ist das Interesse des Individuums zu sehr auf die eigene Person gerichtet, und es fühlt, daß es machtlos oder ein Niemand ist" (Ansbacher/Ansbacher 1982, S. 159f.).

Auf der Grundlage „privater Ansichten und Aktivitäten“ allein ist das Leben nicht zu verstehen und zu bewältigen. Es bedarf vielmehr der Identifikation des Individuums mit den für seine Entwicklung bedeutsamen Gemeinschaften und eine daraus resultierende soziale Sicht auf die eigene Existenz. Aus diesen fundamentalen Zusammenhängen ergibt sich allen individualistischen Träumereien zum Trotz, dass die Grundwerte und Erfordernisse einer Gesellschaft und der jeweiligen Gemeinschaften gegenüber den Bedürfnissen, Interessen und Wertvorstellungen des Einzelnen prinzipiell Vorrang genießen, was aber nicht bedeutet, dass sie ihn in jeder praktisch auftretenden Konfliktsituation haben müssen. Die praktische Schwierigkeit bei der Realisierung dieses Standpunkts besteht darin, dass oft umstritten ist, was denn die „echten“ oder vorrangigen Interessen der Gesellschaft und die damit verbundenen woblverstandenen Interessen der Gemeinschaft sind.

Da in jeder Gesellschaft Menschengruppen leben, die unterschiedliche Interessen vertreten, und viele versuchen, eine Mehrheit für die Unterstützung ihrer Interessen zu gewinnen, liegt in der These von der Dominanz gesellschaftlicher Interessen eine Gefahr, die im Verlaufe der Weltgeschichte in der Wirksamkeit zahlreicher Demagogen und „Volksführer“ sichtbar geworden ist. Diese haben partikulare Interessen als gemeinschaftliche oder gar gesellschaftliche schlechthin ausgegeben und versucht, sie mittels einer Erziehung „, durch die Gemeinschaft und für die Gemeinschaft“ zu verwirklichen. Es ist jedoch falsch, aus diesen Erfahrungen zu folgern, dass ,,individuelle Erziehung des Individuums“ die richtige Orientierung sei. Über den Wert oder Unwert einer Gemeinschaftserziehung kann nur in Abhängigkeit von ihren Zielen bzw. ihren „Führungskräften“ und deren Methoden entschieden werden. Sofern die Ziele und Methoden ihrer Realisierung inhuman sind, müssen die berechtigten bumanen individuellen Interessen den Vorrang haben. So entsprach z. B. das Verlangen nach Reisefreiheit, das zunächst von einer Minderbeit der DDR-Bürger öffentlich artikuliert wurde, den Interessen der Mehrheit und den Menschenrechten. Prinzipiell aber gilt: „Es gibt kein individuelles Leben außerhalb der Gemeinschaft" (Sandel in: „Der Spiegel“" Nr. 46/2012, S. 163). 
Als allgemeine Schlussfolgerung lässt sich auf Grund vorliegender Erfahrungen formulieren: Wenn die vertretenen gesellschaftlichen Werte bzw. Ziele und ihre Realisierungsmethoden dem Wesen nach humanistischen Charakter tragen (was auch die freie Entwicklung des Individuums mit Rücksichtnahme auf das Gemeinwobl einschließt), dann und nur dann gilt der Grundsatz: Erziehung für die Gemeinschaft und durch die Gemeinschaft. Dass dabei in der Praxis Probleme auftreten, resultiert aus den Widersprüchen der Gesellschaft und den damit verbundenen unterschiedlichen Vorstellungen von Humanismus und Persönlichkeitsentwicklung, doch die oben formulierte „Wenn-dann-Beziehung“ wird dadurch nicht ungültig.

\subsection{Merkmale erzieherischer Verhältnisse - Anforderungen an Erzieher}

Die Besonderheiten der Beziehungen zwischen Erziehern und Zöglingen sind im Verlaufe der Geschichte der Pädagogik in unterschiedlicher Weise charakterisiert und bezeichnet worden. W. Kron gibt in seinem Werk „Grundwissen der Pädagogik“ (1991, S. 221ff.) einen Überblick über die wichtigsten Auffassungen dazu. Die nachfolgende Darstellung orientiert sich daran, ergänzt den Überblick aber mit Auffassungen, die Kron nicht berücksichtigt hat.

In seinen Erörterungen zum Wesen erzieherischer Verhältnisse geht Nohl auf Pestalozzi zurück, der ,in der instinktgemäßen Handlungsweise der Mutter gegen ihr Kind das Urbild aller Menschenbildung“ sah und meinte, „dass alle Grundsätze der letzteren in ihrem ganzen Umfang darin enthalten seien“ (Nohl 1963, S. 128/129). Dass sich in der Beziehung der Mutter zu ihrem Kind ein Keim für Menschenbildung abzeichnet, kann nicht bestritten werden; aber dass es sich bei der Zuwendung der Mutter zu ihrem Säugling zunächst einmal um Pflege und Fürsorge handelt, die den Kern der ,instinktmäßigen Handlungsweise ${ }^{\text {‘21 }}$ bilden, legen uns vorliegende Erkenntnisse der Evolutionstheorie und Ethologie nahe. Das „instinktive Verhalten“ der Mutter gegenüber ihrem Säugling konstituiert noch kein erzieherisches Verhältnis, denn dieses ist durch Bewusstheit charakterisiert; aber es bildet seinen natürlichen Keim. Über die reinen Versorgungs- und Pflegemaßnahmen hinaus fungiert die Mutter schließlich zunehmend auch als Lernpartner. Die liebevollen Zuwendungen, hilfreichen Unterstützungen bei entwicklungsfördernden Bewegungen und die ermunternden Worte der Mutter haben durchaus Wirkungen, vor allem im Hinblick auf die emotionale Bindung, die ihrerseits Grundlage ist für die Wirksamkeit (auch künftiger) erzieherischer Maßnahmen.

$21 \mathrm{Ob}$ die Vernachlässigung von Säuglingen durch manche Mütter auch etwas mit der sog. Instinktreduktion bei Menschen zu tun hat, kann hier nicht untersucht bzw. erörtert werden. 
„Das Bedürfnis des Säuglings nach menschlicher Nähe, nach Zuwendung und Geborgenheit ist also offenkundig. Doch welche Bedeutung hat es für ihn? Es ist keinesfalls nur eine kleine »Verschönerung« seines Daseins, sondern hilft ihm, die lebensnotwendige Beziehung zu seinen Betreuern aufrecht zu erhalten. (Dieses Kontaktverhalten ist ein gemeinsamer stammesgeschichtlicher Besitz aller Primaten-Jungtiere, die ihrem biologischen Typus nach weder Nesthocker noch Nestflüchter, sondern Traglinge sind. - Fußnote der Autoren) Er braucht diese ja nicht nur, weil er in seiner Hilfsbedürftigkeit auf die Ernährung, die Pflege und den Schutz durch sie angewiesen ist. Er benötigt seine Betreuer von Anfang an hauptsächlich auch als »Lernpartner«. Im engen körperlichen Kontakt, in der zärtlich geführten »Zwiesprache«, im gemeinsamen Spiel - in allen Formen der Gemeinsamkeit lernt der Säugling: Er lernt sich selbst und seine Verhaltensmöglichkeiten, er lernt schrittweise auch seine nähere Umwelt kennen. Diese Lernprozesse sind eine entscheidende Voraussetzung für seine gesamte weitere geistige und soziale Entwicklung“ (Schmidt/Schneeweiß 1986, S. 76f.).

Über die erschreckenden Auswirkungen mangelhafter emotionaler Zuwendung und unzureichender sozialer Kontakte auf die Entwicklung von Säuglingen und Kleinkindern gibt es Untersuchungen, über die spezielle Abhandlungen informieren (vgl. z. B. Spitz 1987).

Um nun das Wesen des erzieherischen Verhältnisses, das sich in dem Beziehungsgefüge zwischen Mutter und Säugling entwickelt, genauer zu bestimmen, bedarf es eines möglichst klar definierten Erziehungsbegriffs. Die im 1. Kapitel vorgestellte Erziehungsauffassung schließt z. B. die körperliche Pflege des Kindes nicht mit ein, sondern betrachtet sowohl Kinder- als auch Kranken- und Altenpflege als etwas von Erziehung zu Unterscheidendes. Das Wesen erzieherischer Verhältnisse erschließt sich über die Merkmale der Bewusstheit persönlichkeitsverändernder Tätigkeiten und der unmittelbaren Beziehungen zwischen den am Prozess beteiligten Personen. Entwicklungsfördernde Bewusstheit ist bei einem Säugling natürlich noch nicht vorhanden; Keime davon werden allenfalls in den Nachahmungen bzw. Lernbemühungen von Kleinkindern erkennbar. Auch bei Müttern kann erst dann von erzieherischer Bewusstheit gesprochen werden, wenn sie die Aktivitäten ihrer Kinder bewusst zu lenken versuchen.

Die beiden spezifischen Merkmale der Erziehung - Direktheit und Bewusstheit - erfahren eine unterschiedliche Ausprägung in Abhängigkeit von der sozialen Lage, dem physischen und psychischen Entwicklungsstand der Beteiligten sowie den Möglichkeiten und Erfordernissen der natürlichen und gesellschaftlichen Bedingungen, unter denen der Prozess stattfindet. Doch unabhängig von diesen konkreten und besonderen Ausprägungen, auf die auch Nohl hinweist mit den beobachtbaren Unterschieden in den erzieherischen Verhältnissen von Müttern, Vätern, Tanten, Onkeln, Großvätern usw. zu den jeweiligen Zöglingen (vgl. Nohl 1963, S. 134), lassen sich allgemeingültige Merkmale in den Beziehungen feststellen, die im Begriff des eržieherischen Verbältnisses 
erfasst werden. Diese allgemeinen Merkmale hat Nohl in wesentlichen Punkten wie folgt formuliert und mit dem Terminus „pädagogischer Bezug“ belegt:

- „Die Grundlage der Erziehung ist also das leidenschaftliche Verhältnis eines reifen Menschen zu einem werdenden Menschen, und zwar um seiner selbst willen, daß er zu seinem Leben und seiner Form komme“ (a .a. O., S. 134).

- „Das Verhältnis des Erziehers zum Kind ist immer doppelt bestimmt: von der Liebe zu ihm in seiner Wirklichkeit und von der Liebe zu seinem Ziel, dem Ideal des Kindes, beides aber nicht als Getrenntes, sondern als ein Einheitliches: aus dem Kinde machen, was aus ihm zu machen ist, das höhere Leben in ihm entfachen und zu zusammenhängender Leistung führen, nicht um der Leistung willen, sondern weil sich in ihr das Leben des Menschen vollendet“" (a. a. O., S. 136).

- „Entsprechend jener Doppelheit einer Liebe zum Kinde in seiner Wirklichkeit und der Liebe zu seiner Höhe, die Erhebung fordert, wird die pädagogische Gemeinschaft getragen von zwei Mächten: Liebe und Autorität, oder vom Kinde aus gesehen: Liebe und Gehorsam. Diese zwei Mächte bestimmen die eigene pädagogische Struktur der Erziehungsgemeinschaft“ (a. a. O., S. 138).

- Dem Bemühen des Erziehers um das Kind „entspricht im Zögling nun ein Wachstumswille und eine Hingabe, die nach Hilfe und Schutz, Zärtlichkeit und Anerkennung verlangt. Aber auch hier bekommen Wachstumswille und Hingabe erst den erzieherisch-geistigen Charakter, wo der Verkehr mit einem Reiferen gesucht wird, um von ihm Lebenskraft und Form zu gewinnen“ (a. a. O., S. 136).

- „Die pädagogische Wirkung geht nicht aus von einem System von geltenden Werten, sondern immer nur von einem ursprünglichen Selbst, einem Menschen mit einem festen Willen, wie sie auch auf einen wirklichen Menschen gerichtet ist: die Formung aus einer Einheit" (a. a. O., S. 132f.).

- „,...] das pädagogische Verhältnis strebt - das ist sein Schicksal und die Tragik des Lehrerseins - von beiden Seiten dahin, sich überflüssig zu machen und zu lösen, - ein Charakter, der so keinem anderen menschlichen Bezuge eigen ist“" (a. a. O., S. 137).

Wenn man diese Aussagen auf ihren Kern hin überprüft, dann sind folgende Merkmale des erzieherischen Verhältnisses als wesentlich und allgemeingültig zu betrachten:

1. Das Verhältnis zwischen Erziehern und Zöglingen ist grundsätzlich eine beiderseitige Beziehung mit Wechselwirkungen, d. h.:

- dem Erzieher wird ein engagiertes Bestreben zur Entwicklungsförderung des Zöglings mit Rücksicht auf dessen Bestrebungen zugesprochen und

- dem Zögling wird ein Wachstumswille unterstellt, für dessen Wirksamkeit er die Unterstützung des Erziehers erwartet. 
2. Der Erzieher ist dem Zögling geistig, sittlich usw. überlegen (reifer):

- er nimmt ihn so liebe- oder zumindest so verständnisvoll an, wie er ist,

- er bemüht sich engagiert um seine Entwicklung, was auch im Interesse der Gesellschaft liegt.

3. Der Erfolg der Bemühungen des Erziehers hängt entscheidend vom „Wachstumswillen" und von der Bereitschaft des Zöglings ab, den Ratschlägen des Erziehers zu folgen. Nur die durch Personen in sozialer Interaktion erzengten werthaltigen Wirkungen beliebiger Mittel sind pädagogischer Natur; zufällige Wirkungen von Werten oder Gegenständen auf Menschen sind keine erzieherischen, sondern nur persönlichkeitsverändernde Einflüsse (vgl. S. 19).

4. Das erzieherische Verhältnis erstrebt und erfährt durch das beiderseitige Bemühen von Erziehern und Zöglingen mit der relativ „abschließenden Realisierung" der jeweiligen Erziehungsziele zugleich seine Auflösung.

Außer diesen Merkmalen des erzieherischen Verhältnisses finden sich in den obigen Zitaten Behauptungen, die aus der Sicht des hier vertretenen dialektisch-materialistischen Systems pädagogischer Erkenntnisse zumindest fragwürdig erscheinen:

Als erstes fällt bei Nohl und der Mehrzahl seiner Nachfolger auf, dass als Erzieher stets die Erwachsenen, Älteren oder zumindest Reiferen erscheinen und als Zöglinge die Kinder, die Jüngeren oder Unreifen. Das erzieherische Verhältnis wird damit primär an natürliche Unterschiede der beteiligten Personen (Lebensalter) gebunden. Nimmt man das ernst, so gehört Erwachsenenbildung nicht in den Gegenstandsbereich der Pädagogik, denn bei dieser kommt es vor, dass die Lehrkeraft jünger ist und auch über weniger Lebenserfahrung verfügt als mancher ältere Lehrgangsteilnehmer. Außerdem sei in diesem Zusammenhang zustimmend auf Bollnow verwiesen, der schreibt:

„Wenn wir den Menschen in seiner grundsätzlichen Erziehungsbedürftigkeit sehen, dann dürfen wir die Erziehung nicht auf das kindliche Alter beschränken und meinen, sie sei im Augenblick des Erwachsenenwerdens abgeschlossen. Wir müssen vielmehr erkennen, dass der Mensch grundsätzlich und immer erziehungsbedürftig bleibt, weil er sein ganzes Leben hindurch sich immer zu neuen Stufen entwickelt, in denen sich immer neue Aufgaben ergeben. Der Mensch bedarf seines ganzen Lebens hindurch der fortgeführten Erziehung. So gibt es nicht nur eine Erwachsenenbildung im Sinn einer weiteren Vermittlung von Wissen und Fertigkeiten (wie man vielfach, aber einseitig die Volkshochschulen aufgefasst hatte), sondern als fortgeführte, echte, d. h. ihn in seiner sittlichen Person betreffenden Erziehung“" (1983, S. 42).

Zweitens muss Nohls Vorstellung von Autorität kritisch geprüft werden. Er betrachtet sie quasi als ein Qualitätsmerkmal des erwachsenen Erziehers, als eine ihm anhaftende oder zugeordnete Eigentümlichkeit, die dem Gehorsam als Qualitätsmerkmal des kindlichen Zöglings gegenüber gestellt wird: 
„Autorität (ist) nichts anderes als das Gewissen jenes höheren Lebens und das Vorbild jener höheren Form, dem die Seele zugeführt werden soll. [...] Autorität heißt also nicht Gewalt, wenn sie sich auch unter Umständen mit ihr wappnen muß, und Gehorsam heißt nicht aus Angst oder blind folgen, sondern heißt freie Aufnahme des Erwachsenenwillens in den eigenen Willen, spontane Unterordnung als Ausdruck eines inneren Willensverhältnisses, das gegründet ist in der überzeugten Hingabe an die Forderungen des höheren Lebens, das durch den Erzieher vertreten wird“ (a. a. O., S. 138f.).

Mit diesen Aussagen werden nicht die wirklichen Grundlagen pädagogischer Autorität gekennzeichnet, sondern eher mystisch verklärt und in traditioneller Denkweise mit der Vorstellung von „erwachsenen Erziehern“ und ,kindlichen Zöglingen“ verknüpft. Den Kindern wird dann das Merkmal des Gehorsams zugeordnet. Richtig und bedeutsam an Nohls Auffassung ist, dass er Autorität mit dem pädagogischen Bezug verbindet. Das bedeutet: überall dort, wo die Beziehung zwischen den jeweiligen Personen in einem beabsichtigen Erziehungsprozess nicht auch durch Autorität gekennzeichnet ist, gibt es kein erzieherisches Verhältnis, ist keine binreichend funktionstüchtige pädagogische Struktur vorhanden, was zum Scheitern erzieherischer Bemühungen führt.

Als weitere Komponenten erzieherischer Verhältnisse seien hier in Anlehnung an Nohl genannt: Ehrfurcht, Achtung, Pietät und Dankbarkeit (a. a. O., S. 139). Nohl nennt als Merkmal des erzieherischen Bezugs auch die Liebe; die in sehr unterschiedlicher Ausprägung auftreten kann, etwa in Form sog. reiner Menschenliebe und Sympathie oder auch in schwärmerischer Zuneigung bis hin zur Verliebtheit - von welcher Seite auch immer. Bei den zuletzt genannten Ausprägungen handelt es sich um pädagogisch unspezifische Merkmale mit je eigener Problematik. Für Erzieher ist es wichtig, zu erkennen, dass Sympathie vielfach eine „Brücke für die Ideologie“ ist, denn die Übermittlung von Wertvorstellungen wird durch wechselseitige Sympathie befördert. Andererseits kann aber die Sympathie und mehr noch die Liebe mit erotischer Komponente auch zu Konflikten in Erziehungsgemeinschaften führen: angefangen von Eifersüchteleien bis hin zu berechtigten oder unberechtigten Klagen über Bevorzugungen - abgesehen von moralischen Gefahren und schwerwiegenden Verdächtigungen wegen eines möglichen oder tatsächlichem sexuellen Missbrauchs von Schutzbefohlenen.

Kron referiert verschiedene Varianten von Auffassungen zur differenzierten Bestimmung und Darstellung der Wesensmerkmale erzieherischer Verhältnisse, die hier nicht wiederholt werden sollen. Nur auf die Auffassung von Kron bzw. Bollnow sei abschließend noch kurz eingegangen, weil sie Grundfragen der Pädagogik betrifft:

„Mit der Bezeichnung »erzieherisches Verhältnis« [...] kommen denn auch andere Momente ins Spiel als im pädagogischen Bezug. In Anlehnung an Bollnow (1959) sind hier u. a. zu nennen: die Angst, das Scheitern, die Sorge, die Stimmungen, die Geborgenheit, die Krise. Dabei ist von Bedeutung, dass diese »Existentialien« nicht nur den Educandus, sondern auch den Er- 
zieher, also beide, oder alle in einer pädagogischen Beziehung Stehenden betreffen und z. B. in Unsicherheit stürzen bzw. die Beziehungen selbst in ihren eingespielten Ideal- und Machtstrukturen zum Einsturz bringen können; oder anders gesagt: die im Modell des pädagogischen Bezugs unterstellte Stetigkeit wird als grundsätzlich gebrochen angesehen und in dieser Gebrochenheit als unstetig erlebt und radikalisiert. [...] Das Scheitern, das für alle im pädagogischen Feld Tätigen [...] zur Urerfahrung gehört, ist - so Bollnow - im klassischen Sinn unseres Wissenschaftsverständnisses nicht mehr theoretisierbar, wohl aber existentiell erfahrbar und darum auch aussagbar" (Kron 1991, S. 228).

Was Bollnow und Kron über die Gefahr des Scheiterns von Erziehungsbemühungen und erzieherischen Verhältnissen sowie über die damit verbundenen Sorgen und Ängste schreibt, trifft natürlich zu. Das weiß jeder Erzieher aus Erfahrung. Dass erzieherische Verhältnisse durch diese Gefahr ein bestimmtes Gepräge erhalten, leuchtet ein und ist nichts Besonderes, weil es für viele menschliche Beziehungen zutrifft, denn bei welcher Art von menschlichen Beziehungen besteht nicht die Gefahr der Enttäuschungen, des Scheiterns und des Abbruchs? Aber es fragt sich, ob es berechtigt ist, diesen fundamentalen Sachverhalt als „,nicht mehr theoretisierbar“ zu betrachten. Aus der Sicht des dialektisch-materialistischen Wissenschaftsverständnisses kann darauf verwiesen werden, dass sich das mögliche und tatsächliche Scheitern erzieherischer Bemübungen und Beziehungen auf der Grundlage der statistischen Gesetzeskonzeption bzw. der Dialektik von Notwendigkeit und Zufall im Rahmen menschlicher Begegnungen und Ereignisse sehr wohl theoretisch erörtern und erklären lässt. Wenn beispielsweise die hier vorgestellten notwendigen Merkmale funktionierender erzieherischer Verhältnisse im konkreten Falle nicht gegeben oder nur unzureichend entwickelt sind (was in der Regel auch empirisch überprüfbar ist), wird uns ein Scheitern der erzieherischen Bemühungen nicht wundern. Von besonderer Bedeutung ist in diesem Zusammenhang sicher das „Gesetz der ungewollten Nebenwirkungen in der Erziehung“ (Spranger 1962). Gemeint ist damit, dass auch gut durchdachte und zweckmäßig erscheinende Bemühungen des Erziehers Wirkungen hervorbringen, mit denen niemand gerechnet hat. Das liegt daran, dass kein Erzieher alle Befindlichkeiten seiner Zöglinge, alle sonstigen Einflussfaktoren und inneren Verarbeitungsprozesse erkennen und berücksichtigen kann (siehe auch S. 63f.).

Bei der Bestimmungen des Begriffs „erzieherisches Verhältnis“ sind folgende Momente zu berücksichtigen:

- Kompetenzüberlegenheit des Erziehers durch erworbene Befähigungen bezüglich der jeweiligen Aneignungsgegenstände und entsprechender Übermittlungs- und Aneignungsmethoden;

- juristische Berechtigung, an den Zögling Forderungen zu stellen und ihre Erfüllung zu bewerten; 
- die Tatsache, dass der Zögling sich dem durch Kompetenzen begründeten Führungsanspruch des Erziehers unterwirft bzw. unterwerfen muss, wenn er mit dessen Hilfe seine eigenen Kompetenzen entwickeln will;

- ein Mindestmaß an wechselseitigem Vertrauen;

- die Tatsache, dass erzieherische Verhältnisse grundsätzlich nicht allein aus den Beziehungen zwischen Erziehern und Zöglingen heraus zu bestimmen sind, sondern ihre eigentlichen „Wurzeln“ im gesellschaftlichen Reproduktions- bzw. Innovationsprozess und in den individuellen Entwicklungsprozessen der Zöglinge haben; der Erzieher ist daher verpflichtet, Vertreter berechtigter gesellschaftlicher Anforderungen und Anwalt des Zöglings zu sein;

- die Tatsache, dass ein erzieherisches Verhältnis auch die Möglichkeit von Zwangs- und Strafmaßnabmen einschließt, denn Zwang ist manchmal notwendig, um Schlimmeres zu verhindern.

Erzieherische Verhältnisse bilden die personale Grundstruktur von Erziehungsprozessen und enthalten zumindest folgende allgemeine Merkmale:

Unter einem erzieherischen Verhältnis verstehen wir die Beziehung zwischen Erziehern und Zöglingen, die sich ergibt aus einer zielbezogenen Kompetenzüberlegenheit des Erziehers, einer wesentlich dadurch bedingten Abhängigkeit des Zöglings vom Erzieher und dem wechselseitigen Ver trauen beider im Interesse der Persönlichkeitsentwicklung des Zöglings.

Mit dieser Definition des erzieherischen Verhältnisses wird sein sozialer Charakter betont und zugleich eine Abgrenzung zur Ableitung aus dem Generationsverbältnis vorgenommen, das ja seinem Wesen nach ein natürliches Verhältnis ist, wenn auch ein gesellschaftlich modifiziertes. Schleiermacher war der Meinung:

„Es muß also eine Theorie geben, die, von dem Verhältnis der älteren Generation zur jüngeren ausgehend, sich die Frage stellt: Was will eigentlich die ältere Generation mit der jüngeren? [...] Auf diese Grundlage des Verhältnisses der älteren zur jüngeren Generation, was der einen in Beziehung auf die andere obliegt, bauen wir alles, was in das Gebiet dieser Theorie (gemeint ist die Theorie der Erziehung, W. N.) fällt"“ (Schleiermacher 1965, S. 38).

Wenn man die erzieherischen Verhältnisse bis ins 19. Jahrhundert hinein betrachtet, dann hat es den Anschein, als seien sie durch eine natürliche Überlegenheit der älteren Generation über die jüngere bestimmt. Insofern erscheint Schleiermachers Standpunkt plausibel. Dennoch ist er zur Begründung der Pädagogik als Theorie nicht geeignet, denn in Wirklichkeit hatten die Angehörigen der älteren Generation nur schon etwas mehr Zeit als ihre Nachkommen, um das Lebensnotwendige zu lernen und entsprechende 
Erfahrungen zu sammeln, so dass sie mehr oder weniger über die erforderlichen Kompetenzen für den Erhalt und die Reproduktion des gesellschaftlichen bzw. gemeinschaftlichen Lebens unter relativ gleichartigen Bedingungen verfügten.

Spätestens aber seit der Mitte des 20. Jahrhunderts hat die Dynamik gesellschaftlicher Entwicklungsprozesse in fortgeschrittenen Industrieländern dazu geführt, dass sich Vertreter der jüngeren Generation die erforderlichen Kompetenzen zur Bewältigung gesellschaftlicher Anforderungen durch ibr Interesse an der modernen Technik und durch ibre Aufgeschlossenheit gegenüber veränderten Lebensbedingungen relativ selbständig und in wechselseitiger Unterstützung aneignen, wodurch sie älteren Personen vielfach überlegen sind. Im Übrigen stehen Vertreter aller Generationen immer wieder vor neuen Herausforderungen, Aufgaben und Problemen, und wer bei ihrer Bewältigung pädagogische Unterstützung zu geben vermag, wird nicht durch Generationszugehörigkeit, sondern durch Kompetenzüberlegenheit entschieden, wobei Kompetenzen Aufgaben bezogene Fäbigkeiten und juristisch fundierte Befugnisse einschließen. Letzteres gilt z. B. für junge Volkshochschuldozenten gegenüber älteren Hörern ebenso wie für junge staatlich anerkannte Sozialpädagogen gegenüber Eltern.

Die Einbeziehung der Möglichkeit von Zwängen und Ängsten in das erzieherische Verhältnis führt zur Frage nach dem Verbot oder der Zulässigkeit von Zwangs- und Strafmaßnahmen in der Erziehung, die seit Jahrhunderten diskutiert wird und die zu den umstrittensten in der Pädagogik des 20. Jahrhunderts gehört. Zunächst waren Strafmaßnahmen (einschließlich der Prügelstrafe) bei der Erziehung von Kindern und Heranwachsenden über Jahrhunderte hinweg in Europa üblich. Als Rechtfertigung dafür diente der Spruch „Wen Gott liebt, den züchtigt er“ - so jedenfalls hat es der Autor in seiner Kindheit noch erlebt. Natürlich haben humanistisch gesonnene Pädagogen schon im 19. Jahrhundert die weit verbreitete Prügelstrafe zu reduzieren versucht. So heißt es beispielsweise in Herbarts „Umriss pädagogischer Vorlesungen“:

„die körperlichen Züchtigungen, welche da einzutreten pflegen, wo Verweise nicht mehr helfen, würde man umsonst ganz zu verbannen suchen; sie müssen aber so selten sein, dass sie mehr aus der Ferne gefürchtet, als wirklich vollzogen werden“ (Herbart 1922, Bd. 1, S. 319).

Herbart erörtert nach dieser Erklärung noch die negativen Folgen körperlicher Züchtigungen:

- ihre ehrverletzenden Wirkungen und

- $\quad$ die Abhärtung gegen Schläge, so dass sie die beabsichtigte Disziplinierung nicht nur verfehlen, sondern eher noch Widerstand gegen die Erzieher hervorrufen.

Er kommt daher auch zu dem Schluss,

„Daß Auktorität ${ }^{22}$ und Liebe die Regierung mehr sichern als alle harten Mittel, ist sehr bekannt. Auktorität aber kann sich nicht jeder nach Belieben schaffen; es gehört dazu sichtbare Überle genheit des Geistes, der Kenntnisse, des Körpers, der äußeren Verhältnisse. Liebe gutartiger

22 Die Schreibweise lässt noch die Herkunft des Wortes klar erkennen - lateinisch: auctoritas = Ansehen, Einfluss. 
Zöglinge zu erwerben, ist zwar durch ein gefälliges Betragen im Laufe einer längeren Zeit möglich; aber gerade da, wo die Regierung (modern gesagt: die Disziplinierung, W. N.) am nötigsten wird, hört die Gefälligkeit auf, und die Liebe darf nicht durch schwache Nachsicht erkauft werden; sie hat nur einen Wert, wenn sie mit notwendiger Strenge besteht“ (a. a. O., S. 320).

Damit hat Herbart eine pädagogische Grundposition formuliert, die - sofern man die Prügelstrafe generell verbannt - auch in der Gegenwart noch Gültigkeit beanspruchen kann. Strafen sind ein prinzipiell möglicher und leider manchmal auch notwendiger Bestandteil von Erziehung, weil es u. a. auch nach Meinung eines erfahrenen Psychiaters

„,nicht klug (ist), auf jede Möglichkeit der Bestrafung von vorn herein zu verzichten. Für manche Kinder, die sonst mit ihren Trieben allein nicht fertig werden, kann das verhängnisvolle Folgen haben. Moderne Tendenzen in der pädagogischen Psychologie gehen davon aus, dass Belohnung ein ebenso wirksamer Erziehungsfaktor wie Bestrafung sei. Zweifel an dieser Auffassung scheinen angebracht. Eine Belohnung, ein Preis wird ein Verhalten bestärken; dagegen wird eine Bestrafung gewissen Verhaltensweisen, die sich in einigen Subjekten als zu stark aus geprägt zeigen können, Grenzen setzen.

Als ich mit der Entwicklung von Jugendlichen konfrontiert war, die unter Drogenabhängigkeit litten oder wegen Gewalttaten längere Gefängnisstrafen abzusitzen hatten, habe ich mich oft gefragt, ob eine straffe, aber gerechte Erziehung diese Jugendlichen vor ihrem schweren Leidensweg, aus der schrecklichen Lage, in der sie sich befanden, hätte retten können. Eine Gesellschaft ohne Rechtsordnung kann es nicht geben; eine Rechtsordnung ohne Strafe auch nicht. Soll man die Kinder mit der Illusion einer straffreien Gesellschaft erziehen?" (Garcia 1986, S. 185f.).

Allerdings sind manche Strafmethoden in den „special schools“ der USA - z. B. Elektroschocks, die zwei Sekunden lang große Schmerzen verursachen und bei kleinsten „Vergehen“ (z. B. bei lautem Naseputzen) angewendet werden - nicht nur unvereinbar mit den Menschenrechten, sondern auch pädagogisch verwerflich und kontraproduktiv, denn laut Statistik werden die Absolventen privater Drillschulen später häufiger straffällig als andere Jugendliche (vgl. „tv-Hören und Sehen“ vom 04.01.2008, S. 4).

Zwangs- und Strafmaßnahmen unter Wahrung der Menschenwürde und Menschenrechte - und dazu dient u. a. das Folterverbot - sind demnach ein möglicher und unter Umständen sogar notwendiger Bestandteil von Erziehung; sie geben damit dem erzieherischen Verhältnis ein spezifisches Gepräge, das in vielen anderen zwischenmenschlichen Verhältnissen fehlt oder fehlen sollte.

Von besonderer Bedeutung sind weiterhin folgende Merkmale erzieherischer Verhältnisse, die von der persönlichen Qualität des Erziehers abhängig sind:

- $\quad$ eine über die jeweilige mit dem Aneignungsgegenstand verbundene Fachkompetenz hinausgehende pädagogisch-methodische Kompetenz des Erziehers; 
- eine persönliche Zuwendung des Erziehers zum Zögling, die sich in Wohlwollen und Verständnis für dessen Entwicklungsprobleme sowie in einem freundlichen und ermutigenden Umgangston äußert;

- realistische Erwartungen an die Anstrengungsbereitschaft und Leistungsfähigkeit des Zöglings, weil andernfalls die Gefahr des Scheiterns besteht;

- ein angemessenes, für den Zögling einsichtiges, berechenbares und zu bewältigendes Anforderungsregime des Erziehers, das flexibel und konsequent realisiert wird;

- Geduld des Erziehers als „Kunst des Warten-Könnens“, weil Erziehungsprozesse mit den darin eingeschlossenen Entwicklungsprozessen nicht beliebig beschleunigt werden können;

- Humor und die Fähigkeit zur Entwicklung einer optimistischen Grundstimmung.

Dass es sich bei erzieherischen Verhältnissen grundsätzlich um widerspruchsvolle und auch konflikthaltige Beziehungen handelt, liegt auf der Hand, denn mit jeder Forderung, die ein Erzieher an einen Zögling stellt, setət er einen wie auch immer gearteten Widerspruch: z. B. zwischen der Anforderungsstruktur der Aufgabenstellung und der Fähigkeit bzw. Bereitschaft des Zöglings, sie zu erfüllen; zwischen den Wünschen des Zöglings und den Erwartungen des Erziehers usw. Das bedeutet: wie jede menschliche und gesellschaftliche Beziehung ist auch das erzieherische Verhältnis in der Realität aspektreich und widersprïchlich; vor allem ist es dynamisch, was sich in seinen Schwankungen zeigt, die bis an die Grenze des Scheiterns gehen.

Dennoch lässt sich sagen: Die jeweils Wertesystem bezogene Kompetenzüberlegenheit einer Person oder einer Gruppe gegenüber anderen Personen kann ein erzieherisches Verbältnis konstituieren und damit zugleich ein pädagogisches Autoritätsverhältnis gegenüber Einzelnen oder Gruppen begründen, das vor allem in Entwicklungs-Gemeinschaften (vgl. Prüß 2000, S. 271ff.) vielgestaltige Ausprägungen erfährt.

\subsection{Zum Autoritätsproblem in der Pädagogik}

Pädagogische Autorität ist eine wesentliche Determinante in dem Wechselwirkungsverhältnis zwischen Erziehern und Zöglingen, die auf der Kompetenzüberlegenheit des Erziehers beruht und sich darin äußert, dass die Erzieher das Verhalten ibrer Zöglinge weitgehend bestimmen und die Zöglinge die Orientierungen der Erzieher befolgen. Für die Wirkungen von Autoritäten trifft zu, was für alle dialektische Determinationen gilt: sie tragen Wahrscheinlichkeitscharakter! So ist z. B. ein Arzt in der Regel für seine Patienten eine Autorität; ob der Patient aber tatsächlich die verordneten Medikamente immer vorschriftsmäßig einnimmt, ist damit noch nicht entschieden. 
Eine dialektische Determination hängt eben nicht nur von der Qualität der Determinante (etwa den Vorschriften des Arztes oder Forderungen des Erziehers) ab, sondern auch von den Eigenheiten des Determinierten (also des Patienten oder des Zöglings), was sich in der statistischen Verteilung der realen Wirkungen des Autoritätsgesetzes widerspiegelt. In Anwendung der statistischen Gesetzeskonzeption von Hörz können wir zunächst feststellen: notwendige, aber nichtsperifische Wirkungsbedingung des Autoritätsgesetzes ist die Existenz von Sozietäten (Tiergemeinschaften und Menschengruppen), die im Interesse ihres Überlebens u. a. auch Beqiehungen der Über- und Unterordnung oder genauer: des Bestimmens und Befolgens realisieren. Ohne Autoritätsbeziehungen im Sinne des Bestimmens und Befolgens - zumindest einer vereinbarten Norm - zum Zwecke eines koordinierten und berechenbaren Handelns ist eine Gesellschaft nicht lebensfäbig. Der Einzelne kann nicht unabbängig und obne Rücksichtnahme auf andere existieren; diese Abhängigkeit erfordert - in vertretbaren Grenzen - auch die Unterordnung des eigenen Willens unter den Willen der jeweiligen dominierenden gesellschaftlichen Kraft - sei es eine möglichst demokratisch gewählte Regierung, ein Arbeitgeber oder eine Gemeinschaft (z. B. eine Familie).

Das durch Autorität hervorgerufene Bestimmen und Befolgen ist eine allgemein-notwendige und wesentliche Bedingung im Leben von Gemeinschaften. Allerdings gibt es große Unterschiede in der Fundierung und Ausprägung von Autoritätsverhältnissen, die von den gesellschaftlichen Bedingungen abhängen, unter denen dann das Autoritätsgesetz wirk.t. Alle realen Herrschaftssysteme schließen auch institutionelle oder amtliche Autoritätsverbältnisse mit eigener Problematik ein, die ökonomisch, politisch, rechtlich und religiös bzw. ideologisch begründet sind und bis in Familienverhältnisse hinein wirken. Institutionelle Autoritätsverhältnisse sind von pädagogisch begründeten Persönlichkeitsautoritäten zu unterscheiden, auch wenn sie in Verbindung miteinander wirken.

Entsprechend dem Gesetz der transgredienten Determination der Erziehung sind auch pädagogische Autoritätsbeziehungen transgredient bestimmt. Da aber die Erziehung als System über eine relative Eigenständigkeit und Eigengesetzlichkeit verfügt, werden in ihr zugleich spezifische Bedingungen wirksam. Determination durch den Erzieher bedeutet, dass er das Verhalten und Handeln der zu Erziehenden relativ nachhaltig stimulieren, bestimmen, kontrollieren und lenken kann, und zwar in dem Maße, wie die Zöglinge die Impulse und Forderungen des Erziehers aufnehmen, möglichst auch kritisch bedenken, akzeptieren und entsprechend realisieren. In Erziehungs- und Bildungsinstitutionen ist in Verbindung mit der gesetzlich fundierten Amtsautorität (institutionellen Autorität), in der gesellschaftliche Machtstrukturen wirksam sind, die Persönlichkeitsautorität besonders bedeutsam. Diese wird primär durch die Qualitätsmerkmale des Erziehers begründet (siehe S. 274ff.), während Amtsautorität auch von wenig qualifizierten Kräften genutzt oder gar missbraucht wird. Das Autoritätsgesetz. im Bereich der Pädagogik kann mittels folgender Gesetzesaussagen formuliert werden: 
1. Die Wirksamkeit erzieherischer Maßnahmen wird wesentlich durch den Entwicklungsstand der Autorität, insbesondere durch die Persönlichkeitsautorität der erzieherischen Kräfte bestimmt (= qualitative Gesetzesaussage).

2. Wenn das Autoritätsverhältnis - insbesondere die Persönlichkeitsautorität gut entwickelt ist, dann haben Erziehungsmaßnahmen Erfolg (im Sinne der statistischen Gesetzeskonzeption) (= qualitative Gesetzesaussage).

3. Je ausgeprägter die Persönlichkeitsautorität des Erziehers ist, desto wirksamer sind seine pädagogischen Maßnahmen (= komparative Gesetzesaussage).

Das Verbältnis des Bestimmens und Befolgens ist kein lineares oder mechanisches Kausalverhältnis, sondern dem Wesen nach ein Wechselwirkungsverbältnis, in dem sich beide Seiten (Pole) wechselseitig bedingen, einander ausschließen, im Widerspruch zueinander stehen und dadurch aufeinander einwirken und verändern. Dominiert der Einfluss des Erziehers im jeweiligen Erziehungsverhältnis, dann funktioniert der Erziehungsprozess systemgerecht; ist es der Zögling, dann besteht die Gefahr des Scheiterns, zumindest der vom Erzieher beabsichtigten Erziehungsmaßnahmen, manchmal aber auch des gesamten erzieherischen Verhältnisses.

Am Beispiel des Gesetzes vom freien Fall demonstrierte Hörz, wie durch die Existenz der Erde und anderer makrophysikalischer Körper die notwendigen, aber noch nicht sperifischen Bedingungen gegeben sind, die einen allgemeinen und notwendigen $\mathrm{Zu}$ sammenhang zwischen Fallweg, Fallzeit und Anziehung durch einen Himmelskörper konstituieren und damit notwendige Voraussetzungen für das Fallgesetz sind. Wenn sich ein Stein an einem Felshang löst und frei fällt, treten jene Bedingungen ein, die (unter Vernachlässigung unspezifischer Bedingungen) von ihm als Wirkungsbedingungen erster Ordnung bezeichnet werden (siehe auch S. 62), und die sich allgemein in der Formel s $=1 / 2 \cdot g \cdot t^{2}$ ausdrücken. Bekanntlich aber

„hat ein Körper, der aus 10 m Höhe fällt eine andere Fallzeit als derjenige, der aus $20 \mathrm{~m}$ Höhe fällt. Man kann das die spezifische Wirkungsbedingung zweiter Ordnung nennen. Sie legen nicht nur die Spezifik des Gesetzes, also den allgemein-notwendigen und wesentlichen Zusammenhang fest, sondern darüber hinaus eine bestimmte Beziehung zwischen den im Gesetz enthaltenen Variablen“" (Hörz 1971, S. 132 und S. 56f. dieses Buches).

Für die pädagogische Autorität ist der auf Kompetenzüberlegenheit berubende handlungs- und verhaltensbestimmende Einfluss des Erziehers auf den Zögling als Wirkungsbedingung erster Ordnung charakteristisch. Das Gesetz wird in unterschiedlichen pädagogischen Bereichen auch unter verschiedenen Wirkungsbedingungen zweiter bis n-ter Ordnung realisiert, die in ihrer Gesamtheit über seine reale Wirksamkeit entscheiden. Die Übersicht 9 verdeutlicht einige Wirkungsbedingungen zweiter und weiterer Ordnung für das Autoritätsgesetz, und zwar in Abhängigkeit von den jeweils verschieden gearteten oder bedingten Erziehungsprozessen. 


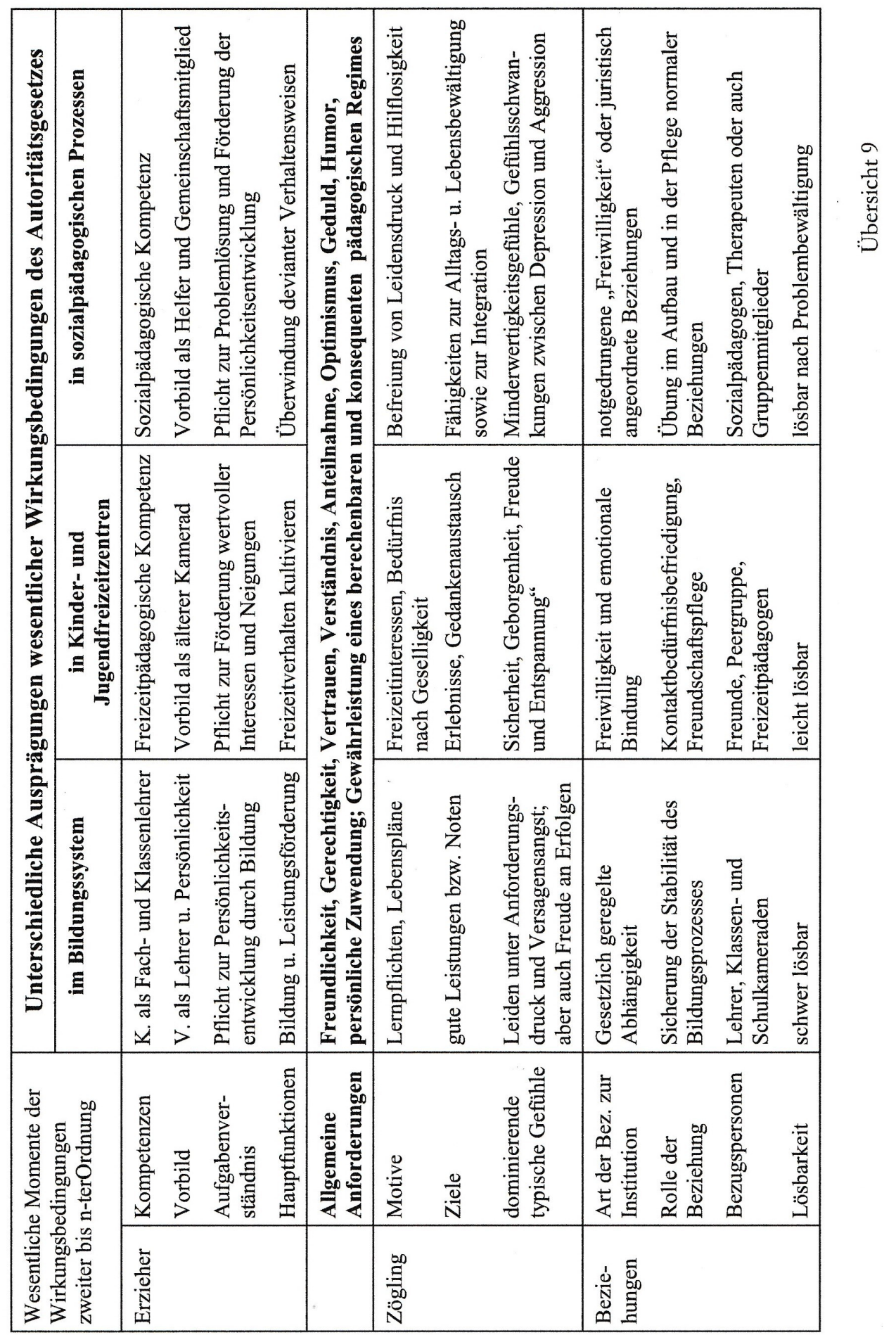


Betrachten wir unter Berücksichtigung der in der Übersicht aufgelisteten Bedingungen die Wirksamkeit des Autoritätsgesetzes in der Schule, dann ist klar (und auch durch empirische Untersuchungen belegt), dass Schüler bei fachlich und didaktisch kompetenten sowie beliebten, freundlichen und konsequent fordernden Lehrern besser lernen als bei unbeliebten (Schneeberg 1976). Die Qualitätsmerkmale erzieherischer Kräfte, die sich in den allgemeinen Anforderungen an Erzieher widerspiegeln, sind generell wichtig. Ferner kommt den jeweiligen spezifischen Merkmalen in den Wirkungsbedingungen insofern eine Bedeutung zu, als sie das Verhalten und Handeln der Lernenden in besonderer Weise stimulieren. Auf der Grundlage von Amtsantorität, die sich in Bildungseinrichtungen $u$. a. in der gesetzlich geforderten Notengebung ausdrückt, lernen viele Schüler auch bei weniger kompetenten oder gar unbeliebten Lehrern meist widerwillig zumindest einiges, weil sie wissen, dass von seinen Bewertungen ihr weiteres Fortkommen und damit u. U. ihre künftige Lebensweise abhängt. Eine große Zahl von Schulschwänzern belegt allerdings, wie wenig heutzutage die Amtsautorität im Schulwesen bewirkt und wie bedeutsam dagegen spezifische Qualitätsmerkmale der Lehrer für eine wirkungsvolle Persönlichkeitsautorität sind.

In der freien Jugendarbeit sind die spezifischen Wirkungsbedingungen qweiter und weiterer Ordnung anders geartet als in der Schule, denn hier ist die Amtsautorität in ihrer Wirksamkeit stark reduziert, d. h., ein Jugendlicher wird sich den Erwartungen und Anforderungen des gemeinsamen Lebens im Jugendklub nur unterordnen, wenn es ihm dort gefällt. Seine Unterordnung hängt nicht von der relativ bescheidenen Amtsautorität des Klubleiters ab, über die dieser natürlich wegen bestehender Rechtsvorschriften auch verfügt, sondern vor allem von dessen menschlichen Qualitäten und freizeitpädagogischen Kompetenzen, also von speziellen Determinanten der Persönlichkeitsautorität. Wenn die Beziehungen zwischen dem Klubleiter bzw. seinen Mitarbeitern und den Jugendlichen durch wechselseitiges Vertrauen und gegenseitige Anerkennung sowie durch kameradschaftliche und verständnisvolle Umgangsformen charakterisiert sind, dann ist auch hier das Autoritätsgesetz wirksam, so dass wertvolle Freizeitbetätigungen gelingen.

In sożialpädagogischen Prozessen wird das Autoritätsverhältnis nachhaltig durch Eigenheiten der Problembelastungen determiniert: Leidensdruck, Misstrauen, Widerstand, Resignation, Passivität, Aggressivität usw. Ängste vor den ungewohnten Anstrengungen eines sog. normalen Lebens erzeugen Abwehrhaltungen gegenüber neuartigen Beziehungen und Anforderungen, die Normalität anstreben. Es bedarf daher großer Anstrengungen zur Herstellung eines ehrlichen und lockeren Umgangstons sowie einer vertrauensvollen Atmosphäre. Die Gewohnheiten und Neigungen der Klienten und die dazu im Widerspruch stehenden ungewohnten und unbequemen Anforderungen des Sozialpädagogen können den Aufbau eines Autoritätsverhältnisses beträchtlich erschweren, vor allem dann, wenn es sich um eine juristisch angeordnete Beqiehung handelt. 
Rasmussen schildert das an Beispielen seiner gerade ins Erziehungsheim Bøgholt eingewiesenen Zöglinge, von denen einige nach Bekanntgabe wesentlicher Positionen der künftigen Tagesgestaltung versuchten, wieder „abzuhauen“ (vgl. S. 292f.). Aber auch dann, wenn sie zunächst bleiben, besteht auf Grund ihrer o. g. Eigenheiten die Gefahr des Abbruchs der Beziehung durch eine Flucht in die alten Verbältnisse. Die von Makarenko und Rasmussen angewandte kategorische Forderung ist offenbar bei der anfänglichen Organisation einer Entwicklungs-Gemeinschaft aus Problembelasteten und bei der Aufnahme neuer Mitglieder unumgänglich! Erst wenn die Klienten die Erfahrung machen, dass ihr Leidensdruck schwindet, persönliche Erfolge in der Gemeinschaftsarbeit erzielt werden und demzufolge ihr Selbstwertgefühl wächst, entwickelt sich auch das Moment der Freiwilligkeit in der Gemeinschaft und eine bewusste Disziplin.

Die praktische Bedeutung einiger Wirkungsbedingungen zweiter Ordnung widerspiegelt sich in pädagogischen Ratschlägen und Regeln, die der Herstellung dieser Wirkungsbedingungen dienen. Sie beschreiben Qualifikationsmerkmale von Erziehern und tragen zur Sicherung ihrer Persönlichkeitsautorität bei:

- Habe Geduld mit den Problembelasteten!

- Sei gerecht und ohne Vorurteil!

- Sei freundlich und humorvoll!

- Begegne den Hilfebedürftigen verständnisvoll, aber auch konsequent!

- Sei Vorbild!

- Beweise deine Kompetenz in jeder Situation, aber scheue dich auch nicht, nötigenfalls deine Grenzen einzugestehen, dadurch kommst du den Hilfebedürftigen näher!

- Sichere in der jeweiligen Institution bzw. Gruppe ein überschaubares und damit berechenbares pädagogisches Regime, das zwar flexibel ist, aber dennoch konsequent eingehalten wird.

Vertreter der antiautoritären Erziehung sehen möglicherweise schon in der Formulierung des Autoritätsgesetzes ein Sakrileg. Dazu ist allerdings zu bemerken, dass auch ein Vorkämpfer der repressionsfreien und antiautoritären Erziehung, nämlich Alexander S. Neill (1883-1973), in seiner Erziehungspraxis vom pädagogischen Autoritätsgesetz. nachhaltig Gebrauch gemacht hat, wie nachfolgender von ihm geschilderte Fall belegt: „Lehrer und Schüler ärgern sich, wenn eine Bande kleiner Mädchen unter Anführung eines der schwierigen Mädchen anderen lästig fällt, sie mit Wasser bespritzt, die Zeit zum Schlafengehen nicht einhält und überhaupt immerfort nur Unfug treibt. Die Anführerin Jean sieht sich daher in der Schulversammlung heftiger Kritik ausgesetzt. Mit scharfen Worten wird ihr Verhalten als Mißbrauch der Freiheit verurteilt. Eine Psychologin, die bei uns zu Gast war, sagte zu mir über 
diesen Fall: »So kann man es nicht machen. Das Gesicht des Mädchens zeigt, dass es unglücklich ist. Jean ist nie geliebt worden, und diese offene Kritik gibt ihr nur noch mehr als vorher das Gefühl, nicht geliebt zu werden. Sie braucht Liebe, nicht Widerspruch«.

»Meine liebe Frau Sowieso«, antwortete ich, »wir haben bereits versucht, sie mit Liebe zu ändern. Wochenlang haben wir sie für ihr gemeinschaftsfeindliches Verhalten belohnt. Wir haben sie mit Zuneigung und Duldsamkeit behandelt, aber auch darauf hat sie nicht im geringsten reagiert. Im Gegenteil, sie betrachtet uns als Trottel und leichte Beute ihrer Aggressionslust. Wir können schließlich nicht die ganze Gemeinschaft für einen einzelnen opfern «"(Neill 1969, S. 68f.).

Dieses Beispiel belegt, dass auch die Schulgemeinschaft, die von einem Experten der antiautoritären Erziehung geleitet wird, ohne Bestimmen und Befolgen - im geschilderten Fall ohne die Unterordnung von Jeans Willen unter den der Gemeinschaft einfach nicht funktioniert. Zu beachten ist dabei allerdings, dass als Erzieher nicht ein pädagogisch ausgebildeter und angestellter Lehrer, sondern die gesamte Schülergemeinschaft in Aktion trat, d. h., die Kompetenzen des realen Erqiehers im Autoritätsverhältnis wurden wirksam. Das Autoritätsverhältnis wurde als gesetzmäßiger Zusammenhang praktisch erlebt, es ist durch die o. g. spezifischen Bedingungen charakterisiert: Zwischen dem kollektiven Erzieher „Schulgemeinschaft" und Jean existiert eine juristische Abhängigkeit (ein Vertrag mit der Schule) und eine emotionale Beqiehung und Bindung zumindest an einige Mitschülerinnen oder Mitschüler; ferner kann die Kompetenz der Schulversammlung von Jean nicht ohne Nachteile für sie ignoriert werden, so dass sie sich ihrer Meinung und ihren Beschlüssen unterordnen muss, wenn sie sich nicht selbst ausschließen will.

Die Schulgemeinschaft bestimmt weitgehend ihre Lebensweise und ihre Entwicklungsmöglichkeiten. Jeans Hilfebedürftigkeit ist offensichtlich und ihre augenscheinliche Betroffenheit lässt erkennen, dass die scharfe Kritik auch eine zweckmäßige Maßnahme gewesen ist. Immerhin erlebte Jean nunmehr die Gefahr, in eine Außenseiterposition zu geraten, und das ist so ziemlich die härteste Strafe (Repression!), die es für ein Gemeinschaftsmitglied, das sich zugehörig füblt, geben kann. Danach gibt es ja nur noch den Ausschluss.

Das Beispiel verdeutlicht fundamentale Sachverhalte im realen Erziehungsprozess:

- Autorität ist keine Eigenschaft einer Person (eines Lehrers, Erziehers, Meisters usw.), sondern eine Determinante in einer wechselseitigen Beziehung zwischen den jeweils realen erzieherischen Kräften und den Zöglingen. In Anlehnung an R. Bellmann (1964) können wir Autorität ibrem Wesen nach auch als ein Regime von Wechselwirkungen betrachten, in dem der reale Erzieher dominiert. So gesehen, kann und sollte es zwar eine Erziehung obne autoritär agierende Erzieherpersönlichkeiten, aber keine Erziehung obne die Autorität des realen Erziehers geben. 
- Auch die sog. repressionsfreie Erziehung kann auf Strafen (bis hin zur Androhung einer Außenseiterposition) nicht verzichten und bestätigt damit, was Makarenko in seinem berühmten pädagogischen Poem „Der Weg ins Leben“ gegenüber einer Vertreterin der Pädologie wie folgt formuliert hat: "Ohne Strafe kann ich nicht erziehen, diese Kunst muß man mir erst noch ${ }^{23}$ beibringen“ (Makarenko 1972, Bd. I, S. 388).

- Ein „herrschaftsfreier Diskurs“ im Sinne von Habermas zur Ermittlung gültiger Normen für menschliches Handeln und Verhalten ist in erzieherischen Verbältnissen nicht möglich, denn es wirkt darin stets Herrschaft von Kompetenz, wenn diese auch nicht immer von vorn herein fixiert ist. Dennoch sind Diskurse möglich und sinnvoll, denn nach erfolgreichem Diskurs müssen sich alle Beteiligten der als gültig erkannten Norm unterordnen, wenn sie weiterhin in der Gemeinschaft leben wollen, in der sie gilt. Wirksam ist aber nicht die Norm, die nur auf dem Papier steht, sondern diejenige, die von aktiven Personen praktisch vertreten wird, indem sie ihre Einhaltung verlangen und durchsetzen.

- Auch eine bewusste und freiwillige Unterordnung (wegen der Kompetenz des Erziehers und der eigenen bewusst gewordenen Hilfebedürftigkeit) hebt das Autoritätsgesetz nicht auf, sondern optimiert eher seine Wirksamkeit.

- Die Ablehnung von Autorität resultiert letztendlich aus einer falschen und irrealen Freiheitsauffassung, mit der sich u. a. Erich Fromm auseinandergesetzt hat, wobei er zu dem Schluss kam:

„Unter Freiheit verstehe ich nicht die Freiheit von allen Leitprinzipien, sondern Freiheit, der Struktur der menschlichen Existenz entsprechend zu wachsen (autonome Restriktionen). Das bedeutet Gehorsam gegenüber den Gesetzen, die die optimale menschliche Entwicklung gewährleisten. Jede Autorität, die dieses Ziel fördert, ist eine »rationale Autorität«, wenn diese Förderung darin besteht, die Aktivität des Kindes zu mobilisieren und seine Fähigkeit zu kritischem Denken und seinen Glauben an das Leben zu stärken“ (Fromm 2000, S. 82/83).

Hörz weist darauf hin, dass sich in manchen gesetzmäßigen Prozessen sog. Begleitbedingungen als so bedeutsam erweisen, dass sie als spezifische Wirkungsbedingungen Berücksichtigung finden müssen. Als solche besonders wichtige Begleitbedingung, die in den Rang einer spezifischen Wirkungsbedingung zweiter Ordnung aufsteigen könnte, wäre z. B. in einer Schulklasse die Existenz bzw. Wirksamkeit einer Clique zu betrachten, die in spürbarer Weise die realen Autoritätsverhältnisse in der Klasse beeinflusst.

23 Das kursiv gesetzte Wort „,noch“ "steht nicht in der Makarenko-Ausgabe des Volk und Wissen Verlags; es wurde auf Empfehlung von Götz Hillig eingefügt. Er hat auch alle folgenden Makarenko-Zitate anhand der Moskauer Originalausgabe überprüft und entsprechende Korrekturen empfohlen, denen in Kursivschrift entsprochen wurde. 


\subsection{Entwicklung und Wirksamkeit von Gemeinschaftsbeziehungen}

\subsubsection{Wesen und Funktionen von Entwicklungs-Gemeinschaften}

Im Abschnitt 5.1 wurde bereits herausgestellt, dass in der Dialektik von Gesellschaft und Individuum, die Gesellschaft in letzter Instanz von übergreifender Bedeutung ist, denn nur im gesellschaftlichen Systemzusammenhang kann ein Individuum überhaupt existieren. Außerdem belegen neuere evolutionstheoretische Erkenntnisse die bedeutende Rolle der Kooperation für die Entwicklung des homo sapiens sapiens. Für ein richtiges Verständnis der Dialektik von Gesellschaft und Individuum ist die Vermittlungsfunktion von Gemeinschaften (im Sinne von Kontaktgruppen) von fundamentaler Bedeutung. Gesellschaftliche Lebensbedingungen und gesellschaftliche Anforderungen erlebt jedes Individuum konkret in seinen jeweiligen Gemeinschaften oder Gruppen, und von diesem Erleben hängt im hohen Maße seine persönliche Entwicklung ab.

„Das vermittelnde Wirken (im vorliegenden Falle von Kontaktgemeinschaften, W. N.) ist ein gesetzmäßiger Zusammenhang, der noch tiefer den Vorgang des Wirkens des bestimmenden Faktors (im vorliegendem Falle der Gesellschaft, W. N.) auf den bestimmten (also das Individuum, W. N.) ausdrückt“" (Cibulka 1964, S. 178).

Die Vermittlungsfunktionen von Gemeinschaften sind vielfältig. Entwicklungs-Gemeinschaften (im Sinne von Prüß) haben aus der Sicht der Gesellschaft die Funktionen,

- das Individuum mit den für seine Entwicklung notwendigen materiellen und kulturellen Gütern zu versorgen (Versorgungsfunktion);

- dem Individuum Schutz für seine Entwicklung zu gewähren (Schutzfunktion);

- dem Individuum die zu seiner Entwicklung erforderlichen soziokulturellen und geistigen Werte der Gesellschaft zu übermitteln (Übermittlungs- oder Förderfunktion);

- das Individuum hinsichtlich seiner Leistungen für die Gesellschaft zu bewerten (Bewertungsfunktion).

Eine Entwicklungs-Gemeinschaft hat aus der Sicht des Individuums die Funktionen,

- ihm als Übungs- und Bewährungsfeld für die reale Aneignung vor allem der sozialen Werte zu dienen (Entwicklungsfeldfunktion);

- dem Individuum Möglichkeiten zur produktiven und kreativen Mitwirkung am gesellschaftlichen Leben und Fortschritt zu geben (Partizipationsfunktion);

- dem Individuum zu signalisieren, in welchem Maße es die Erwartungen der Gesellschaft erfüllt (Spiegelungsfunktion) (vgl. Prüß 2000, S. 129f.).

Die wesentlichen Merkmale von Entwicklungs-Gemeinschaften lassen sich in folgender Definition zusammenfassen: 
Unter Entwicklungs-Gemeinschaften werden in dieser Darstellung jene Kontaktgruppen verstanden,

- die eine prinzipiell humanistische Orientierung in ihren Lebenszielen erkennen lassen,

- in denen die Mitglieder leben, arbeiten, lernen, sich kulturvoll erholen

- und in denen sie auf der Grundlage humanistischer Normen

- in wechselseitigen Kommunikationen und Interaktionen

- relativ stabile Beziehungen emotionaler Verbundenheit, des Vertrauens und der kameradschaftlichen Hilfe entwickeln.

Entwicklungs-Gemeinschaften sind gesellschaftlich eingeordnet und sollten sich als demokratische Verfechter eines entwicklungsfähigen Sozialstaates verstehen, um für ihre Bemühungen eine realitätsnahe und positive Perspektive entwickeln zu können. Sofern Entwicklungs-Gemeinschaften primär erzieherische Aufgaben erfüllen, können sie auch als Erziehungsgemeinschaften betrachtet werden, aber grundsätzlich ist das Spektrum der Funktionen von Entwicklungs-Gemeinschaften breiter.

Die Größe von Entwicklungs-Gemeinschaften ist unterschiedlich: sie reicht von der einflussstarken Primärgruppe (Makarenko nennt sie Grundkollektive mit 7-15 Mitglie$\operatorname{dern}^{24}$ ) bis zu Gemeinschaften oder Gesamtkollektiven (Makarenko 1969, Band V, S. 181) von etwa 300 Mitgliedern, die sich in Primärgruppen und anderen Formationen (Leitungsgremien, zeitweilige Einsatz- und Arbeitsgruppen usw.) organisieren. Entwicklungs-Gemeinschaften (als Gesamtkollektive) können sein: Schulgemeinschaften und Gemeinschaften in Erziehungsheimen, in überbetrieblichen Berufsausbildungszentren für Benachteiligte, in Sportvereinen usw., die eine nach Makarenkos Auffassung zweckmäßige Mitgliederzahl von ca. 300 Personen nicht wesentlich überschreiten. Als günstig haben sich in Makarenkos Kolonien und anderen pädagogischen Einrichtungen Primärgruppen mit Mitgliedern unterschiedlichen Alters erwiesen - ähnlich natürlichen Familien (vgl. Makarenko 1969, Bd. V, S. 173f. und Lietz o. J., S. 28).

Wenn in den nachfolgenden Ausführungen von Gemeinschaften die Rede ist, dann sind - wenn nicht anders vermerkt - Entwicklungs-Gemeinschaften im oben definierten Sinne gemeint. Der Vorschlag von Prüß wird hier aufgegriffen und statt des vielfach gebräuchlichen Begriffs der „Erziehungsgemeinschaft" verwendet, weil er weiter ist als dieser und der Realität besser entspricht. Entwicklungs-Gemeinschaften bilden nicht nur die Strukturen für Erziehungsprozesse, sondern auch für Therapien und produktive Arbeiten - wie z. B. das Projekt „SYNANON“ für freiwillig abstinent lebende

24 Die von Makarenko angegebene optimale Mitgliederzahl einer Primärgruppe ist übrigens nicht neu, denn schon Wichern und seine Mitstreiter haben in ihren Rettungsanstalten Gruppen mit jeweils 12-15 Knaben oder Mädchen gebildet (Rein u. a. 1889, Bd. V, S. 865). 
Drogenabhängige in Berlin-Kreuzberg mit seinen Produktionsstätten in Fleckenbühl bei Marburg (vgl. Günther-Schellheimer 2005, S. 74) und das ehemalige Erziehungsheim von Rasmussen in Bøgholt belegen (vgl. Rasmussen 1993, S. 108ff.).

Im Interesse sachlicher Klarheit werden nachfolgend anstelle des Begriffs „Kollektiv-erziehung“ die Begriffe „Gruppenerziehung“ oder „Gemeinschaftserziehung“ verwendet, und zwar aus folgenden Gründen: In Anlehnung an Wyneken hat Makarenko bis 1927 den Begriff „Gemeinde“ (obščina) verwendet. ${ }^{25}$ Der Kollektivbegriff wurde von ihm selbst und seinen Anhängern in den ehemaligen Ostblockländern mit jeweils zeitgemäßen und schwankenden Auffassungen von sozialistischer Ideologie verbunden. Eine Übernahme des Kollektivbegriffs ist daher unzweckmäßig. Es ist auch nicht ratsam, einen ,ideologisch gereinigten“ Kollektivbegriff zu verwenden, weil dann immer wieder die Frage auftaucht: auf welche Realität bezieht er sich?

In der kritischen und kreativen Auseinandersetzung mit Makarenkos Kollektiverziehung haben dänische Sozialpädagogen die für kapitalistische Verhältnisse verwendbaren Erkenntnisse aus Makarenkos Auffassungen und Erfahrungen extrahiert und unter den Begriff der Gruppenerziehung zusammengefasst (vgl. Rasmussen 1993, S. 105). Diesem Standpunkt schließt sich der Autor an. Wenn also im folgenden Text von Gruppenerziehung die Rede ist, dann handelt es sich um Erziehung in Entwicklungs-Gemeinschaften (entsprechend obiger Definition), die gelegentlich auch schlicht als Gruppen bezeichnet werden. Wenn im Text das Wort „Gemeinschaftserziehung“ verwendet wird, dann handelt es sich - wenn nicht anders vermerkt - auch um Erziehung in Entwicklungs-Gemeinschaften mit humanistischen Wert- und Zielvorstellungen.

Über die erzieherischen Potenzen solcher Gemeinschaften liegen sowohl pädagogischpsychologische Untersuchungen als auch praktische Erfahrungen vor, die von Sozialpädagogen beachtet werden sollten, zumal es sich dabei um Erfahrungen handelt, die gerade in der pädagogischen Arbeit mit jugendlichen Rechtsverletzern gewonnen worden sind. Wenn hier aus der Fülle von Forschungsergebnissen zur Gruppendynamik und Erfahrungen mit der Gemeinschaftserziehung speziell auf die Erkenntnisse des ukrainischen Pädagogen Anton S. Makarenko zurückgegriffen wird, dann hat das folgende Gründe:

- Die pädagogischen Erfolge Makarenkos bei der Erziehung bzw. „Umerziehung" jugendlicher Rechtsverletzer unter sehr schwierigen materiellen und politischen Bedingungen rechtfertigen eine sorgfältige Auswertung dieser Erfahrungen.

- Rasmussen hat nach einem geeigneten Konzept für jugendliche Kriminelle und Drogensüchtige in dem von ihm übernommenen staatlichen Erziehungs-

25 Vgl. Hillig, Götz: Erziehung im Kibbutz - ein Überblick für Pädagogen in der postsowjetischen Ukraine. Tertium comparationis 9 (2003) 2, S. 199. Zitiert nach: http://www.pedocs.de/volltexte/2012/2940/pdf/TC_2_2003_hilli_D_A.pdf (Zugriff: 14.01.2012). 
heim in Bøgholt bei Kopenhagen gesucht und ist dabei mit seinen Mitarbeitern zu der Erkenntnis gelangt:

„Die amerikanisch beeinflusste Kleingruppenpsychologie z. B. war von laboratorienhaften Experimenten und freudianischem Gedankengut geprägt, was meilenweit von den Realitäten der Entwicklung sozialer Beziehungen zwischen Zöglingen eines Erziehungsheimes wie des unseren lag“" (a. a. O., S. 109).

Daher entschied sich er sich mit seinen Mitarbeitern für Makarenkos Konzept.

\subsubsection{Grundelemente bumanistischer Gemeinschaftserziehung}

Die Tatsache, dass konzeptionelle Elemente der Pädagogik Makarenkos unter verschiedenen gesellschaftlichen Bedingungen erfolgreich genutzt wurden, wirft die Frage auf:

Warum und unter welchen Bedingungen bilden Entwicklungs-Gemeinschaften für jedes ibrer Mitglieder generell günstige Voraussetzungen für eine erfolgreiche Erziebung - insbesondere auch für Problembelastete?

Um darauf eine Antwort zu finden, müssen zunächst einmal jene Bedingungen und Prinzipien vorgestellt werden, die sich bei vergleichenden Betrachtungen einiger Entwicklungs-Gemeinschaften als relativ persistente konzeptionelle Grundelemente bumanistischer Gemeinschaftserziehung herausgestellt haben. Damit wird nicht der Anspruch verknüpft, die analysierten Konzepte und Praktiken in hinreichendem Maße historisch aufgearbeitet zu haben. Es geht hier primär um eine systematische Aufbereitung progressiver Erkenntnisse und Erfahrungen in einem Umriss für eine Allgemeine Sozialpädagogik.

Die wichtigsten konzeptionellen Grundelemente humanistischer Gemeinschaftserziehung lassen sich stichpunktartig auflisten, und zwar zunächst unter dem Aspekt grundlegender Strukturen bzw. Strukturmerkmale, die geschaffen bzw. organisiert werden müssen:

- Erziehung durch produktive Arbeit, Bildung, Sport und künstlerische Betätigungen im Rahmen (zumindest partieller) gemeinsamer Lebensgestaltung,

- Souveränität und Selbstverwaltung der Entwicklungs-Gemeinschaft,

- altersunterschiedlich zusammengesetzte Primärgruppen und zeitweilige Arbeits- und Einsatzgruppen sowie Interessengemeinschaften und Zirkel.

Diese Strukturen erfordern und ermöglichen dann die Anwendung folgender Prinzipien:

1. Hohe Achtung gegenüber den Zöglingen in Verbindung mit steigenden Anforderungen und einem konsequenten Anforderungsregime;

2. Paralleles pädagogisches Vorgehen und individuelles Eingehen;

3. Wechsel von Unterordnung und Führung;

4. Entwicklung echter Perspektiven und wertvoller Traditionen; 
5. Sicherung eines sozialintegrativen Stils, eines optimistischen Grundtons und einer öffentlichen Meinung im Sinne humanistischer Erziehungsziele;

6. Sicherheit und Geborgenheit für jeden;

7. Entwicklung einer bewussten und freiwilligen Disziplin bei Wahrung der Möglichkeit differenzierten Strafens.

Die Verbindung von Arbeits- und Lernprozessen ist eine alte Praxis. Sie wurde von Pädagogen der Neuzeit (z. B. Johann H. Pestalozzi, Johann J. Wehrli (1790-1855), Christian G. Salzmann (1744-1811), Robert Owen) in jeweils zeitgemäßer Weise realisiert und als pädagogischer Grundsatz theoretisch reflektiert. Auch Lietz forderte in seiner Programmschrift

„Praktische Arbeit jeder Art [...] (Hervorhebung durch W. N.). Darum muss neben gärtnerischer und landwirtschaftlicher Arbeit jeder wenigstens ein Handwerk erlernen: Tischlerei, Schlosserei, Schmiederei oder Buchbinderei. Da mit jedem Heim ein umfangreicher wirtschaftlicher und technischer Betrieb verbunden ist, die Hauptnahrungsmittel an Ort und Stelle gewonnen und die meisten Gebrauchsgegenstände hier hergestellt werden, so bietet sich allen reichliche Gelegenheit, genauen Einblick in Wirtschaft und Technik zu erhalten, darin mitzuarbeiten, praktische, umsichtige Menschen zu werden“ (Lietz, o. J., S. 8).

Das erstgenannte Prinzip wurde von Makarenko niveauvoll umgesetzt, nämlich mittels anspruchsvoller produktiver Arbeiten (z. B. Herstellung von elektrischen Geräten und Fotoapparaten). Weitz betont dies in Anlehnung an Formulierungen von Makarenko:

„Um voranzukommen, sei eine Absage an den handwerklich-sozialerzieherischen Charakter der Wirtschaft notwendig, an deren Stelle ökonomisch solide Wirtschaftsbetriebe treten müssten, deren komplexe und umfassende Organisation nach den bisherigen Erkenntnissen einen positive Einfluss auf die Mitglieder ausüben“ (Weitz 1989, S. 152).

Makarenko organisierte eine Produktion auf relativ hohem Niveau mit der besten zu seiner Zeit und in seinem Land verfügbaren Technik, weil nur unter solchen Bedingungen „,neue Menschen“ erzogen werden können. Die mit der modernen Produktion verbundenen Anforderungen bieten die alltäglichen Anlässe für Hilfen, Bewertungen und Kritiken, die von den Mitgliedern der Gemeinschaft genutzt werden müssen, wenn das Unternehmen Bestand haben soll. Als erzieherisch wertvoll erwiesen sich sowohl bei Salzmann und Lietz als auch bei Makarenko und Rasmussen die Arbeiten an größeren Projekten (z. B. Sportanlagen) oder umfangreiche Feld- und Gartenarbeiten.

Über den erzieherischen Wert von Existenz sichernden oder zumindest die Existenz stützenden produktiven Arbeiten finden sich bei Rasmussen ebenso bestätigende Hinweise wie in den Berichten über die Arbeit in den Zweckbetrieben von SYNANON, einer Selbsthilfegemeinschaft für freiwillig abstinent lebende Drogenabhängige (vgl. Günther-Schellheimer 2005, S. 73f.). 
Bildung stand im Zentrum aller Entwicklungs-Gemeinschaften, die für die vergleichende Analyse mit herangezogen worden sind, nämlich

- die Armenschule (auch landwirtschaftliche Schule genannt), gegründet 1804 von Philipp E. v. Fellenberg (1771-1844) auf seinem Landgut Wylhof (jetzt: Hofwil bei Bern/Schweiz),

- das Philanthropinum von Salzmann in Schnepfenthal (gegründet 1784),

- die Landerziehungsheime von Lietz (1. Heim gegründet 1898 in Ilsenburg),

- die Freie Schulgemeinde Wickersdorf von Gustav Wyneken (1875-1964),

- die Gor'kij-Kolonie bei Poltava (gegründet 1920) und die Dzieržynskij-Kommune in Charkov (eröffnet 1928) unter Leitung oder Einfluss von Makarenko

- und das Erziehungsheim in Bøgholt bei Kopenhagen, nach 1974 einige Jahre unter der Leitung von Harald Rasmussen.

Was die unterschiedlichen Bildungskonzepte dieser Einrichtungen geleistet haben, kann hier nicht erörtert werden. Es sei nur eine verallgemeinerungswürdige Erfahrung herausgehoben: Die Bildungsarbeit war in dem Maße erfolgreich, wie sie inhaltlich mit den realen Anforderungen des gesamten Lebensprozesses der Gemeinschaft verbunden wurde und demzufolge auch einem realisierbaren und konsequenten Anforderungsregime unterlag.

Natürlich steht diese aus den o. g. Internatsschulen bzw. Erziehungsheimen gewonnene Einsicht der Auffassung von Neill entgegen, der z. B. auf die Frage: „Sind Sie für Hausaufgaben" geantwortet hat:

„Ich halte nicht einmal etwas von Schulstunden, es sei denn, die Kinder entscheiden sich freiwillig dafür“" (1969, S. 338).

Dem widersprechen u. a. aber die Erfahrungen aus Bøgholt ganz eindeutig, wo 1974 zu Beginn der Arbeit bei den eingewiesenen Jugendlichen eine allgemeine Abneigung gegenüber Schulunterricht bestanden hatte. Doch nach der Eingewöhnung in das Anforderungsregime sowie auf der Grundlage persönlicher Erfahrungen und Erfolge in den Arbeits- bzw. Unterrichtsprozessen entwickelte sich bei ihnen ein solches Bildungsstreben, dass sie im Herbst 1977 die Einführung eines qusätzlichen Unterrichts von zwei Stunden am wöchentlichen freien Abend erwirkten, vor allem für Deutsch, Rechnen und Schreibmaschine (vgl. a. a. O., S. 119/120).

In der Programmschrift von Lietz werden vielfältige künstlerische Aktivitäten angeboten und zudem gefordert:

„In der Gesamtanlage der Heime und ihrer Gärten, dem Bau der Häuser, der Ausstattung der Räume soll das Gesetz von Schlichtheit und Schönheit walten. Mit einfachen Mitteln sollen Musik, Malerei, Bildhauer- und Dichtkunst, mimische Darstellung gepflegt werden und das Leben harmonischer gestalten" (Lietz o. J., S. 15). 
Unter seinen Lehrern in Haubinda wirkte auch als Dramaturg und Bühnengestalter Martin Luserke (1880-1968), ,auf den der Begriff des Laienspiels zurückgeht“ (Badry 1994, S. 160).

Theaterspiele und andere musische Betätigungen gab es schon an der von Anton S. Makarenko geleiteten erweiterten (d. h. bis zur 7. Klasse führenden) Grundschule in Krjukov. Für eine intensive Pflege des Laienspiels in der Gor'kij-Kolonie ist nach dem Bericht von Makarenkos Mitarbeiter N. Fere (1953, S. 46ff.) aber wohl ausschlaggebend, dass Makarenko 1925 seinen Urlaub in Moskau verbrachte und nach seiner Rückkehr den Kolonisten von seinen Theaterbesuchen erzählte. Er weckte damit bei vielen Jugendlichen den Wunsch, selbst Theater zu spielen und unterstützte sie durch Bearbeitung geeigneter Stücke und seine eigene Mitwirkung.

Dass in den Landerziehungsheimen der Sport eine große Rolle gespielt hat, ist nicht verwunderlich, denn sowohl Cecil Reddie (1858-1932) in Abbotsholme, bei dem Lietz 1896/1897 gearbeitet hat, als auch Lietz selbst verehrten Christian G. Salzmann, an dessen Philanthropinum in Schnepfenthal bei Gotha ein Wegbereiter des neuzeitlichen Schulsports tätig gewesen ist, nämlich Christoph Friedrich GutsMuths (1759-1839).

Rasmussen berichtet in dem bereits zitierten Vortrag über die sportliche Arbeit mit seinen problembelasteten Jugendlichen in Bøgholt:

„Alle mussten damals an den schwerpunktmäßig sportlich bestimmten Aktivitäten teilnehmen Es war Jahre nicht mehr vorgekommen, daß Pädagogen solche Forderungen an sie gestellt hatten. Die zu dieser Zeit herrschende pädagogische Richtung legte den Akzent auf die Motivierung durch Gespräche und ließ den Kindern und Jugendlichen die freie Wahl, sich für die eine oder andere Aktivität zu entscheiden oder eben überhaupt nicht teilzunehmen“ (a. a. O., S. 113).

Diesem Laissez-faire-Stil im Umgang mit den Jugendlichen erteilte Rasmussen eine prinzipielle Absage; und was eignet sich in der Praxis wohl besser, um Jugendliche an klare Forderungen, gültige Regeln und fairen Umgang miteinander zu gewöhnen, als Sport, und zwar besonders Mannschaftsspiele!

In den analysierten Einrichtungen entwickelten die Zöglinge in allen vier Tätigkeitsbereichen auf natürliche Weise einen jugendlichen Wetteifer (besonders im Sport und in der produktiven Arbeit), der ihre Anstrengungsbereitschaft erhöbte, ihnen ibre persönlichen Stärken erleben und die Anerkennung durch die Gemeinschaft erfahren ließ, was wesentlich zur Entwicklung einer bewussten und freiwilligen Disziplin beitrug. Um jedoch diese persönlichkeitsbildenden Faktoren optimal zur Wirkung zu bringen, bedurfte es der Souveränität der Gemeinschaft.

Die Bedeutung dieser Bedingung für eine erfolgreiche Erziehungsarbeit ist eigentlich erst nach dem Untergang der Sowjetunion richtig deutlich geworden, als nämlich bisher unbekannte Materialien der Forschung zugänglich wurden. So zitiert Götz Hillig 
aus den Arbeitstagebüchern von Ivan A. Sokoljanskij (1889-1960), der u. a. die Funktionen eines Oberinspektors und (späteren) Leiters der Einrichtungen für defektive Kinder des Zentrums bzw. Hauptkomitees für Sozialerziehung in Charkov innehatte:

„Das Geheimnis der Disziplin kann von niemanden außer Makarenko und mir enträtselt werden: Makarenko bezüglich der »Rechtsbrecher« und ich bezüglich der Defektiven. Das Geheimnis der Macht des Einflusses von Makarenko liegt in dessen absoluter Unabbängigkeit (Hervorhebung von W. N.), die übrigens in erster Linie von mir geschaffen wurde. Das hat nichts mit Angeberei oder Hochmut von meiner Seite zu tun, das ist einfach eine Tatsache [...]. Ich nahm eine ziemlich hohe Position ein, was es mir ermöglichte, Makarenko gegenüber den verschiedensten Schurken, die ihm von allen Seiten zusetzten, zu verteidigen. Ich betone: Makarenko war in seinen Handlungen und Taten gerade in der Zeit, als er experimentierte, völlig frei $[\ldots]$.

Makarenko arbeitete hinter einem Rücken, auf den man einschlug und den man dabei zerbrach (Sokoljanskij war 1933 und 1937 wegen angeblicher Zugehörigkeit zu einer »ukrainischen konterrevolutionären Organisation« bzw. zu einer »antisowjetischen nationalistisch-terroristischen Organisation« inhaftiert worden, W. N.); doch hinter diesem Rücken wuchs Makarenko zum Genie heran. Es gab nicht nur einen »Rücken«, aber mein Rücken befand sich an vorderster Stelle $[\ldots]$.

Welche Schlüsse lassen sich aus Makarenkos Erfolgen ziehen? Nur ein einziger - ein Pädagoge muß in seinen Handlungen und Taten völlig selbständig sein“ (Sokoljanskij, zitiert nach Hillig 1993, S. 236/237).

Um den Handlungsspielraum, der mit der jeweiligen Souveränität verbunden ist, ausschöpfen zu können, bedarf es einer funktionstüchtigen demokratischen Selbstverwaltung der Gemeinschaft. Wenn man die Entwicklungs-Gemeinschaften aus verschiedenen historischen Perioden betrachtet, fällt auf, dass es in den Landerziehungsheimen von Lietz bescheidene Anfänge einer Schülerselbstverwaltung gegeben hat, und zwar nicht nur in Gestalt von bevollmächtigen Schülern, sog. Präfekten, sondern auch in Form von Mitgliederversammlungen, in denen die Schüler allgemein interessierende Angelegenheiten des Internatslebens diskutierten, Beschwerden vortrugen und klärten, Vorschläge für die Gestaltung von Feiern und Festen unterbreiteten und über Beschlüsse abstimmten (vgl. Lietz o. J., S. 26f.).

In den Einrichtungen Makarenkos finden wir ebenfalls Mitgliederversammlungen und Beauftragte des Kollektivs mit speziellen Kompetenzen (Kommandeure, Rat der Kommandeure, Brigadeleiter usw.). Von hoher erzieherischer Wirkung waren die kritischen Auseinandersetzungen in Mitgliederversammlungen mit undisziplinierten Kolonisten und mit den Brigadeleitern, die mit undisziplinierten Brigademitgliedern ,nicht fertig wurden“. In diesem Zusammenhang sei daran erinnert, dass in den Schulversammlungen 
von Summerhill sich jene Schüler verantworten mussten, die ihre Freiheiten im Internat missbraucht hatten (vgl. S. 280f. und Neill, 1969, S. 60-70).

Natürlich ist in den genannten Einrichtungen sowohl der Grad der Souveränität als auch der Umfang der Rechte ihrer jugendlichen Bewohner im Rahmen der Selbstverwaltung unterschiedlich. In den Landerziehungsheimen von Lietz bewegten sich die Befugnisse der Schüler in dem engen Rahmen, der ihnen durch den Führungsstil eines im Geiste patriarchalischen Obrigkeitsdenkens erzogenen Bauernsohnes zugestanden wurde. Übrigens war das neben anderen Meinungsverschiedenheiten ein Grund für Wyneken und andere Lehrer, sich von Lietz zu trennen, um 1906 die Freie Schulgemeinde Wickersdorf zu gründen, in der die Schülervertretung größere Mitspracherechte erhielt.

Andererseits hat Neill in seiner „Schule der demokratischen Selbstregierung“ in Summerhill den Schülern wohl zu viele Rechte eingeräumt, und zwar nicht nur in dem Sinne, dass sie dem Unterricht nach Belieben fernbleiben durften. Sie haben in der Schulversammlung den Schulleiter für „abgesetzt“ erklärt und Gesetze beschlossen, die sie dann selbst brachen oder einfach ,vergaßen“ (vgl. Neill 1969, S. 67).

Makarenko entwickelte in dieser Hinsicht ein anderes Konzept. Auch er respektierte die Beschlüsse der Mitgliederversammlung - selbst dann, wenn er mit ihnen nicht einverstanden war. Er wollte die Autorität der Mitgliederversammlung nicht infrage stellen und die Jugendlichen sollten Gelegenheit haben, aus ihren Fehlern zu lernen. Aber er sorgte in wichtigen Angelegenheiten für eine solche Vorbereitung der Beschlüsse, dass das Wohl der Gemeinschaft gesichert wurde, denn die Erfüllung von Beschlüssen war Gesetz. Doch das funktioniert erst dann oder in dem Maße, wie sich aus dem diffusen „Haufen“, der in einer solchen Einrichtung zusammengekommen ist, eine strukturierte und organisierte Gemeinschaft entwickelt hat.

Gruppenstrukturen können auf verschiedene Weise erforscht und dargestellt werden. Zu den bewährten und aufschlussreichen Verfahren gehören z. B. soziometrische Untersuchungen, die jedoch Gegenstand der Psychologie sozialer Prozesse sind und hier nicht erörtert werden können. In Makarenkos sozialpädagogischer Praxis wurden Strukturen entwickelt und reflektiert, die populäre oder plausible Bezeichnungen erhalten haben und praktisch brauchbar sind. Er hat folgende Differenzierungen in seinen Kollektiven vorgenommen:

„Alle Kommunarden gliederten sich für mich in zwei Gruppen: erstens das tätige Aktiv, zweitens die Reserve des Aktivs. Zum tätigen Aktiv gehören alle diejenigen, die - sichtbar für jeden - die Kommune führen, die auf jedes Problem mit Gefühl, mit Leidenschaft, Überzeugung und mit Forderungen reagieren. [...] Aber im Falle der Gefahr, bei einer großen Kampagne, einem Sturmangriff ${ }^{6}$ oder wenn bei irgendeinem Skandal eingegriffen werden muß, haben sie stets

26 Korrektur nach Hillig - vgl. Jahrbuch für Historische Bildungsforschung, 2006, S. 270. 
eine Reserve; [...] sie (ihre Mitglieder, W. N.) kommen dem Aktiv unverzüglich zu Hilfe. [...] Ferner gab es bei uns [...] ein gesundes Passiv. Das waren diejenigen, die noch nicht groß genug waren, die aber an den Zirkeln - Sport, Photozirkel, Wandzeitungsarbeit - teilnahmen; sie folgten gehorsam den Älteren. Wir hatten einige, die ein faulendes Aktiv darstellten“ (Makarenko 1969 , Bd. V, S. 183f.).

Dieses faulende Aktiv, das sich durch Drückebergerei, herrisches Auftreten gegenüber Schwächeren und delinquentes Handeln (Diebstähle, Einbrüche in der Nachbarschaft usw.) „auszeichnete“, wurden von den Kommunarden auch als „Packzeug“ oder „Sumpf“ bezeichnet (a. a. O., S. 184). Eine solche Gruppe ist nicht notwendiger Bestandteil einer Entwicklungs-Gemeinschaft, aber sie kommt vor. Allerdings provozieren die letztgenannten Bezeichnungen die Gefahr, dass einzelnen Mitgliedern u. U. leichtfertig ein verletzendes Etikett angeheftet wird. Daher ist ihr Gebrauch nicht ratsam. Das eigentliche Problem besteht darin: was können und müssen Sozialpädagogen tun, damit sich eine pädagogisch wirksame Gruppenstruktur entwickelt?

Eine erste Antwort darauf enthält zunächst das bereits genannte Prinzip der hohen Achtung gegenüber den Zöglingen in Verbindung mit einem konsequenten Anforderungsregime (siehe auch Konzeptprinzip 4.6.5 und Funktionsprinzip 6.2.5). Rasmussen schildert die Anwendung dieses Prinzips bei Problembelasteten, die sich wegen ihrer devianten Gewohnheiten „Korrekturbemühungen“ zunächst hartnäckig widersetzten, wie folgt:

„Mit wenigen Sätzen hieß ich die Neuankömmlinge in Bøgholt willkommen und begann, ihnen mitzuteilen, wie sich ihr Alltag hier gestalten würde. Wie aus einem Munde unterbrachen sie mich. »Wir wollen keine Schule, das ist tote Hose; und in die Werkstätten wollen wir auch nicht. Nur Schwachköpfe arbeiten; wenn uns etwas fehlt, holen wir’s uns einfach « (so die Mädchen). Ich antwortete nicht darauf, ließ mich auf keine Diskussion ein. Den Zeitpunkt dafür wollte ich mir selbst aussuchen. Ich wandte mich an die zwei anwesenden Sozialpädagogen und bat sie, den Zöglingen ihre Zimmer und die Duschräume zu zeigen.

Alle bleiben heute in den Gebäuden ihrer Abteilung; wenn wir zu Abend gegessen haben, gibt 's Sportfilme. Morgen um sieben Uhr stehen wir auf, und dann beginnt der Alltag. Am Spätnachmittag versuchten drei davonzulaufen, kamen aber nicht vom Gelände herunter, da sie von Pädagogen in Empfang genommen wurden, die schon auf sie gewartet hatten. Ohne Kommentar wurden sie zurück geleitet“ (a. a. O., S. 112).

In den nächsten Tagen galt es immer wieder durch klare Forderungen (Aufstehen, Waschen, Frühstücken, zum Unterricht gehen, in den Werkstätten arbeiten usw.) das erforderliche Tagesregime durchzusetzen, wobei nur bei Gefahr von Gewaltausbrüchen, beim Beleidigungen der Mädchen o. Ä. Disziplinierungsmittel eingesetzt wurden.

„Nach etwa zwei Wochen begannen unsere neuen Bewohner ruhiger zu werden. Da kam ein neuer »Haufen« von zehn Zöglingen derselben Sorte, [...]. Diesmal ging es aber schon leichter, 
die negativsten Elemente unter ihnen zur Einsicht zu bringen, daß gewisse Regeln unbedingt eingehalten werden müssen. Und noch leichter ging es, als der dritte »Haufen« fünf Wochen nach den ersten Zöglingen ankam. Dieser wurde von den »alten« Zöglingen sogleich informiert, warum sie in Bøgholt blieben, die Schule, die Werkstätten usw. besuchten. Hauptargument war, daß die Freizeitaktivitäten hier etwas taugten, [...]“ (a. a. O., S. 113).

Natürlich versuchte gelegentlich ein Zögling, sich vor dem Unterricht zu drücken, indem er sich frühmorgens krank meldete. In solchen Fällen, in denen auch nicht immer gleich zu erkennen war, ob der oder die Betreffende simulierte, wurden sie aufmerksam und fürsorglich wie Kranke behandelt; sie mussten im Bett bleiben, Fieber messen, Tee trinken usw. Dabei zeigte sich, dass die Simulanten ihre Rolle nicht länger als zwei Tage durchhalten konnten.

Dass manche Zöglinge ihre Drohung, auszureißen, gelegentlich auch verwirklichten, ist nicht verwunderlich. Im Unterschied zu ihren früheren Heimen machten die Ausreißer allerdings in Bøgholt die Erfahrung, dass sie nicht beschimpft, sondern ernsthaft und im besorgten Ton nach den Gründen des Ausreißens befragt wurden, wenn sie sich wieder eingefunden hatten. Die verständnisvolle Behandlung führte dazu,

„daß es fast zur Norm wurde, im Falle des Ausreißens mindestens einmal am Tage anzurufen, um wenigstens ein Lebenszeichen zu geben. Der Anruf führte nicht selten dazu, daß die oder der Betroffene um Geld bat, um nach Bøgholt zurückfahren zu können. Besonders die fortgelaufenen Mädchen waren überzeugt davon, daß ich als Heimleiter so besorgt um sie war, daß ich nicht schlafen konnte. Deshalb konnten sie um zwei oder drei Uhr nachts anrufen, um mir zu versichern, daß sie in ein paar Tagen wiederkommen würden. Oft kamen sie dann am Tag nach dem Gespräch“ (a. a. O., S. 113).

Es wurde strickt darauf geachtet, dass in Fällen von Diebstahl in Geschäften die Diebe in Begleitung eines Pädagogen die gestohlenen Sachen zurück brachten. Die Einhaltung der Norm (,wir stehlen nicht“) gehörte mit zu den unabdingbaren Forderungen. Dadurch gelang es, die Diebstähle stark zu reduzieren.

Die Schilderungen lassen erkennen, dass und wie die Erzieher in Bøgholt das Konzeptprinzip der Verbindung von persönlicher Achtung mit angemessen hohen und steigenden Forderungen angewendet haben. Ohne konsequente Anwendung dieses Prinzips wird aus einem „Haufen“ keine Entwicklungs-Gemeinschaft. Aus Rasmussens Schilderung ist auch zu entnehmen, dass und wie paralleles pädagogisches Vorgehen und individuelles Eingehen wirksam wurden. Die erfahreneren Heimbewohner „belehrten“ die Neuankömmlinge über die Vorzüge des Heimes, so dass diese sich schneller einordneten. Aber seine volle Wirksamkeit entfaltet dieses Prinzip erst in tagtäglichen Lebens-, Arbeits- und Lernprozessen, weil dann jene „eiserne Logik des menschlichen Zusammenlebens“ wirkt, von der Ansbacher/Ansbacher in Anlehnung an Adler sprechen (1982, S. 136). 
Jede Nachlässigkeit bei der Wahrnehmung einer Aufgabe wird nämlich zur zusätzlichen Belastung für den „Nachfolger im Amt“ oder einen anderen Kameraden. Da aber niemand gern die Nachlässigkeiten anderer „aufarbeiten“ möchte, kommt es zu jenen zahlreichen erzieherischen Impulsen im Alltag, die unter den Bedingungen der erzieherischen Verhältnisse einer Entwicklungs-Gemeinschaft möglich sind und zum Spezifischen und Wesen der psychosozialen Intensiverziehung gehören.

Mit dem parallelen pädagogischen Vorgehen erübrigt sich keineswegs das individuelle Eingehen auf Besonderheiten des einzelnen Problembelasteten durch den Leiter der Einrichtung oder seine Mitarbeiter. Gerade Makarenkos Pädagogik der Kollektiverziehung, die auch unter dem Aspekt angeblicher Nivellierung der Menschen abgewertet worden ist, hat zu diesem Problem interessante Erfahrungen hinterlassen, nämlich

„daß in der Tat sowohl ein allgemeines »Standard-Programm« als auch ein individuelles Korrektiv dazu vorliegen müsse. Für mich stand nicht die Frage, ob mein Zögling ein tapferer Mensch werden solle oder ob ich einen Feigling erziehen wolle. Hier ließ ich den »Standard« gelten, daß jeder ein tapferer, mutiger, ehrlicher, arbeitsamer Patriot sein müsse. Wie soll man aber vorgehen, wenn man es mit solchen subtilen Seiten der Persönlichkeit wie dem Talent zu tun hat?" (Makarenko 1969, Bd. V, S. 123)

Er erörtert das Problem der gezielten individuellen Förderung am Beispiel des Kolonisten Terentjuk, der ihm wegen seiner schauspielerischen Fähigkeiten in der Laienspielgruppe besonders aufgefallen war. Dieser Junge erreichte auch einen sehr guten Schulabschluss und wollte verständlicherweise studieren. Es war zur Zeit der Industrialisierung der Sowjetunion ein allgemeiner Trend, dass Jungen Ingenieurwissenschaften studierten. Demzufolge bewarb sich auch Terentjuk an einem Technikum und Makarenko ließ ihn gehen, weil er meinte, ,schließlich habe ich nicht das Recht, eine derartige Umstellung (gemeint ist eine Immatrikulation an einer Theaterhochschule, W. N.) herbeizuführen.“ Nach einem halben Jahr merkte Makarenko, dass Terentjuk, der weiterhin im dramatischen Zirkel der Kolonie mitspielte, wahrhaftig die falsche Fachrichtung gewählt hatte und erwirkte mit Hilfe der Mitgliederversammlung, dass der Junge seine Studienrichtung wechselte - zu seinem Glück, denn er wurde ein anerkannter Schauspieler, wie Makarenko berichtet hat (vgl. a. a. O., S. 124).

Das Prinzip des parallelen pädagogischen Vorgehens und der individuellen Förderung kann auch dadurch wirkungsvoll in einer Entwicklungsgemeinschaft genutzt werden, dass ein differenziertes System der Arbeitsteilung und Kompetenzverteilung organisiert wird, wodurch jeder Zögling entsprechend seinem Entwicklungsstand verantwortliche Aufgaben erhält, über deren Erfüllung er gegenüber der Gemeinschaft rechenschaftspflichtig ist - ein Vorgehen, das schon Lietz (o. J., S. 26f.) erfolgreich praktiziert hat. Wenn zur Realisierung bestimmter Aufgaben sog. Einsatz- oder Arbeitsgruppen gebildet und entsprechende Leiter eingesetzt werden, dann kommt bei pädagogisch gut 
durchdachter Organisation jedes Gemeinschaftsmitglied in die Lage, sich zeitweilig einem seiner Kameraden unterzuordnen, aber auch zu führen, d. h. Verantwortung zu tragen und sich durchsetzen zu müssen. Rasmussen berichtet darüber wie folgt:

„Durch wechselnde Verantwortung für die Organisation und Durchführung von praktischen Aufgaben und Freizeitaktivitäten, etwa von gemeinsamen Wochenendausflügen, Ferienreisen usw. eignen sich die Zöglinge Fähigkeiten und Fertigkeiten in der Planung, Organisierung und Leitung solcher Aktivitäten an; sie lernen dabei auch, sich einem Kameraden unterzuordnen, der Verantwortung für die Aktivität trägt, oder im umgekehrten Falle, ihm Anweisungen zu erteilen“ (a. a. O., S. 126).

Das Prinzip kann aber nur dann voll wirksam werden, wenn der jeweils übergeordnete Leiter nicht über den Kopf eines eingesetzten Arbeitsgruppenleiters hinweg in die Arbeitsgruppe „hinein regiert“, denn dadurch würde die Autorität des Arbeitsgruppenleiters untergraben. Außerdem könnte man ihn dann auch für Fehlleistungen in der Gruppenarbeit kaum noch zur Rechenschaft ziehen. Mit der Übertragung verantwortungsvoller Aufgaben und dem Wechsel von Unterordnung und Führung erschließen sich zudem Möglichkeiten zur individuellen Förderung einzelner Gruppenmitglieder.

Bereits bei der Erörterung ursächlicher Bedingungen für deviante Verhaltensweisen wurde auf das Problem der aggressiven Langeweile und die Wirkungen des Gefühls der Perspektivlosigkeit mancher Hauptschüler hingewiesen. Tatsächlich handelt es sich hierbei um ein grundsätzliches Problem, vor dem Sozialpädagogen und Jugendliche stehen: Erziehung bedarf einer gesellschaftlichen Abstützung durch echte und realisierbare Perspektiven für Kinder und Jugendliche! Das heißt konkret: unbedingte Gewährleitung eines Ausbildungsplatzes und Eröffnung einer echten Berufs- und Lebensperspektive! In Entwicklungs-Gemeinschaften geht es darüber hinaus nicht nur um jene weit in die Zukunft reichenden Lebensperspektiven ihrer Mitglieder, sondern auch im Rahmen der täglichen Arbeit um jene nahen und mittleren Perspektiven, die als Freude auf den nächsten Tag erlebt werden können und die wesentlich von der Konzipierung und Realisierung mobilisierender Ziele der Gemeinschaft abhängig sind (z. B. Bau einer Sportanlage, Teilnahme an einem Leistungsvergleich).

Wegen des demografischen Tiefs seit dem sog. Pillenknick müsste es in der Bundesrepublik möglich sein, echte Berufsperspektiven zu eröffnen. Es sollte hierbei nur nicht übersehen werden, dass es auch Versäumnisse in der Erziehung zu Zielstrebigkeit, Anstrengungsbereitschaft, Ausdauer und Verantwortungsbewusstsein sind, die sich als Hindernisse bei der Ausschöpfung vorhandener ökonomischer Möglichkeiten erweisen. Jugendpfarrer Dietrich Lauter aus Neuhofen bei Ludwigshafen stellte schon 1993 fest:

„Eine Umfrage unter ehrenamtlichen jugendlichen MitarbeiterInnen in der Jugendarbeit fördert ein ähnliches Erleben zutage: die Jugendlichen, z. B. 14jährige, mit denen eine Jugend- 
gruppe gegründet werden soll, seien vielfach grob, unverschämt, hätten zu nichts Lust, würden aber gleichzeitig riesige Ansprüche stellen, wollten am liebsten nur bedient werden, würden alles dreckig zurücklassen, [...].

Diese Beispiele stammen [...] aus dem normal-bürgerlichen Bereich, es handelt sich um Kinder und Jugendliche aus meist gut situierten und gesichert lebenden Mittelschichtfamilien. Noch extremer, aber nicht wesentlich verschieden, empfinde ich die Verhaltensweisen von entwurzelten und sozial benachteiligten Jugendlichen“ (Lauter 1993, S. 146).

Lauter hat sich mit Erfolg um die Anwendung pädagogischer Grundsätze Makarenkos in der kirchlichen Jugendarbeit bemüht und ist dabei auf eine recht bemerkenswerte Schwierigkeit gestoßen:

„Ohne [...] Perspektiven, ohne eine optimistische gesellschaftspolitische Zielvorstellung, die sich an Werten wie Solidarität, Kollektivität, Gerechtigkeit orientiert, ist keine Pädagogik im Sinne Makarenkos denkbar“ (Lauter 1993, S. 139).

Und er fügt dem die wenig ermutigende Einschätzung hinzu:

„Es fehlt die Vision einer besseren Welt, die Massen von jungen Menschen begeistern könnte, es gibt keine glaubwürdige Organisation, der sie sich anschließen könnten. Es gibt derzeit kaum einen perspektivischen Entwurf für die Welt - ja wir fragen uns: kann es einen solchen überhaupt noch geben?“ (a. a. O., S. 141).

Diese Erkenntnisse zwingen immer wieder zu den bereits vorn geforderten Forschungen und Diskussionen zum Problem der Umgestaltung der Gesellschaft. Aber Sozialpädagogen müssen unabhängig von der Lösung dieses Grundsatzproblems dem einzelnen Problembelasteten helfen und sollten daher die Möglichkeiten humanistischer Gemeinschaftserziehung nutzen, zumal solche Beispiele wie Bøgholt dazu ermutigen.

Die Entwicklung von Traditionen in einer Gruppe unterstellt eine Mindestdauer ihres Bestehens und die Chance ihres Fortbestehens - also Bedingungen, die nicht nur in Erziehungsheimen oder Sportgruppen, sondern auch in überbetrieblichen Ausbildungszentren für benachteiligte Jugendliche gegeben sind. Welche Traditionen sich in solchen Einrichtungen entwickeln, hängt in hohem Maße von der Kreativität der Beteiligten $\mathrm{ab}$ - sowohl von den Erziehern als auch von den Auszubildenden. Es handelt sich hierbei nicht allein um Bräuche und Feste - wie sie von Lietz und Makarenko eindrucksvoll geschildert worden sind - , sondern auch um bestimmte Verhaltensweisen im alltäglichen Umgang miteinander. Traditionen sind insofern für die Gemeinschaft bedeutsam, als sie ein „stabiles Gerüst“ in der Dynamik des Lebensalltags darstellen und Grundlage sind für ein spezifisches „Wir-Gefühl“. Dieses „Wir-Gefühl“ darf sich nicht auf brutale Aufnahmerituale stützen und in einem unkritischen, blinden und bedingungslosen Gehorsam äußern - wovor auch Adorno eindringlich warnt (1965) - , sondern auf humane Ziele und Prinzipien, die der Soziologe Karl O. Hondrich herausgestellt hat: 
- das Prinzip der Reziprozität, d. h. des Gebens und Erwiderns in der Gemeinschaft,

- das Prinzips der kollektiven Identität, d. h. des Teilhabens oder Dazugehörens und des Ausschließens oder Abgrenzens und

- das Prinzip der ständigen Bewertung (vgl. Lau 2004, S. 30).

Das Prinzip der ständigen Bewertung, das auch eine spontan wirksame Gesetzmäßigkeit in der Gemeinschaft widerspiegelt, kann zugleich als Stimulus und Mittel der psychosozialen Intensiverziehung wirken und das Dazugehören bzw. Ausschließen regeln.

Der Zusammenhalt einer Gemeinschaft hängt außerdem ab

- vom Stil des Umgangs miteinander, von der Grundstimmung im Lebensalltag und vom Wertgehalt der wirksamen öffentlichen Meinung sowie

- von der Geborgenheit und Sicherheit eines jeden Mitgliedes in der Gemeinschaft.

Es ist verständlich, dass Makarenko dem Gefühl der Geborgenheit besondere Bedeutung beigemessen hat, weil seine Kinder und Jugendlichen in den Wirren der Revolution und des Bürgerkrieges verwaist waren bzw. ihr Elternhaus verloren und in der Kolonie eine Heimstätte gefunden hatten. Dennoch bedarf es erzieherischer Anstrengungen, um wirkliche Sicherheit und Geborgenheit und das entsprechende Gefühl bei allen Zöglingen zu erzeugen:

„Es liegt auf der Hand, daß diese Idee des Geborgenseins nicht von selbst kommt; sie muß geschaffen werden und an ihr muß gearbeitet werden. Schafft man in diesem Stil einen ständigen Frohsinn, die Fähigkeit zur Bewegung, zur Energie und zum Handeln, so muss man gleichzeitig auch die Fähigkeit entwickeln, sich zu zügeln. Und gerade das ist es, was dem durchschnittlichen Erzieher verhältnismäßig selten gelingt. Sich selbst zu zügeln ist sehr schwierig, besonders im Kindesalter; das ergibt sich nicht einfach biologisch, sondern dazu muß erzogen werden. Und wenn der Erzieher nicht darauf bedacht ist, zur Selbstbeherrschung zu erziehen, so wird sie sich eben nicht einstellen“ (Makarenko 1969, Bd. V, S. 226f.).

Wie eng das Gefühl der Geborgenheit mit dem gesamten Bedingungsgefüge der Gruppenerziehung zusammenhängt, geht aus folgenden Worten hervor:

„Die Idee des Geborgenseins muß im Kollektiv besonders gegenwärtig sein und seinen Stil auszeichnen. Sie muß dort erwachsen, wo das Kollektiv stolz auf sich selbst ist, wo Forderungen an jeden einzelnen gestellt werden, also dort, wo jeder einzelne sich vor Gewalt, Willkür und Hohn geschützt fühlt.

Dieses Gefühl der Geborgenheit geht aus der Erfahrung hervor. Ich erreichte, daß auch die kleinsten, zartesten Jungen und Mädchen von zehn bis zwölf Jahren sich nicht als die jüngsten Mitglieder des Kollektivs fühlten. In der Arbeit, ja, in der Tätigkeit, ja; aber in ihrem Selbstge fühl, ihrem Selbstvertrauen fühlten sie sich wunderbar geborgen; denn sie fühlten, daß nie- 
mand sie kränken konnte, daß jeder Beleidigte beschützt wurde, nicht nur von seiner Abteilung, von der Brigade, von mir, sondern mehr noch von dem ersten Kameraden, der hinzukam“ (a. a. O., S. 226).

Dieser Grundgedanke ist so wichtig, dass ihn auch Rasmussen in dem von ihm geleiteten Erziehungsheim in Bøgholt konsequent beachtet und realisiert hat (siehe oben und vgl. Rasmussen a. a. O., S. 112 und 128). Besonders nach dem Empfang der problembelasteten Jugendlichen stellte er fest, dass unter ihnen ein recht rüder Umgangston herrschte. Ein solcher Ton, mit dem manche Jugendlichen ihre Coolness oder Überlegenheit zum Ausdruck bringen wollen, belastet in der Regel nicht nur die Atmosphäre, sondern auch die Beziehungen - z. B. zwischen den Jungen und Mädchen. Daher ist es wichtig, dass konsequent ein zivilisierter Umgangston gefordert wird, der schließlich als Norm Eingang findet in die öffentliche Meinung, die generell das „Sammelbecken“ der gültigen Gruppennormen ist und je nach Ansehen ihrer exponierten Verfechter das Verhalten der Gruppenmitglieder relativ nachhaltig bestimmt. Zu den Gruppennormen gehört in der Regel auch das sog. Tabu-Prinzip, denn ,keine Gesellschaft kommt ohne einen Code aus von dem, was mitteilbar ist und was verborgen bleiben soll“ (Lau 2004, S. 30), z. B. zurückliegende Straftaten einzelner Mitglieder.

In der öffentlichen Meinung finden aber nicht nur Gruppennormen ihren Niederschlag, sondern auch Meinungen $z$ den Lebensbedingungen und Vorkommnissen in der Gemeinschaft, was naturgemäß deren Stimmungslage beeinflusst. Treten beispielsweise Kameradendiebstähle auf, kann eine Stimmung des Misstrauens und der Gereiztheit entstehen; werden dagegen besondere Arbeitserfolge erzielt - etwa die Fertigstellung eines Bauvorhabens - wird das eine freudige Stimmung erzeugen. Für den Erfolg der Gruppenerziehung ist eine optimistische Grundstimmung wichtig; daher sollten Vorhaben geplant und organisiert werden, die Optimismus erzeugen und kleinliche Nörgeleien möglichst nicht aufkommen lassen. Makarenko fordert:

„Dur-Stimmung. [...] Nie versagenden Lebensmut, keine finsteren Gesichter, keine sauren Mienen, ständige Tatbereitschaft, sonnige Laune, eben fröhliche, muntere Dur-Stimmung, jedoch keinesfalls Hysterie! Bereitschaft zu nützlichen Taten, zu interessanten Taten, zu inhaltsreichem, sinnvollem Tun, aber niemals zu Unordnung, Geschrei und Gekreisch, [...]“ (Makarenko 1969 , Bd. V, S. 223).

Auf der Grundlage der bisher vorgestellten Bedingungen und Prinzipien einer humanistischen Gemeinschaftserziehung ist es möglich, eine bewusste und freiwillige Disziplin bei den Kindern und Jugendlichen zu entwickeln - ein wichtiges Ziel und Resultat jeglicher Erziehung mit spezifischen moralischen Grundlagen. Bei religiös orientierten Pädagogen wie Lietz und Lauter finden wir das christliche Gebot der Nächstenliebe auch in Verbindung mit Opferbereitschaft -, aus dem im hohen Maße ein freiwilliges und bewusstes Engagement für humanitäre Aktivitäten resultiert. 
Eine areligiöse Pädagogik wie die Makarenkos muss verständlicherweise auf andere Grundlagen zurückgreifen. Seine Basis ist primär die Sinnhaftigkeit der gemeinschaftlichen Anstrengungen zum Woble jedes Einzelnen und der Gemeinschaft. Der Einsicht in diese Sinnhaftigkeit (wenn sie durch das Konzept und seine erlebte Verwirklichung gegeben ist) kann sich auf die Dauer kein Zögling verschließen - abgesehen vielleicht von Ausnahmen. Den Sinn gemeinschaftlicher Anstrengungen erkennen problembelaste Zöglinge zumeist nicht sofort und daher müssen am Anfang des gemeinsamen Entwicklungsprozesses unabdingbare Forderungen stehen. Nach Makarenkos Auffassung

„,ist es unmöglich, die Erziehung eines Kollektivs ohne aufrichtige, offene, von Überzeugung durchdrungene, energische und entschiedene Forderungen zu beginnen. Wer glaubt, mit zaghaften, schmeichlerischen Überredungsversuchen anfangen zu können, der befindet sich im Irrtum“ (Makarenko 1969, Bd. V, S. 157).

Aus dem Gesagten folgt, dass die Entwicklung einer bewussten Disziplin das Ergebnis eines langwierigen Erziehungsprozess ist, in dem es manchmal Disziplinierungsmaßnahmen bedarf, wozu auch Strafen gehören. Die Frage nach dem Verbot oder der Zulässigkeit von Strafmaßnahmen in der Erziehung wird - wie bereits erwähnt - seit Jahrhunderten diskutiert. Makarenko hat dazu seinen Standpunkt klar formuliert: "Ohne Strafe kann ich nicht erziehen, diese Kunst muss man mir erst noch beibringen“" (Makarenko 1972, Bd. I, S. 388). Da er es mit jugendlichen Rechtsverletzern zu tun hatte, musste er sich verständlicherweise sehr gründlich Gedanken machen über die Möglichkeiten und Bedingungen wirkungsvoller Bestrafung; er formulierte das Ergebnis seiner Erkenntnisse in einigen ausgewählten Punkten wie folgt:

„Die Strafe ist eine Form der Einwirkung durch das Kollektiv, die entweder auf dessen direkten Beschlüssen beruht oder aber auf den Beschlüssen der Bevollmächtigten des Kollektivs, die gewählt wurden, um seine Interessen zu wahren.

Von diesem Grundsatz ausgehend, muss unsere Bestrafung unbedingt folgenden Forderungen genügen:

a) Körperlicher Schmerz darf weder ihr Ziel sein, noch darf sie faktisch darauf hinauslaufen.

b) Die Strafe hat nur dann einen Sinn, wenn der davon Betroffene begreift, daß das Kollektiv damit gemeinsame Interessen verteidigt, mit anderen Worten, wenn er weiß, warum das Kollektiv gerade dies von ihm verlangt.

c) Eine Bestrafung soll nur dann erfolgen, wenn wirklich die Interessen des Kollektivs verletzt worden sind und wenn der Schuldige die Tat offen und bewußt verübt hat, indem er die Forderungen des Kollektivs mißachtet.

d) In gewissen Fällen kann von einer Bestrafung abgesehen werden, wenn der Schuldige erklärt, daß er sich den Beschlüssen des Kollektivs fügen und in Zukunft solche Feh- 
ler vermeiden wird (selbstverständlich unter der Voraussetzung, daß diese Erklärung kein direkter Betrug ist)“ (Makarenko 1969, Bd. V, S. 47/48).

In Makarenkos Einrichtungen wurden Strafen verhängt, die aber niemals Willkürmaßnabmen einzelner angestellter Erzieher sein durften, sondern „das Urteil des Kollektivs zum Ausdruck“ brachten (ebenda). Er erreichte schließlich einen solchen Entwicklungsstand in der Dzieržynskij-Kommune, dass er seine Erzieher sogar von ihrer spezifischen Funktion entbinden und in der Schule als Lehrer arbeiten lassen konnte.

„Die ganzen acht Jahre lebte das Kollektiv ohne einen einzigen Erzieher (wenn man von Makarenko als Leiter absieht, W. N.). Der diensthabende Brigadier war vierundzwanzig Stunden hindurch für alles verantwortlich, was in der Kommune geschah: für Genauigkeit und Ordnung des Arbeitsplans, für Ordnung bei der Reinigung, für den Empfang von Gästen, für ein gutes Mittagessen, eine etwaige Fahrt und eine etwa notwendig gewordene zusätzlich Arbeit. Nachts durfte er schlafen“ (a. a. O., S. 277).

Dass dieses Konzept der unbedingten Forderung am Anfang einer Gemeinschaftsentwicklung notwendig und zweckmäßig ist, wird u. a. auch durch das Vorgehen von Rasmussen unter nichtsowjetischen Verhältnissen bestätigt und sogar für die kirchliche Jugendarbeit von Lauter für anwendbar gehalten (vgl. Lauter 1986, S. 234ff. und 1993, S. 155). Über die methodischen Feinheiten in der „Arbeit mit Forderungen“ bis hin zu den originellen Strafen in Makarenkos Einrichtungen geben seine Schriften Auskunft. So war z. B. der Arrest eine Strafe, die nur den Kommunarden, aber nicht unerfahrenen Zöglingen auferlegt werden durfte. Entsprechend eines Beschlusses der Mitgliederversammlung konnte der Leiter der Kommune bis zu 10 Stunden Arrest verhängen, die der Übeltäter im Arbeitszimmer des Leiters absitzen musste, wobei niemand außer dem Leiter das Recht hatte, mit ihm zu sprechen, und auch der Leiter über alles Mögliche, aber nicht über den Arrestgrund reden durfte (vgl. Makarenko 1969, Bd. V, S. 167ff.). Allerdings sollte jedem Bestraften der Sinn der Strafe einleuchten!

Diese Skizze zu konzeptionellen Grundelementen humanistischer Gemeinschaftserziehung wäre gewiss unzulänglich, würde ein Problemkreis ausgespart, der sowohl bei Lietz als auch bei Makarenko eine Rolle gespielt hat: die militärischen Formen im Lebensalltag der Gemeinschaft. Lietz berichtet darüber in der naiven und zeitgemäßen Art, wie man es einem Preußen aus Pommern vorm I. Weltkrieg kaum verübeln kann. In den Erläuterungen zu seinen „Grundsätzen [...]“ schrieb er auf S. 28:

„Ähnlichen Zwecken dienen neben dem der körperlichen Ertüchtigung auch die Felddienstübungen. Bei ihnen helfen die tüchtigsten Jungen, zumeist sind sie zugleich Pfadfinder, als Offiziere mit. Lustig nimmt sich die kleine Armee aus in ihren blauen Spielhosen, den weißen Sweatern, den roten Mützen und ihren Waffen, den kleinen Holzgewehren. Das Musikkorps der Trommler und Flöter übt eifrig und belebt das Ganze beim Marschieren und Stürmen.“ 
In der Zeit des I. Weltkrieges und des Bürgerkriegs in der Sowjetunion spielte ebenfalls alles Militärische im Denken der Jugendlichen eine große Rolle, so dass es nicht verwunderlich ist, wenn sie eine Initiative des Bruders von Anton S. Makarenko, nämlich Vitalij S. Makarenko (1895-1983) ${ }^{27}$ akzeptierten. Vitalij war nach seiner schweren Verwundung als Offizier der russischen Armee ausgemustert worden und an der Schule seines Bruders als Fachlehrer für Mathematik, Zeichnen und Sport tätig. Anton als Schulleiter wehrte sich zunächst gegen die militärischen Formen mit der Begründung: „Ich will hier keine Kaserne“ (Garcia 1986, S. 189), doch Garcia hat in seinen Gesprächen mit Vatalij erfahren:

„Ein anderer Lehrer, Krylov, überzeugte ihn aber davon, daß eine militärische Organisation an sich nichts Schlechtes sei, daß man sie z. B. in der Pfadfinderbewegung habe. Als Anton Makarenko sah, wie das Konzept funktionierte, gab er seine pädagogischen Bedenken auf“ (a. a. O.).

Vitalij S. Makarenko berichtet über seine diesbezüglichen Aktivitäten:

„Warum ich Ihnen das erzähle; ich glaube, daß es die Disziplin in der Gor'kij-Kolonie und in der Dzeržinskij-Kommune ohne mich nicht gegeben hätte. Orchester, Wachestehen, Rapport, der Rat der Kommandeure [...] mein Bruder hat die an und für sich unbedeutende Idee, die ich rein zufällig eingeführt hatte, einfach weiterentwickelt“ (Garcia a. a. O., S. 186).

Garcia weist in seiner Erläuterung mit Recht darauf hin, dass Ordnung und Organisation nicht dasselbe sind, d. h., Anton S. Makarenko übernahm die militärische Organisation, aber nicht die militärische Ordnung. Die Ordnungen in der Gor'kij-Kolonie und in der Dzeržinskij-Kommune stimmten wohl eher mit den Ordnungen der deutschen Landerziehungsheime überein, in denen es Organe der Schülerselbstverwaltung gab und keinen Oberbefehlshaber im militärischen Sinne. Eine originelle Leistung Makarenkos besteht gewiss darin, dass er eine funktionierende Verbindung zwischen dem Prinzip der demokratischen Selbstverwaltung (im Rahmen der bereits erwähnten Souveränität des Kollektivs!) und dem Prinzip der verantwortlichen Einzelleitung der Beauftragten des Kollektivs entwickelt hat. Garcia spricht nicht vom Prinzip der Einzelleitung, sondern vom Kaderprinzip (a. a. O., S. 192) - meint aber offensichtlich den gleichen Sachverhalt. Gegen die Verwendung des Wortes „Kaderprinzip“ spricht der Wechsel von Unterordnung und Führung, durch den statische Unterstellungsverhältnisse - etwa eine Unterordnung der Mehrheit unter Kader im Sinne von planmäßig entwickelten oder gar privilegierten Führungskräften - gerade vermieden werden sollten und in Makarenkos Einrichtungen auch vermieden wurden.

Für die Bewertung der militärischen Formen in Makarenkos Konzeption der Kollektiverziehung sind die Erfahrungen von Jugendpfarrer Dietrich Lauter wichtig: er hat

27 Einen ausführlichen Bericht über die Auffindung von Vitalij S. Makarenko und seine Gewinnung für die Mitarbeit an den Makarenko-Forschungen gibt Götz Hillig in seinem Beitrag „Eine Jugend in Russland“ im Rahmen des 2. Marburger Gesprächs 1986 (Hillig 1989, S. 47-68). 
aus nahe liegenden Gründen und auch angesichts der Tatsache, dass Kriegsdienstverweigerer zu seinen Gruppen gehörten, auf militärische Formen verzichtet und dennoch die pädagogisch wesentlichen Elemente von Makarenko erfolgreich genutzt (vgl. Lauter 1993, S. 132). Übrigens hielt sich auch Makarenkos Begeisterung für militärische Formen durchaus in Grenzen, was sich in folgenden Worten äußert:

„Ich bin ein Gegner des ständigen Marschierens, für das sich einige junge Pädagogen begeistern: Geht man in den Speisesaal, wird marschiert, geht man zur Arbeit, wird marschiert, immer wird marschiert. Das ist weder schön noch notwendig“ (Makarenko 1969, Bd. V, S. 134).

Militärische Formen sind also kein notwendiges Element humanistischer Gemeinschaftserziehung. Daran knüpft sich überhaupt die Frage, der wir hier nicht weiter nachgehen können: Welche Elemente sind noch entbehrlich? Immerhin belegen die Erfahrungen Lauters, dass es auch außerbalb von Erziehungsheimen oder ähnlichen Lebensgemeinschaften möglich ist, wesentliche Prinzipien Makarenkos erfolgreich anzuwenden.

\subsubsection{Historische und theoretische Gründe für eine universelle Nutzung grundlegender Elemente bu- manistischer Gemeinschaftserziehung}

Die vorliegende Darstellung hat bereits deutlich eine ganze Reihe von Analogien, die zwischen den Einrichtungen von Makarenko und den Landerziehungsheimen bestehen, erkennen lassen. Inzwischen ist vor allem dank der intensiven Forschungsarbeiten des Marburger Makarenko-Referats nachgewiesen, dass die Analogien nicht zufälliger Natur sind. Außerdem lässt sich eine ca. 200-jährige Entwicklung der konzeptionellen Ideen und Praktiken vermittels folgender Einrichtungen und Personen nachweisen:

- Landwirtschaftliche Armenschule Wylhof (gegr. 1804), in der Johann J. Wehrli (1790-1855) die Ideen von Pestalozzi erfolgreich praktizierte und weiterentwickelte, sowie weitere Bildungseinrichtungen von Philipp E. v. Fellenberg;

- Philanthropinum in Schnepfenthal (von Salzmann gegründet 1784), das Goethe gut kannte und dessen Vorstellungen und Erfahrungen ebenso wie die Fellenbergs und Wehrlis Eingang gefunden haben in die „Pädagogische Provinz" von Goethe (Bd. 11, 1976, S. 601 u. 632; Wilhelm Meisters Wanderjabre);

- Internatsschule in Abbotsholme von Cecil Reddie (gegr. 1889 in Derbyshire/ Großbritanien), in der Lietz ein Jahr praktiziert hat (vgl. Lietz 1935, S. 60ff.);

- Landerziehungsheime von Lietz (1. Heim in Ilsenburg am Harz, gegründet 1898) und die Freie Schulgemeinde Wickersdorf von Wyneken (gegr. 1906);

- Arbeitskolonien für jugendliche Rechtsverletzer in der Ukraine unter Leitung Makarenkos (Übernahme seiner ersten Kolonie in Triby bei Poltava 1920);

- Erziehungsheim in Bøgholt (Dänemark) unter Rasmussens Leitung. 
Folgende Nachweise belegen den Informationsaustausch zwischen deutschen Reformpädagogen und Vertretern der russischen bzw. sowjetischen Pädagogik:

- Hillig verweist auf die Publikationsreihe „Russische Lehrer im Ausland“, die von 1910 bis 1915 in Moskau erschienen ist und viele Berichte von Lehrern aus Russland über Einrichtungen der deutschen Reformpädagogik enthält. Gestützt auf eine Arbeit von Mchitarjan (Hamburg 1998) vermerkt er:

„Berlin war in den Jahren 1909-1913 mit 3441 Lehrern aus Rußland die am häufigsten besuchte deutsche Stadt, gefolgt von München (1778), Dresden (1567)) und Leipzig (573)“ (Hillig 2006, S. 254).

- Makarenkos „Bibliothek, die sich heute im Makarenko-Museum in KremenčugKrjukov (Ukraine) befindet, enthält [...] ein Exemplar eines 1913 in Moskau erschienenen russischsprachigen Buchs - »Die gegenwärtigen pädagogischen Strömungen in Westeuropa und in Amerika« von A. F. Muzyčenko, dem Direktor des Kiever Pädagogischen Museums (Muzyčenko 1913) ${ }^{28}$ - mit Anstreichungen von Makarenkos Hand in jenem Abschnitt, welcher der FSG (= Freie Schulgemeinde Wickersdorf, W. N.) und dem Arndt-Gymnasium in Dahlem bei Berlin gewidmet ist, das 1909 ein neues Gebäude mit einer Schülerheim-Kolonie bezogen hatte. Dort heißt es u. a.:

»Die Freie Schulgemeinde in Wickersdorf wurde von einer Gruppe von Pädagogen gegründet, die sich von Lietz wegen Meinungsverschiedenheiten getrennt hatten, vor allem bezüglich dreier Punkte: Diese Pädagogen hatten eine freiere Vorstellung vom Religionsunterricht und bestanden auf dessen historischer Vermittlung mit Ergänzungen philosophischer Art; sie forderten die Zulassung eines gemeinsamen Unterrichts von Jungen und Mädchen und erlaubten schließlich größere Mitsprache der Schüler in wirtschaftlichen Fragen der Lehranstalt. Alle diese Neuerungen wurden in der sich jetzt erfolgreich entwickelnden Wickersdorfer Schule verwirklicht. Die Erfahrungen dieser Privatschulen führten zu derart glänzenden Ergebnissen, daß sich auch die Regierung dafür interessierte. Erst kürzlich hat das Preußische Ministerium für Volksbildung in einem Wald (Hervorhebung durch W. N.) ein klassisches Gymnasium mit Internat nach den Prinzipien der Schule von Lietz gegründet. Das ist eine regelrechte Kolonie mit einem Haupt- und vier Nebengebäuden, wo die Schüler in familienähnliche Gruppen aufgeteilt sind.« (Muzyčenko 1913, S. 203f.)“ (zitiert nach Hillig 2006, S. 261).

- Die Wörter „in einem Wald“ (russ.: v lesu) im zitieren Buch (S. 204) hat Makarenko laut Hillig unterstrichen. In Makarenkos Brief vom 24.03.1923 an Antonia P. Sugak, eine Lehrerin in Krjukov, die er für die Gor'kij-Kolonie gewinnen wollte, heißt es u. a.:

28 Laut Hillig handelt es sich bei dem zitierten Buch um eine separat gebundene Ausgabe von Kapterev, P. F. und Muzyčenko, M. F.: Sovremennye pedagogičeskie tečenija. Moskva 1913. 
„Übrigens gehen in Deutschland gerade sogenannte Waldschulen, die ebenfalls abgelegen sind und ebenfalls sämtlicher äußerer Anzeichen der gebildeten Gesellschaft entbehren, allen voran“ (Hillig 2006, S. 261f. und Makarenko 1976, Bd. VII, S. 480).

In Anbetracht dieser nachgewiesenen Zusammenhänge stellt sich die Frage, weshalb Makarenko in seinen Schriften und Vorträgen nie auf diese deutschen Quellen verwiesen hat. Darauf gibt Günther-Schellheimer eine einleuchtende Antwort:

„Es wird ihm (gemeint ist Makarenko W. N.) nicht entgangen sein, wie zahlreiche ukrainische und russische Pädagogen von Stalins NKWD verfolgt worden sind, weil man sie beschuldigte, sich auf deutsche Pädagogen zu beziehen, die damals von der Sowjetführung offiziell alle als profaschistisch bewertet wurden“" (2005, S. 69).

Makarenkos Besorgnis war nicht unbegründet, denn während der revolutionären Unruhen um 1905 stand er den Sozialrevolutionären nahe (vgl. Hillig 1989, S. 61 und Sünkel 1993, S. 15). Außerdem war sein Bruder Vitalij nach dem Bürgerkrieg als ehemaliger weißgardistischer Offizier nach Frankreich emigriert, wo er bis zu seinem Tode 1983 gelebt hat. Ferner waren nach Makarenkos Übersiedlung nach Moskau 1937 seine ehemaligen Vorgesetzten im ukrainischen NKWD im Zuge der Stalinschen „Reorganisation“ des Sicherheitsapparats verhaftet und z. T. als „Volksfeinde“ erschossen worden. Im Herbst 1937 ging bei der Leitung des Allunions-Schriftstellerverbandes in Moskau eine „Meldung“ ein, die Makarenko der „Kontakte zu Volksfeinden" beschuldigte, so dass seine Verhaftung drohte. Es ist der Intervention und Fürsprache der Schriftsteller Michail A. Šolochow (Nobelpreis 1965) und Aleksandr A. Fadeev bei Stalin zu verdanken, dass die Verhaftung abgewendet werden konnte. Makarenko hatte Kenntnis von dieser Gefahr. Als Mittler zu ihrer Abwendung fungierte Jurij B. Lukin, der sich als Verlagslektor für den Druck von Makarenkos Büchern engagiert hatte und mit Šolochow befreundet war (vgl. Bejlinson 2007, S. 102).

Kritikwürdig (wenn auch für Regimekenner verständlich) ist die „Hyperparteilichkeit“, mit der Makarenko in seinen letzten beiden Lebensjahren in Moskau versucht hat, durch Vorträge und Rezensionen mit teilweise unsachlicher und erbarmungsloser Kritik an Werken anderer Autoren ein möglichst hohes Ansehen bei den Vertretern des stalinistischen Terrorregimes zu erlangen. Der seit 1994 in der Bundesrepublik lebende Valentin Bejlinson berichtet (a. a. O., S. 96-98) über eine Silvesterfeier (1938/39), auf der der Schriftsteller Vikenty V. Veresaev am Ende einer kritischen Analyse von Makarenkos politischem und menschlichem Verhalten feststellt, „dass er (also Makarenko) als Mensch am Ende ist, das ist eine Tatsache“ (a. a. O., S. 98).

Bei allen Betrachtungen zu den Analogien zwischen Makarenkos Kolonien und den Landerziehungsheimen dürfen natürlich nicht die jeweils verschiedenen politischen und sozialen Bedingungen ihrer Wirksamkeit außer Acht gelassen werden, denn es ist ein großer 
Unterschied, ob Kinder wohlhabender Eltern in Internatsschulen mit Elitecharakter oder verwahrloste Waisenkinder und straffällige Jugendliche in Erziehungsheimen für Rechtsverletzer erzogen werden. Gerade das führt zur Frage: Warum ist es möglich, in schöpferischer Anwendung der vorgestellten konzeptionellen Grundelemente bumanistischer Gemeinschaftserziehung unter recht unterschiedlichen gesellschaftlichen und soziokulturellen Bedingungen erfolgreiche Erziehungsarbeit zu leisten - speziell auch im Bereich der Sozialpädagogik?

Als allgemeine Antwort kann hier folgende Erklärung formuliert werden: Die konzeptionellen Grundelemente humanistischer Gemeinschaftserziehung entsprechen prinzipiell den invarianten und basalen Bedürfnissen des Menschen, also:

- dem Bedürfnis zu leben und sich zu entwickeln,

- den Bedürfnissen nach Aktivität und Entspannung,

- den Bedürfnissen nach Sicherheit und Abenteuer,

- den Bedürfnissen nach Zugehörigkeit und Souveränität,

- den Bedürfnissen nach Anerkennung und Partizipation,

- den Bedürfnissen nach Erkenntnis und Beherrschung der eigenen Verhältnisse und

- den Bedürfnissen nach Kommunikation und Selbstbesinnung.

Garcia erörtert nun noch einen weiteren Grund für die Entwicklung funktionierender Kollektive bei Makarenko:

„Die Fähigkeit und der Drang, ja der Trieb, sich zu organisieren, ist dem Menschen angeboren. Sich zu organisieren, ist eine sehr zweckmäßige Weise, um im Kampf ums Dasein bestehen zu können. Der Trieb bzw. Drang, sich zu organisieren, ist sozio-physiologisch. Ich sage soziophysiologisch, weil dieser Drang, dieser Trieb des Menschen zur Sozialität lebenswichtig ist" (a. a. O., S. 190).

Die These vom „,angeborenem Drang zur Sozialorganisation“ ist plausibel, denn ein solches Bestreben durchzieht die gesamte Anthropogenese und wirkt weiter. Ohne diesen „Drang“, der auch schon bei Primaten und anderen in Sozietäten lebenden Säugetieren zu beobachten ist, hätte es in Anbetracht des Mangels an natürlichen Waffen für menschliche Urhorden gar keine Überlebens- bzw. Entwicklungschance gegeben. Es taucht daher die Frage auf, ob es sich bei dem „Trieb zur Sozialorganisation“ nicht auch um ein invariantes Bedürfnis im Sinne Rapoports handelt, das an die Stelle des von ihm genannten und zu weit gefassten invarianten Bedürfnisses nach Ordnung treten kann (siehe S. 218), zumal nur auf der Basis einer sozialen Ordnung auch die vorher genannten invarianten Bedürfnisse befriedigt werden können. Aus alledem folgt, dass die Liste der invarianten und basalen Bedürfnisse zu ergänzen ist durch

- das Bedürfnis nach Sozialorganisation. 
Das Hauptanliegen dieses Kapitels bestand darin, wesentliche Merkmale erzieherischer Verbältnisse herauszuarbeiten und nachzuweisen, dass diese nicht nur zwischen einem Erwachsenen und einem Heranwachsenden bestehen, sondern auch Bestandteil der Beziehungen in Entwicklungs-Gemeinschaften sind, wo sie vielfach erst ibre volle Wirksamkeit im Sinne psychosozialer Intensiverziehung entfalten. Dabei wird nicht übersehen, dass es außer den Prinzipien und methodischen Hinweisen, die wir bei Makarenko finden, noch weitere Konzepte gibt, die im Rahmen erzieherischer Verhältnisse von Gemeinschaften angewendet werden. Es sei beispielsweise nur an die Erlebnispädagogik erinnert oder an die Themenzentrierte Interaktion (vgl. Kamps 1992).

Elementare Voraussetzung für erfolgreiche psychosoziale Intensiverziehung ist, dass die Problembelasteten die jeweiligen erzieherischen Kräfte akzeptieren. Das betrifft sowohl die Sozialpädagogen als auch deren fachkompetente Helfer bzw. die progressiven Kräfte in der jeweiligen Gemeinschaft. Sozialpädagogisches Handeln muss daher nachdrücklich auf die Gestaltung der Beziehungen in der psychosozialen Intensiverziehung gerichtet sein, wozu nachfolgende Strukturprinzipien wichtige Hinweise geben.

\subsection{Sozialpädagogische Strukturprinzipien - ihre Begründung und Be- deutung für die psychosoziale Intensiverziehung}

Die Anwendung sozialpädagogischer Strukturprinzipien dient dazu, eine funktionstüchtige Struktur des sozialpädagogischen Prozesses zu entwickeln, zu stabilisieren und zu vervollkommnen. Dabei wird unter Struktur sozialpädagogischer Prozesse das System der erzieherisch relevanten Beziehungen zwischen den an der psychosozialen Intensiverziehung beteiligten Personen einschließlich ihrer Institutionen verstanden.

Ausgangspunkt der Strukturbildung ist das zu entwickelnde erzieherische Verhältnis zwischen dem jeweiligen Problembelasteten und dem Sozialpädagogen, der zur Hilfeleistung herangezogen wird. Es genügt nicht, dass ein Sozialpädagoge über die im Abschnitt 5.3 geforderten Qualitäten verfügt - er muss sie den Problembelasteten und Problembeteiligten bewusst werden lassen im eigenen Erleben, so dass sie möglichst bald echtes Zutrauen und volles Vertrauen gewinnen, das dann aber auch nicht enttäuscht werden darf.

Auf dieses, den gesamten Prozess bestimmende Strukturprinzip verweist

- das Prinzip der Präsentation von Kompetenz. und Natürlicbkeit im Umgang mit den Klienten sowie der Wabrung von Diskretion.

Die Problembelasteten müssen besonders die ersten Gespräche so erleben, dass sie sich ihrerseits auf eine Beziehung zu ihrem Helfer einlassen, ihr möglicherweise anfänglich 
vorhandenes Misstrauen abbauen und sich bereit finden, sachlich über die Problemlage zu reden. Ob dies gelingt, hängt wesentlich ab von der Realisierung des

- Prinzips der Verbindung von unvoreingenommener Problemannabme, verständnisvoller Anteilnahme und Echtheit zwecks Öffnung, Ermutigung und Aktivierung der Klienten.

Die unvoreingenommene Problemannahme und Anteilnahme führt manchmal dazu, dass ein Problembelasteter in dem Sozialpädagogen seinen Anwalt sieht, der ihn gegenüber allen Konfliktgegnern und Behörden uneingeschränkt und kompromisslos vertreten soll, da ihm für die Vermittlungsfunktion des Sozialpädagogen (also für dessen zweites Mandat) manchmal das rechte Verständnis fehlt. Wenn Problembeteiligte unzureichendes Engagement des Sozialpädagogen vermuten, droht u. U. ein Abbruch der Beziehung und somit des Problemlösungsprozesses. Damit das aber nicht geschieht, muss vom Sozialpädagogen folgendes Strukturprinzip beachtet und den Klienten auch bewusst gemacht werden:

- das Prinzip der Verbindung von Interposition mit parteilichem Engagement für besonders Bedürttige und Benachteiligte.

Handelt es sich um einen komplizierten Problemfall, der mehrere Schwierigkeiten einschließt (z. B. Arbeitslosigkeit, Drogenabhängigkeit, Überschuldung und familiäre Konflikte), dann wird ein einzelner Sozialpädagoge allein damit nicht fertig. Das erzieherische Verhältnis zwischen dem Sozialarbeiter und „seinem Klienten“ muss also strukturell erweitert und ergänzt werden durch die Anwendung des

- Prinzips der Verbindung von Beratung und Verhandlungsfübrung mit Kooperationsbildung im Interesse der Klienten.

Das bedeutet die Einbeziehung fachkompetenter Kooperationspartner (Therapeuten, Schuldnerberater usw.) und möglicher Helfer aus dem lokalen sozialen Netz. Dabei kann die Kooperationsbildung aber auch so weit gehen, dass der Problembelastete in eine Entwicklungs-Gemeinschaft eingeordnet wird. In jedem Falle aber gilt

- das Prinzip der Verbindung von Handlungsherrschaft des Sozialpädagogen mit der Selbständigkeitsförderung der Klienten.

\subsubsection{Das Prinzip der Präsentation von Kompetenz. und Natürlichkeit im Umgang mit den Klien- ten sowie der Wahrung von Diskretion}

Sozialpädagogen müssen auf der Grundlage hoher fachlicher Kompetenz und durch natürliche, dem Niveau der Problembeteiligten angepasste Vorgehensweisen ein Vertrauensverhältnis entwickeln, das Diskretion einschließt und der Problemlösung dient, obgleich diesem Bemühen soziallogische Denkweisen der Problembeteiligten entgegenstehen können. 


\section{Begründung:}

Das unmittelbare Ziel des Prinzips ist die wechselseitige Akzeptanz von Sozialpädagogen und Klienten als Voraussetzung für einen erfolgreichen Problemlösungsprozess. Dieses unmittelbare Ziel des Prinzips entspricht normalerweise der Erwartungshaltung der Klienten, denn sie möchten ja akzeptiert werden. Die Klienten ihrerseits werden den Sozialpädagogen dann akzeptieren, wenn sie sich verstanden fühlen und davon überzeugt sind, dass ihnen auf der Grundlage ihrer Offenbarungen keine weiteren Nachteile erwachsen, weil diese diskret behandelt werden.

Die an wissenschaftlichen Kriterien geschulte Denkweise von Sozialpädagogen steht häufig im Widerspruch zum sog. soziallogischen Denken der Problembelasteten, das vorwiegend durch emotional begründete Einstellungen bestimmt wird. So sieht z. B. mancher Kindesvater nicht ein, dass er seine Alimente auch dann bezahlen muss, wenn die Mutter ihm den Umgang mit dem Kind verwehrt. Die Kindesmutter wiederum akzeptiert nicht das Recht des Kindesvaters, weil sie sich von ihm im Stich gelassen fühlt usw. Die Kompeten z des Sozialpädagogen und seine Akzeptanz durch den Klienten sind allgemeine, wesentliche und notwendige Bedingungen für die Entwicklung eines Vertrauensverbältnisses, das wichtig ist für eine fundierte Analyse der Problemsituation, für die Überwindung der Barrieren des soziallogischen Denkens (siehe S. 343) und für die Einhaltung der getroffenen Vereinbarungen.

\section{Handlungshinweise:}

Das Prinzip orientiert auf wichtige Bedingungen für die Entstehung eines Vertrauensverhältnisses, das Bestandteil des umfassenderen erzieherischen Verhältnisses ist. Das Gefühl der Fremdheit, das bei jeder Kontaktaufnahme mehr oder weniger auftritt, sollte nicht durch betont vornehme Kleidung, den Gebrauch psychologischer Fachwörter und dergleichen verschärft, sondern durch natürliches Verhalten reduziert bzw. beseitigt werden. Sozialpädagogen dürfen sich aber auch nicht so weit an Eigenheiten der Klienten in Sprache, Kleidung und Umgangsformen anpassen, dass sie damit ihr persönliches und professionelles Profil verleugnen oder aufgeben, vielmehr sollten sie immer bestrebt sein, ihre Klienten „zu sich heraufzuziehen“, indem sie sich ihnen verständnisvoll zuwenden und sie auch in ihrer persönlichen Kultur fördern.

Es darf weder der Eindruck einer herablassenden Behandlung noch der Anbiederung erweckt werden, vielmehr ist Natürlichkeit im Umgang mit den Klienten notwendig. Der Forderung nach Natürlichkeit widerspricht es, wenn Sozialpädagogen den Jargon ihrer Klienten nachahmen oder sich ihrem Outfit ganz und gar anpassen, auch hier geht es um die Balance von Nähe und Distanz. Auf soziallogisches Denken der Problembelasteten muss der Sozialpädagoge verständnisvoll reagieren und versuchen, es sachlich zu überwinden, wenn es sich als Hemmnis im Problemlösungsprozess erweist. 
Bei hartnäckiger persönlicher Abneigung ist es ratsam, einen für den betreffenden Klienten geeigneteren Sozialpädagogen heranzuziehen. Prinzipiell unterliegen die Informationen des Klienten der Schweigepflicht seitens des Sozialpädagogen, wobei es allerdings im Falle möglicher krimineller Hintergründe des sozialen Problems einer rechtlichen Prüfung und Entscheidung in Übereinstimmung mit dem geltenden Recht bedarf, denn Sozialpädagogen besitzen vor Gericht kein berufsbezogenes Zeugnisverweigerungsrecht.

\subsubsection{Das Prinzip der Verbindung von unvoreingenommener Problemannahme, verständnisvoller Anteilnahme und Echtheit zwecks Öffnung, Ermutigung und Aktivierung der Klienten}

Sozialpädagogen müssen die Probleme ihrer Klienten unvoreingenommen aufnehmen und die Letztgenannten durch echte und mitfühlende Anteilnahme in eine möglichst normale Gefühlslage bringen, damit sie sich öffnen und für die Problemlösung ermutigt und aktiviert werden.

\section{Begründung:}

Ziel des Hilfesuchenden und des Sozialpädagogen ist die Lösung der Probleme, die den Klienten zumeist auch psychisch bedrücken, was sich in Mutlosigkeit, Verzagtheit und depressiver Grundstimmung oder auch Verärgerung, Zorn und Wut äußert (je nach Art des Problems und Charakter des Hilfesuchenden). Das Ziel der Wiederherstellung des psychischen Gleichgewichts (sog. Gefühlsfunktionalisierung) liegt sowohl im Interesse des Klienten als auch des Sozialpädagogen, und zwar nicht nur wegen der damit verbundenen psychischen Entlastung, sondern weil damit bessere Voraussetzungen für ein besonnenes Vorgehen bei der Problemlösung geschaffen werden.

Freundliche und verständnisvolle Anteilnahme des Sozialpädagogen am Schicksal seines Klienten bilden eine allgemeine, notwendige und wesentliche Voraussetzung für die Akzeptanz. Desgleichen hängt der Erfolg aller Bemühungen davon ab, inwieweit sich der Klient dem Sozialpädagogen anvertraut, d. h. sich öffnet und damit in die komplizierten Zusammenhänge der Problemstruktur Einsicht gewährt. Erst eine relativ gründliche Kenntnis der Zusammenhänge lässt auch echte Ansatzpunkte für wirkungsvolle Ermutigungen deutlich werden, die im Interesse der Aktivierung der Klienten wesentlich und notwendig sind.

\section{Handlungshinweise:}

Der Sozialpädagoge muss den Hilfesuchenden ohne Vorurteile und freundlich, aber durchaus kritisch und damit echt annehmen, so dass diese sich ernst genommen fühlen. Die verständnisvolle Äußerung des Mitgefühls sollte durch die Balance von Anteilnahme und Abgrenzung (vgl. Schulz v. Thun 1990, Bd. 2, S. 89) gekennzeichnet sein, weil sonst die Gefahr besteht, dass der Sozialpädagoge für den Hilfebedürftigen mehr tut als zur Entwicklung von dessen Eigenständigkeit gut ist. Außerdem entgeht er dadurch eher der Gefahr, sich selbst aufzureiben (Gefahr des Burnouts!). Das bedeutet, dass er dem 
Klienten deutlich sagt, worin sein Fehler bestand oder besteht (siehe auch Prinzip 6.2.3), obne ihn jedoch als Persönlichkeit qu verurteilen. Bei der Beratung von Maßnahmen sagt der Sozialpädagoge klar, was er vom Klienten an eigenen Bemühungen erwartet (Klärung der Rollen! Vgl. S. 347).

Mangelndes Verständnis bei den Mitmenschen und Störungen in den sozialen Beziehungen gehören zu den wesentlichen Ursachen sozialer Probleme; daher ist zumindest eine partielle Beseitigung dieser gesetzmäßigen Entstehungsbedingungen sozialer Probleme unabdingbare Voraussetzung für erfolgreiches sozialpädagogischen Handeln. Günstig ist es daher in vielen Fällen, wenn der Hilfebedürftige so weit wie möglich seine „Vergangenheit konsequent hinter sich“ lässt (vgl. Fall Max im Abschnitt 2.4).

Erst das Erlebnis der Anerkennung vermag innere Barrieren (Vorbehalte und Misstrauen) bei den Klienten abzubauen und sie emotional zu lockern. Ermutigung führt darüber hinaus zur Entwicklung jenes Selbstbewusstseins und Selbstwertgefühls, das Grundlage ist für einen erfolgreichen sozialpädagogischen Prozess und für die Stabilisierung der Persönlichkeit des Klienten insgesamt, was ihn künftig vor devianten Verhaltensweisen oder Rückfällen bewahren kann.

\subsubsection{Das Prinzip der Verbindung von Interposition mit parteilichem Engagement für besonders Be- dürftige und Benachteiligte}

Sozialpädagogen müssen durch ihre Zwischenstellung, d. h. durch ein ausgewogenes Verhältnis von Nähe und Distanz zu den Problembeteiligten deren Akzeptanz erwirken und zugleich ihre eigene Unabhängigkeit und Entscheidungsfreiheit sichern, wobei sie aber durch ihr parteiliches Engagement für besonders Bedürftige und Benachteiligte wesentlich ihr Ansehen und ihren Erfolg bestimmen.

\section{Begründung:}

Das Doppelmandat des Sozialarbeiters/Sozialpädagogen erfordert seine Interposition zwischen allen Problembeteiligten, die ihm zugleich auch die erforderliche Akzeptanz und Souveränität sichern hilft, und zwar zum Zwecke des Problemlösungshandelns im Interesse aller Beteiligten. Ein Verlassen der Interposition ist mit der Gefahr verbunden, dass im Falle einer einseitigen Zuwendung zu einer Partei der benachteiligte Problembelastete den Problemlösungsprozess abbricht. Im Falle einer zu großen Nähe zum Problembelasteten wird der Sozialpädagoge so in den Problemkreis eingebunden, dass er sich selbst überfordert und überlastet. Außer dieser sozialen und psychologischen Begründung für die Forderung nach Interposition gibt es eine pädagogisch-psychologische, die Hans Josef Tymister wie folgt formuliert:

"Wer im Bereich der Pädagogik beraterische Hilfe gibt, lässt sich nicht zur Einseitigkeit verführen. Hilfesuchende Eltern und Lehrer erwarten spontan, dass der Helfer ihr Erziehungsanlie- 
gen teilt und sich damit auf ihre Seite stellt. Wenn dies gelänge, wäre die Chance des Helfers, mit den Kindern/Jugendlichen eine pädagogische Beziehung aufzubauen, vertan, bevor die beraterische Hilfe in Gang gekommen wäre“ (Tymister 1996, S. 87).

\section{Handlungshinweise:}

Wirksamkeit und Nachhaltigkeit sozialpädagogischer Maßnahmen hängen auch davon ab, wie das Ziel der Selbständigkeit, das sowohl im Interesse der Klienten als auch des Sozialarbeiters liegt, erreicht und bereits im Problemlösungsprozess realisiert wird. $\mathrm{Zu}$ große Nähe des Sozialpädagogen zu einem Klienten kann zu Abhängigkeiten führen, die der Entwicklung von Selbständigkeit entgegenstehen. Sie erschwert oder verhindert außerdem in den Fällen, in denen zwischenmenschliche Konflikte Inhalte des sozialen Problems sind, die Problemlösung, da sich die Konfliktpartner ungern von parteiischen Vermittlern etwas sagen lassen.

Andererseits kann ein Klient zu seinem Sozialpädagogen kein Vertrauensverhältnis aufbauen, wenn sich dieser zu ihm distanziert verhält. Die Zwischenstellung des Vermittlers muss daher parteiliches Engagement für den Bedürftigen und Benachteiligten einschließen, und zwar so, dass dieser es auch spürt, aber der weniger Bedürftige oder „Nicht-Benachteiligte“ nicht ungerecht behandelt wird bzw. sich nicht ungerecht behandelt fühlt. Das zeitliche und emotionale Engagement für besonders Bedürftige darf allerdings nicht so weit gehen, dass der Sozialpädagoge selbst in die Gefahr gerät, zum Problemfall zu werden, weil sein privates und persönliches Leben zu sehr belastet wird durch zu große Nähe zu seinen Klienten. Supervisionen zum Zwecke psychischer Entlastung durch kompetente Fachkräfte sind daher nicht nur ratsam, sondern unbedingt erforderlich.

Durch ihre Interposition sichern sich Sozialarbeiter/Sozialpädagogen ihre Souveränität sowohl gegenüber den problembeteiligten Klienten als auch den Institutionen, die im Problemlösungsprozess eine Rolle spielen. Das ermöglicht ihnen ein offensives Engagement und bewahrt sie vor einer Vereinnahmung. Die Gestaltung eines ausgewogenen Verhältnisses von Nähe und Distanz erleichtert auch die Ablösung des Klienten vom Sozialpädagogen nach erfolgter Problemlösung.

\subsubsection{Prinzip der Verbindung von Beratung und Verhandlungsführung mit Kooperationsbildung im Interesse der Klienten}

Sozialpädagogen müssen persönliche Beratungen und Verhandlungen mit potenziellen Helfern durchführen, um zweckmäßige Kooperationsbeziehungen aufzubauen und den problembelasteten Klienten in ein soziales Netz entwicklungsfördernder Beziehungen zu vermitteln, ihn nötigenfalls also auch von Problembeteiligten zu trennen. 


\section{Begründung:}

Autorität, Kompetenz und Handlungsherrschaft des Sozialpädagogen werden erst dann voll wirksam, wenn er persönliche Interaktions- und Kommunikationsprozesse mit den Problembelasteten, Problembeteiligten und Helfern pflegt, die Problembelasteten in ein soziales Netz. entwicklungsfördernder Beqiehungen vermittelt und nicht primär über Briefe und Telefonate versucht, den Problemlösungsprozess zu führen.

\section{Handlungshinweise:}

Die persönliche Verhandlungsführung zwecks Lösung sozialer und pädagogischer Probleme (statt schriftlicher Bescheide!) verleiht der Sozialen Arbeit erst ihre sozialpädagogische Komponente, denn unmittelbare zwischenmenschliche Beziehungen und die damit verbundenen Kommunikationen ermöglichen jene individuelle Arbeitsweise, die Soziale Arbeit von Sozialpolitik und Sozialverwaltung unterscheidet. Da persönliche Verhandlungsführungen in der Regel zeitaufwendig sind, müssen Sozialpädagogen darauf bedacht sein, im Umfeld ihrer Klienten Unterstützung zu finden, also Kooperationen aufzubauen oder soziale Netzwerke zu nutzen. Kooperation schließt aber nicht nur Zusammenarbeit von Sozialpädagogen untereinander und mit den Problembeteiligten ein, sondern vor allem auch wirksame Beziehungen zu Sozialexperten und zu speziellen Therapeuten in jenen Fällen, bei deren Lösung es ihrer bedarf (Schuldnerberater, Ärzte, Suchttherapeuten, Psychotherapeuten, Spezialisten für die Behandlung von Legasthenie und Diskalkulie usw.). Eine wirkungsvolle Form der Kooperationsbildung im Bereich der Sozialpädagogik ist die Schaffung von funktionstüchtigen Entwicklungs-Gemeinschaften, in die der Problembelastete integriert wird.

\subsubsection{Das Prinzip der Verbindung von Handlungsherrschaft des Sozialpädagogen mit der Selbstän- digkeitsförderung der Klienten}

Sozialpädagogen müssen unter Einbeziehung aller Problembeteiligten (und Berücksichtigung ihrer Meinungen und Erwartungen) ihre Verantwortung bis zur Problemlösung wahrnehmen und sind daher verpflichtet, in dem Wechselwirkungsverhältnis mit ihren Klienten zu dominieren, um den Lösungsprozess professionell zu strukturieren und dabei auch die Selbständigkeit der Klienten zu fördern.

\section{Begründung:}

Mit ihrer Berufsentscheidung übernehmen Sozialpädagogen eine hohe Verantwortung gegenüber künftigen Klienten und der Gesellschaft, nämlich im Sinne sozialethischer Prinzipien und der Überwindung sozialer Notlagen. Es muss ihnen darum gehen, sowohl den einzelnen Personen zu helfen als auch für den sozialen Frieden in der Gesellschaft zu wirken. Diese moralische Verpflichtung und die zu ihrer Erfüllung einzusetzenden finanziellen Mittel begründen den Anspruch der Sozialarbeiter/Sozialpädagogen 
auf Handlungsherrschaft, die sie auf der Grundlage ihrer Kompetenzen auch realisieren können, wobei sie den Klienten aber nicht alle Lasten abnehmen, sondern sie zur Selbsthilfe befähigen müssen. In der Anerkennung der Handlungsherrschaft des Sozialpädagogen durch die Klienten äußert sich auch die Akzeptanz.

\section{Handlungshinweise:}

Bei der Rollenklärung zu Beginn eines sozialpädagogischen Prozesses müssen die Problembelasteten und die möglicherweise einbezogenen Problembeteiligten erkennen, dass dem Sozialpädagogen auf der Grundlage seiner persönlichen Kompetenz und gesellschaftlichen Verantwortung (z. B. für die verfügbaren Finanzmittel) eine gewisse Führungsrolle oder eben Handlungsherrschaft im gemeinsamen Bemühen zukommt. Das bedeutet nicht Herrschaft über den Problembelasteten und auch nicht, dass ein Sozialpädagoge dem Problembelasteten alle Handlungen vorschreibt. Es bedeutet vielmehr, dass dem Sozialpädagogen die Führung im Gespräch obliegt und das Recht zur Unterbreitung von Problemlösungsvorschlägen, zum Abschluss von Vereinbarungen mit den Klienten sowie die Kontrolle über die Einhaltung getroffener Vereinbarungen zusteht.

Hält sich der Problembelastete nicht an die Vereinbarungen, riskiert er den Abbruch der Hilfemaßnahmen, denn der Sozialpädagoge ist nicht berechtigt, die verfügbaren finanziellen Mittel zur Hilfeleistung zu vergeuden. Wie in jedem Erziehungsprozess ist das erzieherische Verhältnis auch in der psychosozialen Intensiverziehung darauf gerichtet, sich wieder aufzuheben und damit die Handlungsherrschaft des Sozialpädagogen überflüssig zu machen. Daher müssen Sozialarbeiter alles tun, um die Klienten zur selbständigen Bewältigung ihrer Lebenssituation zu befähigen. Das ist zuweilen schwierig, weil sich manche Klienten gern „an ihren Stützen festhalten“ wollen; es ist manchmal unmöglich, weil ihnen tatsächlich die physiologischen und/oder psychischen Voraussetzungen für ein selbständiges Leben fehlen, so dass sie einer helfenden Begleitung und Betreuung bedürfen.

\subsection{Fallbeispiel zur Anwendung der Strukturprinzipien}

\section{Vorbemerkung}

Nachfolgender Fall wurde von Petra Hirt bearbeitet und in ihrer Hausarbeit zur Prüfung als „Sozialpädagogische Jugend- und Familienberaterin“ am Bildungszentrum Dessau (Außenstelle Güstrow) dargestellt. Petra Hirt übernahm als Mitarbeiterin der Hanseatischen Weiterbildungsund Beschäftigungsgemeinschaft Rostock GmbH (HWBR) im Jahr 2002 eine Gruppe von Jugendlichen als sozialpädagogische Betreuerin. Teile ihrer Darstellung wurden unter Beibehaltung der Ich-Erzähler-Position der Autorin übernommen und redaktionell bearbeitet. 


\section{Zur Vorgeschichte (Anamnese)}

Renate wurde 1979 in Stralsund geboren. Sie ist die Zweitälteste von drei Geschwistern in der Ehe. Beide Elternteile nahmen ihre Rolle als Erziehende unzureichend wahr. Renate übernahm teilweise Funktionen der Eltern und kümmerte sich um ihre Geschwister. Der Vater war Alkoholiker und ständig auf Montage. Die Mutter war in Teilzeit beschäftigt. Renate und ihre Geschwister wurden häufig geschlagen, eingesperrt und litten unter den drakonischen Erziehungsmaßnahmen. Renate lernte schon früh sich durchzusetzen: Beulen, blaue Flecken, Schrammen o. Ä. nahm sie in Kauf, um sich das zu nehmen, was sie haben wollte. Sie wurde deshalb von den anderen Kindern oft gemieden: diese hatten Angst vor ihrer Aggressivität und ihren Wutausbrüchen.

Sie besuchte von 1985 bis 1994 eine Schule für Lernbehinderte. 1988 ließen sich die Eltern scheiden. Mit 13 Jahren (1992) verließ Renate das Elternhaus und lebte bei älteren Freunden. Wegen ihrer Beteiligung an Einbrüchen bekam sie es mit der Polizei zu tun und zog zur Schwester ihres Vaters. Nach zwei Monaten zog sie wieder zu Freunden, nahm Drogen und Alkohol und verbrachte viele Nächte in der Diskothek. Ihre Mutter zog unterdessen mit ihren anderen Kindern und einem neuen Lebenspartner nach Würzburg. Der Vater blieb in Stralsund. Renate konnte selbst entscheiden, bei wem sie leben möchte. Sie entschloss sich nach Würzburg zu ziehen, wo sie bei einer Freundin der Mutter wohnte.

Von 1997 bis 1998 lebte Renate ohne Ausbildung oder Arbeitstätigkeit. Von 1998 bis 1999 besuchte sie eine Maßnahme zur Bildungs- und Berufseingliederung mit einer geplanten Ausbildung zur Kosmetikerin, die sie jedoch abbrach. Sie verbrachte während dieser Zeit einen Urlaub auf Rügen und lernte dort ihren späteren Ehemann kennen. Ihre Kontakte nach Würzburg hat sie daraufhin spontan abgebrochen, um mit ihm zusammen zu ziehen und dann zu heiraten. Noch 1998 kam das gemeinsame Kind zur Welt. Schon bald kam es in der Ehe aber zu Komplikationen. Ihr Mann war sehr eifersüchtig, wollte zunächst sogar die Vaterschaft nicht anerkennen. Sie wurde von ihm ständig im Hinblick auf ihr Aussehen, ihre Kleidung kritisiert und unter Druck gesetzt. Es kam zu gewalttätigen Ausschreitungen. Ihr Ehemann hat sie geschlagen und getreten. Sie ging schließlich zur Polizei, um ihren Mann wegen versuchten Totschlags anzuzeigen. Mit Hilfe der Polizei holte sie ihr Kind und zog ins Frauenhaus. Bald darauf reichte sie die Scheidung ein. Sie stellte Antrag auf Sozialhilfe und bekam Erziehungsgeld. Über das Sozialamt kam sie ins betreute Wohnen. Seit der Geburt ihres Kindes lebte sie im Erziehungsurlaub. Im Jahre 2001 kam Renate nach Rostock.

Im Februar 2001 begann sie mit einer überbetrieblichen Ausbildung in der HWBR GmbH zur Verkaufshilfe. Sie kam ein Vierteljahr später in das Unternehmen, konnte sich aber gut in die Gemeinschaft integrieren. Sie hat sämtliche Kontakte zur Mutter und zu ehemaligen Freunden abgebrochen und baute sich ein neues Zuhause auf. Im Laufe der Zeit lernte sie einige Männer kennen, bis sie jemanden traf, der auch ihren Sohn akzeptierte. Die drei zogen zusammen. Der neue Freund war auf Bewährung aus dem Gefängnis entlassen worden und pflegte weiterhin 
Kontakte mit anderen Kriminellen. Ihr Freund war extrem eifersüchtig und schlug sie. Renate erstattete abermals Anzeige und zog im Juni 2003 mit ihrem Kind in eine andere Wohnung.

\section{Darstellung der Problembearbeitung}

Im ersten Gespräch erzählte Renate mir ihre Lebensgeschichte. Sie reagierte mir gegenüber verängstigt und unsicher, weil sie bisher von Erwachsenen immer enttäuscht worden war. Das Gespräch verlief zunächst oberflächlich und bruchstückhaft. Sie verbarg sich hinter einem Schutzmantel. Ich nahm mir sehr viel Zeit und es gelang mir, ein Vertrauensverhältnis zu ihr aufzubauen. Ich ermutigte sie durch ein freundliches, unvoreingenommenes Gespräch zur Darlegung ihrer Probleme (Strukturprinzip 5.5.2). Es gelang mir auch, sie etwas von ihren Schuldgefühlen zu entlasten, indem ich begründet darauf verweisen konnte, dass sie nicht in allen Phasen ihrer Lebensentwicklung Schuld auf sich geladen hatte. Ich erklärte ihr, dass wir gemeinsam Lösungen für ihre kritische Lebenssituation finden können, aber für den Erfolg ihre aktive Mitarbeit erforderlich ist (Strukturprinzip 5.5.5).

Die Einsicht in die Notwendigkeit einer aktiven Zusammenarbeit erlangte sie allerdings erst im Verlauf des weiteren Ausbildungsjahres. In dieser Zeit fand eine intensive Betreuung in zahlreichen Einzelgesprächen statt. Dabei trafen wir stets Zielvereinbarungen, deren Realisierungsstand wir jeweils im darauf folgenden Gespräch auswerteten. Zu ihren Hauptsorgen gehörten ihre Schulden. Sie musste ihrem damaligen Freund Geld geben, das sie nie zurück bekam. Sie erhielt Rechnungen, die sie nie begleichen konnte. Es stellte sich heraus, dass auch Renate selbst nicht gelernt hatte, mit Geld umzugehen. Ich machte ihr verständlich, dass sie mit dem ihr zur Verfügung stehenden Geld alle anstehenden Ausgaben bestreiten muss und half ihr bei der Klärung von Zahlungsschwierigkeiten (Strukturprinzip 5.5.3). Wir formulierten Schreiben, in denen Renate sich zu Ratenzahlungen bereit erklärte. Sie reagierte darauf erleichtert und dankbar. Wegen des Umfangs der Schulden suchten wir zusätzlich eine Beratungsstelle auf (Strukturprinzip 5.5.4), da meine Kompetenz nicht ausreichte, um ihr umfassend zu helfen. Weitere Problem wurden deutlich:

- Renates berufliche Laufbahn war gefährdet. Sie erzählte von den Eifersuchtsszenen ihres Partners und davon, dass er sie geschlagen und getreten habe. Deshalb wollte sie sich von ihm trennen. Sie erstattete eine Anzeige bei der Polizei. Ihr Partner wurde daraufhin von der Polizei gesucht. Ich schlug ihr vor, sich sofort eine neue Wohnung zu nehmen, womit sie einverstanden war. Nachdem Renate sich für eine kostengünstigere Wohnung entschieden hatte, stellten wir eine Liste mit den wichtigsten anstehenden Aufgaben auf. Es wurden darauf Termine vermerkt, die sie einhalten musste. Wir besichtigten zusammen die neue Wohnung und teilten die Freude. Renate wurde dadurch angespornt und bewältigte den Umzug termingerecht. 
- Bei Renate hatten sich durch Hänseleien in der Vergangenheit Komplexe entwickelt, die den Wunsch weckten, sich einer kosmetischen Operation zu unterziehen; sie meinte: „Meine Brüste sind zu klein, meine Nase ist zu spitz.“

- Ich habe sie auf mögliche gesundheitliche Folgen aufmerksam gemacht. Darauf ging sie gar nicht ein. Ihr stehen allerdings nur begrenzt finanzielle Mittel zur Verfügung, so dass ihr Wunsch ohnehin illusorischer Natur war.

- Ihre Bindungen zu Männern sind nicht von langer Dauer. Endlich fand sie jemanden, der ihr Liebe und Geborgenheit geben wollte. Aber damit konnte Renate überhaupt nicht umgehen, sie trennte sich von ihm mit der Begründung: „der ist zu lieb“. Sie lässt sich weiterhin auf Männer ein, die gewalttätig und aggressiv sind. ${ }^{29}$ Zwar hat sie das Bedürfnis nach Geborgenheit und nach Liebe; sie ist auch bereit, Liebe zu geben, doch wegen der nicht aufgearbeiteten Erlebnisse ist es ihr offenbar nicht möglich, dieses Problem zu lösen. Dafür bedarf es noch zusätzlicher intensiver fachlicher Beratung und Hilfe.

Erste positive Wirkungen unserer Bemühungen zeigten sich u. a. darin, dass Renate das Bestreben erkennen ließ, ihre Ausbildung erfolgreich abzuschließen. Sie ist selbstbewusster geworden und hat erkannt, dass sie ihre Zukunft eigenverantwortlich gestalten muss. Ihre Wohnung hält sie in Ordnung und dank ihrer handwerklichen Fähigkeiten gestaltet sie diese nach ihren eigenen Vorstellungen.

Gruppenarbeit ist ein maßgeblicher Baustein in der Betreuung der Jugendlichen in der überbetrieblichen Erstausbildung. Allerdings war es nicht einfach für mich, Problemstellungen zu finden, die auf der einen Seite den Interessen der Jugendlichen entsprachen und auf der anderen Seite zu notwendigen Erkenntnissen für ihre eigene Lebensgestaltung führen konnten. Ein beeindruckendes Gruppengespräch entstand nach dem gemeinsamen Betrachten des Kinofilms „Wir Kinder vom Bahnhof Zoo“. Zunächst nur als Anregung für eine sozialpädagogische Diskussion ausgewählt, bot der Film Stoff für eine Reihe von Problemdiskussionen. Die Gruppenmitglieder erlangten durch die Gespräche über die Filmproblematik einige Klarheit über ihr oftmals unbewusstes Rollenverhalten. Dieser Film mit seinen sozialen Konflikten ähnelte ihren eigenen Biographien. Durch diesen Film wurden den Jugendlichen wesentliche Erkenntnisse in ihrer Sprache vermittelt. Ein zentraler Diskussionspunkt war die Frage, ob die weiteren Lebensläufe durch ihre bisherigen Biographien für jede Zeit vorbestimmt seien oder ob sie durch das Erkennen ihres fehlerhaften Lebensstils diesen überwinden und auf ihre Lebensperspektive positiven Einfluss nehmen können.

Wir (Ausbilderin, Stützlehrerin, Sozialpädagogin) werteten im Team die von mir gesammelten Informationen aus und entwickelten auch für Renate Förderschwerpunkte:

29 Eine aufschlussreiche Analyse solcher Phänomene liefert Werner Schreiber bei Jansen u. a. 2006, S. 66ff. 
- Stärkung ihres Selbstbewusstsein und Entwicklung einer positiver Einstellung zur Ausbildung durch Überwindung ihrer Defizite im Fach Mathematik;

- Übungen zur Überwindung ihrer Konzentrationsschwierigkeiten unter Leitung der Stützlehrerin und der Sozialpädagogin;

- Förderung ihrer Sozialkompetenz durch eine entsprechende Gestaltung der Gruppenarbeit.

Wir besprachen mit Renate entsprechende Maßnahmen und vereinbarten Termine.

In Absprache mit dem Praktikumsbetrieb (Strukturprinzip 5.5.4) kam Renate zu uns in die Einrichtung, um die vereinbarten Maßnahmen zu realisieren. Hinzu kamen „sozialpädagogische Stunden“ nach Feierabend, in denen sie ihre Probleme ,abladen“ und letztlich ihr Selbstbewusstsein stärken konnte. Ihre Entwicklung nahm zunächst einen positiven Verlauf. Ihre schulischen Leistungen, besonders in Mathematik, verbesserten sich. Die Erfolge wurden besprochen und im Förderplan notiert. Das motivierte Renate zu größeren Anstrengungen in der Ausbildung, doch diese Motivation hielt nicht lange an. Durch private Schwierigkeiten wurde sie aus dem Ausbildungsalltag herausgerissen und agierte zunehmend unzuverlässig. In unseren Gesprächen motivierte ich sie. Ich hielt ihr ihre Ziele und Bedürfnisse vor Augen und verwies immer wieder auf die gemeinsam getroffenen Vereinbarungen (Strukturprinzipien 5.5.2, 5.5.5).

Die Arbeit im Betrieb war für Renate nicht nur von fachlicher Bedeutung, sondern stellte für sie eine andere soziale Komponente dar: sie machte positive Erfahrungen im Umgang mit Kunden, Kollegen und Vorgesetzten und verbesserte so ihre Sozialkompetenz. Ich besuchte Renate einmal wöchentlich im Praktikumsbetrieb und informierte mich über ihre Arbeitsdisziplin und ihre Anwesenheit. Die Ausbilder sagten, dass sie Arbeitsaufträge selbständig und lobenswert ausführt (Strukturprinそip 5.5.4). Mir war wichtig, dass sie bei diesen Gesprächen mit anwesend war. So hatte sie eine direkte Rückmeldung über ihr Arbeitsverhalten, erlebte die Wertschätzung ihrer geleisteten Arbeit und erfuhr persönliche Anerkennung.

Ich pflegte auch wöchentlichen Kontakt mit Renates Klassenleiterin in der Berufsschule (Strukturprinzip 5.5.4). Bei diesen Gesprächen gingen wir auf bestimmte Unterrichtsinhalte ein, die für den Stütz- und Förderunterricht bedeutsam waren. Mit Renate sprach ich, um eventuelle Probleme gemeinsam lösen zu können. Ihre Leistungen stabilisierten sich so, dass die Klassenleiterin einer vorzeitigen Beendigung der Ausbildung zustimmte. Normalerweise hätte Renate ein halbes Jahr länger lernen müssen als ihre Klassenkameraden wegen ihres verspäteten Ausbildungsbeginns. Wir Pädagogen entschlossen uns zu diesem Schritt, um Renates relativ kontinuierliche Entwicklung nicht durch Veränderungen in den nunmehr entwickelten relativ günstigen sozialen Beziehungen zu gefährden (Strukturprinzip 5.5.3). 
Renates Lebensverhältnisse haben sich inzwischen stabilisiert. Die erfolgreiche Beendigung ihrer Ausbildung hat sie so motiviert, dass sie sich auch bei anderen Aufgaben engagiert. Sie nimmt selbständig die Termine bei der Beratungsstelle wahr. Sie gestaltet selbständig ihre Wohnung. Von besonderer Bedeutung für sie ist ihre Perspektive: der Praktikumsbetrieb plant, sie wegen ihrer guten Leistungen zu übernehmen! Ihre Unsicherheit gegenüber älteren Personen konnte sie abbauen. Jetzt erscheint sie als aufgeschlossene, temperamentvolle und freundliche junge Frau.

\section{Kommentar}

Die Biografie von Renate zeigt die negativen Auswirkungen gestörter zwischenmenschlicher Beziehungen auf ibre Entwicklung. Da die Sozialpädagogin dies erkannt hat, konzentriert sie sichauf die Entwicklung vertrauensvoller Beziehungen zwischen den Beteiligten am Ausbildungsprozess und in der Ausbildungsgruppe, und zwar sowohl mittels offener Diskussionen über die Probleme der Jugendlichen als auch mit Hilfe eines klaren Anforderungsprogramms, durch dessen erfolgreiche Realisierung Renate ihre Selbstkompetenz und ihre Sozialkompetenz verbesserte. Von ausschlaggebender Bedeutung für Renates erfolgreiche Entwicklung während der intensiven Betreuungsphase war sicherlich ibre Einordnung in ein Netz sozialer Beziehungen, in dem ihre Leistungsbemühungen und positiven sozialen Verbaltensweisen herausgefordert und anerkannt wurden (Strukturprinzip 5.5.4).

Die praktische Fallbearbeitung lässt außer dem Konzeptprinzip 4.6.5 (hohe Achtung und steigende Anforderungen) kaum Bezüge zu Grundelementen humanistischer Gemeinschaftserziehung in Anlehnung an Makarenko erkennen. Das ist auch nicht verwunderlich, denn

1. aus nahe liegenden Gründen war die Erörterung solcher Zusammenhänge aus dem Bereich „der Kollektiverziehung“ in pädagogischen Einrichtungen der neuen Bundesländer nahezu tabu - selbst wenn sie praktisch existierten;

2. Makarenkos Erkenntnisse und konzeptionelle Vorstellungen waren in den neuen Bundesländern bis zum Abschluss des Kurses weder für die Lehre noch für die Praxis historisch hinreichend aufgearbeitet;

3. zu den Ausbildungsgruppen bzw. Gruppen im betreuten Wohnen bei der HWBR gehören auch Mütter mit Kleinkindern, die in den vorliegenden Konzepten Makarenkos und Rasmussens keine Rolle gespielt haben; sie stellen ein neues und spezielles Problem für eine Theorie der humanistischen Gemeinschaftserziehung unter den angegebenen Bedingungen dar. 
6. Kapitel

Zur organisatorisch-methodischen Gestaltung sozialpädagogischer Prozesse 


\subsection{Theoretische Grundlagen einer funktionalen Betrachtung und Dar- stellung sozialpädagogischer Prozesse}

\subsubsection{Versuche zur Prozessbeschreibung in der Pädagogik}

In der Geschichte der Pädagogik gibt es zahlreiche Versuche, pädagogische Prozessverläufe so darzustellen, dass die erzieherischen Kräfte bzw. Lehrenden damit eine möglichst praktikable Anleitung zur Prozessgestaltung erhalten. Während wir bei Ratke und Komenský erste Ansätze zur Prozessbeschreibung im Zusammenhang mit bestimmten Unterrichtsinhalten (Sachkenntnissen, Muttersprache, Fremdsprachen, Religion usw.) finden, unternimmt Herbart den Versuch, grundlegende und allgemeine Elemente jedes Unterrichtsprozessverlaufes herauszuarbeiten, die er mit den Begriffen Klarbeit, Assoziation, System, Methode zu erfassen suchte. Diese „Stufen des Unterrichts“ sollten als Orientierungsgrundlage für das Handeln der Lehrenden und Lernenden dienen und sind auch unter dem Begriff der „Artikulation des Unterrichts“ in die Schulpraxis und Geschichte der Pädagogik eingegangen (vgl. Herbart 1922, Bd. 2, S. 189).

Die Herbartschen Vorstellungen haben beträchtlichen Einfluss auf die Entwicklung der Auffassungen vom Unterrichtsprozessverlauf gehabt. Eine recht differenzierte und Herbarts Verdienste würdigende Darstellung dieser Entwicklung hat Hilbert Meyer in seinem Buch „Unterrichtsmethoden I: Theorieband“ gegeben. Eine ähnliche, wenn auch kürzere Fassung von Herbarts Verdiensten um die wissenschaftliche Darstellung des Unterrichtsprozesses ist in dem Lehrbuch „Didaktik“ von Heino Liimets und Werner Naumann nachzulesen. In diesem Buch wird zugleich eine Konzeption zur Betrachtung von Unterrichtprozessverläufen mit der Absicht vorgestellt, die mit den Begriffen der „Stufen“ oder „Phasen“ verbundenen schematischen und groben Reduktionen in der Prozessdarstellung zu überwinden, und zwar mit Hilfe einer hierarchischen und flexiblen heterarchischen ${ }^{30}$ Strukturierung des Prozessverlaufs nach Funktionskomplexen, Funktionseinheiten und Funktionen (vgl. Liimets/Naumann 1982, S. $103 \mathrm{ff}$. oder 1985, S. 104ff.).

Das Wort „Phase“ ist im Bereich der Physik und Astronomie sehr gebräuchlich und bezeichnet dort den zeitlich begrenzten Verlauf einer Bewegung. Es findet in einer angereicherten Bedeutung auch in der belebten Natur und in der Psychologie Anwendung. So schreibt z. B. Hildegard Rauh in ihren Ausführungen zur frühen Kindheit:

„Sehr bald in der Neugeborenenphase reagieren sie (die Säuglinge) mit ihrem Saugen bereits auf Außenreize. Wenn sie aufmerken oder aufhorchen (Orientierungsreaktion), sich also dem Stimulus zuwenden, unterbrechen sie das Saugen und eventuell auch das Atmen; es weiten sich

30 Heterarchie meint den flexiblen situationsabhängigen Wechsel von Über- und Unterordnung der Funktionen, wodurch einer starren Hierarchie in der Struktur und einer schematischen Anwendung der Funktionen vorgebeugt werden soll. 
die Pupillen, es sinken die Seh- und Hörschwellen, der Herzschlag verlangsamt sich, die elektrische Leitfähigkeit der Haut erhöht sich, und die periphere Durchblutung verringert sich zugunsten der Erhöhung der Gehirndurchblutung. Diese Orientierungsreaktion oder Orientierungsphase wird dann von der Verarbeitungsphase abgelöst" ( nach: Oerter/Montada 1998, S. 188). In diesem Text wird das Wort Phase sowohl für den relativ langen Entwicklungsabschnitt der Nengeborenenphase - also für die ersten sechs Monate - als auch für die Daner relativ kurzzeitiger Reaktionen des Säuglings im alltäglichen Lebensablauf verwendet. Obgleich es sich offensichtlich um verschiedene Phasendimensionen handelt, sind als gemeinsame Merkmale jeweils folgende erkennbar:

- Es handelt sich um zeitlich begrenzte Abschnitte im Lebensverlauf des Säuglings.

- Die den jeweiligen Abschnitt charakterisierende Gesamtheit der Merkmale ist in dieser Konstellation typisch und begründet relativ deutliche Abgrenzungen.

- Der Abschluss einer Phase ist jeweils eine Voraussetzung für den Beginn und Erfolg der nächsten.

- Die Merkmale resultieren aus natürlichen Vorgängen und sind ihrem Wesen nach nicht bewusst gestenert.

Der wissenschaftliche und praktische Wert von Phasendifferenzierungen im biologischen Bereich besteht u. a. darin, dass mit dem Abschluss einer bestimmten Phase die Voraussetzungen für eine nächste im Entwicklungsprozess gegeben sind, was für die Analyse von Entwicklungsprozessen und die Bewertung des jeweils erreichten Entwicklungsstandes bedeutsam ist. Allerdings hat die neuere Psychologie bezüglich der Phasenmodelle in der Entwicklungspsychologie begründete Bedenken angemeldet: So heißt es z. B. im „Lexikon der Psychologie“, Band 3 (2001):

„Phasen- bzw. Stufeneinteilungen lassen das Entwicklungsgeschehen innerhalb eines Abschnittes weitaus einheitlicher erscheinen, als es tatsächlich ist (die Regel scheint eher die Asynchronie individueller Verläufe zu sein)“ (a. a. O., S. 259).

Das bedeutet: interindividuelle Unterschiede werden bei Phasenkonstrukten negiert. Im Bereich bewusst beeinflusster psychischer Prozesse ist die Anwendung des Wortes Phase noch problematischer. Es fragt sich daher, ob der Inhalt des Begriffs, der bisher durch das Wort Phase bezeichnet wurde, geeignet ist, um die kompliziertere Struktur bewusst gestalteter Prozessabschnitte zu erfassen, und wie weit es berechtigt oder zweckmäßig ist, in Anbetracht der Unterschiede zwischen belebter und unbelebter Materie die ,zeitlichen Abschnitte in Lebensprozessen“" mit dem Wort Phase zu bezeichnen. Zumindest muss beachtet werden, dass es sich um unterschiedliche Phasenbegriffe handelt.

Wie kompliziert die bewusste Beeinflussung oder „Steuerung“ von psychischen Entwicklungsprozessen ist, wird an den ungewollten Nebenwirkungen und Misserfolgen deutlich, die vielfach auftreten, was $z u$ wiederholten und korrigierenden Bemühungen führt. 
Nicht selten treten erst zu einem späteren Zeitpunkt, der außerhalb der „geplanten Phase“ liegt, die ursprünglich angestrebten Effekte ein. Daraus resultiert, dass es sowohl bei fremd- als auch bei selbstgesteuerten Prozessen keine solch relativ klaren Phasenabgrenzungen gibt wie bei Bewegungen und Kreisläufen der unbelebten Materie (z. B. bei Gestirnen). Zwecks wissenschaftlicher Erfassung komplizierterer Prozessverläufe ist es daher sinnvoll, andere Begriffe zu bilden und neue Bezeichnungen zu wählen.

Da nun aber in der Psychologie ungeachtet des qualitativen Unterschiedes zwischen spontan ablaufenden und bewusst gestalteten Prozessen das Wort Phase verwendet wurde und wird, ist es nicht verwunderlich, dass es in der Pädagogik sogar die Herbartsche Bezeichnung Stufen (des Unterrichts) verdrängt bzw. abgelöst hat. In pädagogischen Schriften bezieht sich das Wort Phase auf einen Begriff, der erfasst:

- $\quad$ eine Zeitspanne im handlungsbestimmten Prozessverlauf,

- die der Realisierung eines pädagogischen Zieles oder einer Gruppe von Zielen dient,

- durch deren Realisierung zugleich wesentliche Voraussetzungen für weiterführende Phasen bzw. Ziele geschaffen werden.

So wie in der Schuldidaktik finden wir auch in sozialpädagogischen Schriften Beschreibungen zu Prozessverläufen mit Hilfe des Phasenbegriffes. Schilling (1993, S. 272) bietet beispielsweise folgenden Orientierungsrahmen an:

\begin{tabular}{|l|l|l|l|}
\hline $\begin{array}{l}\text { 3. Didaktisch/ } \\
\text { methodische } \\
\text { Überlegungen }\end{array}$ & $\begin{array}{l}\text { Feinziele } \\
\text { Didaktischer } \\
\text { Kommentar }\end{array}$ & $\begin{array}{l}\text { Vermittlungs- } \\
\text { variablen }\end{array}$ & Zeit \\
\hline $\begin{array}{l}\text { 3.1 Einstiegsphase } \\
\text { Kontaktaufnahme } \\
\text { Motivation } \\
\text { Problem }\end{array}$ & & & \\
\hline $\begin{array}{l}\text { 3.2. Hauptphase } \\
\text { Information } \\
\text { Diskussion } \\
\text { Austausch }\end{array}$ & & & \\
\hline $\begin{array}{l}\text { 3.3. Schlußphase } \\
\text { Zusammenfassung } \\
\text { Transfer } \\
\text { Auswertung }\end{array}$ & & & \\
\hline
\end{tabular}

Die Phasen (3.1-3.3) werden mit einem didaktischen Planungsgitter für ein Situationskonzept verbunden, das noch eine ganze Reihe weiterer wichtiger Überlegungen zur Planung erfordert, wodurch der Autor offensichtlich die Mängel der schematischen 
Reduktion mildern will, was zweifellos für den Anfänger in der praktischen Sozialarbeit hilfreich ist, denn immerhin enthält das Planungsgitter wichtige Hinweise zu dem, was in der jeweiligen Phase eigentlich - sozialpädagogisch betrachtet - gemacht werden soll. Die Schwächen des Modells sind aber im Prinzip die gleichen wie bei den meisten pädagogischen Phasenmodellen (auch in der Didaktik): die verwendeten Begriffe lassen z. T. nicht hinreichend klar erkennen, was in den jeweiligen Phasen pädagogisch erreicht werden soll. Die Phase „Diskussion“lässt z. B. offen, worauf sich die Diskussion bezieht bzw. was sie bewirken soll. Es wird nicht beachtet, dass die Dis kussion eine Kommunikationsform ist, die schon bei der Problemfindung (also bei 3.1) auftritt und auch beim Austausch und Transfer eine Rolle spielen kann. Zudem erscheint die vorgenommene Reduktion auf einige Momente des Prozessverlaufs willkürlich und unzureichend begründet, was zur Folge hat, dass wichtige fehlen.

Trotz dieser Schwächen finden wir in sozialpädagogischen Schriften weitere ähnlich geartete Phasenmodelle. Als Beispiel für eine praktisch gebräuchliche Phasendarstellung des sozialpädagogischen Prozesses sei hier ein Modell zitiert, das von einem Rostocker freien Träger der Sozialarbeit genutzt wird:

1. „Einführung: Sie dient dem persönlichen Kennenlernen der Gruppenmitglieder und der Betreuer.

2. Orientierung: Die Teilnehmer durchlaufen 5 verschiedene Berufsfelder in jeweils 3 Wochen und sollen einen groben Überblick über Inhalte, Anforderungen und spätere Einstiegschancen in den Arbeitsmarkt bekommen. Kompetenzfeststellung. Es werden kleinere typische Tätigkeiten erlernt.

3. Vertiefung: Die Teilnehmer entscheiden sich für ein Berufsfeld entsprechend ihres zukünftigen Berufswunsches und erproben sich 7 Monate, wobei 2 Praktika und der Jahresurlaub mit eingeschlossen sind. Sie sind in Kleingruppen (max. 12 Jugendliche) zusammengefasst. Es ist die Zeit der intensivsten Arbeit des jeweiligen Pädagogenteams mit den Teilnehmern.

4. Ablösung: Der Berufswunsch steht fest, und es ist eine Aussage über eine Lehrstelle getroffen. Durch verschiedene Freizeitaktivitäten (Abschlussfahrt), notwendige Behördengänge zur Vorbereitung des Übergang in die Ausbildung und die Abschlussfeier mit Zertifikatsübergabe erfolgt die Beendigung des Lehrgangs“ (Pecher 2003, S. 2).

Die Verwendung von Phasenmodellen ist trotz der oben geäußerten kritischen Bedenken notwendig, weil praktisches sozialpädagogisches Handeln in der Regel auch Verwaltungshandeln mit einschließt. Das bedeutet: es werden ungeachtet der realen Dynamik individueller Prozessverläufe in der Ausbildung der Jugendlichen relativ strenge Zäsuren vorgenommen, weil zu bestimmten, konzeptionell festgelegten Zeitpunkten ganz einfach verwaltungstechnisch und organisatorisch notwendige Maßnahmen ergriffen werden 
müssen, z. B. Stundenplanungen, Gruppeneinteilungen, Festlegungen zum Kräfteeinsatz und zum Praktikumsbeginn bzw. -abschluss sowie zu finanziellen Abrechnungen.

Sofern also Phasenmodelle mit deutlichem Bezug auf praktisches Verwaltungshandeln in soziapädagogischen Prozessen angeboten werden, sind sie auch wissenschaftlich vertretbar. Aber sie können nicht den Anspruch erheben, die Dynamik und Dialektik des spezifischen sozialpädagogischen Prozessverlaufes auch nur einigermaßen differenziert abzubilden.

\subsubsection{Begründung und Bestimmung eines pädagogischen Funktionsbegriffs}

Für eine sozialpädagogische Prozesstheorie sind nicht „verwaltungstechnisch“ verursachte Planungs- und Abrechnungstermine und dadurch bedingte organisatorische Maßnahmen bestimmend, sondern psychologisch und pädagogisch begründete Aktivitäten der Sozialpädagogen und Problembelasteten, die Fortschritte im Problemlösungsprozess bewirken. Diese sich wechselseitig bedingenden Aktivitäten zur Lösung eines sozialpädagogischen Problems können begrifflich als sozialpädagogische Funktionen gefasst werden. Für ein richtiges Verständnis eines pädagogischen Funktionsbegriffs, der zugleich auch Grundlage für den sozialpädagogischen ist, sind folgende Erkenntnisse und Überlegungen bedeutsam:

- In Anlehnung an die Bedeutung des Wortes „Funktion“ in der Umgangssprache können darunter eine Aufgabe und die zu ihrer Lösung erforderlichen Operationen der Funktionsträger (der Erzieher und Zöglinge) verstanden werden.

- In der Technik meint das Wort „Funktion“ zweckgebundene Verrichtungen und Wirkungen von Geräten.

- In der Informationstheorie versteht man unter der Funktion eines Elementes die Art und Weise der Aufnabme, Verarbeitung und Abgabe von Informationen (vgl. Klaus 1967, S. 215). Da Erzieher und zu Erziehende zugleich aktive Elemente in pädagogisch geprägten Informationsprozessen sind, ist klar, dass auch sie wechselseitig Informationen abgeben bzw. aufnehmen und verarbeiten.

- „Im Anschluss an eine Festlegung, die Leonhard EULER (1707-1783) bereits im Jahre 1740 gegeben hat, erklärt man oft eine Funktion als eine veränderliche Größe, die von einer anderen veränderlichen Größe abhängt. Für manche Zwecke genügt eine solche Bestimmung des Funktionsbegriffs“ (Kleine Enzyklopädie Mathematik 1968, S. 125). Nun sind natürlich Erzieher und zu Erziehende keine Größen im mathematischen Sinne, aber die Abbängigkeit von veränderlichen Elementen entsprechend einer Vorschrift der Zuordnung, also der Operationen der Zöglinge durch die der Erzieher auf der Grundlage wirksamer Autorität, kann in den pädagogischen Funktionsbegriff aufgenommen werden. 
Pädagogische Funktionen sind jene durch pädagogische Autorität maßgeblich bestimmten, voneinander abhängigen und miteinander in Wechselwirkung stehenden Operationsfolgen der Informationsabgabe, Informationsaufnahme und Informationsverarbeitung aller Beteiligten, die zielgemäße Beiträge zur Persönlichkeitsentwicklung der Zöglinge leisten.

Grundlage für die Formulierung pädagogischer Funktionen sind die zur Zielrealisierung notwendigen Lernhandlungen der Zöglinge, denen der Erzieher bei der Gestaltung des Interaktionsprozesses Rechnung tragen muss, so dass wir sagen können:

Die Operationen sind Bestandteile von spielerischen, erkennenden, kommunikativen, künstlerischen, praktisch-produktiven, sportlichen, sozialen $u$. a. Handlungen, die dem Prozessverlauf jeweils ein spezifisches Gepräge geben. Die Realisierung pädagogischer Funktionen erfordert die Beachtung psychischer Gesetzmäßigkeiten, die sich auch in pädagogischen Prinzipien widerspiegeln.

Wichtig für ein richtiges Verständnis des pädagogischen Funktionsbegriffs ist der Zusammenhang zwischen den unmittelbaren Wirkungen der jeweiligen Funktion und den übergeordneten pädagogischen Zielen, zu deren Realisierung sie beitragen. So dienen die Funktionen der Motivierung und Ermutigung nicht nur dazu, den Lernenden zu bewegen, eine bestimmte Aufgabe in Angriff zu nehmen, sondern über ihre erfolgreiche Bewältigung generell sein Selbstvertrauen zu stärken. Die Funktion der Vereinbarung dient nicht nur der möglichst eindeutigen Verständigung darüber, wer was zu tun hat, sondern zielt auf eine moralische Verpflichtung des Hilfesuchenden im Interesse der Problemlösung und auf die Entwicklung damit verbundener Persönlichkeitseigenschaften, z. B. auf die Gewöhnung an die Einhaltung gegebener Versprechen und auf Zuverlässigkeit als Persönlichkeitsmerkmal. So lassen sich bei jeder Funktion unmittelbar beabsichtigte Zwecke der jeweiligen Operationen angeben und auch damit verbundene weitergehende Wirkungen im Sinne übergeordneter Ziele. Der oben definierte allgemeine pädagogische Funktionsbegriff lässt sich für den Bereich der Sozialpädagogik wie folgt inhaltlich näher bestimmen:

Sozialpädagogische Funktionen sind von Sozialpädagogen geführte, von-
einander abhängige Operationsfolgen aller Prozessbeteiligten, durch die
primär die Problembelasteten in Beratungen und damit verbundenen Lern-
und Arbeitsprozessen zur Problemlösung befähigt werden, was Einstel-
lungsänderungen und Umgewöhnungsprozesse mit einschließt.

Für ein richtiges Verständnis der sozialpädagogischen Funktionen im definierten Sinne ist ferner bedeutsam, dass und wie sie sich in der Praxis wechselseitig durchdringen, einander überlagern und entsprechend den objektiven Erfordernissen eines erfolgreichen Prozessverlaufs in ibrer 
Abfolge vertauschen und wiederholen. Da es eine relativ große Anzahl von Funktionen in jedem vollständigen pädagogischen Prozessverlauf gibt, erscheint es zweckmäßig, sie aus Gründen der Übersichtlichkeit zu Funktionseinheiten zusammenzufassen, für die auch gilt, was soeben über die Flexibilität der einzelnen Funktionen gesagt worden ist. Da wir die Vorgehensweise als wesentlichen Aspekt pädagogischer Methoden betrachten (siehe S. 70), stellen pädagogische Funktionen, realisiert durch miteinander verkettete Operationen von Erziehern und Zöglingen, die methodische Grundstruktur von pädagogischen Prozessverläufen dar (siehe Schemata 9 und 10 auf S. 333 bzw. S. 336).

\subsubsection{Zur Konstruktion eines Funktionsmodells für sozialpädagogische Prozesse}

Einer Anregung von H. J. Tymister folgend, wurde geprüft, wie Ferdinand Birnbaum (1892-1947) auf der Grundlage der Individualpsychologie von Adler versucht hat, „für die einzelnen schwererziehbaren Kinder erziehungstechnische Operationspläne auszuarbeiten“ (Birnbaum 1931, S. 172; Hervorhebungen wie im Original!). In seinen Veröffentlichungen (1931 und 1932) hat er wesentliche Erkenntnisse und Erfahrungen zu einem individualpsychologischen Beratungskonzept dargestellt, das er an einer Volksschule in Wien, die am 15. September 1931 den Status einer individualpsychologischen Versuchsschule erhielt, erfolgreich realisieren konnte.

Aus der Sicht einer funktionalen Betrachtung pädagogischer Prozessverläufe sind folgende Momente der Konzeption von F. Birnbaum bedeutsam:

- Die Arbeit an der o. g. Schule war so angelegt, dass sie „,vor allem der innigen Durchdringung von Beratungs- und Durchführungsarbeit dienen" sollte, d. h., der Beratungsprozess lief nicht als eine Art von „Reparaturprozess“ nebenher, sondern durchdrang mit seinen Konsequenzen den gesamten pädagogischen Prozess an der Schule, verlieh ihm gegebenenfalls auch einen sozialpädagogischen Charakter.

- Birnbaum hat sich ausdrücklich bemüht, „die Erfahrungen (seiner) Tätigkeit in eine lehrbare Form zu bringen" (Birnbaum 1932, S. 178), und daher auch eine ,'technologische' Einstellung“ und Darstellung gewählt, die der Allgemeinheit nützt (vgl. Birnbaum 1932, S. 177). Er versucht offenbar auch mechanistischen Interpretationen vorzubeugen, indem er z. B. nicht von Phasen des Prozesses, sondern von Funktionen spricht, was unserem (dem von Knöchel und Naumann) unabhängig davon entwickelten Konzept zur Darstellung pädagogischer Prozessverläufe entgegenkommt.

- In Birnbaums individualpsychologisch geprägten Artikeln zu schulpädagogischen Fragen finden sich Positionen, die von der dialektisch-materialistischen Pädagogik ebenfalls vertreten werden, z. B.: 
- die Auffassung von der ,zentralen Stellung der Schule im gesamten Erziehungsgefüge“, die er in Anlehnung an Adler fordert (Birnbaum 1931, S. 171);

- die Auffassung von der „Einheit in unserem erzieherischen und unterrichtlichen Arbeiten“ (Birnbaum 1932, S. 177); wenn auch mögliche Unterschiede in den Erziehungszielen nicht übersehen werden dürfen, so grenzen sich doch beide pädagogische Richtungen (die individualpsychologische und die dialektisch-materialistische) deutlich ab von jenen, die die Erziehungsfunktion der Schule bestreiten oder unterschätzen - allerdings werden inzwischen die negativen Auswirkungen dieser Unterschätzung zunehmend erkannt;

- die Auffassung von der erzieherischen Kraft einer Klassengemeinschaft und der Möglichkeit des Lehrers, „einmal die Wucht der gesammelten Energie der ganzen Schulklasse ein(zu)schalten, ein andermal die intime Wirkung der Zweiergemeinschaft oder einer kleinen Gruppe aus(zu)lösen“ (Birnbaum 1931, S. 179), wenn Erziehungsprobleme vorliegen;

- die Auffassung von der zunehmenden Bedeutung der indirekten pädagogischen Führung des Lehrers, wofür Makarenko das „Prinzip des parallelen pädagogischen Vorgehens“ formuliert hat, da er die erzieherischen Wirkungsmöglichkeiten einer Gemeinschaft ebenfalls hoch einschätzte;

- die Auffassung vom einheitlich handelnden Lehrerkollegium, wobei er zugleich davor warnt, „den Schein der Einheitlichkeit“ vorzutäuschen, und empfiehlt, den Schülern ,lieber die dialektische Überbrückung der Gegensätze zu zeigen“" (a. a. O., S. 179).

Sicher können noch mehr Berührungspunkte oder gar übereinstimmende Positionen, aber natürlich auch Unterschiede zwischen den beiden Richtungen herausgefunden werden. Doch das wäre ein anderes Thema; hier geht es nur darum, zu erklären, wes halb gerade individualpsychologische Positionen als Ausgangspunkte für eine differenzierte funktionale Betrachtungsweise des sozialpädagogischen Prozesses geeignet sind. Birnbaum hat mit seiner Darstellung wichtiger Funktionen und Merkmale des sozialpädagogischen Beratungsprozesses im Rahmen des gesamten schulischen Erziehungsprozesses zugleich die Grundlage für die nachfolgende differenzierte Ausarbeitung eines Funktionsmodells vom sozialpädagogischen Prozess geschaffen:

„[...] wir haben tatsächlich begonnen, vorläufig für die einzelnen schwererziehbaren Kinder erziehungstechnische Operationspläne auszuarbeiten. Ein solcher Operationsplan besteht aus zwei Hauptteilen: aus einem Grundplan (Enthüllungsplan) und einer Behandlungsanweisung“" (Birnbaum 1931, S. 171/172; Hervorhebungen im Original!). 
Danach folgt eine Erläuterung dessen, was die beiden Bestandteile des Operationsplanes zu leisten haben. Betrachten wir zunächst den Grund- oder Enthüllungsplan. Dieser zielt auf

- „eine geordnete Darstellung unserer individualpsychologischen Kenntnisse über das Kind:

- $\quad$ seinen geheimen Lebensplan, samt den Verführungen, die es einst bewirkt haben, dass es in ein auswegloses Gelände hineingeschlittert ist,

- die Ausdrucksformen seiner Entmutigung,

- $\quad$ die Mittel, die es heute anwendet, um seine unnützliche Lebensform gegen erzieherische Eingriffe zu sichern“ (Birnbaum 1931, S. 172).

Zur „Behandlungsanweisung“, die den „Grund- oder Enthüllungsplan“ ergänzt, schreibt er:

„Diese Anweisung nun lege ich wirklich in die Hand der Eltern. Sie enthält Ratschläge

- zur Gewinnung bzw. Wiedergewinnung des entfremdeten Kindes,

- Ratschläge zum Selbständigmachen,

- Mittel zur Vermeidung neuerlicher Misserfolge und Niederlagen des Kindes und schließlich

- Übungen in der Bewältigung von Schwierigkeiten, alle für den besonderen Fall ausgewählt" (a. a. O.).

Aus den Erfahrungen mit der Anwendung seiner „Operationspläne“ folgert er, „daß es kein unfruchtbares Beginnen ist, einmal planmäßig nach solchen Kontakt-, Ablösungs-, Entlastungs- und Trainingsmitteln Umschau zu halten“ (Birnbaum 1931, S. 172).

An späterer Stelle schreibt Birnbaum, er habe

„versucht, die grundlegenden Funktionen aller Erziehung festzustellen und [...] sie als »Analyse« (heute würde ich nur »Enthüllung« sagen), als »Kontakt und Ablösung«, als »Entlastung und Belastung (Training)« bezeichnet" (Birnbaum 1931, S. 175).

Damit vollzieht er den Übergang zur funktionalen Betrachtungs- und Bęeichnungsweise, wobei er zugleich jene Funktionen nennt, die eine dynamische methodische Grundstruktur des Prozessverlaufes andeuten und daher auch bei einem differenzierten Ausbau des Modells beachtet werden müssen.

Bei der Konstruktion des nachfolgend dargestellten Funktionsmodells dienten vor allem drei Erkenntnissysteme als Quelle:

Erstens ist sicher erkennbar, dass der pädagogische Funktionsbegriff in einem inneren Zusammenhang steht mit dem im Abschnitt 1.1 definierten Eriiehungsbegriff, in dem die Widersprüche und Wechselwirkungen zwischen den Handlungen der Erzieher und Zöglinge als wesentliche innere Triebkräfte des Prozesses angegeben worden sind. In 
den nachfolgenden Funktionsmodellen werden die prozessspezifischen Erscheinungsformen dieser Wechselwirkungen deutlich.

Zweitens wurde das System der transgredienten Grundlagen und immanenten Momente und die darauf basierende funktionale Betrachtung des Erziehungsprozesses, die von Schallers Schülern - (vgl. Knöchel 1967 und Naumann 1975, 1980, 1986) - entwickelt worden ist, als allgemeine theoretische Grundlage und als „Rahmen“ genutzt.

Drittens wurde dieser „Rahmen“ - ausgehend von den Positionen Adlers bzw. Birnbaums - mit differenzierten Erkenntnissen ausgefüllt, und zwar durch Auswertung zablreicher Fallanalysen von Sozialpädagogen, die nach der Wende an der Sozialakademie Mecklenburg-Vorpommern ihre berufsbegleitende Zusatzqualifikation erhalten und in ihren Beleg- und Abschlussarbeiten solche Fallanalysen vorgenommen haben.

Ausgangspunkt für die Modellkonstruktion war das allgemeine pädagogische Funktionsmodell, das der Autor bereits 1975 (S. 152) vorgestellt hat und dessen Konkretisierung für den Unterrichtsprozess in der „Didaktik“ (Liimets/Naumann 1982 u. 1985) erfolgte (siehe S. 335), bei der sich die Bündelung und Gruppierung der verschiedenen didaktischen Funktionen zu Funktionseinheiten als zweckmäßig erwiesen hat.

Im Unterschied zum Unterricht erwachsen sozialpädagogische Prozesse in der Regel aus sozialen Notlagen und pädagogischen Problemsituationen; sie beginnen demzufolge mit der Kontaktaufnahme zwischen Problembeteiligten und Sozialpädagogen. Zwar gibt es immer auch einige Planungs- und Vorbereitungsmaßnahmen - z. B. die Einrichtung des Büros, die Festlegung der Sprechzeiten bzw. die Terminvereinbarungen zwischen Problembeteiligten und Sozialpädagogen - aber die konkrete Prozessplanung erfolgt entsprechend dem Prinzip der Wechselwirkung von Verstehen und Handeln (Lüssi 1992, S. 217ff.), d. h., auf der Grundlage der jeweiligen Analyseergebnisse des Beratungsgesprächs werden die nächsten Operationen geplant und realisiert. Allerdings setzt die prozess-immanente Planung klare konzeptionelle Vorstellungen der Sozialpädagogen voraus. Grundlage dafür sind vielfältige Erkenntnisse und Erfahrungen

- aus dem Bereich der Ökonomie, Soziologie, Biologie und Psychologie bezüglich der Bedingungen und Ursachen für die Entwicklung devianter Verhaltensweisen und der Möglichkeiten sowie Grenzen ihrer Überwindung;

- aus dem Bereich der Kommunikationspsychologie bezüglich der sprachlichen Gestaltung von Beratungs- und Erziehungsprozessen;

- aus dem Bereichen der Ethik und Pädagogik bezüglich der inhaltlichen und methodischen Gestaltung von Erziehungsprozessen;

- aus dem Bereich der Rechtswissenschaften zwecks Beachtung juristischer Bestimmungen im Umgang mit devianten und delinquenten Problembelasteten und der Nutzung von Förder- und Rechtsmitteln bei Interventionen u. Ä. 
Um die vielfältigen Wissenselemente zur Bewältigung aller Arten sozialpädagogischer Probleme in einer Disziplin zu erfassen, muss die Sozialpädagogik als transdisziplinäre Handlungswissenschaft konzipiert werden. Für die speziellen Arbeitsfelder wären sozialpädagogische Didaktiken zu entwickeln - ähnlich wie es zur Allgemeinen Didaktik im Bildungswesen spezielle Fachdidaktiken gibt.

Das Funktionsmodell sozialpädagogischer Prozesse ist als Hilfsmittel und Orientierungsgrundlage gedacht, um den Integrations- und Anwendungsprozess von Wissenselementen aus den Bezugswissenschaften zu unterstützen. Die nebeneinander stehenden Handlungsarten von Lüssi (siehe S. 132) entsprechen sicher den Belangen der Sozialarbeit. Das Funktionsmodell auf Seite 333 dagegen beschreibt sozialpädagogische „Handlungsarten" in ihrer dynamischen Verknüpfung; es repräsentiert eine transdisұiplinäre dynamischfunktionale Betrachtungsweise und relativiert durch die miteinander verflochtenen Operationen von Erziehern und Zöglingen zugleich die These von der Inkommensurabilität von Erziehen und Lernen (vgl. Prange 2000, S. 144ff.).

Unter Prozessplanung verstehen wir die ideelle Vorwegnahme wesentlicher Momente des künftigen Prozessverlaufs. Gerade diese Momente werden in allgemeiner Form mittels einer Modellvorstellung angeboten, die dann in der Praxis situationsgerecht und flexibel umgesetzt werden kann. Für diese Umsetzung sind Funktionsprinzipien (Abschnitt 6.2) als Hilfen zur Auswahl und Kombination der sozialpädagogischen Funktionen bedeutsam.

Pädagogische Beratungsprozesse resultieren aus sozialen Notlagen und pädagogischen Problemen, sie entwickeln Problemlösungsideen und führen zu Vereinbarungen, die z. B. in Hilfeplänen ihren Niederschlag finden. Die Hilfepläne stellen ein pädagogisches Programm dar, das über den Rahmen des Beratungsvorgangs hinausführt, d. h., ein wesentliches Merkmal sozialpädagogischer Prozesse besteht darin, dass Beratungsprozesse mit andersartigen pädagogischen Prozessen verknüpft werden - etwa mit einem schulpädagogischen Prozess (einschließlich des Unterrichts) wie z. B. in der Wiener Volksschule von Birnbaum. Aber es kann sich auch um Ausbildungsprozesse für jugendliche Benachteiligte in überbetrieblichen Ausbildungszentren oder um spezielle Maßnahmen der sozialpädagogischen Familienbilfe handeln, die dann den Lebensalltag der Familie durchdringen.

Der reale Erziehungsprozess beginnt mit einer Funktion, die Birnbaum Kontakt nennt; gemeint hat er die Herstellung des Kontakts zwischen dem „schwererziehbaren Schüler“ und dem Pädagogen oder verallgemeinert: dem Problembelasteten und dem Sozialpädagogen. Er „endet“ mit der Funktion der Ablösung des Klienten vom Sozialpädagogen (vgl. Birnbaum 1931, S. 179). Birnbaum versteht unter Kontakt allerdings weit mehr als eine persönliche Vorstellung und Problemerörterung, denn der Lehrer wird „die Lebenspläne seiner Schüler nur dann richtig stellen [...] - wenn er die einzelnen Schülerindividualitäten der Einwirkung der Klassengemeinschaft aufgeschlossen hat" (Birnbaum 1931, S. 174 - Hervorhebung durch W. N.). 
Dieser Satz macht den eigentlichen Zweck der Kontaktherstellung deutlich: das Aufschließen, das in vierfachem Sinne verstanden werden kann:

- Aufschließen im Sinne der Weckung einer notwendigen Bereitschaft zur Selbstoffenbarung, also der Bereitschaft offen und ehrlich über die Problemsituation zu sprechen, so dass eine psychische Entlastung erfolgen kann - speziell auch eine Entlastung von Vorstellungen, die zu „unproduktiven Minderwertigkeitsgefühlen anregen“" (Birnbaum 1932, S. 179);

- Aufschließen im Sinne der Weckung von Bereitschaft, eine vertrauensvolle Beziehung einzugehen;

- Aufschließen heißt auch Weckung der Bereitschaft, Lösungswege zu suchen, zu besprechen und eventuell weitere Personen einzubeziehen, also auch „einzuweihen“;

- Aufschließen für die Annabme der Hilfsangebote.

Da ohne ein so verstandenes Aufschließen kein nächster Schritt in der Problembearbeitung mit Aussicht auf Erfolg gegangen werden kann, wird im vorliegenden Buch dieser komplexe Begriff genutzt, um die erste Funktionseinheit zu charakterisieren, die in einzelne Funktionen aufgegliedert werden kann (siehe Schema 9).

Den Kern der zweiten Funktionseinheit, des Aufklärens, bildet aus individualpsychologischer Sicht die Enthüllung, d. h. das Auffinden des Grundirrtums im Denken und „geheimen Lebensplan“ bzw. Lebensstil des Problembelasteten (z. B. die Auffassung „niemand beachtet mich - also muss ich mich auf meine Weise bemerkbar machen"). Zwar ist die Erkenntnis des jeweiligen Grundirrtums des Problembelasteten als innerer Ansatzpunkt für die pädagogische Intervention wichtig, um aber wirklich einen Wandel herbeizuführen, muss der mit ihm verknüpfte Widerstand gegen die notwendigen Korrekturen überwunden werden. Dazu ist es erforderlich, auch die objektiven Bedingungen für die Problementwicklung zu untersuchen und die Ressourcen im sozialen Umfeld der Klienten zu erkunden, z. B. um zu prüfen, ob eine Herausnabme des Klienten aus seinem Milieu „überlebensnotwendig“ ist oder die Aussicht auf seine erfolgreiche Entwicklung eröffnet.

„Wir müssen in jedem Falle die ganze uns erschließbare Lebensgeschichte vor Augen haben, um den Ansatzpunkt für unsere Einwirkung zu finden“ (Birnbaum 1931, S. 181).

Daher ist der weite Begriff des „Aufklärens“ für die Charakterisierung der zweiten Funktionseinheit sicher zweckmäßig. Auch dieser Funktionseinheit lassen sich mehrere Funktionen zuordnen (siehe Schema 9). Außerdem kann sich während der Realisierung der Funktionseinheit Aufklären herausstellen, dass noch spezielle Diagnosen und Therapien notwendig sind, was zu weiteren Verknüpfungen verschiedener Aktivitäten im Problemlösungsprozess führt, die im Modell nur schwer erfassbar sind.

Den Kern der dritten Funktionseinheit bildet die Belastungsfunktion, die durch Training der neuen Handlungs- und Verhaltensweisen realisiert wird. Da das Training ein 
spezifisches pädagogisches Arrangement erfordert, ist es zweckmäßig, die Belastung in eine umfassende Funktionseinheit Ausführen einzuordnen - siehe Schema 9 (S. 333) und Schema 11 (S. 336). Die Ausführung der im Hilfeplan bzw. in den Vereinbarungen festgelegten Maßnahmen schließt einen ganzen Komplex von Aktivitäten der Problembelasteten und ihrer Helfer ein. Birnbaum schreibt:

„Wir müssen dem Kinde helfen, sich jener Lasten zu entledigen, die es zu unproduktiven Minderwertigkeitsgefühlen anregen; und wir müssen ihm zu gleicher Zeit Gelegenheit geben, an der Überwindung von Schwierigkeiten zu wachsen. Die Kinder bilden Stützgemeinschaften, um einander bei der Überwindung von Schwierigkeiten beizustehen“" (1932, S. 179/180).

Und an anderer Stelle heißt es:

„[...] so kann man auch versuchen, über die Enthüllfunktion (Hervorhebung durch W. N.) hinaus zu schreiten und eine Art lebenskundlichen Unterrichts heranwachsen zu lassen“ (1931, S. 175).

Der Hinweis auf die Verknüpfung von Beratungstätigkeit mit Unterrichtsprozessen unter Berücksichtigung der Erkenntnisse und Vereinbarungen aus der Beratung ist für langfristige sozialpädagogische Prozesse wichtig. Das rechtfertigt die Verknüpfung des sozialpädagogischen mit dem didaktischen Funktionsmodell wie sie im Schema 11 angedeutet wird. In der Praxis wird die Belastungsfunktion unterschiedlich realisiert, d. h., die Funktionseinheit Ausfübren wirkt in andere Systemzusammenhänge binein und kann sie mit determinieren. Bei Birnbaum beeinflusste sie nicht nur den Unterricht, sondern die gesamte schulische Arbeit sowie die Familienerziehung, ja mehr noch: die Funktionseinheit Ausfübren kann mit einem therapeutischen Prozess verknüpft sein (siehe Seite 345/346), der wiederum seine spezifische Struktur und Dynamik hat.

Mit der vierten Funktionseinheit, dem Auswerten, sollen sowohl die prozessimmanenten als auch die abschließenden Kontroll- und Auswertungsaktivitäten erfasst werden. Wenn die Probleme gelöst sind, wird normalerweise das Beratungs- bzw. Betreuungsverhältnis durch einen Ablöseprozess beendet. Dies sollte nicht abrupt im Sinne eines Beziehungsabbruches geschehen, denn die Erfahrungen zeigen, dass auch Ablöseprozesse pädagogisch gestaltet werden müssen, weil manche Klienten dazu neigen, durch einen bewusst herbeigeführten „Rückfall“ wieder in den Genuss der als angenehm empfundenen Betreuung zu gelangen.

Zusammenfassend lassen sich diese Erkenntnisse als Funktionsmodell in schematischer Form darstellen. Die Funktionen charakterisieren wesentliche Momente der Dynamik des Prozessverlaufs, wobei die von Birnbaum genannten Funktionen kursiv markiert sind (siehe S. 321). Alle Bemühungen um Modellbildungen in diesem Buch sind begründet durch eine Position, die Mario Bunge wie folgt formuliert hat:

„Die Wissenschaft entwickelt sich nicht in erster Linie dadurch, daß sie isolierte empirische Daten anhäuft, sondern daß sie adäquate theoretische Modelle schafft" (Bunge 1968, S. 122). 
Sozialpädagogisches Funktionsmodell

\begin{tabular}{|c|c|c|}
\hline Strukturprinzipien & Funktionseinheiten & Funktionsprinzipien \\
\hline $\begin{array}{l}\text { 1. Prinzip hoher fachlicher } \\
\text { Kompetenz und Natür- } \\
\text { lichkeit im Umgang mit Kli- } \\
\text { enten sowie Wahrung von } \\
\text { Diskretion } \\
\text { 2. Prinzip der Verbindung von } \\
\text { unvoreingenommener Pro- } \\
\text { blemannahme, verständnis- } \\
\text { voller Anteilnahme und } \\
\text { Echtheit zwecks Öffnung, } \\
\text { Ermutigung und Aktivie- } \\
\text { rung der Klienten } \\
\text { 3. Prinzip der Verbindung von } \\
\text { Interposition mit par- } \\
\text { teilichem Engagement für } \\
\text { besonders Bedürftige und } \\
\text { Benachteiligte } \\
\text { Prinzip der Verbindung von } \\
\text { Beratung und Ver- } \\
\text { handlungsführung mit Ko- } \\
\text { operationsbildung im Inter- } \\
\text { esse der Klienten }\end{array}$ & $\begin{array}{l}\text { Aufschließen } \\
>\text { Kontakt-Aufnahme } \\
>\text { Entlastung oder Erhöhung von } \\
\text { Leidensdruck } \\
>\text { Motivierung und Ermutigung } \\
>\text { Klärung der Rollen } \\
>\text { Verständigung über Ziele } \\
\quad \text { Aufklären } \\
>\text { Situations- } \text { Analyse und Pro- } \\
\text { blemdefinition, verbunden mit } \\
\text { Enthüllungen und Erklärungen } \\
>\text { Erschließen von Ressourcen } \\
>\text { Suche nach Lösungsvarianten } \\
>\text { Maßnahmeplanung, verbunden } \\
\text { mit Zielorientierungen } \\
>\text { Vereinbarungen (einschließlich An- } \\
\text { gabe der Folgen bei Nicht- } \\
\text { einhaltung) } \\
\quad \text { Ausführen } \\
>\text { Anleitung zu Problemlösungs- } \\
\text { schritten und Training } \\
>\text { Belastung durch Problembe- } \\
\text { wältigung (mit und ohne Hilfe) } \\
>\text { Selbstüberwindung und Ge- } \\
\text { wöhnung (trotz Rückfällen) } \\
\text { Auswerten } \\
\text { Bechenschaftslegung } \\
\text { Bewertung der praktischen Ergeb- } \\
\text { lichkeitsentwicklung } \\
\text { Schlussfolgerungen } \\
\text { Resultate es erlauben }\end{array}$ & $\begin{array}{l}\text { 1. Prinzip der Verbindung von } \\
\text { Freiwilligkeitsvorrang, Zeit- } \\
\text { richtigkeit, Zielstrebigkeit und } \\
\text { Flexibilität im Hilfeprozess } \\
\text { 2. Prinzip der Verbindung von } \\
\text { Tatsachenermittlung und Er- } \\
\text { klärungsbemühungen unter } \\
\text { Berücksichtigung der Lebens- } \\
\text { welt und des soziallogischen } \\
\text { Denkens der Problembelaste- } \\
\text { ten } \\
\text { Prinzip der Verbindung von } \\
\text { Nichtbeschuldigung mit der } \\
\text { Anknüpfung an persönliche } \\
\text { Stärken der Klienten } \\
\text { 4rinzip der Verbindung von in- } \\
\text { strumenteller Problemde- } \\
\text { finition mit der Konzentration } \\
\text { auf zentrale Problemvariable }\end{array}$ \\
\hline
\end{tabular}

Die fett und kursiv gesetzten Wörter markieren den Modellansatz von Birnbaum (vgl. 1931, S. 171 ff. / 1950, S. 234-256).

\section{Schema 9}

Bei der Interpretation des Modells ist zwischen seiner Darstellungs- und Anwendungsweise zu unterscheiden. Während sich bei der Darstellung ein lineares Nacheinander der Funktionseinheiten und Funktionen nicht vermeiden lässt, ist die Anwendungsweise durch ein flexibles situationsabhängiges, aber zielgerichtetes „Durcheinander" charakterisiert, in dem sich die einzelnen Funktionen in ihrer Abfolge vertauschen, überlagern und einander durchdringen. Der Sozialpädagoge kann nämlich nicht willkürlich eine bestimmte Abfolge von Funktionen festlegen, sondern muss sie konkret in Abhängigkeit vom Fortschritt im Problemlösungsprozess (insbesondere vom Lern- und Entwicklungsfortschritt des Problembelasteten) und 
den damit möglichen Zielen ermitteln. Didaktische und sozialpädagogische Funktionen sind zugleich auch gruppierte pädagogisch relevante Kommunikations- und Interaktionsprozesse, in denen jede Operationsfolge von der Wirkung der vorangegangenen abhängt.

„Lernen besitzt selbst eine kommunikative prozeßhafte Struktur, in der der Weg konstitutiv dafür ist (Hervorhebung durch W. N.), was als Resultat letzten Endes 'herauskommt" “ (Lippitz - zitiert nach Hierdeis/Hug 1991, S. 97).

Um einen Abbruch der Kommunikation und damit auch der psychosozialen Intensiverziehung zu vermeiden, sind u. a. die Erkenntnisse der Kommunikationspsychologie zu beachten und in Verbindung damit der ziel-, zöglings- und situationsgerechte Einsatz der sozialpädagogischen Funktionen. Die reale Abfolge der Funktionen und ihre Überlagerungen ergeben sich aus dem jeweils im Prozess Erreichten und nunmehr Möglichen im Sinne der Zielrealisierung, was der Sozialpädagoge erkennen kann mit Hilfe der Fragen:

- Welche Funktionen wurden erfolgreich realisiert?

- Welche Funktionen müssen und können im Interesse eines zielstrebigen Prozessverlaufs als nächste realisiert werden?

Indem der Sozialpädagoge im Handlungsprozess innehält, um diese Fragen zu beantworten, realisiert er prozessimmanente Planung, d. h., er bestimmt die nächstmöglichen und in Verbindung mit dem Ziel nächstnotwendigen Funktionen sowie die ihnen entsprechenden Operationsfolgen. Diese fundamentale Anforderung widerspiegelt sich auch in dem von Lüssi formulierten Prinzip der Wechselwirkung von Verstehen und Handeln, wodurch eine schematische Anwendung des Funktionsmodells vermieden werden kann.

Gewiss haben auch emotionale Momente, die im Prozessverlauf auftreten, große Bedeutung für das Resultat. Leider kann das Funktionsmodell diese Seite des Geschehens nicht hinreichend präsentieren. Nur bei einigen Funktionen werden emotionale Momente angedeutet, z. B. bei der Problembeschreibung das Gefühl des Verstandenwerdens, bei der Funktion der Entlastung von Leidensdruck das Gefühl der Erleichterung, bei der Funktion der Belastung die damit verbundene Anspannung und bei der Bewertung einer erfolgreichen Problemlösung die Gefüble der Erleichterung und der Befriedigung.

Bei der Realisierung der Funktionen müssen die jeweils damit verbundenen juristischen, ökonomischen, kulturellen, religiösen bzw. weltanschaulichen, moralischen, soziologischen, psychologischen, medizinischen usw. Gegebenheiten und Erfordernisse berücksichtigt werden, d. h., das Funktionsmodell ist zugleich auch ein Hilfsmittel für ein inter-und transdisziplinär begründetes Vorgehen im Problemlösungsprozess.

Die von Birnbaum angestrebte und praktizierte Verknüpfung sozialpädagogischer Beratungen bzw. Interventionen mit anderen pädagogischen Prozessen wird durch Schema 11 angedeutet. Die Verknüpfung macht die analoge Konstruktionsweise der Modelle deutlich. 


\begin{tabular}{|c|c|c|}
\hline \multicolumn{3}{|c|}{$\begin{array}{l}\text { Modell zum System didaktischer Funktionen und Prinzipien } \\
\text { für Unterrichts- und unterrichtsähnliche Prozesse }\end{array}$} \\
\hline Funktionsprinzipien & Funktionseinheiten & Funktionen \\
\hline $\begin{array}{l}\text { 1. Prinzip der Einheit von Organi- } \\
\text { siertheit und Zielstrebigkeit des Un- } \\
\text { terrichtsprozesses } \\
\text { 2. Prinzip der Einheit von Bewusst- } \\
\text { heit und Aktivität der Schüler }\end{array}$ & $\begin{array}{l}\text { I. } \\
\text { Einführung } \\
\text { Aktivierung } \\
\text { Organisierung }\end{array}$ & $\begin{aligned}> & \text { Sichern normaler Unterrichtsbedin- } \\
& \text { gungen } \\
> & \text { Zielorientieren und Vermitteln von } \\
& \text { Orientierungsgrundlagen } \\
> & \text { Motivieren und Reaktivieren }\end{aligned}$ \\
\hline $\begin{array}{l}\text { 3. Prinzip der Einheit von Konkre- } \\
\text { tem und Abstraktem im Erkenntnis- } \\
\text { prozess } \\
\text { 4. Prinzip der Einheit von Imitation } \\
\text { und Kreation im Gestaltungsprozess }\end{array}$ & $\begin{array}{l}\text { II. } \\
\text { Erstvermittlung } \\
\text { Verarbeitung } \\
\text { Gestaltung }\end{array}$ & $\begin{aligned}> & \text { Informieren und Definieren } \\
> & \text { Erklären und Voraussagen } \\
> & \text { Werten (logisch, moralisch, politisch, öko- } \\
& \text { nomisch, ökologisch, juristisch, ästhetisch, } \\
& \text { technologisch, medizinisch usw.) } \\
> & \text { Begründen, Belegen, Widerlegen, } \\
& \text { Beweisen, Zweifeln, Vergewissern } \\
> & \text { Konzipieren, Entwerfen, Konstruieren }\end{aligned}$ \\
\hline $\begin{array}{l}\text { 5. Prinzip der wissenschaftlichen } \\
\text { Systematik, der praktischen Komple- } \\
\text { xität bzw. ästhetischen Ganzheit des } \\
\text { Unterrichtsinhalts } \\
\text { 6. Prinzip der Dauerhaftigkeit und } \\
\text { Anwendbarkeit des Gelernten }\end{array}$ & $\begin{array}{l}\text { III. } \\
\text { Festigung } \\
\text { Meisterung } \\
\text { Bewährung }\end{array}$ & $\begin{array}{l}>\text { Wiederholen und Üben } \\
>\text { Systematisieren und Integrieren } \\
>\text { Üben und Anwenden } \\
>\text { Ausführen und Vervollkommnen }\end{array}$ \\
\hline $\begin{array}{l}\text { 7. Prinzip der Sicherung von Er- } \\
\text { folgserlebnissen auf der Basis } \\
\text { steigender Anforderungen } \\
\text { 8. Prinzip der Einheit von objektiver } \\
\text { und persönlichkeitsfördernder } \\
\text { Resultatsbewertung }\end{array}$ & $\begin{array}{c}\text { IV. } \\
\text { Kontrolle } \\
\text { immanente oder } \\
\text { explizite Prüfung/ } \\
\text { Selbstprüfung } \\
\text { Interaktive } \\
\text { Auswertung } \\
\text { Postinteraktive } \\
\text { Reflexionen }\end{array}$ & $\begin{array}{l}>\text { Stellen und Lösen von Aufgaben und } \\
\text { Problemen } \\
>\text { Bewerten/Zensieren } \\
>\text { Fehleranalyse mit Schlussfolgerungen }\end{array}$ \\
\hline
\end{tabular}

Schema 10

31 Präzisierte Fassung aus der „Didaktik“ von H. Liimets und W. Naumann 1985, S. 104; Begründung des Modells: Siehe a. a. O., S. $77 \mathrm{ff}$. 


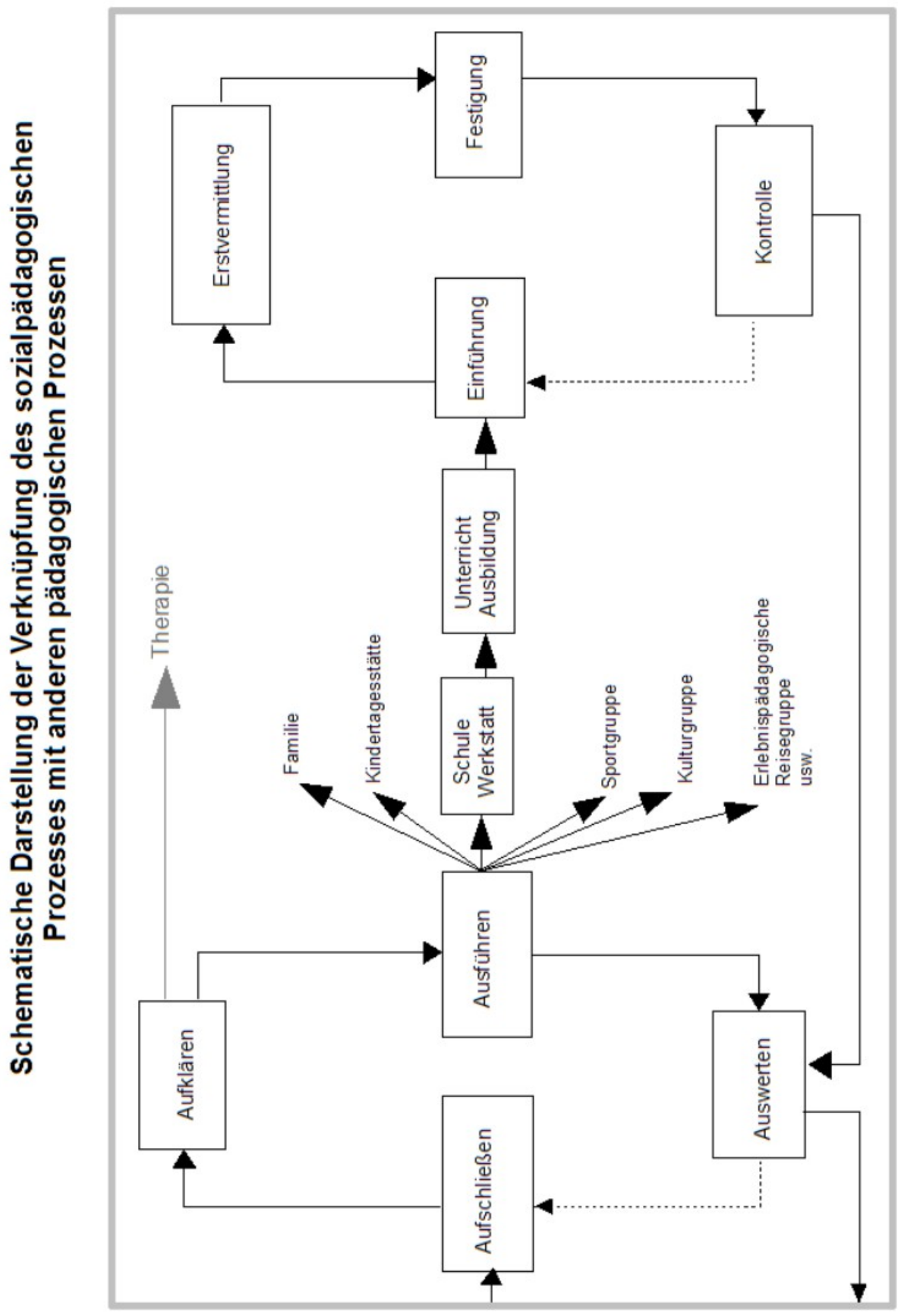

Schema 11 
Die hier vorgestellten Bemühungen um wissenschaftlich begründete und praktikable Darstellungen pädagogischer Prozessverläufe reihen sich ein in das Bestreben vieler Pädagogen um die Entwicklung der Pädagogik zur Wissenschaft, wie sie bereits von Kant gefordert worden ist. Er schrieb:

„Der Mechanismus in der Erziehungskunst muß in Wissenschaft verwandelt werden, sonst wird sie nie ein zusammenhängendes Bestreben werden“ (Kant 1890, S. 126).

Tenorth betont diesen Gedanken ebenfalls in seiner Darstellung zur Entwicklung der Erziehungswissenschaft und fügt hinzu:

„In seiner eigenen Antwort entwarf er (gemeint ist Kant; W. N.) die wissenschaftliche Pädagogik letztlich als eine »technisch-praktische« und nicht als »moralisch-praktische« Wissenschaft. Kant wählte und begründete diese Perspektive auch explizit, denn er verknüpfte deutlich die Erwartungen an die Theorie mit der Reflexion einer Technologie“ (Tenorth 2004, S. 346).

Mannschatz hat 2003 ein Buch unter dem Titel „Gemeinsame Aufgabenbewältigung als Medium sozialpädagogischer Tätigkeit“ veröffentlicht. Seine These von „Erziehung als gemeinsamer Aufgabenbewältigung“ ist mit der im vorliegenden Buch vertretenen Erziehungsauffassung durchaus vereinbar, da Aufgaben ja ein Aspekt der Funktionen sind. Allerdings betrachtet er den Erziehungsprozess vorwiegend unter dem Gesichtspunkt des „Arrangements“ der Aufgaben, d. h. also eines Erziehungsmanagements. Offenbar in Fortführung der Diskussionen um praktikable Darstellungen pädagogischer Prozessverläufe, die in den 70er und 80er Jahren in der DDR geführt worden sind, hält er dabei an dem Konzept der Erarbeitung und Darstellung von methodischen Ratschlägen zur Bewältigung typischer pädagogischer Situationen fest (vgl. Neuner 1980, Fuhrmann/Weck 1976, S. 87ff.), indem er schreibt:

„Erst in Konturen zeichnet sich z. B. ab, daß es offenbar möglich ist, herangereifte Lebenssituationen erzieherisch zu nutzen oder sie absichtsvoll herbeizuführen. Zu vermuten sind differenzierte Typen von entwicklungsfördernden Situationen, die jeweils in spezifischer Weise das Verhalten der Kinder ausprägen, festigen oder korrigieren“ (Mannschatz 2003, S. 126).

Die Möglichkeit der erzieherischen Nutzung herangereifter Lebenssituationen und auch ihre Herbeiführung zeichnet sich nicht erst in Konturen ab, sondern ist Menschheitspraxis seit Jahrtausenden und von der Historischen Pädagogik reflektiert worden - es sei nur an die Initiationsbräuche in urgeschichtlichen Gemeinschaften erinnert. Zu Typen von entwicklungsfördernden Situationen oder typischen Unterrichts- und Erziehungssituationen hat sich der Autor bereits 1981 (Bastian/Naumann 1981, S. 94 ff.) kritisch geäußert und dabei der Betrachtung pädagogischer Prozesse unter dem Aspekt typischer Situationen eine dynamisch-funktionale Betrachtungsweise entgegengestellt. Methodische Betrachtungen und Beschreibungen typischer pädagogischer Situationen stoßen schnell an ihre Grenzen, wenn in der Praxis etwas Untypisches passiert, und außerdem bleibt 
vielfach die Frage nach der Verknüpfung der Situationen offen. Dagegen lassen die zielund verlaufsabhängigen flexiblen Verknüpfungen der Funktionen den prozesshaften oder dynamisch-funktionalen Charakter der Modellbildung erkennen.

Die Funktionsmodelle sind Versuche, auf die Frage nach einer praktikablen Prozessdarstellung differenzierte Antworten zu finden mit Hilfe einer ,technologischen Betrachtungsweise" wie sie im 20. Jahrhundert schon Birnbaum für notwendig hielt (vgl. S. 314) und auch Makarenko gefordert hat, der feststellte:

„Unsere pädagogische Tätigkeit wurde nie auf technischer Logik aufgebaut, sondern immer auf der Logik der Moralpredigt. Das macht sich besonders in der eigentlichen Erziehung bemerkbar; in der Unterrichtspraxis ist es leichter. Eben deshalb fehlen bei uns alle wichtigen Elemente der Produktion: der technologische Prozeß, die Berechnung der Operationen, die Konstruktionen [...] und die Gütekontrolle. Als ich am Fuße des »Olymps« solche Gedanken zaghaft äußerte, warfen die Götter (gemeint sind damals führende Pädagogen der Sowjetunion;

W. N.) mit Ziegelsteinen nach mir und schrien, das sei eine mechanische Theorie“ (Makarenko 1972, Bd. I, S. 593).

Ferner war er der Meinung

„daß die Methodik der Erziehungsarbeit ihre eigene Logik besitzt, die von der Logik der Bildungsarbeit relativ unabhängig ist“" (Makarenko 1969, Bd. V, S. 117).

Hierbei muss zunächst beachtet werden, dass Makarenko den Begriff der Logik im Sinne von realer Dynamik objektiver Prozesse fasst und nicht zur Kennzeichnung von Denkstrukturen. Er spricht beispielsweise auch von der „Logik der Produktion“ (a. a. O., S. 208), obgleich es um technische Prozesse geht, die ihre Widerspiegelung finden in Technologien und nicht in einer Logik. Aber ungeachtet dieser historisch und/oder personell bedingten Wortwahl geht es hier um eine Position, die in den beiden - miteinander verknüpfbaren - Funktionsmodellen (Schema 11) differenziert und übersichtlich Ausdruck finden. Beide Modelle geben u. a. auch jeweils prozesspezifische „Aufgabenfolgen“ an, die von Erziehern und Zöglingen gemeinsam zu bewältigen sind - Aufgaben sind ja Bestandteile von Funktionen! Darüber hinaus umfassen sie „Prozess-Sequenzen“ von individuell unterschiedlicher Dauer oder „Inkubationszeit“ (Makarenko, vgl. Weitz 1989, S. 167). Manche mutmaßlichen Resultate sind auch nicht immer stabil, denn es gibt Rückschläge.

Die Funktionsmodelle bilden sozialpädagogische Prozesse und didaktische Prozesse als „Regelkreise“ ab (vgl. S. 117), die mit ihrer Umwelt in Wechselwirkung stehen und zugleich offen sind für weitere Differenzierungen der Funktionseinheiten und Funktionen. Das ist leicht erkennbar in der Funktionseinheit „Ausführen“, die prinzipiell durch viele Tätigkeiten (Spielen, Lernen, Arbeiten, künstlerisches Gestalten usw.) realisiert werden kann. Die vorgestellten Funktionsmodelle möchte der Autor als verallgemeinerte technolo- 
gische Reflexionen pädagogischer Prozessverläufe verstanden wissen, die unbedingt im Zusammenhang zu sehen sind mit Prinzipien. Schon Kant forderte:

„Die Erziehung und Unterweisung muß nicht bloß mechanisch sein, sondern auf Principien beruhen“ (Kant 1890, S. 131).

Erst durch eine bewusste oder intuitive Berücksichtigung von Prinzipien ist es möglich, die Funktionen in der Praxis situationsgerecht, flexibel und erfolgreich zu realisieren.

\subsection{Sozialpädagogische Funktionsprinzipien - ihre Begründung und Be- deutung für die Prozessgestaltung}

Das sozialpädagogische Funktionsmodell vermittelt einen Überblick über wichtige Aktivitäten der Sozialpädagogen und ihrer Klienten bei der Prozessgestaltung. Es gibt gewissermaßen an, was getan werden muss; aber das genügt für eine möglichst konkrete Anleitung noch nicht. Allein die Menge der Funktionen wirft die Frage auf: wann soll welche Funktion wie ausgeführt werden? Es bedarf also möglichst klarer und zuverlässiger Auswahlkriterien und begründeter Ausführungshinweise. In Anbetracht der konkreten Vielfalt sozialpädagogischer Fälle und ihrer jeweils individuellen Eigenarten ist es natürlich nicht möglich, ein rezeptartiges Regelwerk vorzugeben. Aber im Sinne heuristischer Hinweise können Prinzipien hilfreich sein, wie praktische Beispiele zeigen.

Mehrfach wurde herausgearbeitet und betont (S. 232ff., S. 317ff.), dass es für die unmittelbar aus Notlagen erwachsenden sozialpädagogischen Prozesse keine differenzierte vorausgehende Planung gibt. Die Planung psychosozialer Intensiverziehung ist erst auf der Grundlage von Problemanalysen zu Beginn und während des Prozessverlaufs möglich. Daher muss der Sozialpädagoge die dafür erforderlichen Konzeptprinzipien, die im Abschnitt 4.6 behandelt worden sind, als Entscheidungshilfen verfügbar haben. Die Strukturprinzipien sind insofern für die Gestaltung des sozialpädagogischen Prozesses bedeutsam, als sie zur Entwicklung funktionstüchtiger Strukturen (insbesondere erzieherischer Verhältnisse) beitragen. Sie gelten für den gesamten Prozessverlauf, sind aber bei den Funktionen Kontaktaufnahme, Entlastung, Klärung der Rollen, Enthüllung und Erschließen von Ressourcen besonders zu beachten, denn hier konzentrieren sich die Bemühungen auf die Gestaltung der Beziehungen zwischen Sozialpädagogen und Klienten, eventuell auch noch zu weiteren Spezialisten und Helfern. Die Funktionen beschreiben wesentliche Momente des Prozessverlaufs und die ihn bewegenden Operationsfolgen und Handlungen, die unter Beachtung der Funktionsprinzipien realisiert werden müssen, wobei folgende Zuordnungen im Sinne von Schwerpunkten der Beachtung möglich sind: 
Die Funktion Kontaktaufnahme im Rahmen der Funktionseinheit Aufschließen wird wesentlich bestimmt durch das

- Funktionsprinzip der Verbindung von Freiwilligkeitsvorrang, Zeitrichtigkeit, Zielstrebigkeit und Flexibilität im Hilfeprozess,

denn ein Kontakt wird aufgenommen, wenn jemand freiwillig um Hilfe nachsucht oder wenn wegen der Gefahr für Leib und Leben der Problembelasteten eine zielgerichtete und flexible Hilfemaßnahme eingeleitet werden muss. Mit der Forderung nach Zeitrichtigkeit ist gemeint, dass man nicht wartet bis es zu spät ist oder - sofern zu verantworten - den Leidensdruck so lange ansteigen lässt, bis der potenzielle Klient Einsicht in die Notwendigkeit einer Hilfeannahme signalisiert - es sei denn, es handelt sich um ein hilfloses Kind, dem unbedingt und sofort zielstrebig geholfen werden muss.

Für die Funktionseinheit Aufklären sind besonders bedeutsam die Funktionsprinzipien

- der Verbindung von Tatsachenermittlung und Erklärungsbemühungen unter Berücksichtigung der Lebenswelt und des soziallogischen Denkens der Problembelasteten sowie

- der Verbindung von Nichtbeschuldigung mit der Anknüpfung an persönliche Stärken der Klienten.

Sowohl die Sozialpädagogen und ihre Kooperationspartner als auch die Problembelasteten und Problembeteiligten müssen die jeweilige Problemlage wenigstens so weit erkennen, dass sie begründet handeln können. Das bedeutet vor allem, dass sie die Tatsachen zur Kenntnis nehmen bzw. akezeptieren sowie wesentliche Ursachen der Problemsituation erkennen. Dabei zeigt sich nicht selten, dass die Klienten wegen ihrer soziallogischen Denkweise Schwierigkeiten haben, die erforderlichen Einsichten zu gewinnen und die daran geknüpften Konsequenzen bzw. Maßnahmen zu akzeptieren. Sowohl bei der Problemanalyse als auch bei der Beratung möglicher Maßnahmen müssen die lebensweltlichen Bedingungen der Klienten, insbesondere auch die Eigenheiten möglicher Subkulturen der Problembeteiligten und ihre damit zusammenhängenden Lebensgewohnheiten und Sichtweisen berücksichtigt werden.

Bei der Tatsachenermittlung und den Erklärungsbemühungen kommen auch die jeweiligen persönlichen Febler und Mängel im Handeln und Verbalten der Problembelasteten und Problembeteiligten zur Sprache, denn in der Regel liegen jeder Problemsitation auch Momente des persönlichen Versagens zugrunde, die in Abhängigkeit von Alter und Entwicklungsstand der Betroffenen unterschiedlich bewertet werden. Solche Wertungen empfinden die Betroffenen verständlicherweise als Kritik. Deshalb ist darauf zu achten, dass diese Kritik auf einzelne, eindeutig zu erkennende Feblhandlungen und deren Ursachen gerichtet ist und nicht etwa die Persönlichkeit im Ganzen abwertet.

In pädagogischen Prozessen wird - im Unterschied zu juristischen - nicht mit Schuldsprüchen operiert, weil sie die Minderwertigkeitskomplexe der Problembelasteten nur 
verstärken würden. Oft wissen die Betroffenen selbst, was sie falsch gemacht haben; und wenn das der Fall ist, muss man es ihnen nicht noch zusätzlich vorhalten. Wenn ihnen ihr Fehlverhalten nicht klar ist, muss es ihnen bei der Problemanalyse - speziell in der Enthüllung - bewusst gemacht werden.

Für die Funktionseinheit Ausführen hat das

- Funktionsprinzip der Verbindung von instrumenteller Problemdefinition mit der Konzentration auf die zentralen Problemvariablen und deren Bearbeitung

besondere Bedeutung. Das heißt: Im Ergebnis der Problemanalyse ist eine solche Beschreibung der Problemsituation vorzunehmen, dass sowohl die Ansatzpunkte für ibre Lösung als auch die wichtigsten Maßnabmen zu ihrer Bewältigung für alle Beteiligten klar werden. Da deviante Verhaltensweisen aus vielfältigen ursächlichen Bedingungen resultieren, kommt es darauf an, diejenigen herauszufinden, die als wesentlich und vor allem auch als eliminierbar oder zumindest veränderbar angesehen werden können. Sie werden als zentrale Problemvariable konzentriert bearbeitet, ohne dass der Gesamtzusammenhang außer Acht gelassen wird. Es ist durchaus normal, dass in der Funktionseinheit Ausführen mancherlei Hindernisse auftreten, die vom Ziel ablenken.

Um dem zu begegnen, ist die Funktionseinheit Auswerten zu beachten. Sie steht ja nicht nur am Ende eines Problemlösungsprozesses, sondern durchzieht ihn im Sinne eines möglichst kontinuierlichen Feedbacks mit entsprechenden Reflexionen und wird wesentlich bestimmt durch das

- Funktionsprinzip der Einheit von Anforderungen und Kontrollen im Prolemlöseprozess.

Das bedeutet: ein psychosozialer Erziehungsprozess funktioniert prinzipiell auf der Grundlage von Anforderungen, die den Zöglingen in unterschiedlicher Weise bewusst gemacht werden und die in dem Maße wirksam sind, wie Kontrollen sie begleiten. Je nach dem wie er die Anforderungen erfüllt, folgen Bestätigungen bzw. Belohnungen oder Kritik bzw. Sanktionen.

Betrachten wir nun diese Funktionsprinzipien im Einzelnen, bevor dann Hinweise zu ihrer praktischen Anwendung im Zusammenhang mit den Erläuterungen zum Funktionsmodell im Abschnitt 6.3 erörtert werden.

\subsubsection{Das Prinzip der Verbindung von Freiwilligkeitsvorrang, Zeitrichtigkeit, Zielstrebigkeit und Flexibilität im Hilfeprozess}

Sozialpädagogen müssen der freiwilligen Entscheidung der Klienten für eine bestimmte Art von Hilfe den Vorrang geben und die Hilfemaßnahmen zeitlich so ansetzen, dass sie optimal wirksam werden können, vor allem unter möglichst zielstrebiger Mitwirkung der Klienten oder auch Dritter. 


\section{Begründung:}

Art und Zeitpunkt des Hilfsangebotes müssen der Erwartung des Klienten Rechnung tragen, da bereitwilliges oder gar freiwilliges Lernen aus eigenem Antrieb erwiesenermaßen erfolgreicher ist als erzwungenes und zudem noch das Selbstwertgefühl stärkt. Außerdem entspricht die Forderung nach dem Freiwilligkeitsvorrang zur Annahme von Hilfemaßnahmen auch dem sozialethischen Grundsatz nach Achtung der Menschenwürde. Allerdings kann auch Zwang (mit Kontrolle!) zur Verhaltensänderung (mit einem entsprechenden Lernprozess) aus Gründen der Lebensrettung, der Bewahrung vor schweren Gesundheitsschäden oder der Vorbeugung von Rückfällen (z. B. bei Rechtsverletzern) notwendig sein; auch in diesem Sinne ist also Flexibilität erforderlich.

Objektiv begründeter Zwang ist gerechtfertigt und zu unterscheiden von subjektiven Willkürmaßnahmen von Erziehern bzw. Sozialpädagogen (falschem Zwang). Zubilligung von „Freiwilligkeit um jeden Preis“ ist moralisch nicht zu verantworten und kann sogar strafbar sein wegen unterlassener Hilfeleistung.

\section{Handlungshinweise:}

Die Entscheidung über den richtigen Zeitpunkt von Hilfemaßnahmen ist praktisch höchst bedeutsam und nicht ohne Risiko. Es kann nämlich sein, dass erst bei relativ hohem Leidensdruck die Bereitschaft zur Hilfeannahme entsteht und vorzeitiges Eingreifen das Erkennen der Tragweite einer sozialen Problemsituation erschwert. Umgekehrt können verzögerte Hilfemaßnahmen auch zu spät kommen. Es sei hier nur an den Fall des zweijährigen Kevin in Gröpelingen bei Bremen erinnert. Für Kevin war eine Vormundschaft des Jugendamtes eingerichtet worden, die aber die dafür Verantwortlichen nicht konsequent wahrgenommen haben. Der beauftragte Sozialarbeiter hat sich - sozusagen im Sinne falsch verstandener Freiwilligkeit bei der Annahme von Hilfemaßnahmen - vom drogenabhängigen Pflegevater des Kindes abweisen lassen, mit dem Ergebnis, dass Kevin schließlich am 10. Oktober 2006 tot in der Kühltruhe aufgefunden worden ist (vgl. [online] Kreiszeitung Bremen vom 21. April 2007, S. 1).

Ein ähnlicher Vorfall ereignete sich im November 2007 in Schwerin, wo die fünfjährige Lea-Sophie schließlich so stark unterernährt und dehydriert in die Klinik eingeliefert wurde, dass ihr Leben nicht mehr gerettet werden konnte. Auch hier haben zwei Sozialarbeiter vom Jugendamt, die 14 Tage zuvor die Familie besucht hatten, offensichtlich versagt, indem sie den Zustand des Kindes nicht wirklich kontrollierten, d. h. sich vom Vater des Kindes an der Wohnungstür ,abfertigen ließen" (vgl. Schweriner Volkszeitung vom 22.11.2007, 10.01.2008, 17.01.2008 und 16.04.2008). Um ähnlich zaghaftem oder unzureichend zielstrebigem Agieren, das möglicherweise auch aus Fehlinterpretationen des Artikels 6 Abs. 2 des Grundgesetzes und der missverständlichen Fassung des Prinzips resultiert, vorzubeugen, wird hier die Formulierung Lüssis vom Vorrang der 
Freiwilligkeit übernommen und nicht schlechthin vom Prinzip der Freiwilligkeit gesprochen. Das bedeutet, dass verantwortungsethisch und folgenkritisch entschieden werden muss, wie dem grundgesetzlich geschützten Elternrecht bzw. dem Selbstbestimmungsrecht der Problembeteiligten und dem Kindeswobl am besten entsprochen werden kann, wobei es manchmal schwer ist, einzuschätzen, was dem Kindeswohl wirklich dient. In den beiden genannten Fällen aber wäre eine ordnungsgemäße Überprïfung (auch gegen den Willen der Väter!) notwendig gewesen.

\subsubsection{Das Prinzip der Verbindung von Tatsachenermittlung und Erklärungsbemühungen unter Be- rücksichtigung der Lebenswelt und des soziallogischen Denkens der Problembelasteten}

Sozialpädagogen und Klienten müssen die mit dem sozialen bzw. pädagogischen Problem verbundenen Tatsachen zur Kenntnis nehmen und nach zutreffenden Erklärungen suchen, wobei dem Klienten so viel erklärt wird, wie im Interesse seiner Mitwirkung unter den gegebenen Bedingungen möglich und zweckmäßig ist.

\section{Begründung:}

Die Aufklärung einer Problemsituation schließt die Untersuchung der Bedingungen und Zusammenhänge ein, die das Problem verursacht haben. Das ist wesentlich und notwendig, um Lösungsideen zu finden. Die Problembeteiligten sollten davon so viel erfahren, wie für ihre Aktivierung und Mitwirkung am Problemlösungsprozess erforderlich ist. Dazu gehört, dass ihm auch unangenehme Tatsachen bewusst gemacht werden müssen. Dabei sind die lebensweltlich und subkulturell geprägten persönlichen Auffassungen und Wertungen der Klienten, ibr soziallogisches Denken (z. B. zu den Problemursachen oder „Schuldigen") zu berücksichtigen, d. h. zu nutzen oder aber zu überwinden, wenn sie sich als Hindernisse im Problemlösungsprozess erweisen.

\section{Handlungshinweise:}

Die Konfrontation mit Tatsachen aus dem Bedingungsgefüge des Problems kann für die Problembeteiligten zusätzlich schmerzhaft sein, vor allem wenn es um Fehlhandlungen der Klienten geht, die im ursächlichen Zusammenhang mit der Notlage stehen. Hier müssen Sozialpädagogen entscheiden, wie hart sie die Betreffenden mit den Tatsachen oder mit der „vollen Wahrheit“ konfrontieren bzw. wie weit sie mit Rücksicht auf die Prinzipien 5.5.2 (Ermutigung und Aktivierung) und 6.2.3 (Nichtbeschuldigung) gehen können. Ohne Offenlegung („Enthüllung“) der Tatsachen können keine Einsichten in die kausalen und teleologischen Zusammenhänge gewonnen werden, was aber notwendig ist, um echte Lösungsansätze zu finden und die Klienten zur Mitwirkung zu bewegen.

Sozialogisches Denken treffen wir verstärkt bei problembelasteten Personen an, weil sie nämlich häufig objektive soziale Strukturen in einer ihnen plausiblen und angenehmen Weise (objektiv betrachtet: verzerrt!) widerspiegeln. Sie schieben die Ursachen ihrer 
Probleme allen möglichen Umständen oder Personen zu (sog. Kausalattribuierung), nur um ihr ohnehin angeschlagenes Selbstbewusstsein nicht noch zusätzlich mit Schuldeingeständnissen oder Selbstvorwürfen zu belasten.

Sozialpädagogen müssen daher die Denkweise der Problembelasteten, die vor allem aus ihrer Lebenswelt und ihrem Problemerleben entspringt, berücksichtigen. Dieser Forderungskreis ist so wichtig, dass Böhnisch daraus sogar mehrere differenzierte Prinzipien abgeleitet hat (vgl. Böhnisch 1993, S. 245ff.). Er formuliert speziell für die Sozialpädagogik im Kindes- und Jugendalter ein „sozialräumliches Prinzip,“ ein „Zeitprinzip“ und ein „Milieuprinzip“. Wesentliche Forderungen des sozialräumlichen Prinzips und des Milieuprinzips werden in der bereits oben formulierten „Berücksichtigung der Lebenswelt der Problembeteiligten " mit erfasst, wenn man diese differenziert betrachtet.

Das Zeitprinzip, das ja die Beachtung der jeweiligen jugendlichen Denkweisen fordert, ist in dem umfassenderen Prinzip des soziallogischen Denkens mit enthalten. Denn auch das „Gegenwarts-Zukunfts-Verständnis“ von Jugendlichen, das bei Böhnisch den Kern seines Zeitprinzips ausmacht, kann als Erscheinungsform soziallogischen Denkens betrachtet werden: Es entspringt der eigentümlichen Verarbeitung sozialer Erfahrungen durch die Jugendlichen und äußert sich in ihren jugendgemäßen Denkweisen, die bei Erwachsenen oft auf Unverständnis stoßen.

Berücksichtigung des soziallogischen Denkens der Klienten bedeutet für Sozialpädagogen, dass sie einerseits Verständnis für deren eigentümliche Denkweisen und Wertvorstellungen haben und andererseits diesen Eigentümlichkeiten im Problemlösungsprozess Rechnung tragen, indem sie beispielsweise wegen modischer Extravaganzen keine Vorschriften machen. Allerdings müssen sie in den Fragen, bei denen es um Ursachen und Wirkungen devianter Verhaltensweisen geht, konsequent sachlich vorgehen und (wenn nötig) die Problembelasteten auch zur Anerkennung eigener Versäumnisse und Verfehlungen bewegen. In jedem Falle müssen sie Lösungswege einschlagen, die unter Berücksichtigung der soziallogischen Denkweise der Klienten zum Erfolg führen. Wenn ein Klient z. B. meint, dass eine bestimmte Personengruppe (Clique, Trinkkumpane o. Ä.) an seinem Unglück „Schuld“ sei, kann und muss ein Sozialpädagoge die konsequente Trennung von ihr fordern, um den ungünstigen Einfluss der Gruppe auszuschalten. Aber der „persönliche Anteil“ des Klienten an den zu bewältigenden Problemen ist damit in der Regel noch nicht geklärt; er bleibt weiterhin im Zentrum sozialpädagogischer Bemühungen.

Die Strukturen sozialer Situationen enthalten zumeist mehrere Möglichkeiten des sozialen Handelns. Verständnis für die Lebenswelt und für soziallogisches Denken bedeutet daher für Sozialpädagogen im Problemlösungsprozess die Berücksichtigung der realen und aussichtsreichsten Möglichkeiten in den Ressourcen der lebensweltlichen Zusammenhänge und in den individuellen Denkweisen der Klienten. 


\subsubsection{Das Prinzip der Verbindung von Nichtbeschuldigung mit der Anknüpfung an persönliche Stärken der Klienten}

Sozialarbeiter dürfen die Problembelasteten nicht pauschal beschuldigen; sie müssen vielmehr die persönlichen Stärken ihrer Klienten für die Problemlösung nutzen.

\section{Begründung:}

Ziel sozialpädagogischer Maßnahmen ist stets auch die Entwicklung eines normalen Selbstbewusstseins und gesunden Selbstvertrauens der Klienten; das aber würde durch grobe Schuldzuweisungen eher verhindert. Auch Vorwürfe sind überflüssig, weil viele Klienten ohnehin wissen, was sie falsch gemacht haben. Hilfe zur Selbsthilfe gelingt am ehesten dann, wenn die starken Seiten der Problembelasteten und Problembeteiligten erkannt, angesprochen und für die Problemlösung mobilisiert werden.

\section{Handlungshinweise:}

Nichtbeschuldigung bedeutet, den Klienten nicht zu beschimpfen oder zu verurteilen, heißt aber nicht, seine devianten Handlungs- und Verbaltensweisen zu übersehen oder zu verharmlosen. Schon die professionelle Problemanalyse führt näherungsweise zur Aufdeckung der Ursachen des sozialen Problems und damit auch zu Schwächen des Klienten. Die Funktion der Enthüllung und des Erklärens stößt schnell an ihre Grenzen, wenn man das Prinzip der Nichtbeschuldigung zu streng interpretiert. Denn dann dürfte kein subjektives Versäumnis, das die soziale Notlage mit verursacht hat, genannt werden, obgleich gerade das notwendig ist, um der Wiederholung des Fehlers vorzubeugen.

Nichtbeschuldigung bedeutet praktisch, dass bloße Schuldvorwürfe vermieden werden. Die jeweilige Fallanalyse muss zur Erkenntnis des fragwürdigen Lebensstils und möglicher Versäumnisse oder Fehlhandlungen hinführen und sie auch bewusst machen. Wenn dadurch Schuldgefühle entstehen, so ist das solange kein Fehler, wie damit der Vorsatz verbunden wird, die Schuld - wenn möglich - abzutragen und künftig ähnliches Handeln und Verhalten zu vermeiden. Ungerechtfertigte und quälende Schuldgefühle sollten - u. U. unter Mitwirkung von Therapeuten - überwunden werden. Vor allem aber muss die Analyse auch Ansatzpunkte zur Lösung der Probleme bei den Klienten suchen, also solche Bedürfnisse, Interessen, Fähigkeiten und Verhaltensweisen erkennen, die Anerkennung verdienen und zur Problemlösung genutzt werden können.

\subsubsection{Prinzip der Verbindung von instrumenteller Problemdefinition mit der Konzentration auf die zentralen Problemvariablen}

Sozialpädagogen müssen nach Erkennen der Problemlage ihrer Klienten die Problemlösung in Form realisierbarer Maßnabmen und Handlungsschritte planen, die sich auf wesentliche und veränderbare Bedingungen in der Problemsituation richten und möglichst keine neuen Probleme erzeugen. 


\section{Begründung:}

Auf der Grundlage der zunehmend differenzierteren und genaueren Problemanalyse (vgl. Konzeptprinzip 4.6.3) werden Ansatzpunkte zur Problemlösung sichtbar, von denen aber nur diejenigen ausgewählt und in das flexible Problemlösungsprogramm aufgenommen werden, von denen mit hoher Wahrscheinlichkeit die Problemlösung abhängt, wobei mit Rücksicht auf die Gefühle und Erwartungen der Klienten solche Faktoren bewusst ausgeklammert werden, deren „Bearbeitung“ zum Hindernis im Problemlösungsprozess würde, z. B. ein „Wühlen in der Vergangenheit“, um den „wahren Schuldigen" zu ermitteln.

In der Regel bestimmt jeder Gesprächspartner den Beginn eines Konflikts (und damit den „Schuldigen“) aus seiner Sicht. Bei Kindern begegnet uns die dafür typische Äußerung: der oder die hat aber angefangen! Die Problembearbeitung sollte sich auf die Frage konzentrieren: wie wollen wir es in Zukunft miteinander halten und was ist dazu notwendig? Der Problemlösungsprozess wird dann zügig und effizient verlaufen, wenn sich die Problembeteiligten darüber einig sind, worauf es im Problemlösungsprozess wirklich ankommt, d. h. sich auf jene wesentlichen Bedingungen (Problemvariablen) konzentrieren, deren Veränderung wahrscheinlich den Erfolg bestimmt.

\section{Handlungshinweise:}

Instrumentelle Problemdefinition bedeutet, dass sich Sozialpädagogen mit ihren Klienten möglichst übereinstimmend über die Bedingungen und Schritte zur Lösung des Problems verständigen, die dann auch von allen akzeptiert und eingehalten werden müssen. Die handlungsleitende Problemdefinition findet in dem vereinbarten Maßnahmekatalog ibren Ausdruck, denn dieser ist das individuell angepasste Handlungskonzept der Problemlösung. Mit der Formierung aller beteiligten Kräfte und Einbeziehung aller Ressourcen in den zu vereinbarenden Hilfeplan schaffen sich die Sozialpädagogen das Instrumentarium für eine erfolgreiche Arbeit; Lüssi spricht daher auch von instrumenteller Problemdefinition.

\subsubsection{Das Prinzip der Einheit von steigenden Anforderungen und kontinuierlichen Kontrollen}

Sozialpädagogen müssen an ihre Klienten entsprechend der handlungsleitenden Problemdefinition und den sich wandelnden Bedingungen im Problemlösungsprozess klare und steigende Anforderungen stellen sowie deren Erfüllung kontrollieren und bewerten.

\section{Begründung:}

Problembelastete können sich entsprechend dem grundlegenden Gesetz der Persönlichkeitsentwicklung nur durch eigene Anstrengungen in der Tätigkeit entwickeln, und dazu bedarf es eines klaren Anforderungsregimes, auf dessen Grundlage die Kontrollen erfolgen, die nach Bedarf auch explizite Bewertungen mit einschließen. 


\section{Handlungshinweise:}

Jede sozialpädagogische Hilfe enthält im Kern ein Spektrum von Anforderungen an den Problembelasteten, das ihn in dem Maße stimuliert und aktiviert, wie er es akzeptiert und zunehmend erfolgreich bewältigt. Kontrollen dienen vor allem dazu, dem Problembelasteten durch helfende oder kritische Hinweise die notwendige Unterstützung zu geben. Unter Umständen sind sogar Strafmaßnahmen notwendig, wobei die auf den Seiten 261 und 287f. erläuterten Kriterien und Regeln zu beachten sind. Entsprechend dem Konzeptprinzip der Wechselwirkung von Verstehen und Handeln erfolgt bei zu großen Schwierigkeiten im Problemlösungsprozess eine Präzisierung des Hilfeplans. Dabei müssen überhöhte Anforderungen korrigiert werden, um ein realisierbares Verbältnis von Anforderungsregime und Leistungsmöglichkeiten der Problembelasteten zu gewährleisten. Das dient nicht nur der aktuellen Problemlösung, sondern auch der Befähigung der Klienten zu künftig eigenständiger und kreativer Bewältigung ihrer Lebenssituationen. Zugleich wird damit auf die „Entlassung in die Selbständigkeit“, d. h. auf die Ablösung hingearbeitet.

\subsection{Sozialpädagogische Funktionen und Prinzipien in ihrer Anwendung bei der Prozessgestaltung}

\subsubsection{Zur organisatorisch-methodischen Gestaltung der Funktionseinheit „Aufschließen“}

Um nach der Kontaktaufnahme eine Problemlösung mit Aussicht auf Erfolg in Angriff nehmen zu können, müssen dafür die Hilfebedürftigen aufgeschlossen werden.

Die Funktionseinheit Aufschließen dient dazu, die Hilfebedürftigen, die nicht immer freiwillig, sondern auf Initiative oder Drängen anderer vorstellig geworden sind, zu bewegen, sich über ihre Problemlage möglichst freimütig zu äußern, um die Voraussetzung zu schaffen für ein richtiges Verständnis der Problemsituation und der Problembelasteten. Zugleich soll ihre Bereitschaft geweckt werden, gemeinsam die Problemlösung zu beraten und sich auf Maßnahmen der Hilfe zur Selbsthilfe einzulassen.

Um nach der Kontaktaufnahme eine Problemlösung mit Aussicht auf Erfolg in Angriff nehmen zu können, müssen mehrere Aufgaben gelöst werden, die aus Gründen der Übersichtlichkeit in der Funktionseinheit Aufschließen zusammengefasst sind.

Die Funktionseinheit lässt sich in folgende Funktionen aufgliedern:

- Kontaktaufnahme und Problembeschreibung,

- Entlastung oder Erhöhung von Leidensdruck, 
- Motivierung und Ermutigung,

- Klärung der Rollen,

- Verständigung über Erwartungen, die verbunden sind mit den Zweckbestimmungen der künftigen Bemühungen.

Die Kontaktaufnahme zwischen Hilfebedürftigen und Sozialpädagogen beginnt üblicherweise mit einer freundlichen Begrüßung und der wechselseitigen namentlichen Vorstellung. Wenn es sich um eine Familienberatung handelt, wird der Sozialpädagoge sich mit den Gesprächsteilnehmern darüber verständigen, ob alle Problembeteiligten zusammen oder - was sich in den individualpsychologisch fundierten Beratungen von H. J. Tymister bewährt hat - in getrennten Gesprächen ihre Problemsicht darlegen wollen. Diese zunächst auf die Vorstellung und Verfahrensfragen gerichtete Unterhaltung ist geeignet, die Ratsuchenden auf die Situation einzustellen, so dass sich das Gefühl der Fremdheit reduziert. Zugleich erleben sie bereits mit dem Beginn der Beratung, dass ihre Meinung gefragt ist, dass sie ernst genommen werden - eine Erfahrung, die im weiteren Verlauf verbreitert werden muss.

Der Hauptpunkt der ersten Kontaktaufnahme besteht in der Regel darin, dass der Hilfebedürftige über seine Problemsituation berichtet, und zwar so wie er sie sieht und sprachlich darstellen kann. Der Sozialpädagoge ist dabei vor allem aktiver Zuhörer, der sich durch einfühlendes Verstehen auszeichnet. Dieses äußert sich in der Art seines Zuhörens, indem er

- den Hilfebedürftigen ausreden lässt,

- den Blickkontakt während des Gesprächs aufrecht erbält und

- durch sinnvolle Rückfragen - sog. Paraphrasieren oder Spiegeln - dem Hilfebedürftigen signalisiert, dass er um ein richtiges Verständnis seiner Aussagen und Befindlichkeit bemüht ist, etwa mit den Worten: Habe ich dich (bzw. Sie) richtig verstanden, wenn du meinst (Sie meinen), dass ...

Durch dieses Spiegeln erkennt der Klient die Anteilnahme und das Bemühen um ein richtiges Verständnis für seine Problemsituation, und der Sozialpädagoge verschafft sich Gewissheit darüber, ob er seinen nicht immer wortgewandten Klienten richtig verstanden hat. Das damit dokumentierte „einfühlende Verstehen“ ist eine wichtige Grundlage für die angestrebte vertrauensvolle Beziehung im Rahmen des erzieherischen Verhältnisses. Natürlich sollten solche Spiegelungen gut dosiert und wirklich nur an wesentlichen Punkten der Darstellung des Klienten erfolgen. Wenn der Hilfebedürftige die Äußerung des Sozialpädagogen bestätigt oder berichtigt hat, kann die Problembeschreibung fortgesetzt werden. Das aktive Zuhören kann dazu führen, dass der Sozialpädagoge sich sehr in die Lage des Problembelasteten hinein versetzt, was u. U. die Analyse erschwert, weil diese eine Distanz des „objektiven Betrachters“ erfordert. 
Der Sozialpädagoge hat hier also einen schwierigen Balanceakt zu meistern und muss sich in diesem Sinne selbst kontrollieren.

Eine weitere Schwierigkeit in der ersten Kontaktaufnahme und Problembeschreibung kann darin bestehen, dass der Hilfebedürftige seine Problemsituation ungeordnet, bruchstückhaft oder auch mehr oder weniger verzerrt darstellt. Auch in diesem Falle gilt: ausreden lassen und bei stockender Darstellung durch aufschließende Fragen ermutigen! Wenn der Hilfebedürftige seine Sicht zur Problemsituation dargelegt und dabei vielleicht ein ganzes Problemknäuel beschrieben hat, ist es notwendig, dieses zu entwirren, d. h. zu strukturieren, indem z. B. gefragt wird, welche Rangfolge der Problembelastete aufstellen würde. Diese Rangliste kann zugleich Ansatzpunkte für die Problemanalyse und Problemdefinition liefern, die nach der Problemanalyse gemeinsam vorgenommen wird; natürlich kann die Problembeschreibung und -analyse später auch noch ergänzt werden. Auf jeden Fall sollte der Sozialpädagoge durch Rangfolge und Begrenzung der Probleme auf die vordringlichen dazu beitragen, das Gefühl der Uferlosigkeit und der damit verbundenen Hoffnungslosigkeit zu überwinden. Die Verständigung über die lösbaren und zu lösenden Probleme findet ihren Niederschlag in den Zweckbestimmungen (vgl. S. 34, 116f., 215, 360) aller Bemühungen und im Hilfeplan. Unabhängig von der Kompliziertheit der Problemsituation und eines möglicherweise gravierenden Fehlverhaltens sollte der Sozialpädagoge dem Hilfebedürftigen unbedingt mit positiver Zuwendung begegnen. Das bedeutet: der Sozialpädagoge behandelt den Hilfebedürftigen vorurteilsfrei und macht seine Anteilnahme an dessen Schicksal nicht von irgendwelchen Leistungen im Sinne des Wohlverhaltens abhängig. Der Klient muss sich einfach angenommen fühlen, damit er sich öffnen kann. Welch fundamentale Bedeutung diese sog. Grundakzeptanz für sozialpädagogisches Handeln hat, belegen u. a. die Erfahrungen von Irma Jansen im Umgang mit Strafgefangenen (2006).

Im Interesse einer möglichst symmetrischen Kommunikation oder eines wechselseitigen Informationsaustausches sollte der Sozialpädagoge - sobald er wesentliche Elemente der Problemsituation erfasst hat - den Problembelasteten über die Möglichkeiten seiner Hilfe und Unterstützung informieren, ohne voreilige Versprechungen zu machen. Auf diese Weise können überhöhte Erwartungen der Klienten und Hemmungen im Offenbarungsprozess abgebaut werden. Es ist wichtig für den Klienten, zu erkennen, dass und wie ihm geholfen werden kann, damit er seine Probleme möglichst vollständig darlegt.

Im weiteren Verlauf des sozialpädagogischen Prozesses - wenn es sich also nicht um Erstkontakte handelt - kann auch die bedingte Zuwendung auf der Basis der Grundakzeptanz. wirksam sein, d. h., das Maß der Freundlichkeit in der Zuwendung wird davon abhängig gemacht, wie der Hilfebedürftige sich an getroffene Vereinbarungen hält. Das drückt sich auch in der Wortwahl des Sozialpädagogen aus, indem z. B. auf lobenswerte oder kritikwürdige Verhaltensweisen, die im Zusammenhang mit der getroffenen Vereinbarung 
stehen, Bezug genommen wird. Etwa: Ich habe mich darüber gefreut, dass du nach unserem letzten Gespräch ... oder: ich bin enttäuscht darüber, dass du dein Versprechen im Punkt ... nicht eingehalten hast. Abzulehnen ist jene negative Zuwendung, wie sie etwa in den Worten zum Ausdruck kommt: „Dir ist einfach nicht zu helfen.“

Ferner achtet der Sozialpädagoge darauf, inwieweit Wortwahl, Tonfall und Gestik bzw. Mimik des Hilfesuchenden miteinander übereinstimmen. Fallen ihm sog. Kanaldiskrepanzen auf (Diskrepanzen zwischen Wortwahl, Tonfall und Körpersprache), dann ist das ein Signal für spätere Nachfragen, um die wirkliche Meinung oder Befindlichkeit in Erfahrung zu bringen. Das intensive Zuhören schließt innere Bewegungen des Sozialpädagogen natürlich nicht aus, aber er sollte nicht durch Kopfschütteln oder Stirnrunzeln seine Wertungen zum Verhalten des Hilfesuchenden andeuten, um ihn nicht zu verunsichern. Im Gegenteil: durch Teilnahme bekundende Fragen, aus denen der Hilfebedürftige echtes Interesse an seinen Problemen entnehmen kann, sollte er sein Bemühen um richtiges Verständnis ausdrücken. Sinnvolle Rückfragen können dem Sozialpädagogen selbst helfen, seine Gedanken auf die Aufnahme der Problembeschreibung zu konzentrieren und nicht schon in weiterführende „diagnostische Überlegungen“ abzugleiten. Die unvoreingenommene Problemannahme und Anteilnahme ist allerdings stets mit Echtheit in den eigenen Reaktionen zu verbinden, d. h., das Kritikwürdige am Verhalten des Hilfesuchenden wird nicht verharmlost, sondern im Verlaufe des Gespräches bewusst gemacht, ohne damit die Persönlichkeit im Ganzen zu verurteilen. Besonders für die Funktionseinheit Aufschließen gilt also das Prinzip der unvoreingenommenen Problemannabme, der verständnisvollen Anteilnahme und Echtheit zwecks Öffnung, Ermutigung und Aktivierung.

Der Sozialpädagoge muss dem Hilfebedürftigen auch in einer möglichst natürlichen Sprechweise begegnen. Er sollte sich daher nicht bemühen, im Jargon des Klienten zu reden, weil er etwa meint, dadurch einen besseren Zugang zum Hilfebedürftigen zu finden. Diesem ist ohnehin klar, dass ihm ein Gebildeter oder „Andersartiger“ gegenüber sitzt, und er würde eine solche äußerliche Anpassungsbemühung möglicherweise nur als Anbiederungsversuch bewerten. Eine gewisse Distanz als Gegenpol zur Nähe ist eine Grundvoraussetzung für ein pädagogisches Verhältnis (vgl. Jansen u. a. 2006, S. 49). Wichtig ist, dass der Sozialpädagoge noch vor der Problemerörterung sagt, dass er dem Hilfebedürftigen oder Ratsuchenden das Recht zubilligt, auch bestimmte Fragen nicht zu beantworten - etwa nach dem Motto: alles, was hier gesagt wird, muss wahr sein, aber nicht alles, was wahr ist, muss hier gesagt werden! Außerdem muss er Diskretion zusichern und wahren, wenn es sich um ein Gespräch unter vier Augen, im Expertenkreis oder im engen Kreis der Problembeteiligten handelt.

Bei der ersten Kontaktaufnahme sollte der Sozialpädagoge beachten, dass der Hilfebedürftige eine beträchtliche Barriere überwinden muss, da es immer schwierig ist, einem 
Fremden seine Problemen zu offenbaren; das gilt natürlich besonders für Belastete. In dem Falle trifft häufig ein, was Friedemann Schulz v. Thun als Selbstoffenbarungsangst bezeichnet hat (1990, Bd. 2, S. 14). Daher ist es verständlich, wenn sog. Fassadentechniken benutzt werden (um ,nicht gar so schlecht dazustehen“) oder wenn aus gewohntem Misstrauen und verfestigter Abwehrhaltung heraus schon bei harmlosen Nachfragen mit überraschender Schärfe abweisend reagiert wird. Der Sozialpädagoge sollte sich dadurch nicht aus der Fassung bringen lassen oder persönlich angegriffen fühlen. Vielmehr ist zu prüfen, inwieweit der Problembelastete sich in ein besonderes Licht rücken will (z. B. als ewig Benachteiligter und eigentlich Unschuldiger oder als leider völlig Hilfloser usw.) oder inwieweit er einfach frühere und gewohnte Reaktionsweisen im Umgang mit seinen Mitmenschen (speziell mit Angehörigen) auf die Kommunikation mit dem Sozialpädagogen überträgt.

Die eigene Sicht und Selbstdarstellung des Klienten bedarf im Sinne des Aufklärens einer besonderen Betrachtung. Eventuelle Übertragungen gewohnter Reaktionsweisen (z. B. beleidigende Zurückweisungen bei Zwischenfragen wie sie der Hilfesuchende im familiären Umgang vielleicht gewohnheitsmäßig praktiziert) auf die Kommunikation im Beratungsgespräch sollte der Sozialpädagoge durchkreuzen, indem er gerade nicht so reagiert wie der Klient es in solchen Situationen bei seinen Angehörigen erlebt hat. Der größte Fehler in dieser Situation wäre eine „Gegenübertragung“, d. h., der Sozialpädagoge reagiert mit einer ähnlichen Zurechtweisung wie sie der Hilfebedürftige auch schon früher (z. B. bei den Eltern oder Lehrern) häufig erlebt hat, denn damit würde der Zugang zur Problemlösung nahezu versperrt.

Eine andere Quelle von Missverständnissen oder Fehlern im Gespräch, in dem der Hilfebedürftige seine Beschreibung der Problemsituation darbietet, besteht darin, dass durch Zwischenfragen des Sozialpädagogen der Klient veranlasst wird, das zu sagen, was seiner Meinung nach der Fragesteller gern hören möchte, oder meint, im Sinne des sozial Erwünschten antworten zu müssen. Um eine solche „unechte Beschreibung“ zu vermeiden, sollte der Problembelastete unbedingt ausreden können - auch wenn die Struktur der Darlegungen etwas wirr erscheinen mag. Wenn der Klient geendet hat, besteht immer noch die Möglichkeit zu gezielten Nachfragen und Strukturierungen, etwa nach der Dringlichkeit erkennbarer Probleme in der Gesamtsituation.

Nachfragen sind vor allem auch deshalb nötig, um die Art des Problemfalls möglichst genau zu erkennen, weil davon abhängt, dass er den wirklich zuständigen Helfern zugeordnet werden kann. Burkhard Müller unterscheidet zu diesem Zweck zwischen dem Fall von ..., dem Fall für ... und dem Fall mit ... (vgl. 1994, S. 28ff.).

Da sozialpädagogisches Handeln vielfach in Verwaltungshandeln eingebunden ist und die Frage der Zuständigkeit ja auch finanzielle Bedeutung hat, muss also durch die Beschreibung der Problemsituation deutlich werden, 
- um welchen Typus von Problemfall es sich handelt ( z. B. ob um einen Fall von Eingliederungshilfe nach \39 BSHG oder entsprechend dem KJHG \10 Absatz 2),

- welchen Fachleuten er zur Behandlung zugeordnet werden sollte (z. B als Fall für die Suchttherapie, für die Psychotherapie usw.) und

- was mit welchem Problembelasteten und Problembeteiligten zweckmäßigerweise zu tun ist.

Die Antworten auf diese Fragen werden zweifellos den weiteren Verlauf des Gesprächs und vor allem den Inhalt der Vereinbarungen (des Hilfeplans) bestimmen. Wichtig ist in diesem Zusammenhang, dass der Sozialpädagoge, der mit dem Problemfall konfrontiert wird, über hinreichendes „Vermittlungswissen“ verfügt und die Beziehungen zu den jeweiligen Fachleuten (₹. B. Therapeuten) herstellen kann (vgl. B. Müller 1994, S. 28ff.), die dann auf ihre Weise den Prozess wieder aufgreifen und fortführen, was zu einer Verknüpfung der Funktionseinheit Ausfübrung mit notwendigen speziellen pädagogischen oder auch therapeutischen Maßnahmen fübrt (siehe Schema 11 und Strukturprinzip 5.5.4). In diesem Zusammenhang ist die Kenntnis der Symptome bzw. Kriterien für eine Drogenabhängigkeit wichtig, auch wenn sie nicht bei allen Süchten in gleicher Weise auftreten, nämlich:

1. starkes Verlangen nach dem Mittel (illegale Droge, Alkohol, Computer usw.),

2. große Schwierigkeiten, den „Konsum“ aufzugeben,

3. Dosissteigerung, um die gewünschte Wirkung zu erreichen,

4. körperliche Entzugserscheinungen (z. B. starkes Schwitzen oder Unruhe),

5. allmählicher Verlust des Interesses an der Umwelt,

6. Folgeschäden wie etwa nachlassendes Konzentrationsvermögen, Depressionen, Unfall unter dem Einfluss der Drogen oder Medikamente.

Als hilfreich für den Aufbau eines Vertrauensverhältnisses mit dem Problembelasteten erweist es sich, wenn der Sozialpädagoge in seiner Fragestellung und Reaktionsweise die Lebenswelt seines Klienten berücksichtigt. Daher können Vorinformationen von groBem Wert sein, denn sie eröffnen das Verständnis für bestimmte Verhaltensweisen, die ja nicht nur durch einzelne individuelle Charakterzüge, sondern vielfach durch Lebenswelttypisches bestimmt werden. Aber auch im Gespräch selbst sollte der Sozialpädagoge versuchen, möglichst viel von der Lebenswelt der Hilfebedürftigen zu erfahren, weil auf diese Weise oftmals schon wichtige be- oder entlastende Faktoren erkannt werden können.

Die Funktionseinheit Aufschließen erstrebt - wie in der Definition angedeutet - zunächst einmal die Bereitschaft der Problembelasteten, sich möglichst freimütig und vollständig über ihre Lage zu äußern. Dieses Anliegen wird aber im Erstgespräch oft noch nicht in hinreichendem Maße realisiert, weil es nicht möglich ist, so schnell das dafür 
erforderliche Vertrauensverhältnis herzustellen. So kann es bspw. geschehen, dass benachteiligte Jugendliche in einer überbetrieblichen Ausbildung erst nach einiger Zeit, in der sie zu einem sozialpädagogischen Mitarbeiter des Unternehmens Vertrauen gefasst haben, mit ihren eigentlichen Problemen „herausrücken“. Diese sind manchmal viel komplizierter und gravierender als die zunächst festgestellten Schwierigkeiten bei der Lehrstellenfindung, die das Erstgespräch ausgefüllt und zur Aufnahme in die Einrichtung geführt haben.

Bei den tiefer liegenden Problemen kann es sich um Schwächen des Klienten handeln, die er nicht gern offenbaren möchte (siehe den Fall Sven weiter unten!), oder um Rücksichtnahme des Klienten auf nahe stehende Personen wie im Fall Axel, der an einem Lehrgang zur Berufsvorbereitung teilnahm und die wahren Gründe seiner Unpünktlichkeiten und Fehlzeiten verschwieg, weil er nicht über seine belastende Situation im Elternhaus sprechen wollte. Seine Mutter und deren Lebensgefährte waren Alkoholiker, feierten täglich „Partys“, während sich Axel um viele Dinge des Haushalts kümmerte. Aus Liebe zu seiner Mutter nahm er alle Erschwernisse auf sich und fand daher kaum Zeit und Kraft für seine eigenen Angelegenheiten. Erst nachdem sich das Vertrauensverhältnis zum Sozialarbeiter der Ausbildungseinrichtung hinreichend entwickelt hatte und ernsthafte Konsequenzen aus seinen Fehlzeiten drohten, öffnete er sich, stellte er seine Lebenssituation relativ vollständig dar und erfuhr die wirklich notwendige Unterstützung, die es ihm ermöglichte, den Lehrgang erfolgreich zu beenden (Koschnitzki, Belegarbeit 2003).

Wenn ein Hilfebedürftiger von sich aus um Rat und Hilfe nachsucht, hat er bei der Kontaktaufnahme verständlicherweise das Bedürfnis, seinem Herzen Luft zu machen. Auch wenn die Darstellung des Problembündels recht ungeordnet oder gar widersprüchlich erfolgt, sollte man zunächst keine Einwände erheben, denn es geht in dieser Funktionseinheit im hohen Maße auch um eine Entlastung vom Leidensdruck. Dabei handelt es sich keineswegs nur oder in erster Linie um physische Leiden - wie sie etwa bei Obdachlosen in schlechter Jahreszeit oder bei Suchtkranken auftreten können sondern auch um psychische Bedrückungen oder Verzweiflungsstimmungen.

Eine völlige Befreiung vom Leidensdruck wird erst mit der Problemlösung erfolgen. Doch viele Probleme des Hilfebedürftigen resultieren gerade daraus, dass er meint, niemand würde ihm richtig zuhören und keiner würde ihn verstehen. Ein „richtiges Verständnis“" wird dem Klienten nicht nur durch geduldiges Zuhören, sondern auch durch die Beachtung des Prinzips der Verbindung von Nichtbeschuldigung mit der Anknüpfung an persönliche Stärken der Klienten und deren Anerkennung signalisiert. Jemanden gefunden zu haben, der ohne vorwurfsvolle Einwände zuhört, verschafft schon etwas Erleichterung und ist daher in jedem Falle ein Gewinn, der auch für die Entwicklung eines Vertrauensverhältnisses wichtig ist. 
Die Begegnung mit einem Menschen, der aufmerksam zuhört und das Erlebnis vermittelt, „endlich verstanden zu werden“, dient

- auch dem Abbau von Angst bzw. Furcht oder Ärger und Wut, d. h. also der Wiederherstellung eines solchen seelischen Gleichgewichts, das es möglich macht, die vorliegende Problemsituation sachlich zu betrachten, zu analysieren und gemeinsam nach Lösungen zu suchen (Strukturprinzip 5.5.2),

- $\quad$ sowie der Weckung von Hoffnung und Zuversicht hinsichtlich einer Problemlösung und damit der Ermutigung zu eigenen Anstrengungen.

Der Abbau von Angst erfolgt nicht dadurch, dass der Sozialpädagoge dem Hilfebedürftigen erklärt, dass das ,alles nicht so schlimm“ sei, sondern nur, wenn er durch seine Reaktionen beim Zuhören Verständnis signalisiert, andernfalls fühlt sich der Hilfebedürftige nicht ganz ernst genommen. Außerdem sollte jeder Hoffnungsschimmer möglichst im Zusammenhang mit erkennbaren starken Seiten des Klienten - zur Motivation für künftige Bemühungen um die Problemlösung genutzt werden.

Natürlich wird sich die Problemsicht des Hilfebedürftigen von der des Sozialpädagogen - bei allem Bemühen um Verständnis - unterscheiden, ja sogar unterscheiden müssen. Das hat mehrere Gründe: Problembelastete erleben sich als Hilflose, Leidende oder Schuldige und beschreiben ihre Problemsituation in einer jeweils dadurch geprägten Färbung. Je nach Charakter, Lebensstil, intellektuellem Niveau und Mentalität können sie ihre Problemsituation recht unterschiedlich darstellen, z. B.

- $\quad$ sehr knapp und verhalten, um sich nicht zusätzlich eine Blöße zu geben,

- $\quad$ auf Leiden und Krankheiten verweisend und dadurch Mitleid erregend, um ein Maximum an Hilfe zu erheischen,

- aggressiv und vorwurfsvoll gegenüber der eigenen Umwelt, um als „armes Opfer" zu erscheinen.

In jedem Falle muss sich der Sozialpädagoge bemühen, sowohl die objektive Problemsituation möglichst adäquat zu erfassen als auch die reale Befindlichkeit des Klienten zu verstehen, um auf diese richtig eingehen zu können. In der Praxis bedarf es unbedingt der sorgfältigen Analyse bei der Ermittlung der Ausgangslage, die auf keinen Fall durch eine voreilige „Krankschreibung“ ersetzt werden darf, weil das u. U. eine ungerechtfertigte Pathologisierung des Täters und die Gefahr des Therapismus bedeutet, vor der v. Hentig mit vollem Recht gewarnt hat. Es sollte auch nicht übersehen werden, dass sich manche Problembelastete in die Krankheit flüchten, um auf diese Weise Anforderungen aus dem Wege zu gehen, die ihnen zu unbequem und zu anstrengend erscheinen, vor allem wenn sie durch ihre Lebensweise nicht an größere Anstrengungen gewöhnt sind und ihr „Ausweichverhalten trainieren“ konnten. Das gilt sowohl in physischer als auch in psychischer Hinsicht. In solchen Fällen bedarf es 
eines Systems steigender und unausweichlicher Anforderungen, das am besten in funktionstüchtigen Entwicklungs-Gemeinschaften und in Verbindung mit interessanten Projekten realisiert werden kann.

Um sich ein möglichst reales Bild über die jeweilige Problemsituation zu verschaffen, ist es unter Umständen notwendig, dass sich der Sozialpädagoge auch bei den Problembeteiligten (z. B. bei Angehörigen, Freunden oder auch Ämtern) erkundigt und deren Sichtweise bei der Problemanalyse berücksichtigt, aber möglichst ohne sich dadurch ein Vorurteil zu bilden. Wenn in Anwendung tiefenpsychologischer oder individualpsychologischer Analysemethoden auch traumatische Erlebnisse des Klienten aus seiner Kindheit zur Sprache kommen, deren Besprechung vielfach eine entlastende Funktion haben, weil dadurch Schuldgefühle reduziert werden, so ist doch auch zu beachten, dass nicht einfach die „Schuld an allem“ den Eltern, den Erziehern, den Lehrern usw. zugeschoben wird, denn es geht darum, dem Klienten die eigenen Irrtümer bzw. Illusionen in seinem Lebenskonzept bewusst zu machen, damit er sie überwinden kann. Im Falle aufsuchender Sozialarbeit oder „verordneter Hilfesuche“ ist die Funktionseinheit des Aufschließens im Allgemeinen schwieriger zu gestalten, weil ein wirksamer Leidensdruck als Motiv, über seine Probleme zu sprechen, fehlt. Dennoch sind auch in solchen Fällen zumeist Zeichen des Unbehagens beim Hilfebedürftigen zu erkennen, die genutzt werden sollten, um die Problemsituation bewusst zu machen, deren Folgewirkungen vom Klienten oft nicht übersehen oder nicht ernst genommen werden.

Wenn ein Klient jedoch jedwedes Hilfsangebot als Einmischung in persönliche Angelegenheiten ablehnt, hat es keinen Zweck zu versuchen, ihn zu seinem Glück zu zwingen. Dann ist es ratsam, ihn erst noch die Nachteile oder leidvollen Folgen seines Handelns und Verhaltens (Folgewirkungen!) erfahren zu lassen, und zwar durch Verweigerung von Hilfe, was in der Regel zu einer Erhöhung des Leidensdrucks führt. Bei der Erhöhung des Leidensdrucks ist allerdings zu beachten, was der französische Aufklärer Helvetius in einer Fußnote seines berühmten Werkes „Vom Menschen“ geschrieben hat: „Bis zu einem gewissen Punkt klärt das Leiden auf. Geht es darüber hinaus, dann stumpft es ab" (Helvetius 1976, S. 483). Durch zeitweilige Verweigerung von Hilfe kann dem Prinzip der Verbindung von Freiwilligkeitsvorrang, Zeitrichtigkeit, Zielstrebigkeit und Flexibilität im Hilfeprozess entsprochen werden, d. h., eine Hilfe zum späteren Zeitpunkt - wenn der Hilfebedürftige die notwendigen Einsichten dafür gewonnen hat - kann eher zum Erfolg führen als eine Hilfe auf der Basis einer „erzwungenen Einwilligung“. Eine Erhöhung des Leidensdrucks kann nicht nur infolge des „Weiter-machen-Lassens“ eintreten, sondern auch durch eine bewusst herbeigeführte Verschärfung der Situation oder durch ein Bewusstmachen des Ernstes der Lage. So wurde z. B. in Rostock festgestellt, dass etwa $50 \%$ der von Zwangsräumung bedrohten Mietschuldner schließlich doch zur Annahme von Hilfsangeboten bereit waren, 
nachdem der Gerichtsvollzieher den Räumungstermin bestimmt hatte und den Betroffenen klar wurde, dass die Lage wirklich ernst war (Zühlke 2003, S. 5).

Wenn Problembelastete auf sozialpädagogische Hilfe verzichten, entstehen allerdings oft auch Risiken durch eine Erhöhung des Leidensdruckes; es muss daher geprüft werden, inwieweit mit dem Gewährenlassen solche Gefahren für Leib und Leben entstehen können, dass ein Nichthandeln dem Sozialpädagogen als unterlassene Hilfeleistung angelastet werden kann. Daher sind Hilfsmaßnahmen ohne Rücksicht auf das Einverständnis der Hilfebedürftigen auch nicht völlig zu vermeiden. Doch zunächst muss der Sozialpädagoge den Problembelasteten im Falle von Widerständen nachdrücklich auf die möglichen Gefahren des „Weitermachens“ hinweisen und ihm sagen, dass er jetzt möglicherweise seine letzte Chance zur Rettung versäumt, wenn er die angebotene Hilfe ablehnt. Da aber klar ist, dass dem Klienten nicht wirksam geholfen werden kann, wenn er sich nicht helfen lassen will oder jede ernsthafte Mitwirkung am Problemlösungsprozess verweigert, bleibt die spontane Verschärfung oder bewusste Erhöhung von Leidensdruck die im Augenblick einzig sinnvolle Entscheidung, die natürlich keine endgültige sein sollte. Der Klient wird mit dem Hinweis aus dem Gespräch verabschiedet, dass er wiederkommen kann, wenn er es sich anders überlegt hat und ein ähnliches Hilfsangebot in der Zukunft noch existiert, denn es kann keine „unbegrenzte Auffanggarantie“ gegeben werden.

Dass ein Bewusstmachen des Ernstes der Lage als Leidensdruck mit beachtlicher Wirkung von den Problembelasteten erlebt werden kann, zeigt der Fall des alkoholkranken Max (vgl. Abschnitt 2.4). Er hatte in der Wende seine Arbeit verloren und vertrieb sich die Zeit verstärkt vor einer Kaufhalle bei Bier und Schnaps mit seinen Kumpeln. Er erlebte, wie einer davon infolge seines langjährigen übermäßigen Alkoholkonsums starb. Als er wieder einmal wegen einer Alkoholvergiftung in die Klinik musste, machten ihm die Ärzte klar, dass auch sein Ende nicht mehr weit ist, wenn er so weiter trinkt. Max aber wollte leben und unterzog sich einer Therapie. Als er danach wieder bei seinen Kumpeln vor der Kaufhalle auftauchte, weigerte er sich, den Willkommenstrunk anzunehmen. Er war noch so naiv zu glauben, er könne bei einer Limonade mit seinen alten Freunden plaudern. Da er fest bei seiner Ablehnung des Alkohols blieb, kam es schließlich zu einer Schlägerei mit dem erfreulichen Resultat, dass Max die Beziehungen abbrach - seine Angst vor dem Tode war offensichtlich größer als seine Verbundenheit mit den Trinkkumpanen. Tatsächlich war auch Max zum Zeitpunkt des Berichts - drei Jahre nach der Therapie - noch trocken, hatte neue Freunde, eine ordentliche Wohnung und einen Hund, den die Nachbarn versorgten, wenn er auf Arbeit war (Bunk/Ziegler 2003, S. 47/48). Die Entlastung oder Verstärkung von Leidensdruck ist nicht nur zu Beginn eines sozialpädagogischen Hilfeprozesses möglich. Sie kann auch während der Ausführung wieder aktuell werden - etwa wie folgt: 
Ein durch multiple Sklerose belasteter und drogenabhängiger junger Mann namens Sven wird in einer Einrichtung zur Förderung von Benachteiligten durch einen Sozialpädagogen betreut. Sven war in der Einrichtung bereits durch unentschuldigtes Fehlen und häufige Krankschreibungen aufgefallen. Nach einer schweren Verletzung durch einen Motorradunfall hatte er die Ausbildung wieder aufgenommen. Da aber ähnliche Schwierigkeiten auftraten wie zuvor, verhärteten sich die Fronten zwischen ihm und den Ausbildern ziemlich schnell. In dieser Situation erkannte Lutz Sch. - Sozialpädagoge in der Ausbildungseinrichtung - Svens schwierige Lage und wandte sich ihm zu, so dass Sven nach einiger Zeit Vertrauen zu ihm fasste; er akzeptierte dessen Hilfsangebote, z. B. Nachhilfeunterricht in Wirtschaftsrechnen und Computernutzung (Vereinbarung!). Allerdings ergab sich eine Situation, die Lutz wie folgt beschreibt: „Schnell merkte ich, dass ein Unterricht durch Svens morgentlichen Drogenkonsum kaum möglich war. Seine Konzentrations- und vor allem seine Merkfähigkeit waren stark eingeschränkt. Da der Unterricht und die Ausbildung nahezu ergebnislos waren, wenn Sven morgens oder in der Mittagspause Drogen nahm, wollte ich hier unbedingt eine erste entscheidende Veränderung schaffen [...]. Ich teilte ihm meine Erkenntnis über seinen Drogenkonsum mit. Vorerst stritt er diesen ab, gelangte aber relativ schnell zu der Einsicht, dass dies zwecklos ist (Entbüllung).

Da ihn erste Erfolgserlebnisse durch die Umstellung des Unterrichts motiviert hatten, machte ich ihm klar, dass im Falle von Drogenkonsum vor dem Unterricht ein solcher nicht stattfindet (Kennzeichnung der Folgen des Bruchs der Vereinbarung!). In diesem Fall erhielt er Aufgaben, die er allein bearbeiten sollte. Auch führte ich dann keine ernsthaften Gespräche mit ihm. Aber ich beschimpfte und beschuldigte ihn auch nicht (im Sinne des Prinzips der Nichtbeschuldigung) wie er es sonst gewohnt war. Weiterhin stellte ich ihm in Aussicht: sollte er am nächsten Tag nüchtern kommen, würde ich die Ausbildung und den Unterricht normal und vorbehaltlos fortführen und mich auch wieder seinen Problemen (Verhandlungen mit Behörden, Polizei, Gericht wegen seines vorangegangenen Verkehrsunfalls) widmen“ (Schuller, Belegarbeit 2002, S. 5). Tatsächlich ging Sven auf diese Vorschläge ein. Offenbar wirkte schon der Gedanke, die sich anbahnende positive Beziehung, die Betreuung mit ihren erfreulichen Resultaten in der Ausbildung zu verlieren, im Sinne einer „Erböhung von Leidensdruck“. Das bedeutet: auch die Erkenntnis einer möglichen Erböhung des Leidensdruckes kann positives Bemühen erzeugen. Außerdem forderte der Sozialarbeiter ja nicht den Drogenverzicht, sondern nur die Verschiebung des Konsums auf den Abend oder das Wochenende. Die Vereinbarung funktionierte - wenn auch mit gelegentlichen Rückefällen.

An diesem Beispiel soll verdeutlicht werden, dass und wie gute zwischenmenschliche Beziehungen und echte Erfolgsaussichten sowie die Angst vor erneuten Schwierigkeiten auch in einem recht komplizierten Fall motivierend wirken können. Nachdem Sven schließlich erkannte, dass der Drogenkonsum nicht die richtige Reaktion auf die Probleme seiner multiplen Sklerose sein kann (Enthüllung der Mängel seines Lebensstils) 
und er sich zu einer Therapie entschloss (erneute Vereinbarung!), konnte er den Grundmangel seines Lebensstils so weit überwinden, dass es ihm möglich wurde, seine Ausbildung erfolgreich abzuschließen.

Die Art der Motivierung des Hilfebedürftigen im Interesse der Hilfe zur Selbsthilfe hängt natürlich wesentlich von der Art der Kontaktaufnahme ab. Hilfesuchende sind in der Regel leichter zu motivieren als Problembelastete, die aufgesucht oder vermittelt worden sind. Grundsätzlich handelt es sich bei der Motivierung aus der Sicht des Sozialpädagogen um ein Angebot möglicher Motive an den Klienten, von denen vermutet wird, dass sie von diesem als bedeutsam erkannt und akzeptiert werden. Letztlich entscheidet sich der Klient aus den ibm wichtig erscheinenden Gründen für - oder auch gegen - einen Hilfeprozess und die damit verbundenen eigenen Bemühungen. Das ist der Kern der Motivierung, d. h., auch sie ist eine Leistung des Klienten selbst und nicht eine bloße Folge guten Zuredens durch den Helfer.

Die möglichen Motive, die der Sozialpädagoge zur Sprache bringt, wählt er aus mit Rücksicht auf die Bedürfnisstruktur des Klienten. Eine grobe Orientierungshilfe bietet die Übersicht 6 auf der Seite 205, um davon ausgehend jene Handlungsgründe anzubieten, die dem Klienten einsichtig und wertvoll erscheinen könnten. Es geht darum, in Abhängigkeit von den jeweils feststellbaren Stärken und Defiziten geeignete Hilfemaßnahmen zu finden und mit einer wirkungsvollen Motivierung zu verknüpfen. So können die vorhandenen Aktivitätspotenziale in Verbindung mit Neugier sowie dem Bedürfnis nach Anerkennung und Gemeinschaft in einem interessanten Gemeinschaftsprojekt dem Klienten helfen, bestimmte Schwächen und Schwierigkeiten (z. B. mangelhafte Zielstrebigkeit und Ausdauer oder unangemessenes Sozialverhalten) zu überwinden. Vor allem lassen auch die feststellbaren Entwicklungsresultate bzw. Deformationserscheinungen erkennen, welche Anlagen vermutlich nicht in richtiger Weise entwickelt worden sind. Ansatzpunkte für Veränderungen ergeben sich daraus, dass erkennbare Dispositionen und positive Entwicklungsresultate als Stärken zur Überwindung von Deformationserscheinungen bzw. devianten Verhaltensweisen genutzt werden.

Eng mit der Motivierung verbunden ist die Ermutigung, denn mit der Akzeptanz einiger im Gespräch angebotener möglicher Motive für ein bestimmtes Handeln entstehen Erwartungen auf Besserung der persönlichen Situation und die Hoffnung auf die Lösung der Probleme - das macht Mut! Dieses Mut-Machen bezieht sich zwar zunächst auf die Bemühungen um die Bewältigung der unmittelbar anstehenden Aufgaben, ist aber nicht nur Bestandteil der Funktionseinheit Aufschließen. Auch während des Ausführens werden immer wieder Zweifel oder Rückfälle auftreten, deren Überwindung Ermutigung erfordert; und schließlich geht es ja überhaupt um die Entwicklung des zumeist unzureichenden Selbstvertrauens der Problembelasteten, so dass alle Mittel für die Ermutigung genutzt werden müssen, vor allem die jeweils erreichten Erfolge selbst. Übrigens 
belegt jeder Rückfall, dass es zuvor einen Fortschritt gegeben hat, und daran sollte die Ermutigung anknüpfen.

Um ein Gespräch über mögliche Problemlösungsvarianten führen zu können, muss bereits nach der Problembeschreibung dem Hilfesuchenden klar werden, dass eine Problemlösung nur möglich ist, wenn er sie will und sich ernsthaft bemüht, denn seine Bemühungen entscheiden über den Erfolg. Es wäre ein Irrtum, wenn er annehmen würde, der Sozialpädagoge oder andere Helfer regeln alles und die Lösung würde ihm geschenkt. Der Sozialpädagoge kann ihm eigentlich nur behilflich sein, mögliche Lösungswege zu erkunden und zu finden. Dabei muss der Helfer dem Problembelasteten auch klar machen, dass er wegen seiner Doppelverpflichtung - nämlich gegenüber den Hilfebedürftigen und der Gesellschaft - niemals einseitig die Interessen von Klienten wahrnehmen kann, sondern die aller Problembeteiligten und auch die der Gesellschaft berücksichtigen muss.

Die grundsät_liche Erklärung der Rollen beider Seiten im Problemlösungsprozess kann mit der Frage an den Problembelasteten eingeleitet werden: „Wie stellen Sie sich (bzw. stellst du dir) denn überhaupt eine Lösung der Probleme vor?" Aus der Antwort ergeben sich naturgemäß die Ansatzpunkte zur Klarstellung der Rollen. Diese widerspiegeln sich in der instrumentellen oder handlungsleitenden Problemdefinition und in der entsprechen Vereinbarung, die in jeder „Zwischenauswertung“ Konkretisierungen erfährt, indem festgelegt wird, wer was bis wann zu tun hat. Außerdem ist die Rollenklärung auch immer mit einer Verständigung über die „problemlösende Rollenerlaubnis" verbunden (vgl. Lüssi 1992, S. 105f.), d. h., der Sozialpädagoge vergewissert sich im Zweifelsfall durch Rückfragen bei den Problembeteiligten, ob sie mit einer bestimmten Maßnahme (etwa mit der Einbeziehung Dritter) einverstanden sind, damit der Gefahr des Vorwurfs von Verstößen gegen die zugesicherte Diskretion vorgebeugt wird.

Mit der Klärung der Rollen ist die Bestimmung der Beziehungen zwischen Sozialpädagogen und Problembelasteten verbunden. Weil es darum geht, deutlich zu machen, wer was von wem will und erwarten kann, wird jede sprachliche Äußerung auch unterm Beziehungsaspekt wahrgenommen und reflektiert, d. h., der Hilfesuchende registriert über die Reaktionen des Sozialpädagogen, ob er verstanden und angenommen wird. Der Sozialarbeiter erkennt, in welchem Maße sich der Hilfesuchende öffnet und ehrlich seine Befindlichkeit und Auffassung äußert, so dass jeder vom anderen ein Bild bekommt und jeder den Charakter der sich anbahnenden Beziehung „,erfühlt“.

Grundsätzlich unterscheidet Schulz v. Thun vier Reaktionsmöglichkeiten bei einem „Beziehungsvorschlag“, der naturgemäß auch in einem Gespräch beim Erstkontakt schon ,atmosphärisch“ deutlich wird: Der jeweilige Vorschlag zur Beziehungsdefinition (So stehen wir zueinander, nicht wahr?) kann vom Gesprächspartner 
- $\quad$ voll akzeptiert werden,

- mit gewissen Vorbehalten hingenommen werden,

- $\quad$ zurückgewiesen werden oder

- $\quad$ ignoriert werden (vgl. Schulz v. Thun 1990, Bd. 1, S. 180).

Für den Erfolg des Prozessverlaufs ist wesentlich, dass sich zunächst eine komplementäre Beziehung entwickelt, in welcher der Sozialpädagoge die Handlungsherrschaft bewahrt und der Hilfebedürftige in Anerkennung der Kompetenz des Sozialpädagogen zur freiwilligen Unterordnung bereit ist, die sich mit dem erzieherischen Verhältnis im Prozess der Ablösung wieder aufhebt. Wenn sich die Beziehung als freundlich, hoffnungsvoll und aussichtsreich im Hinblick auf die Problemlösung ,anlässt“, ist das für die Rollenklärung förderlich. Wenn jedoch der Hilfebedürftige sich in seinen Erwartungen enttäuscht sieht (weil ihm seiner Meinung nach „nicht genug geboten“wird), besteht die Gefahr eines „Beziehungsmanövers“ in dem Sinne, dass der Problembelastete versucht, die Beziehung - und in Verbindung damit auch die Rollen - umzudefinieren: z. B. kann ein als besonders hilflos auftretender Klient versuchen, die Gutherzigkeit des Helfers für sich auszunutzen und die Last der Anstrengungen im Problemlösungsprozess dem Sozialarbeiter zuzuschieben.

Doch bevor Details in der Rollenbestimmung geklärt werden können, bedarf es zunächst einer Verständigung darüber, welche Zwecke die künftigen Bemühungen erfüllen sollen und welche Ziele der Persönlichkeitsveränderung dafür angestrebt werden müssen. Handelt es sich also um einen Schuldenabbau, um eine Suchtproblematik, um einen Ausbildungsplatz oder um Erziehungsschwierigkeiten und Konfliktregelungen in einer Familie. Vielfach fehlen mehrere Basisgegenstände, so dass für ihre Beschaffung ein Programm aufgestellt werden muss, dessen Realisierung in der Regel nicht nur organisatorische Maßnahmen erfordert, sondern auch Veränderungen in den Aktivitäten und Verhaltensweisen der Problembelasteten. Diese notwendigen Veränderungen in den Verhaltensweisen und in den ihnen zugrunde liegenden Einstellungen des jeweiligen Problembelasteten finden in der Zielorientierung ihren Ausdruck, also in einer Vereinbarung darüber, was der Klient an sich selbst verändern will. Das lässt sich dann nach der Problemanalyse und der Problemdefinition sowie nach der Klärung der Ressourcen und der Prüfung von Lösungsvarianten in einem Maßnahme- oder Hilfeplan fixieren.

Im Rahmen der Funktionseinheit Aufschließen geht es ja zunächst um eine erste Verständigung darüber, welche Emwartungen des Hilfebedürftigen grundsätzlich realisierbar sind. Beispielsweise muss dem Hilfesuchenden in der Schuldnerberatung unter Umständen erst einmal klar gemacht werden, dass nur er selbst und niemand sonst seine Schulden bezablen kann und muss. Oder dem Jugendlichen in der Benachteiligtenförderung muss deutlich gesagt werden, dass auch großes Verständnis und Hilfestellungen 
der Ausbilder, Lehrkräfte und Sozialpädagogen ihm die eigenen Anstrengungen nicht ersparen können. Damit werden dem Hilfebedürftigen zugleich die grundsätə̨lichen Erwartungen der Helfer bewusst gemacht. Die Erwartungen der Hilfesuchenden richten sich nämlich in der Regel auf die Lösung des unmittelbar drückenden Problems, d. h. vor allem auf die Beschaffung der fehlenden Basisgegenstände.

Der Problembelastete muss u. U. erst einmal erkennen, dass sein Problem kein einfaches organisatorisches Beschaffungsproblem ist, sondern eigentlich ein Problem seiner Einstellungsänderung und Befähigung, d. h., er muss zu Aktivitäten und Veränderungen bereit sein, wenn die Hilfe nachhaltig sein soll. Die Funktionseinheit des Aufschließens zielt also darauf $\mathrm{ab}$, dass sich der Klient auf ein Hilfesystem einlässt, indem er sich dem Einfluss der helfenden Kräfte öffnet (vgl. Birnbaum 1930, S. 174) und bereit ist, auch die damit verbundenen Anstrengungen auf sich zu nehmen.

Um aber zu realisierbaren pädagogischen Zielvorstellungen zu gelangen, bedarf es einer möglichst gründlichen Aufklärung der gesamtem Problemsituation einschließlich der inneren Voraussetzungen und äußeren Ressourcen der Klienten.

\subsubsection{Zur organisatorisch-methodischen Gestaltung der Funktionseinheit „Aufklären“}

Die Funktionseinheit Aufklären umfasst alle Bemühungen des Sozialpädagogen und der Hilfebedürftigen, die dazu dienen, die Ursachen für die entstandene soziale Problemsituation sowie die individuellen und gesellschaftlichen Ressourcen für ibre Lösung zu ermitteln, um auf dieser Grundlage einen realisierbaren Hilfeplan aufzustellen, der auch von den Klienten innerlich akzeptiert wird.

Im Einzelnen umfasst diese Funktionseinheit die Funktionen

- Analyse objektiver Bedingungen und subjektiver Schwierigkeiten zwecks

- Problemdefinition, verbunden mit

- Erklärungen und Enthüllungen (einschließlich Verstehen),

- Erkundung und Erschließung von Ressourcen,

- Prüfung der Lösungsvarianten,

- Zielorientierung und Maßnahmeplanung.

- Vereinbarungen (mit Kennzeichnung möglicher Folgen ihres Bruchs),

Die Notwendigkeit einer möglichst genauen Problemdefinition ergibt sich nicht nur aus der Kompliziertheit eines Problembündels, sondern auch aus der Tatsache, dass viel davon abhängt, von ,welchem Ende her“ das Problem angepackt wird und welche Mittel zur Problemlösung tatsächlich zur Verfügung stehen. Die Analyse der objekti- 
ven Bedingungen und subjektiven Schwierigkeiten des Problembelasteten dient dazu, allen an der Problemlösung Beteiligten das notwendige und hinreichende Verständnis für die Spezifik der Problemsituation zu verschaffen, denn erst auf dieser Grundlage kann ein realisierbarer Hilfeplan erarbeitet werden. Bei der Diagnose dessen, was der Klient über seine Schwierigkeiten äußert, muss der Sozialpädagoge sorgfältig unterscheiden zwischen den Tatsachen (dem wirklich Vorgefallenen), den Interpretationen zum Vorgefallenen (,aus Wut hat er ...") und den Bewertungen bestimmter Handlungen und Verhaltensweisen („der wollte mich doch damit ..."). Nur eine korrekte Problemsituationsanalyse führt zu einem angemessenem Problemverständnis, und deshalb sind folgende Gesichtspunkte zu beachten.

Zunächst müssen im hinreichenden Maße die Tatsachen, in denen die Schwierigkeiten des Problembelasteten zum Ausdruck kommen - also das Erscheinungsbild der Problemsituation - im Gespräch deutlich werden. Erst dann ist es möglich - unter Umständen mit Hilfe von Rückfragen zur Entwicklung des Problembelasteten - die Entstehung des jeweiligen sozialen Problems unter kausalanalytischem Aspekt zu betrachten, aber „die kausale Betrachtung der Analysis muss [...] durch eine teleologische Betrachtung ergänzt werden“, schreibt Josef L. Blaß (1978, Bd. 1, S. 136). Das heißt: es müssen wichtige Ereignisse und Bedingungen für die Entstehung des sozialen Problems ermittelt werden (=Anamnese) und im Zusammenhang damit auch die Ziele und Handlungszwecke des Hilfebedürftigen, die sich nach Auffassung von Adler im Lebensstil äußern. Während die Kausalanalyse die Erklärung des jeweiligen sozialen Problems - zumindest in seinen Grundzügen - anstrebt, zielt die teleologische Betrachtung auf ein richtiges Verstehen der Verhaltensweisen des Problembelasteten und der Problembeteiligten. Zu diesem Verständnis gelangt der Sozialpädagoge, wenn er die jeweilige Persönlichkeit des Klienten in ihrer Entwicklung und in ihrer Ganz̧heit zu erkennen sucht, was ohne tätige Mitwirkung der Betroffenen schwierig ist. Wie schon erwähnt, ist es für den Erfolg der psychosozialen Intensiverziehung wichtig, dass der Problembelastete selbst seinen eigentlichen Lebensplan und den darin enthaltenen Grundirrtum erkennt, der seine Sichtund Handlungsweise bestimmt und seinen persönlichen Anteil an den Schwierigkeiten und Problemen deutlich werden lässt (vgl. Birnbaum 1931, S. 173ff.).

Dabei beschränkt sich Verstehen nicht auf das geistige Auf- und Erfassen bestimmter Fakten und Zusammenhänge durch das erkennende Subjekt. In Anlehnung an Peter Fausers Auffassung zu Verstehensprozessen im Unterricht kann auch für den sozialpädagogischen Prozess gesagt werden: Verstehen ist ein produktiver Prozess, in dem auf der Grundlage der erhaltenen Informationen mit Hilfe eigener Kenntnisse und Erfahrungen und in Reflexion darüber eine modellhafte Vorstellung von der Problemsituation und der Befindlichkeit der Beteiligten geschaffen wird (vgl. Fauser 2003, S. 13). Weiter formuliert er: „2. Verstehen ist ko-konstruktiv und verbindet den Aufbau von 
Wissen und Können mit der Erfahrung von Zugehörigkeit und Anerkennung“ (a. a. O.). Fauser meint damit, dass Schüler unter Anleitung des Lehrers auf der Grundlage bisherigen Wissens erweiterte oder neue Wissenssysteme (Modellvorstellungen) aufbauen und mit dem Erleben, etwas Wichtiges verstanden zu haben, sich zugleich auch als zugehörig zur Klasse oder Gruppe der erfolgreich Lernenden füblen. Während Schüler, die nichts verstehen, sich als nicht dazugehörig füblen und das oft auch durch Schulschwänzen dokumentieren. In einer 3. Aussage formuliert Fauser: „Verstehen ist selbstverstärkend und fördert den Aufbau von Selbstwirksamkeitsüberzeugung“ (a. a. O., S. 14), was sicher nicht nur für Lehrer und Schüler, sondern auch für Sozialpädagogen und Klienten gilt.

Auch im sozialpädagogischen Prozess kommt es darauf an, dass der Klient seine Situation richtig erkennt und die Angebote des Sozialpädagogen versteht, sich also rational und emotional begründet dem Hilfesystem anvertraut. Das wird ihm leichter fallen, wenn er vom Sozialpädagogen verstanden wird und den Sozialpädagogen versteht. Allerdings kann ein Klient die Tatsache, dass der Sozialpädagoge ihn versteht, auch als Enthüllung im Sinne eines „Durchschautwerden“ erleben, was zunächst als unangenehm weil als Niederlage - bewertet wird. Für den Problemlösungsprozess ist jedoch die Enthüllung und damit auch ein solches durchschauendes Verständnis geradezu eine Grundlage für den Erfolg, wie der oben geschilderte Fall Sven erkennen lässt. Erst als er nämlich einsehen musste, dass der Sozialpädagoge auch seine Drogensucht erkannt hatte, konnten beide den Hilfeprozess auf einer ehrlichen Grundlage zum Erfolg führen. Und als er schließlich selbst den Grundirrtum seines Lebensstils - Drogenkonsum als falsche Reaktion auf die Probleme seiner multiplen Sklerose - erkannt hatte, war das Haupthindernis für einen erfolgreichen Änderungsprozess enthüllt.

Am nachfolgenden Beispiel soll nun die Vorgehensweise bei der Problemanalyse bis hin zur Problemdefinition erläutert werden:

Die Schulsozialpädagogin Angelika U. wurde im Oktober 2000 von Lisas Klassenlehrerin darüber informiert, dass sie mit dieser 14-jährigen Schülerin in der 7. Klasse große Schwierigkeiten habe, und gebeten, sich dieses Mädchens anzunehmen. Daraufhin begann Angelika, sich mit Lisa und ihrem Umfeld zu beschäftigen. In mehreren Gesprächen mit Lisa und den Problembeteiligten (ihren Eltern und Lehrern) erfuhr sie folgende Tatsachen, die sowohl für eine Erklärung der komplizierten Problemsituation als auch für ein richtiges Verständnis für die Problembeteiligten bedeutsam waren.

- Lisas Familie war zwei Jahre zuvor aus finanziellen Gründen in einen anderen Stadtteil gezogen, so dass mit dem dadurch bedingten Wechsel der Schule und des Wohnumfeldes alte und z. T. langjährige Freundschaften abgebrochen wurden. 
- Lisa hat eine fünf Jahre jüngere Schwester, die von der Mutter stets als viel unkomplizierter und artiger als Lisa geschildert wird.

- Zwischen Lisa und den anderen Familienmitgliedern kam es häufig zu lautstarken und z. T. körperlichen Auseinandersetzungen, die auch Lisa auslöste.

- Nach Lisas Wechsel in die neue Schule (5. Klasse der Realschule) kam es häufig zu massiven Störungen im Unterricht, zu Leistungsversagen, Schwänzen des Unterrichts und Gewalttätigkeiten gegenüber Mitschülerinnen, so dass sie im Dezember 2000 nur knapp einem zwangsweisen Schulwechsel entging.

- Lisa bewegte sich in einem Freundeskreis, in dem sie gelegentlich Suchtmittel einnahm und sich verschuldete.

- Die Eltern konnten Lisa praktisch nicht mehr steuern, denn Lisa ging und kam, wann sie wollte, bediente sich nach Belieben aus dem Kühlschrank und stahl auch Geld im Elternhaus.

Vom Standpunkt der Sozialarbeit (bzw. Lüssis) aus betrachtet, hatte Lisa Defizite hinsichtlich des Basisgegenstandes „funktionelles Verhältnis zu notwendigen Bezugspersonen“ und des Basisgegenstandes „Erziehung“. Das gesamte Problembündel erforderte zu seiner Bewältigung natürlich auch psychosoziale Intensiverziehung in besonders hohem Maße, denn keiner der Problembeteiligten hatte bislang einen Ausweg aus der komplizierten Problemsituation gefunden. In einer kausalanalytischen und teleologischen Betrachtung des Problembündels wird deutlich: Lisa leidet an mangelnder Zuwendung und Anerkennung in der Familie und in der Schule, sie produziert daher ein Verhalten, durch das sie viel Aufmerksamkeit auf sich lenkt (was sie ja auch will!), aber zugleich sich selbst und ibren Mitmenschen Schaden zufügt.

Die Ursachen dafür sind sicher vielschichtig, aber dass sie von ihren Familienangehörigen nicht in erforderlichem Maße angenommen und geliebt wird, ist deutlich zu erkennen. Das kann man Lisa gegenüber auch in einem verständnisvollen Bedauern zum Ausdruck bringen. Allerdings wäre es falsch, sie in ihrer kritischen Ablehnung der Mutter zu unterstützen. Daher wurde sie auch darauf hingewiesen, dass sie es mit ihrem Verhalten der Mutter sehr schwer macht, liebevoll mit ihr umzugehen. Allerdings war sie der Meinung, dass es Sache der Mutter sei, sich ihr zuzuwenden - eben weil sie die Mutter ist.

Aufklärung kann auch eine Aufarbeitung der Familiensituation mit der Klientin in dem Sinne einschließen, dass ihr begreiflich gemacht wird, weshalb sie das Verhalten ihrer Eltern in der beklagten Weise erlebt, wobei nicht nur eigenes Fehlverhalten erörtert wird, sondern erlebte Versäumnisse oder pädagogische Fehlleistungen der Eltern aus deren Entwicklungs- und Lebensbedingungen heraus erklärt werden, so dass sie nicht mehr als blanke Bösartigkeiten erscheinen. Beispielsweise kann ihr bewusst gemacht werden, dass ein Säugling mehr Fürsorge und Zuwendung benötigt als ein Kindergartenkind oder eine Schülerin. Wenn Enthüllungen dieser Art dazu führen, dass Lisa erkennt, 
wie falsch und nachteilig es ist, wenn sie sich nur aus der Sicht der „,bösartig Vernachlässigten“ betrachtet, wird einem Wandlungsprozess vorgearbeitet. Völlig unfruchtbar wäre im vorliegenden Fall eine Diskussion darüber, wer womit die Beziehungsstörungen ausgelöst hat und „die Schuldige“ ist, denn hier wirkt das 3. Axiom Watzlawicks „die Natur einer Beziehung ist durch die Interpunktion der Kommunikationsabläufe seitens der Partner bedingt" (zitiert nach Hobmair/Betscher-Ott u. a. 1992, S. 317). Die Äußerungen der Mutter über die artige jüngere Tochter und die schwierige Lisa belegen das in gewisser Weise, denn Lisa ist natürlich der Meinung, dass sie immer benachteiligt werde und sieht damit die Schuld bei der Mutter. Die Beziehungsstörung ist aber nur zu überwinden, wenn beide Seiten es wirklich wollen; und auf diese zukünftige Aufgabe sollten sich beide orientieren. Übrigens ist bemerkenswert, dass Lisa sich an so schlechte Beziehungen zu ihrer Mutter in der frühen Kindheit - also vor der Geburt der Schwester - nicht erinnern kann!

Diese unterschiedlichen Sichtweisen und die damit verbundenen Gefühle muss der Sozialpädagoge verstehen, um die entsprechenden Zusammenhänge zu enthüllen, zu erklären und geeignete Maßnahmen vereinbaren zu können. Dabei ist zu beachten: die Verbindung von Tatsachenermittlungen und Erklärungsbemühungen unter Berücksichtigung des soziallogischen Denkens erfordert ja nicht, dass alle Tatsachen benannt werden und jedem alles erklärt wird. Vielmehr muss sich der Sozialpädagoge möglichst umfassend informieren, um alle wichtigen Tatsachen berücksichtigen zu können und den Problembeteiligten so viel erklären, wie zur Problemlösung notwendig ist. So wäre es sicher nicht hilfreich, der Mutter Versäumnisse in der Zuwendung zu Lisa nach der Geburt der jüngeren Tochter vorzuwerfen, zumal ja verständlich ist, dass das Neugeborene mehr Aufmerksamkeit erfährt als die ältere Schwester. Für die Sozialpädagogin war wichtig, die Wirkungen der von Lisa erlebten Zurücksetzung und das soziallogische Denken der Mutter zu verstehen. So machte die Mutter den Vorschlag, Lisa in ein Heim zu bringen, wobei sie zugleich ein schlechtes Gewissen dazu äußerte. Auf der Grundlage dieses Problemverständnisses war es richtig, den Vorschlag der Mutter abzulehnen, zumal die Sozialpädagogin bei Lisa innere Voraussetzungen (Ressourcen) erkannte, die eine Problemlösung obne Heimeinweisung nahe legten. Entscheidend war, dass die beteiligten erzieherischen Kräfte (Schulsozialpädagogin, Klassenlehrerin, Lehrer, Eltern) lernten, Lisa zu verstehen, d. h. ihr Bestreben nach Anerkennung von einer Gemeinschaft als zentrale Problemvariable akzeptierten und mit ihr gemeinsam nach Lösungswegen zur Realisierung dieses Ziels suchten.

Unter kausalanalytischem Aspekt erkennen wir die ursächlichen Bedingungen, die zur Entstehung des Problembündels bzw. seiner Zuspitzung im Verhalten von Lisa geführt haben. Unter teleologischem Aspekt, der sich auf die Erkenntnis der mehr oder weniger bewussten Zwecke von Lisas Handlungs- und Verhaltensweisen richtet, erkennen wir 
die wesentlichen Ansatzpunkte für eine zweckmäßige sozialpädagogische Intervention. Abstrakt betrachtet, wären ja mehrere Maßnahmen als Lösungsvarianten denkbar:

1. eine Konzentration auf die Eltern, speziell auf die Mutter, um sie zur liebevolleren Behandlung ihrer Tochter zu bewegen;

2. Lisas Unterbringung in einer anderen Gemeinschaft, um dem Wunsch der Mutter zu entsprechen und sie aus der ausweglos erscheinenden Familiensituation zumindest zeitweilig herauszulösen;

3. ein Schulwechsel für Lisa, um ihr in anderer Umgebung und unter günstigeren Bedingungen einen neuen Start zu ermöglichen;

4. ein System verstärkter Hilfen für Lisa unter den gegebenen Bedingungen.

Die Schulsozialpädagogin entschied sich in der Beratung mit den Lehrern und Eltern für die Lösungsvariante 4: In Anwendung des Prinzips der Verbindung von Beratung und Verhandlungsführung mit Kooperationsbildung im Interesse aller Problembeteiligten wurden von der Sozialpädagogin zunächst die Lehrer darauf orientiert, mit Lisa verständnisvoller umzugehen. Zugleich wurde damit auch dem Konzeptprinzip der Verknüpfung von sozialethischen und sozialökologischen Positionen bei der Bestimmung des vertretbaren Aufwands an materiellen und personellen Mitteln zur Problemlösung durch notwendige, aber möglichst kleine Eingriffe entsprochen.

Für Lisa wurde ein Nachhilfeunterricht organisiert, der ihr helfen sollte, auch im Unterricht wieder Erfolgserlebnisse zu erzielen. Es zeigte sich allerdings, dass diese Maßnahme nicht zweckmäßig war, weil durch Nachhilfeunterricht der Anschluss an das allgemeine Klassenniveau nicht hergestellt werden konnte - die Lücken waren einfach zu groß. Daher wurde entsprechend dem Prinzip der Wechselwirkung von Verstehen (in diesem Falle der realen Möglichkeiten von Lisa) und Handeln beschlossen, sie in die Hauptschulklasse der verbundenen Haupt- und Realschule überwechseln zu lassen, wo sie später tatsächlich den entsprechenden Schulabschluss erreichte (Präzisierung des Maßnahmeplanes entsprechend dem Konzeptprinzip 4.6.3 und dem Funktionsprinzip 6.2.1). Die Lösungsvariante 4 erfuhr also im Prozessverlauf dadurch eine Präzisierung, dass ein rationeller Grundgedanke der Variante 3 in modifizierter Form realisiert wurde - zwar nicht Versetzung an eine andere Schule, aber in die Hauptschulklasse der vertrauten Schule.

Im vorliegenden Fall machte Lisas Bestreben nach Anerkennung durch ibre Umwelt den Kern des Problems und damit die zentrale Problemvariable aus. Die erforderlichen Hilfemaßnahmen - festgehalten in den Vereinbarungen des Hilfeplans - können als die von allen Beteiligten anerkannte ,instrumentelle Problemdefinition“ (Lüssi 1992, S. 270ff.) angesehen werden. Wenn es Lisa gelingt, sich die gewünschte Anerkennung und Zuwendung zu verschaffen, werden sich mehrere „alte Folgeprobleme“ leichter lösen lassen. 
Auf diese Weise wird auch dem Prinzip der Verbindung von instrumenteller Problemdefinition mit der Konzentration auf die zentralen Problemvariablen und deren Bearbeitung entsprochen. Der entscheidende Durchbruch hinsichtlich der Problemlösung wurde (in zielstrebiger und kreativer Weise!) dadurch erreicht, dass die Schulsozialpädagogin eine neue Ressource erschloss, indem sie mit Lisa eine Mädchenhandballmannschaft beim Training besuchte. Lisa fand schnell Gefallen an dem, was sie da sah und an der Art, wie der Trainer ihr entgegen kam. Sie erklärte sich bereit, der Sportgemeinschaft beizutreten und ihren problembeteiligten alten Freundeskreis aufzugeben. In der neuen Gemeinschaft erlebte sie Erfolge und Anerkennung, was auch ibr Verhalten in der Familie positiv beeinflusste, zumal die Eltern sich ihrerseits im Sinne der Problemlösung um Lisa bemühten. Nach dem erfolgreichen Hauptschulabschluss nahm sie eine Lehre auf, die - wie die Schulsozialpädagogin nach einem Jahr bei einer Begegnung erfuhr - erfolgreich verlief.

Der Fall macht deutlich, wie wichtig die gründliche Problemanalyse und möglichst exakte instrumentelle Problemdefinition für den Lösungsprozess ist. Vor allem ist erkennbar, dass auch im sozialpädagogischen Prozess nach gesetzmäßigen Beziehungen gesucht werden kann und muss, um die Entstehung des sozialen Problems zu erklären. Ganz offensichtlich ist dem invarianten Bedürnis eines jeden beranwachsenden Menschen (also auch Lisas) nach Zuwendung, Liebe und Anerkennung in der Familie und sodann auch in der Schule nicht hinreichend entsprochen worden, was die Beziehungsstörungen und devianten Verhaltensweisen erklärt. Wichtig ist, dass die Analyse nicht bei dieser kausalen Betrachtung zur Erklärung des Problems stehen bleibt, sondern durch die teleologische ergänzt und vervollständigt wird. Gemeint ist damit das Bestreben der Sozialpädagogin, die Handlungszwecke der Problembeteiligten aufzudecken und ihre Verhaltensweisen richtig zu deuten, um die zentrale Problemvariable - nämlich Lisas Bestreben nach Anerkennung durch ihre Umwelt - zu finden. Diese musste für die instrumentelle Problemdefinition genutzt werden, da sie zugleich auf das von allen anerkannte „Problemlösungsmittel“ hinweist. Eine Kurafassung der instrumentellen Problemdefinition lautet im gegebenen Fall: Es sind alle Möglichkeiten zu nutzen, um Lisas Bestreben nach Anerkennung durch die Umwelt, insbesondere durch ibre Angehörigen und Lehrer sowie durch positiv wirksame Altersgefährten (z. B. Sportfreundinnen) auf akzeptable Weise zu befriedigen. Mit dem Hilfeplan erhielt die instrumentelle Problemdefinition ihre ausführliche, aber auch noch präzisierbare Fassung.

Selbstverständlich wurden in der Problemanalyse weit mehr Zusammenhänge sichtbar als in der obigen gestrafften Darstellung reflektiert worden sind. Beispielsweise wurde deutlich, dass auch die Eltern ihre Probleme hatten, und zwar mit der Akzeptanz der ältesten Tochter Lisa, der Bevorzugung der jüngeren und dem damit zusammenhängenden Umgangston und Erziehungsstil. Es war jedoch aus der Sicht der Schulsozialpädagogin nicht angebracht, das Problem der Mutter ins Zentrum der Bemühungen zu rücken, wie das im Falle einer sozialpädagogischen Familienhilfe nach \31 KJHG prinzi- 
piell möglich, aber vermutlich nicht zweckmäßig wäre. Hier ging es um die Nutzung aller Ressourcen aus der Sicht einer Schulsozialpädagogin und dies ist gelungen.

Im geschilderten Fall gab es zwar recht unterschiedliche Situationsbewertungen durch die Problembeteiligten - etwa in der Frage, wer nachgeben oder einlenken sollte: Mutter oder Tochter. Aber prinzipiell war Lisa ja bereit, an der Überwindung ihrer persönlichen Schwächen zu arbeiten. Wesentlich komplizierter gestaltet sich ein Prozess, wenn bereits bei der Zielbestimmung Schwierigkeiten in der Weise auftreten, dass der oder die Problembelastete - sei es aus Gründen der Selbstbehauptung oder geistiger Enge - einfach nicht begreifen will oder kann, dass er bzw. sie sich verändern und bemühen muss. Hierbei ist es manchmal auch nicht damit getan, dass man den Leidensdruck des Problembelasteten steigen lässt, vielmehr muss durch intensivere Arbeit mit ihm möglichst in einer Gruppe - die Erfahrung vermittelt werden, dass er seine Sicht auf die Umwelt sowie seine Ansprüche und Verbaltensweisen verändern muss, wenn er überhaupt in der Gesellschaft ein selbständiges und von seinen Mitmenschen akzeptiertes Leben führen will. Das erste sozialpädagogische Ziel, von dessen Realisierung alle weiteren Fortschritte abhängen, wäre also die Bereitschaft zur Korrektur des Selbstbildes bzw. diese Korrektur selbst, die wahrscheinlich am besten in einem Gruppenarbeitsprozess erfolgen kann, z. B. auch in einer natürlich agierenden Sportgruppe.

Im beschriebenen Fall „Lisa“ war die Schulsozialpädagogin in der Lage, die zur erfolgreichen Problemlösung erforderliche Problemanalyse selbst durchzuführen, wobei sie die verschiedenen Umwelteinflüsse, die auf Lisa wirkten, in hinreichendem Maße in die Analyse mit einbezogen hat. Ja mehr noch: es gelang ihr, mit der Eingliederung Lisas in die Sportgruppe auch solche Einflüsse zu organisieren, die offensichtlich die Problemlösung förderten. Es treten aber auch Fälle auf, bei denen für die Problemanalyse ein zusätzlicher Aufwand durch diagnostische Tätigkeiten von Psychologen bzw. Experten notwendig ist.

So hatte sich beispielsweise in einer überbetrieblichen Ausbildungseinrichtung in Rostock ein junger Mann gemeldet, der Elektriker werden wollte, nachdem er schon mehrere Ausbildungsverhältnisse wegen schwacher Leistungen in der Berufsschule abgebrochen hatte. Da der junge Mann nunmehr für seine Familie mit zwei Kindern zu sorgen hatte, wollte er unbedingt einen möglichst qualifizierten Beruf erlernen. Hier ergab sich das Problem: welche Erfolgsaussichten hätte er in einer noch anspruchsvolleren Lehre als in den bereits abgebrochenen? Ihn einfach wegen der hohen Motivation aufzunehmen, wäre ein hohes Risiko, denn wenn er abermals scheitern würde, hätte das gewiss nachteilige Auswirkungen auf seine Persönlichkeit. Daher wurde er von Psychologen auf seine intellektuelle Leistungsfähigkeit hin untersucht, und zwar mit dem Ergebnis, dass ihm ein anderer Weg zur Erlangung einer Berufsausbildung mit der Aussicht auf ein höheres Arbeitseinkommen gewiesen werden musste und konnte. 
Zusammenfassend ergeben sich folgende Gesichtspunkte für die Problemsituationsanalyse, die zugleich Grundlage sind für Fragestellungen beim Aufschließen und Aufklären, zur Anamnese sowie zur Erarbeitung der Konzeption für die Problemlösung:

\section{Problemerkennung}

a) Anteilnehmende Aufnahme der Problembeschreibung des bzw. der Hilfebedürftigen;

b) Feststellung der fehlenden Basisgegenstände;

c) Ermittlung früherer und aktueller positiver und negativer Umwelteinflüsse, die bei der Problembearbeitung zu berücksichtigen sind;

d) Differenzierte Bestimmung der problematischen Verhaltens- und Handlungsweisen der Problembelasteten und -beteiligten sowie ihrer psychischen Strukturen;

e) Reflexion der Gefühle und Bewertungen der Problembelasteten und -beteiligten sowie der eigenen.

\section{Erklärung und Deutung}

a) Analytische Erörterung der Daten aus der Anamnese zwecks Erklärung der problematischen Verhaltensweisen mit Bezugnahme auf soziologische und psychologische Theorien;

b) Analyse der individuellen Eigenheiten, Lebensstile, Beziehungen und Sichtweisen der Problembelasteten und -beteiligten, um sie zu verstehen und Ansatzpunkte für die Intervention zu finden;

c) Erörterung der gewonnenen Einsichten mit den Problembelasteten und -beteiligten, um ihnen ihr Verhalten - soweit möglich und erforderlich zu erklären und sie zu ermutigen.

\section{Erarbeitung von Lösungsvorschlägen}

a) Auswertung möglicher bisheriger Interventionen im vorliegenden Problemfall und Prüfung weiterer Lösungsvarianten;

b) Erschließung von Ressourcen für eine optimale Lösung;

c) Kennzeichnung und Begründung der Zwecke und Ziele sowie Maßnahmen, die als angemessen erachtet werden, und zwar bezogen auf die Hauptperson(en) und Mitwirkende, wobei wichtig erscheinende sozialpädagogische Prinzipien sowie relevante gesetzliche Bestimmungen (KJHG, BGB usw.) zu berücksichtigen sind;

d) Treffen von Vereinbarungen, Fixierung des Hilfeplanes (einschließlich der Bestimmung der zentralen Problemvariablen). 
Bei der Darstellung des Falles „Lisa“ ist sicher deutlich geworden, dass für das Auffinden der Lösungsidee die Erkenntnis des Lebensstils des bzw. der Problembelasteten wichtig ist. Dabei tritt nun allerdings in vielen Beratungsprozessen - vor allem bei jugendlichen Benachteiligten - die Frage auf: wie realistisch oder realisierbar sind die Erwartungen und Pläne der Jugendlichen in einer Gesellschaft, in der es nicht mehr für alle Erwachsenen Arbeitsplätze gibt, von deren Bezablung die Arbeitenden ibren Lebensunterhalt bestreiten können? (Erfreulich ist immerhin, dass viele befragte Schüler und Auszubildende dennoch die Hoffnung auf einen Arbeitsplatz haben!) Was bedeuten nun aber die realen Schwierigkeiten bei der Arbeitssuche für den Sozialpädagogen, der das Prinzip der Verbindung von Tatsachenermittlung und Erklärungsbemühungen unter Berücksichtigung des soziallogischen Denkens sowie das Prinzip der Verbindung von unvoreingenommener Problemannahme, freundlicher Anteilnahme und Echtheit zwecks Öffnung, Ermutigung und Aktivierung anwenden möchte? Soll er den benachteiligten Jugendlichen erklären, dass sie eigentlich keine echte Chancen zur Realisierung ihrer berechtigten Ansprüche auf eine Existenz sichernde Erwerbsarbeit haben oder dass ihre Arbeitskraft nicht gebraucht wird und sie möglicherweise immer von sozialen Unterstützungen abhängig, also nie wirklich selbständig oder souverän sein werden?

Hier stoßen Sozialarbeit und Sozialpädagogik offensichtlich an ihre Grenzen. An dieser Stelle wird deutlich, dass der Kapitalismus auch in seiner Gestalt als soziale Marktwirtschaft mit einem Widerspruch belastet ist, zu dessen Lösung noch ganz andere Reformen bzw. Innovationen notwendig sind als die bislang in der Öffentlichkeit diskutierten. Wenn die kapitalistische Gesellschaft nicht bereit ist, finanzielle Mittel für vorbandene - wenn auch nicht unbedingt profitable - Arbeit bereitzustellen, wird sie das Problem nicht lösen. Die entscheidende Frage ist dabei natürlich: woher sollen die dafür notwendigen finanziellen Mittel kommen? Hierauf können Sozialarbeiter/Sozialpädagogen keine fundierten Antworten geben, aber sie können und müssen sich als Experten für soziale Notlagen bei den Politikern Gehör verschaffen und darauf drängen, dass eine Finanz- und Steuerpolitik im Interesse der sozial Benachteiligten und des sozialen Friedens realisiert wird.

Außerdem müssen viele Bildungseinrichtungen ihre Ziele neu definieren, und zwar so, dass ihre Absolventen befähigt werden, auch in ehrenamtlichen Tätigkeiten und niveauvollen Freizeitbeschäftigungen einen Lebensinhalt zu finden. Vor allem aber muss die familiäre Kindererziehung als eine höchst wichtige und gesellschaftlich notwendige Arbeit anerkannt werden, die nötigenfalls verpflichtend angeleitet und finanziell anerkannt wird. Es muss alles getan werden, um das Problem der finanziellen Abbängigkeit von staatlichen Alimenten zugunsten selbst erarbeiteter Ansprüche zu lösen, denn die Arbeitstätigkeit ist nun einmal ein Wesensmerkmal des Menschen, und wer ihm dieses vorenthält, deformiert oder zerstört ihn! 
Doch zurück zum sozialpädagogischen Prozess: Durch die Problemanalyse werden in der Regel auch jene Defizite in der Persönlichkeitsstruktur des Problembelasteten deutlich, die zur Zielfindung und zur Erkenntnis der Möglichkeiten und Ressourcen der Problemlösung führen. Dabei ist die Zielbestimmung schon eine beachtliche schöpferische Leistung, an deren Zustandekommen auch der Problembelastete und die Problembeteiligten mitwirken sollten - und sei es auch nur durch ihre Einwände zu dem, „was ihrer Meinung nach geht und was nicht geht“. Die Ziele sollen das Handeln der Beteiligten orientieren und die Problembelasteten möglichst auch motivieren, d. h., diese sollen die Ziele für erstrebenswert halten, was nur möglich ist, wenn sie selbst bei der Zielbestimmung aktiv mitwirken und entsprechende Maßnahmen mit auswählen bzw. festlegen können. In der Zielorientierung widerspiegelt sich sowohl das angestrebte und für erreichbar gehaltene „,bessere Können und Verhalten“ des Problembelasteten als auch die „Richtung“ für die Bemühungen und Anstrengungen aller am Problemlösungsprozess bewusst Beteiligten.

Bei der Erörterung des Hilfeplanes kommt es darauf an, das innere Einverständnis der Problembelasteten zu erreichen, und sei es auch nur die Einsicht, dass es eben keinen bequemeren Lösungsweg gibt. Wenn die Hilfebedürftigen den vorgeschlagenen Zielen und Maßnahmen zustimmen, muss ihnen zugleich bewusst gemacht werden, dass sie damit eine Vereinbarung eingehen, die sie einhalten müssen, um die angestrebte Problemlösung zu erreichen. Dabei genügt es nicht, den Klienten die pädagogischen und sozialen Konsequenzen bei Nichteinhaltung der Vereinbarung bewusst zu machen (z. B. Abbruch der Hilfemaßnahme); es müssen ihnen auch die möglichen Rechtsfolgen mit ibren existenziellen Nachteilen für die Problembelasteten erläutert werden, die bei bestimmten Verweigerungen eintreten. So kann z. B. die Arbeitsagentur nach \62 des SGB I einen Leistungsbezieher zu einer ärztlichen und/oder psychologischen Untersuchung auffordern, wenn dies für die Entscheidung über die Sozialleistung (z. B. im Zusammenhang mit der Eignung für einen Ausbildungsplatz) notwendig ist. Wenn der Leistungsbezieher solche Untersuchungen verweigert, kann nach \ 66 des SGB I ein Leistungsentzug erfolgen.

Die Verbindlichkeit des Hilfeplanes darf jedoch nicht zu mangelhafter Flexibilität im Problemlösungsprozess führen. Daher ist es notwendig, dass beim Auftreten von Schwierigkeiten nicht etwa eine ,schleichende Abweichung“ vom Hilfeplan zugelassen wird, sondern auf der Grundlage einer nüchternen Zwischenbilanz der Plan möglichst einvernehmlich den veränderten Bedingungen angepasst wird. Mit der Zielorientierung und Maßnahmeplanung sind also Entscheidungen verbunden, die an die Realisierung der Problemlösung heranführen, d. h. in die Funktionseinheit Ausfübren überleiten, die im nächsten Abschnitt behandelt wird. 


\subsubsection{Zur organisatorisch-methodischen Gestaltung der Funktionseinheit „Ausfübren“}

Die Funktionseinheit Ausführen umfasst alle organisatorischen und inhaltlich-methodischen Aktivitäten der sozialpädagogischen Kräfte und Klienten, die geeignet sind, die Vereinbarungen flexibel umzusetzen und die Probleme zu lösen.

Zur Funktionseinheit Ausfübren gehören die Funktionen:

- Anleitung zu Problemlösungsschritten mit Training,

- Belastung durch Problembewältigung (mit und ohne Hilfe),

- Selbstüberwindung und Gewöhnung (trotz der Rückfälle).

Bei der Beratung von Lösungsvarianten sollten die von Jürgen Habermas formulierten Regeln für den Diskurs beachtet werden. Ein Diskurs dient dazu - in einem Gespräch, das nur den „zwanglosen Zwang“ des besseren Arguments gelten lässt - den Wahrheitsgehalt einer Erkenntnis oder die Gültigkeit eines Wertes bzw. einer Norm herauszufinden. Bei der Erarbeitung gültiger Ziele in der Sozialpädagogik ist ein wirklich „herrschaftsfreier Diskurs" nicht möglich (vgl. S. 235). Außerdem gibt es Zustände (z. B. verfügbare Finanzmittel), die gerade bei der Suche nach einem gültigen Ziel in Verbindung mit einer sozialpädagogischen Maßnahme die Meinungsbildung mit beeinflussen, u. U. also auch einen äußeren Zwang (z. B. ökonomischer Natur) ausüben. In jedem Falle sollte versucht werden, zu einem Konsens zu gelangen, und zwar auf der Basis klarer sprachlicher Formulierungen sowie logischer Exaktheit in der Argumentation.

Das Gefühl, an der Entscheidungsfindung ernsthaft mit beteiligt gewesen zu sein, führt bei den Klienten in der Regel zu einer Entscheidung mit der inneren Verpflichtung und Bereitschaft, alles zu ihrer Realisierung zu tun, was möglich ist. Wenn sie nach all den Überlegungen auf der Grundlage der vorangegangenen Aufklärung der Problemzusammenhänge und Ressourcen zur Problemlösung die Entscheidungen für den Hilfeplan mit fällen oder zumindest innerlich akzeptieren, gehen sie praktisch den ersten Schritt zur Problemlösung. Die einvernehmlich vorgenommenen Entscheidungen bzw. Formulierungen des Hilfeplanes ist der praktische Beginn des Problemlösungsprozesses und leitet in die Funktionseinheit Ausfübren über. Die Erörterungen im Rahmen der Aufklärung über eventuell zweckmäßige Ziele und Maßnahmen bewegen sich noch auf der Ebene von Möglichkeiten; mit der Entscheidung für bestimmte Ziele und Maßnahmen ist im Bewusstsein des Klienten eine erste wichtige Veränderung im Sinne der Problemlösung verbunden, nämlich die Bildung des Vorsatzes: ich will ...! Das aber ist schon eine andere Position als die vorangegangene, die gekennzeichnet war durch die Fragen: wer oder was könnte mir helfen oder was soll ich machen?

Hilfepläne sind allerdings unterschiedlich geartet. Es kann sich dabei handeln um: 
- persönliche Vereinbarungen zwischen Hilfebedürftigen und Sozialpädagogen, die aus dem vorangegangenen Gesprächen erwachsen sind;

- vereinbarte und schriftlich fixierte Maßnahmen entsprechend den gesetzlichen Bestimmungen (z. B. des KJHG) und den materiellen bzw. finanziellen sowie personellen Ressourcen des jeweiligen Trägers der Maßnahme;

- Eingliederungen in bestehende Systeme, die zur Hilfe für bestimmte Personengruppen mit Problemen geschaffen worden sind (z. B. Ausbildungseinrichtungen zur Förderung von Benachteiligten, Einrichtungen für Suchttherapie usw.);

- Entwicklung eines neuen Systems für Hilfebedürftige, in das diese entsprechend ihrer Bedürftigkeit und Eignung eingegliedert werden.

Der Hilfeplan kann auch aus Kombinationen o. g. Möglichkeiten bestehen. So wurde bei dem vorn vorgestellten Fall „Sven“ der genannte Klient in eine Förder- bzw. Ausbildungsmaßnahme für Benachteiligte eingegliedert und außerdem - nach der entsprechenden Bereitschaftserklärung - zur Drogentherapie geschickt. Lisa wurde von der Schulsozialpädagogin betreut und erklärte sich schließlich bereit, in der Handballmannschaft eines Sportvereins mitzuspielen, in dem ihr Streben nach Anerkennung befriedigt, ihr Selbstwertgefühl aufgebaut und ihre Gemeinschaftsfähigkeit gefördert wurde. E. Hucht und W. Nickolai berichten darüber, wie jugendliche Straftäter, die bestimmte Bedingungen erfüllten, während ihrer Haftzeit zu Rettungsschwimmern ausgebildet und an einem Ostseestrand zum Einsatz kamen, um damit den Resozialisierungsprozess nachhaltig zu fördern. Bekanntlich sind die Bedingungen in einer Justizvollzugsanstalt für die Resozialisierung nicht optimal (eindrucksvolle Analysen dazu liefern z. B. Jansen u. a. 2006); aber die verantwortungsvolle Aufgabe, die der Gruppe und damit jedem Einzelnen übertragen und unter nahezu normalen Bedingungen realisiert wurde (nämlich am freien Ostseestrand unter in Freiheit lebenden Bürgern), führte zu sehr guten Resultaten (vgl. Bauer/Nickolai 1998, S. 73-92).

Bei der Hilfeplanung ist zwischen schlichten Vereinbarungen zwischen Sozialpädagogen und Klienten einerseits und Vereinbarungen zwischen Problembelasteten und dem Jugendamt andererseits zu unterscheiden, auch wenn es sich - pädagogisch betrachtet - um gleichartige Prozesse handelt. Das Hilfeplanverfahren, das auf der Grundlage des KJHG durchgeführt wird, ist darüber hinaus ein Verwaltungsakt, der nach rechtlichen Vorschriften vollzogen werden muss. So genügt es u. U. nicht, dass die Klienten ihre Sicht darstellen, um zu Vereinbarungen zu gelangen, sondern es muss auf der Grundlage fachgerechter Analysen und/oder in einer Fachkonferenz die Meinung von Fachleuten eingeholt werden, und zwar je nach Eigenart des Falls von Ärzten, Psychologen, Lehrern, Schulsozialpädagogen, Erzieherinnen usw. 
Jedes „Modul“332in einem Hilfeplan (z. B. die soziale Gruppenarbeit oder die Erziehung in einer Tagesgruppe) hat seine eigene Struktur und Funktionsweise, die in Abhandlungen zu den verschiedenen sozialpädagogischen Arbeitsfeldern dargestellt sind oder werden sollten. In der schematischen Darstellung des sozialpädagogischen Funktionsmodells wird nur eine relativ allgemeine und grundsätzliche Orientierung für die Bearbeitung der Probleme gegeben. Ganz gleich, ob es sich um Gruppenspiele wie im Falle „Beate“ zum Zwecke der Förderung von Gemeinschaftsfähigkeit in einer Tagesgruppe, um die Unterstützung einer Mutter bei der rationellen Haushaltsführung im Rahmen einer sozialpädagogischen Familienhilfe oder um die Förderung von benachteiligten Jugendlichen in einem überbetrieblichen Ausbildungszentrum handelt - immer bedarf es auch einer arbeitsfeldspezifischen Konzeption für die Entwicklung der erforderlichen Kompetenzen für die Problemlösung. Die hier vorgestellten allgemeinen sozialpädagogischen Erkenntnisse sind sicher nützlich, aber nicht hinreichend für die verschiedenen Arbeitsfelder, da diese auch spezielle Kompetenzen erfordern.

Die konkreten Konzepte der Ausführung - die natürlich Besonderheiten in ihren Funktionen aufweisen - sollten den allgemeinen Zielen des Funktionsmodells entsprechen. Gemeint sind damit jene Ziele, die mit den bereits genannten sozialpädagogischen Funktionen verbunden sind. So zielt die Anleitung zu Problemlösungsschritten auf die Realisierung jener Ziele der Persönlichkeitsentwicklung, die sich in der Problemanalyse als notwendig herausgestellt haben, z. B. bei den Überschuldeten auf die Fähigkeit zum rationellen Umgang mit dem Geld, bei Gewalttätigen auf die Befähigung zu gewaltfreier Konfliktlösung, bei den Drogenabhängigen auf ein Leben in Abstinenz, bei Schulverweigerern auf die Fähigkeit und Bereitschaft - zumindest unter unterrichtsähnlichen Bedingungen - einen planmäßigen Lernprozess wieder aufzunehmen usw.

Es ist klar, dass all diese Probleme nicht allein durch die vom Problembelasteten zu erlernenden (und damit auch einzü̈benden!) Fähigkeiten gelöst werden, sondern dass zu ihrer Bewältigung Einstellungsänderungen und Umgewöhnungsprozesse notwendig sind. Diese werden aber nicht durch Reden, sondern nur in Verhaltensweisen und Handlungsprozessen - mit praktischen Übungen sowie physischen und psychischen Belastungen realisiert, die oft ein hohes Maß an Selbstüberwindung erfordern. Das Wort „Training“ zur Bezeichnung wiederholter praktischen Aktivitäten wurde für das vorliegende Modell von Birnbaum übernommen. Da es sich in sozialpädagogischen Prozessen nicht nur und zumeist nicht einmal primär um die Entwicklung von Fertigkeiten handelt (wozu man Übungen benötigt), sondern um die Veränderung von Verhaltensweisen, ist ein inhaltsreicher bzw. weiter Begriff des Trainings entstanden und gebräuchlich geworden, wie etwa die Konzepte zum Coolnesstraining belegen.

32 Das Wort Modul wurde in Anführungszeichen gesetzt, weil es sich nicht um vorgefertigte aufeinander abgestimmte relativ selbständige Prozessbestandteile handelt, wie das bei echten Modulen der Fall ist, sondern um kreative Verknüpfungen von Standardkonzeptionen mit individuell zugeschnittenen Maßnahmen. 
Aus unserem Lebensalltag und vorliegenden psychologischen Erkenntnissen wissen wir, dass Einstellungen und Gewohnheiten für jeden Menschen unverzichtbare Regulatoren seines Handelns und Verhaltens sind. Einstellungen und Gewohnheiten sind für das Zusammenleben der Menschen und für die Berechenbarkeit des einen durch den anderen außerordentlich wichtig, denn:

„Einstellungen sind relativ lang andauernde, im Verlauf des Lebens erworbene Bereitschaften, auf bestimmte Objekte aus der Umwelt mit kognitiven Vorgängen und Gefühlen sowie offenen Verhaltensweisen in einer bestimmten beständigen Weise zu reagieren“ (Hobmair, Betscher-Ott u. a. 1992, S. 335).

Allerdings darf die Festigkeit des Zusammenhangs zwischen Einstellung und Verhalten auch nicht überschätzt werden, weil das reale Verhalten auch situationsabhängig ist. Das bedeutet, dass sich ein Mensch manchmal auch ganz anders verhält als man auf Grund seiner Einstellung erwartet.

Am Beispiel der fremdenfeindlichen Einstellung lässt sich die Aussage der oben zitierten Definition über die Bereitschaft, offen einstellungsabhängig zu reagieren, leicht erklären. Wenn z. B. fremdenfeindlich eingestellte Menschen einen farbigen Mitbürger in der Straßenbahn sehen, kann es passieren, dass in ihnen sofort das Gefühl der Ablehnung entsteht, was aggressive Handlungen auslösen kann. Dabei wird u. U. nicht berücksichtigt, dass der farbige Bürger ein gebürtiger Berliner ist, der noch nach DDR-Recht von Geburt an die deutsche Staatsbürgerschaft besitzt. Wichtig ist für eine einstellungsabhängige und gewohnheitsmäßige Reaktionsweise oft schon ein einziges äußeres Merkmal des „Einstellungsobjektes“ (z. B. die Hautfarbe). So kann eine positive und verständnisvolle Einstellung zu Personen mit Behinderungen bewirken, dass ihnen bei der Wahrnehmung ihrer Schwierigkeiten im Straßenverkehr sofort geholfen wird.

Einstellungen basieren auf einem Wertesystem, das sich jeder Mensch während seines Sozialisationsprozesses angeeignet hat. Vielfach übernehmen die Heranwachsenden ihre Wertvorstellungen von den Eltern - sogar dann, wenn sie aus jugendlicher Protesthaltung heraus diesen kritisch oder ablehnend gegenüber stehen. Die verinnerlichten Wertvorstellungen bilden die Basis einer inneren, verhaltensregulierenden Instanz, die allgemein als Gewissen bezeichnet wird. Das Gewissen signalisiert dem Menschen, ob er recht oder unrecht tut, d. h., es zeigt an, ob seine Verhaltensweisen und Handlungen mit den verinnerlichten Wertvorstellungen und Normen übereinstimmen. Die Frage ist nur, welche Wertvorstellungen das Gewissen prägen.

Positive Einstellungsänderungen erfolgen durch Aneignung und Verfestigung allgemein akzeptabler Wertvorstellungen und damit zugleich auch durch Veränderung und Entwicklung des Gewissens. Das aber ist nicht nur ein rationaler Akt der Aneignung oder Übermittlung, indem etwa Inhalt und Bedeutung bestimmter Wertvorstellungen 
erläutert und begründet werden. Vielmehr ist auch eine emotionale Verankerung dieser Wertvorstellungen notwendig, und das ist nur über vielfältige und anstrengende Aktivitäten möglich, bei denen sich die veränderten Wertvorstellungen als notwendig und zweckmäßig bewähren. Auf diesen Sachverhalt zielt offenbar auch Birnbaums Funktion der Belastung.

Gewohnheiten gehören zu den automatisierten Komponenten psychischer Prozesse (ähnlich wie Fertigkeiten), nur dass sie im Unterschied zu den Fertigkeiten mit dem Bedürfnis nach Ausführung der entsprechenden Handlung oder Verhaltensweise verbunden sind (vgl. Kossakowski, Kühn u. a. 1988, S. 144). Positive Gewohnheiten verleihen dem Leben des Menschen eine gewisse Stabilität (oftmals sogar Sicherheit) und verschaffen ihm die Befriedigung desjenigen Bedürfnisses, das der Gewohnheit zugrunde liegt. So wird z. B. die gewohnheitsmäßige höfliche Behandlung eines Fremden in der Regel mit Freundlichkeit quittiert, woran ja den meisten Menschen gelegen ist. Ohne an dieser Stelle die vorliegenden psychologischen Theorien zu den sozialen Einstellungen und Gewohnheiten referieren zu können, sollen hier einige jener Momente genannt werden, die für Prozesse der Einstellungsänderung und Umgewöhnung bedeutsam sind und daher in der Funktionseinheit Ausführen eine Rolle spielen.

Einstellungen, Wertvorstellungen und Gewohnheiten, mit denen ein Mensch sich und anderen schadet, sind trotz erfahrener und erlebter Unzweckmäßigkeit schwer zu verändern. Das hängt wohl damit zusammen, dass die betreffenden Menschen den Zusammenhang zwischen ihren Problemen und ihren „unzweckmäßigen“ (weil allgemein als schädlich bewerteten) Einstellungen und Gewohnheiten nicht erkennen können oder wahrhaben wollen. In der Auseinandersetzung mit diesem Problem gelten folgende Regeln:

- Da jede Einstellung und Übung ihre kognitiven Grundlagen hat, sind bei der Anleitung von Übungen Argumente zu verwenden, die die Notwendigkeit und Zweckmäßigkeit der andersartigen und zu praktizierenden Einstellungen und Gewohnheiten möglichst einsichtig begründen. Vor allem muss der Zusammenhang zwischen den jeweiligen Problemen und den bisher praktizierten Einstellungen und Gewohnheiten - Birnbaum sprach in Übereinstimmung mit Adler vom Grundirrtum im Lebensstil - bewusst gemacht werden.

- Da jede Einstellung und Gewohnheit mit Gefüblen verbunden ist, sind Situationen zu organisieren, in denen erlebt wird, dass bei Verzicht auf alte Gewohnbeiten bessere Gefühle entstehen und durch einen Einstellungswandel die eigentlich angestrebten Ziele (z. B. Zuwendung und Anerkennung durch andere) eher erreicht werden als durch die frühere Einstellung und das kritikwürdige Agieren.

- Da sich Einstellungen und soziales Verhalten mit den ihnen zugrunde liegenden Wertvorstellungen nur im Zusammenleben mit anderen Menschen äußern 
und verändern, sind gemeinschaftliche Aktivitäten (in denen es wechselseitige Abhängigkeiten und Verpflichtungen, Verantwortung für andere Menschen und Kameradschaftlichkeit gibt) eine unverzichtbare Basis aller Bemühungen. Die von Schreiber und Jansen (2006) am Beispiel von Strafgefangenen beschriebenen Widerstände gegen sozialpädagogische Maßnahmen können am ehesten in Entwicklungs-Gemeinschaften überwunden werden, wie z. B. auch Rasmussen bei den Rechtsverletzern in Bøgholt praktisch nachgewiesen hat (1993, S. 128). Wenn nämlich bestimmte Anforderungen von anerkannten Gemeinschaftsmitgliedern dem einzelnen Problembelasteten gegenüber konsequent vertreten werden, bleibt demjenigen, der auf seine Zugehörigkeit zu dieser Gemeinschaft Wert legt, nichts anderes übrig als sich anzupassen; andernfalls gerät er in eine Außenseiterposition oder wird sogar formell ausgeschlossen.

Um Einstellungsänderungen herbeizuführen, sind manchmal auch ungewöhnliche Erlebnisse mit „Schockwirkung“ hilfreich, um das der Einstellung zugrunde liegende Vorurteil zu erschüttern. So hatte beispielsweise der Leiter eines Kinder- und Jugendfreizeitzentrums in Wismar unter den Besuchern und Nutzern des Hauses auch stark rechtsorientierte Jugendliche, deren fremdenfeindliche Einstellung und Geringschätzung von Behinderten ihm im Verlaufe mehrerer Begegnungen deutlich geworden waren. Da er zu vielen Jugendgruppen und Einrichtungen Beziehungen hatte, organisierte er folgende Aktion: Für einen späten Nachmittag, an dem die Jugendlichen erfahrungsgemäß wieder seine Gäste sein würden, lud er eine Gruppe Behinderter in das Freizeitzentrum zu einer Veranstaltung ein.

Die Gruppe kam zum vereinbarten Termin und an ihrer Spitze schob ein farbiger Betreuer (afrikanischer Herkunft) einen Gebbebinderten im Rollstubl durch den Raum. Die rechtsorientierten Jugendlichen waren schockiert von diesem Anblick, der so gar nicht in ,ihr Weltbild“ passte, wie der Leiter des Freizeitzentrums Thomas Hake berichtete. Diesen Schock nutzte er für Gespräche mit dem Resultat, dass sie sich bereit erklärten, einem gehbehinderten Bewohner des Hauses, in dem sich das Freizeitzentrum befand, den Rollstuhl die Treppen hinunter und hinauf zu tragen. Natürlich ist nicht nur ein starker Eindruck für Einstellungsänderungen wichtig, sondern ein Handeln entsprechend der neuen Einsicht - verbunden mit entsprechender Anerkennung.

Über die Zweckmäßigkeit des Schockierens als Auftakt für einen Prozess der Umerziehung hat übrigens Makarenko unter der Überschrift „Methode der Explosion“ interessante Erfahrungen reflektiert, die unter den Bedingungen der Gemeinschaftserziehung unbedingt beachtet werden sollten (vgl. Makarenko 1969, Bd. V, S. 264, 397ff., 526ff.).

Es ist sicher oft schwierig, die psychischen Belastungen des Problemlösungsprozesses abzuschätzen. Vor allem kennt ein Sozialpädagoge zu Beginn des Hilfeprozesses nicht die Belastbarkeit des Klienten, und dieser selbst weiß auch nicht immer, was er sich 
zutrauen kann. Hinzu kommt vielfach eine Neigung zum Ausweichverhalten, dem der Sozialpädagoge mit allen Mitteln begegnen muss. Auch Selbstüberwindung und Anstrengungsbereitschaft müssen erlernt werden. Solange diese fehlen, ist es verständlich, wenn ein Klient aufgibt oder es zu Rückfällen kommt - sei es, dass der Süchtige wieder ,zugreift“", der Gewalttätige wieder 'mal zuschlägt oder der Autodieb wieder einen Wagen knackt, um die ersehnte Spritztour zu fahren. Natürlich richtet ein Rückfall Schaden an - dennoch sollte er nicht nur negativ gesehen werden; immerhin ist er ein Zeichen dafür, dass es inzwischen auch einen Fortschritt gegeben hat. Aus diesem Grunde und vor allem auch aus der humanistischen Verpflichtung gegenüber den Hilfebedürftigen sollte entsprechend den normativen Prinzipien möglichst kein Problemlösungsprozess abgebrochen werden. Vielmehr sind die Bedingungen des Rückfalls zu analysieren, um das Hilfeprogramm entsprechend den gewonnenen Erfahrungen wieder aufzunehmen bzw. in modifizierter Weise fortzusetzen.

\subsubsection{Zur organisatorisch-methodischen Gestaltung der Funktionseinheit „Auswerten“}

Die Funktionseinheit Auswerten umfasst sowohl die prozessimmanente als auch die abschließende Kontrolle und Bewertung der erzieherischen Resultate und sozialen Ergebnisse, verbunden mit Schlussfolgerungen für den Ablöseprozess.

Im Einzelnen enthält sie die Funktionen:

- Rechenschaftslegungen,

- Bewertungen,

- Schlussfolgerungen und

- bei einem nachweislichen Erfolg den Beginn der Ablösung.

Grundsätzlich kann ein pädagogischer Prozess nur dann zielstrebig geführt werden, wenn zwischen den Beteiligten wechselseitig Informationen über den Prozessverlauf und die jeweils erreichten Resultate ausgetauscht werden. In der Kommunikationswissenschaft werden die jeweiligen Rückmeldungen über die Wirkung von Informationen an den Sender als Feedback bezeichnet. In der psychosozialen Intensiverziehung handelt es sich aber bei der Auswertung nicht nur um Reaktionen und Bewertungen auf soeben Gesagtes, sondern um wechselseitige Informationen über viele prozessrelevante Ereignisse sowie um Reflexionen darüber, die auch gemeinsam in einer Gruppe erfolgen können.

Traditionell verfolgt ein Erzieher die Wirkungen seiner Bemühungen beim Zögling durch Beobachtungen und Kontrollen. Dabei wird gelegentlich übersehen, dass es für die Entwicklung von Selbständigkeit und Verantwortungsbewusstsein unbedingt notwendig ist, die Lernenden auch unbeobachtet handeln zu lassen. Es muss gewährleistet sein, 
dass der Hilfebedürftige eigenen Entscheidungsspielraum für selbständiges Handeln besitzt und nicht immer unter den kontrollierenden Augen seines Betreuers oder mit dem Gefübl der sichernden Abstützung durch Betreuer agiert. Er soll ja zur Selbsthilfe befähigt werden und dazu gehört echtes selbständiges Handeln, das häufig auch Risiken einschließt. Über die Phasen selbständigen Agierens kann und wird sich der Sozialpädagoge informieren lassen - vor allem dann, wenn etwas besonders gut gelungen ist oder wenn es Schwierigkeiten gegeben hat. Aus diesem Grunde ist es günstiger, in kleinen Rechenschaftslegungen von Zeit zu Zeit den jeweils erreichten Stand der Realisierung des Hilfeplanes bzw. der Vereinbarungen zu besprechen, als zu versuchen, eine lückenlose Kontrolle zu organisieren - was ja ohnehin kaum gelingt.

Rechenschaftslegungen sind als prozessbegleitende Funktion (Zwischenberichte) und als prozessabschließende Auswertungen zu realisieren. Entsprechend der Zweck- und Zielplanung beziehen sie sich gegebenenfalls auf beide Bestandteile des Problemlösungsprozesses: die Sozialarbeit und die psychosoziale Intensiverziehung, d. h., es wird geprüft,

- welche sozialen Ergebnisse bisher erreicht wurden, z. B. in welchem Maße die Schulden reduziert, die Beziehung zu den Angehörigen verbessert, eine Bewerbung um eine Arbeitsstelle erfolgreich realisiert wurde o. Ä. und

- welche pädagogischen Resultate erzielt wurden, d. h., es werden Fortschritte und Probleme in der Persönlichkeitsentwicklung der Klienten sowie in der persönlichen Befindlichkeit der Problembeteiligten betrachtet, bewertet und weiterführende Schlussfolgerungen abgeleitet.

Die Bewertung schließt die Analyse des Erreichten ein und vergleicht dieses mit den vereinbarten Zwecksetzungen und Zielstellungen. Der Grad der Übereinstimmung zwischen dem Geplanten und dem Erreichten drückt sich nicht nur in Werturteilen aus, sondern auch in den Gefüblen der Beteiligten, die reflektiert werden sollten. Bewertungen sind in der Regel auch mit Kritik verbunden. Für die Wirksamkeit der Kritik ist es wichtig, dass sie als Denkimpuls und nicht als Nörgelei oder Herabsetzung der Persönlichkeit formuliert und verstanden wird.

Bei den Rechenschaftslegungen geht es darum, die Resultate bisheriger sozialpädagogischer Bemühungen beider Seiten unter Berücksichtigung vielfältiger Einflüsse „,von außen“ zu erfassen, zu bewerten, um daraus Schlussfolgerungen für das weitere Vorgehen abzuleiten. Für die Rechenschaftslegung sind folgende Regeln beachtenswert:

- Führe die Rechenschaftslegung dann durch,

- wenn es diskussionswürdige Fortschritte oder Schwierigkeiten gibt,

- wenn das zu Diskutierende noch frisch in Erinnerung ist,

- wenn die Problembeteiligten dafür „den Kopf frei haben“ (also nicht unter anderem Druck stehen). 
- Unterstelle den Klienten keine Motive für ihr kritikwürdiges Handeln oder Verhalten und bewerte in kritischen Fällen nur das, was konkret kritikwürdig ist.

- Stelle die erreichten Fortschritte in der Bewältigung des sozialen Problems und in den positiven Veränderungen der Persönlichkeit der Klienten heraus, um sie zu ermutigen.

Die Schlussfolgerungen bei prozessbegleitenden Rechenschaftslegungen konkretisieren das weitere Vorgehen bei der Realisierung des Hilfeplanes oder führen auch zu seiner begründeten und bewussten Veränderung, denn nichts ist schädlicher für den Problemlösungsprozess, als wenn die Vereinbarungen im Prozessverlauf unterlaufen werden und schließlich nicht mehr klar ist, was eigentlich erreicht werden soll. Regulierendes Eingreifen sollte sich auf jene Situationen beschränken, in denen Gefahr an Leib und Leben erkennbar wird, andernfalls entsteht leicht eine prozessbegleitende Bevormundung der Klienten, die den Zielen der psychosozialen Intensiverziehung widerspricht.

Wenn es sich um eine prozessabschließende Auswertung handelt und eine Ablösung der Klienten von ihren Helfern vorgesehen ist, muss bedacht werden, was ein plötzlicher Abbruch einer inzwischen entwickelten sozialen Beziehung für sie bedeuten kann. Ihnen muss unbedingt erklärt werden, dass Sozialpädagogen es mit vielen hilfebedürftigen Menschen zu tun haben und daher nicht mit allen auch weiterhin intensive Kontakte pflegen können. Daher sollte ein schrittweiser Ablöseprozess vereinbart werden, der nach Möglichkeit auch Begegnungen in bestimmten Abständen einschließt. Es hat sich nämlich in der Praxis gezeigt, dass manche Klienten bei einem schlagartigen Abbruch der Beqiehung zum Helfer schon deshalb rückfällig werden, weil sie die abgebrochene Beziehung wieder herstellen wollen. Wenn trotz aller Bemühungen ein Klient nach dem Ablöseprozess rückfällig wird, dann sollte der Sozialpädagoge nicht sich selbst oder den Sinn seiner Bemühungen infrage stellen; immerhin hat er in der Zeit der Zusammenarbeit dem Problembelasteten und möglicherweise auch den Problembeteiligten eine höhere Lebensqualität verschaffen können.

Allerdings gibt es auch Fälle, in denen eine ,endgültige Ablösung“ nicht möglich ist, weil die Problembelasteten nicht über die physiologischen und/oder psychischen bzw. intellektuellen Voraussetzungen für eine selbständige und souveräne Lebensgestaltung verfügen. In solchen Fällen ist es wohl zweckmäßig, eine helfende Begleitung zu organisieren - wie sie etwa der alkoholkranke Max (siehe S. 118ff.) erhalten hat. Als helfende Begleiter müssen nicht unbedingt professionelle Sozialpädagogen fungieren 


\section{Schlussbemerkungen}

Im vorliegenden Buch hat der Autor den Versuch unternommen, mit Hilfe des Schaller'schen Systemansatzes der transgredienten Grundlagen und immanenten Momente der Erziehung eine Allgemeine Soz̨ialpädagogik in theoretischer Abgrenzung zur Sozialarbeit und Jugendhilfe als erziehungswissenschaftliche Disziplin zu kon₹ipieren. Dabei wurde die bereits von Schaller verwendete Methode zur Darstellung pädagogischer Erkenntnisse durch Charakterisierung von Besonderheiten der immanenten Momente der Erziehung und wichtiger Wechselwirkungen zwischen ibnen für die Bestimmung des Gegenstandes der Sozialpädagogik genutzt. Auf der Grundlage einer spezifischen Zöglings-Ziel-Relation und in Anlehnung an Buchka u. a. wurde Sozialpädagogik als Wissenschaft von der psychosozialen Intensiverziehung Problembelaster und der erzieherischen Beeinflussung Problembeteiligter definiert. Prozesse der psychosozialen Intensiverziehung werden oft in Verbindung mit Therapien und sozialen Hilfemaßnahmen im Rahmen der Sozialen Arbeit entsprechend dem Prinzip der Hilfe zur Selbsthilfe realisiert, aber auch relativ eigenständig, $z$. T. in eigens dafür geschaffenen Einrichtungen, z. B. in Erziehungsberatungsstellen.

Für ein wissenschaftlich fundiertes Vorgehen in der psychosozialen Intensiverziehung sind Kenntnisse zu den Entstehungsbedingungen devianten Handelns und Verhaltens notwendig. Wegen der komplizierten und komplexen Bedingungen und Determinationen bei der Entwicklung von Devianzen gibt es mehrere Theorien (Bezugswissenschaften). Sie untersuchen jeweils aus ihrer Sicht die spezifischen Entstehungsbedingungen und Determinanten devianten Verhaltens und Möglichkeiten seiner Überwindung. Indem wichtige Erkenntnisse und Methoden der Bezugswissenschaften in die Sozialpädagogik integriert werden, entsteht ihr transdisziplinärer Charakter, gewinnt sie theoretische Grundlagen und Ansatzpunkte für sozialpädagogische Interventionen.

Für den Erfolg aller Erziehungsprozesse - also auch der psychosozialen Intensiverziehung - sind funktionstüchtige Strukturen von großer Bedeutung. Diese äußern sich in erzieherischen Verbältnissen, die geprägt sind von wechselseitigem Vertrauen der am Prozess Beteiligten, von Kompetenz, Zuwendung, Verständnis und Geduld der Erzieher gegenüber den Zöglingen, von persönlich begründeter Autorität sowie von Engagement und Optimismus. Seinem Wesen nach ist ein erzieherisches Verhältnis die Beziebung zwischen einem kompetenzü̈berlegenen Erzieher und seinem bilfebedürftigen Zögling. Diese Beziehung kann auch Bestandteil von Gemeinschaftsbęiehungen sein, wobei es keine starren Zuordnungen der Erzieher- und Zöglingsfunktionen zu bestimmten Personen gibt. Beispielsweise verleiht der Wechsel der Funktionen in Entwicklungs-Gemeinschaften diesen eine besondere „Erziehungskraft“, die in der kollektiven psychosozialen Intensiverziehung genutzt werden kann und sollte. 
In Anwendung der von Knöchel und Naumann entwickelten funktionalen Betrachtungsweise pädagogischer Prozesse und unter Berücksichtigung individualpsychologisch fundierter sozialpädagogischer Erkenntnisse von Birnbaum konnte ein differenziertes und handlungsorientierendes Funktionsmodell der psychosozialen Intensiverziehung erarbeitet werden. Die sozialpädagogischen Funktionen widerspiegeln wesentliche Momente und flexible Sequenzen des Prozessverlaufs unter methodischem Aspekt. Durch die Verknüpfung der im Modell ausgewiesenen Funktionseinheiten mit sozialpädagogischen Prinzipien ergab sich ein allgemeines sozialpädagogisches Handlungskonzept, in das Erkenntnisse verschiedener Wissenschaften integriert sind und weiterhin integriert werden können.

Die im 1. Kapitel definierte dialektisch-materialistisch und evolutionär begründete zentrale Kategorie „Erziehung“ betont die wechselseitige Abhängigkeit von Erzieher- und Zöglingshandlungen, die sich dann auch in den Wesensmerkmalen der pädagogischen Funktionen und in den Modellen vom Verlauf pädagogischer Prozesse widerspiegelt. Die im 1. Kapitel vorgestellte statistische Gesetzeskonzeption in ihrer Anwendung auf Erziehung dient zugleich der Fundierung einer wissenschaftlichen Vorstellung vom theoretischen Wesen und praktischen Wert pädagogischer Prinzipien.

Entsprechend der Erkenntnisse A. Adlers zur „eisernen Logik des menschlichen Zusammenlebens“ (Ansbacher/Ansbacher 1982, S. 136) und der Erfahrungen Makarenkos mit der Kollektiverziehung jugendlicher Rechtsverletzer wurden Probleme der Gemeinschaftserziehung unter aktuellen gesellschaftlichen Bedingungen erörtert. Es ging darum, allgemeingültige Erkenntnisse zur Gestaltung funktionstüchtiger Strukturen von Prozessen der psychosozialen Intensiverziehung in EntwicklungsGemeinschaften herauszuarbeiten und damit ein allgemeines und dennoch differenziertes methodischen Instrumentarium sozialpädagogischen Handelns in Form eines dynamisch-funktionalen Konzepts anzubieten. Die Struktur- und Funktionsmodelle enthalten zugleich wesentliche Orientierungspunkte für Reflexionen im pädagogischen Handeln.

Ein Urteil über den Wert dieser Bemühungen bleibt dem Leser überlassen, wobei er bedenken möge, dass es sich hier um einen Umriss einer Allgemeinen Sozialpädagogik als einer transdisziplinären Wissenschaftsdisziplin handelt, der natürlich der weiteren Präzisierung und vor allem der Ergänzung durch Didaktiken sozialpädagogischen Handelns für die verschiedenen Arbeitsfelder bedarf (vgl. Seite 92f.). Bei der Prüfung des Wahrheitsgehalts der Aussagen und der Gültigkeit der Prinzipien in der vorliegenden Darstellung sollte berücksichtigt werden, dass auch eine sorgfältige Anwendung des dargestellten Orientierungswissens nicht in jedem Falle zum gewünschten Erfolg führt, weil ja in den zu gestaltenden Prozessen probabilistische Gesetzmäßigkeiten wirken und auBerdem - zumindest auf absehbare Zeit - nicht alle sozialen Probleme mit den Mitteln der Sozialen Arbeit bzw. Sozialpädagogik gelöst werden können. 
Anlagen 


\section{Aufgaben der Sozialen Arbeit}

\section{„Unmittelbare Arbeit mit Klientinnen und Klienten}

Aufnabme- und Planung

- Klärung der Zuständigkeit

- Informationsvermittlung

- Ressourcen- und Problemanalyse

- Erstellung von Gutachten

- Zielformulierung

- Arbeitsvereinbarung

\section{Intervention}

- Finanzielle Beratung und Unterstützung, evtl. Sicherung der materiellen Grundversorgung

- Einbezug des familiären Umfeldes/der Bezugspersonen

- Beantragung/Durchführung von Maßnahmen

- Koordination und Kooperation mit anderen Organisationen und deren Fachleuten

- Dokumentation der Interventionen (Aktenführung, Rechenschaftsberichte)

- Standortbestimmung/Zwischenevaluation

Abschluss und Nachsorge

- Ergebniskontrolle und Schlussevaluation

- Angebote der Nachbetreuung

- Evtl. Überweisung an andere Stellen

\section{Gruppen- und Teamarbeit}

Hier kann es sich um Gruppen gleichermaßen Betroffener handeln (Alleinerziehende, Arbeitslose, Bürgerinnen und Bürger eines Quartiers, Freiwillige, Eltern), aber auch um Arbeitsteams einer Organisation.

- Definition der Ziele und Anliegen einer Gruppe oder eines Teams und Suche nach Wegen zu deren Realisierung

- Steuerung des Prozesses (erfordert Kenntnisse über Gesetzmäßigkeiten einer Gruppe und die Beherrschung der entsprechenden Techniken)

- Soziokulturelle Animation: Erlebnis- und Freizeitpädagogik, sozialpädagogische Gemeinwesenarbeit, soziale Kultur- und Bildungsarbeit 


\section{Gemeinwesenarbeit: Quartiermanagement und Sozialplanung}

- Sozialraumanalysen in Quartieren, Gemeinden, Regionen

- Bedürfnis- und Bedarfsermittlung (z. B. durch Zukunftswerkstätten und Planspiele)

- Beteiligung von Bürgerinnen und Bürgern (Mitwirkung)

- Projektarbeit: Planung, Projektierung und Durchführung sowie Evaluation von Projekten

- Netzwerkarbeit und Unterstützungsmanagement

\section{Managementaufgaben}

- Zusammenarbeit mit der Trägerschaft und deren Repräsentanten

- Finanzplanung, Mittelbeschaffung

- Kooperation und Koordination mit anderen Organisationen

- Personalführung

- Personalrekrutierung, -entwicklung,-qualifikation

- Entwicklung von Arbeitsprozessen und Organisationsstrukturen

- Mitarbeit in Supervision, Intervision und Fallbesprechungen

- Anleitung von Studierenden der Sozialen Arbeit im Rahmen der Praxisausbildung

\section{Aufgaben im Bereich der Öffentlichkeit}

Sozialinformation und Öffentlichkeitsarbeit

- Sozialinformation (Information an potenzielle Benützerinnen und Benutzer)

- Öffentlichkeitsarbeit (Information von Behörden, Vereinen, Medien und Fachleuten anderer Disziplinen über Zielsetzung und Angebot der Stelle)

- Publikationen

Sozialpolitische Aktivitäten

- Mitarbeit in Projekten bzw. Vertretung der Institution in Gremien

- Verfassen von Stellungnahmen zu sozialen Problemen oder von fachlichen Beiträgen zu aktuellen sozialpolitischen Problemen

- Mitarbeit bei öffentlichen Veranstaltungen zu sozialen Problemen“(a. a. O., S. 5f.). ${ }^{\text {" }}$ 


\section{Auszug aus dem Inhaltsverzeichnis: Peter Lüssi: Systemische Sozialabeit}

„3. Die Methode der Sozialarbeit

3.1 Das Wesen der sozialarbeiterischen Methodik

3.2 Die methodischen Prinzipien der Sozialarbeit

3.21 Konzeptprinzipien

a) Problemindividuelles Verstehen

b) Wechselwirkung Verstehen - Handeln

c) Systemisches Prinzip

d) Soziallogisches Denken

e) Sozialethisches Prinzip

f) Kreativitätsprinzip

3.22 Handlungsprinzipien

3.221 Handlungsprinzipien allgemeiner Art

a) Lösungszentriertheit

1. Zielsetzung

2. Handlungsimperativ

3. Lösungsdynamismus

4. Positivität

5. Flexibilität

6. Effizienz

b) Primat der sozialarbeiterischen Funktion

c) Prinzip des allseitigen Nutzens

3.222 Handlungsprinzipien betreffend das Verhältnis zwischen Sozialarbeiter und Problembeteiligten

a) Interposition

b) Handlungsherrschaft

c) Kommunikationsprinzip (Kontaktprinzip)

d) Gefühlsfunktionalisierung

1. Abnahme dysfunktioneller Gefühle

2. Gefühlsklärung

3. Förderung funktioneller Gefühle

e) Pädagogische Verhaltensbeeinflussung Modell-Verhalten

1. Adäquate Forderungen

2. Belehrung und Anleitung

3. Gratifikation und Sanktion

4. Selbständigkeitsförderung 
3.223 Handlungsprinzipien betreffend das Problemlösungsvorgehen

a) Instrumentelle Problemdefinition

b) Natürlichkeitsprinzip

c) Sozialökologisches Prinzip

1. Aktivierung natürlicher sozialer Netze

2. Prinzip des kleinstmöglichen Eingriffs

d) Verhandlungsprinzip

1. Vorrang der Verhandlung

2. Vorrang der reinen Verhandlung

3. Vorrang der direkten Verhandlung

e) Tatsachenprinzip

f) Konzentration auf die zentralen Problemvariablen

g) Zeitrichtigkeit

1. Rasches Handeln

2. Zuwarten

3. Richtige Handlungsreihenfolge

h) Freiwilligkeitsvorrang

i) Kooperationsprinzip

k) Problemöffnung

1. Nichthandeln (Nichthelfen)

2. Problembelastete angreifen

3. Eine Krise auslösen

4. Negatives Verhalten bestärken

5. Unmögliches verlangen

3.23 Akzeptanzprinzipien

3.231 Die sozialarbeiterische Akzeptanz

3.232 Die akzeptanzfördernden methodischen Prinzipien

a) Problemannahme

b) Freundliche Teilnahme

c) Anpassungsprinzip

d) Präsumption des guten Willens

e) Nichtbeschuldigung

f) Kompetenzprinzip

g) Erklärungsprinzip

h) Diskretionsprinzip“ (Lüssi 1992, S. 10-12) 


\section{Sozialpädagogische Prinzipien (gruppiert von W. Naumann)}

1. Normative Prinzipien

1.1 Rettungsprinzip

1.2 Heilungsprinzip

1.3 Förderungsprinzip

2. Konzeptprinzipien

2.1 Prinzip der Verbindung von sozialer Hilfe mit direkter und indirekter pädagogischer Einflussnahme als Anleitung zur Selbsthilfe

2.2 Prinzip der Verbindung von systemischem Herangehen mit problemindividuellem Verstehen und Vorgehen

2.3 Prinzip der Wechselwirkung von Verstehen und Handeln

2.4 Prinzip der Verknüpfung von sozialethischen und sozialökologischen Positionen bei der Bestimmung des vertretbaren Aufwands an materiellen und personellen Mitteln zur Problemlösung

2.5 Prinzip der Verbindung von persönlicher Achtung mit angemessen hohen und steigenden Forderungen

\section{Strukturprinzipien}

3.1 Prinzip der Präsentation von Kompetenz und Natürlichkeit im Umgang mit den Problembeteiligten sowie der Wahrung von Diskretion

3.2 Prinzip der Verbindung von unvoreingenommener Problemannahme, verständnisvoller Anteilnahme und Echtheit zwecks Öffnung, Ermutigung und Aktivierung der Klienten

3.3 Prinzip der Verbindung von Interposition mit parteilichem Engagement für besonders Bedürftige und Benachteiligte

3.4 Prinzip der Verbindung von Beratung und Verhandlungsführung mit Kooperationsbildung im Interesse der Klienten

3.5 Prinzip der Verbindung von Handlungsherrschaft des Sozialpädagogen mit der Selbständigkeitsförderung der Klienten

\section{Funktionsprinzipien}

4.1 Prinzip der Verbindung von Freiwilligkeitsvorrang, Zeitrichtigkeit, Zielstrebigkeit und Flexibilität im Hilfeprozess

4.2 Prinzip der Verbindung von Tatsachenermittlung und Erklärungsbemühungen unter Berücksichtigung der Lebenswelt und des soziallogischen Denkens der Problembelasteten

4.3 Prinzip der Verbindung von Nichtbeschuldigung mit der Anknüpfung an persönliche Stärken der Klienten

4.4 Prinzip der Verbindung von instrumenteller Problemdefinition mit der Konzentration auf die zentralen Problemvariablen

4.5 Prinzip der Einheit von steigenden Anforderungen und kontinuierlichen Kontrollen im Problemlösungsprozess. 


\section{Literaturverzeichnis}

Adler, Alfred: Menschenkenntnis, Fischer Taschenbuch Verlag, Frankfurt a. M. 1991

Adorno, Theodor, W.: Erziehung nach Auschwitz. Gesammelte Schriften, Bd. 10. 2; 2003

Ansbacher, Heinz; Ansbacher, Rowena (Hrsg.): Alfred Adlers Individualpsychologie. Eine systematische Lehre in Auszügen aus seinen Schriften. 3., ergänzte Auflage, Ernst Reinhardt Verlag, München/Basel 1982

Alt, Robert: Vorlesungen über Erziehung auf frühen Stufen der Menschheitsentwicklung. Volk und Wissen Volkseigener Verlag. Berlin 1965

Ahrbeck, Rosemarie: Die allseitige Entwicklung der Persönlichkeit. Studie zur Geschichte des humanistischen Bildungsideals. Volk und Wissen Verlag, Berlin 1984

Bachmair, Sabine/Jan Faber/Claudius Hennig/Rüdiger Kolb/Wolfgang Willig: Beraten will gelernt sein. Beltz Taschenbuch. Weinheim 1989

Badry, Elisabeth: Die Gründer der Landerziehungsheime. In: Scheuerl, Hans (Hrsg.): Klassiker der Pädagogik. Beck'sche Verlagsbuchhandlung, München 1979, S. 152-169

Badry, Elisabeth; Buchka, Maximilian; Knapp, Rudolf (Hrsg.): Pädagogik - Grundlagen und Arbeitsfelder. Hermann Luchterhand Verlag GmbH, Neuwied 1994

Banse, Gerhard/Lutz-Günther Fleischer (Hrsg.): Wissenschaft im Kontext. Inter- und Transdisziplinarität in Theorie und Praxis. trafo Wissenschaftsverlag, Berlin 2011

Baring, Arnulf: Deutschland, was nun? Goldmann Verlag, Augsburg 1991

Bauer, Hans G.; Nickolai, Werner : Erlebnispädagogik in der Sozialen Arbeit. Verlag Klaus Neubauer, Lüneburg 1991

Bauer, Hannah; Westphalen, Nina: Hilfen für schulaversive Kinder und deren Eltern. [online] UnterrichtsaversivesVerhalten. doc (Zugriff: 27.01.2010)

Bastian, Ingeborg; Naumann, Werner: Zur didaktischen und erziehungstheoretischen Modellierung des pädagogischen Prozesses als einer theoretischen Grundlage seiner Gestaltung. In: Pädagogische Forschung, 1981, Nr. 2, S. 94-108

Becker, H. S.: Außenseiter. Zur Soziologie abweichenden Verhaltens. Frankfurt a. M. 1973

Bejlinson, Valentin: A. S. Makarenko in Moskau. In: JahrBuch für Forschungen zur Geschichte der Arbeiterbewegung, NDZ-GmbH München, Mai 2007, S. 94-107

Bellmann, Rainer: Verschiedene Typen von Gesetzen der Wissenschaft. (Dissertation) Berlin 1964 (Maschinenschriftliches Manuskript)

Benner, Dietrich: Systematische Pädagogik - die Pädagogik und ihre wissenschaftliche Begründung. In: Leo Roth (Hrsg.): Pädagogik - Handbuch für Studium und Praxis. Ehrenwirth Verlag GmbH, München 1991, S. 5-18

Benner, Dietrich;Oelkers, Jürgen (Hrsg.): Historisches Wörterbuch der Pädagogik. Beltz Verlag, Weinheim/Basel 2004

van Beugen, Marinus: Agogische Intervention - Planung und Strategie. Lambertus-Verlag, Freiburg i. B. 1972

Die Bibel oder die ganze Heilige Schrift des Alten und Neuen Testaments nach der Übersetzung Martin Luthers. Revidierter Text AT 1964, NT 1975. Berlin

Biermann, Benno; Bock-Rosenthal, Erika; Doehlemann, Martin; Grohall, Karl-Heinz; Kühn, Dietrich: Soziologie - Gesellschaftliche Probleme und sozialberufliches Handeln. Luchterhand Verlag, Neuwied/Kriftel/Berlin 1992

Birnbaum, Ferdinand: Die praktischen Auswirkungen der Individualpsychologie in der Schule. In: Internationale Zeitschrift für Individualpsychologie. 1931, Heft 9, S.171-182

Birnbaum, Ferdinand: Die individualpsychologische Versuchsschule in Wien. In: Internationale Zeitschrift für Individualpsychologie. 1932, Heft 10, S. 176-183 
Blaß, Josef Leonard: Modelle pädagogischer Theoriebildung. Band 1; Urban-Taschenbücher, Kohlhammer-Verlag, Stuttgart/Berlin/Köln/Mainz 1978

Blech Jörg;von Bredow, Rafaela: Die Grammatik des Guten. Muss jedes Kind von Grund auf lernen, was richtig und was falsch ist? Oder ist dem Menschen ein Sinn für Moral angeboren? Eine ungewöhnliche Allianz aus Rechtsphilosophen, Affenforschern und Neurowissenschaftlern glaubt die Wurzeln der Moral gefunden zu haben. In: „Der Spiegel“, 2007, Heft 31, S. 108 -116

Bleidick, Ulrich: Praxis zwischen Rezept und Theorielosigkeit und die Forderung nach einer Theorie für die Praxis. In: Die neue Sonderschule - Zeitschrift für Theorie und Praxis der pädagogischen Rehabilitation. 2001, Heft 3, S. 159-168

Bloch, Ernst: Das Prinzip Hofnung. Aufbau-Verlag, Berlin 1954

Böhnisch, Lothar: Sozialpädagogik des Kindes- und Jugendalters. Eine Einführung. Juventa Verlag, Weinheim und München 1993

Bohle, Hans Hartwig: Abweichendes Verhalten. In: Eyferth, Hanns; Otto, Hans-Uwe; Thiersch, Hans (Hrsg.): Handbuch zur Sozialarbeit/Sozialpädagogik. Eine systematische Darstellung für Wissenschaft, Studium und Praxis. Studienausgabe. H. Luchterhand Verlag, Neuwied/Darmstadt 1987, S.1-11

Bohn, Irina (Hrsg.): Dokumentation der Fachtagung „Resilienz - Was Kinder aus armen Familien stark macht" am 13. September 2005 in Frankfurt a. M. Institut für Sozialarbeit und Sozialpädagogik, ISS-Aktuell 2/2006; http://www.iss-ffm.de/downloads/tagungsberichte/doku ft resilienz 2006 09.pdf (Zugriff: 02.06.2008)

Bollnow, Otto Fr.: Anthropologische Pädagogik. Verlag P. Haupt, Bern/Stuttgart 1983

Bornemann, Ernst: Sozialerziehung in akademischer Forschung und Lehre. In: Horst Wollenweber (Hrsg.): Sozialpädagogik in Wissenschaft und Unterricht. Verlag Ferdinand Schöningh, Paderborn 1978, S. 9-32

Bourdieu, Pierre: Satz und Gegensatz. Über die Verantwortung des Intellektuellen. Verlag Paul Wagenbach, Berlin 1989

Bokelmann, Hans: Pädagogik, Erziehung, Erziehungswissenschaft. In: Speck, Josef; Wehle, Gerhard (Hrsg.): Handbuch pädagogischer Grundbegriffe. Bd. 2; Kösel Verlag, München 1970 , S. $178-267$

Braun-Thürmann, Holger: Die gesellschaftliche Bedeutung von Innovationen. In: Wissenschaftsnotizen. Wissenschaftsforum der Sozialdemokratie, 2005, S. 29-34

Brezinka, Wolfgang: Grundbegriffe der Erziehungswissenschaft. Analyse, Kritik, Vorschläge (UTB 332) Ernst Reinhardt Verlag, München/Basel 1974

Brezinka, Wolfgang: Aufklärung über Erziehungstheorien. Beiträge zur Kritik der Pädagogik. Ernst Reinhardt Verlag, München/Basel 1989

Brezinka, Wolfgang: Zur Problematik von Erziehungszielen in pluralistischen Gesellschaften. In: Bildung und Erziehung an der Schwelle zum dritten Jahrtausend. Multidisziplinäre Aspekte, Analysen, Positionen, Perspektiven. Norbert Seibert/Helmut J. Serve (Hrsg.), PimS-Verlag GmbH. München 1994, S. 590-634

Buchka, Maximilian: Sozialpädagogik und Heilpädagogik. In: Badry, Elisabeth; Buchka, Maximilian; Knapp, Rudolf (Hrsg.): Pädagogik - Grundlagen und Arbeitsfelder. Hermann Luchterhand Verlag GmbH, Neuwied/Kriftel/Berlin 1994, S. 155-159

Buchka, Maximilian: Sozialpädagogik im Wandel der Zeit. In: Badry, Elisabeth; Buchka, Maximilian; Knapp, Rudolf (Hrsg.): Pädagogik - Grundlagen und Arbeitsfelder. Hermann Luchterhand Verlag GmbH, Neuwied/Kriftel/Berlin 1994, S. 137-154

Bunge, Mario: Arten und Kriterien wissenschaftlicher Gesetze. In: Günter Kröber (Hrsg.): Der Gesetzesbegriff in der Philosophie und den Einzelwissenschaften. Akademie-Verlag, Berlin 1968, S. 117-146 
Bunge, Mario/Martin Mahner: Über die Natur der Dinge - Materialismus und Wissenschaft. S. Hirzel Verlag, Stuttgart/Leipzig 2004

Bunk, Lothar; Ziegler, Sabine: Möglichkeiten zur Lösung sozialer Probleme unter den Bedingungen des ambulanten betreuten Wohnens im Individualwohnraum und ihre Nutzung - dargestellt am Beispiel des Klienten M. Abschlussarbeit im Kurs „Sozialpädagogischer Jugend- und Familienberater“ (VDP) beim Bildungszentrum Dessau, Schulungsort Güstrow 2003

Burow, Olaf-Axel: Prinzipien erfolgreicher Erziehung. Verlag Julius Klinghardt, Bad Heilbrunn/Obb. 2003

Cibulka, Jozef: Über die innere Gegensätzlichkeit objektiver Gesetzmäßigkeiten. In: Igor Hrušovský (Wissenschaftlicher Redakteur): Das dialektische Gesetz. Vydatelstvo Slovenskey Akadémie Vied, Bratislava 1964, S. 131-208

Clauß, Günter; Hiebsch, Hans: Kinderpsychologie. Volk und Wissen Verlag, Berlin 1961

Comenius, Jan Amos: Große Didaktik. Volk und Wissen Volkseigener Verlag, Berlin 1957

Cube, Felix von: Verhaltensbiologie und Pädagogik. In: Leo Roth (Hrsg.): Pädagogik - Handbuch für Studium und Praxis. Ehrenwirth Verlag, München 1991, S. 122-131

Degen, Rolf: Das Ende des Bösen - Die Naturwissenschaft entdeckt das Gute im Menschen. Piper Verlag GmbH, München/Zürich 2007

Die Reichsschulkonferenz 1920 - Ihre Vorgeschichte und Vorbereitung und ihre Verhandlungen. Amtlicher Bericht, erstattet vom Reichsministerium des Innern. Verlag von Quelle \& Meyer, Leipzig 1922

Diesterweg, Friedrich Adolph Wilhelm: Wegweiser zur Bildung für deutsche Lehrer. 4. Auflage, Verlag von Bädeker, Essen 1850

Diesterweg, Friedrich Adolph Wilhelm: Sämtliche Werke, Band III, bearbeitet von Ruth Hohendorf. Volk und Wissen Volkseigener Verlag, Berlin 1959

Diesterweg, Friedrich Adolph Wilhelm: Kirchenlehre oder Pädagogik? In: Sämtliche Werke, Band IX, Ruth Hohendorf (Hrsg.), Volk und Wissen Verlag, Berlin 1967

Dilthey, Wilhelm: Schriften zur Pädagogik. H.-H. Groothoff/Ulrich Herrmann (Hrsg.), Verlag Ferdinand Schöningh, Paderborn 1971

Dilthey, Wilhelm: Gesammelte Schriften, Band V. Die geistige Welt. Einleitung in die Philosophie des Lebens. Erste Hälfte. Abhandlungen zur Grundlegung der Geisteswissenschaften. B. G. Teubner Verlagsgesellschaft, Stuttgart. Vandenhoeck \& Ruprecht in Göttingen. 1990 (8. unveränderte Auflage)

Dudek, Peter: Jugend und Jugendbilder in der pädagogischen Reflexion seit dem späten 18. Jahrhundert. In: Niemeyer, Christian; Schröer, Wolfgang; Böhnisch, Lothar (Hrsg.): Grundlinien Historischer Pädagogik - Traditionsbezüge, Reflexionen und übergreifende Sozialdiskurse. Juventa Verlag, Weinheim/München 1997, S. 43-58

Engels, Friedrich: Von der Autorität. In: Marx/Engels: Werke, Bd. 18, Dietz Verlag., Berlin 1962, S. 305-308

Erster Jahresbericht der Kleinkinderschule in Wismar. Rathsbuchdruckerei von J.G.W. Oesten Witwe, Wismar 1840

Eyferth, Hanns; Otto, Hans-Uwe; Thiersch, Hans (Hrsg.): Handbuch zur Sozialarbeit/Sozialpädagogik. Eine systematische Darstellung für Wissenschaft, Studium und Praxis. Hermann Luchterhand Verlag, Neuwied/ Darmstadt 1987

Fauser, Peter: Grenzwertig - Gewalt und Erziehung. Vortrag bei der Weimarer Psychotherapiewoche am 14. 09. 2003 (Vortragsmanuskript)

Fere, Nikolaj E.: Makarenko - mein Lehrer. Verlag Neues Leben, Berlin 1953 
Fouts, Roger; Mills, Stephen Tukel: Unsere nächsten Verwandten. Von Schimpansen lernen, was es heißt, ein Mensch zu sein. Droemersche Verlagsanstalt Th. Knaur Nachf., München 2000

Friedrich, Walter: Jugend heute. Theoretische Probleme, empirische Daten, pädagogische Konsequenzen. VEB Deutscher Verlag der Wissenschaften, Berlin 1966

Fröbel, Friedrich Wilhelm August: Die Menschenerziehung, die Erziehungs-, Unterrichts- und Lehrkunst, angestrebt in der allgemeinen deutschen Erziehungsanstalt zu Keilhau; dargestellt von dem Stifter, Begründer und Vorsteher derselben. Verlag von Philipp Reclam jun. Leipzig, Ohne Jahresangabe

Froese, Leonhard: Makarenko zwischen Ost und West. Kritische Bemerkungen zu Repliken unserer Kritiker. In: Götz Hillig/Siegfried Weitz (Hrsg.): Makarenko-Diskussionen International. Protokoll des 2. Marburger Gesprächs (1.-4. Mai 1986). Minerva-Publikation, München 1989, S. 5-13

Fromm, Erich: Haben oder Sein. Deutscher Taschenbuchverlag, München 2000 (28. Aufl.)

Fromm, Erich: Über den Ungehorsam. Dt. Taschenbuchverlag, München 1990 (4. Aufl.)

Fromm, Erich: Wege aus einer kranken Gesellschaft. Eine sozialpsychologische Untersuchung. Verlag Ullstein, Frankfurt a. M. 1981 (nach 10., überarbeiteter Auflage)

Fuhrmann, Elisabeth; Weck, Helmut (unter Mitarbeit von Karl Eggert und Karl-Heinz Walter): Forschungsproblem Unterrichtsmethoden. Beiträge zur Pädagogik, Bd. 4, Volk und Wissen Volkseigner Verlag, Berlin 1976

Füllgrabe, Uwe: Serienscharfschützen und der Caligulaeffekt. In: Kriminalistik. Unabhängige Zeitschrift für kriminalistische Wissenschaft und Praxis, Kriminalistik Verlag Heidelberg. 2002, Heft 12, S. 730-734

Gaertner, Karlheinz/Fadi Saad: Kampfzone Straße - Jugendliche Gewalttäter stoppen. Verlag Herder GmbH, Freiburg im Breisgau 2012

Gamm, Hans-Jochen: Erziehung und Mündigkeit. In: Hans-Jochen Gamm/Gernot Koneffke (Hrsg.): Jahrbuch für Pädagogik. Peter Lang GmbH Europäischer Verlag der Wissenschaften, Frankfurt a. M./Berlin/Bern/New York/Paris/Wien 1997, S. 115-128

Gangloff, Tilmann, P.: Der Kampf zwischen Gut und Böse. In: Mogge-Stubbe, Birgitta (Hrsg.): Gewalt macht keine Schule - Ursachen, Sensibilisierung, Gegenstrategien. Verlag Olzog GmbH, München 2002

Gaschke, Susanne: Die Erziehungskatastrophe - Kinder brauchen starke Eltern. Heyne Verlag, München 2003

Garcia, Joseph: Individuum und Kollektiv in der Pädagogik aus der Sicht eines Außenseiters. In: Götz Hillig/Siegfried Weitz (Hrsg.): Makarenko-Diskussionen International. Protokoll des 2. Marburger Gesprächs (1.-4. Mai 1986). Minerva-Publikation, München 1989, S. 177-199

Gerhardt, Volker: Die Einheit des Wissens. In: Aus Politik und Zeitgeschichte, 2007/Nr. 46, S. 6-14 (Beilage zur Wochenzeitung „Das Parlament“ vom 12.11.2007)

Giesecke, Hermann: Erziehung oder Lernhilfe? Zur Strategie sozialpädagogischen Handelns. In: Friedhelm G. Vahsen/Karin Böllert (Hrsg.): Paradigmenwechsel in der Sozialpädagogik. KT-Verlag, Bielefeld 1992

Giesecke, Hermann: Das Ende der Erziehung - Neue Chancen für Familie und Schule. KlettCotta, Stuttgart 1996

Goethe, Johann Wolfgang v.: Poetische Werke, Romane und Erzählungen III. Berliner Ausgabe, Band 11. Aufbau Verlag, Berlin/Weimar 1976

Grüntgens, Willi J.: Didaktische Prinzipien als Lern-Behinderungen. In: Die neue Sonderschule, 2001, Heft 1, S. 25-38 
Günther-Schellheimer, Edgar: Makarenko in meinem Leben. NORA Verlagsgemeinschaft Dyck \& Westerheide. Berlin 2005

Gührs, Manfred; Nowak, Claus: Das konstruktive Gespräch. Limmer Verlag, Meezen 1991

Hake, Thomas: Probleme und Konflikte bei der sozialpädagogischen Betreuung von Kindern und Jugendlichen im Kinder- und Jugendfreizeitzentrum Wismar. Abschlussarbeit an der Sozialakademie Güstrow, Schulungsort Wismar 1998

Harnisch, Wilhelm: Handbuch für das Deutsche Volksschulwesen. Hrsg.: Dr. Friedrich Bartels. Verlag Hermann Beyer \& Söhne, Langensalza 1893

Hassenstein, Bernhard: Abbildende Begriffe. In: Verhandlungen der Deutschen Zoologischen Gesellschaft, 1954, S. 197-214. http://www.bernhard-hassenstein.de/literatur_online/Abbildende-Begriffe (Zugriff: 28.2.2011)

Hegel, Georg Wilh. Friedrich: Phänomenologie des Geistes. Akademie Verlag. Berlin 1964

Heiderich, Rolf; Rohr, Gerhart: Bildung heute - Wege aus der PISA-Katastrophe. Olzog Verlag $\mathrm{GmbH}$, München 2002

Helvetius, Claude-Adrien: Vom Menschen. Aufbau-Verlag, Berlin/Weimar 1976

Hentig, Hartmut von: Ach, die Werte. Über eine Erziehung für das 21. Jahrhundert. Taschenbuch 66, Beltz Verlag, Weinheim/Basel 2001

Herbart, Johann Friedrich: Pädagogische Schriften (in 2 Bänden). F. Bartholomäi (Hrsg.), Beyer \& Söhne, Langensalza 1922 (8. Auflage)

Herriger, Norbert: Verwahrlosung - Eine Einführung in Theorien sozialer Auffälligkeit. Juventa Verlag, München 1979

Hillig, Götz: Eine Jugend in Russland. In: Hillig, Götz; Weitz, Siegfried (Hrsg.): MakarenkoDiskussionen International. Protokoll des 2. Marburger Gesprächs (1.-4. Mai 1986). Minerva-Publikation, München 1989, S. 47-68

Hillig, Götz: Sie schufen Freiräume für Experimente. In: Weitz, Siegfried (Hrsg.): MakarenkoStudien International. Makarenko in Ost und West Teil II. td publications. München 1993, S. 193-245

Hillig, Götz: „Zumindest gibt es in Wickersdorf keinen Kaiser, keinen Gott und keine Kaser-

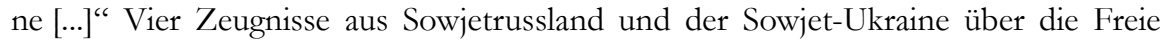
Schulgemeinde Wickersdorf (1922-1925), eingeführt, übersetzt und kommentiert von Götz Hillig. Jahrbuch für Historische Bildungsforschung 2006, Verlag Julius Klinghardt, Bad Heilbrunn/Obb. 2006, S. 251-280

Hierdeis, Helmwart; Hug, Theo: Pädagogische Alltagstheorien und erziehungswissenschaftliches Handeln. Studienbrief der Fernuniversität Hagen 1991

Hirt, Petra: Sozialpädagogische Arbeit in der überbetrieblichen Erstausbildung - Fallbei-spiel "Renate". Abschlussarbeit im Kurs "Sozialpädagogischer Jugend- und Familienberater" (VDP) beim Bildungszentrum Dessau - Außenstelle Güstrow 2003

Hobmair, Hermann (Hrsg.), S. Altenthan/W. Dirrigl/W. Gotthardt./R. Höhlein/W. Ott/K.H. Schneider: Pädagogik. , Stam-Verlag. Köln, München 1989

Hobmair, Hermann (Hrsg.), S. Altenthan/S. Betscher-Ott/W. Dirrigl/M. Fischer-Frödhoff/W. Gotthardt/W. Ott/S. Rätzsch: Psychologie. Stam-Verlag, Köln 1992

Höhler, Gertrud: Neue Werte für eine Welt im Wandel. In: Norbert Seibert/Helmut J. Serve (Hrsg.): Bildung und Erziehung an der Schwelle zum dritten Jahrtausend. Multidisziplinäre Aspekte, Analysen, Positionen, Perspektiven. PimS-Verlag GmbH, München 1994, S. 116-134

Hörz, Herbert: Der dialektische Determinismus in Natur und Gesellschaft. VEB Deutscher Verlag der Wissenschaften, Berlin 1971

Hörz, Herbert: Zufall - Eine philosophische Untersuchung. Akademie-Verlag, Berlin 1980 
Hörz, Herbert; Wessel, Karl-Friedrich: Philosophische Entwicklungstheorie. VEB Deutscher Verlag der Wissenschaften, Berlin 1983

Hörz, Herbert: Bemerkungen zur statischen Gesetzeskonzeption in den Darlegungen von W. Naumann. Brief vom 18.03.2004, (Privatarchiv des Autors)

D' Holbach, Paul Thiry: System der Natur oder von den Gesetzen der physischen und moralischen Welt. Aufbau Verlag, Berlin 1959

Hompesch-Cornetz, Ingeborg; Hompesch, Raimund: Sozialpädagogik und Therapie. In: H. Eyferth/H.-U. Otto/H. Thiersch (Hrsg.): Handbuch zur Sozialarbeit/Sozialpädagogik. Eine systematische Darstellung für Wissenschaft, Studium und Praxis. Hermann Luchterhand Verlag. Neuwied/Darmstadt 1987, S. 1028-1044

Hüther, Gerald: Zuwendung ist der wichtigste Erzieher. In: Mogge-Stubbe, Birgitta (Hrsg.): Gewalt macht keine Schule - Ursachen, Sensibilisierung, Gegenstrategien. Verlag Olzog GmbH, München 2002

Ilse, Peter: Einführung in die Pädagogik mit Sonderpädagogik für Berufe im Gesundheitswesen. Stam Verlag/Bardtenschlager Verlag, Köln 1994

Jansen, Irma/Oliver Peters/Werner Schreiber: Devianzpädagogische Analysen - Integrative sozialpädagogische Arbeit mit einer psycho-sozial belasteten Klientel. Books on Demand GmbH, Norderstedt 2006

Informationsdienst Jugendsekten 1/96 (Febr. 1996) [online], herausgegeben vom "Arbeitskreis Sekten e. V."/Verein zur Bekämpfung geistiger und seelischer Abhängigkeit - Mitglied im Diakonischen Werk der Evangelischen Kirche von Westfalen.

Justiz auf einem Blick. Ausgabe 2011, Statistisches Bundesamt, Wiesbaden 2011

Kaiser, Arnim; Kaiser, Ruth: Studienbuch Pädagogik - Grund- und Prüfungswissen. Cornelsen Scriptor. Frankfurt a. M. 1991 (5. Auflage)

Kamps, Walter: Gruppenpädagogik und Themenzentrierte Interaktion. Die Sozialphilosophie Jean Paul Sartres als Rahmentheorie für gruppenbezogene Bildungsprozesse. Österreichischer Studien-Verlag, Innsbruck 1992

Kant, Immanuel: Kritik der praktischen Vernunft. Verlag Philipp Reclam jun. Leipzig 1978

Kant, Immanuel: Gesammelte Schriften. Bd. VIII. Herausgegeben von der Königl. Preußischen Akademie der Wissenschaften. Verlag G. Reimer, Berlin 1912

Kant, Immanuel: Gesammelte Schriften. Bd. IX. Herausgegeben von der Königl. Preußischen Akademie der Wissenschaften. W. de Gruyter \& Co. Berlin/ Leipzig 1923

Kant, Immanuel: Über Pädagogik. In: G. Fröhlich (Hrsg.): Die Klassiker der Pädagogik, Band XI. Schulbuchhandlung von F. G. Greßler, Langensalza 1890

Kessel, Wolfgang; Hentschel, Günter: Zur Rolle sozialer Beziehungen und kollektiver Tätigkeiten für die psychische Entwicklung der Persönlichkeit. In: Psychologische Grundlagen der Persönlichkeitsentwicklung im pädagogischen Prozess. Leiter des Redaktionskollegiums: Adolf Kossakowski. Volk und Wissen Verlag, Berlin 1988

Kinder- und Jugendhilfegesetz (Achtes Buch Sozialgesetzbuch) (abgekürzt: KJHG) Herausgeber: Bundesministerium für Frauen und Jugend, Bonn. 5. Auflage 1993

Kirchhöfer, Dieter: Der Prinzipienbegriff in der Philosophie. In: Deutsche Zeitschrift für Philosophie. Deutscher Verlag der Wissenschaften, Berlin 1974, Heft 4,S. 411-428

Klafki, Wolfgang: Neue Studien zur Bildungstheorie und Didaktik. Beltz Verlag, Weinheim/Basel 1985

Klaus, Georg: Einführung in die Formale Logik. Dt. Verl. der Wissenschaften Berlin 1958

Klaus, Georg: Moderne Logik. Abriss der Formalen Logik. VEB Deutscher Verlag der Wissenschaften, Berlin 1964

Klaus, Georg: Wörterbuch der Kybernetik. Dietz Verlag, Berlin 1967

Kleine Enzyklopädie - Mathematik. Bibliographisches Institut, Leipzig 1968 
Kleiß, Katrin: Möglichkeiten der sozialpädagogischen Beratung bei der Problematik „Rückfälle bei Essstörungen“ - dargestellt an einem Fallbeispiel. Abschlussarbeit im Kurs „Sozialpädagogische Jugend- und Familienberater". Güstrow 2002

Knöchel, Wolfram: Grundlagenprobleme der Pädagogik in kybernetischer Sicht. Volk und Wissen Volkseigener Verlag, Berlin 1967

Knoll, Jörg; Lehnert, Marion Annett; Otto, Volker (Hrsg.): Gestalt und Ziel. Beiträge zur Geschichte der Leipziger Erwachsenenbildung. Leipzig 2007

Koalitionsvertrag der Bundesregierung vom 11.11.2005: Gemeinsam für Deutschland - mit Mut und Menschlichkeit.[online] http://www.cdu_de_doc_pdf_05_11_11_Koalitionsvertrag. pdf. (Zugriff: 26.06.2009)

Kossakowski, Adolf; Kühn, Horst; Lompscher, Joachim; Rosenfeld, Gerhard u. a.: Psychologische Grundlagen der Persönlichkeitsentwicklung im pädagogischen Prozeß. 5. Auflage. Volk und Wissen Volkseigener Verlag, Berlin 1988

Koschnitzki, Andreas: Zur Anwendung sozialpädagogischer Funktionen und Prinzipien bei der Gestaltung eines sozialpädagogischen Prozesses, dargestellt am Beispiel eines Schülers, der ein berufsvorbereitendes Jahr besuchte. Belegarbeit für die Qualifikation zum sozialpädagogischen Jugend- und Familienberater (VDP) beim Bildungszentrum Dessau, Schulungsort Rostock 2003

Kozdon, Baldur: Erziehungsfragen in der Gegenwart. In: Norbert Seibert/Helmut J. Serve (Hrsg.): Bildung und Erziehung an der Schwelle zum dritten Jahrtausend. Multidisziplinäre Aspekte, Analysen, Positionen, Perspektiven. PimS-Verlag GmbH, München 1994, S. 696-727

Kreutz, Henrik: Auffälliges Verhalten bei Jugendlichen. In: Dieter Lenzen/Aji Schründer (Hrsg.): Enzyklopädie Erziehungswissenschaft. Band 8, Erziehung im Jugendalter Sekundarstufe I. Klett-Cotta, Stuttgart 1983, S. 135-149

Kron, Friedrich W.: Grundwissen Pädagogik. Ernst Reinhardt Verlag, München/Basel 1991 (3., überarbeitete Auflage)

Kronen, Heinrich: Sozialpädagogik - Geschichte und Bedeutung des Begriffs. Haag + Herchen Verlag GmbH, Frankfurt a. M. 1980

Krüger, Heinz-Hermann: Erziehungswissenschaft und Sozialpädagogik. In: Werner Thole (Hrsg.): Grundriss Soziale Arbeit - Ein einführendes Handbuch. Opladen 2002, S. 273-283

Kuhfuß, Helmut; Sandvoß, Andreas: „Ich mach Dich platt, Du Bastard“ - oder Anti-Gewalt/ Coolnesstraining - Ein Konzept gegen Gewalt und Machtmissbrauch. 2004 [online] http://www.lvr.de/app/resources/jugendhilfe3.pdf (Zugriff: 03.02.2010)

Kuhlmann, Carola: „So erzieht man keinen Menschen!“ Lebens- und Berufserinnerungen aus der Heimerziehung der 50er und 60er Jahre. Verlag für Sozialwissenschaften 2008

Kurth, B.-M.: Symposium zur Studie zur Gesundheit von Kindern und Jugendlichen in Deutschland. Bundesgesundheitsblatt - Gesundheitsforschung - Gesundheitsschutz. 2006, Nr. 10, S. 1050-1058. [online] http://www.kiggs.de/experten/downloads/dokumente/bgbl KiGGS erste Ergebnisse 2006.pdf (Zugriff: 4.11. 2006)

Lamnek, Siegfried: Neue Theorien abweichenden Verhaltens, München 1994

Landwehr, Rolf/Rüdeger Baron (Hrsg.): Geschichte der Sozialarbeit - Hauptlinien ihrer Entwicklung im 19. und 20. Jahrhundert. Beltz Verlag, Weinheim/Basel 1991

Langewand, Alfred: Bildung. In: Erziehungswissenschaft. Ein Grundkurs. Rowohlts Enzyklopädie. Rowohlt Taschenbuch Verlag, Reinbek bei Hamburg 1994 (S. 69-98)

Lau, Jörg: Die Macht der kollektiven Gefühle. In: DIE ZEIT, 2004/Nr. 03, S. 30

Lauter, Dietrich: Makarenko in der kirchlichen Jugendarbeit - Bericht über einen Versuch. In: Götz Hillig/Siegfried Weitz (Hrsg.): Makarenko-Diskussionen International. Proto- 
koll des 2. Marburger Gesprächs (1.-4. Mai 1986). Minerva-Publikation, München 1989, S. 225-241

Lauter, Dietrich: Makarenko ohne Perspektive? In: Siegfried Weitz (Hrsg.): Makarenko Studien International. Makarenko in Ost und West Teil II. td publications. München 1993, S. 130-160

Leber, Aloys: Heilpädagogik. In: Eyferth, Hanns; Otto, Hans-Uwe; Thiersch, Hans (Hrsg.): Handbuch zur Sozialarbeit/Sozialpädagogik. Eine systematische Darstellung für Wissenschaft, Studium und Praxis. Hermann Luchterhand Verlag, Neuwied/Darmstadt 1987, S. 475-486

Lenzen, Dieter (Mitarb. von Rost, F.) (Hrsg.): Erziehungswissenschaft. Ein Grundkurs. rowohlts enzyklopädie. Rowohlt Taschenbuch Verlag, Reinbek bei Hamburg 1994

Lewin, Karl/Lippitt, R. \& White, R. K.: Patterns of aggressive behavior in experimentally created social climates. Journal of Social Psychology. (1939) 10, 271-299.

Lexikon der Psychologie in fünf Bänden. Spektrum Akademischer Verlag, Heidelberg/Berlin 2001

Lietz, Hermann: Deutsche Land-Erziehungs-Heime - Grundsätze und Einrichtungen. Verlag A. W. Zickfeldt, Osterwieck a. Harz (ohne Jahresangabe)

Lietz, Hermann: Emlohstobba - Roman oder Wirklichkeit? Bilder aus dem Schulleben der Vergangenheit, Gegenwart oder Zukunft? Rudolf Lassahn (Hrsg.), Heinsberg 1997

Lietz, Hermann: Ein Tag im Schulstaat Emlohstobba. Ferd. Dümmlers Verlagsbuchhandlung, Berlin 1897

Lietz, Hermann: Lebenserinnerungen. Neu herausgegeben und durch Briefe und Berichte ergänzt von Alfred Andreesen. H. Lietz Verlag, Weimar 1935

Liimets, Heino; Naumann, Werner: Didaktik - Eine Unterrichtstheorie für die Mittel- und Oberstufe. Volk und Wissen Volkseigener Verlag, Berlin 1985 (2. Auflage)

Lochner, Rudolf: Erziehungswissenschaft im Abriss. Wolfenbütteler Verlagsanstalt GmbH, Wolfenbüttel/Hannover 1947

Loeser, Franz: Deontik - Planung und Leitung der moralischen Entwicklung. VEB Deutscher Verlag der Wissenschaften, Berlin 1966

Lück, Helmut E.: Psychologie sozialer Prozesse. Leske + Budrich, Opladen 1993

Lüssi, Peter: Systemische Sozialarbeit. Praktisches Lehrbuch der Sozialberatung. Verlag Paul Haupt, Bern/Stuttgart/Wien 1992 (2. Auflage)

Mager, Karl: Schule und Leben. Glossen zu Dr. Curtmanns Preisschrift. In: Pädagogische Revue. Centralorgan für Pädagogik, Didaktik und Culturpolitik, 8. Band, K. Mager (Hrsg.), Verlag der J. F. Cast'schen Buchhandlung, Stuttgart 1844, S. 395-409

Mager, Karl: Was ist Pädagogik? In: Pädagogische Revue. Centralorgan für Pädagogik, Didaktik und Culturpolitik, 12. Band, K. Mager (Hrsg.), Druck und Verlag von Friedrich Schultheß. Zürich 1846, S. 1-42

Makarenko, Anton Semënovič.: Werke. Band I. Volk und Wissen Volkseigener Verlag, Berlin 1972 (4. Auflage)

Makarenko, Anton Semënovič: Werke. Band V. Volk und Wissen Volkseigener Verlag, Berlin 1969 (5. Auflage)

Makarenko, Anton Semënovič: Werke. Band VII. Volk und Wissen Volkseigener Verlag, Berlin 1976 (3. Auflage)

Mannschatz, Eberhard: Jugendhilfe und Heimerziehung in der DDR und über ihre Rolle im heutigen sozialpädagogischen Diskurs. Berlin 1998

Mannschatz, Eberhard: Erziehung als Gestaltungsproblem. In: Wiss. Zeitschrift der Humboldt-Universität zu Berlin. Gesellschaftswissenschaften. 1988, Nr. 8, S. 761-802 
Mannschatz, Eberhard: Jugendhilfe in der DDR. Autobiographische Skizzen aus meinem Berufsleben. Trafo Verlag, Berlin 2002

Mannschatz, Eberhard: Gemeinsame Aufgabenbewältigung als Medium sozialpädagogischer Tätigkeit. Denkanstöße für die Wiedergewinnung des Pädagogischen aus der Makarenko-Rezeption. Trafo Verlag, Berlin 2003

Marburger, Helga: Entwicklung und Konzepte der Sozialpädagogik. Juventa Verlag, München 1981

Markowitsch, Hans; Reemtsma, Philipp: „Neuronen sind nicht böse“. Interview in: „Der Spiegel“", 2007, Heft 31, S. 117-123

Marx, Karl; Engels, Friedrich: Werke, Band 3. Dietz Verlag, Berlin 1962a

Marx, Karl; Engels, Friedrich: Werke, Band 4. Dietz Verlag, Berlin 1980

Marx, Karl; Engels, Friedrich: Werke. Band 20. Dietz Verlag, Berlin 1962

Marx, Karl; Engels, Friedrich: Werke. Band 23. Dietz Verlag, Berlin 1983

Marx, Karl; Engels, Friedrich: Werke. Band 31 (Abt.I.), Akademie Verlag, Berlin 2002

Marx, Karl; Engels, Friedrich: Werke, Band 40. Dietz Verlag, Berlin 1956ff. In: Digitale Bibliothek: Marx/Engels, Ausgew. Werke. Directmedia Publishing, Berlin 2004

Marx, Karl; Engels, Friedrich: Werke, Band 42. Dietz Verlag, Berlin 1983

Marx, Karl; Engels, Friedrich: Über Religion. Dietz Verlag, Berlin 1958

Meier, Artur: Soziologie des Bildungswesens. Eine Einführung. Volk und Wissen Volkseigener Verlag, Berlin 1974

Meier-Gräve, Uta: Armut von Kindern: Welche Bedeutung hat die Förderung von Resilienz? In: Dokumentation der Fachtagung „Resilienz - Was Kinder aus armen Familien stark macht" am 13. September 2005 in Frankfurt a. M. Institut für Sozialarbeit und Sozialpädagogik, ISS-Aktuell 2/2006 bzw. [online] info@iss-ffm.de

Melzer, Wolfgang: Gewaltemergenz - Erscheinungsformen und Ursachen von Gewalt in der Schule. In: S. Müller/H. Sünker/Th. Olk/ K. Böllert (Hrsg.): Soziale Arbeit - Gesellschaftliche Bedingungen und professionelle Perspektiven. Hermann Luchterhand Verlag GmbH, Neuwied/Kriftel 2000, S. 79-98

Meleghy, Tamás: Verhaltenstheoretischen Soziologie: Georg Caspar Homans. In: Julius Morel u. a.: Soziologische Theorie - Abriß der Ansätze ihrer Hauptvertreter. R. Oldenbourg Verlag, München/Wien 1989, S. 31-50

Merten, Roland: Zur Binnenstruktur professionellen Handelns in der Sozialen Arbeit. In: Müller; Siegfried; Sünker, Heinz; Olk, Thomas; Böllert, Karin (Hrsg.): Soziale Arbeit - Gesellschaftliche Bedingungen und professionelle Perspektiven. Hermann Luchterhand Verlag GmbH, Neuwied/Kriftel 2000, S. 399-416

Meyer, Hilbert: Unterrichtsmethoden I: Theorieband. Scriptor Verlag, Frankfurt a. M. 1989

Mühlum, Albert: Sozialarbeit und Sozialpädagogik. Ein Vergleich. Eigenverlag des Deutschen Vereins für öffentliche und private Fürsorge. Frankfurt a. M. 2001. (3., überarbeitete und aktualisierte Auflage)

Müller, Burkhard: Sozialpädagogisches Können. Ein Lehrbuch zur multiperspektivischen Fallarbeit. Lambertus Verlag, Freiburg im Breisgau 1994 (2. Aufl.)

Müller, C. Wolfgang: Fachlichkeit als Gesamtkunstwerk. Von der Notwendigkeit in Epochen zu denken. In: Müller, Siegfried; Sünker, Heinz; Olk, Thomas; Böllert, Karin (Hrsg.): Soziale Arbeit - Gesellschaftliche Bedingungen und professionelle Perspektiven. H. Luchterhand Verlag GmbH, Neuwied/Kriftel 2000, S. 417-427

Müller, Carsten: Sozialpädagogik als Bürgererziehungswissenschaft. In: Zeitschrift für pädagogische Historiographie. Neue Pestalozziblätter, 2005, Heft 1, S 3-8 
Müller, Hans Rüdiger: Sozialpädagogik und Therapie. Über die Notwendigkeit pädagogischer Perspektiven in Therapeutischen Wohngemeinschaften für Drogenabhängige. Juventa Verlag, Weinheim/München 1990

Müller, J. L.: Goethes Beziehungen zu Schnepfenthal. In: Schnepfenthäler Nachrichten. 1932, Heft 2, S. 5-10

Münchmeier, Richard: Paradigmenwechsel in der Sozialen Arbeit. In: Friedhelm G.Vahsen (Hrsg.): Paradigmenwechsel in der Sozialpädagogik. Karin Böllert KT-Verlag, Bielefeld 1992, S. 24-48

Mogge-Stubbe, Birgitta (Hrsg.): Gewalt macht keine Schule - Ursachen, Sensibilisierung, Gegenstrategien. Verlag Olzog GmbH, München 2002

Mohr, Hans: Biologische und kulturelle Evolution der Moral. In: INITIAL - Zeitschrift für Politik und Gesellschaft, 1990, Heft 6, S. 555-562

Mollenhauer, Klaus: Einführung in die Sozialpädagogik. Beltz Verlag, Weinheim/Basel 1991 (9. Auflage)

Natorp, Paul: Sozialpädagogik. Theorie der Willenserziehung auf der Grundlage der Gemeinschaft. Fr. Fromanns Verlag (E. Hauff), Stuttgart 1920

Naumann, Werner: Einführung in die Pädagogik. Volk und Wissen Volkseigener Verlag, Berlin 1975 (1. Auflage), 1980 (3. Auflage), 1986 (6. Auflage)

Naumann, Werner: Zum Gegenstand der Pädagogik - Definition, System und Gesetzmäßigkeiten der Erziehung (Ein Beitrag zu den theoretischen und methodologischen Grundlagen einer materialistisch-dialektischen Erziehungswissenschaft). Habilitationsschrift, Leipzig 1968

Naumann, Werner: Bemerkungen eines Erwachsenenbildners zur Bildung im frühen Kindesalter. In: Kirchhöfer, Dieter; Neumann, Karl; Neuner, Gerhart; Uhlig, Christa (Hrsg.): Abhandlungen der Leibniz-Sozietät, Band 16. Bewahranstalt oder Kreativschule? Bildung in der frühen Kindheit in Deutschland im 20. Jahrhundert - Empirie, Theorie, Utopie. Trafo Verlag Berlin 2004a, S. 103-108

Naumann, Werner: Missverstandene didaktische Prinzipien als mögliche Lernbehinderungen. In: Die neue Sonderschule. Zeitschrift für Theorie und Praxis der pädagogischen Rehabilitation. Beltz Verlag, Weinheim/Berlin, 2002, Heft 3, S. 222-227

Naumann, Werner (Hrsg.): Sozialpädagogische Betreuung von Alkoholkranken in Heimen unter besonderer Berücksichtigung des kontrollierten Trinkens. Neuer Hochschulschriftenverlag, Rostock 1999

Naumann, Werner: Zur Geschichte der Wismarer Kleinkinderschule im 19. Jahrhundert. In Friedrich Fröbel - Beiträge einer Konferenz. Herausgegeben vom Kulturbund Mecklenburg-Vorpommern e. V. und von der Gesellschaft für Schulgeschichte Mecklenburgs und Vorpommerns e. V. 2002, S. 36-48

Neill, Alexander Sutherland: Theorie und Praxis der antiautoritären Erziehung. Das Beispiel Summerhill. Rowohlt Taschenbuch Verlag, Reinbek bei Hamburg 1969

Neumann, Karl: Zwei Kindheitskonzepte - zwei Konzeptionen von Vorschulerziehung. Frühpädagogik in der BRD und DDR. In: Dieter Kirchhöfer/Karl Neumann/Gerhart Neuner \& Christa Uhlig, (Hrsg.): Bewahranstalt oder Kreativschule? Bildung in der frühen Kindheit in Deutschland im 20. Jahrhundert - Empirie, Theorie, Utopie. Trafo Verlag, Berlin 2004, S. 57-66

Neuner, Gerhart: Konstruktive Synthese - wichtige Richtung pädagogischen Denkens und Forschens. In: Pädagogik. Herausgegeben von der Akademie der Pädagogischen Wissenschaften der DDR, 1980, Heft 5, S. 349-364 
Niemeyer, August Hermann: Grundsätze der Erziehung und des Unterrichts. Erster Teil, Ausgewählte Pädagogische Schriften in zwei Bänden. Schulbuchhandlung von F. G. L. Greßler, Langensalza 1888

Niemeyer, Christian; Schröer, Wolfgang; Böhnisch, Lothar: Grundlinien Historischer Sozialpädagogik. Traditionsbezüge, Reflexionen und übergangene Sozialdiskurse. Ju-venta Verlag, Weinheim/München 1997

Nipkow, Karl Ernst: Zukunft - Überleben - Religion. Analysen im Überschneidungsfeld von Evolutionstheorie, Theologie, Pädagogik und Religionspädagogik. In: Seibert, Norbert; Serve, Helmut J. (Hrsg.): Bildung und Erziehung an der Schwelle zum dritten Jahrtausend. Multidisziplinäre Aspekte, Analysen, Positionen, Perspektiven. PimSVerlag GmbH, München 1994, S. 728-772

Nitz, Marianne: Möglichkeiten zur Verhinderung von einer Heimeinweisung durch Nutzung von Hilfe zur Erziehung in der Tagesgruppe ( $(32 \mathrm{KJHG})$. Hausarbeit, eingereicht zur Abschlussprüfung als „Sozialpädagogische Jugend- und Familienberaterin“ (VDP) beim Bildungszentrum Dessau, Schulungsort Güstrow 2003

Nohl, Herman: Die pädagogische Bewegung in Deutschland und ihre Theorie. Verlag G. Schultze-Bulmke, Frankfurt a. M. 1957 und 1963

Northoff, Robert: Ohne Vorurteil und Verlegenheit. Die DDR - ein kriminalpräventives Gesamtkunstwerk? In: Kriminalistik. Unabhängige Zeitschrift für kriminalistische Wissenschaft und Praxis. Kriminalistik Verlag, Heidelberg 1995, Heft 1, S. 51-54 und 1995, Heft 2, S. 129-133

Obrecht, Werner: Probleme der Sozialen Arbeit als Handlungswissenschaft und Bedingungen ihrer kumulativen Entwicklung. In: Bernd Birgmeier/Eric Mührel (Hrsg.): Die Sozialarbeitswissenschaft und ihre Theorie(n) - Positionen, Kontroversen, Perspektiven. VS Verlag für Sozialwissenschaften/GWV Fachverlag GmbH, Wiesbaden 2009, S. 113-129

Obrecht, Werner: Philosophische Grundlagen der Sozialarbeitswissenschaft als integrative Handlungswissenschaft. In. Fach- und Forschungskolloquium Soziale Arbeit und ihre Wissenschaften, 21./22.11.03 [online] http//www.webnetwork-nordwest.de/ dokumente/obrecht emden.pdf (Zugriff: 8.10.2010)

Oelkers, Jürgen: Erziehung. In: Benner, Dietrich; Oelkers, Jürgen (Hrsg.): Historisches Wörterbuch der Pädagogik. Beltz Verlag. Weinheim/Basel 2004, S. 303-340

Oerter, Rolf; Montada, Leo (Hrsg.): Entwicklungspsychologie. Beltz Psychologie Verlags Union; Weinheim 1998 (4. Auflage)

Opaschowski, Horst W.: Eine Einführung in die freizeitkulturelle Breitenarbeit. Methoden und Modelle der Animation. Bad Heilbrunn 1979

Opaschowski, Horst W.: Methoden der Animation. Praxisbeispiele. Bad Heilbrunn 1981

Owen, Robert: Pädagogische Schriften. Volk und Wissen Verlag, Berlin 1955

Pädagogische Enzyklopädie (in 2 Bänden). Frankiewicz, Heinz; Brauer, Helmut; Czerwinka, Johann; Günther, Karl-Heinz; Schulze, Günter; Wutzler,Günter (Hrsg.), VEB Deutscher Verlag der Wissenschaften, Berlin 1963

Pecher, Christiane: Zur Anwendung sozialpädagogischer Funktionen und Prinzipien bei der Gestaltung eines sozialpädagogischen Prozesses, dargestellt am Beispiel „Andreas Barth“. Belegarbeit für die Qualifikation zur „Sozialreferentin“ (VDP) beim Bildungszentrum Dessau, Schulungsort Rostock 2003

Peters, Uwe Henrik: Lexikon - Psychiatrie/Psychotherapie/Medizinische Psychologie. Urban \& Fischer Verl., München/Jena, Lizenzausg. f. Weltbildverlag 2004 (5. Aufl.)

Petri, Horst: Was sind Werte noch wert? Der Verrat an der jungen Generation. In: „Neues Deutschland" vom 2./3. November 2002, S. 24 
Petri, Horst: Jugend auf der Suche - Der Verrat an der jungen Generation. Herder Taschenbuch, Freiburg/Basel/Wien 2006

Pfeiffer, Christian: Problematische Schüler als Zeichen veränderter gesellschaftlicher Rahmenbedingungen. In: Dokumentation: Schwierige Schüler, mehr Erziehung - Brauchen wir Schulsozialarbeit? Verband Bildung und Erziehung, Kitzingen 2003

Pick, Brigitte: Kopfschüsse - Wer PISA nicht versteht, muss mit RÜTLI rechnen. VSA-Verlag, Hamburg 2007

Plewig, Hans-Joachim: Devianzpädagogik. In: Stimmer, Franz (Hrsg.): Lexikon der Sozialpädagogik und der Sozialarbeit. R. Oldenbourg Verlag, München/Wien 2000, S. 138-144 (4., überarbeitete und erweiterte Auflage)

Prange, Klaus: Plädoyer für Erziehung. Schneider-Verlag, Hohengehren 2000

Prüß, Franz: Individuum und Gemeinschaft - Gegensatz oder Bedingung. In: Müller; Siegfried; Sünker, Heinz; Olk, Thomas; Böllert, Karin (Hrsg.): Soziale Arbeit - Gesellschaftliche Bedingungen und professionelle Perspektiven. Hermann Luchterhand Verlag GmbH, Neuwied/Kriftel 2000, S. 119-135

Psychologische Grundlagen der Persönlichkeitsentwicklung im pädagogischen Prozess. Redaktionskollegium: Kossakowski, Adolf; Kühn, Horst; Lompscher, Joachim; Rosenfeld, Gerhard. Volk und Wissen Volkseigener Verlag, Berlin 1988

Quellen zur Geschichte der Erziehung. Günther, Karl-Heinz; Hofmann, Franz; Hohndorf, Gerd; König, Helmut; Schuffenhauer, Heinz (Hrsg.), Volk und Wissen Volkseigener Verlag, Berlin 1968 (5.,verbesserte Auflage)

Quellen zur Geschichte der Vorschulerziehung. Krecker, Margot (Hrsg.), Volk und Wissen Volkseigener Verlag, Berlin 1971

Rapoport, Anatol: philosophie heute und morgen. einführung ins operationale denken. 3. unveränderte Auflage, Verlag Darmstädter Blätter, ohne Jahresangabe - Vorwort 1970

Rasmussen, Harald: Zur Rezeption Makarenkos in Dänemark. Der Praxisversuch im staatlichen Erziehungsheim Bøgholt. In: Weitz, Siegfried (Hrsg.): Makarenko Studien International. Makarenko in Ost und West Teil II. td publications, München 1993, S. 100 129

Ratke, Wolfgang: Die neue Lehrart - Pädagogische Schriften Wolfgang Ratkes. Volk und Wissen Volkseigener Verlag, Berlin 1957

Rein, Wilhelm: Encyklopädisches Handbuch der Pädagogik. Band II. Verlag von Hermann Beyer \& Söhne, Langensalza 1896

Rein, Wilhelm: Encyklopädisches Handbuch der Pädagogik. Band V. Verlag von Hermann Beyer \& Söhne, Langensalza 1898

Rehbein, Klaus: Was heißt und zu welchem Ende studiert man Sozialpädagogik. Schneider Verlag, Hohengehren 2005

Richtlinien der Deutschen Verwaltung für Volksbildung in der sowjetischen Besatzungszone Deutschlands für das Schulwesen. Stand vom 1. März 1948. Volk und Wissen Verlag GmbH, Berlin/Leipzig 1948

Rijt-Plooij, Hedwig van de/Frans X. Plooij: Schimpansen. In: Stamm, Roger A.; Zeier Hans (Hrsg.): Lorenz und die Folgen. „Psychologie des 20. Jahrhunderts“ Band VI, S. 177188., Kindler, Zürich 1978

Rousseau, Jean Jacques: Über Erziehung. Volk und Wissen Verlag, Berlin 1958

Roth, Leo (Hrsg.): Pädagogik - Handbuch für Studium und Praxis. Ehrenwirt Verlag GmbH, München 1991

Rubinstein, S. L.: Grundlagen der Allgemeinen Psychologie. Volk und Wissen Volkseigener Verlag, Berlin 1958 
Salzmannschule Schnepfenthal 1784-1984 - Gothaer Museumsheft. Abhandlungen und Berichte zur Regionalgeschichte. 200 Jahre Salzmannschule; 1984, Sonderheft 1

Sachße, Christoph/Florian Tennstedt: Armenfürsorge, Soziale Fürsorge, Sozialarbeit. In: Christa Berg (Hrsg.): Handbuch der deutschen Bildungsgeschichte. Bd. 4, München 1991, S. 411-440

Schaller, Herbert: Vorlesung zur Systematischen Pädagogik. Stenographische und redigierte Mitschrift von Herrn Gensel, Stenograph am Instituts für Erwachsenenbildung, Leipzig 1959 (Privatarchiv von W. N.)

Schaller, Herbert (Hrsg.) Erziehungswissenschaft - Grundlagen der Erziehung. Lehrbriefe für das Fernstudium am Institut für Erwachsenenbildung der Karl-Marx-Universität Leipzig, 1960 (1. Auflage) und 1963 (2., erweiterte Auflage)

Scherr, Albert: Sozialarbeitswissenschaft - Grundzüge eines theoretischen Programms. In: Thole, Werner (Hrsg.): Grundriss Soziale Arbeit. Ein einführendes Handbuch. Verlag Leske + Budrich, Opladen 2002, S. 259-272

Scheunpflug, Annette: Biologische Grundlagen des Lernens. Cornelsen Verlag, Berlin 2001

Schilling, Johannes: Didaktik/Methodik der Sozialpädagogik - Grundlagen und Konzepte. H. Luchterhand Verlag GmbH \& Co. KG, Neuwied/Kriftel/Berlin 1993

Schilling, Johannes: Soziale Arbeit - Geschichte, Theorie, Profession. E. Reinhardt Verlag, München/Basel 2005

Schleiermacher, Friedrich Daniel: Ausgewählte pädagogische Vorlesungen und Schriften. Volk und Wissen Volkseigener Verlag, Berlin 1965

Schmidt, Hans Dieter; Schneeweiß, Burkhard (Hrsg.): Schritt um Schritt. Die Entwicklung des Kindes bis ins 7. Lebensjahr. VEB Verlag Volk und Gesundheit, Berlin 1986

Schmitter, Elke: „Kein Gen für Faulheit“. In: „Der Spiegel“, 2007, Heft 32, S. 142-143

Schmid, K. A., Hauber, Wildermuth und andere: Encyklopädie des gesammten Unterrichtsund Erziehungswesens. 5. Band, Fues's Verlag. Leipzig 1883

Schneider, Hans Joachim: Kinder und Jugendliche als Mörder - Kriminalpsychologie der tödlichen Schulgewalt. In: Kriminalistik. Unabhängige Zeitschrift für kriminalistische Wissenschaft und Praxis. Kriminalistik Verlag, Heidelberg. 2002, Heft 10, S. 609-615

Schneeberg, Ulrich: Pädagogisches Führungsverhalten und berufsrelevante Einstellungen von Oberstufenlehrern. (Dissertation A) Leipzig 1975

Schopenhauer, Arthur: Preisschrift über die Freiheit des Willens, gekrönt von der Königlich Norwegischen Societät der Wissenschaften, zu Drontheim, am 26. Januar 1839. In: Arthur Schoppenhauers sämtliche Werke. Band IV. Schriften zur Naturphilosophie und Ethik. F. A. Brockhaus GmbH, Mannheim 1988

Schorlemmer, Friedrich: Gibt es eine Wahrheit im Plural? Über Religion und Toleranz und den Kampf der Kulturen. Verlag Otto Lembeck, Frankfurt a. M. 2004

Schorn, August: Geschichte der Pädagogik in Vorbildern und Bildern. Verlag der Dürr' schen Buchhandlung, Leipzig 1911

Schülerduden „Philosophie“ 2., völlig neu bearbeitete Auflage. Herausgegeben und bearbeitet von der Redaktion Schule und Leben. Dudenverlag, Mannheim/Leipzig/ Wien/Zürich 2002

Schuller, Lutz: Zur Anwendung sozialpädagogischer Prinzipien bei der Realisierung sozialpädagogischer Funktionen im sozialpädagogischen Prozess, dargestellt am Beispiel des Drogensüchtigen Sven R. Belegarbeit in Sozialpädagogik im Kurs zur Ausbildung als „Sozialpädagogischer Jugend- und Familienberater“ (VDP) beim Bildungszentrum Dessau, Schulungsort Güstrow 2002 
Schulz v. Thun, Friedemann: Miteinander Reden, Band 1. Störungen und Klärungen. Allgemeine Psychologie der Kommunikation. Rowohlt Verlag, Reinbek 1990

Schulz v. Thun, Friedemann: Miteinander Reden, Band 2. Stile, Werte und Persönlichkeitsentwicklung. Rowohlt Taschenbuch Verlag, Reinbek 1990

Schumann, Wolfgang: Therapie und Erziehung. Zum Verständnis beider Begriffe und zu ihrem Verhältnis zueinander unter schulischen Aspekten. Verlag J. Klinkhardt, Bad Heilbrunn 1993

Schweizer, Stefan: Deutscher Idealismus, Autopoiese und Radikaler Konstruktivismus. [online] http://electroneubio.secyt.gov.ar/Stefan_Schweizer_Autopoiesis.htm (Zugriff: 10.08. 2012)

Schwenk, Bernhard: Erziehung. In: Lenzen, Dieter (u. Rost), (Hrsg.): Pädagogische Grundbegriffe. Bd. 1. Rowohlts Enzyklopädie. Reinbek bei Hamburg 1993, S. 429-439 .

Seibert, Norbert: Erzieher oder Therapeut. In: Seibert, Norbert; Serve, Helmut J. (Hrsg.): Bildung und Erziehung an der Schwelle zum dritten Jahrtausend - Multidisziplinäre Aspekte, Analysen, Positionen, Perspektiven. PimS-Verlag, München 1994

Seiffert, Helmut: Erziehungswissenschaft im Umriß. Mit 700 Titeln Fachbibliographie. W. Kohlhammer Verlag, Stuttgart/Berlin/Köln/Mainz 1969

Städler, Thomas: Lexikon der Psychologie. Alfred Kröner Verlag, Regensburg 2003

Staub-Bernasconi, Silvia: Klarer oder trügerischer Konsens über eine Wissenschaftsdefinition in den Debatten über Sozialarbeitswissenschaft? In: Pfaffenberger, Hans; Scherr, Albert; Sorg, Richard (Hrsg.): Von der Wissenschaft des Sozialwesens. Neuer Hochschulschriftenverlag, Rostock 2000, S. 144-175

Staub-Bernasconi, Silvia: Soziale Arbeit als Handlungswissenschaft. Systemtheoretische Grundlagen und professionelle Praxis - ein Lehrbuch. Haupt Verlag, Bern/Stuttgart/Wien 2007

Staub-Bernasconi, Silvia: Soziale Arbeit als Handlungswissenschaft. In: Birgmeier, Bernd; Mührel, Eric (Hrsg.): Die Sozialarbeitswissenschaft und ihre Theorie(n) - Positionen, Kontroversen, Perspektiven. VS Verlag für Sozialwissenschaften/GWV Fachverlag GmbH, Wiesbaden 2009, (S. 131-146)

Stegmüller, Wolfgang: Das Problem der Kausalität. In: Topitsch, Ernst (Hrsg.): Probleme der Wissenschaftstheorie. Festschrift für Victor Kraft. Springer-Verlag, Wien 1960

Skrodzki, Klaus: Statement für die Fachveranstaltung: „Aufmerksamkeitsdefizitsyndrom Auswirkungen für die betroffenen Kinder und Familien - Konsequenzen für Politik und Gesellschaft.“ Dokumentation des öffentlichen Gesprächs der Arbeitsgruppe Kinderpolitik der SPD-Landtagsfraktion vom 22.11.2001 im Bayrischen Landtag. [online] www.spd.bayern.landtag.de (Zugriff: 23.05.2008)

Sozialreport '90 - Hrsg.: Gunnar Winkler. Verlag Die Wirtschaft, Berlin 1990

Spaemann, Robert: Moralische Grundbegriffe. Verlag C. H. Beck, München 1999 (6. Aufl.)

Spitz, Rene A.: Vom Säugling zum Kleinkind. Verlag Klett-Cotta, Stuttgart 1987

Spitzer, Manfred: Bildschirme raus aus Kinderzimmern! Interview mit dem Neurowissenschaftler Prof. Dr. M. Spitzer am 10. März 2005 unter: http:/www.dradio.de/ dkultur/sendungen/kulturinterwiev/354959

Spitzer, Manfred: Vorsicht Bildschirm. Klett-Verlag, Stuttgart 2006

Spranger, Eduard: Das Gesetz der ungewollten Nebenwirkungen in der Erziehung. Quelle \& Meyer, Heidelberg 1962

Stimmer, Franz (Hrsg.): Suchtlexikon. R. Oldenbourg Verlag, München/Wien 2000

Sünkel, Wolfgang: Klinische Praxis - partisanische Theorie. In: Hillig, Götz; Weitz, Siegfried (Hrsg.): Makarenko-Diskussionen International. Protokoll des 2. Marburger Gesprächs (1.-4. Mai 1986). Minerva-Publikation, München 1989, S. 33-41 
Sünkel, Wolfgang: Der Untergang der Sowjetunion und die Pädagogik Makarenkos - Versuch einer Rezeptionshermeneutik. In: Weitz, Siegfried (Hrsg.): Makarenko Studien International. Makarenko in Ost und West Teil II. td publications, München 1993, S. 7-27

Sutter, Tilmann: Moral aus der Perspektive der Amoral. Centaurus-Verlagsgesellschaft, Pfaffenweiler 1990

Tamás, György: Die wissenschaftliche Definition. Akademiai Kiado, Budapest 1964

Tausch, Anne Marie; Tausch, Reinhard: Erziehungspsychologie. Göttingen 1971

Tenorth, Heinz-Elmar: Erziehungswissenschaft. In: Benner, Dietrich; Oelkers, Jürgen (Hrsg.): Historisches Wörterbuch der Pädagogik. Beltz Verlag, Weinheim/Basel 2004, S. 341382

Thiersch, Hans: Sozialpädagogik und Erziehungswissenschaft. In: Krüger, Heinz-Hermann; Rauschenbach, Th. (Hrsg.): Erziehungswissenschaft. Weinheim/München 1994

Thimm, Karlheinz: Schulverweigerung. Ist unsere Schule noch kinder- und jugendgerecht? [online] wmw.gan₹tagsschulverband.de/gsv/page/.../Schulverweigerung Thimm. pdf (2007) (Zugriff: 23.05.2008)

Thole, Werner: Soziale Arbeit als Profession und Disziplin. In: Thole, Werner (Hrsg.): Grundriss Soziale Arbeit. Ein einführendes Handbuch. Verlag Leske + Budrich, Opladen 2002, S. 13-62

Trapp, Ernst Christian: Versuch einer Pädagogik. Fritzsch, Theodor (Hrsg.), Verlag von K. F. Koehler, Leipzig 1913

Tymister, Hans Josef: Pädagogische Beratung mit Kindern und Jugendlichen - Fallbeispiele und Konsequenzen für Familie und Schule. Bergmann + Helbig, Hamburg 1996

Ulrich, Andreas: Gefühl der Ohnmacht. In: „Der Spiegel“, 2006, Heft 8, S. 54-55

Uplegger, Angelika: Der Fall „Lisa“ in der Schulsozialarbeit. Belegarbeit im Fach Sozialpädagogik im Kurs „Sozialpädagogischer Jugend- und Familienberater“ (VDP) beim Bildungszentrum Dessau, Schulungsort Güstrow 2002

Vahsen, Friedhelm G. (Hrsg.): Paradigmenwechsel in der Sozialpädagogik. Karin Böllert KTVerlag, Bielefeld 1992

Wächter, Wolfgang: Zur methodischen Funktion von Prinzipien in der Forschung. In: Heinrich Parthey (Hrsg.): Problem und Methode der Forschung. Akademie Verlag, Berlin 1978, S. $48-70$

Waitz, Theodor: Allgemeine Pädagogik. Schulbuchhandlung von F.G.L. Greßler, Langensalza 1910 (2. Auflage)

Wehr, Helmut: Fromm zur Einführung. Junius Verlag, Hamburg 1990

Weiß, Hans, Armut als Entwicklungsrisiko - Möglichkeiten der Prävention und Intervention. Vortrag am 14.09.2004 im Rahmen der bundesweiten, abschließenden Fachtagung „Früh übt sich [...]“ zum Modellprojekt »ópstapje Schritt für Schritt« [online] http://www.dii.de/bibs/321 4172Vortrag Weiss Abschlusstagung.pdf (Zugriff: $\underline{01.07 .2012)}$

Weitz, Siegfried: Makarenko als Pädagoge - Versuch einer Standortbestimmung. In: Hillig, Götz; Weitz, Siegfried (Hrsg.): Makarenko-Diskussionen International. Protokoll des 2. Marburger Gesprächs. Minerva-Publikation, München 1989, S. 141-174

Werner, Emmy: Gefährdete Kindheit in der Moderne: Protektive Faktoren. In: Vierteljah-resschrift für Heilpädagogik und ihre Nachbargebiete, 1997, Nr. 66, S. 192- 203

Wensierski, Peter: Schläge im Namen des Herrn. Das verdrängte Schicksal der Heimkinder in der Bundesrepublik Deutschland. Spiegel-Buch/Deutsche Verlagsanstalt 2006

Wessel, Karl-Friedrich: Der souveräne Mensch - Souveränität in der Humanontogenese. Vortrag, gehalten am 14.06.2005 pdf [online] (Zugriff: 21.01.2010) 
Wichern, Joh. Hinrich (und Henske): Rettungsanstalten als Erziehungshäuser in Deutschland. In: Encyklopädie des gesammten Erziehungs- und Unterrichtswesens - herausgegeben unter Mitwirkung der DD. Palmer und Wildermuth von Prälat Dr. K. A. Schmid. Zweite, verbesserte Auflage fortgeführt von Geh. Regierungsrat D. Dr. Wilhelm Schrader. 7. Band, I. Teil. Fues's Verlag, Leipzig 1886; S. 93-156

Winterhoff, Michael: Warum unsere Kinder Tyrannen werden - Oder: Die Abschaffung der Kindheit. Gütersloher Verlagshaus 2009

Wollenweber, Horst (Hrsg.): Sozialpädagogik in Wissenschaft und Unterricht. Verlag Ferdinand Schöningh, Paderborn 1978

Wurr, Rüdiger; Trabandt; Henning: Abweichendes Verhalten und sozialpädagogisches Handeln. Verlag W. Kohlhammer, Stuttgart/Berlin/Köln 1989

Wustmann, Corina: Das Konzept der Resilienz und seine Bedeutung für das pädagogische Handeln. In: Dokumentation der Fachtagung „Resilienz - Was Kinder aus armen Familien stark macht" am 13. September 2005 in Frankfurt a. M. Institut für Sozialarbeit und Sozialpädagogik. http://www.iss-ffm.de/downloads/tagungsberichte/ doku_ft_resilienz_2006_09.pdf (Zugriff: 03.09.2008)

Zimbardo, Philip G.: Psychologie. Springer Verlag, Berlin/Heidelberg/New York/London/ Paris/Tokyo/Hong Kong/Barcelona/Budapest 1992 (5. Auflage)

Zühlke, Ina: Konzept zur Vermeidung und Überwindung von Obdachlosigkeit in der Hansestadt Rostock. Abschlussarbeit zum Kurs „Sozialpädagogische Jugend- und Familienberaterin“(VDP) im Bildungszentrum Dessau, Schulungsort Güstrow 2003 


\section{Stichwortverzeichnis}

A

Aggressivität

Abbau von A

158, 196

Aggressionsbereitschaft........167, 190, 245

aggressive Langeweile......

158, 188

Frustrations-Aggressions-Hypothese..162

Gründe für A. 153

mediengeschürte A.

196, 198

Prävention bezüglich A.

159

reaktive $A$.

$.167,193$

Angst

A. im erzieherischen Verhältnis.............270

Angstabbau.....................................................354

Angstkompensation..................................165

mediengeschürte A. ................................150

Schulangst.................................................. 187

Selbstoffenbarungsangst.........................351

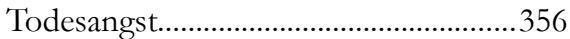

Versagensangst.............................................185

Arbeit

A. als Erziehungsmittel....27, 286f., 292f., 294, 298, 300, 317

A. als Grundlage von Erziehung...81, 151

A. als Kinderarbeit

. .84

A. als Lernmotivation

178,187

A. als Motivation für Erziehung..

.23

A. als Spezifikum des Menschen.

.226

A. in Entwicklungs-Gemeinschaften 287, 289

Arbeitserziehung.....

126, 286, 289

Arbeitslosigkeit

A. als demotivierender Faktor. 175

A. als Risikofaktor für Devianzentwick-

lungen...

158

Autorität

A. im erzieherischen Verhältnis............268

A. im sozialpädagogischen Prozess.....279

A. in der freien Jugendarbeit..................279

A. nach Fromm.

.282

A. nach Herbart

.273

A. nach Neill

A. nach Nohl

270

Amtsautorität.

276

Autoritätsbegriff.

275, 281

Autoritätsgesetz $275 f$.

Persönlichkeitsautorität........276, 280, 381
Regeln für den Aufbau von Persönlich-

keitsautorität. 280

B

Bedürfnisse

Art der B.

individuelle u. gemeinschaftl. B.....265 invariante B. nach Naumann. 225, 305 invariante B. nach Rapoport...153, 218

kindliche $\mathrm{B}$.

183

künstliche B...........................................166

natürliche B...............................161, 164

primäre B..............................................2217

B. als Ansatzpunkte für Erziehung....205,

251, 305

B. und Basisgegenstände der SA..........116

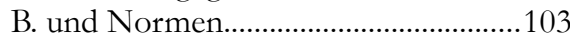

B. und Werte..............................................226

Erziehungsbedürftigkeit...........12, 30, 269

Kommunikationsbedürfnis...................220

Beratung

B. und Diskurs.........................................245

B. und psycho-soziale Intensiverziehung

B. und Schule. 326,330

B. und Sozialarbeit......................................114

Beratungsgespräch.................................175

Gesprächsführung..........................................

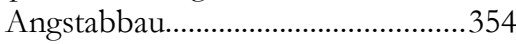

Diskretion...............................................350

Durchkreuzung...................................351

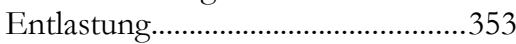

Fassadentechnik..................................351

Kanaldiskrepanz.................................350

negative Zuwendung.........................350

Offenbarungsprozess........................349

Paraphrasieren.....................................348

Selbstoffenbarungsangst...................351

Übertragung............................................351

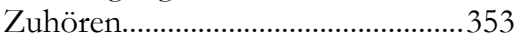

Beziehungen

B. der Zugehörigkeit...............................281

B. zwischen Mutter und Kind........12, 267

Gemeinschaftsbeziehungen...................381

Gruppenstrukturen..................................291

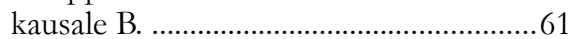

technisch vermittelte B. ...........................15 
teleologische B. $\mathbf{5 4 , 1 2 3 , 3 6 2 , 3 6 7}$

zwischenmenschliche B. ....15, 17, 19, 357 Bildung

B. in Gemeinschaften .288

B. und Erziehung... .24

Erwachsenenbildung.........20, 80, 143, 269

Wortbedeutungen.

D

Devianz

Devianzbegriff 101, 146, 148

Devianzforschung. 103

Devianzprobleme. .152

Erklärungsversuche entwicklungspsychologische E. .....178 Etikettierungstheorie. 201 individualpsychologische E. ..........171 lernpsychologische E. 176 medienwissenschaftliche E. 194 politischer Extremismus und religiöser Fundamentalismus 191 sozialökonomische E. .168 sozialpsychologische E. .164

Theorie der jugendlichen Bande....188 Theorien der Deindividuation und der Dehumanisierung. 189 verhaltenstheor. soziologische E. . 160 primäre und sekundäre $\mathrm{D}$. 102 progressive D. 102, 107, 146 regressive $\mathrm{D}$. 102, 103 sekundäres regressives deviantes Verhalten. 145, 244

Toleranzgrenzen. 147

Verwahrlosung. 102

Diskurs.

D. in der Hilfeplanung...........228, 282, 372

D. und Autorität.

Diskursregeln. 246

\section{E}

Einstellungen

Einstellungsänderung. 109, 143, 191, 374, 376

fremdenfeindliche Ei. $155,192,375$

Eltern

erodierende Erziehungskompetenz bei E. 181

erzieherische Verantwortung der E. ...170 Erkenntnismethoden

Abstraktion $16,19,29,54,225$

Analyse-Synthese.
Begriff der Erkenntnismethoden. 69

dialektische Definition.................................14

Erklären.........................................................53

hermeneutische EM. .................................. 54

kausalanalytische EM. .....................54, 362

Synthese. 132

teleologische Betrachtung.................54, 362

Verstehen.................................................... 53

Wert von Definitionen..............................26

Erzieher (siehe auch Sozialpädagogen)

als Kategorie. 32,34

E. und gesellschaftliche Kräfte................77

erzieherische Bewusstheit......................267

Erziehungsgemeinschaft als E. ................34

Kompetenzen des E. .............................273

Kompetenzüberlegenheit des E. .........272

Optimismus des E. $43,47,381$

pädagogische Bewusstheit.........................35

Qualitäten des E. ..........................187, 274

Vertrauen zum E. ....................................174

Wortbedeutungen..........................................34

Erzieherisches Verhältnis

e. V. als Bestandteil umfassender Ge-

meinschaftsbeziehungen..........................381

e. V. nach Bollnow....................................2270

e. V. nach Schleiermacher........................2272

Merkmale des e. V..........................268, 271

pädagogischer Bezug (Nohl)..................268

Regeln für den Aufbau eines e. V. .......280

Erziehung

als Kategorie

12,16

Arten von E

anérische $\mathrm{E}$ 159

direkte E. 15,251

funktionale E. ......................................22

gemeinschaftliche E. .........................264

indirekte E. ..........................................250

Individualerziehung....82, 86, 109, 264

intentionale E. .....................................22

psychosoziale Intensiverzieh....111,294

repressionsfreie E. ............................282

Sozialerziehung..........82, 100, 101, 109

Auffassungen von E. .

E. nach Bokelmann.............................22

E. nach Bollnow..................................269

E. nach Giesecke...........................16, 18

E. nach Kant...............................12, 13

E. nach Makarenko............35, 159, 251

E. nach Natorp. 
E. nach Naumann..............................19

E. nach Oelker.......................................2

E. nach Schaller......................................12

E. und andere Prozesse

E. und Arbeit.........................10, 23, 27

E. und Bildung..................................24f.

E. und Enkulturation............................24

E. und Individuation..........................23

E. und Manipulation............................42

E. und Medieneinflüsse......27, 34, 170

E. und Personalisation.........................23

E. und Selbsterziehung ......................23

E. und Sozialisation. 23f., 88, 108, 154

E. und Therapie......129, 284, 331, 358

Erziehungsfehler. .18, 179

Erziehungsstil. autoritärer Stil. 257

E. als Moment von Methode...70, 257 Laissez-faire-Stil. 257 sozialintegrativer Stil 257

Erziehungswissenschaft

E. und Pädagogik.. . .77

Gruppen erziehungswissenschaftlicher Disziplinen. .. .96

Hauptaufgabe der E. .68

Konstituierungskriterien erziehungswis-

senschaftlicher Disziplinen. .95

Struktur der E. (nach Krüger) 89 Ethik.

ethische Werte. .224

Evolutionäre Ethik 154

Gesinnungsethik. 229

moralische Entscheidung.......................227

moralische Forderungen.........................227

sozialethische Prinzipien........................254

Verantwortungsethik.

F

Funktionen

didaktische Funktionen. 335

sozialpädagogische Funktionseinheiten....

Aufklären $331,340,361$

Aufschließen. $331,340,347$

Ausführen $332,341,372$

Auswerten. $332,341,378$

Funktionsbegriff in der Pädagogik.......324

Funktionseinheit. .329

G

Gemeinschaft

Entwicklungs-Gemeinschaft .283
Formierung einer E-G 280, 292

Funktionen der E-G. 283

Gemeinschaftserziehung........286, 305

Kompetenzverteilung in der E-G 290,

294

Ordnung u. Organisation d. E-G. .301

Primärgruppen...................................284

Selbstverwaltung in E-G. ................290

Souveränität der E-G. .....................289

Strukturen in E-G. .291

erzieherische Kraft der G. 251, 327

Erziehungsgemeinschaft. 268,284

Gemeinschaftsfähigkeit. 231,264 gemeinschaftsfeindliches Verhalten.....281 Gemeinschaftsgefühl. 264,265

Kontakt-Gemeinschaft. 264, 283

Prinzipien d. Gemeinschaftserziehung286

Schulgemeinschaft.. .281

Stabilität der G. 222

Stützgemeinschaft. .332 Gesetz

G. und Prinzip. $.64,66$

Gesetzesaussagen. 60

Gesetzmäßigkeiten...............................54, 55

Möglichkeiten und Gesetze.......................63

statistischer Charakter sozialer GesetzmäBigkeiten. $\mathbf{5 6}, 60,62$

I

Wortbedeutungen. .50

Inhalt der Erziehung

I. als pädagogische Kategorie. .32

Werte als I................98, 147, 167, 217, 220

J

I. und Gegenstand in der Erziehung...128

Jugendhilfe

Aufgaben der JH......................................109

$\mathrm{JH}$ in Abgrenzung zur SP.......................381

$\mathrm{JH}$ in der DDR........................................256

K

JH und damit verbundene Prozesse....112

Kindertagesstätte

K. als Vorschuleinrichtung. .110

sozialpädagogische Funktion der K....110 Kompetenzen.

$\mathrm{K}$. als Zielbündelungen. 213

Kompetenzfeststellung. 323

Sachkompetenzen 125,247

Selbstkompetenz...........100, 125, 247, 318

Sozialkompetenz.................125, 247, $317 f$ f. 
Kriminalität

Jugenddelinquenz. 183

K. und Sozialpädagogik. 102

Kriminalitätsbekämpfung in der DDR 149

Kriminalitätsentwicklung nach 1990 in

Deutschland. 150

L

Kriminalprävention........151, 178, 181, 184

Lernen

L. als Einheit von Neulernen und Umler-

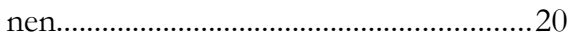

L. aus eigenem Antrieb.............................342

L. und Erziehung..........................................15

L. und Selbsterziehung.............................18

Lernbedingungen...................187, 204, 279

Lernbegriff..................................................20

Lernfähigkeit............................................. 11

Lernpartner (............................................267

Lernziele..................................................211

Umlernen........................................178, 376

Verbindung von L. und Arbeiten..........287

M

Medien

Mediensucht. 200

Medienwirkungen. 185, 194

Mensch

Entfremdung des M. $.164,166$

Marketing-Charakter des M. 165

Selbstveränderung des M. .......15, 45, 205

Wesensmerkmal des M. .370

Methode (

als pädagogische Kategorie.......................33

Erziehungsmethoden.... . .69

Klassifizierungsproblem bei M. .............71

methodisches Grundgerüst der SP......326

Multifunktionalität der M.

. .71

Wesensmerkmale pädagogischer M.69, 71

Minderwertigkeitskomplex

Folgen von Minderwertigkeitskomplexen 106, 157, 172, 194, 196

gesteigertes Minderwertigkeitsgefühl..172

Kompensation von Minderwertigkeits-

komplexen.....

M. und Lebensstil. 105

Modell

Darstellungs- und Anwendungsweise von Modellen.. .333 didaktisches Dreieck..................................38

pädagogischer Kegel von Derbolav........38

pädagogisches Dreieck................................38

sozialpädagogisches Funktionsmodell 332

sozialpädagogisches Phasenmodell......322

Struktur- und Funktionsmodell der Sozi-

alarbeit. 116

Struktur- und Funktionsmodell vom Er-

ziehungsprozess. 117

Verknüpfung sozialpädagogischer und

didaktischer Modelle.

$\mathbf{N}$

Normen

Arten von $\mathrm{N}$.

Aushandlungsbedürftigkeit soziokulturel-

ler $\mathrm{N}$. 104, 227

Begriff der Normen.................50, 103, 228

Begründung von N. ...............................51f.

Durchsetzung soziokultureller N. .......217

ethische N. ...............................................224

Funktion von N. ....................................228

gesellschaftl. Normensystem ........103, 201

Gruppennormen......................21, 188, 191

Gültigkeit von N. .....................................83

individuelle N. ...........................................103

Kodifizierung von Normen....................222

Menschenrechtsnormen.................67, 175

N. und Interessen.....................................246

N. und öffentliche Meinung...................298

N. und Toleranz..........................................103

nicht normierbare Handlungs- bzw.

Verhaltensweisen.......................................22

nichtsoziale N. ..............................................51

Normalitätsvorstellungen.......................146

Normative Prinzipien...............................67

normativistisches Wirklichkeitsverständ-

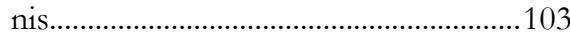

Normenaneignung....................70, 109, 177

Normendiskurs.........................................246

Normenrigidität.......................................192

Normensetzung.............................................78

Normenverstöße............145, 189, 244, 254

Normenwandel.........................................245

Relativität gesellschaftlicher N..............104

schichtenspezifische N.............................147

soziale Normen.............................................50

O

Organisation

als pädagogische Kategorie.......................33 
militärische Formen in Entwicklungs-Gemeinschaften. .301, 302 Organisation der Erziehung............35, 295 Organisation von Entwicklungs-Gemeinschaften. $251,280,287$

Organisationsformen der SA. .71 soziale Organisation $.63,305$

\section{$\mathbf{P}$}

Pädagogik

Autonomie der Pädagogik. .76

Entwicklung der P. zur Wissenschaft. .29, 76

Gegenstand der P. ........21, 24, 77, 81, 269 geisteswissenschaftliche P. . .53

P. als selbständige Wissenschaft.......24, 74

P. als technisch-praktische Wissenschaft 337, 338

P. und Erziehungswissenschaft................77

pädagogische Disziplinen.........................95

Wortbedeutungen.................................74, 76

Persönlichkeit

Persönlichkeitsbegriff

PB von Ihlefeld und Naumann........14

$P B$ von Zimbardo.

Persönlichkeitseigenschaften

Kompetenzen. 211,247

$\mathrm{PE}$ als Zielvorstellungen. .210

Persönlichkeitsentwicklung autogene Faktoren der P...........48, 205 endogene Faktoren der P....................48

Erbe-Umwelt-Problematik................48 exogene Faktoren der P.......................48

Nativismus.............................................47

sensible Phasen in der P...................204

Urvertrauen...........................................184

Planung

Begriff der $\mathrm{Pl}$

Hilfeplan.......346f., 349f, 360f, 366, 372ff.

Hilfeplanung....................................245, 373

Kontrolle entsprechend Hilfeplan......379

Konzeption 249, 252, 329

prozessimmanente Planung. 138, 249, 253

Verbindlichkeit des Hilfeplans................371

Vereinbarung... 313,325

Zielbestimmung

$.215,248$

Zweck- und Zielbestimmungen. 118

Prävention

Bedingungen erfolgreicher P. 180

Kriminalprävention.
Primärprävention. 110, 111, 178 sekundäre P. 111f.

Suchtprävention. 110

tertiäre $\mathrm{P}$. 111

Prinzipien der Sozialpädagogik

Funktionsprinzipien. .388

Pr. der Einheit von steigenden Anforderungen und kontinuierlichen Kontrollen . 346

Pr. der Verbindung von Freiwilligkeitsvorrang, Zeitrichtigkeit, Zielstrebigkeit und Flexibilität im Hilfeprozess

Pr. der Verbindung von instrumenteller Problemdefinition mit der Konzentration auf die zentralen Problemvariablen 345

Pr. der Verbindung von Nichtbeschuldigung mit der Anknüpfung an persönliche Stärken der Klienten...345 Pr, der Verbindung von Tatsachenermittlung und Erklärungsbemühungen unter Berücksichtigung der Lebenswelt und des soziallogischen Denkens der Problembelasteten. .343

Konzeptprinzipien

Pr. der Verbindung von sozialer Hilfe mit direkter und indirekter pädagogischer Einflussnahme durch Anleitung zur Selbsthilfe. 250

Pr. der Verbindung von systemischem Herangehen mit problemindividuellem Verstehen und Vorgehen.........251 Pr. der Verknüpfung von sozialethischen und sozialökologischen Positionen bei der Bestimmung des vertretbaren Aufwands an materiellen und personellen Mitteln zur Problemlösung. 254

Pri. der Wechselwirkung von Verstehen und Handeln. 253 Pr. der Verbindung von persönlicher Achtung mit angemessen hohen und steigenden Forderungen .................256

Normative Prinzipien

Heilungsprinzip. 66,137

Rettungsprinzip 66,137

Förderungsprinzip (Ertüchtigung) 66,137 
Strukturprinzipien

Pr. der Präsentation von Kompetenz und Natürlichkeit im Umgang mit den Klienten sowie der Wahrung von Diskretion 307

Pr. der Verbindung von Beratung und Verhandlungsführung mit Kooperationsbildung im Interesse der Klienten 311

Pr. der Verbindung von Handlungsherrschaft des Sozialpädagogen mit der Selbständigkeitsförderung der Klienten...... 312 Pr. der Verbindung von Interposition mit parteilichem Engagement für besonders Bedürftige und Benachteiligte 310

Pr. der Verbindung von unvoreingenommener Problemannahme, verständnisvoller Anteilnahme und Echtheit zwecks Öffnung, Ermutigung und Aktivierung 309

Prinzipien der Soziologie

Pr. der kollektiven Identität....................297

Pr. der Reziprozität..................................2297

Pr. der ständigen Bewertung..................297

Tabu-Prinzip,...........................................298

Prinzipien in der Pädagogik

als pädagogische Kategorien.

nach Burow..... .65

nach Kirchhöfer. . .68

nach Naumann $64,66,68,69$

nach Niemeyer. 135

Pr. und Regeln. 68f., 132

Prinzipien in der Sozialarbeit

Pr. der Echtheit. 137

Pr. der Ermutigung. 67, 176

Pr. der Hilfe zur Selbsthilfe....115, 358

Pr. de Einheit von Nähe und Distanz $311,348,350$

Pr. der Selbstbestimmung..... ...65

Pr. der Selbsttätigkeit.............27, 53, 67

Funktionen von Prinzipien....................... 70

Geltungsbereich von Prinzpien........66, 70

Gruppen von Prinzipien.

Funktionsprinzipien. 138, 339

Konzeptprinzipien 138,250 normative Prinzipien........66, 137, 206 Strukturprinzipien. 138,306
Persistenz von Pr. 136

Prinzipien der Gemeinschaftserziehung.... Pr. der Entwicklung echter Perspektiven und wertvoller Traditionen......295 Pr. der Entwicklung einer bewussten und freiwilligen Disziplin bei Wahrung der Möglichkeit differenzierten Strafens. 287

Pr. der Geborgenheit und Sicherheit eines jeden Mitgliedes in der Gemeinschaft... 297

Pr. der Sicherung eines kameradschaftlichen, sozialintegrativen Stils, eines optimistischen Grundtons und einer werthaltigen öffentlichen Meinung...... 287 Pr. der Verbindung von persönlicher Achtung mit angemessenen hohen und steigenden Forderungen.........293 Pr. der Verbindung von produktiver Arbeit, Bildung, Sport und künstlerischen Betätigungen. .286 Pr. d. parallelen pädagogischen Vorgehens u. d. individuellen Förderung 251, 294

Prinzipien in der Sozialarbeit

Gruppen von Pr. nach Lüssi..................133 methodischen Prinzipien..........................386

Systemcharakter der Pr. nach Lüssi.....133 Wesensmerkmale von Pr. in der SA nach Lüssi. 133

Problem

als soziales P. 114

multiple Problembelastungen................127

Problemanalyse.......................340, 345, 355

Problembelastete........................................144

Problembeteiligte......................................144

Problemdefinition.......346, 349, 359, 361, 363, 366, 367

Problemlösung....107, 114, 120, 135, 245, 250, 252, 254f., 257, 310ff., 330, 345

Problemlösungsprozess.................308, 343

Problemsituationsanalyse...............362, 369

Problemvariable............341, 346, 365, 367

$\mathbf{R}$

Regeln

Begründung von R..............................53, 83

Funktion von R..........................................66

Geltungsbereich von R..............................69 
R. als relativ allgemeine Handlungsorientierungen. 132

R. und Gesetze. . .64

R. und Methode. . .69

Wesensmerkmale pädagogischer R........70 Resilienz

Resilienzförderung 180

Resilienzforschung. 180

Vulnerabilität.. 180

Resultat.

als pädagogische Kategorie .33

Leistungsbewertung

Resultatsabbildungen

Resultatsbewertung. 117

Resultatsermittlung. 118, 379

Rückfälle........111, 310, 342, 358, 372, 378

\section{S}

Selbstbewertung.

Sozialarbeit.

Basisgegenstände der SA. 113

Handlungsarten der SA. 132

SA nach Lüssi. 114 soziales Problem. 114

Soziale Arbeit

Aufgaben der S. A. .99

Managementwissenschaft für die S. A...94

S. A. als zweckgerichtete Verknüpfungen von Elementen aus mehreren Hand-

lungs- und Wissensbereichen...................91

Unterscheidung von Sozialarbeit und Sozialpädagogik im Rahmen der Sozialen

Arbeit.

Sozialpädagogen

Autorität von S. .279

Funktionen ihrer Aktivitäten.

Handlungsherrschaft des S.

312

Kompetenzen des S. 94, 308

Qualifikationsmerkmale von S. ...........280 relevante Wissenschaften für die Ausbildung von $\mathrm{S}$.

Sozialpädagogik

Auffassungen von SP

nach Buchka 108

nach Diesterweg..

nach Krüger.

nach Mager.

nach Naumann 111

nach Röhrs

Übersicht von Marburger..
Strafen

Regeln wirkungsvoller Bestrafung.......299

St. nach Garcia..........................................2274

St. nach Makarenko. 282, 299

Sucht

Suchtgefährdungen Jugendlicher..... .185

Suchtprävention.

Suchttherapie.

Symptome. 352

Suizid

S. als ethisches Problem .224

Selbstmordattentäter. 161,225

$\mathbf{T}$

Therapie

Gefahr des Therapismus. 130,354

therapeutische Wirkung v. Erziehung..128

Transdisziplinarität.

transdisziplinäre Begründung pädagogi-

scher Handlungen. 83,91

transdisziplinäre Begründung pädagogi-

scher Prinzipien. .64 transdisziplinäre Charakter pädagogischer Disziplinen. $.92,98,330$, transdisziplinäre Handlungswissenschaft 5 transdisziplinäre Sozialarbeitswissenschaft. transdiziplinärer Charakter der Sozialpädagogik $5,82,112,139,382$

V

Verhalten

Ausweichverhalten. 106

biologische Grundlagen des V...........10, 30

deviantes $\mathrm{V}$. 100, 145

dissoziales $\mathrm{V}$.

Erklärung von Verhaltensweisen.....54, 64 kriminelles V.

neurologische Grundlagen des V..

Protestverhalten. .102

schulaversives V. 37,185

soziales V. .99

V. und Wertvorstellungen...........................41

Verantwortung für persönliches V.........49

Verhaltensänderung... $.21,376$

Verhaltensanforderungen........................24

Verhaltensbiologie 156

Verhaltensdetermination. .64 verhaltensdeterminierender Einfluss von

Personen. .61

Verhaltensdrill 25 
Verhaltenseigenschaften..........................24

Verhaltensmuster........................................14

Verhaltensnormen.........................................50

Verhaltensschwierigkeiten........................18

Verhaltensstörungen.................................102

verhaltenstheoretische Lerntheorie...160,

verhaltenstheoretische Psychologie.....160

W

verhaltenstheoretische Soziologie

Werte

Funktionen von Wertvorstellungen...217, 225

Grundwerte...............................................226

moralische Werte.........................................222

Wertebegründung............................217, 221

Wertekonflikt...........................................224

Werteverfall.................................................224

Wertevermittlung..........................217, 223

Werteverteidigung....................................231

Wertewandel.....................................224, 243

Wertgefühle...................................................223

Wertvorstellungen...........................221, 223

$\mathrm{Z}$

Ziel

als pädagogische Kategorie
Formulierung pädagogischer Ziele......210

Funktionen pädagogischer Ziele..........248

Grundqualifikationen....................213, 247

Hauptziel p.-s. Intensiverziehung.........109

Legitimation pädagogischer Ziele........214

Leitziele...................................................2230

Teil- und Etappenziele..............................246

Z. und Prinzip....................................64, 66

Z. und Zweck in der Pädagogik...........212

Ziel-Resultats-Vergleich..........................258

Zielbegründung..........................................54

Zielbestimmung.......34, 109, 215, 216, 243

Zielformulierung......................................247

Zielgruppe der SP...........................105, 108

Zielpräzisierung........................................245

Zielsysteme................................................2213

Zielvereinbarungen....................................315

Zielvorstellungen ........................................35

Zögling

als pädagogische Kategorie...............32, 34

Problembelasteter

Bedürfnisse Poblembelasteter........108

Merkmale Problembelasteter. 144, 145

P. und Problembeteiligte...................144

Wortbedeutungen.......................................142

Zöglingsfunktion......................................142 

Die täglichen Meldungen über aggressive Gewalttaten, Diebstähle, Koma-Trinker oder Kindesvernachlässigungen werfen immer wieder die Fragen auf: Was sind die Ursachen solcher abweichenden Verhaltensweisen und was kann zu ihrer Überwindung getan werden? Das vorliegende Buch bietet einen konzentrierten Einblick in 12 Theorien, die jeweils aus ihrer Sicht Erklärungen für deviantes Verhalten liefern. Es stellt damit praktisch tätigen und künftigen Sozialpädagogen und Sozialarbeitern - also vor allem auch Studierenden - ein theoretisch begründetes und differenziertes Handlungskonzept für die psychosoziale Intensiverziehung deviant Handelnder zur Verfügung.

In dieses Konzept der humanistischen Gemeinschaftserziehung hat der Autor unter anderem die Erfahrungen des Wiener Volksschuldirektors Ferdinand Birnbaum (Schüler Alfred Adlers), Erkenntnisse aus der Gemeinschaftserziehung in Landerziehungsheimen (Hermann Lietz, Gustav Wyneken) und rationelle Elemente der Kollektiverziehung des ukrainischen Pädagogen Anton S. Makarenko einfließen lassen. Darin verarbeitet wurden auch neuere Erfahrungen, die Harald Rasmussen im staatlichen Erziehungsheim Bøgholt bei Kopenhagen, Pfarrer Dietrich Lauter in Ludwigshafen in der kirchlichen Jugendarbeit und die Mitglieder der inzwischen bundesweit agierenden Suchthilfe-Gemeinschaft SYNANON gesammelt haben.

Das Buch will aber nicht nur praktisches sozialpädagogisches Handeln, sondern auch wissenschaftliche Diskussionen um den Gegenstand der Sozialpädagogik und ihre Möglichkeiten in der Sozialen Arbeit fördern. Es unterbreitet ein entsprechendes konzeptionelles Angebot, das aus der eigenen Lehrtätigkeit in der Ausbildung von Staatlich anerkannten Sozialarbeitern/Sozialpädagogen in Mecklenburg-Vorpommern erwachsen ist.

\section{Logos Verlag Berlin}

